\begin{tabular}{|c|c|c|}
\hline ENGINEERING CHANGE NOTICE & Pape 1 of 2 & $\begin{array}{l}\text { 1. ECN } 628814 \\
\text { Proj. } \\
\text { ECN }\end{array}$ \\
\hline
\end{tabular}

\begin{tabular}{|c|c|c|c|c|c|c|}
\hline \multirow{3}{*}{$\begin{array}{l}\text { 2. ECN Category } \\
\text { (mark one) } \\
\text { Supplemental } \\
\text { Direct Revision } \\
\text { Change ECN } \\
\text { Temporary } \\
\text { Standby } \\
\text { Supersedure } \\
\text { Cancel/Void }\end{array}$} & \multirow{3}{*}{$\begin{array}{r}{[} \\
{[x]} \\
{[]} \\
{[]} \\
{[]} \\
{[]} \\
{[]}\end{array}$} & \multicolumn{2}{|c|}{$\begin{array}{l}\text { 3. Originator's Name, Organization, MSIN, } \\
\text { and Telephone No. } \\
\text { BD Zimmerman, 74F30, H6-35,6-7440 }\end{array}$} & \multicolumn{2}{|c|}{$\begin{array}{l}\text { 4. USQ Required? } \\
\text { [] Yes }[X] \text { No }\end{array}$} & $\begin{array}{l}\text { 5. Date } \\
\text { Sept. } 30,1996\end{array}$ \\
\hline & & \multicolumn{2}{|c|}{$\begin{array}{l}\text { 6. Project Title/No./Work order No. } \\
\text { TWRS Functions and Requirements } \\
\text { Document }\end{array}$} & \multicolumn{2}{|c|}{$\begin{array}{c}\text { 7. Bldg./Sys./Fac. No. } \\
\text { NA }\end{array}$} & $\begin{array}{l}\text { 8. Approval Designator } \\
\text { ESQS gr ** }\end{array}$ \\
\hline & & \multicolumn{2}{|c|}{$\begin{array}{l}\text { 9. Document Numbers Changed by this ECN } \\
\text { (includes sheet no. and rev.) } \\
\text { WHC-SD-WM-FRD-020 Rev. } 0 \\
\text { (complete replacement) }\end{array}$} & \multicolumn{2}{|c|}{$\begin{array}{l}\text { 10. Related ECK No(s). } \\
\text { NA }\end{array}$} & $\begin{array}{l}\text { 11. Related PO No. } \\
\text { NA }\end{array}$ \\
\hline \multirow{2}{*}{\multicolumn{2}{|c|}{$\begin{array}{l}\text { 12a. Modification Work } \\
\text { [] Yes (fill out Blk. } \\
\text { [X] No (NA Blks. 12b, } \\
\text { 12c, 12d) }\end{array}$}} & \multirow[t]{2}{*}{$\begin{array}{l}\text { 12b. Work Package } \\
\text { No. } \\
\text { NA }\end{array}$} & \multicolumn{2}{|c|}{$\begin{array}{l}\text { 12c. Modification Work Complete } \\
\text { NA }\end{array}$} & \multicolumn{2}{|c|}{$\begin{array}{l}\text { 12d. Restored to Original Condi- } \\
\text { tion (Temp. or Standby ECN only) } \\
\text { NA }\end{array}$} \\
\hline & & & \multicolumn{2}{|c|}{$\begin{array}{l}\text { Design Authority/Cog. Engineer } \\
\text { Signature \& Date }\end{array}$} & \multicolumn{2}{|c|}{$\begin{array}{l}\text { Design Authority/Cog. Engineer } \\
\text { Signature \& Date }\end{array}$} \\
\hline
\end{tabular}

* *er B. D. Zimmerman , 10/3.

14a. Justification (mark one)

$\left.\begin{array}{llllllll}\text { Criteria Change [] } & \text { Design Improvement } & {[X]} & \text { Environmental } & {[]} & \text { Facility Deactivation [] } \\ \text { As-Found } & {[]} & \text { Facilitate Const } & {[]} & \text { Const. Error/Omission } & {[]} & \text { Design Error/Omission }\end{array}\right]$

14b. Justification Details

This document is rev.1 of the TWRS Functions and Requirements document. It is completely replacing the previously issued rev. 0 . The replacement is based on addition of new information, correction of previously contained information, resolution of comments, and DOE direction.

15. Distribution (include name, MSIN, and no. of copies)

Separate distribution sheet prepared.

A-7900-013-2 (05/96) GEF095 


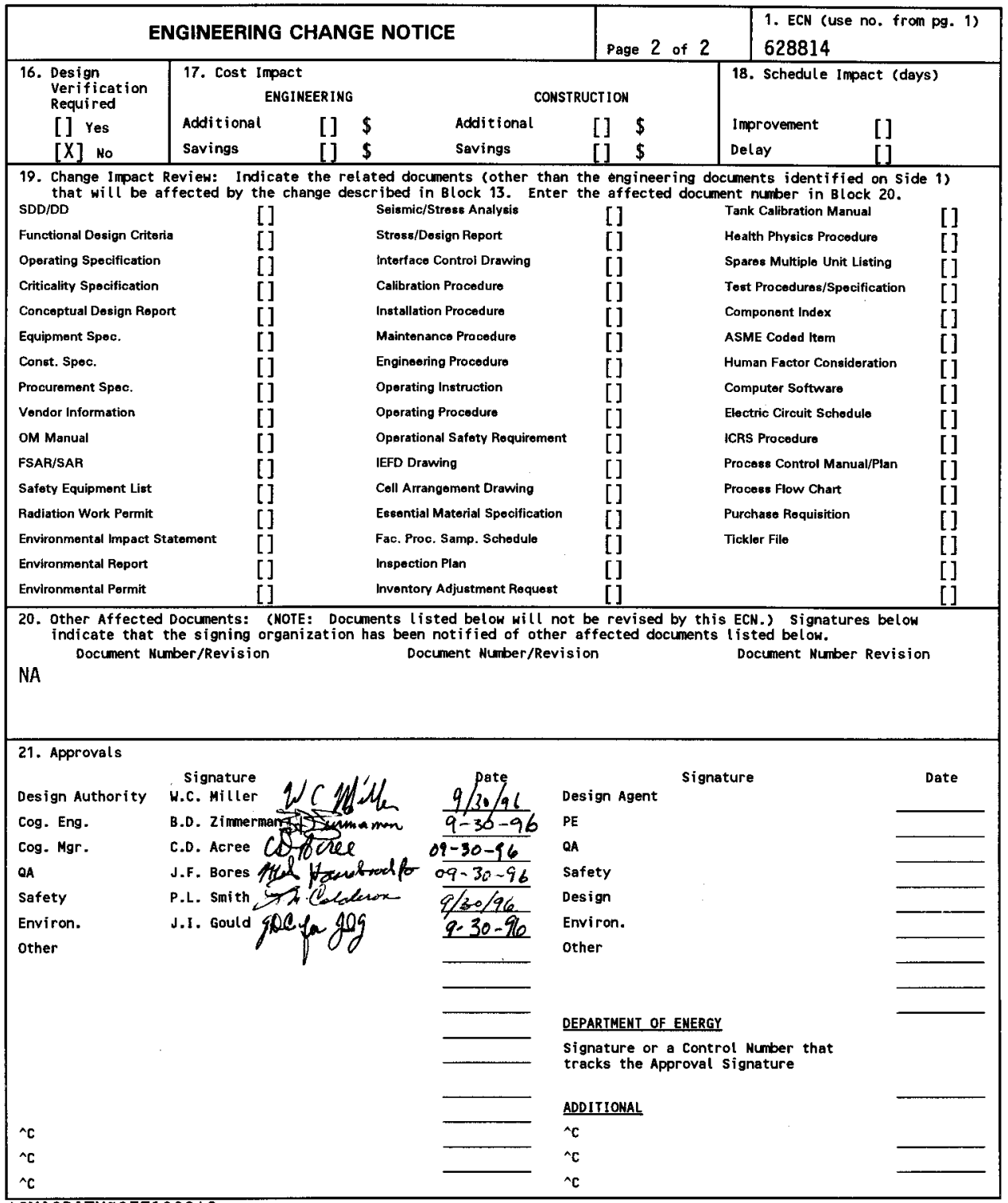

${ }^{\wedge}$ GMACPATH ${ }^{\sim}$ GEF $1000^{\wedge} \mathrm{G}$ 


\title{
Tank Waste Remediation System Functions and Requirements Document
}

\author{
Westinghouse Hanford Company \\ Westinghouse Hanford Company, Richland, WA 99352 \\ U.S. Department of Energy Contract DE-AC06-87RL10930 \\ EDT/ECN: 628814 \\ UC: 2030 \\ Org Code: $74 \mathrm{~F} 30$ \\ Charge Code: D1M88 \\ B\&R Code: EW3120075 \\ Total Pages: 986
}

Key Words: TWRS, Functions, Requirements, Architecture, Process, Process Waste, Tanks, and Waste

\begin{abstract}
This is the Tank Waste Remediation System (TWRS) Functions and Requirements Document derived from the TWRS Technical Baseline. The document consists of several text sections that provide the purpose, scope, background information, and an explanation of how this document assists the application of Systems Engineering to the TWRS. The primary functions identified in the TWRS Functions and Requirements Document are identified in Figure 4.1 (Section 4.0) Currently, this document is part of the overall effort to develop the TWRS Funtional Requirements Baseline, and contains the functions and requirements needed to properly define the top three TWRS function levels. TWRS Technical Baseline information (RDD-100 database) included in the appendices of the attached document contain the TWRS functions, requirements, and architecture necessary to define the TWRS Functional Requirements Baseline. Document organization and user directions are provided in the introductory text. This document will contimue to be modified during the TWRS life-cycle.
\end{abstract}

TRADEMARK DISCLAIMER. Reference herein to any specific commercial product, process, or service by trade name, trademark, manufacturer, or otherwise, does not necessarily constitute or imply its endorsement, recommendation, or favoring by the United States Government or any agency thereof or its contractors or subcontractors.

Printed in the United States of America. To obtain copies of this document, contact: WHC/BCS Document Control Services, P.O. Box 1970, Mailstop H6-08, Richland WA 99352, Phone (509) 372_2420;_Eax (509) 376-4989.

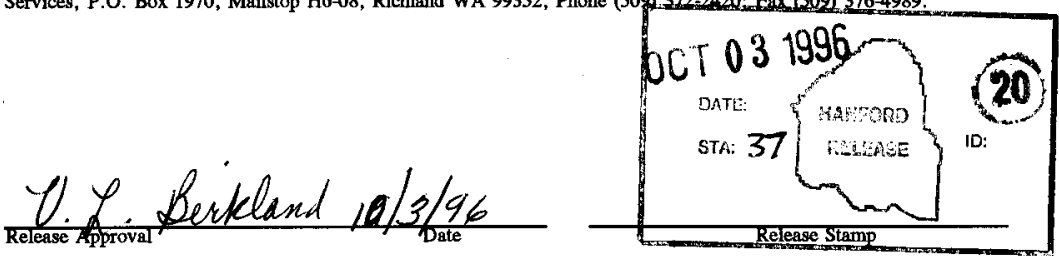


(2) Title

Tank Waste Remediation System Functions and Requirements Document CHAMGE CONTROL RECORD

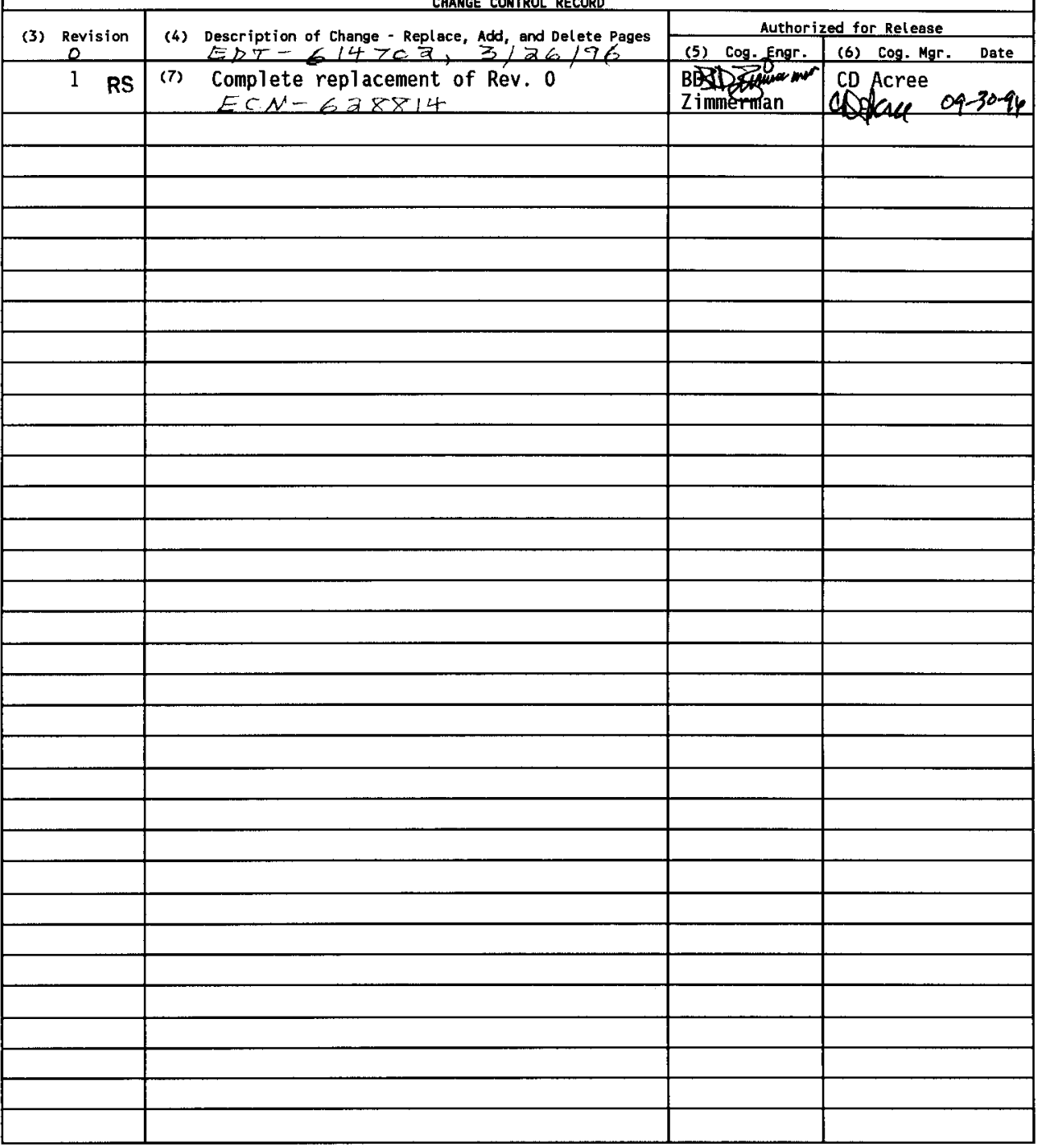


WHC-SD-WM-FRD-020

Revision 1

\section{TANK WASTE REMEDIATION SYSTEM}

\section{FUNCTIONS AND REQUIREMENTS DOCUMENT}

September 1996

Westinghouse Hanford Company

Richland, Washington 
Tank Waste Remediation System Functions and Requirements Document WHC-SD-WM-FRD-020 Rev. 1

Signature Page
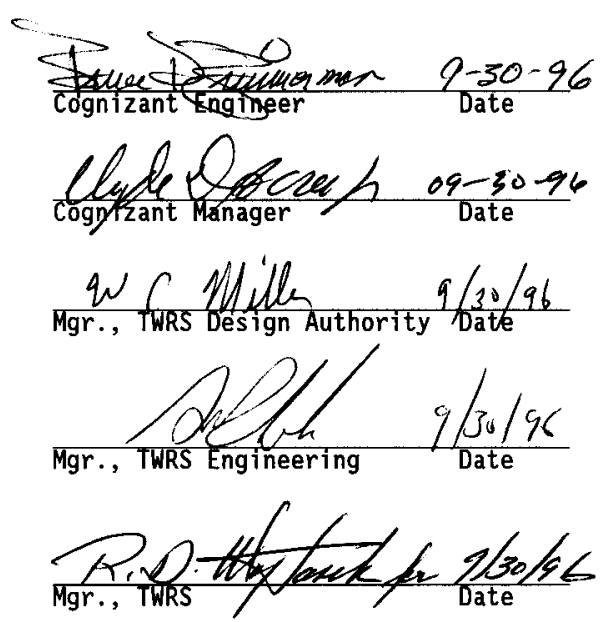

i 
WHC-SD-WM-FRD-020

Revision 1

\section{FOREWORD}

This is the Tank Waste Remediation System (TWRS) Functions and Requirements Document derived from the TWRS Technical Baseline. The document consists of several text sections that provide the purpose, scope, background information, and an explanation of how this document assists the application of Systems Engineering to the TWRS. The primary functions identified in the TWRS Functions and Requirements Document are identified in Figure 4.1 (Section 4.0). Currently, this document is part of the overall effort to develop the TWRS Functional Requirements Baseline, and contains the functions and requirements needed to properly define the top three TWRS function levels. TWRS Technical Baseline information (RDD-100 database) included in the appendices of the attached document contain the TWRS functions, requirements, and architecture necessary to define the TWRS Functional Requirements Baseline. Document organization and user directions are provided in the introductory text. This document will continue to be modified during the TWRS life-cycle. 


\section{WHC-SD-WM-FRD-020}

\section{Revision 1}

This page intentionally left blank. 


\section{WHC-SD-WM-FRD-020}

Revision 1

\section{LIST OF FIGURES}

4-1 Hanford Site Technical Baseline ... . . . . . . . . . . . . 3

4-2 TWRS Systems Engineering Functional Levels $\ldots \ldots \ldots \ldots$. . . . . . . . . . 4

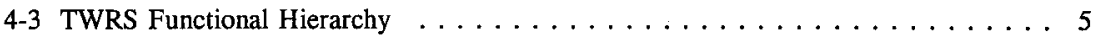




\section{WHC-SD-WM-FRD-020 \\ Revision 1}

\section{LIST OF TERMS}

$\begin{array}{ll}\text { AEA } & \text { Atomic Energy Act of 1954 } \\ \text { ALARA } & \text { As Low As Reasonably Achievable } \\ \text { BAT } & \text { Best Available Technology } \\ \text { BSD } & \text { Baseline System Description } \\ \text { CERCLA } & \text { Comprehensive Environmental, Response, Compensation, and } \\ & \text { Liability Act of 1980 } \\ \text { CFR } & \text { Code of Federal Regulations } \\ \text { CRWMS } & \text { Civilian Radioactive Waste Management System } \\ \text { CW } & \text { Concentrate Waste } \\ \text { DCG } & \text { Derived Concentration Guide } \\ \text { DEF } & \text { Disposition Excess Facilities } \\ \text { DGE } & \text { Disposition Gaseous Effluent } \\ \text { DOE } & \text { U.S. Department of Energy } \\ \text { DLE } & \text { Disposition Liquid Effluent } \\ \text { DQO } & \text { Data Quality Objective } \\ \text { DRM } & \text { Disposition Reusable Materials } \\ \text { DST } & \text { Double-Shell Tank } \\ \text { DSW } & \text { Disposition Solid Waste } \\ \text { Ecology } & \text { Washington State Department of Ecology } \\ \text { EPA } & \text { U.S. Environmental Protection Agency } \\ \text { F\&R } & \text { Functions and Requirements } \\ \text { FR } & \text { Federal Register } \\ \text { FRD } & \text { Functions and Requirements Document } \\ \text { HLW } & \text { High-level radioactive Waste } \\ \text { HQ } & \text { U.S. Department of Energy, Headquarters } \\ \text { ICRP } & \text { International Commission on Radiological Protection } \\ \text { IHLW } & \text { Immobilized High-Level Waste } \\ \text { ILLW } & \text { Immobilized Low-Level Waste } \\ \text { ILLTW } & \text { Immobilized Low-Level Tank Waste } \\ \text { ITRU } & \text { Immobilized Transuranic } \\ \text { LAW } & \text { Low-Activity Radioactive Waste } \\ \text { LDR } & \text { Land Disposal Restriction } \\ \text { LLW } & \text { Low-Level radioactive Waste } \\ \text { LLTW } & \text { Low-Level Tank Waste } \\ \text { M\&O } & \text { Maintenance and Operations } \\ \text { MGDS } & \text { Mined Geologic Disposal System } \\ \text { MTW } & \text { Manage Tank Waste } \\ \text { MUST } & \text { Miscellaneous Underground Storage Tanks } \\ \text { NCRP } & \text { National Council on Radiation Protection } \\ \text { NEPA } & \text { National Environmental Policy Act of 1969 } \\ & \end{array}$


WHC-SD-WM-FRD-020

Revision 1

\section{LIST OF TERMS (continued)}

NIOSH

NRC

OCRWM

OSHA

PL

PW

QARD

RCRA

RCW

RFP

RL

RLIP

ROD

RW

RTW

SAR

SE

SEMP

SG

SNF

SRD

SST

SW

TBD

TCP

Tri-Party

TRU

Agreement

TSD

TSR

TW

TWRS

TWS

UST

WA-SRD

WHC

WIPP

WA

WAC

WQR
National Institute of Safety and Health

U.S. Nuclear Regulatory Commission

Office of Civilian Radioactive Waste Management

Occupational Safety and Health Administration

Public Law

Process Waste

Quality Assurance Requirements Document

Resource Conservation and Recovery Act of 1976

Revised Code of Washington

Request for Proposal

U.S. Department of Energy, Richland Operations Office

U.S. Department of Energy, Richland Operations Office

Implementing Procedure

Record of Decision

Retrieve Waste

Remediate Tank Waste

Safety Analysis Report

Systems Engineering

Systems Engineering Management Plan

System Generated

Spent Nuclear Fuel

System Requirements Description

Single-Shell Tank

Secondary Waste

To Be Determined

Transportation Control Plan

Hanford Federal Facility Agreement and Consent Order

Transuranic

Treatment, Storage, and Disposal

Technical Safety Requirement

Tank Waste

Tank Waste Remediation System

Tank Waste System

Underground Storage Tank

Waste Acceptance System Requirements Document

Westinghouse Hanford Company

Waste Isolation Pilot Plant

Waste Acceptance

Washington State Administrative Code

Waste Qualification Report 
WHC-SD-WM-FRD-020

Revision 1

TANK WASTE REMEDIATION SYSTEM

FUNCTIONS AND REQUIREMENTS DOCUMENT

\subsection{PURPOSE}

The Tank Waste Remediation System (TWRS) Functions and Requirements Document (FRD) transforms the criteria contained in the TWRS Mission Analysis Report, WHC-SDWM-MAR-008, Rev. 0 (Knutson 1995) (see FRD Section 4.1) into a set of executable functions constrained by derived and imposed requirements. The TWRS Mission Analysis Report, TWRS FRD, initial TWRS Baseline System Description (BSD), WHC-EP-0856 (Johnson 1995), and System Assessments establish the TWRS Functional Requirements Baseline.

Included in the FRD are the top three levels (Section 4.2) of the TWRS functions required to satisfy the TWRS mission needs, the requirements necessary to adequately perform the system functions, and the architectures that perform the functions. The TWRS FRD was developed according to applicable methods outlined in the TWRS Systems Engineering Management Plan (SEMP), WHC-SD-WM-SEMP-002, Rev. 0 (Peck 1996). The comprehensive description of the top three levels in the TWRS FRD provide a firm foundation for applying the Systems Engineering (SE) process to the TWRS, and ultimately completing the TWRS mission. The SEMP provides an overview of the SE process being implemented at the TWRS and identifies how the TWRS FRD will assist baseline development. The TWRS FRD is important for properly applying SE to the remediation of tank waste.

\subsection{SCOPE}

The requirements provided in this document, which are allocated to and within the TWRS, originate from many sources. These sources include Codes of Federal Regulations (CFRs), U.S. Department of Energy (DOE) Orders, Washington Administrative Codes (WACs), the Hanford Federal Facility Agreement and Consent Order (Tri-Party Agreement, Ecology et al. 1994), and relevant standards and procedures. Although additional source documents will continue to be reviewed for applicability, this document provides requirements from identified sources that are sufficient to establish an initial baseline of functional requirements. Continued application of the SE process will result in a level of detail that is sufficient to define the missions of individual TWRS projects. 
WHC-SD-WM-FRD-020

Revision 1

The TWRS FRD provides a link between the TWRS mission statement and necessary functional decompositions, and serves as a baseline for further decompositions of TWRS functions. Function decomposition, as defined in the TWRS SE procedures WHC-IP-1117, SEP-3.0 Rev 0, consists of dividing a well-defined function into two or more subfunctions, in an iterative process until all functions required to define the system are determined. Applicable requirements are then allocated to the defined functions, and architectures generated to perform the functions.

\subsection{BACKGROUND}

The TWRS was established in December 1991, when the Secretary of Energy recognized a need to better direct tank waste management activities at the Hanford Site. The Secretary directed the DOE, Richland Field Office (RL) to plan and execute an integrated TWRS Program for the Hanford Site. In November 1992, SE was adopted as the standard for development and management of the TWRS Program.

\subsection{HANFORD SITE TECHNICAL BASELINE}

As shown in Figure 4-1, the starting point for the Hanford Site Technical Baseline is the site mission "Clean Up Hanford" (level 0). Figure 4-1 graphically shows how the site mission is divided into functions, and that in order to accomplish the Site mission utilizing $\mathrm{SE}$, six functions must be realized. One of the six critical Site functions is "Remedy Unsafe and Unacceptable Conditions" (identified as item 4 on Figure 4-1). In order to execute this level 1 function, "Remedy Unsafe and Unacceptable Conditions" was functionally decomposed into six additional functional areas. One of the level 2 functions required to "Remedy Unsafe and Unacceptable Conditions" is "Remediate Tank Waste" (identified as item 4.2 on Figure 4-1); Remediate Tank Waste is the first function necessary to fulfill the TWRS mission.

Figure 4-2 provides a graphic representation of the SE functional "levels". These levels begin with the Site mission (Clean Up Hanford, level 0 ) to the level 3 functions required to execute the TWRS mission. Figure 4-3 continues this evolution by identifying the first three function levels for the TWRS (level 2 through level 4). These SE function "levels" will be referred to throughout Section 4.0. Functional decomposition of the TWRS will continue beyond level 4 as SE evaluation and optimization tools (SE procedures) are applied. 
Figure 4-1. Hanford Site Technical Baseline.

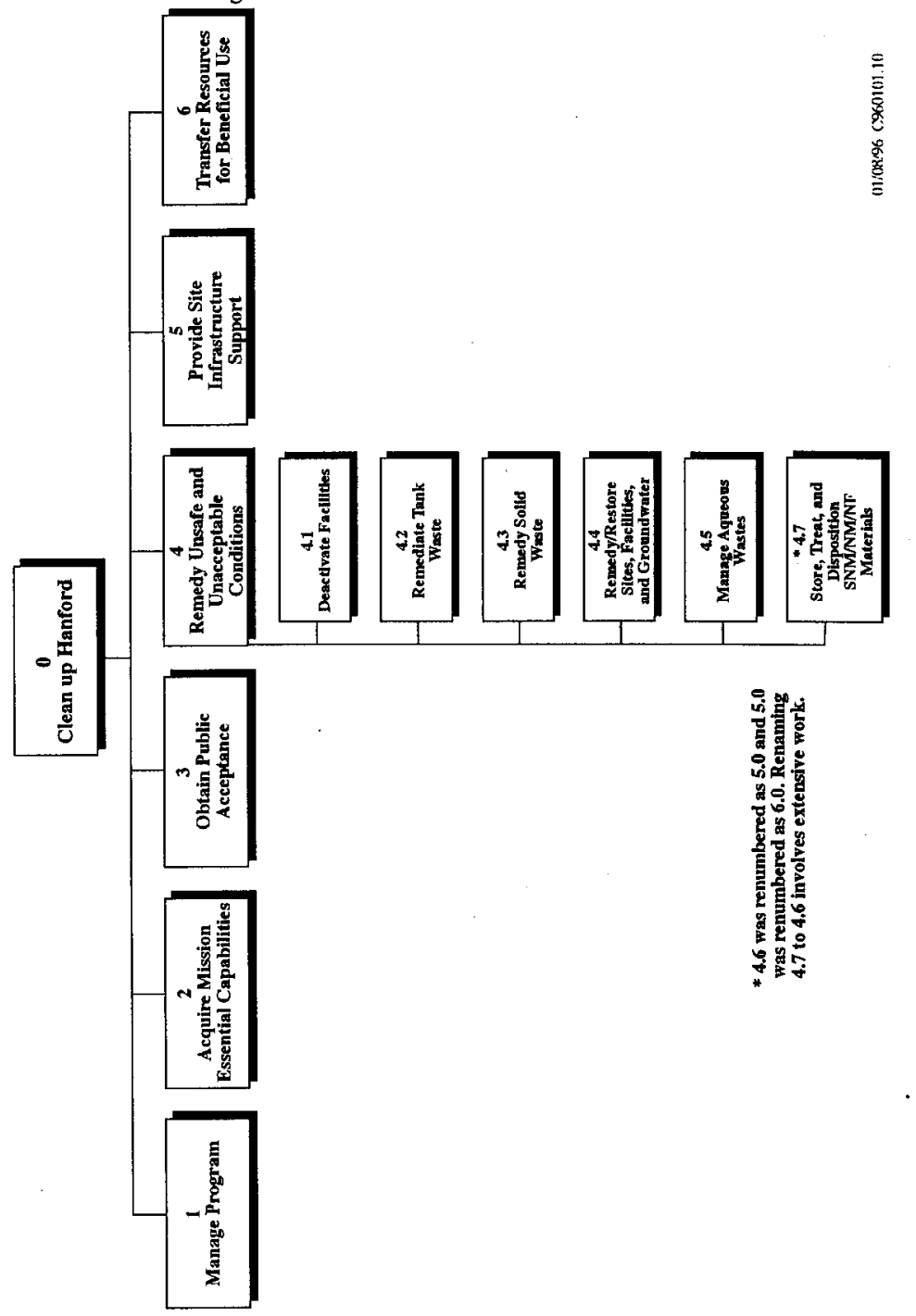


Revision 1

Figure 4-2. TWRS Systems Engineering Functional Levels.

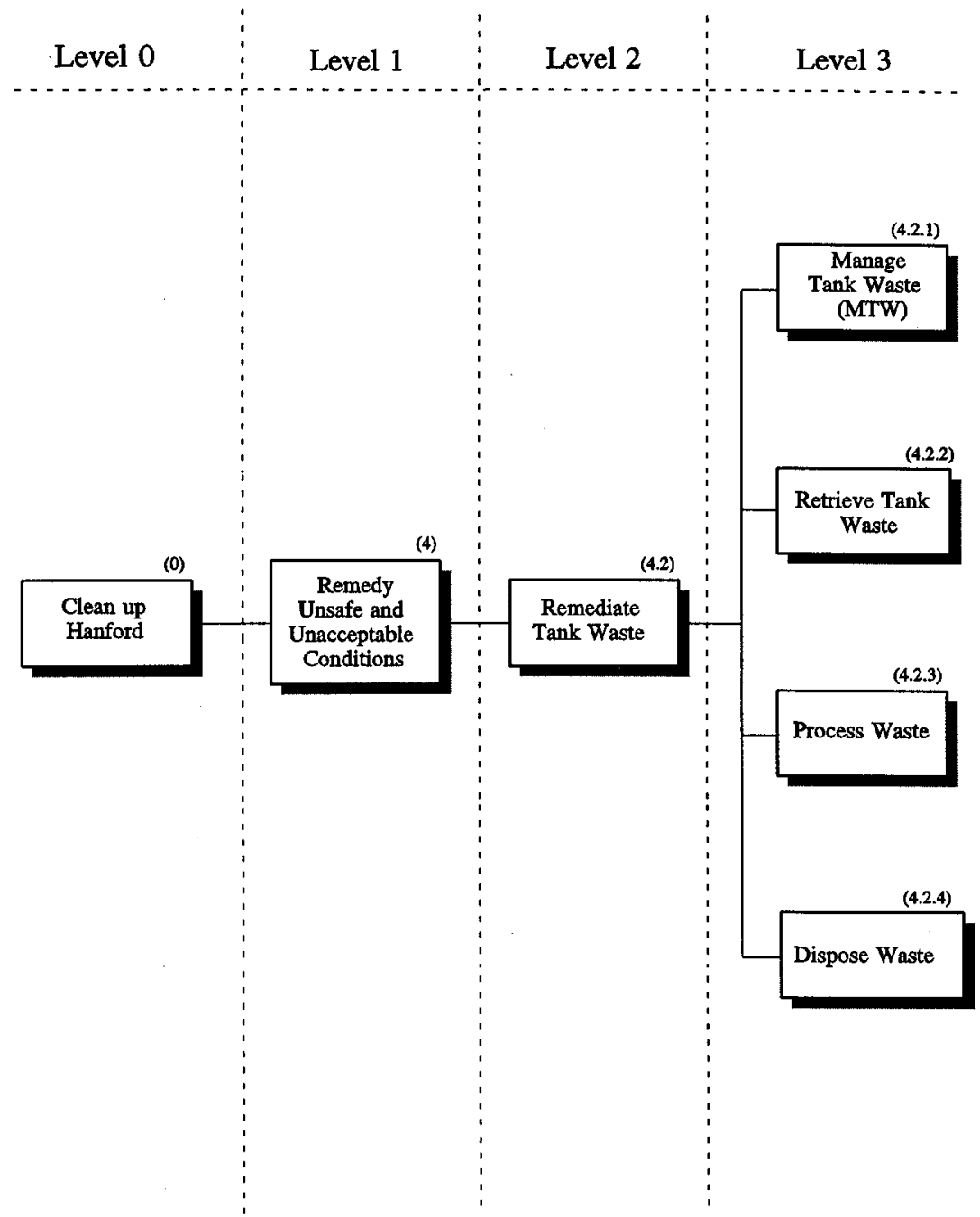


Figure 4-3. TWRS Functional Hierarchy.

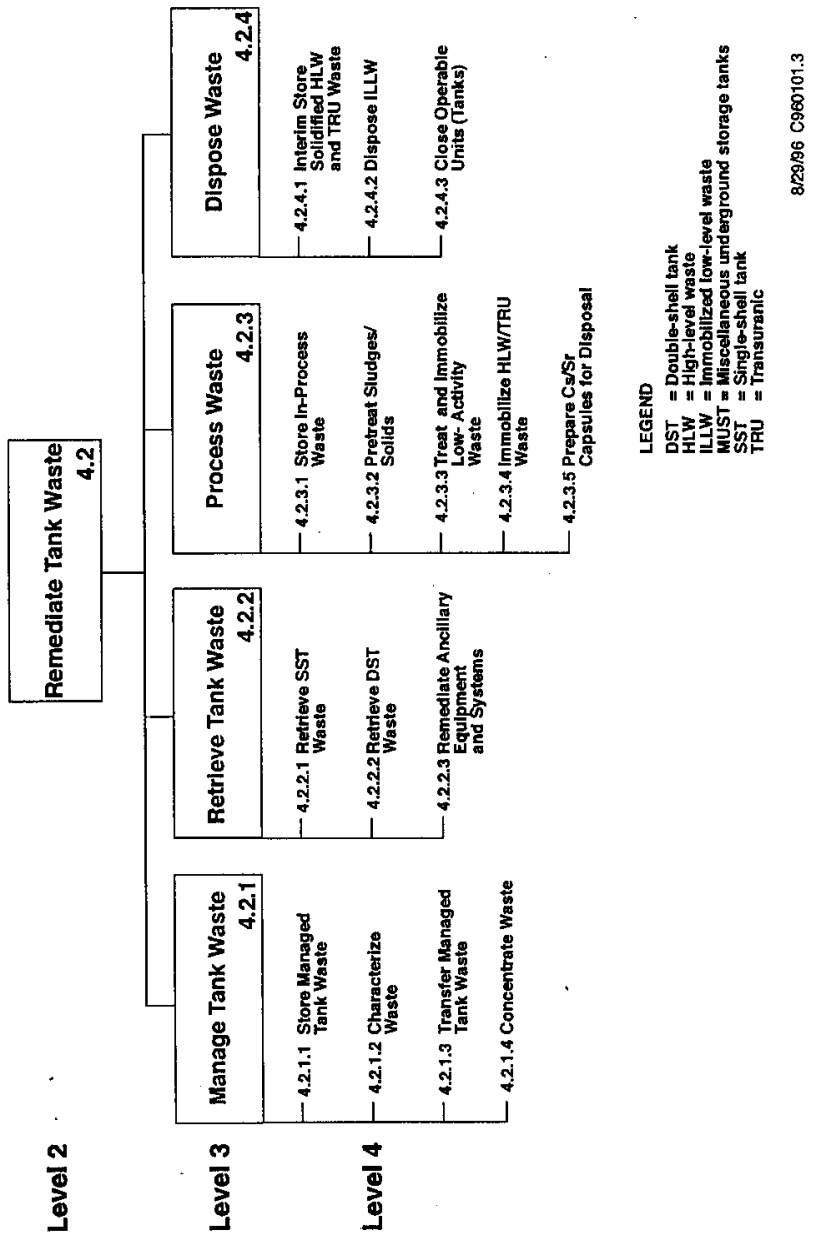


WHC-SD-WM-FRD-020

Revision 1

\subsection{TWRS MISSION ANALYSIS}

As identified in the TWRS Mission Analysis Report, the TWRS Program was established by DOE to: 1) manage and dispose of waste contained in underground storage tanks at the Hanford Site, 2) dispose of the encapsulated cesium and strontium, 3) close assigned operable units, and 4) decontamination and decommissioning most of TWRS facilities.

As defined in DOE Order 4700.1 (DOE 1987), an SE process is a sequence of activities that transform a mission need into a description of system performance parameters and a preferred system configuration. The TWRS Mission Analysis Report is crucial to the successful implementation of SE, and provides the connection between customer needs and system development. The mission analysis identifies initial system conditions and defines an acceptable end state. It is performed to transform a problem into a well- defined mission statement and establish the mission boundaries. The TWRS mission statement describes a top-level function (Remediate Tank Waste, level 2) suitable for functional decomposition and subsequent applications of the TWRS SE procedures. The TWRS Mission Analysis Report incorporates input from the values of the stakeholders into the decision-making process, and provides the analyses necessary to identify system-level requirements.

\subsection{TWRS FUNCTIONS AND REQUIREMENTS}

As shown in Figure 4-3, the level 2 function "Remediate Tank Waste" (RTW) has been decomposed into level 3 and level 4 functions necessary to accomplish the TWRS mission. The following text describes the database information supplied in Appendices A, B, C, D, E, F, G, and H. The appendices support the TWRS functional hierarchy (Figure 4-3), and provide the applicable TWRS functions, requirements, and architecture. The TWRS uses a database (RDD- $100^{*}$ ) as a tool for managing the TWRS Technical Baseline. The RDD-100 database accommodates several methods to sort data, and can produce various reports or specifications. The database information provided in the appendices is one method of sorting this information.

- Appendix A - Boundary Diagrams

- Appendix B - Function Description Tables

- Appendix C - Requirements Allocation Tables

- Appendix D - Constraints Definitions

- Appendix E - Performance Requirements Definitions

- Appendix F - Requirements Allocation Tables - Phase II

- Appendix G - Issues and Required Analyses

- Appendix H - Architecture Description.

Appendix A - Boundary Diagrams

"RDD-100 is a trademark of Ascent Logic Corporation. 


\section{Appendix A - Boundary Diagrams}

This appendix contains boundary diagrams for all level 2, 3, and 4 TWRS functions; refer to page A-3 to assist in this description. The boundary diagrams provide a graphic display of the functions' Inputs, Outputs, definition, and subfunctions. The diagrams identify the Inputs necessary for the defined function to be administered, and the Outputs realized after the function has been accomplished. Note that the intent of the boundary diagrams is not to track Inputs and Outputs throughout the TWRS functional levels; Appendices B and C are provided for that purpose.

\section{Appendix B - Function Description Tables}

Items contained in the TWRS FRD database are listed below. A short description of the data contained in each section follow the section heading, with necessary references for understanding the data noted. Refer to pages B-3 through B-7 to assist the following description. The roman numerals are consistent with the database identifiers.

I. FUNCTION ID NUMBER - A unique identification number for each TWRS function. The number scheme is based on using 4.2 to identify level 2 of the TWRS function tree, 4.2.i at level 3, 4.2.i.j for level 4 , and so forth. The function numbers (i.e., 4.2.1.2) equate to the function level. NOTE: The database can use the function ID number as a search value.

II. FUNCTION TITLE - A short description of the function. The description is usually a verb followed by a noun or a noun phrase. NOTE: The database can use the function title as a search value.

III. FUNCTION DEFINITION - A brief description or statement of primary purpose; the definition of what a system or subsystem must accomplish for the mission. Function definitions may include criteria the function must satisfy.

IV. INPUTS - An item that is needed in order for a function to produce desired outputs. The Input title is followed by a brief definition of each Input. To the right of most Input titles, the function FROM which the input originated is provided (see page B-3). Inputs can be classified as either internal (programmatic) or external, depending on whether they originated from within TWRS or the outside environment.

V. OUTPUTS - An item that is produced by the function after the function purpose has been realized. The output title is followed by a brief definition of each output of the function. To the right of most Output titles, the function TO which the Output is transferred is provided (see page B-4). 


\section{Appendix C - Requirements Allocation Tables}

This appendix provides a cross-reference to identify the requirements allocated to the TWRS functions, function Inputs, or function Outputs. As defined in this document, a requirement is a qualitative or quantitative statement of how well a function must be performed. Requirements may be one of two types: Constraints or Performance Requirements (see Appendices D and E). Refer to Appendix C to facilitate the following discussion.

Appendix $\mathrm{C}$ is sorted to show requirements allocated to specific TWRS functions (i.e., 4.2, Remediate Tank Waste). The columns identify the Constraints and Performance Requirements that have been allocated to the functions. Following the requirements allocated to the function, the Inputs for the function are sorted alphanumerically (i.e., Allocated Resources [Tank Waste], page C-9) with the columns displaying the requirements applicable to each Input. The Outputs from the function are again sorted alphanumerically and the allocated requirements shown in the columns [i.e., Closed Immobilized Low-Level Waste (ILLW) Sites, page C-13]. Note that Inputs and Outputs (Time Items) are provided to establish relationships between the TWRS functions. Typically, all functional requirements are displayed on the functions in Appendix C. The functional requirements are then grouped to applicable outputs from the sending function. At the receiver's function, the requirements allocated to the outputs sending functions are duplicated on the receiving inputs. This process continues until all of the requirements allocated to the TWRS functions and function Outputs are presented [i.e., 4.2.1 Manage Tank Waste (MTW)]. A special case exists for the functions being privatized during Phase I waste processing and immobilization. The Constraints and Performance Requirements shown in this appendix for functions 4.2.3.3 and 4.2.3.4 are limited to those applicable during Phase I. Refer to Appendix F for requirements applicable to Phase II.

\section{Appendix D - Constraints Definitions}

Constraints are requirements allocated to a function by the external environment (e.g., U.S. Congress, Washington State, EPA, DOE Orders). Constraints define applicable laws and regulations and are typically non-negotiable (some constraints will change with time, while others may be negotiated through a waiver process). The Constraints are comprehensive statutory, regulatory, and DOE Order-based statements of expectations. They place certain limits on the Performance Requirements. Refer to page D-3 to assist the following discussion. The appendix lists, in alphanumeric order, applicable constraint documents or sections thereof. If a Constraint title is listed in Appendices C, F, or G, refer to this Appendix for a description of the requirement.

\section{Appendix E - Performance Requirements}

'Performance Requirements are allocated to a function by the TWRS Program or a specific project. These requirements may be traded with other performance requirements to optimize overall system performance. Performance Requirements are characteristically more specific than Constraints, and are expected to be continually revised and improved during the 
mission life-cycle. Refer to page E-3 to assist in the following discussion. The appendix lists, in alphanumeric order, applicable Performance Requirements for the TWRS.

Following the Performance Requirement Definition, the source(s) of the requirement is listed in parentheses. If a Performance Requirement title is listed in Appendices $\mathrm{C}$ or $\mathrm{G}$, refer to this Appendix for a description of the requirement.

\section{Appendix F - Requirements Allocation Tables - Phase II}

Due to the special case of the functions being privatized as a result of the Phase I RFP (see special case in Appendix C), Appendix F was created to identify the functional requirements, which may be applicable to functions 4.2.3.3 and 4.2.3.4 during the second phase of waste processing and immobilization privatization. Though the requirements contained in the tables of this appendix are subject to change prior to initiating the Phase II effort, the requirements can be used as a starting point for the functions associated with Phase II waste processing and immobilization. These allocation tables are sorted in the same fashion as those in Appendix C.

\section{Appendix G - Issues and Required Analyses}

This appendix lists Issues and Required Analyses associated with the TWRS functions, requirements, and Time Items (Inputs and Outputs). An Issue may be a point of clarification needed, a discrepancy that exists, or an item that needs further evaluation to support the TWRS Functional Requirements Baseline. Each Issue has a related Required Analysis, which is necessary to resolve the Issue and further develop the TWRS technical bases. As shown in the first column on page G-3, the Issues and Required Analyses are sorted alphanumerically by title. The second column identifies, by title or function number, the affected Functions (Appendix B), Time Items (Inputs and Outputs, Appendices B, C, and F), Constraints (Appendix D), and Performance Requirements (Appendix E) linked to each Issue and Required Analysis.

\section{Appendix H - Architecture Description}

This appendix lists the TWRS Architectures that perform the applicable TWRS functions. Refer to page $\mathrm{H}-3$ to assist in the following discussion. The appendix lists the architecture definition, alternatives considered, rational for selecting alternatives, enabling assumptions, required analyses, and the functions performed by the architecture. 
WHC-SD-WM-FRD-020

Revision 1

\subsection{RISKS}

Appendix G lists currently known Issues and Required Analyses associated with the TWRS Functions and Requirements. From a programmatic viewpoint, these Issues present risks for proceeding with the implementation of some elements of the TWRS. A TWRS Risk Management List, WHC-SD-WM-RPT-201 (Collard 1995) has been produced to identify programmatic (cost, schedule) and technical risks associated with the program until all of the identified Issues are resolved. The TWRS Risk Management List will be modified throughout the TWRS life cycle as Issues are resolved, or new Issues are identified. 
WHC-SD-WM-FRD-020

Revision 1

\subsection{REFERENCES}

An overview of the references is included in this section. The list of references used in this document is extensive and made up of the following types of documents:

- Energy, Labor, and Environmental Protection CFRs

- DOE Orders

- DOE Guidance Documents

- Westinghouse Hanford Company Documents

- Secretarial Notices

- Tri-Party Agreement

- WACs

- NRC Technical Position

- Hanford Manuals.

References not shown in this section can be traced with their respective heading and titles provided in the appendices in this document.

10 CFR 60, 1992, "Disposal of High-Level Radioactive Wastes in Geologic Repositories," Code of Federal Regulations, as amended.

10 CFR 61, 1992, "Licensing Requirements for Land Disposal of Radioactive Waste," Code of Federal Regulations, as amended.

29 CFR 1910, 1992, "Occupational Health and Safety Standards, " Code of Federal Regulations, as amended.

40 CFR 50, 1991, "National Primary and Secondary Ambient Air Quality Standards," Code of Federal Regulations, as amended.

40 CFR 61, 1991, "National Emission Standards for Hazardous Air Pollutants," Code of Federal Regulations, as amended.

40 CFR 141, 1991, "National Primary Drinking Water Regulations," Code of Federal Regulations, as amended.

40 CFR 191, 1991, "Environmental Radiation Protection Standards for Management and Disposal of Spent Nuclear Fuel, High-Level and Transuranic Radioactive Wastes," Code of Federal Regulations, as amended.

40 CFR 264, 1991, "Standards for Owners and Operators of Hazardous Waste Treatment, Storage, and Disposal (TSD) Facilities," Code of Federal Regulations, as amended. 
WHC-SD-WM-FRD-020

Revision 1

40 CFR 265, 1991, "Interim Standards for Owners and Operators of Hazardous Waste Treatment, Storage, and Disposal Facilities, " Code of Federal Regulations, as amended.

40 CFR 268, 1991, "Land Disposal Restrictions (LDR)," Code of Federal Regulations, as amended.

Atomic Energy Act of 1954, as amended, 42 USC 201 1, et seq.

Comprehensive Environmental Response, Compensation, and Liability Act of 1980, as amended, 42 USC 9601 , et seq.

Energy Reorganization Act of 1974, as amended, 42 USC 5801, et seq.

National Environmental Policy Act of 1969, as amended, 42 USC 4321, et seq.

Nuclear Waste Policy Act, as amended, 42 USC 10101.

Resource Conservation and Recovery Act of 1976, as amended, 42 USC 6901 et seq.

Washington Hazardous Waste Management Act, Revised Code of Washington, RCW 70.105,

DOE 1987, Project Management System, DOE Order 4700.1, U.S. Department of Energy, Washington, D.C.

DOE 1988, General Environmental Protection Program, DOE Order 5400.1, U.S. Department of Energy, Washington, D.C.

DOE 1989, Comprehensive Environmental Response, Compensation, and Liability Act Requirements, DOE Order 5400.4,U.S. Department of Energy, Washington, D.C.

DOE 1990, Radiation Protection of the Public and the Environment, DOE Order 5400.5, U.S. Department of Energy, Washington, D.C.

DOE 1984, Environmental Protection, Safety, and Health Protection Standards, DOE Order 5480.4, U.S. Department of Energy, Washington, D.C.

DOE 1988a, Radiation Protection for Occupational Workers, DOE Order 5480.11, U.S. Department of Energy, Washington, D.C.

DOE 1988b, Radioactive Waste Management, DOE Order 5820.2A, U.S. Department of Energy, Washington, D.C. 
WHC-SD-WM-FRD-020

Revision 1

DOE 1989, General Design Criteria, DOE Order 6430.1A, U.S. Department of Energy, Washington, D.C.

DOE/EM, 1995, Waste Acceptance Product Specifications for Vitrified High-Level Waste Forms (WAPS), DOE/EM-0093, U.S. Department of Energy, Office of Environmental Management, Washington, D.C.

WAC 173-200, "Water Quality Standards for Groundwaters of the State of Washington," Washington Administrative Code, as amended.

WAC 173-303, "Dangerous Waste Regulations," Washington Administrative Code, as amended.

WAC 173-480, "Ambient Air Quality Standards and Emission Limits for Radionuclides," Washington Administrative Code, as amended.

WAC 246-247, "Radiation Protection - Air Emissions," Washington Administrative Code, as amended.

Armacost, L.L., D. von Winterfeldt, J. Creighton, M. Robershotte, Public Values Related to Decisions in the Tank Waste Remediation System Program, PNL-10107, 1994, Pacific Northwest Laboratory, Richland Washington

Boothe, G. F., 1995, Remediation and Cleanout Levels for Hanford Single-Shell Tanks, WHC-SD-WM-TI-711, Rev. 0, Westinghouse Hanford Company, Richland, Washington.

Collard, L., 1995, TWRS Risk Management List, WHC-SD-WM-RPT-201, Westinghouse Hanford Company, Richland, Washington.

DOE, 1991, Nuclear Safety Policy, SEN-35-91, U.S. Department of Energy, Washington, D.C.

DOE-OCRWM, 1993, Waste Acceptance System Requirements Document (WA-SRD), DOE/RW-0351P, Rev. 0, Office of Civilian Radioactive Waste Management, Washington, D.C.

DOE/RL, 1993, Hanford Mission Plan, Volume 1, Site Guidance, DOE/RL-93-08, U.S. Department of Energy, Richland Operations Office, Richland, Washington.

DOE/RL, 1994, TWRS Systems Engineering Management Plan, DOE/RL-93-106 Draft, U.S. Department of Energy, Richland Operations Office, Richland, Washington. 
DOE/RL, Hanford Site Budget Requests - Activity Data Sheets, ADS numbers 1200-0, $1210-0,1220-0,1230-0,1280-0,1240-0,1100-0,1110-0,1120-0,1130-0$, April 13, 1995, United States Department of Energy, Richland, Washington.

Ecology, EPA, and DOE, 1994, Hanford Federal Facility Agreement and Consent Order, as amended, Washington State Department of Ecology, U.S. Environmental Protection Agency, and U.S. Department of Energy, Olympia, Washington.

Hanford Tank Waste Task Force (HTWTF), Hanford Tank Waste Task Force (Final Report), 1993, Submitted by the Hanford Waste Tank Task Force to the Washington State Department of Ecology, U.S. Department of Energy, and the U.S. Environmental Protection Agency

Hanlon, B. M., 1993, Tank Farms Surveillance and Waste Status Summary Report for August 1993, WHC-EP-0182-65, Westinghouse Hanford Company, Richland, Washington.

Johnson, M. E., 1994, Tank Waste Remediation System Decisions and Risk Assessment, WHC-EP-0786, Westinghouse Hanford Company, Richland, Washington.

Johnson, M. E., 1995, Tank Waste Remediation System Baseline System Description, WHC-EP-0856, Rev. 0, Westinghouse Hanford Company, Richland, Washington.

Knutson, B. ., 1995, Tank Waste Remediation System Mission Analysis Report, WHC-SD-WM-MAR-008, Rev. 0, Westinghouse Hanford Company, Richland Washington.

Peck, L. G., 1996, Systems Engineering Management Plan, WHC-SD-WM-SEMP-002, Rev, 0, Westinghouse Hanford Company, Richland, Washington.

PNL, 1994, Integrated Risk Assessment Program: Methodology and Results from Qualitative Evaluation of Current Hanford Site Risks to the Public, PNL-10154, Pacific Northwest Laboratory, Richland, Washington.

PNL, 1995, Methodology and Result from Qualitative Evaluation of Current Hanford HighLevel Waste Tanks Risks to the Public, PNL-10725, Pacific Northwest Laboratory, Richland, Washington.

Wagoner, J. D., 1994, "Change to Single-Shell Tank Memoradum of Agreement," (letter \#40517 to J. E. Baudlitz and J. E. Lytle, August 12, 1994) U.S. Department of Energy, Richland Operations Office, Richland, Washington. 
WHC-SD-WM-FRD-020

Revision 1

Working Group (The Hanford Future Site Uses Working Group) The future for Hanford: Uses and Cleanup, 1992, The Final Report of the Hanford Future Site Uses Working Group, Chairman Dr. Marshall E. Drummond, Eastern Washington University, Cheney, Washington.

WHC, 1996, Environmental Compliance Manual, WHC-CM-7-5, Westinghouse Hanford Company, Richland, Washington. 
WHC-SD-WM-FRD-020

Revision 1

This page intentionally left blank. 
WHC-SD-WM-FRD-020

Revision 1

\subsection{GLOSSARY OF KEY TERMS}

Architecture Description: The architecture description provides the architecture definition, alternatives considered, rational for selecting alternatives, enabling assumptions, required analyses, and the functions performed by the architecture.

Baseline System Description: The BSD presents a description of the physical systems for accomplishing the TWRS mission and is consistent with the defined TWRS functions and requirements. The BSD document provides a simple, top-level technical description of the TWRS Program including architectures, and operations and maintenance concepts.

Boundary Diagrams: The boundary diagrams provide a graphic display of the functions' inputs, outputs, definition, and subfunctions. The diagrams identify the Inputs necessary for the defined function to be administered, and the Outputs realized after the function has been accomplished (See Appendix A).

Constraints: Constraints are requirements allocated to a function by the external environment (e.g., U.S. Congress, Washington State, EPA, DOE Orders). Constraints . define applicable laws and regulations and are typically non-negotiable (some constraints will change with time, while others may be negotiated through a waiver process), however, changes must be approved by the external agency or group responsible for the constraint source. Constraints are selected based on their applicability to the system being developed.

Function Decomposition: Function decomposition consists of dividing a well-defined function into two or more subfunctions.

Function Definition: A primary statement of purpose; a definition of what a system or subsystem must accomplish to meet the overall mission. The function definition is a brief description of what the particular function must accomplish. Function definitions may also identify the criteria for completing the functions' purpose.

Functional Requirements: Functional requirements are verifiable statements that define what the system must accomplish or must be able to do. Functional requirements are developed from function definitions in the early phases of the system analysis and often are developed into quantified performance requirements.

Inputs: Also identified as a Time Item (see Outputs), Inputs are items needed for a function to produce desired outputs. Inputs can be classified as either internal (programmatic) or external, depending on whether they originated from within TWRS or from the outside environment, respectively. 
Issues and Required Analyses: Issues and Required Analyses are associated with requirements, functions, and Time Items (Inputs and Outputs). An Issue identifies a point of clarification needed, a discrepancy that exists, or an item that needs further evaluation to support the TWRS Functional Requirements Baseline. Each Issue has a related Required Analysis that identifies any action that is necessary to resolve the Issue and further develop the TWRS technical bases.

Low-Activity Radioactive Waste (LAW): The residual product of separation processes from HLW, from which the largest technically and economically practicable amount of apportioned total site activity attributable to HLW has been isolated for disposal in a deep geological repository, and which, when solidified, is at a lower than NRC Class C low-level waste radioisotope concentration limits.

Low-Level Radioactive Waste (LLW): Waste that contains radioactivity and is not classified as high-level radioactive waste, spent nuclear fuel, or by-product material (as defined in section IIc(2) of the Atomic Energy Act of 1954, \{42 USC 2014(e)(2)\}). This includes the fraction of the Hanford tank waste remaining after separating out, to the extent technically possible, insoluble HLW solids, ${ }^{137} \mathrm{Cs},{ }^{99} \mathrm{Tc},{ }^{90} \mathrm{Sr}$, and TRU. The LLW fraction reside in the tanks in the form of a high-sodium content, alkaline supernatant (mostly in double-shell tanks), or as a saltcake produced by removing the water from the supernatant (mostly in single-shell tanks). The feed to the LLW plant will be a supernatant requiring the radionuclide separations listed above.

Outputs: Also identified as a Time Item (see Inputs), Outputs are items produced by the function after the function purpose has been realized.

Performance Requirements: Performance requirements are allocated to a function by the TWRS Program or a specific project. These requirements may be traded with other performance requirements to optimize overall system performance. Performance Requirements are characteristically more specific than Constraints, and are expected to be continually revised and improved during the mission life-cycle.

Requirements: A requirement is a qualitative or quantitative statement of how well a function must be performed.

Systems Engineering: The systematic approach used by management and engineering to transform technical objectives into an optimized, operational, physical system that achieves the mission. The iterative technical and management process applied throughout the system life-cycle that produces and maintains a well defined and documented system technical baseline.

Systems Engineering Management Plan (SEMP): The Systems Engineering Management Plan (SEMP) describes how the Westinghouse Hanford Company (WHC) will implement Systems Engineering in TWRS Programs. 
Tank Waste Remediation System (TWRS): An integrated solution for carrying out the specific functions associated with remediating tank waste at the Hanford Site.

TWRS Mission: As identified in the TWRS Mission Analysis Report, the TWRS Program was established by DOE to: 1) manage and dispose of waste contained in underground storage tanks at the Hanford Site, 2) dispose of the encapsulated cesium and strontium, 3) close assigned operable units, 4) decontamination and decommissioning most of TWRS facilities. 
WHC-SD-WM-FRD-020

Revision 1

This page intentionally left blank. 
WHC-SD-WM-FRD-020

Revision 1

APPENDIX A

BOUNDARY DIAGRAMS

A-1 
WHC-SD-WM-FRD-020

Revision 1

This appendix contains boundary diagrams for all level 2, 3, and 4 TWRS functions; refer to page A-3 to assist in this description. The boundary diagrams provide a graphic display of the functions' Inputs, Outputs, definition, and subfunctions. The diagrams identify the Inputs necessary for the defined function to be administered, and the Outputs realized after the function has been accomplished. 

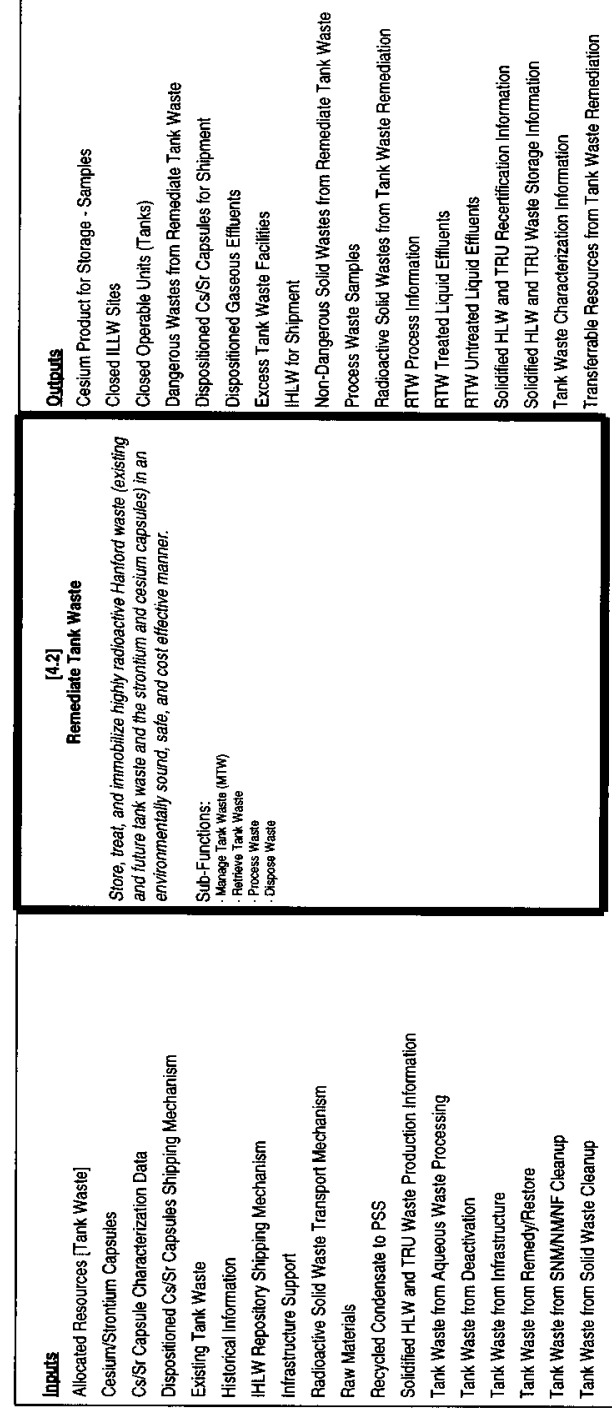

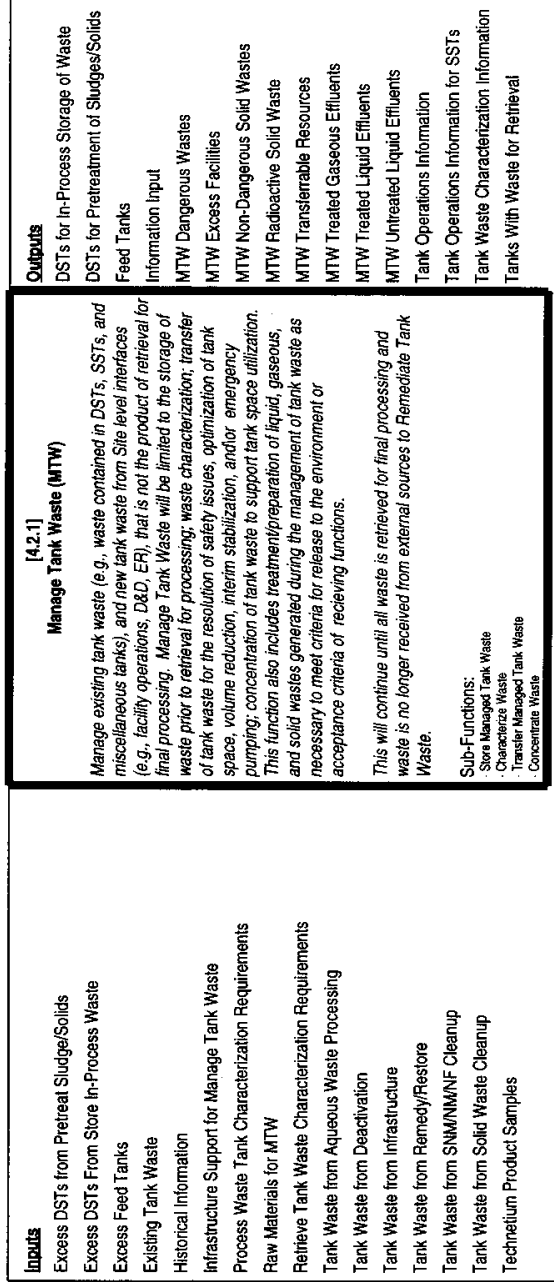


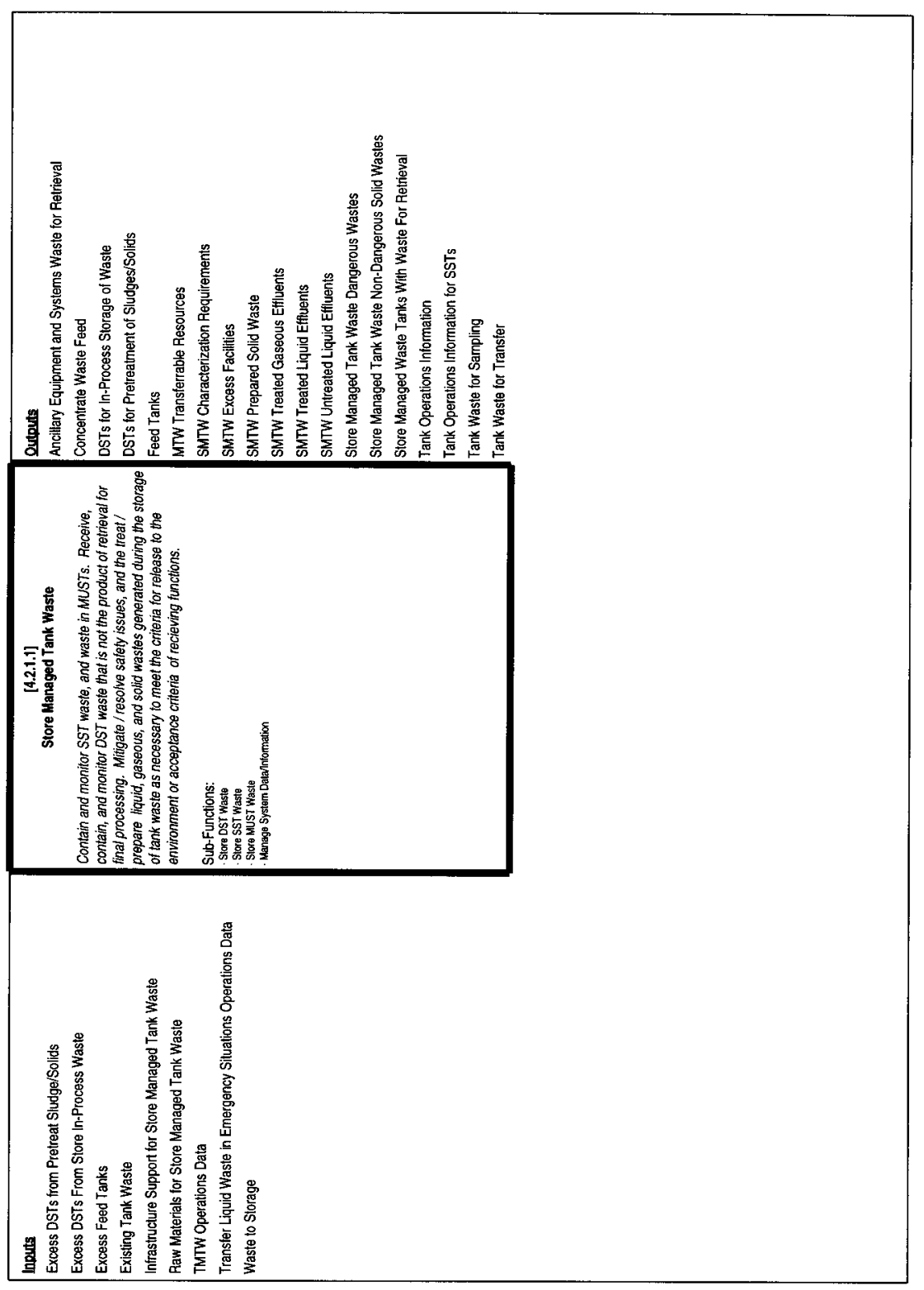




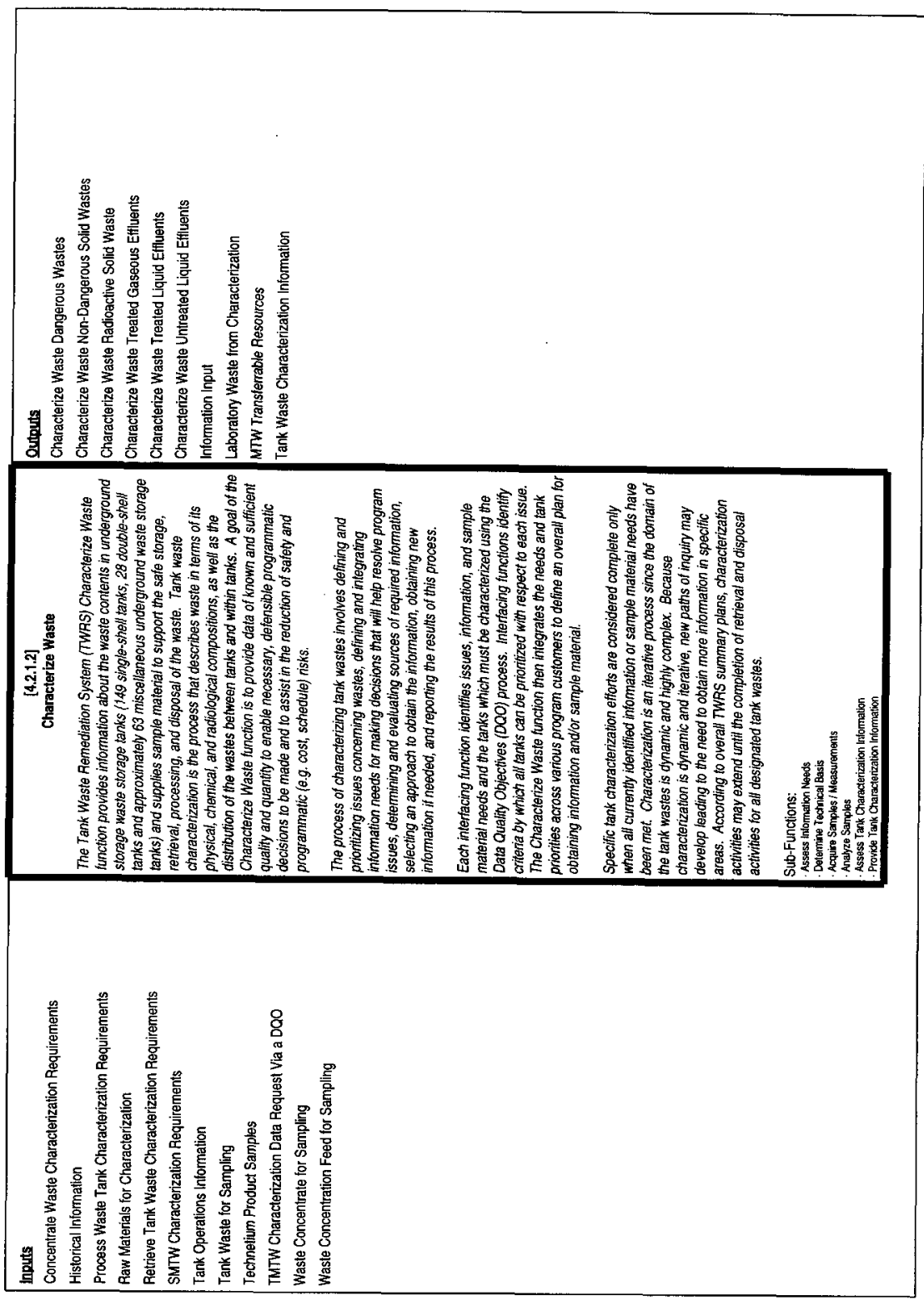



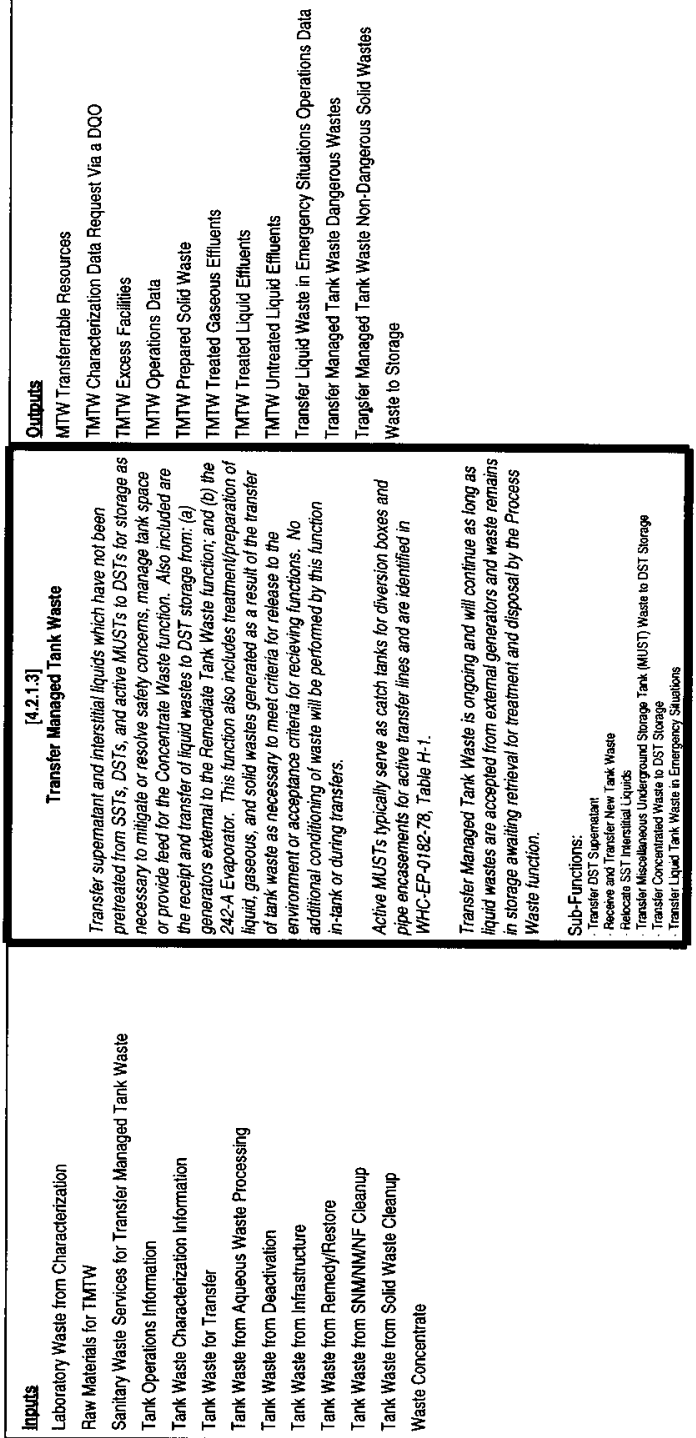


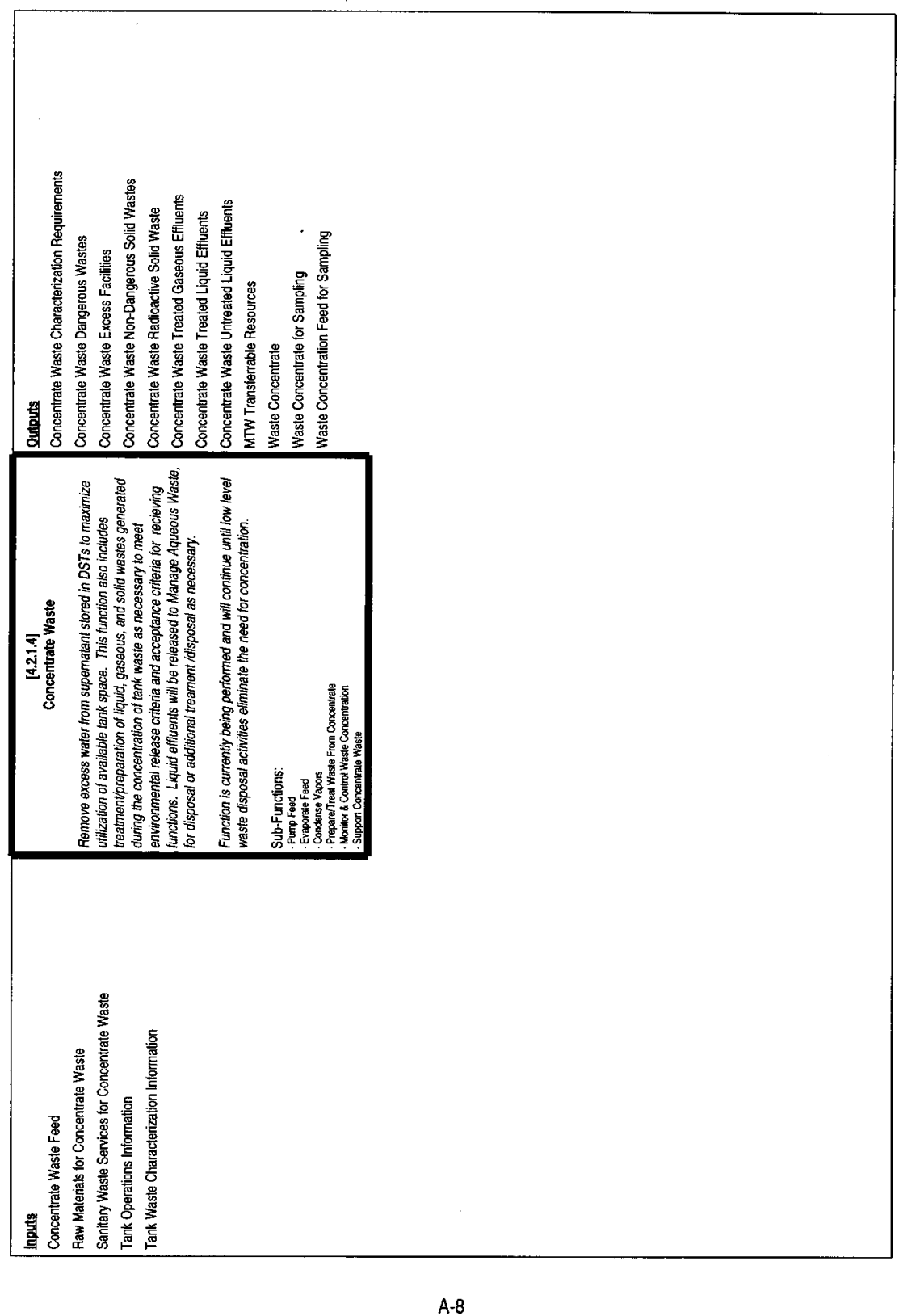




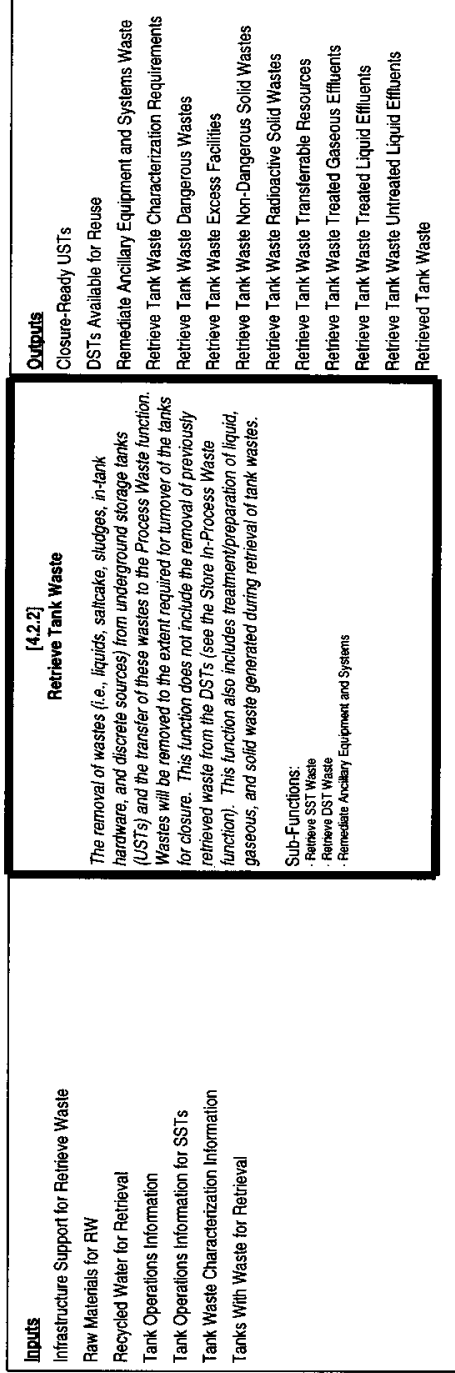




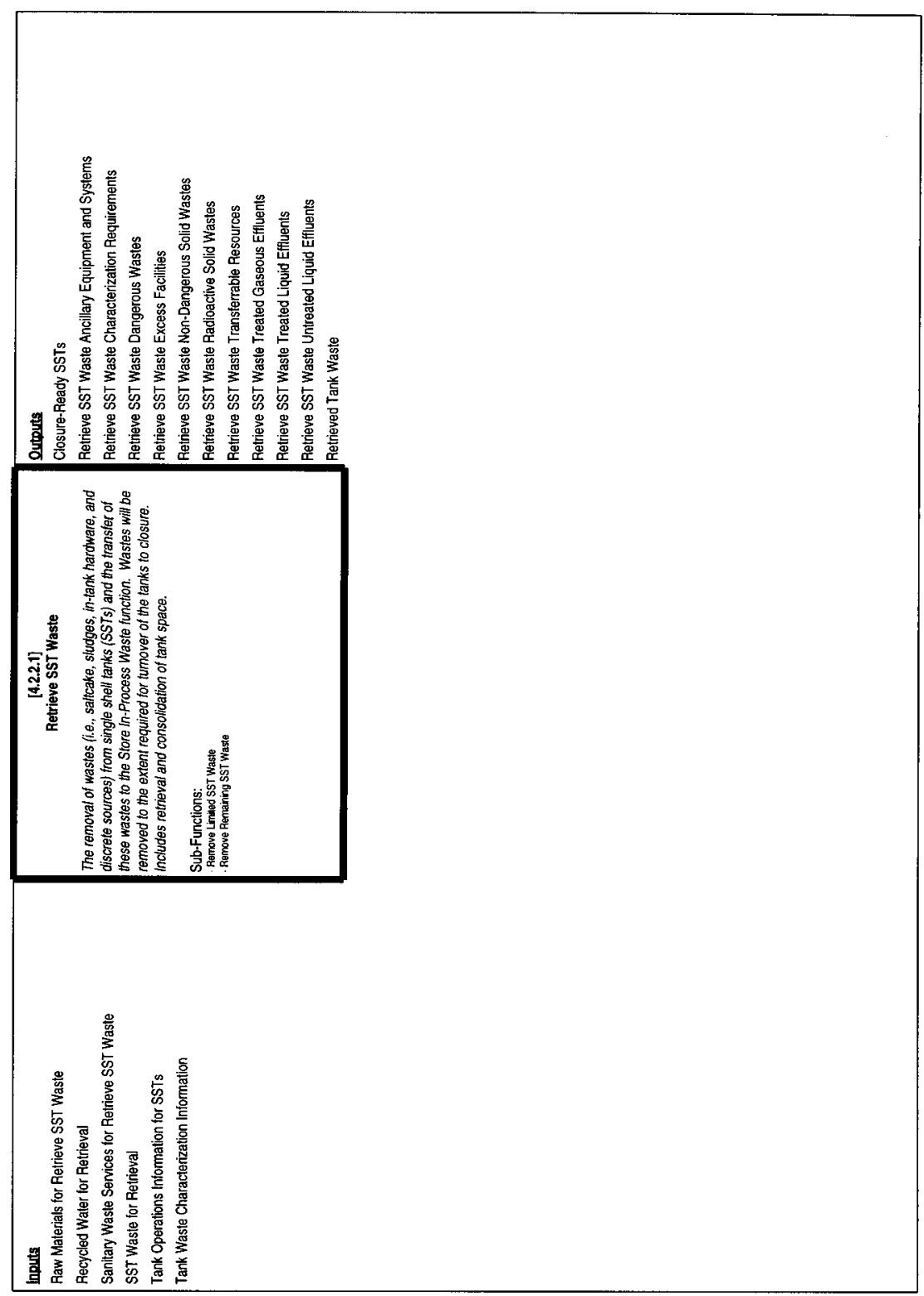




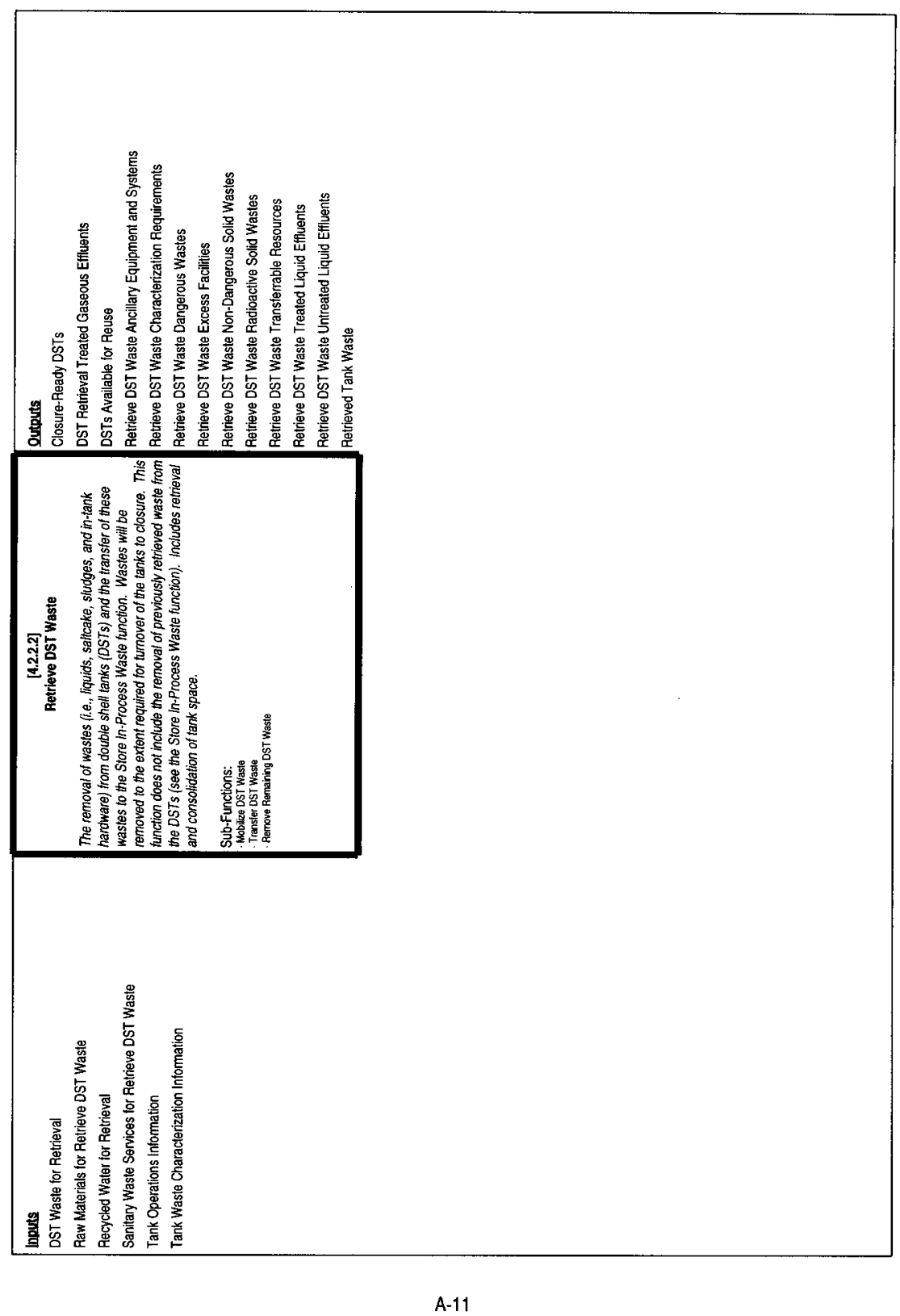



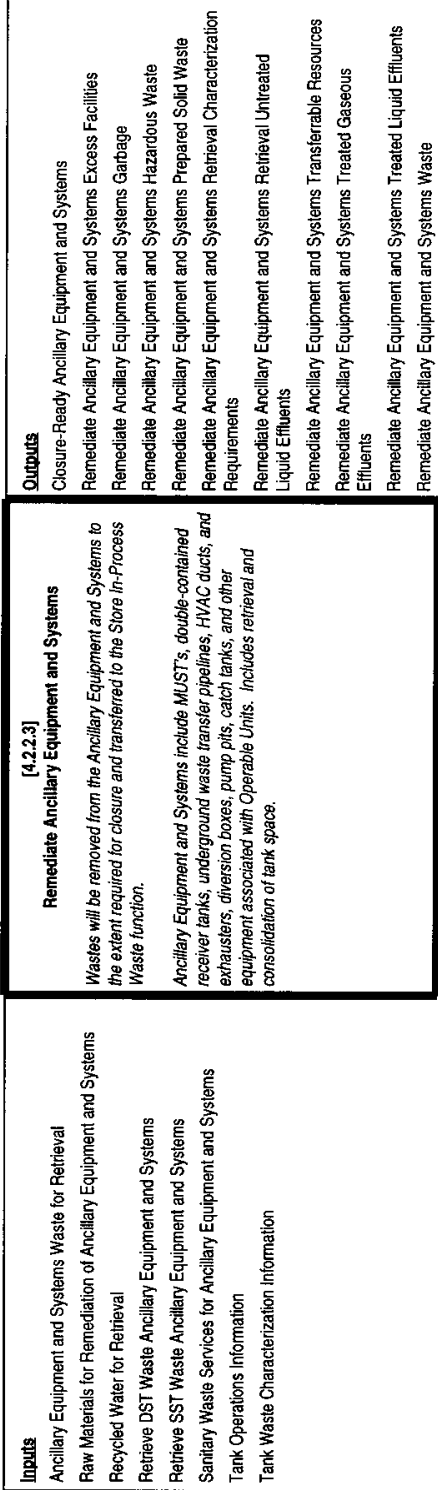

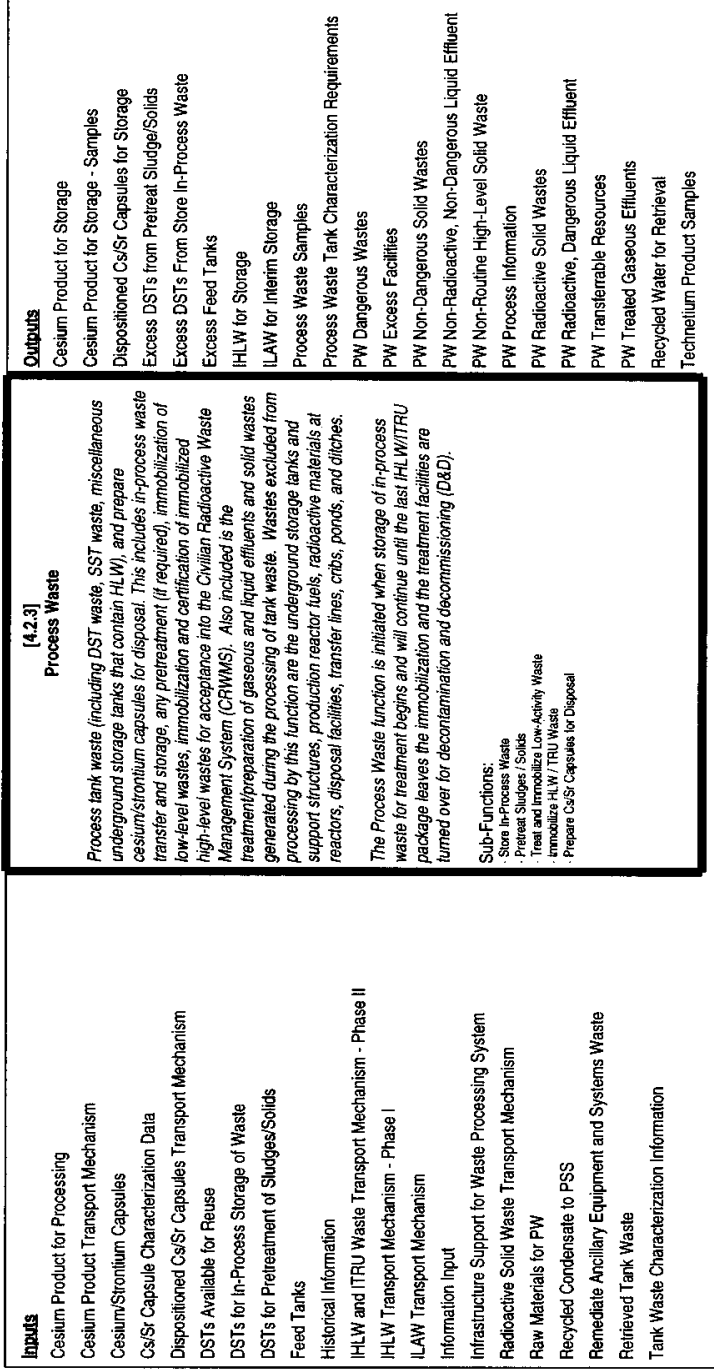


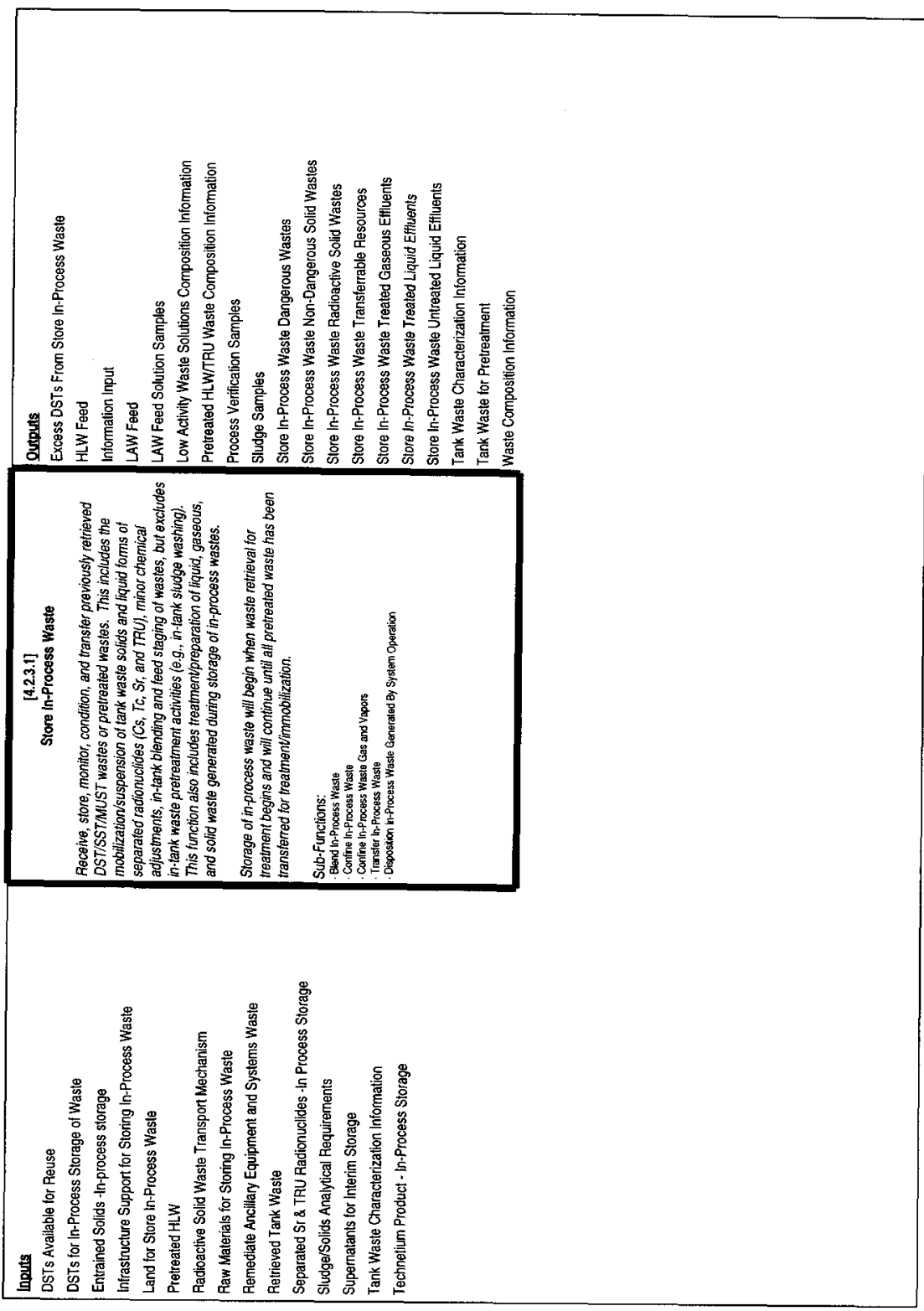



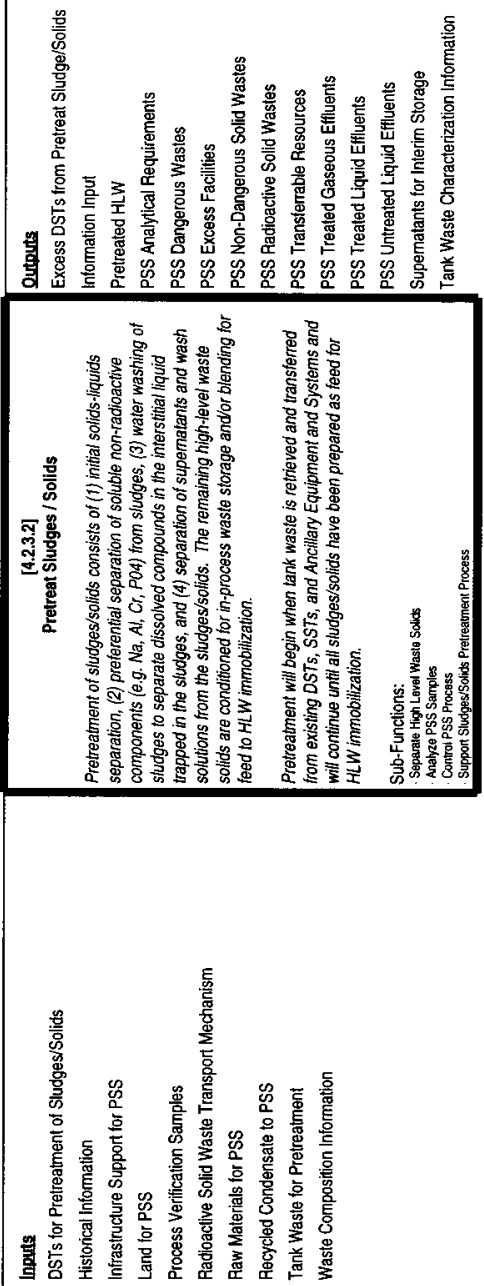

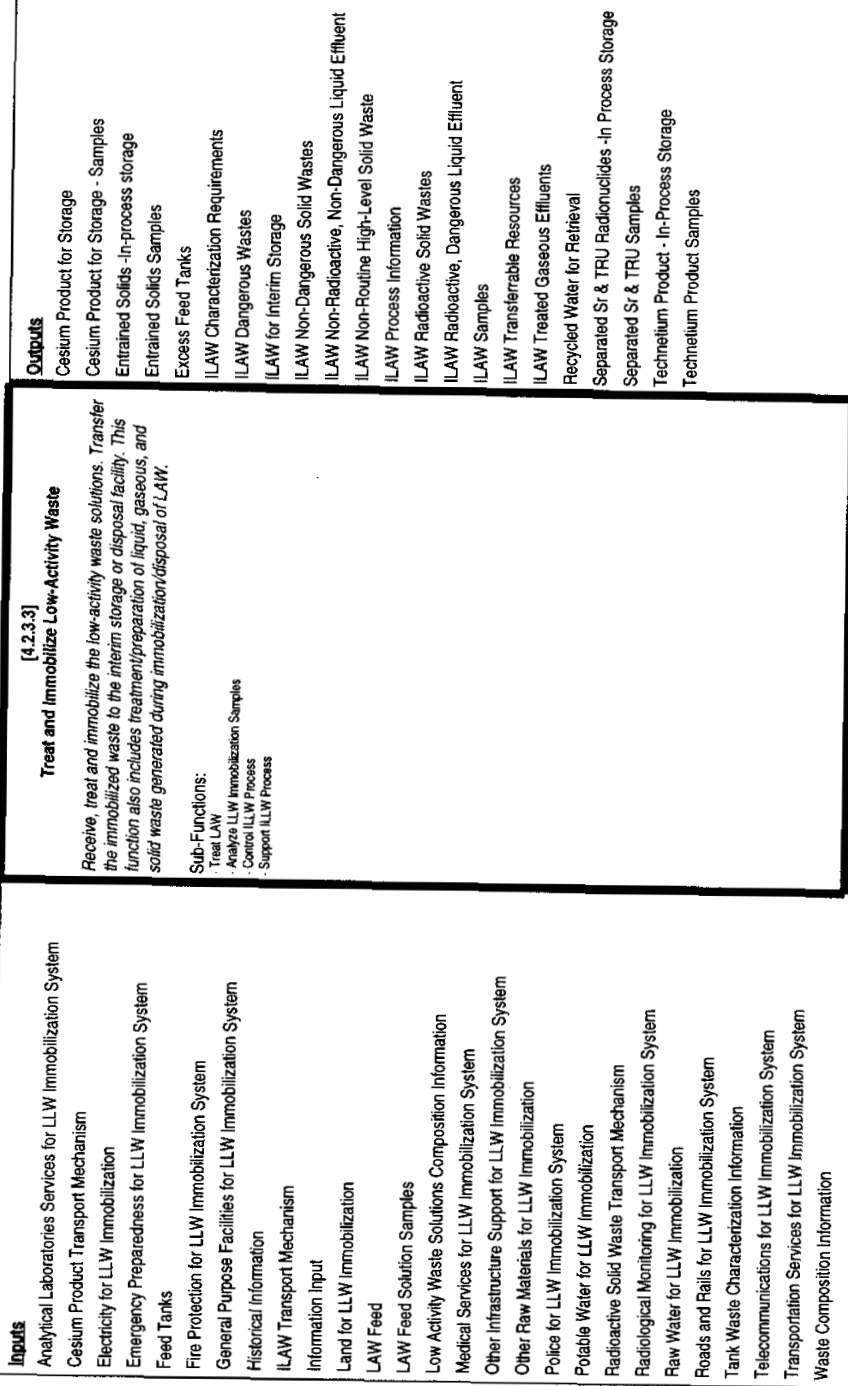


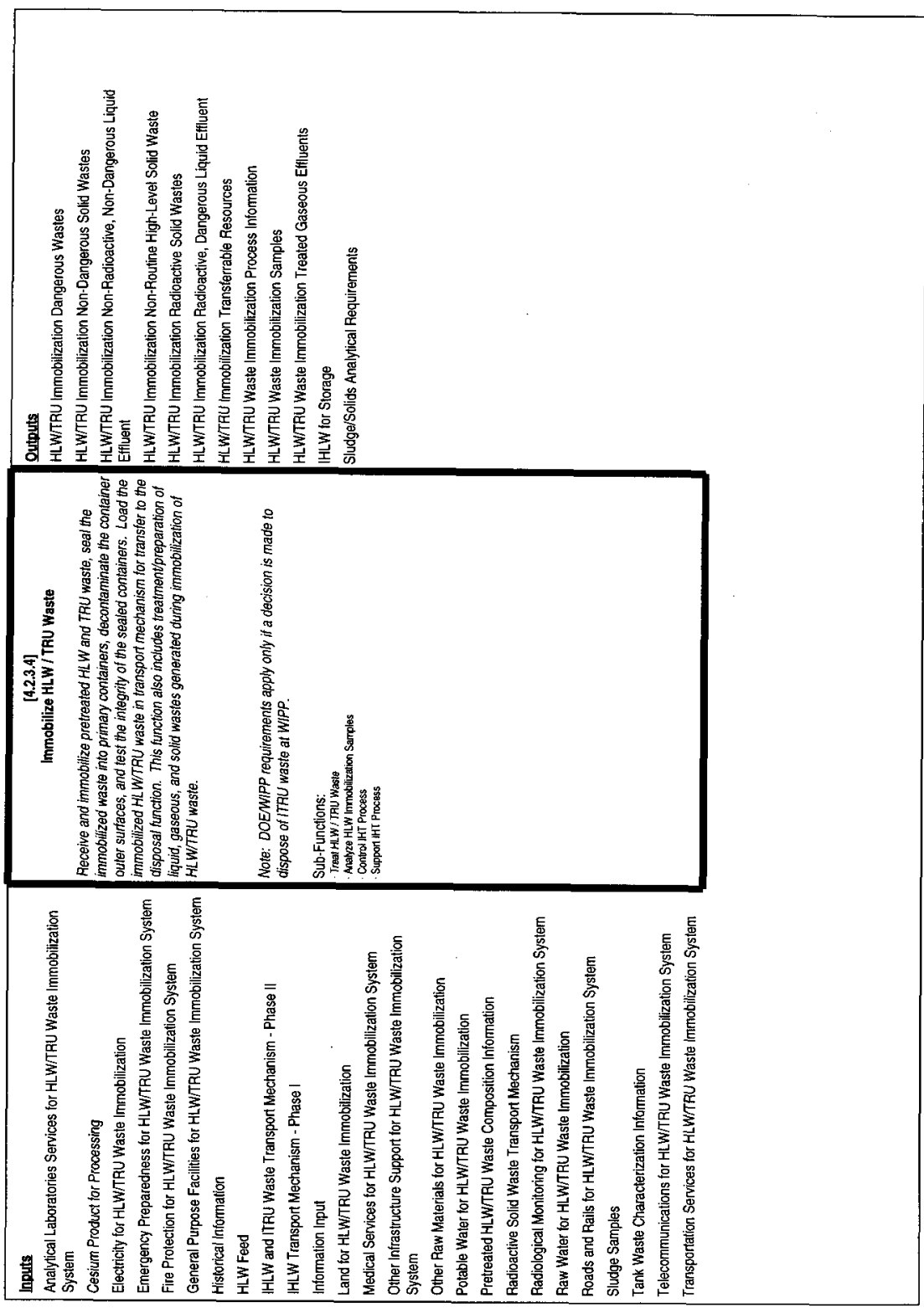




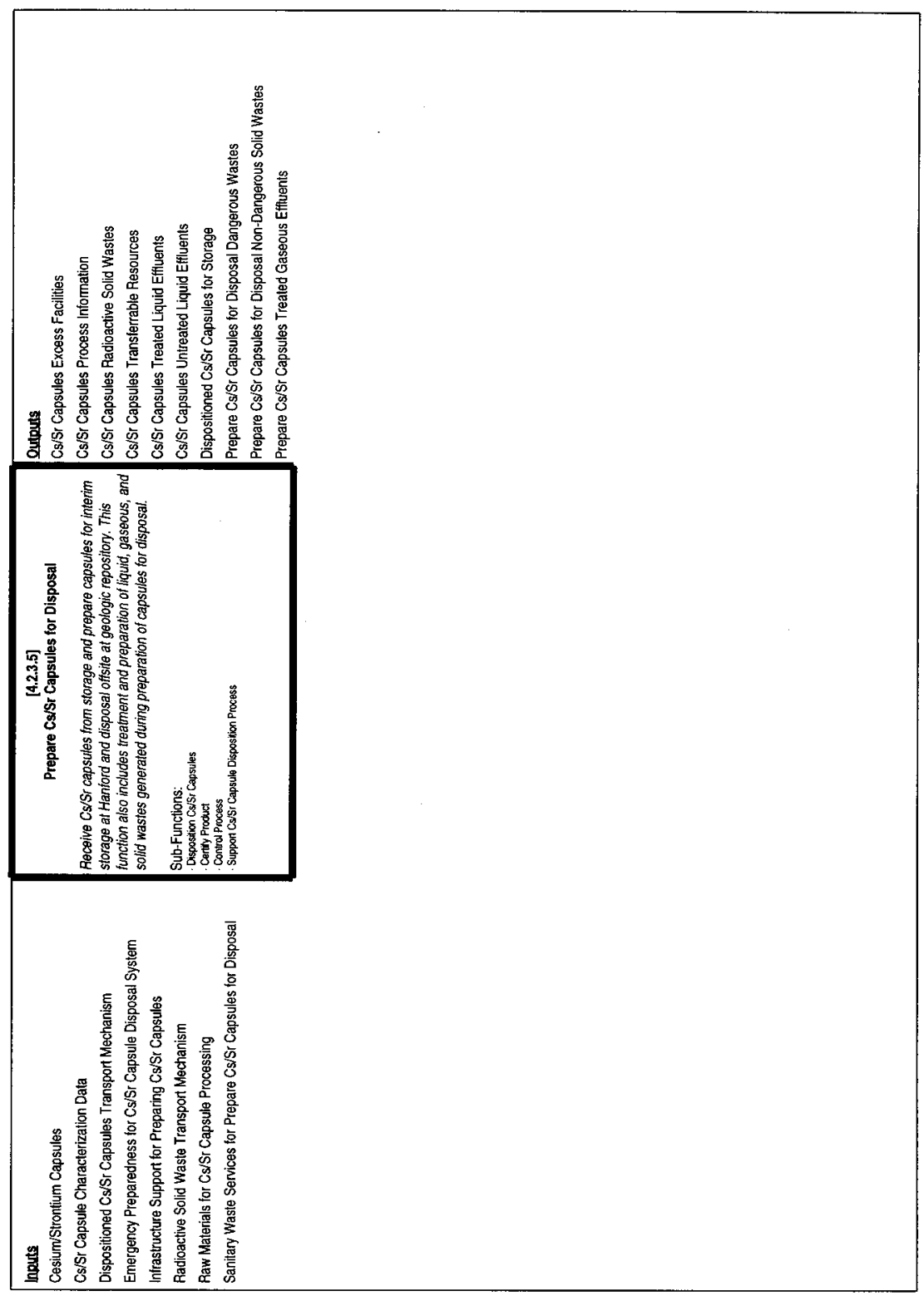




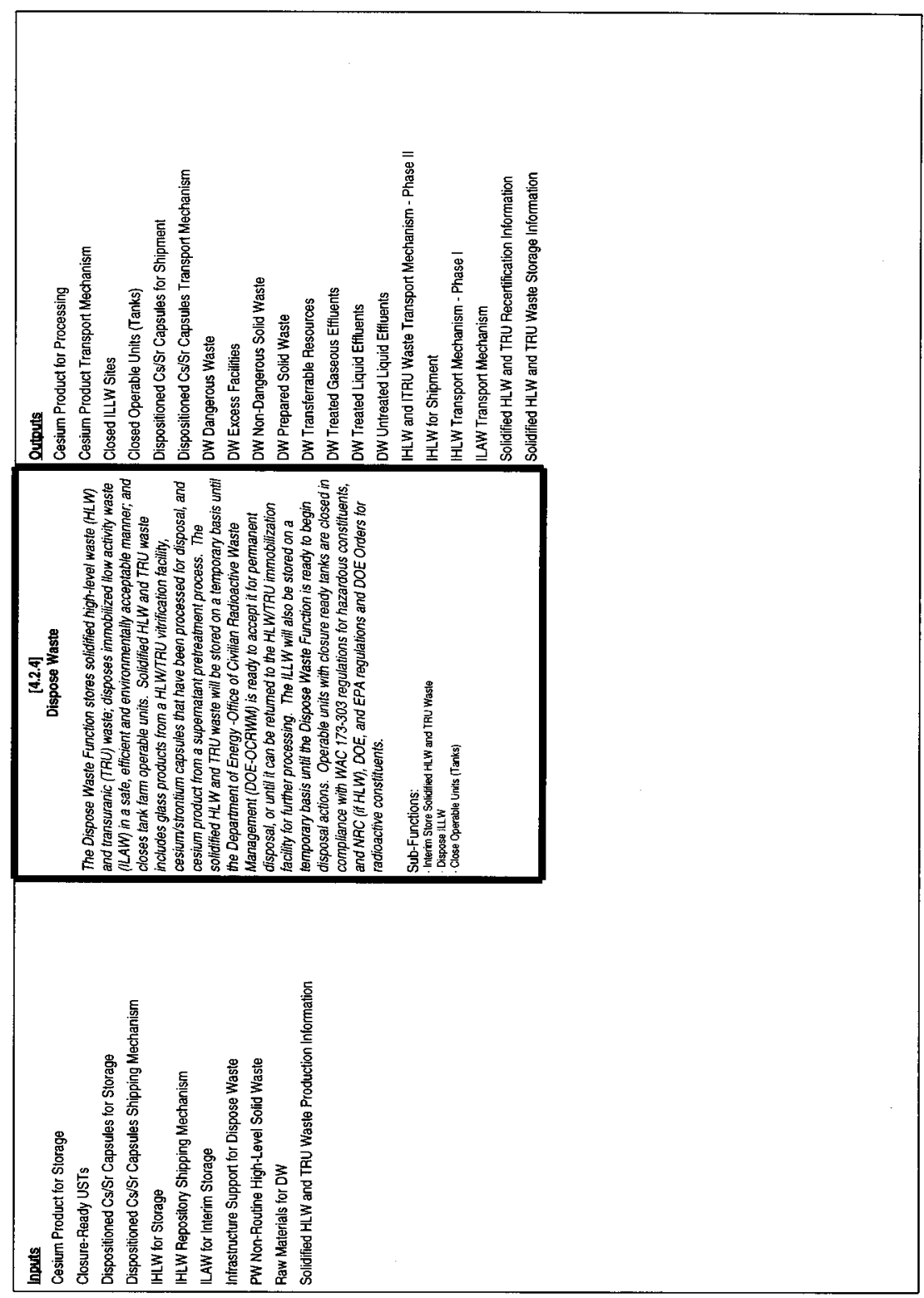



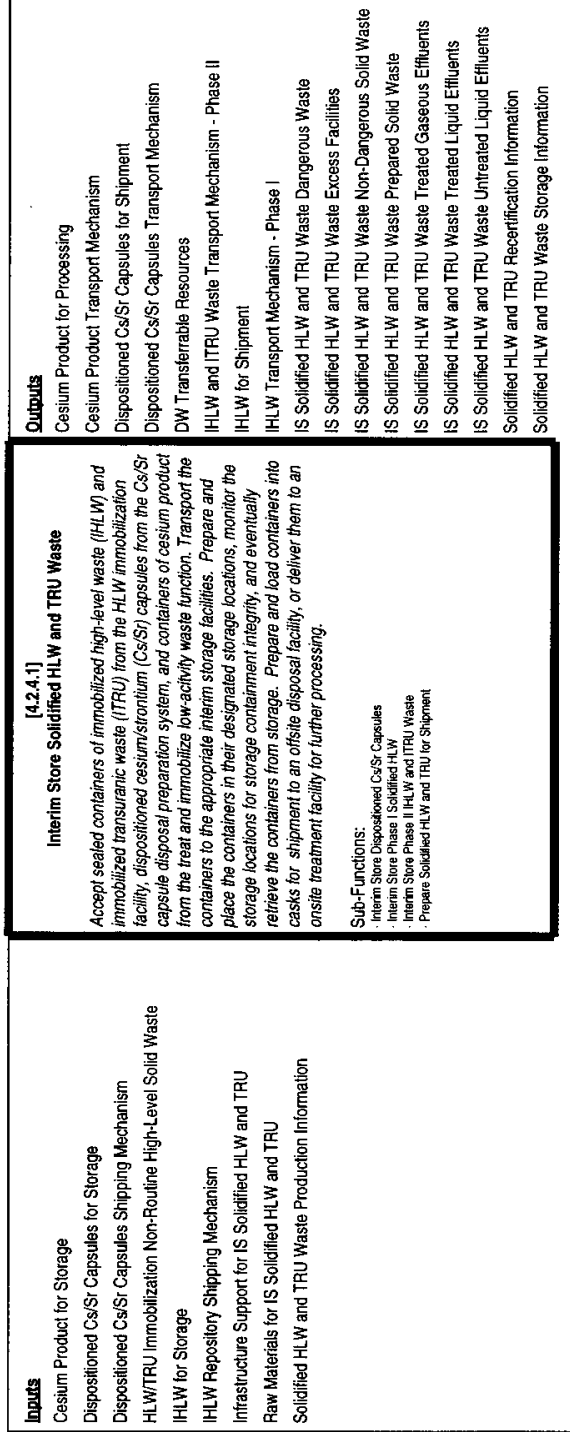

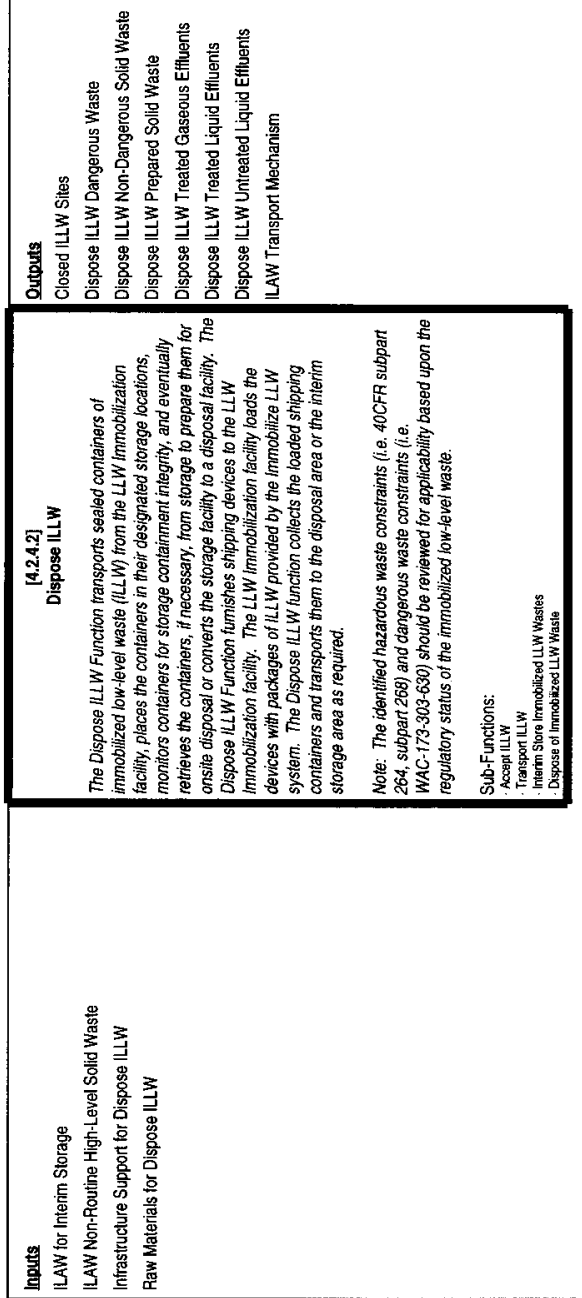

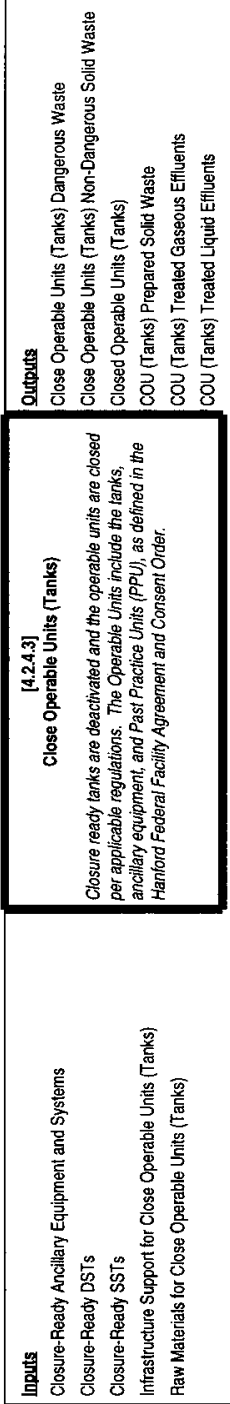
WHC-SD-WM-FRD-020

Revision 1

APPENDIX B

FUNCTION DESCRIPTION TABLES

B-1 
WHC-SD-WM-FRD-020

Revision 1

A short description of the data contained in each section follow the section heading.

I. Function ID Number - A unique identification number for each TWRS function.

II. Function Title - A short description of the function.

III. Function Definition - A brief description or statement of primary purpose; the definition of what a system or subsystem must accomplish for the mission.

IV. Inputs - An item that is needed in order for a function to produce desired outputs.

V. Outputs - An item that is produced by the function after the function purpose has been realized. 


\section{FUNCTION ID NUMBER: 4.2}

II. FUNCTION TITLE: Remediate Tank Waste

\section{FUNCTION DEFINITION:}

Store, treat, and immobilize highly radioactive Hanford waste (existing and future tank waste and the strontium and cesium capsules) in an environmentally sound, safe, and cost effective manner.

\section{INPUTS:}

\subsection{I1 Allocated Resources [Tank Waste]}

From: 1

Financial resources authorized to the implementing organization for completion of the function.

\subsection{Cesium/Strontium Capsules}

$\mathrm{Cs} / \mathrm{Sr}$ capsules removed from storage to be dispositioned.

\subsection{I3 Cs/Sr Capsule Characterization Data}

Certification data describing the radiological, chemical, and physical attributes of Cs and Sr capsules.

\subsection{I4 Dispositioned Cs/Sr Capsules Shipping Mechanism}

The shipping cask and vehicle provided by DOE-OCRWM for the shipment of containers of dispositioned $\mathrm{Cs} / \mathrm{Sr}$ capsule product to the geologic repository.

\subsection{I5 Existing Tank Waste}

From: External

Radioactive mixed waste generated from processing spent nuclear fuels and currently stored in DSTs, SSTs, and miscellaneous underground storage tanks (MUSTs). This waste also includes the in-tank hardware and discrete radioactive sources found in the waste tanks which will require retrieval for disposal purposes.

\subsection{I6 Historical Information}

From: External

Historical information is made up of chemical process and waste management information. These include documented and institutional knowledge, historical derived information transcribed to tank layer models, and historical tank content estimates.

Historical data includes: chemical process operations technical manuals (text and flowsheets); interviews with long-time operations and engineering personnel; process aids; reports, memos and logbooks; transfer histories; and simulant studies.

\subsection{IHLW Repository Shipping Mechanism}

From: External

The shipping cask and vehicle provided by DOE-OCRWM for the shipment of sealed IHLW containers 
Appendix B - Function 4.2

to the geologic repository.

\subsection{I8 Infrastructure Support}

From: 5

General infrastructure support needed to store, treat and immobilize tank waste. This will include but is not limited to fire protection, police, emergency preparedness, medical services, road services, telecommunications, radiological services, laboratory services, transportation and sewer. This includes land for siting facilities.

\subsection{I9 Radioactive Solid Waste Transport Mechanism}

From: 4.3

Equipment and service for on-site transport of packaged radioactive solid wastes.

\subsection{I10 Raw Materials}

From: External

Any material needed from outside of the Remediate Tank Waste function for storing, treating, or immobilization and disposal of tank waste.

\subsection{I11 Recycled Condensate to PSS}

From: 4.5

Treated process condensates suitable for washing tank wastes.

\subsection{I12 Solidified HLW and TRU Waste Production Information}

From: 1

Documentation supplied by production facilities certifying that containers comply with solidified HLW and TRU waste interim storage facility acceptance specifications and the HLW or TRU waste repository waste acceptance specifications.

\subsection{I13 Tank Waste from Aqueous Waste Processing}

From: 4.5

Tank waste materials resulting from processing of aqueous waste containing hazardous or mixed waste.

\subsection{I14 Tank Waste from Deactivation}

From: 4.1

Liquid waste contaminated with radioactive or hazardous materials resulting from deactivating site facilities. This waste stream also includes radioactive or hazardous liquid waste resulting from maintaining site facilities: (a) prior to deactivation; and (b) until demolition or transfer.

\subsection{I15 Tank Waste from Infrastructure}

From: 5

Liquid waste materials contaminated with radioactive or hazardous materials resulting from correcting unsafe or non-compliant conditions or from operation of Hanford Cleanup mission infrastructure systems.

\subsection{I16 Tank Waste from Remedy/Restore}

From: 4.4

Liquid waste resulting from functions associated with site remediation and restoration.

\subsection{I17 Tank Waste from SNM/NM/NF Cleanup}


Tank waste resulting from the cleanup of Special Nuclear Materials (SNM) which have applications in the manufacturing of nuclear weapons, Nuclear Materials (NM) radioactive elements which can be used as nuclear reactor fuel, and Nuclear Fuel (NF) or nuclear reactor fuel which has not been irradiated containing radioactive, hazardous, or mixed waste.

\subsection{I18 Tank Waste from Solid Waste Cleanup}

From: 4.3

Tank waste materials resulting from cleanup of solid waste items containing hazardous or mixed waste.

\section{OUTPUTS:}

\subsection{O1 Cesium Product for Storage - Samples}

Samples of the dry cesium product provided for chemical analysis and testing.

\subsection{O2 Closed ILLW Sites}

To: External

The closed engineered disposal structures containing the immobilized LLW.

\subsection{O3 Closed Operable Units (Tanks)}

RCRA regulations require the removal of all waste from the tanks, and ancillary equipment to close as a tank system. If all the waste can not be removed from the operable units, then the units would either under go modified closure or be closed as a landfill. According to Condition II.K.3. of the Hanford Facility Resource Conservation and Recovery Act Permit (Hanford RCRA Permit), if dangerous waste concentration in TSD units that leave waste inplace are above MCTA Method B levels (residential-based scenario) but below MCTA Method C levels (industrial-based scenario) then a 'modified' closure option might be used (Ecology 1994). This option would not require a cover be placed over the waste left in place. Closure as a landfill would require a cover be placed over the waste left in place. Past Practice Units (PPU) associated with the tank system have closure requirements which are independent of the tank system but the PPU shall be closed as part of the Operable Unit.

A closure plan must be prepared and approved which will direct the final condition of the closed operable unit. If either a modified or landfill closure option is used, a post-closure permit application would have to be submitted to the regulators. This document would contain information on postclosure care and the final design of the landfill cover, if necessary."

\subsection{O4 Dangerous Wastes from Remediate Tank Waste}

To: External

Solid waste that is classified as dangerous per EPA or State of Washington regulations.

\subsection{OS Dispositioned Cs/Sr Capsules for Shipment}

To: External

$\mathrm{Cs} / \mathrm{Sr}$ capsules prepared to meet repository acceptance requirements, loaded into the shipping mechanism for shipment to the repository. 
Conditioned gases appropriate for discharge directly to the environment from process and containment buildings.

\subsection{O7 Excess Tank Waste Facilities}

TWRS (non-tank) facilities that have been emptied, decontaminated, disabled, except for essential surveilance and monitoring systems and are ready for transfer to the site-level Deactivate Facilities (4.1) function for reuse or deactivation. Includes transfer pipelines, diversion boxes and associated components; excludes the waste tanks.

\subsection{IHLW for Shipment}

To: External

Sealed containers of immobilized HLW derived from treatment of tank wastes (e.g., existing and new tank wastes). The containers of IHLW are placed in a shipping cask, that is loaded onto a shipping vehicle and shipped to the repository by DOE - OCRWM personnel. At the time of shipment to the repository, the waste will be certified to meet repository acceptance requirements.

\subsection{Non-Dangerous Solid Wastes from Remediate Tank Waste}

To: 5

Ordinary non-radioactive, non-dangerous solid wastes suitable for disposal in a sanitary landfill.

\subsection{O10 Process Waste Samples}

Samples of process solutions and materials generated during processing of tank waste. Samples of the waste may be obtained for verification testing.

\subsection{O11 Radioactive Solid Wastes from Tank Waste Remediation}

Radioactive and radioactive dangerous solid wastes generated within the Remediate Tank Waste function that has been prepared in accordance with acceptance criteria for the Remediate Solid Waste (4.3) function. Preparation will require some level of preparation including segregation, size reduction, and packaging for acceptance by function 4.3 for management and disposal. Examples of this output include the failed long length equipment removed from DSTs and SSTs, failed HLW melters, failed process equipment, expended support equipment (i.e., HEPA filters), materials used for radiological control (i.e., visqueen, framing materials, kraft paper, rags), and any in-tank hardware or discrete sources found in the tanks.

\subsection{O12 RTW Process Information}

To: 1

Data generated by the operations of the Remediate Tank Waste function.

\subsection{O13 RTW Treated Liquid Effluents}

Liquid effluents which meet interface acceptance criteria for discharge directly to the 200 Area Treated Effluent Disposal Facility (TEDF). 


\subsection{O14 RTW Untreated Liquid Effluents}

Generated liquid effluents which require treatment and meet interface acceptance criteria for discharge directly to the Liquid Effluent Retention Facility (LERF) and subsequent treatment in the Effluent Treatment Facility (ETF).

\subsection{O15 Solidified HLW and TRU Recertification Information}

Documentation certifying that the solidified HLW and TRU waste containers meet the repository acceptance criteria at the time of loading into repository shipping casks.

\subsection{O16 Solidified HLW and TRU Waste Storage Information}

Documentation supplied by the solidified HLW and TRU interim storage facility certifying that containers of solidified HLW or TRU Waste were stored in accordance with interim storage specifications and the applicable repository waste acceptance specifications.

\subsection{O17 Tank Waste Characterization Information}

Tank Waste Characterization Information consists of the technical basis sampling priority list, Tank Waste Analysis Plan, Tank Characterization Plans, Sampling and Analysis Plans, Sampling Schedule, Historical Tank Content Estimates (HTCEs), waste analysis data packages, waste in-situ measurement data, Tank Characterization Reports (TCRs), and other statistical data analysis and technical reports.

\subsection{O18 Transferrable Resources from Tank Waste Remediation}

Resources from Tank Waste Remediation activities that have no further mission and are transferred to Site-Level, Transitition Resources For Beneficial Uses function (5.0). These include valuable technology, work force, materials, equipment, facilities, and infrastructure. Includes excess resources inventory information. 


\section{FUNCTION ID NUMBER: 4.2 .1}

\section{FUNCTION TITLE: Manage Tank Waste (MTW)}

\section{FUNCTION DEFINITION:}

Manage existing tank waste (e.g., waste contained in DSTs, SSTs, and miscellaneous tanks), and new tank waste from Site level interfaces (e.g., facility operations, D\&D, ER), that is not the product of retrieval for final processing. Manage Tank Waste will be limited to the storage of waste prior to retrieval for processing; waste characterization; transfer of tank waste for the resolution of safety issues, optimization of tank space, volume reduction, interim stabilization, andlor emergency pumping; concentration of tank waste to support tank space utilization. This function also includes treatment/preparation of liquid, gaseous, and solid wastes generated during the management of tank waste as necessary to meet criteria for release to the environment or acceptance criteria of recieving functions.

This will continue until all waste is retrieved for final processing and waste is no longer received from external sources to Remediate Tank Waste.

\section{INPUTS:}

\subsubsection{I1 Excess DSTs from Pretreat Sludge/Solids}

DSTs which were utilized for the pretreatment of sludges/solids and have no further use by the PSS function.

\subsubsection{I2 Excess DSTs From Store In-Process Waste}

DSTs which were utilized for the storage of in-process wastes and have no further use by the Store In-Process Waste function.

\subsubsection{I3 Excess Feed Tanks}

Double-shell tanks (DSTs) and ancillary equipment which were used by the low-activity waste treatment system as process feed tanks. When these feed tanks are no longer needed for low-activity waste treatment, the custody of these feed tanks is transferred back to the DST waste storage system.

\subsubsection{I4 Existing Tank Waste}

From: External

Radioactive mixed waste generated from processing spent nuclear fuels and currently stored in DSTs, SSTs, and miscellaneous underground storage tanks (MUSTs). This waste also includes the in-tank hardware and discrete radioactive sources found in the waste tanks which will require retrieval for disposal purposes. 
Historical information is made up of chemical process and waste management information. These include documented and institutional knowledge, historical derived information transcribed to tank layer models, and historical tank content estimates.

Historical data includes: chemical process operations technical manuals (text and flowsheets); interviews with long-time operations and engineering personnel; process aids; reports, memos and logbooks; transfer histories; and simulant studies.

\subsubsection{I6 Infrastructure Support for Manage Tank Waste}

From: 5

General infrastructure support needed to manage tank waste. This will include but is not limited to fire protection, police, emergency preparedness, medical services, telecommunications, radiological services, laboratory services, transportation system and sewer. This includes land for siting facilities.

\subsubsection{I7 Process Waste Tank Characterization Requirements}

From: 4.2 .3

Characterize Waste requires information and sample material requirements to support the pretreatment of supernatants, sludges, and solids and immobilize low-level and high-level wastes from single and double shell tanks. The information is identified in the Data Quality Objectives (DQO) document developed by the Process Waste function. This DQO and the companion tank specific documentation (e.g., tank characterization plans, sample analysis plans, etc.) contain the decisions, error tolerances, in-situ measurement and sampling requirements (such as number and location), and analysis requirements (such as type, precision and accuracy) necessary to support the development of pretreatment processes.

\subsubsection{I8 Raw Materials for MTW}

From: External

Any material (e.g. steam, water, air, process chemicals, electricity) needed from outside TWRS for managing tank waste.

\subsubsection{I9 Retrieve Tank Waste Characterization Requirements}

From: 4.2 .2

Characterize Waste requires information to support the design, development and operation of single and double shell tank retrieval systems. The information is identified in the Data Quality Objectives (DQO) document developed by the Retrieve Waste function. This DQO and the companion tank specific documentation (e.g., tank characterization plans, sample analysis plans, etc.) contain the decisions, error tolerances, in-situ measurement and sampling requirements (such as number and location), and analysis requirements (such as type, precision and accuracy).

\subsubsection{I10 Tank Waste from Aqueous Waste Processing}

From: 4.5

Tank waste materials resulting from processing of aqueous waste containing hazardous or mixed waste.

\subsubsection{Tank Waste from Deactivation}

From: 4.1

Liquid waste contaminated with radioactive or hazardous materials resulting from deactivating site facilities. This waste stream also includes radioactive or hazardous liquid waste resulting from maintaining site facilities: (a) prior to deactivation; and (b) until demolition or transfer. 
Liquid waste materials contaminated with radioactive or hazardous materials resulting from correcting unsafe or non-compliant conditions or from operation of Hanford Cleanup mission infrastructure systems.

\subsubsection{I13 Tank Waste from Remedy/Restore}

From: 4.4

Liquid waste resulting from functions associated with site remediation and restoration.

\subsubsection{I14 Tank Waste from SNM/NM/NF Cleanup}

From: 4.7

Tank waste resulting from the cleanup of Special Nuclear Materials (SNM) which have applications in the manufacturing of nuclear weapons, Nuclear Materials (NM) radioactive elements which can be used as nuclear reactor fuel, and Nuclear Fuel (NF) or nuclear reactor fuel which has not been irradiated containing radioactive, hazardous, or mixed waste.

\subsubsection{I15 Tank Waste from Solid Waste Cleanup}

From: 4.3

Tank waste materials resulting from cleanup of solid waste items containing hazardous or mixed waste.

\subsubsection{I16 Technetium Product Samples}

Samples of the liquid technetium product provided for chemical analysis and testing

\section{OUTPUTS:}

\subsubsection{O1 DSTs for In-Process Storage of Waste}

Double shell tanks allocated for storage of in-process wastes.

\subsubsection{O2 DSTs for Pretreatment of Sludges/Solids}

Double shell tanks for use within the Pretreat Sludge/Solids function.

\subsubsection{O3 Feed Tanks}

Double-shell tanks (DSTs) and ancillary equipment transferred to the custody of the supernatant pretreatment system for use as process feed tanks. The custody will revert to the DST waste storage system when the use of these feed tanks by the supernatant pretreatment system is no longer needed.

\subsubsection{O4 Information Input}

To: 4.2 .3

4.2 .3 .3

Miscellaneous informational input to the Privatizatin Contractor from DOE or the PHMC. Typically used for review and approval of various documents, work plans, permits, etc. These are inputs to the enable 
Appendix B - Function 4.2.1

the function and not to the outputs from the function.

\subsubsection{O5 MTW Dangerous Wastes}

To: External

Solid wastes generated within the Manage Tank Waste function that is classified as dangerous per EPA or State of Washington regulations.

\subsubsection{O6 MTW Excess Facilities}

Excess facilities that, having fulfilled their original purposes and completed the functions/processes described in the MTW function, are now available and appropriate for reuse or deactivation. Reuse will be decided at the Site level.

\subsubsection{O7 MTW Non-Dangerous Solid Wastes}

To: 5

Ordinary non-radioactive, non-dangerous solid wastes generated within the Manage Tank Waste function, suitable for disposal in a sanitary landfill.

\subsubsection{O8 MTW Radioactive Solid Waste}

To: 4.3

Radioactive and radioactive dangerous solid waste generated within the Manage Tank Waste function that has been prepared in accordance with the acceptance criteria for the Remediate Solid Waste (4.3) function. Preparation will include segregation, packaging, assaying, and certification of the solid waste for transfer for management and disposal. Examples of this output include the failed long length equipment removed from DSTs and SSTs, failed process equipment, expended support equipment (i.e., HEPA filters), materials used for radiological control(i.e., visqueen, framing materials, kraft paper, rags), and any in-tank hardware or discrete sources found in the tanks.

\subsubsection{O9 MTW Transferrable Resources}

To: 6

Resources from Manage Tank Waste activities that have no further MTW mission. These include valuable technology, work force, materials, equipment, facilities and infrastructure. Includes excess resources inventory information.

\subsubsection{O10 MTW Treated Gaseous Effluents}

To: External

Conditioned gases appropriate for discharge directly to the environment originating from processes such as concentration of tank waste, vessel ventilation as required for the transferring andlor cooling of wastes in storage, and the control of radionuclide migration from primary and secondary containment structures.

\subsubsection{O11 MTW Treated Liquid Effluents}

To: 4.5

Liquid effluents which meet interface acceptance criteria for discharge directly to the 200 Area Treated Effluent Disposal Facility (TEDF).

\subsubsection{O12 MTW Untreated Liquid Effluents}

To: 4.5

Generated liquid effluents which require treatment and meet interface acceptance criteria for discharge directly to the Liquid Effluent Retention Facility (LERF) and subsequent treatment in the Effluent 
Treatment Facility (ETF).

Tank operations information consisting of monitoring and surveillance data which includes: in-tank temperature measurements, pressure measurements, waste level measurements, photographs, emission monitoring data, data from specialty equipment, as well as information related to the structure of the tank and its safety status. Tank operations information is provided by the Store Managed Tank Waste function (sub-function Manage System Data/Information).

\subsubsection{O14 Tank Operations Information for SSTs}

Tank operations information consisting of monitoring and surveillance data which includes: in-tank temperature measurements, pressure measurements, waste level measurements, photographs, emission monitoring data, data from specialty equipment, as well as information related to the structure of the tank and its safety status. Tank operations information is provided by the Store Managed Tank Waste function (sub-function Manage System Data/Information).

\subsubsection{O15 Tank Waste Characterization Information}

Tank Waste Characterization Information consists of the technical basis sampling priority list, Tank Waste Analysis Plan, Tank Characterization Plans, Sampling and Analysis Plans, Sampling Schedule, Historical Tank Content Estimates (HTCEs), waste analysis data packages, waste in-situ measurement data, Tank Characterization Reports (TCRs), and other statistical data analysis and technical reports.

\subsubsection{O16 Tanks With Waste for Retrieval}

Underground storage tanks (DSTs, SSTs, and MUSTs) and the wastes contained with in that are to be retrieved by the "Retrieve Tank Waste " function for safety issues resolution, pretreatment, or disposal purposes. The waste includes in-tank hardware and discrete sources which will be dispositioned by the Hanford Site function "Remediate Solid Waste", as well as saltcake, sludge and supernatant. 
Appendix B - Function 4.2.1 


\section{FUNCTION ID NUMBER: 4.2.1.1}

II. FUNCTION TITLE: Store Managed Tank Waste

\section{FUNCTION DEFINITION:}

Contain and monitor SST waste, and waste in MUSTs. Receive, contain, and monitor DST waste that is not the product of retrieval for final processing. Mitigate / resolve safety issues, and the treat / prepare liquid, gaseous, and solid wastes generated during the storage of tank waste as necessary to meet the criteria for release to the environment or acceptance criteria of recieving functions.

\section{INPUTS:}

\subsubsection{I1 Excess DSTs from Pretreat Sludge/Solids}

DSTs which were utilized for the pretreatment of sludges/solids and have no further use by the PSS function.

\subsubsection{I2 Excess DSTs From Store In-Process Waste}

DSTs which were utilized for the storage of in-process wastes and have no further use by the Store In-Process Waste function.

\subsubsection{I3 Excess Feed Tanks}

Double-shell tanks (DSTs) and ancillary equipment which were used by the low-activity waste treatment system as process feed tanks. When these feed tanks are no longer needed for low-activity waste treatment, the custody of these feed tanks is transferred back to the DST waste storage system.

\subsubsection{I4 Existing Tank Waste}

From: External

Radioactive mixed waste generated from processing spent nuclear fuels and currently stored in DSTs, SSTs, and miscellaneous underground storage tanks (MUSTs). This waste also includes the in-tank hardware and discrete radioactive sources found in the waste tanks which will require retrieval for disposal purposes.

\subsubsection{I5 Infrastructure Support for Store Managed Tank Waste}

From: 5

General infrastructure support is needed to manage tank waste. This will include but is not limited to fire protection, police, emergency preparedness, medical services, telecommunications, radiological services, laboratory services, transportation systems, electrical utilities, and sewer. This includes land for siting facillities. 
Any material (e.g., steam, water, air, process chemicals) needed from outside TWRS for storing managed tank waste.

\subsubsection{17 TMTW Operations Data}

From: 4.2.1.3

Information on TMTW operations that impact safety, environmental and waste tank/facility status or trending which is to be compiled by the Manage System Information function (4.2.1.1.4).

\subsubsection{I8 Transfer Liquid Waste in Emergency Situations Operations Data}

From: 4.2.1.3

Information on emergency liquid waste transfer operations that impact waste tank/facility status or trending which is to be compiled by the Manage System Information

function (4.2.1.1.4).

\subsubsection{19 Waste to Storage}

From: 4.2.1.3

Waste transferred from various site locations to DST storage for the purposes of maximizing existing storage space, to resolve safety issues, and/or to accommodate safe storage and future processing of liquid wastes generated from other site activities. The transferred wastes include DST slurries,supernates; new liquid waste from activities external to the Remediated Tank Waste function; SST slurries, SST supernates, interstitial liquids, and liquid organic wastes; liquid wastes from active MUSTs; and concentrated waste (DSSF) from the Concentrate Waste function.

\section{v. OUTPUTS:}

\subsubsection{O1 Ancillary Equipment and Systems Waste for Retrieval}

To: 4.2 .2 .3

Ancillary Systems (e.g. MUSTs, DCRTs, diversions boxes, pump pits, catch tanks, and other equipment associated with operable units) and waste contained within that are to be retrieved by the Retrieve Tank Waste function for pre-treatment, safety issue resolution, or disposal. This waste includes supernates, saltcake, and sludges. Any ancillary equipment, in-tank hardware or discrete radioactive sources found in the MUSTs will be dispositioned by the Hanford Site function "Remediate Solid Waste".

\subsubsection{O2 Concentrate Waste Feed}

To: 4.2.1.4

Low-level DST waste that is sent to the Concentrate Waste function (4.2.1.4) for removal of excess water as part of tank space optimization efforts.

\subsubsection{O3 DSTs for In-Process Storage of Waste}

Double shell tanks allocated for storage of in-process wastes.

4.2.1.1 O4 DSTs for Pretreatment of Sludges/Solids

Double shell tanks for use within the Pretreat Sludge/Solids function. 
Double-shell tanks (DSTs) and ancillary equipment transferred to the custody of the supernatant pretreatment system for use as process feed tanks. The custody will revert to the DST waste storage system when the use of these feed tanks by the supernatant pretreatment system is no longer needed.

\subsubsection{O6 MTW Transferrable Resources}

Resources from Manage Tank Waste activities that have no further MTW mission. These include valuable technology, work force, materials, equipment, facilities and infrastructure. Includes excess resources inventory information.

\subsubsection{O7 SMTW Characterization Requirements}

Characterize Waste requires information to support the continuing storage operations of single and double shell tanks waste. The information is identified in a set of safety related Data Quality Objectives (DQO) documents developed by the Store Managed Tank Waste function and in the Double Shell Tank Waste Analysis Plan. These DQOs and their companion tank specific documentation (e.g., tank characterization plans, sample analysis plans, etc.) contain the decisions, error tolerances, in-situ measurements and sampling requirements (such as number and location), and analysis requirements (such as type, precision and accuracy) necessary to support compliance with the established safety basis of the facilities.

\subsubsection{O8 SMTW Excess Facilities}

Excess facilities(everything other than the tanks) that, having fulfilled their original purposes and completed the functions/processes described in the Store Manage Tank Waste function, are now available and appropriate for reuse or deactivation. Reuse will be decided at the Site level.

\subsubsection{09 SMTW Prepared Solid Waste}

Solid waste generated within the Store Managed Tank Waste function that has been prepared in accordance with the acceptance criteria for the Remediate Solid Waste (4.3) function. This includes mixed, and radioactive wastes. Preparation will include segregation, packaging, assaying, and certification of the solid waste for transfer for further treatment or disposal. Examples of this output include the failed long length equipment removed from DSTs and SSTs, the organic layer removed from tanks for off site destruction, failed process equipment, expended support equipment (i.e., HEPA filters), materials used for radiological control(i.e., visqueen, framing materials, kraft paper, rags), and any in-tank hardware or discrete sources found in the tanks.

\subsubsection{O10 SMTW Treated Gaseous Effluents}

To: External

Conditioned gases appropriate for discharge directly to the environment originating from vessel ventilation as required for the transferring andlor cooling of wastes in storage, and the control of radionuclide migration from primary and secondary containment structures.

\subsubsection{O11 SMTW Treated Liquid Effluents}

Liquid effluents which meet interface acceptance criteria for discharge directly to the 200 Area Treated Effluent Disposal Facility (TEDF). 
Generated liquid effluents which require treatment and meet interface acceptance criteria for discharge directly to the Liquid Effluent Retention Facility (LERF) and subsequent treatment in the Effluent Treatment Facility (ETF).

\subsubsection{O13 Store Managed Tank Waste Dangerous Wastes}

To: External

Solid wastes generated within the Store Managed Tank Waste function that is classified as dangerous per EPA or State of Washington regulations.

\subsubsection{O14 Store Managed Tank Waste Non-Dangerous Solid Wastes}

Ordinary non-radioactive, non-hazardous solid waste generated within the Store Managed Tank Waste function, suitable for disposal in a sanitary landfill.

\subsubsection{O15 Store Managed Waste Tanks With Waste For Retrieval}

Underground storage tanks (DSTs, SSTs, and MUSTs) and the wastes contained within that are to be retrieved by the "Retrieve Tank Waste " function for safety issues resolution, pretreatment, or disposal purposes. The waste includes in-tank hardware and discrete sources which will be dispositioned by the Hanford Site function "Remediate Solid Waste", as well as saltcake, sludge and supernatant.

\subsubsection{O16 Tank Operations Information}

To: 4.2 .1 .2

4.2.1.3

4.2.1.4

Tank operations information consisting of monitoring and surveillance data which includes: in-tank temperature measurements, pressure measurements, waste level measurements, photographs, emission monitoring data, data from specialty equipment, as well as information related to the structure of the tank and its safety status. Tank operations information is provided by the Store Managed Tank Waste function (sub-function Manage System Data/Information).

\subsubsection{O17 Tank Operations Information for SSTs}

Tank operations information consisting of monitoring and surveillance data which includes: in-tank temperature measurements, pressure measurements, waste level measurements, photographs, emission monitoring data, data from specialty equipment, as well as information related to the structure of the tank and its safety status. Tank operations information is provided by the Store Managed Tank Waste function (sub-function Manage System Data/Information).

\subsubsection{O18 Tank Waste for Sampling}

To: 4.2.1.2

Tank waste for sampling consists of solids, liquids, and gases in the Store Managed Tank Waste function 
Appendix B - Function 4.2.1.1

identified for characterization to satisfy the Data Quality Objective requirements.

\subsubsection{O19 Tank Waste for Transfer}

To: 4.2 .1 .3

Liquids stored as tank waste awaiting transfer. Only liquids that do not require mobilization/conditioning as a prerequisite to recovery and transfer (e.g., supernatant, interstitial liquids, and organic layers). 


\section{FUNCTION ID NUMBER: $\quad 4.2 .1 .2$}

\section{FUNCTION TITLE: Characterize Waste}

\section{FUNCTION DEFINITION:}

The Tank Waste Remediation System (TWRS) Characterize Waste function provides information about the waste contents in underground storage waste storage tanks (149 single-shell tanks, 28 double-shell tanks and approximately 63 miscellaneous underground waste storage tanks) and supplies sample material to support the safe storage, retrieval, processing, and disposal of the waste. Tank waste characterization is the process that describes waste in terms of its physical, chemical, and radiological compositions, as well as the distribution of the wastes between tanks and within tanks. A goal of the Characterize Waste function is to provide data of known and sufficient quality and quantity to enable necessary, defensible programmatic decisions to be made and to assist in the reduction of safety and programmatic (e.g. cost, schedule) risks.

The process of characterizing tank wastes involves defining and prioritizing issues concerning wastes, defining and integrating information needs for making decisions that will help resolve program issues, determining and evaluating sources of required information, selecting an approach to obtain the information, obtaining new information if needed, and reporting the results of this process.

Each interfacing function identifies issues, information, and sample material needs and the tanks which must be characterized using the Data Quality Objectives (DQO) process. Interfacing functions identify criteria by which all tanks can be prioritized with respect to each issue. The Characterize Waste function then integrates the needs and tank priorities across various program customers to define an overall plan for obtaining information and/or sample material.

Specific tank characterization efforts are considered complete only when all currently identified information or sample material needs have been met. Characterization is an iterative process since the domain of the tank wastes is dynamic and highly complex. Because characterization is dynamic and iterative, new paths of inquiry may develop leading to the need to obtain more information in specific areas. According to overall TWRS summary plans, characterization activities may extend until the completion of retrieval and disposal activities for all designated tank wastes.

\section{INPUTS:}

\subsubsection{I1 Concentrate Waste Characterization Requirements}

From: 4.2.1.4

Characterize Waste requires information to support the concentration of mixed waste (slurry) solutions from single and double shell tanks. The information is identified inthe Data Quality Objectives (DQO) document developed in the Concentrate Waste (sub-function Monitor \& Control Waste Concentration). This DQO and the companion tank specific documentation (e.g., work packages) contain the decisions, error tolerances, in-situ measurement and sampling requirements (such as number and location), and analysis requirements (such as type, precision and accuracy) necessary to support the safety, regulatory compliance, and process control needs of the facility.

\subsubsection{I2 Historical Information}

From: External 
Historical information is made up of chemical process and waste management information. These include documented and institutional knowledge, historical derived information transcribed to tank layer models, and historical tank content estimates.

Historical data includes: chemical process operations technical manuals (text and flowsheets); interviews with long-time operations and engineering personnel; process aids; reports, memos and logbooks; transfer histories; and simulant studies.

\subsubsection{I3 Process Waste Tank Characterization Requirements}

From: 4.2 .3

Characterize Waste requires information and sample material requirements to support the pretreatment of supernatants, sludges, and solids and immobilize low-level and high-level wastes from single and double shell tanks. The information is identified in the Data Quality Objectives (DQO) document developed by the Process Waste function. This DQO and the companion tank specific documentation (e.g., tank characterization plans, sample analysis plans, etc.) contain the decisions, error tolerances, in-situ measurement and sampling requirements (such as number and location), and analysis requirements (such as type, precision and accuracy) necessary to support the development of pretreatment processes.

\subsubsection{I4 Raw Materials for Characterization}

From: External

Characterize Waste requires materials and services (e.g., steam, water, air, process chemicals, electricity, hardware, maintenance) to be provided by other functions and site services.

\subsubsection{I5 Retrieve Tank Waste Characterization Requirements}

From: 4.2 .2

Characterize Waste requires information to support the design, development and operation of single and double shell tank retrieval systems. The information is identified in the Data Quality Objectives (DQO) document developed by the Retrieve Waste function. This DQO and the companion tank specific documentation (e.g., tank characterization plans, sample analysis plans, etc.) contain the decisions, error tolerances, in-situ measurement and sampling requirements (such as number and location), and analysis requirements (such as type, precision and accuracy).

\subsubsection{I6 SMTW Characterization Requirements}

From: 4.2.1.1

Characterize Waste requires information to support the continuing storage operations of single and double shell tanks waste. The information is identified in a set of safety related Data Quality Objectives (DQO) documents developed by the Store Managed Tank Waste function and in the Double Shell Tank Waste Analysis Plan. These DQOs and their companion tank specific documentation (e.g., tank characterization plans, sample analysis plans, etc.) contain the decisions, error tolerances, in-situ measurements and sampling requirements (such as number and location), and analysis requirements (such as type, precision and accuracy) necessary to support compliance with the established safety basis of the facilities.

\subsubsection{I7 Tank Operations Information}

Tank operations information consisting of monitoring and surveillance data which includes: in-tank temperature measurements, pressure measurements, waste level measurements, photographs, emission monitoring data, data from specialty equipment, as well as information related to the structure of the tank and its safety status. Tank operations information is provided by the Store Managed Tank Waste function 
(sub-function Manage System Data/Information).

\subsubsection{I8 Tank Waste for Sampling}

Tank waste for sampling consists of solids, liquids, and gases in the Store Managed Tank Waste function identified for characterization to satisfy the Data Quality Objective requirements.

\subsubsection{I9 Technetium Product Samples}

Samples of the liquid technetium product provided for chemical analysis and testing

\subsubsection{I10 TMTW Characterization Data Request Via a DQO}

From: 4.2.1.3

Characterize Waste requires information to support the continuing transfer operations of single and double shell tank waste. The information is identified in the Data Quality Objectives (DQO) document developed by the Transfer Managed Tank Waste function. This DQO and the companion tank specific documentation (e.g., work packages) contain the decisions, error tolerances, sampling requirements (such as number and location), and analysis requirements (such as type, precision and accuracy) necessary to support the safety, regulatory compliance and process control needs of the facility.

\subsubsection{I11 Waste Concentrate for Sampling}

From: 4.2.1.4

Waste concentrate for sampling is the concentrated waste product of the Concentrate Waste function that has been identified for characterization prior to transfer and storage for process control purposes.

\subsubsection{I12 Waste Concentration Feed for Sampling}

From: 4.2.1.4

Waste concentrate feed for sampling is mixed waste (slurry) solutions fed to the Concentrate Waste function that has been identified for characterization for process control purposes.

\section{OUTPUTS:}

\subsubsection{O1 Characterize Waste Dangerous Wastes}

To: External

Solid wastes generated within the Characterize Waste function that is classified as dangerous per EPA or State of Washington regulations.

\subsubsection{O2 Characterize Waste Non-Dangerous Solid Wastes}

Ordinary non-radioactive, non-dangerous solid wastes generated within the Characterize Waste function, suitable for disposal in a sanitary landfill.

\subsubsection{O3 Characterize Waste Radioactive Solid Waste}

Radioactive and radioactive dangerous solid waste generated within the Characterize Waste function that has been prepared in accordance with the acceptance criteria for the Remedy Solid Waste function. Preparation will require the solid waste to be segregated, packaged, assayed, and certified for transfer to the Remedy Solid Waste function for management and disposal. Examples of this output include used 
drill string, sampler, old core sampling trucks and casks, expended support equipment (i.e., HEPA filters), and material used for radiological control (e.g., visqueen, framing materials, kraft paper, and rags).

\subsubsection{O4 Characterize Waste Treated Gaseous Effluents}

To: External

Conditioned gases from sampling and laboratory facilities appropriate for discharge directly to the environment originating from ventilation systems used to control the release of radionuclides.

\subsubsection{O5 Characterize Waste Treated Liquid Effluents}

To: 4.5

Liquid effluents which meet interface acceptance criteria for discharge directly to the 200 Area Treated Effluent Disposal Facility (TEDF).

\subsubsection{O6 Characterize Waste Untreated Liquid Effluents}

To: 4.5

Generated liquid effluents which require treatment and meet interface acceptance criteria for discharge directly to the Liquid Effluent Retention Facility (LERF) and subsequent treatment in the Effluent Treatment Facility (ETF).

\subsubsection{07 Information Input}

Miscellaneous informational input to the Privatizatin Contractor from DOE or the PHMC. Typically used for review and approval of various documents, work plans, permits, etc. These are inputs to the enable the function and not to the outputs from the function.

\subsubsection{O8 Laboratory Waste from Characterization}

To: 4.2 .1 .3

Laboratory waste from characterization consists of waste solutions (liquid and solids) generated by the laboratories during the handling, preparing, and analyzing of samples. This waste also includes excess samples that are disposed of by the laboratory. These wastes are collected and transferred to the double shell tanks.

\subsubsection{O9 MTW Transferrable Resources}

Resources from Manage Tank Waste activities that have no further MTW mission. These include valuable technology, work force, materials, equipment, facilities and infrastructure. Includes excess resources inventory information.

\subsubsection{O10 Tank Waste Characterization Information}


Tank Waste Characterization Information consists of the technical basis sampling priority list, Tank Waste Analysis Plan, Tank Characterization Plans, Sampling and Analysis Plans, Sampling Schedule, Historical Tank Content Estimates (HTCEs), waste analysis data packages, waste in-situ measurement data, Tank Characterization Reports (TCRs), and other statistical data analysis and technical reports. 


\section{FUNCTION ID NUMBER: 4.2 .1 .3}

\section{FUNCTION TITLE: Transfer Managed Tank Waste}

\section{FUNCTION DEFINITION:}

Transfer supernatant and interstitial liquids which have not been pretreated from SSTs, DSTs, and active MUSTs to DSTs for storage as necessary to mitigate or resolve safety concerns, manage tank space or provide feed for the Concentrate Waste function. Also included are the receipt and transfer of liquid wastes to DST storage from: (a) generators external to the Remediate Tank Waste function; and (b) the 242-A Evaporator. This function also includes treatment/preparation of liquid, gaseous, and solid wastes generated as a result of the transfer of tank waste as necessary to meet criteria for release to the environment or acceptance criteria for recieving functions. No additional conditioning of waste will be performed by this function in-tank or during transfers.

Active MUSTs typically serve as catch tanks for diversion boxes and pipe encasements for active transfer lines and are identified in WHC-EP-0182-78, Table H-1.

Transfer Managed Tank Waste is ongoing and will continue as long as liquid wastes are accepted from external generators and waste remains in storage awaiting retrieval for treatment and disposal by the Process Waste function.

\section{INPUTS:}

\subsubsection{I1 Laboratory Waste from Characterization}

From: 4.2.1.2

Laboratory waste from characterization consists of waste solutions (liquid and solids) generated by the laboratories during the handling, preparing, and analyzing of samples. This waste also includes excess samples that are disposed of by the laboratory. These wastes are collected and transferred to the double shell tanks.

\subsubsection{I2 Raw Materials for TMTW}

From: External

Any material (e.g., steam, air, process chemicals) needed from outside TWRS for transferring waste.

\subsubsection{I3 Sanitary Waste Services for Transfer Managed Tank Waste}

From: 5

A service that receives, collects, and transfers all sanitary domestic sewer wastes from the Transfer Managed Tank Waste function for processing in a domestic waste-water sewer treatment processing system.

\subsubsection{I4 Tank Operations Information}

Tank operations information consisting of monitoring and surveillance data which includes: in-tank temperature measurements, pressure measurements, waste level measurements, photographs, emission monitoring data, data from specialty equipment, as well as information related to the structure of the tank and its safety status. Tank operations information is provided by the Store Managed Tank Waste function 
(sub-function Manage System Data/Information).

4.2.1.3 I5 Tank Waste Characterization Information

Tank Waste Characterization Information consists of the technical basis sampling priority list, Tank Waste Analysis Plan, Tank Characterization Plans, Sampling and Analysis Plans, Sampling Schedule, Historical Tank Content Estimates (HTCEs), waste analysis data packages, waste in-situ measurement data, Tank Characterization Reports (TCRs), and other statistical data analysis and technical reports.

\subsubsection{I6 Tank Waste for Transfer}

From: 4.2.1.1

Liquids stored as tank waste awaiting transfer. Only liquids that do not require mobilization/conditioning as a prerequisite to recovery and transfer (e.g., supernatant, interstitial liquids, and organic layers).

\subsubsection{I7 Tank Waste from Aqueous Waste Processing}

Tank waste materials resulting from processing of aqueous waste containing hazardous or mixed waste.

\subsubsection{I8 Tank Waste from Deactivation}

From: 4.1

Liquid waste contaminated with radioactive or hazardous materials resulting from deactivating site facilities. This waste stream also includes radioactive or hazardous liquid waste resulting from maintaining site facilities: (a) prior to deactivation; and (b) until demolition or transfer.

\subsubsection{I9 Tank Waste from Infrastructure}

Liquid waste materials contaminated with radioactive or hazardous materials resulting from correcting unsafe or non-compliant conditions or from operation of Hanford Cleanup mission infrastructure systems.

\subsubsection{I10 Tank Waste from Remedy/Restore}

Liquid waste resulting from functions associated with site remediation and restoration.

\subsubsection{I11 Tank Waste from SNM/NM/NF Cleanup}

From: 4.7

Tank waste resulting from the cleanup of Special Nuclear Materials (SNM) which have applications in the manufacturing of nuclear weapons, Nuclear Materials (NM) radioactive elements which can be used as nuclear reactor fuel, and Nuclear Fuel (NF) or nuclear reactor fuel which has not been irradiated containing radioactive, hazardous, or mixed waste.

\subsubsection{I12 Tank Waste from Solid Waste Cleanup}

Tank waste materials resulting from cleanup of solid waste items containing hazardous or mixed waste. 
The concentrated product generated by removal of excess moisture from tank waste, to be returned to the DST's. The concentrated product returned to the DSTs is referred to as Double Shell Slurry Feed (DSSF). DSSF is defined as a slurry with a chemical composition that is below the sodium-aluminate boundary but that could be concentrated past the sodium-aluminate boundary, with a single additional pass through the Evaporator. The viscosity of DSSF typically ranges from 20 to $40 \mathrm{cP}$.

\section{OUTPUTS:}

\subsubsection{O1 MTW Transferrable Resources}

To: 6

Resources from Manage Tank Waste activities that have no further MTW mission. These include valuable technology, work force, materials, equipment, facilities and infrastructure. Includes excess resources inventory information.

\subsubsection{O2 TMTW Characterization Data Request Via a DQO}

To: 4.2.1.2

Characterize Waste requires information to support the continuing transfer operations of single and double shell tank waste. The information is identified in the Data Quality Objectives (DQO) document developed by the Transfer Managed Tank Waste function. This DQO and the companion tank specific documentation (e.g., work packages) contain the decisions, error tolerances, sampling requirements (such as number and location), and analysis requirements (such as type, precision and accuracy) necessary to support the safety, regulatory compliance and process control needs of the facility.

\subsubsection{O3 TMTW Excess Facilities}

Excess facilities that, having fulfilled their original purposes and completed the functions/processes described in the Transfer Manage Tank Waste function, are now available and appropriate for reuse or deactivation. Reuse will be decided at the Site level.

\subsubsection{O4 TMTW Operations Data}

To: 4.2 .1 .1

Information on TMTW operations that impact safety, environmental and waste tank/facility status or trending which is to be compiled by the Manage System Information function (4.2.1.1.4).

\subsubsection{O5 TMTW Prepared Solid Waste}

Solid waste generated within the Transfer Manage Tank Waste function that has been prepared in accordance with the acceptance criteria for the Remediate Solid Waste (4.3) function. This includes mixed, and radioactive wastes. Preparation will required the solid waste to be segregated, packaged, assayed, and certified for transfer for further treatment or disposal. Examples of this output include failed jumpers, transfer pumps and other equipment, expended support equipment(i.e., HEPA filters), and materials used for radiological control(i.e., visqueen, framing materials, kraft paper, rags).

\subsubsection{O6 TMTW Treated Gaseous Effluents}

To: External

Conditioned gases appropriate for discharge directly to the environment which originate from containment vessel-external environment pressure differentials resulting from performing the TMTW function. Conditioning of the gases is performed to control migration of radionuclides from primary and 
secondary containment structures to the external environment.

4.2.1.3 O7 TMTW Treated Liquid Effluents

To: 4.5

Liquid effluents which meet interface acceptance criteria for discharge directly to the 200 Area Treated Effluent Disposal Facility (TEDF).

\subsubsection{O8 TMTW Untreated Liquid Effluents}

To: 4.5

Generated liquid effluents which require treatment and meet interface acceptance criteria for discharge directly to the Liquid Effluent Retention Facility (LERF) and subsequent treatment in the Effluent Treatment Facility (ETF).

\subsubsection{09 Transfer Liquid Waste in Emergency Situations Operations Data}

Information on emergency liquid waste transfer operations that impact waste tank/facility status or trending which is to be compiled by the Manage System Information function (4.2.1.1.4).

\subsubsection{O10 Transfer Managed Tank Waste Dangerous Wastes}

To: External

Solid wastes generated within the Transfer Managed Tank Waste function that is classified as dangerous per EPA or State of Washington regulations.

\subsubsection{O11 Transfer Managed Tank Waste Non-Dangerous Solid Wastes $\quad$ To: External}

Ordinary non-radioactive, non-dangerous solid wastes generated within the Transfer Managed Tank Waste function, suitable for disposal in a sanitary landfill.

\subsubsection{O12 Waste to Storage}

To: 4.2 .1 .1

Waste transferred from various site locations to DST storage for the purposes of maximizing existing storage space, to resolve safety issues, and/or to accommodate safe storage and future processing of liquid wastes generated from other site activities. The transferred wastes include DST slurries,supernates; new liquid waste from activities external to the Remediated Tank Waste function; SST slurries, SST supernates, interstitial liquids, and liquid organic wastes; liquid wastes from active MUSTs; and concentrated waste (DSSF) from the Concentrate Waste function. 


\section{FUNCTION ID NUMBER: $\quad 4.2 .1 .4$}

II. FUNCTION TITLE: Concentrate Waste

\section{FUNCTION DEFINITION:}

Remove excess water from supernatant stored in DSTs to maximize utilization of available tank space. This function also includes treatment/preparation of liquid, gaseous, and solid wastes generated during the concentration of tank waste as necessary to meet environmental release criteria and acceptance criteria for recieving functions. Liquid effluents will be released to Manage Aqueous Waste, for disposal or additional treament/disposal as necessary.

Function is currently being performed and will continue until low level waste disposal activities eliminate the need for concentration.

\section{INPUTS:}

\subsubsection{I1 Concentrate Waste Feed}

From: 4.2.1.1

Low-level DST waste that is sent to the Concentrate Waste function (4.2.1.4) for removal of excess water as part of tank space optimization efforts.

\subsubsection{I2 Raw Materials for Concentrate Waste}

From: External

Any material or services (e.g., steam, water, air, process chemicals, electricity) needed from outside TWRS for concentrating waste.

\subsubsection{I3 Sanitary Waste Services for Concentrate Waste}

A service that receives, collects, and transfers all sanitary domestic sewer wastes from the Concentrate Waste function for processing in a domestic waste-water sewer treatment processing system.

\subsubsection{I4 Tank Operations Information}

Tank operations information consisting of monitoring and surveillance data which includes: in-tank temperature measurements, pressure measurements, waste level measurements, photographs, emission monitoring data, data from specialty equipment, as well as information related to the structure of the tank and its safety status. Tank operations information is provided by the Store Managed Tank Waste function (sub-function Manage System Data/Information).

\subsubsection{I5 Tank Waste Characterization Information}

Tank Waste Characterization Information consists of the technical basis sampling priority list, Tank 
Waste Analysis Plan, Tank Characterization Plans, Sampling and Analysis Plans, Sampling Schedule, Historical Tank Content Estimates (HTCEs), waste analysis data packages, waste in-situ measurement data, Tank Characterization Reports (TCRs), and other statistical data analysis and technical reports.

\section{OUTPUTS:}

\subsubsection{O1 Concentrate Waste Characterization Requirements}

Characterize Waste requires information to support the concentration of mixed waste (slurry) solutions from single and double shell tanks. The information is identified inthe Data Quality Objectives (DQO) document developed in the Concentrate Waste (sub-function Monitor \& Control Waste Concentration). This DQO and the companion tank specific documentation (e.g., work packages) contain the decisions, error tolerances, in-situ measurement and sampling requirements (such as number and location), and analysis requirements (such as type, precision and accuracy) necessary to support the safety, regulatory compliance, and process control needs of the facility.

\subsubsection{O2 Concentrate Waste Dangerous Wastes}

To: External

Solid wastes generated within the Concentrate Waste function that is classified as dangerous per EPA or State of Washington regulations.

\subsubsection{O3 Concentrate Waste Excess Facilities}

Excess facilities that, having fulfilled their original purposes and completed the functions/processes described in the Concentrate Waste function, are now available and appropriate for reuse or deactivation. Reuse will be decided at the Site level.

\subsubsection{O4 Concentrate Waste Non-Dangerous Solid Wastes}

To: 5

Ordinary non-radioactive, non-dangerous solid wastes generated within the Concentrate Waste function, suitable for disposal in a sanitary landfill.

\subsubsection{O5 Concentrate Waste Radioactive Solid Waste}

Radioactive and radioactive dangerous waste in a solid form generated within the Concentrate Waste function that has been prepared in accordance with the acceptance criteria for the Remediate Solid Waste (4.3) function. Preparation will required the solid waste to be segregated, packaged, assayed, and certified for transfer for management and disposal. Examples of this output include failed process equipment, spent ion exchange resins, expended support equipment(i.e., HEPA filters), and materials used for radiological control(i.e., visqueen, framing materials, kraft paper, rags).

\subsubsection{O6 Concentrate Waste Treated Gaseous Efnuents}

To: External

Conditioned gases appropriate for discharge directly to the environment originating from concentration processes, vessel ventilation as required for transferring materials, and the control of radionuclide migration from primary and secondary containment structures. 
Liquid effluents which meet interface acceptance criteria for discharge directly to the 200 Area Treated Effluent Disposal Facility (TEDF) 216-B-3 Expansion Pond.

\subsubsection{O8 Concentrate Waste Untreated Liquid Effluents}

Generated liquid effluents which require treatment and meet interface acceptance criteria for discharge directly to the Liquid Effluent Retention Facility (LERF) and subsequent treatment in the Effluent Treatment Facility (ETF).

\subsubsection{O9 MTW Transferrable Resources}

Resources from Manage Tank Waste activities that have no further MTW mission. These include valuable technology, work force, materials, equipment, facilities and infrastructure. Includes excess resources inventory information.

\subsubsection{O10 Waste Concentrate}

The concentrated product generated by removal of excess moisture from tank waste, to be returned to the DST's. The concentrated product returned to the DSTs is referred to as Double Shell Slurry Feed (DSSF). DSSF is defined as a slurry with a chemical composition that is below the sodium-aluminate boundary but that could be concentrated past the sodium-aluminate boundary, with a single additional pass through the Evaporator. The viscosity of DSSF typically ranges from 20 to $40 \mathrm{cP}$.

\subsubsection{O11 Waste Concentrate for Sampling}

To: 4.2.1.2

Waste concentrate for sampling is the concentrated waste product of the Concentrate Waste function that has been identified for characterization prior to transfer and storage for process control purposes.

\subsubsection{O12 Waste Concentration Feed for Sampling}

Waste concentrate feed for sampling is mixed waste (slurry) solutions fed to the Concentrate Waste function that has been identified for characterization for process control purposes. 


\section{FUNCTION ID NUMBER: $\quad 4.2 .2$}

\section{FUNCTION TITLE: Retrieve Tank Waste}

\section{FUNCTION DEFINITION:}

The removal of wastes (i.e., liquids, saltcake, sludges, in-tank hardware, and discrete sources) from underground storage tanks (USTs) and the transfer of these wastes to the Process Waste function. Wastes will be removed to the extent required for turnover of the tanks for closure. This function does not include the removal of previously retrieved waste from the DSTs (see the Store In-Process Waste function). This function also includes treatment/preparation of liquid, gaseous, and solid waste generated during retrieval of tank wastes.

\section{INPUTS:}

\subsubsection{I1 Infrastructure Support for Retrieve Waste}

From: 5

General infrastructure support needed to retrieve tank waste. This will include but is not limited to fire protection, police, emergency preparedness, medical services, road services, telecommunications, radiological services, laboratory services, transportation and sewer. This includes land for siting facilities.

\subsubsection{I2 Raw Materials for RW}

From: External

Any material or services (e.g., steam, water, air, process chemicals, electricity) needed from outside TWRS for retrieving tank waste.

\subsubsection{I3 Recycled Water for Retrieval}

Water used during processing of tank wastes that is now available and appropriate for use by the Retrieve Tank Waste function.

\subsubsection{I4 Tank Operations Information}

From: 4.2.1

Tank operations information consisting of monitoring and surveillance data which includes: in-tank temperature measurements, pressure measurements, waste level measurements, photographs, emission monitoring data, data from specialty equipment, as well as information related to the structure of the tank and its safety status. Tank operations information is provided by the Store Managed Tank Waste function (sub-function Manage System Data/Information).

\subsubsection{I5 Tank Operations Information for SSTs}

Tank operations information consisting of monitoring and surveillance data which includes: in-tank temperature measurements, pressure measurements, waste level measurements, photographs, emission monitoring data, data from specialty equipment, as well as information related to the structure of the tank 
and its safety status. Tank operations information is provided by the Store Managed Tank Waste function (sub-function Manage System Data/Information).

\subsubsection{I6 Tank Waste Characterization Information}

Tank Waste Characterization Information consists of the technical basis sampling priority list, Tank Waste Analysis Plan, Tank Characterization Plans, Sampling and Analysis Plans, Sampling Schedule, Historical Tank Content Estimates (HTCEs), waste analysis data packages, waste in-situ measurement data, Tank Characterization Reports (TCRs), and other statistical data analysis and technical reports.

\subsubsection{I7 Tanks With Waste for Retrieval}

From: 4.2.1

Underground storage tanks (DSTs, SSTs, and MUSTs) and the wastes contained within that are to be retrieved by the "Retrieve Tank Waste " function for safety issues resolution, pretreatment, or disposal purposes. The waste includes in-tank hardware and discrete sources which will be dispositioned by the Hanford Site function "Remediate Solid Waste", as well as saltcake, sludge and supernatant.

\section{OUTPUTS:}

\subsubsection{O1 Closure-Ready USTs}

USTs from which sufficient waste has been retrieved to meet closure requirements.

\subsubsection{O2 DSTs Available for Reuse}

DSTs which have waste removed and are suitable and available for reuse to store waste.

\subsubsection{O3 Remediate Ancillary Equipment and Systems Waste}

Wastes retrieved from ancillary systems (e.g. MUSTs, DCRTs, diversion boxes, pump pits, catch tanks, and other equipment associated with operable units) for treatment, safety issue resolution, or disposal. This waste includes supernates, saltcake, and sludges. Any ancillary equipment, in-tank hardware or discrete sources found in the MUSTs will be dispositioned by the Hanford Site function "Remediate Solid Waste".

\subsubsection{O4 Retrieve Tank Waste Characterization Requirements}

Characterize Waste requires information to support the design, development and operation of single and double shell tank retrieval systems. The information is identified in the Data Quality Objectives (DQO) document developed by the Retrieve Waste function. This DQO and the companion tank specific documentation (e.g., tank characterization plans, sample analysis plans, etc.) contain the decisions, error tolerances, in-situ measurement and sampling requirements (such as number and location), and analysis 
requirements (such as type, precision and accuracy).

4.2.2 O5 Retrieve Tank Waste Dangerous Wastes

To: External

Solid wastes generated within the Retrieve Tank Tank Waste function that is classified as dangerous per EPA or State of Washington regulations.

\subsubsection{O6 Retrieve Tank Waste Excess Facilities}

To: 4.1

Facilities that, having fulfilled their original purposes and completed the function/processes described in the Retrieve Tank Waste function, are now available and appropriate for reuse or deactivation. Reuse will be decided at the site level.

\subsubsection{O7 Retrieve Tank Waste Non-Dangerous Solid Wastes}

To: 5

Ordinary non-radioactive, non-dangerous solid wastes generated within the Retrieve Tank Waste function, suitable for disposal in a sanitary landfill.

\subsubsection{O8 Retrieve Tank Waste Radioactive Solid Wastes}

To: 4.3

Radioactive and radioactive dangerous solid wastes generated from the Retrieve Tank Waste function that has been segregated, packaged, assayed, and certified for transfer to Hanford Site Function 4.3; Remedy Solid Waste, for management and disposal.

\subsubsection{Retrieve Tank Waste Transferrable Resources}

To: 6

Resources from Retrieve Tank Waste activities that have no further RW mission. These include technology, work force, materials, equipment, facilities and infrastructure.

\subsubsection{O10 Retrieve Tank Waste Treated Gaseous Effluents}

To: External

Treated gaseous waste from functions associated with retrieval of tank wastes. Treated gaseous effluents are discharged to the atmosphere.

\subsubsection{O11 Retrieve Tank Waste Treated Liquid Effluents}

Liquid effluents which meet interface acceptance criteria for discharge directly to the 200 Area Treated Effluent Disposal Facility (TEDF).

\subsubsection{O12 Retrieve Tank Waste Untreated Liquid Effluents}

To: 4.5

Generated liquid effluents which require treatment and meet interface acceptance criteria for discharge directly to the Liquid Effluent Retention Facility (LERF) and subsequent treatment in the Effluent Treatment Facility (ETF).

\subsubsection{O13 Retrieved Tank Waste}

Waste retrieved and transfered to another facility for interim storage and feed staging. 
Revision 1

Appendix B - Function 4.2.2 


\section{FUNCTION ID NUMBER: 4.2.2.1}

\section{FUNCTION TITLE: Retrieve SST Waste}

\section{FUNCTION DEFINITION:}

The removal of wastes (i.e., saltcake, sludges, in-tank hardware, and discrete sources) from single shell tanks (SSTs) and the transfer of these wastes to the Store In-Process Waste function. Wastes will be removed to the extent required for turnover of the tanks to closure. Includes retrieval and consolidation of tank space.

IV. INPUTS:

\subsubsection{I1 Raw Materials for Retrieve SST Waste}

From: External

Any material or services (e.g., steam, water, air, process chemicals, electricity) needed from outside TWRS for retrieving SST waste.

\subsubsection{I2 Recycled Water for Retrieval}

Water used during processing of tank wastes that is now available and appropriate for use by the Retrieve Tank Waste function.

\subsubsection{I3 Sanitary Waste Services for Retrieve SST Waste}

From: 5

A service that receives, collects, and transfers all sanitary domestic sewer wastes from the Retrieve SST Waste function for processing in a domestic waste-water sewer treatment processing system.

\subsubsection{I4 SST Waste for Retrieval}

From: 4.2 .1

Wastes stored in underground SSTs which are to be retrieved for treatment, safety issue resolution, or disposal purposes. This waste includes saltcake, sludge, and in-tank hardware. In-tank hardware and discrete sources will be dispositioned by the Hanford Site function "Remediate Solid Waste".

\subsubsection{I5 Tank Operations Information for SSTs}

Tank operations information consisting of monitoring and surveillance data which includes: in-tank temperature measurements, pressure measurements, waste level measurements, photographs, emission monitoring data, data from specialty equipment, as well as information related to the structure of the tank and its safety status. Tank operations information is provided by the Store Managed Tank Waste function (sub-function Manage System Data/Information).

\subsubsection{I6 Tank Waste Characterization Information}


Tank Waste Characterization Information consists of the technical basis sampling priority list, Tank Waste Analysis Plan, Tank Characterization Plans, Sampling and Analysis Plans, Sampling Schedule, Historical Tank Content Estimates (HTCEs), waste analysis data packages, waste in-situ measurement data, Tank Characterization Reports (TCRs), and other statistical data analysis and technical reports.

\section{OUTPUTS:}

\subsubsection{O1 Closure-Ready SSTs}

To: 4.2 .4 .3

SSTs from which sufficient waste has been retrieved to meet closure requirements.

\subsubsection{O2 Retrieve SST Waste Ancillary Equipment and Systems}

Wastes retrieved from SST ancillary equipment and systems (e.g. MUSTs, DCRTs, underground waste transfer pipelines, HVAC ducts and exhausters, diversion boxes, pump pits, catch tanks, and other equipment asscoiated with SST operable units).

\subsubsection{O3 Retrieve SST Waste Characterization Requirements}

Characterization information needs of the SST Retrieve/Transfer Waste function that can be transformed into data quality objectives with requirements for analytical measurements, precision, and accuracy.

\subsubsection{O4 Retrieve SST Waste Dangerous Wastes}

To: External

Solid wastes generated within the Retrieve SST Waste function that is classified as dangerous per EPA or State of Washington regulations.

\subsubsection{O5 Retrieve SST Waste Excess Facilities}

Facilities that have reached the end of their useful life or have no identifiable or planned programmatic use by the Retrieve SST Waste function. Excess facilities are transferred to Hanford Site Function 4.1; Deactivate Facilities.

\subsubsection{O6 Retrieve SST Waste Non-Dangerous Solid Wastes}

To: 5

Ordinary non-radioactive, non-dangerous solid wastes generated within the Retrieve SST Tank Waste function, suitable for disposal in a sanitary landfill.

\subsubsection{O7 Retrieve SST Waste Radioactive Solid Wastes}

Radioactive and radioactive dangerous solid wastes generated from the retrieve/transfer SST waste function that has been segregated, packaged, assayed, and certified for transfer to Hanford Site Function 4.3; Remedy Solid Waste, for management and disposal. 
Resources from Retrieve SST Waste activities that have no further Retrieve SST Waste mission. These include technology, work force, materials, equipment, facilities and infrastructure.

\subsubsection{O9 Retrieve SST Waste Treated Gaseous Effluents}

To: External

Treated gaseous waste from functions associated with SST retrieval. Treated gaseous effluents are discharged to the atmosphere.

\subsubsection{O10 Retrieve SST Waste Treated Liquid Effluents}

Liquid effluents which meet interface acceptance criteria for discharge directly to the 200 Area Treated Effluent Disposal Facility (TEDF).

\subsubsection{O11 Retrieve SST Waste Untreated Liquid Effluents}

Generated liquid effluents which require treatment and meet interface acceptance criteria for discharge directly to the Liquid Effluent Retention Facility (LERF) and subsequent treatment in the Effluent Treatment Facility (ETF).

\subsubsection{O12 Retrieved Tank Waste}

Waste retrieved and transfered to another facility for interim storage and feed staging. 


\section{FUNCTION ID NUMBER: $\quad 4.2 .2 .2$}

\section{FUNCTION TITLE: Retrieve DST Waste}

\section{FUNCTION DEFINITION:}

The removal of wastes (i.e., liquids, saltcake, sludges, and in-tank hardware) from double shell tanks (DSTs) and the transfer of these wastes to the Store In-Process Waste function. Wastes will be removed to the extent required for tumover of the tanks to closure. This function does not include the removal of previously retrieved waste from the DSTs (see the Store In-Process Waste function). Includes retrieval and consolidation of tank space.

\section{INPUTS:}

\subsubsection{I1 DST Waste for Retrieval}

From: 4.2.1

Wastes stored in underground DSTs that are to be retrieved for treatment, safety issue resolution, or disposal. This waste includes the supernate, saltcake, sludge, and in-tank hardware. In-tank hardware and discrete sources will be dispositioned by the Remediate Solid Waste function.

\subsubsection{I2 Raw Materials for Retrieve DST Waste}

From: External

Any material or services (e.g., steam, water, air, process chemicals, electricity) needed from outside TWRS for retrieving DST waste.

\subsubsection{I3 Recycled Water for Retrieval}

Water used during processing of tank wastes that is now available and appropriate for use by the Retrieve Tank Waste function.

\subsubsection{I4 Sanitary Waste Services for Retrieve DST Waste}

A service that receives, collects, and transfers all sanitary domestic sewer wastes from the Retrieve DST Waste function for processing in a domestic waste-water sewer treatment processing system.

\subsubsection{I5 Tank Operations Information}

Tank operations information consisting of monitoring and surveillance data which includes: in-tank temperature measurements, pressure measurements, waste level measurements, photographs, emission monitoring data, data from specialty equipment, as well as information related to the structure of the tank and its safety status. Tank operations information is provided by the Store Managed Tank Waste function (sub-function Manage System Data/Information). 
Tank Waste Characterization Information consists of the technical basis sampling priority list, Tank Waste Analysis Plan, Tank Characterization Plans, Sampling and Analysis Plans, Sampling Schedule, Historical Tank Content Estimates (HTCEs), waste analysis data packages, waste in-situ measurement data, Tank Characterization Reports (TCRs), and other statistical data analysis and technical reports.

\section{OUTPUTS:}

\subsubsection{O1 Closure-Ready DSTs}

To: 4.2 .4 .3

DSTs from which sufficient waste has been retrieved to meet closure requirements.

\subsubsection{O2 DST Retrieval Treated Gaseous Effluents}

To: External

Treated gaseous waste from functions associated with DST retrieval. Treated gaseous effluents are discharged to the atmosphere.

DSTs which have waste removed and are suitable and available for reuse to store waste.

\subsubsection{O4 Retrieve DST Waste Ancillary Equipment and Systems}

To: 4.2 .2 .3

Wastes retrieved from DST ancillary equipment and systems (e.g. MUSTs, DCRTs, underground waste transfer pipelines, HVAC ducts and exhausters, diversion boxes, pump pits, catch tanks, and other equipment asscoiated with DST operable units).

\subsubsection{O5 Retrieve DST Waste Characterization Requirements}

Characterization information needs of the Retrieve/Transfer DST Waste function that can be transformed into data quality objectives with requirements on analytical measurements, precision, and accuracy.

\subsubsection{O6 Retrieve DST Waste Dangerous Wastes}

To: External

Solid wastes generated within the Retrieve DST Waste function that is classified as dangerous per EPA or State of Washington regulations.

\subsubsection{O7 Retrieve DST Waste Excess Facilities}

Facilities that have reached the end of their useful life or have no identifiable or planned programmatic use by the Retrieve DST Waste function. Excess facilities are transferred to Hanford Site Function 4.1; Deactivate Facilities. 
Ordinary non-radioactive, non-dangerous solid wastes generated within the Retrieve DST Tank Waste function, suitable for disposal in a sanitary landfill.

\subsubsection{O9 Retrieve DST Waste Radioactive Solid Wastes}

Radioactive and radioactive dangerous solid wastes generated from the retrieve/transfer DST waste function that has been segregated, packaged, assayed, and certified for transfer to Hanford Site Function 4.3; Remedy Solid Waste, for management and disposal.

\subsubsection{O10 Retrieve DST Waste Transferrable Resources}

To: 6

Resources from Retrieve DST Waste activities that have no further Retrieve DST Waste mission. These include technology, work force, materials, equipment, facilities and infrastructure.

\subsubsection{O11 Retrieve DST Waste Treated Liquid Effluents}

Liquid effluents which meet interface acceptance criteria for discharge directly to the 200 Area Treated Effluent Disposal Facility (TEDF).

\subsubsection{O12 Retrieve DST Waste Untreated Liquid Effluents}

Generated liquid effluents which require treatment and meet interface acceptance criteria for discharge directly to the Liquid Effluent Retention Facility (LERF) and subsequent treatment in the Effluent Treatment Facility (ETF).

\subsubsection{O13 Retrieved Tank Waste}

To: 4.2 .3

Waste retrieved and transfered to another facility for interim storage and feed staging. 


\section{FUNCTION ID NUMBER: $\quad 4.2 .2 .3$}

II. FUNCTION TITLE: Remediate Ancillary Equipment and Systems

\section{FUNCTION DEFINITION:}

Wastes will be removed from the Ancillary Equipment and Systems to the extent required for closure and transferred to the Store In-Process Waste function.

Ancillary Equipment and Systems include MUST's, double-contained receiver tanks, underground waste transfer pipelines, HVAC ducts, and exhausters, diversion boxes, pump pits, catch tanks, and other equipment associated with Operable Units. Includes retrieval and consolidation of tank space.

\section{INPUTS:}

\subsubsection{I1 Ancillary Equipment and Systems Waste for Retrieval}

From: 4.2 .1 .1

Ancillary Systems (e.g. MUSTs, DCRTs, diversions boxes, pump pits, catch tanks, and other equipment associated with operable units) and waste contained within that are to be retrieved by the Retrieve Tank Waste function for pre-treatment, safety issue resolution, or disposal. This waste includes supernates, saltcake, and sludges. Any ancillary equipment, in-tank hardware or discrete radioactive sources found in the MUSTs will be dispositioned by the Hanford Site function "Remediate Solid Waste".

\subsubsection{I2 Raw Materials for Remediation of Ancillary Equipment and Systems $\quad$ From: External}

Any material or services (e.g., steam, water, air, process chemicals, electricity) needed from outside TWRS for remediation of ancillary equipment and systems.

\subsubsection{I3 Recycled Water for Retrieval}

Water used during processing of tank wastes that is now available and appropriate for use by the Retrieve Tank Waste function.

\subsubsection{I4 Retrieve DST Waste Ancillary Equipment and Systems}

From: 4.2.2.2

Wastes retrieved from DST ancillary equipment and systems (e.g. MUSTs, DCRTs, underground waste transfer pipelines, HVAC ducts and exhausters, diversion boxes, pump pits, catch tanks, and other equipment asscoiated with DST operable units).

\subsubsection{I5 Retrieve SST Waste Ancillary Equipment and Systems}

From: 4.2.2.1

Wastes retrieved from SST ancillary equipment and systems (e.g. MUSTs, DCRTs, underground waste transfer pipelines, HVAC ducts and exhausters, diversion boxes, pump pits, catch tanks, and other equipment asscoiated with SST operable units). 
A service that receives, collects, and transfers all sanitary domestic sewer wastes from the Retrieve MUST Waste function for processing in a domestic waste-water sewer treatment processing system.

\subsubsection{I7 Tank Operations Information}

Tank operations information consisting of monitoring and surveillance data which includes: in-tank temperature measurements, pressure measurements, waste level measurements, photographs, emission monitoring data, data from specialty equipment, as well as information related to the structure of the tank and its safety status. Tank operations information is provided by the Store Managed Tank Waste function (sub-function Manage System Data/Information).

\subsubsection{I8 Tank Waste Characterization Information}

Tank Waste Characterization Information consists of the technical basis sampling priority list, Tank Waste Analysis Plan, Tank Characterization Plans, Sampling and Analysis Plans, Sampling Schedule, Historical Tank Content Estimates (HTCEs), waste analysis data packages, waste in-situ measurement data, Tank Characterization Reports (TCRs), and other statistical data analysis and technical reports.

\section{v. OUTPUTS:}

\subsubsection{01 Closure-Ready Ancillary Equipment and Systems}

To: 4.2 .4 .3

Ancillary equipment and systems from which sufficient waste has been retrieved to meet closure requirements.

\subsubsection{O2 Remediate Ancillary Equipment and Systems Excess Facilities}

Facilities that have reached the end of their useful life or have no identifiable or planned programmatic use by the Remediate Ancillary Equipment and Systems function. Excess facilities are transferred to Hanford Site Function 4.1; Deactivate Facilities.

\subsubsection{O3 Remediate Ancillary Equipment and Systems Garbage}

Ordinary non-radioactive, non-hazardous solid waste generated within the Remediate Ancillary Equipment and Systems function, suitable for disposal in a sanitary landfill.

\subsubsection{O4 Remediate Ancillary Equipment and Systems Hazardous Waste}

To: External

Solid waste generated within the Remediate Ancillary Equipment and Systems function that is classified as hazardous (dangerous) per EPA or State of Washington regulations.

Solid waste generated from the Remediate Ancillary Equipment and Systems function that has been 
segregated, packaged, assayed, and certified for transfer to Hanford Site Function 4.3; Remedy Solid Waste, for further treatment or disposal.

\subsubsection{O6 Remediate Ancillary Equipment and Systems Retrieval Characterization RequirEmeh?sl}

Remediate Ancillary Equipment and Systems Characterization information needs of the Retrieve/Transfer Waste function that can be transformed into data quality objectives with requirements for analytical measurements, precision, and accuracy.

\subsubsection{07 Remediate Ancillary Equipment and Systems Retrieval Untreated Liquid Effluent5o: 4.5}

Generated liquid effluents which require treatment and meet interface acceptance criteria for discharge directly to the Liquid Effluent Retention Facility (LERF) and subsequent treatment in the Effluent Treatment Facility (ETF).

\subsubsection{O8 Remediate Ancillary Equipment and Systems Transferrable Resources}

Resources from Remediate Ancillary Equipment and Systems activities that have no further Remediate Ancillary Equipment and Systems mission. These include technology, work force, materials, equipment, facilities and infrastructure.

\subsubsection{09 Remediate Ancillary Equipment and Systems Treated Gaseous Effluents $\quad$ To: External}

Treated gaseous waste from functions associated with remediation of ancillary equipment and systems. Treated gaseous effluents are discharged to the atmosphere.

\subsubsection{O10 Remediate Ancillary Equipment and Systems Treated Liquid Effluents}

Liquid effluents which meet interface acceptance criteria for discharge directly to the 200 Area Treated Effluent Disposal Facility (TEDF).

\subsubsection{O11 Remediate Ancillary Equipment and Systems Waste}

Wastes retrieved from ancillary systems (e.g. MUSTs, DCRTs, diversion boxes, pump pits, catch tanks, and other equipment associated with operable units) for treatment, safety issue resolution, or disposal. This waste includes supernates, saltcake, and sludges. Any ancillary equipment, in-tank hardware or discrete sources found in the MUSTs will be dispositioned by the Hanford Site function "Remediate Solid Waste". 


\section{FUNCTION ID NUMBER: 4.2 .3}

\section{FUNCTION TITLE: Process Waste}

\section{FUNCTION DEFINITION:}

Process tank waste (including DST waste, SST waste, miscellaneous underground storage tanks that contain HLW), and prepare cesium/strontium capsules for disposal. This includes in-process waste transfer and storage, any pretreatment (if required), immobilization of low-level wastes, immobilization and certification of immobilized high-level wastes for acceptance into the Civilian Radioactive Waste Management System (CRWMS). Also included is the treatment/preparation of gaseous and liquid effluents and solid wastes generated during the processing of tank waste. Wastes excluded from processing by this function are the underground storage tanks and support structures, production reactor fuels, radioactive materials at reactors, disposal facilities, transfer lines, cribs, ponds, and ditches.

The Process Waste function is initiated when storage of in-process waste for treatment begins and will continue until the last IHLW/ITRU package leaves the immobilization and the treatment facilities are turned over for decontamination and decommissioning (D\&D).

\section{INPUTS:}

4.2.3 I1 Cesium Product for Processing

From: 4.2 .4

Cesium product delivered from the interim storage facility to a HLW immobilization facility. This interface is active only during phase 2 processing of tank wastes.

\subsubsection{Cesium Product Transport Mechanism}

From: 4.2 .4

The ready-to-use cask and vehicle for on-site transport of cesium product from the Phase I LLW Immobilization Facility to the interim storage facility. The transport mechanism is provided by the Interim Store Solidified HLW and TRU Waste function (4.2.4.1).

\subsubsection{I3 Cesium/Strontium Capsules}

From: 4.7

$\mathrm{Cs} / \mathrm{Sr}$ capsules removed from storage to be dispositioned.

\subsubsection{I4 Cs/Sr Capsule Characterization Data}

From: 4.7

Certification data describing the radiological, chemical, and physical attributes of Cs and Sr capsules.

\subsubsection{I5 Dispositioned Cs/Sr Capsules Transport Mechanism}

From: 4.2 .4

The device(s) for on-site transport of dispositioned $\mathrm{Cs} / \mathrm{Sr}$ capsules from the capsule preparation system to the interim storage facility. The transport mechanism is provided by the Interim Store Solidified HLW and TRU Waste function (4.2.4.1). 
Appendix B - Function 4.2.3

A shielded transport mechanism for transport of ILAW containers from the ILAW immobilization facility to the ILAW disposal facility or interim storage.

\subsubsection{I14 Information Input}

From: 4.2 .1

4.2.1.2

4.2.3.1

4.2.3.2

Miscellaneous informational input to the Privatizatin Contractor from DOE or the PHMC. Typically used for review and approval of various documents, work plans, permits, etc. These are inputs to the enable the function and not to the outputs from the function.

\subsubsection{I15 Infrastructure Support for Waste Processing System}

From: 5

General infrastructure support needed to treat and immobilize tank waste. This will include but is not limited to fire protection, police, emergency preparedness, medical services, road services, telecommunications, radiological services, laboratory services, transportation and sewer. This includes land for siting facilities.

\subsubsection{I16 Radioactive Solid Waste Transport Mechanism}

From: 4.3

Equipment and service for on-site transport of packaged radioactive solid wastes.

\subsubsection{I17 Raw Materials for PW}

From: External

Any material (e.g., steam, water, air, electricity, process chemical, laundry, hardware, IHLW transport vehicles, casks, etc.) needed from outside TWRS for storing, pretreating, and immobilizing tank waste.

\subsubsection{I18 Recycled Condensate to PSS}

From: 4.5

Treated process condensates suitable for washing tank wastes.

\subsubsection{I19 Remediate Ancillary Equipment and Systems Waste}

Wastes retrieved from ancillary systems (e.g. MUSTs, DCRTs, diversion boxes, pump pits, catch tanks, and other equipment associated with operable units) for treatment, safety issue resolution, or disposal. This waste includes supernates, saltcake, and sludges. Any ancillary equipment, in-tank hardware or discrete sources found in the MUSTs will be dispositioned by the Hanford Site function "Remediate Solid Waste".

\subsubsection{I20 Retrieved Tank Waste}

Waste retrieved and transfered to another facility for interim storage and feed staging. 
Tank Waste Characterization Information consists of the technical basis sampling priority list, Tank Waste Analysis Plan, Tank Characterization Plans, Sampling and Analysis Plans, Sampling Schedule, Historical Tank Content Estimates (HTCEs), waste analysis data packages, waste in-situ measurement data, Tank Characterization Reports (TCRs), and other statistical data analysis and technical reports.

\section{V, OUTPUTS:}

\subsubsection{O1 Cesium Product for Storage}

Containers of solidified cesium that has been separated from the low-activity waste solutions. This interface exists for the private contractor providing only the low-activity waste treatment services.

Private contractor providing the high-level waste and low-activity waste treatment services is not allowed to generated a separate cesium product. At the time of transport to the interim storage facility the waste will be certified to meet interim storage requirements.

\subsubsection{O2 Cesium Product for Storage - Samples}

Samples of the dry cesium product provided for chemical analysis and testing.

\subsubsection{O3 Dispositioned Cs/Sr Capsules for Storage}

$\mathrm{Cs} / \mathrm{Sr}$ capsules dispositioned in a manner suitable for interim onsite storage and eventual offsite disposal.

\subsubsection{O4 Excess DSTs from Pretreat Sludge/Solids}

DSTs which were utilized for the pretreatment of sludges/solids and have no further use by the PSS function.

\subsubsection{O5 Excess DSTs From Store In-Process Waste}

DSTs which were utilized for the storage of in-process wastes and have no further use by the Store In-Process Waste function.

\subsubsection{O6 Excess Feed Tanks}

Double-shell tanks (DSTs) and ancillary equipment which were used by the low-activity waste treatment system as process feed tanks. When these feed tanks are no longer needed for low-activity waste 
treatment, the custody of these feed tanks is transferred back to the DST waste storage system.

\subsubsection{O7 IHLW for Storage}

IHLW sealed in canisters suitable for interim on-site storage and eventual emplacement in HLW geologic repository. At time of transfer to the interim storage function the waste will be certified to meet product acceptance requirements.

\subsubsection{O8 ILAW for Interim Storage}

Immobilized low-activity waste packages placed in the transport container and loaded onto the transport mechanism.

\subsubsection{O9 Process Waste Samples}

Samples of process solutions and materials generated during processing of tank waste. Samples of the waste may be obtained for verification testing.

\subsubsection{O10 Process Waste Tank Characterization Requirements}

Characterize Waste requires information and sample material requirements to support the pretreatment of supernatants, sludges, and solids and immobilize low-level and high-level wastes from single and double shell tanks. The information is identified in the Data Quality Objectives (DQO) document developed by the Process Waste function. This DQO and the companion tank specific documentation (e.g., tank characterization plans, sample analysis plans, etc.) contain the decisions, error tolerances, in-situ measurement and sampling requirements (such as number and location), and analysis requirements (such as type, precision and accuracy) necessary to support the development of pretreatment processes.

\subsubsection{O11 PW Dangerous Wastes}

To: External

Dangerous, non-radioactive solid wastes will be generated. The DOE will not accept dangerous, non-radioactive waste from the privatization contractors. These wastes must be sent to an external treatment, storage, and disposal facility.

\subsubsection{O12 PW Excess Facilities}

To: 4.1

Facilities that, having fulfilled their original purposes and completed the function/processes described in the process waste function, are now available and appropriate for reuse or deactivation. Excess facilities are transferred to Hanford Site Function 4.1; Deactivate Facilities. Reuse will be decided at the site level.

\subsubsection{O13 PW Non-Dangerous Solid Wastes}

This function will generate ordinary non-radioactive, non-dangerous solid wastes suitable for disposal at a sanitary landfill. 
Appendix B - Function 4.2.3

4.2.3 O14 PW Non-Radioactive, Non-Dangerous Liquid Effluent

To: 4.5

Uncontaminated waste water which meets interface acceptance criteria for discharge directly to the 200 Area Treated Effluent Disposal Facility (TEDF) as specified in State Waste Discharge Permit No. ST-4502.

\subsubsection{O15 PW Non-Routine High-Level Solid Waste}

To: 4.2 .4

Processing of tank wastes may generate secondary radioactive solid waste that meets the NRC's source-based definition of High-Level Waste. DOE anticipates that small quantities of such waste may be produced on a non-routine basis during privatization Part B operations, particularly during deactivation.

\subsubsection{O16 PW Process Information}

To: 1

Data generated by the operations of the Process Waste function.

\subsubsection{O17 PW Radioactive Solid Wastes}

Radioactive and radioactive dangerous solid wastes will be generated. These wastes will be transferred to the Hanford Site Function 4.3; Remedy Solid Waste for management and disposal.

\subsubsection{O18 PW Radioactive, Dangerous Liquid Effluent}

Dilute process waste liquid effluents which require treatment and meet interface acceptance criteria for discharge directly, or with minimal pretreatment, to the Liquid Effluent Retention Facility (LERF) and/or to the Effluent Treatment Facility (ETF) for subsequent treatment in accordance with State Waste Discharge Permit No. ST-4500.

\subsubsection{O19 PW Transferrable Resources}

Resources from Process Waste activities that have no further PW mission. These include technology, materials, land, equipment, facilities and infrastructure. Includes excess resources inventory information.

\subsubsection{O20 PW Treated Gaseous Effluents}

To: External

Treated gaseous waste from functions associated with processing tank wastes. Treated gaseous effluents are discharged to the atmosphere.

\subsubsection{O21 Recycled Water for Retrieval}

Water used during processing of tank wastes that is now available and appropriate for use by the Retrieve Tank Waste function. 
Appendix B - Function 4.2.3

4.2.1.2

Samples of the liquid technetium product provided for chemical analysis and testing 


\section{FUNCTION ID NUMBER: 4.2.3.1}

II. FUNCTION TITLE: Store In-Process Waste

\section{FUNCTION DEFINITION:}

Receive, store, monitor, condition, and transfer previously retrieved DST/SST/MUST wastes or pretreated wastes. This includes the mobilization/suspension of tank waste solids and liquid forms of separated radionuclides ( $\mathrm{Cs}, \mathrm{Tc}, \mathrm{Sr}$, and TRU), minor chemical adjustments, in-tank blending and feed staging of wastes, but excludes in-tank waste pretreatment activities (e.g., in-tank sludge washing). This function also includes treatment/preparation of liquid, gaseous, and solid waste generated during storage of in-process wastes.

Storage of in-process waste will begin when waste retrieval for treatment begins and will continue until all pretreated waste has been transferred for treatment/immobilization.

\section{INPUTS:}

\subsubsection{I1 DSTs Available for Reuse}

DSTs which have waste removed and are suitable and available for reuse to store waste.

\subsubsection{I2 DSTs for In-Process Storage of Waste}

Double shell tanks allocated for storage of in-process wastes.

\subsubsection{I3 Entrained Solids -In-process storage}

From: 4.2.3.3

Solids separated from the low-activity waste feed solutions as necessary to meet process requirements and sent to In Process Storage.

\subsubsection{I4 Infrastructure Support for Storing In-Process Waste}

From: 5

General infrastructure support needed to in-process store tank waste. This will include but is not limited to fire protection, police, emergency preparedness, medical services, road services, telecommunications, radiological services, laboratory services, transportation and sewer.

\subsubsection{I5 Land for Store In-Process Waste}

From: 5

The land needed in the 200 Area for the Store In-Process Waste function, up to any outer-perimeter fence line that separates the facility from the rest of the Hanford site. The Site Infrastructure function will provide this function with land for siting.

\subsubsection{I6 Pretreated HLW}

From: 4.2.3.2

Pretreated solids that meet the HLW/TRU Waste immobilization feed specification or are suitable for 
blending with other solids to meet the HLW/TRU Waste immobilization feed specification.

\subsubsection{I7 Radioactive Solid Waste Transport Mechanism}

Equipment and service for on-site transport of packaged radioactive solid wastes.

\subsubsection{I8 Raw Materials for Storing In-Process Waste}

From: External

Any materials (e.g., steam, water, air, process chemicals, electricity) needed from outside TWRS for storing in-process wastes.

\subsubsection{I9 Remediate Ancillary Equipment and Systems Waste}

Wastes retrieved from ancillary systems (e.g. MUSTs, DCRTs, diversion boxes, pump pits, catch tanks, and other equipment associated with operable units) for treatment, safety issue resolution, or disposal. This waste includes supernates, saltcake, and sludges. Any ancillary equipment, in-tank hardware or discrete sources found in the MUSTs will be dispositioned by the Hanford Site function "Remediate Solid Waste".

\subsubsection{I10 Retrieved Tank Waste}

Waste retrieved and transfered to another facility for interim storage and feed staging.

\subsubsection{I1l Separated Sr \& TRU Radionuclides -In Process Storage}

From: 4.2 .3 .3

Strontium and TRU elements separated from the low-activity waste solutions. These radionuclides are separated from the low-activity waste solutions as necessary to meet process requirements and sent to In-Process Storage.

\subsubsection{I12 Sludge/Solids Analytical Requirements}

From: 4.2 .3 .4

The Immobilize HLW/TRU Waste function identifies analytical information needs concerning sludges and solids.

\subsubsection{I13 Supernatants for Interim Storage}

From: 4.2.3.2

Liquids and unintentionally entrained solids transferred to store in-process waste function and generated by the pretreatment of sludges and solids.

\subsubsection{I14 Tank Waste Characterization Information}

Tank Waste Characterization Information consists of the technical basis sampling priority list, Tank 
Appendix B - Function 4.2.3.1

Waste Analysis Plan, Tank Characterization Plans, Sampling and Analysis Plans, Sampling Schedule, Historical Tank Content Estimates (HTCEs), waste analysis data packages, waste in-situ measurement data, Tank Characterization Reports (TCRs), and other statistical data analysis and technical reports.

\subsubsection{I15 Technetium Product - In-Process Storage}

From: 4.2.3.3

Technetium that has been separated from the low-activity waste solutions, stored at the private contractors facilities and transferred at the conclusion of services to the to the in-process storage function. This interface exists for the private contractor providing only the low-activity waste treatment services. The private contractor providing the high-level waste and low-activity waste treatment services is not allowed to generate a separate technetium product.

\section{OUTPUTS:}

\subsubsection{O1 Excess DSTs From Store In-Process Waste}

DSTs which were utilized for the storage of in-process wastes and have no further use by the Store In-Process Waste function.

\subsubsection{O2 HLW Feed}

To: 4.2 .3 .4

Pretreated HLW blended to a composition meeting feed specifications and transferred to the Immobilize HLW/TRU function

\subsubsection{O3 Information Input}

To: 4.2 .3

4.2.3.3

4.2.3.4

Miscellaneous informational input to the Privatizatin Contractor from DOE or the PHMC. Typically used for review and approval of various documents, work plans, permits, etc. These are inputs to the enable the function and not to the outputs from the function.

\subsubsection{O4 LAW Feed}

To: 4.2 .3 .3

Liquids and unintentionally entrained solids transferred to the low-activity waste treatment function.

\subsubsection{O5 LAW Feed Solution Samples}

To: 4.2 .3 .3

Samples of low-activity feed solutions for process verification and testing by the low-activity waste treatment function.

\subsubsection{O6 Low Activity Waste Solutions Composition Information}

To: 4.2 .3 .3

Physical and chemical waste properties of the low activity waste solutions.

\subsubsection{O7 Pretreated HLW/TRU Waste Composition Information}

To: 4.2 .3 .4

Physical and chemical waste properties of Pretreated HLW and Pretreated TRU waste. 
Samples of tank waste for pretreatment to verify sludges/solids processibility.

\subsubsection{O9 Sludge Samples}

To: 4.2.3.4

Samples of pretreated HLW/TRU waste for process verification and testing by the HLW/TRU Waste Immobilization function.

\subsubsection{O10 Store In-Process Waste Dangerous Wastes}

To: External

Solid wastes generated within the Store In-Process Waste function that is classified as dangerous per EPA or State of Washington regulations.

\subsubsection{O11 Store In-Process Waste Non-Dangerous Solid Wastes}

Ordinary non-radioactive, non-dangerous solid wastes generated within the Store In-Process Waste function, suitable for disposal in a sanitary landfill.

\subsubsection{O12 Store In-Process Waste Radioactive Solid Wastes}

Radioactive and radioactive danagerous solid wastes generated within the store in-process waste function which has been prepared in accordance with the acceptance criteria for the Remedy Solid Waste (4.3) function. Preparation will require the solid waste to be segregated, packaged, assayed, and certified for transfer to the Remedy Solid Waste function for management and disposal. Examples of this output include failed equipment removed from in-process waste vessels, expended support equipment (i.e., HEPA filters), and materials used for radiological control (i.e., visqueen, framing materials, kraft paper, rags).

\subsubsection{O13 Store In-Process Waste Transferrable Resources}

Resources from Store In-Process Waste activities that have no further Store In-Process Waste mission. These include technology, materials, equipment, facilities, land and infrastructure. Includes excess resources inventory information.

\subsubsection{O14 Store In-Process Waste Treated Gaseous Effluents}

To: External

Treated gaseous waste from functions associated with storage of in-process waste. Treated gaseous effluents are discharged to the atmosphere.

\subsubsection{O15 Store In-Process Waste Treated Liquid Effluents}

Treated liquid waste generated from functions associated with storage of in-process waste.

\subsubsection{O16 Store In-Process Waste Untreated Liquid Effluents}

Generated liquid effluents which require treatment and meet interface acceptance criteria for discharge directly to the Liquid Effluent Retention Facility (LERF) and subsequent treatment in the Effluent 
Treatment Facility (ETF).

4.2.3.1 O17 Tank Waste Characterization Information

To: 4.2 .1 .3

4.2.1.4

4.2 .2

4.2.2.1

$4,2.2 .2$

4.2.2.3

4.2 .3

4.2.3.1

4.2.3.3

4.2.3.4

Tank Waste Characterization Information consists of the technical basis sampling priority list, Tank Waste Analysis Plan, Tank Characterization Plans, Sampling and Analysis Plans, Sampling Schedule, Historical Tank Content Estimates (HTCEs), waste analysis data packages, waste in-situ measurement data, Tank Characterization Reports (TCRs), and other statistical data analysis and technical reports.

\subsubsection{O18 Tank Waste for Pretreatment}

To: 4.2 .3 .2

Tank wastes ready for processing.

\subsubsection{O19 Waste Composition Information}

Physical and chemical waste properties of retrieved tank wastes for pretreatment 


\section{FUNCTION ID NUMBER: $\quad 4.2 .3 .2$}

\section{FUNCTION TITLE: Pretreat Sludges / Solids}

\section{FUNCTION DEFINITION:}

Pretreatment of sludges/solids consists of (1) initial solids-liquids separation, (2) preferential separation of soluble non-radioactive components (e.g. Na, Al, Cr, P04) from sludges, (3) water washing of sludges to separate dissolved compounds in the interstitial liquid trapped in the sludges, and (4) separation of supernatants and wash solutions from the sludges/solids. The remaining high-level waste solids are conditioned for in-process waste storage and/or blending for feed to HLW immobilization.

Pretreatment will begin when tank waste is retrieved and transferred from existing DSTs, SSTs, and Ancillary Equipment and Systems and will continue until all sludges/solids have been prepared as feed for HLW immobilization.

\section{INPUTS:}

\subsubsection{I1 DSTs for Pretreatment of Sludges/Solids}

Double shell tanks for use within the Pretreat Sludge/Solids function.

\subsubsection{I2 Historical Information}

From: External

Historical information is made up of chemical process and waste management information. These include documented and institutional knowledge, historical derived information transcribed to tank layer models, and historical tank content estimates.

Historical data includes: chemical process operations technical manuals (text and flowsheets); interviews with long-time operations and engineering personnel; process aids; reports, memos and logbooks; transfer histories; and simulant studies.

\subsubsection{I3 Infrastructure Support for PSS}

From: 5

General infrastructure support needed to pretreat sludges and solids. This will include but is not limited to laundry, fire protection, police, emergency preparedness, medical services, road services, telecommunications, radiological services, laboratory services, transportation and sewer.

\subsubsection{I4 Land for PSS}

From: 5

The land needed in the 200 Area for the Pretreat Sludges / Solids function, up to any outer-perimeter fence line that separates the facility from the rest of the Hanford site. The Site Infrastructure function will provide this function with land for siting.

\subsubsection{I5 Process Verification Samples}

From: 4.2.3.1

Samples of tank waste for pretreatment to verify sludges/solids processibility. 
4.2.3.2 I6 Radioactive Solid Waste Transport Mechanism

From: 4.3

Equipment and service for on-site transport of packaged radioactive solid wastes.

\subsubsection{I 7 Raw Materials for PSS}

From: External

Any material (e.g., steam water, air, electricity, process chemical, hardware, etc.) needed from outside TWRS for pretreating tank waste sludges/solids

\subsubsection{I8 Recycled Condensate to PSS}

From: 4.5

Treated process condensates suitable for washing tank wastes.

\subsubsection{I9 Tank Waste for Pretreatment}

Tank wastes ready for processing.

\subsubsection{I10 Waste Composition Information}

From: 4.2.3.1

Physical and chemical waste properties of retrieved tank wastes for pretreatment

\section{OUTPUTS:}

\subsubsection{O1 Excess DSTs from Pretreat Sludge/Solids}

DSTs which were utilized for the pretreatment of sludges/solids and have no further use by the PSS function.

\subsubsection{O2 Information Input}

Miscellaneous informational input to the Privatizatin Contractor from DOE or the PHMC. Typically used for review and approval of various documents, work plans, permits, etc. These are inputs to the enable the function and not to the outputs from the function.

\subsubsection{O3 Pretreated HLW}

To: 4.2.3.1

Pretreated solids that meet the HLW/TRU Waste immobilization feed specification or are suitable for blending with other solids to meet the HLW/TRU Waste immobilization feed specification.

\subsubsection{O4 PSS Analytical Requirements}

The analytical information needs of the Pretreat Sludges/Solids function concerning tank waste for pretreatment. The analytical requirements will be transformed into data quality objectives with requirements for analytical measurements, precision, and accuracy. 
Solid wastes generated within the Pretreat Sludges/Solids function that is classified as dangerous per EPA or State of Washington regulations.

\subsubsection{O6 PSS Excess Facilities}

Excess facilities that, having fulfilled their original purposes and completed the functions/processes described in the Pretreat Sludges function, are now available and appropriate for reuse or deactivation. Includes buildings, equipment, instrumentation, etc. Excess facilities are transferred to Hanford Site Function 4.1; Deactivate Facilities. Reuse will be decided at the Site level.

\subsubsection{O7 PSS Non-Dangerous Solid Wastes}

Ordinary non-radioactive, non-dangerous solid wastes generated within the Pretreat Sludges/Solids function, suitable for disposal in a sanitary landfill.

\subsubsection{O8 PSS Radioactive Solid Wastes}

Radioactive and radioactive dangerous solid wastes generated from the Pretreat Sludges/Solids function that has been segregated, packaged, assayed, and certified for transfer to Hanford Site Function 4.3; Remedy Solid Waste for management and disposal.

\subsubsection{09 PSS Transferrable Resources}

Resources from PSS activities that have no further PSS mission. These include technology, materials, equipment, facilities, land, and infrastructure.

\subsubsection{O10 PSS Treated Gaseous Effluents}

To: External

Treated gaseous waste from functions associated with pretreatment of sludges/solids. Treated gaseous effluents are discharged to the atmosphere.

\subsubsection{O11 PSS Treated Liquid Effluents}

Liquid effluents which meet interface acceptance criteria for discharge directly to the 200 Area Treated Effluent Disposal Facility (TEDF).

\subsubsection{O12 PSS Untreated Liquid Effluents}

Generated liquid effluents which require treatment and meet interface acceptance criteria for discharge directly to the Liquid Effluent Retention Facility (LERF) and subsequent treatment in the Effluent Treatment Facility (ETF).

\subsubsection{O13 Supernatants for Interim Storage}

Liquids and unintentionally entrained solids transferred to store in-process waste function and generated by the pretreatment of sludges and solids. 
Appendix B - Function 4.2.3.2

4.2.3.2 O14 Tank Waste Characterization Information To: 4.2 .1 .3

4.2.1.4

4.2.2

4.2.2.1

4.2.2.2

4.2 .2 .3

4.2.3.1

4.2.3.3

Tank Waste Characterization Information consists of the technical basis sampling priority list, Tank Waste Analysis Plan, Tank Characterization Plans, Sampling and Analysis Plans, Sampling Schedule, Historical Tank Content Estimates (HTCEs), waste analysis data packages, waste in-situ measurement data, Tank Characterization Reports (TCRs), and other statistical data analysis and technical reports. 


\section{FUNCTION ID NUMBER: $\quad 4,2.3 .3$}

II. FUNCTION TITLE: Treat and Immobilize Low-Activity Waste

\section{FUNCTION DEFINITION:}

Receive, treat and immobilize the low-activity waste solutions. Transfer the immobilized waste to the interim storage or disposal facility. This function also includes treatment/preparation of liquid, gaseous, and solid waste generated during immobilization/disposal of LAW.

\section{INPUTS:}

\subsubsection{I1 Cesium Product Transport Mechanism}

The ready-to-use cask and vehicle for on-site transport of cesium product from the Phase I LLW Immobilization Facility to the interim storage facility. The transport mechanism is provided by the Interim Store Solidified HLW and TRU Waste function (4.2.4.1).

\subsubsection{I2 Electricity for LLW Immobilization}

From: External

$20 \mathrm{MW}$ at $13.8 \mathrm{kV}, 60 \mathrm{~Hz}$, three-phase $\mathrm{AC}$, will be available to the privatization contractor's site electrical distribution system.

\subsubsection{I3 Feed Tanks}

Double-shell tanks (DSTs) and ancillary equipment transferred to the custody of the supernatant pretreatment system for use as process feed tanks. The custody will revert to the DST waste storage system when the use of these feed tanks by the supernatant pretreatment system is no longer needed.

\subsubsection{I4 Historical Information}

From: External

Historical information is made up of chemical process and waste management information. These include documented and institutional knowledge, historical derived information transcribed to tank layer models, and historical tank content estimates.

Historical data includes: chemical process operations technical manuals (text and flowsheets); interviews with long-time operations and engineering personnel; process aids; reports, memos and logbooks; transfer histories; and simulant studies.

\subsubsection{I5 ILAW Transport Mechanism}

From: 4.2 .4

A shielded transport mechanism for transport of ILAW containers from the ILAW immobilization facility to the ILAW disposal facility or interim storage. 
Miscellaneous informational input to the Privatizatin Contractor from DOE or the PHMC. Typically used for review and approval of various documents, work plans, permits, etc. These are inputs to the enable the function and not to the outputs from the function.

\subsubsection{I7 Land for LLW Immobilization}

From: 5

The appropriate land required in the 200 East Area for waste treatment services. Land for facility siting will be provided to the Contractor under a no-cost lease that authorizes the Contractor to utilize the property for construction, operation, and deactivation.

\subsubsection{I8 LAW Feed}

From: 4.2.3.1

Liquids and unintentionally entrained solids transferred to the low-activity waste treatment function.

\subsubsection{19 LAW Feed Solution Samples}

From: 4.2.3.1

Samples of low-activity feed solutions for process verification and testing by the low-activity waste treatment function.

\subsubsection{I10 Low Activity Waste Solutions Composition Information}

Physical and chemical waste properties of the low activity waste solutions.

\subsubsection{I11 Potable Water for LLW Immobilization}

From: External

The 200-East Sanitary Water System provides potable water for domestic and special purpose use. Potable water is treated to meet WAC-246-290 water quality requirements. The sanitary water (potable) supply is interruptible for maintenance, failures, etc.

\subsubsection{I12 Radioactive Solid Waste Transport Mechanism}

From: 4.3

Equipment and service for on-site transport of packaged radioactive solid wastes.

\subsubsection{I13 Raw Water for LLW Immobilization}

From: External

The 200-East Raw Water System provides raw make-up water for the process use and fire water for the 200-East Area. The Hanford Site raw water supply is unfiltered, untreated Columbia River water subject to seasonal changes in temperature and composition. The raw water supply system is interruptible for maintenance, failures, etc.

\subsubsection{I14 Roads and Rails for LLW Immobilization System}

The primary roadway and rail system access to the 200 Areas needed by the Immobilize Low-Level Waste function. 


\subsubsection{I15 Transportation Services for LLW Immobilization System}

From: 5

Provide the transport infrastructure, transport containers and transport vehicles to transport all solid radioactive waste products and secondary radioactive wastes generated by the Immobilize Low-Level Waste function to their proper storage or disposal locations. Also perform the actual transportation.

\section{OUTPUTS:}

\subsubsection{O1 Cesium Product for Storage}

Containers of solidified cesium that has been separated from the low-activity waste solutions. This interface exists for the private contractor providing only the low-activity waste treatment services. Private contractor providing the high-level waste and low-activity waste treatment services is not allowed to generated a separate cesium product. At the time of transport to the interim storage facility the waste will be certified to meet interim storage requirements.

\subsubsection{O2 Cesium Product for Storage - Samples}

Samples of the dry cesium product provided for chemical analysis and testing.

\subsubsection{03 Entrained Solids -In-process storage}

Solids separated from the low-activity waste feed solutions as necessary to meet process requirements and sent to In Process Storage.

\subsubsection{O4 Entrained Solids Samples}

To: 5.4 .2

Samples of entrained solids separated from low-activity waste feed solutions provided for chemical analysis and testing.

\subsubsection{O5 Excess Feed Tanks}

Double-shell tanks (DSTs) and ancillary equipment which were used by the low-activity waste treatment system as process feed tanks. When these feed tanks are no longer needed for low-activity waste treatment, the custody of these feed tanks is transferred back to the DST waste storage system.

\subsubsection{O6 ILAW Characterization Requirements}

The characterization information needs of the LAW Immobilization function for the pretreated wastes that are delivered to it. The characterization requirements will be transformed into requirements for analytical measurements and precision and accuracy requirements. 
Dangerous, non-radioactive solid wastes will be generated. The DOE will not accept dangerous, non-radioactive waste from the privatization contractors. These wastes must be sent to an external treatment, storage, and disposal facility.

This service is to be obtained by the Pivatization Contractor at the COntractor's discretion and expense.

\subsubsection{O8 ILAW for Interim Storage}

To: 4.2 .4

Immobilized low-activity waste packages placed in the transport container and loaded onto the transport mechanism.

\subsubsection{09 ILAW Non-Dangerous Solid Wastes}

To: 5

This function will generate odrinary non-radioactive, non-dangerous solid wastes suitable for disposal at a sanitary landfill.

\subsubsection{O10 ILAW Non-Radioactive, Non-Dangerous Liquid Effluent}

Uncontaminated waste water which meets interface acceptance criteria for discharge directly to the 200 Area Treated Effluent Disposal Facility (TEDF) as specified in State Waste Discharge Permit No. ST-4502.

\subsubsection{O11 ILAW Non-Routine High-Level Solid Waste}

Processing of tank wastes may generate secondary radioactive solid waste that meets the NRC's source-based definition of High-Level Waste. DOE anticipates that small quantities of such waste may be produced on a non-routine basis during privatization Part B operations, particularly during deactivation.

\subsubsection{O12 ILAW Process Information}

Process technology documentation, business strategy and conduct plans, environmental documentation, regulatory documentation, and data generated by the operations of the ILAW function.

\subsubsection{O13 ILAW Radioactive Solid Wastes}

To: 4.3

Radioactive and radioactive dangerous solid wastes generated from the Support ILAW Process function that has been segregated, packaged, assayed, and certified for transfer to Hanford Site Function 4.3; Remedy Solid Waste for management and disposal.

\subsubsection{O14 ILAW Radioactive, Dangerous Liquid Effluent}

Dilute process waste liquid effluents which require treatment and meet interface acceptance criteria for discharge directly, or with minimal pretreatment, to the Liquid Effluent Retention Facility (LERF) and/or to the Effluent Treatment Facility (ETF) for subsequent treatment in accordance with State Waste Discharge Permit No. ST-4500. 


\subsubsection{O15 ILAW Samples}

Samples of process solutions and materials generated during the immobilization of low-activity wastes. Samples of the immobilized low-activity waste may be obtained for verification testing.

\subsubsection{O16 ILAW Transferrable Resources}

Resources from ILAW activities that have no further ILAW mission. These include technology, materials, equipment, land, facilities, and infrastructure. Includes excess resources inventory information.

\subsubsection{017 ILAW Treated Gaseous Effluents}

To: External

Treated gaseous waste generated from functions associated with immobilizing LAW. Treated gaseous effluents are discharged to the atmosphere.

\subsubsection{O18 Separated Sr \& TRU Radionuclides -In Process Storage}

To: 4.2 .3 .1

Strontium and TRU elements separated from the low-activity waste solutions. These radionuclides are separated from the low-activity waste solutions as necessary to meet process requirements and sent to In-Process Storage.

\subsubsection{O19 Separated Sr \& TRU Samples}

Samples of the strontium and TRU solution/slurry provided for chemical analysis and testing.

\subsubsection{O20 Technetium Product - In-Process Storage}

To: 4.2.3.1

Technetium that has been separated from the low-activity waste solutions, stored at the private contractors facilities and transferred at the conclusion of services to the to the in-process storage function. This interface exists for the private contractor providing only the low-activity waste treatment services. The private contractor providing the high-level waste and low-activity waste treatment services is not allowed to generate a separate technetium product.

\subsubsection{O21 Technetium Product Samples}

Samples of the liquid technetium product provided for chemical analysis and testing 


\section{FUNCTION ID NUMBER: $\quad 4.2 .3 .4$}

II. FUNCTION TITLE: Immobilize HLW / TRU Waste

\section{FUNCTION DEFINITION:}

Receive and immobilize pretreated HLW and TRU waste, seal the immobilized waste into primary containers, decontaminate the container outer surfaces, and test the integrity of the sealed containers. Load the immobilized HLW/TRU waste in transport mechanism for transfer to the disposal function. This function also includes treatment/preparation of liquid, gaseous, and solid wastes generated during immobilization of HLW/TRU waste.

Note: DOE/WIPP requirements apply only if a decision is made to dispose of ITRU waste at WIPP.

\section{INPUTS:}

\subsubsection{I1 Electricity for HLW/TRU Waste Immobilization}

From: External

$20 \mathrm{MW}$ at $13.8 \mathrm{kV}, 60 \mathrm{~Hz}$, three-phase $\mathrm{AC}$, will be available to the privatization contractor's site electrical distribution system.

\subsubsection{12 Historical Information}

From: External

Historical information is made up of chemical process and waste management information. These include documented and institutional knowledge, historical derived information transcribed to tank layer models, and historical tank content estimates.

Historical data includes: chemical process operations technical manuals (text and flowsheets); interviews with long-time operations and engineering personnel; process aids; reports, memos and logbooks; transfer histories; and simulant studies.

\subsubsection{I3 HLW Feed}

From: 4.2.3.1

Pretreated HLW blended to a composition meeting feed specifications and transferred to the Immobilize HLW/TRU function

\subsubsection{I4 IHLW Transport Mechanism - Phase I}

The device(s) for on-site transport of IHLW from the Phase I HLW immobilization facility to the interim storage facility to the interim storage facility. The transport mechanism is provided by the Interim Store Solidified HLW and TRU Waste function (4.2.4.1).

\subsubsection{I5 Information Input}

From: 4.2 .1 
Miscellaneous informational input to the Privatizatin Contractor from DOE or the PHMC. Typically used for review and approval of various documents, work plans, permits, etc. These are inputs to the enable the function and not to the outputs from the function.

\subsubsection{I6 Land for HLW/TRU Waste Immobilization}

From: 5

The appropriate land required in the 200 East Area for waste treatment services. Land for facility siting will be provided to the Contractor under a no-cost lease that authorizes the Contractor to utilize the property for construction, operation, and deactivation.

\subsubsection{I7 Potable Water for HLW/TRU Waste Immobilization}

From: External

The 200-East Sanitary Water System provides potable water for domestic and special purpose use. Potable water is treated to meet WAC-246-290 water quality requirements. The sanitary water (potable) supply is interruptible for maintenance, failures, etc.

\subsubsection{I8 Pretreated HLW/TRU Waste Composition Information}

From: 4.2.3.1

Physical and chemical waste properties of Pretreated HLW and Pretreated TRU waste.

\subsubsection{19 Radioactive Solid Waste Transport Mechanism}

From: 4.3

Equipment and service for on-site transport of packaged radioactive solid wastes.

\subsubsection{I10 Raw Water for HLW/TRU Waste Immobilization}

From: External

The 200-East Raw Water System provides raw make-up water for the process use and fire water for the 200-East Area. The Hanford Site raw water supply is unfiltered, untreated Columbia River water subject to seasonal changes in temperature and composition. The raw water supply system is interruptible for maintenance, failures, etc.

\subsubsection{I11 Roads and Rails for HLW/TRU Waste Immobilization System}

From: 5

The primary roadway and rail system access to the 200 Areas needed by the Immobilize HLW / TRU Waste function.

\subsubsection{I12 Sludge Samples}

From: 4.2.3.1

Samples of pretreated HLW/TRU waste for process verification and testing by the HLW/TRU Waste Immobilization function.

\subsubsection{I13 Transportation Services for HLW/TRU Waste Immobilization System}

From: 5

Provide the transport infrastructure, transport containers and transport vehicles to transport all solid radioactive waste products and secondary radioactive wastes generated by the Immobilize HLW / TRU Waste function to their proper storage or disposal locations. Also perform the actual transportation. 


\section{OUTPUTS:}

\subsubsection{O1 HLW/TRU Immobilization Dangerous Wastes}

To: External

Dangerous, non-radioactive solid wastes will be generated. The DOE will not accept dangerous, non-radioactive waste from the privatization contractors. These wastes must be sent to an external treatment, storage, and disposal facility.

This service is to be obtained by the Pivatization Contractor at the Contractor's discretion and expense.

\subsubsection{O2 HLW/TRU Immobilization Non-Dangerous Solid Wastes}

This function will generate odrinary non-radioactive, non-dangerous solid wastes suitable for disposal at a sanitary landfill.

This service is to be obtained by the Pivatization Contractor at the Contractor's discretion and expense.

\subsubsection{O3 HLW/TRU Immobilization Non-Radioactive, Non-Dangerous Liquid Effluent To: 4.5}

Uncontaminated waste water which meets interface acceptance criteria for discharge directly to the 200 Area Treated Effluent Disposal Facility (TEDF) as specified in State Waste Discharge Permit No. ST-4502.

\subsubsection{O4 HLW/TRU Immobilization Non-Routine High-Level Solid Waste}

Processing of tank wastes may generate secondary radioactive solid waste that meets the NRC's source-based definition of High-Level Waste. DOE anticipates that small quantities of such waste may be produced on a non-routine basis during privatization Part B operations, particularly during deactivation.

\subsubsection{O5 HLW/TRU Immobilization Radioactive Solid Wastes}

Radioactive and radioactive dangerous solid wastes will be generated from the Immobilize HLW/TRU Waste function that has been segregated, packaged, assayed, and certified for transfer to Hanford Site Function 4.3; Remedy Solid Waste for management and disposal.

\subsubsection{O6 HLW/TRU Immobilization Radioactive, Dangerous Liquid Effluent}

Dilute process waste liquid effluents which require treatment and meet interface acceptance criteria for discharge directly, or with minimal pretreatment, to the Liquid Effluent Retention Facility (LERF) and/or to the Effluent Treatment Facility (ETF) for subsequent treatment in accordance with State Waste Discharge Permit No. ST-4500.

\subsubsection{O7 HLW/TRU Immobilization Transferrable Resources}

Resources from HLW Immobilization activities that have no further HLW Immobilization mission. These include technology, materials, equipment, land, facilities, and infrastructure. Includes excess resources inventory information. 


\subsubsection{O8 HLW/TRU Waste Immobilization Process Information}

Process technology documentation, business strategy and conduct plans, environmental documentation, regulatory documentation, and data generated by operations of the HLW/TRU Waste Immobilization function.

\subsubsection{O9 HLW/TRU Waste Immobilization Samples}

To: 5.4 .2

Samples of process solutions and materials generated during the immobilization of HLW/TRU wastes. Samples of the immobilized HLW/TRU waste may be obtained for verification testing.

\subsubsection{O10 HLW/TRU Waste Immobilization Treated Gaseous Effluents}

To: External

Treated gaseous waste from functions associated with treatment of HLW. Treated gaseous effluents are discharged to the atmosphere.

\subsubsection{O11 IHLW for Storage}

IHLW sealed in canisters suitable for interim on-site storage and eventual emplacement in HLW geologic repository. At time of transfer to the interim storage function the waste will be certified to meet product acceptance requirements. 


\section{FUNCTION ID NUMBER: $\quad 4,2.3 .5$}

II. FUnCTION TITLE: Prepare Cs/Sr Capsules for Disposal

\section{FUNCTION DEFINITION:}

Receive $\mathrm{Cs} / \mathrm{Sr}$ capsules from storage and prepare capsules for interim storage at Hanford and disposal offsite at geologic repository. This function also includes treatment and preparation of liquid, gaseous, and solid wastes generated during preparation of capsules for disposal.

\section{INPUTS:}

\subsubsection{I1 Cesium/Strontium Capsules}

$\mathrm{Cs} / \mathrm{Sr}$ capsules removed from storage to be dispositioned.

\subsubsection{I2 $\mathrm{Cs} / \mathrm{Sr}$ Capsule Characterization Data}

Certification data describing the radiological, chemical, and physical attributes of $\mathrm{Cs}$ and $\mathrm{Sr}$ capsules.

\subsubsection{I3 Dispositioned Cs/Sr Capsules Transport Mechanism}

The device(s) for on-site transport of dispositioned $\mathrm{Cs} / \mathrm{Sr}$ capsules from the capsule preparation system to the interim storage facility. The transport mechanism is provided by the Interim Store Solidified HLW and TRU Waste function (4.2.4.1).

\subsubsection{I4 Emergency Preparedness for Cs/Sr Capsule Disposal System}

Emergency preparedness services to the Cs/Sr Capsule Disposal function. This includes ensuring compliance to federal, state and DOE requirements and regulations for emergency preparedness and response. Provide liaison services in order to, if necessary, bring Hanford wide capabilities into incident mitigation activities. Provide assistance and review of privatization developed hazard assessments and emergency/contingency plans for facilities and operations.

\subsubsection{I5 Infrastructure Support for Preparing Cs/Sr Capsules}

From: 5

General infrastructure support needed to prepare $\mathrm{Cs} / \mathrm{Sr}$ capsules. This will include but is not limited to fire protection, police, medical services, road services, telecommunications, radiological services, laboratory services, transportation and sewer. This includes land for siting facilities.

\subsubsection{I6 Radioactive Solid Waste Transport Mechanism}

Equipment and service for on-site transport of packaged radioactive solid wastes.

\subsubsection{17 Raw Materials for Cs/Sr Capsule Processing}

Containers, utilities, chemicals, replacement equipment, spare parts, supplies, etc. necessary for 
Appendix B - Function 4.2.3.5

preparation of $\mathrm{Cs} / \mathrm{Sr}$ capsules for interim storage onsite and offsite disposal.

\subsubsection{I8 Sanitary Waste Services for Prepare Cs/Sr Capsules for Disposal}

From: 5

A service that receives, collects, and transfers all sanitary domestic sewer wastes from the Prepare $\mathrm{Cs} / \mathrm{Sr}$ Capsules for Disposal function for processing in a domestic waste-water sewer treatment processing system.

\section{OUTPUTS:}

\subsubsection{O1 Cs/Sr Capsules Excess Facilities}

Facilities that, having fulfilled their original purposes and completed the function/processes described in the prepare $\mathrm{Cs} / \mathrm{Sr}$ capsules function, are now available and appropriate for reuse or deactivation. Excess facilities are transferred to Hanford Site Function 4.1; Deactivate Facilities. Reuse will be decided at the site level.

\subsubsection{O2 Cs/Sr Capsules Process Information}

To: 1

Data generated by operations of the Prepare Cs/Sr Capsules for Disposal function

\subsubsection{O3 Cs/Sr Capsules Radioactive Solid Wastes}

Radioactive and radioactive dangerous solid wastes generated from the prepare $\mathrm{Cs} / \mathrm{Sr}$ capsules function that has been segregated, packaged, assayed, and certified for transfer to Hanford Site Function 4.3;

Remedy Solid Waste, for management and disposal.

\subsubsection{O4 Cs/Sr Capsules Transferrable Resources}

Resources from $\mathrm{Cs} / \mathrm{Sr}$ Capsules activities that have no further $\mathrm{Cs} / \mathrm{Sr}$ Capsules mission. These include technology, materials, equipment, land, facilities, and infrastructure. Includes excess resources inventory information.

\subsubsection{O5 Cs/Sr Capsules Treated Liquid Effluents}

Liquid effluents which meet interface acceptance criteria for discharge directly to the 200 Area Treated Effluent Disposal Facility (TEDF).

\subsubsection{O6 Cs/Sr Capsules Untreated Liquid Effluents}

Generated liquid effluents which require treatment and meet interface acceptance criteria for discharge directly to the Liquid Effluent Retention Facility (LERF) and subsequent treatment in the Effluent Treatment Facility (ETF).

\subsubsection{O7 Dispositioned Cs/Sr Capsules for Storage}

$\mathrm{Cs} / \mathrm{Sr}$ capsules dispositioned in a manner suitable for interim onsite storage and eventual offsite disposal. 
Solid wastes generated within the Immobilize Prepare $\mathrm{Cs} / \mathrm{Sr}$ Capsules for Disposal function that is classified as dangerous per EPA or State of Washington regulations.

\subsubsection{O9 Prepare Cs/Sr Capsules for Disposal Non-Dangerous Solid Wastes}

Ordinary non-radioactive, non-dangerous solid wastes generated within the Prepare $\mathrm{Cs} / \mathrm{Sr}$ Capsules for Disposal function, suitable for disposal in a sanitary landfill.

\subsubsection{O10 Prepare Cs/Sr Capsules Treated Gaseous Effluents}

Treated gaseous waste from functions associated with preparing $\mathrm{Cs} / \mathrm{Sr}$ capsules. Treated gaseous effluents are discharged to the atmosphere. 


\section{FUNCTION ID NUMBER: $\quad 4.2 .4$}

II. FUNCTION TITLE: Dispose Waste

\section{FUNCTION DEFINITION:}

The Dispose Waste Function stores solidified high-level waste (HLW) and transuranic (TRU) waste; disposes immobilized llow activity waste (ILAW) in a safe, efficient and environmentally acceptable manner; and closes tank farm operable units. Solidified HLW and TRU waste includes glass products from a HLW/TRU vitrification facility, cesium/strontium capsules that have been processed for disposal, and cesium product from a supernatant pretreatment process. The solidified HLW and TRU waste will be stored on a temporary basis until the Department of Energy -Office of Civilian Radioactive Waste Management (DOE-OCRWM) is ready to accept it for permanent disposal, or until it can be returned to the HLW/TRU immobilization facility for further processing. The ILLW will also be stored on a temporary basis until the Dispose Waste Function is ready to begin disposal actions. Operable units with closure ready tanks are closed in compliance with WAC 173-303 regulations for hazardous constituents, and $\mathrm{NRC}$ (if HLW), DOE, and EPA regulations and DOE Orders for radioactive constituents.

\section{INPUTS:}

\subsubsection{I1 Cesium Product for Storage}

Containers of solidified cesium that has been separated from the low-activity waste solutions. This interface exists for the private contractor providing only the low-activity waste treatment services. Private contractor providing the high-level waste and low-activity waste treatment services is not allowed to generated a separate cesium product. At the time of transport to the interim storage facility the waste will be certified to meet interim storage requirements.

\subsubsection{I2 Closure-Ready USTs}

From: 4.2 .2

USTs from which sufficient waste has been retrieved to meet closure requirements.

\subsubsection{I3 Dispositioned Cs/Sr Capsules for Storage}

$\mathrm{Cs} / \mathrm{Sr}$ capsules dispositioned in a manner suitable for interim onsite storage and eventual offsite disposal.

\subsubsection{I4 Dispositioned Cs/Sr Capsules Shipping Mechanism}

From: External

The shipping cask and vehicle provided by DOE-OCRWM for the shipment of containers of dispositioned $\mathrm{Cs} / \mathrm{Sr}$ capsule product to the geologic repository.

\subsubsection{I5 IHLW for Storage}

From: 4.2 .3

IHLW sealed in canisters suitable for interim on-site storage and eventual emplacement in HLW geologic repository. At time of transfer to the interim storage function the waste will be certified to meet product 
acceptance requirements.

\subsubsection{I6 IHLW Repository Shipping Mechanism}

From: External

The shipping cask and vehicle provided by DOE-OCRWM for the shipment of sealed IHLW containers to the geologic repository.

\subsubsection{I7 ILAW for Interim Storage}

From: 4.2 .3

Immobilized low-activity waste packages placed in the transport container and loaded onto the transport mechanism.

\subsubsection{I8 Infrastructure Support for Dispose Waste}

From: 5

General infrastructure support needed to interim store and dispose tank waste products. This will include but is not limited to fire protection, police, emergency preparedness, medical services, road services, telecommunications, radiological services, laboratory services, transportation and sewer. This includes land for siting facilities.

\subsubsection{I9 PW Non-Routine High-Level Solid Waste}

From: 4.2 .3

Processing of tank wastes may generate secondary radioactive solid waste that meets the NRC's source-based definition of High-Level Waste. DOE anticipates that small quantities of such waste may be produced on a non-routine basis during privatization Part B operations, particularly during deactivation.

\subsubsection{I10 Raw Materials for DW}

From: External

Materials necessary for interim storage of solidified HLW, disposal of ILLW, and closure of operable units. These materials include but are not limited to chemicals, utilities, replacement equipment, spare parts, and supplies.

\subsubsection{I11 Solidified HLW and TRU Waste Production Information}

From: 1

Documentation supplied by production facilities certifying that containers comply with solidified HLW and TRU waste interim storage facility acceptance specifications and the HLW or TRU waste repository waste acceptance specifications.

\section{OUTPUTS:}

\subsubsection{O1 Cesium Product for Processing}

Cesium product delivered from the interim storage facility to a HLW immobilization facility. This interface is active only during phase 2 processing of tank wastes. 
The ready-to-use cask and vehicle for on-site transport of cesium product from the Phase I LLW Immobilization Facility to the interim storage facility. The transport mechanism is provided by the Interim Store Solidified HLW and TRU Waste function (4.2.4.1).

\subsubsection{O3 Closed ILLW Sites}

To: External

The closed engineered disposal structures containing the immobilized LLW.

\subsubsection{O4 Closed Operable Units (Tanks)}

To: 4.1

RCRA regulations require the removal of all waste from the tanks, and ancillary equipment to close as a tank system. If all the waste can not be removed from the operable units, then the units would either under go modified closure or be closed as a landfill. According to Condition II.K.3. of the Hanford Facility Resource Conservation and Recovery Act Permit (Hanford RCRA Permit), if dangerous waste concentration in TSD units that leave waste inplace are above MCTA Method B levels (residential-based scenario) but below MCTA Method C levels (industrial-based scenario) then a 'modified' closure option might be used (Ecology 1994). This option would not require a cover be placed over the waste left in place. Closure as a landfill would require a cover be placed over the waste left in place. Past Practice Units (PPU) associated with the tank system have closure requirements which are independent of the tank system but the PPU shall be closed as part of the Operable Unit.

A closure plan must be prepared and approved which will direct the final condition of the closed operable unit. If either a modified or landfill closure option is used, a post-closure permit application would have to be submitted to the regulators. This document would contain information on postclosure care and the final design of the landfill cover, if necessary."

\subsubsection{O5 Dispositioned Cs/Sr Capsules for Shipment}

To: External

$\mathrm{Cs} / \mathrm{Sr}$ capsules prepared to meet repository acceptance requirements, loaded into the shipping mechanism for shipment to the repository.

\subsubsection{O6 Dispositioned Cs/Sr Capsules Transport Mechanism}

The device(s) for on-site transport of dispositioned $\mathrm{Cs} / \mathrm{Sr}$ capsules from the capsule preparation system to the interim storage facility. The transport mechanism is provided by the Interim Store Solidified HLW and TRU Waste function (4.2.4.1).

\subsubsection{O7 DW Dangerous Waste}

To: External

Solid waste generated within the Dispose Waste function that is classified as dangerous per EPA or State of Washington regulations.

\subsubsection{O8 DW Excess Facilities}

Facilities that, having fulfilled their original purposes and completed the function/processes described in the dispose waste function, are now available and appropriate for reuse or deactivation. Excess facilities are transferred to Hanford Site Function 4.1; Deactivate Facilities. Reuse will be decided at the site level. 
Ordinary non-radioactive, non-dangerous solid wastes generated within the Dispose Waste function, suitable for disposal in a sanitary landfill.

\subsubsection{O10 DW Prepared Solid Waste}

To: 4.3

Solid waste generated from the dispose waste function that has been segregated, packaged, assayed, and certified for transfer to Hanford Site Function 4.3; Remedy Solid Waste, for further treatment or disposal. This includes mixed, and radioactive wastes.

\subsubsection{O11 DW Transferrable Resources}

Resources from Dispose Waste activities that have no further DW mission. These include valuable technology, work force, materials, equipment, facilities and infrastructure. Includes excess resources inventory information.

\subsubsection{O12 DW Treated Gaseous Effluents}

To: External

Treated gaseous waste from functions associated with the dispose waste. Treated gaseous effluents are discharged to the atmosphere.

4.2.4 O13 DW Treated Liquid Effluents

Liquid effluents which meet interface acceptance criteria for discharge directly to the 200 Area Treated Effluent Disposal Facility (TEDF).

\subsubsection{DW Untreated Liquid Effluents}

To: 4.5

Generated liquid effluents which require treatment and meet interface acceptance criteria for discharge directly to the Liquid Effluent Retention Facility (LERF) and subsequent treatment in the Effluent Treatment Facility (ETF).

\subsubsection{O15 IHLW and ITRU Waste Transport Mechanism - Phase II}

The device(s) for onsite transport of immobilized HLW and TRU waste from the Phase II HLW immobilization facility to the interim storage facility. The transport mechanism is provided by the Interim Store Solidified HLW and TRU Waste function (4.2.4.1).

\subsubsection{O16 IHLW for Shipment}

To: External

Sealed containers of immobilized HLW derived from treatment of tank wastes (e.g., existing and new tank wastes). The containers of IHLW are placed in a shipping cask, that is loaded onto a shipping vehicle and shipped to the repository by DOE - OCRWM personnel. At the time of shipment to the repository, the waste will be certified to meet repository acceptance requirements. 
The device(s) for on-site transport of IHLW from the Phase I HLW immobilization facility to the interim storage facility to the interim storage facility. The transport mechanism is provided by the Interim Store Solidified HLW and TRU Waste function (4.2.4.1).

\subsubsection{O18 ILAW Transport Mechanism}

A shielded transport mechanism for transport of ILAW containers from the ILAW immobilization facility to the ILAW disposal facility or interim storage.

\subsubsection{O19 Solidified HLW and TRU Recertification Information}

Documentation certifying that the solidified HLW and TRU waste containers meet the repository acceptance criteria at the time of loading into repository shipping casks.

\subsubsection{O20 Solidified HLW and TRU Waste Storage Information}

To: 1

Documentation supplied by the solidified HLW and TRU interim storage facility certifying that containers of solidified HLW or TRU Waste were stored in accordance with interim storage specifications and the applicable repository waste acceptance specifications. 


\section{FUNCTION ID NUMBER: 4.2 .4 .1}

\section{FUNCTION TITLE: Interim Store Solidified HLW and TRU Waste}

\section{FUNCTION DEFINITION:}

Accept sealed containers of immobilized high-level waste (IHLW) and immobilized transuranic waste (ITRU) from the HLW immobilization facility, dispositioned cesium/strontium ( $\mathrm{Cs} / \mathrm{Sr}$ ) capsules from the $\mathrm{Cs} / \mathrm{Sr}$ capsule disposal preparation system, and containers of cesium product from the treat and immobilize low-acitvity waste function. Transport the containers to the appropriate interim storage facilities. Prepare and place the containers in their designated storage locations, monitor the storage locations for storage containment integrity, and eventually retrieve the containers from storage. Prepare and load containers into casks for shipment to an offsite disposal facility, or deliver them to an onsite treatment facility for further processing.

\section{INPUTS:}

\subsubsection{I1 Cesium Product for Storage}

Containers of solidified cesium that has been separated from the low-activity waste solutions. This interface exists for the private contractor providing only the low-activity waste treatment services. Private contractor providing the high-level waste and low-activity waste treatment services is not allowed to generated a separate cesium product. At the time of transport to the interim storage facility the waste will be certified to meet interim storage requirements.

\subsubsection{I2 Dispositioned Cs/Sr Capsules for Storage}

$\mathrm{Cs} / \mathrm{Sr}$ capsules dispositioned in a manner suitable for interim onsite storage and eventual offsite disposal.

\subsubsection{I3 Dispositioned Cs/Sr Capsules Shipping Mechanism}

From: External

The shipping cask and vehicle provided by DOE-OCRWM for the shipment of containers of dispositioned $\mathrm{Cs} / \mathrm{Sr}$ capsule product to the geologic repository.

\subsubsection{I4 HLW/TRU Immobilization Non-Routine High-Level Solid Waste}

From: 4.2.3.4

Processing of tank wastes may generate secondary radioactive solid waste that meets the NRC's source-based definition of High-Level Waste. DOE anticipates that small quantities of such waste may be produced on a non-routine basis during privatization Part B operations, particularly during deactivation.

IHLW sealed in canisters suitable for interim on-site storage and eventual emplacement in HLW geologic repository. At time of transfer to the interim storage function the waste will be certified to meet product 
acceptance requirements.

\subsubsection{I6 IHLW Repository Shipping Mechanism}

From: External

The shipping cask and vehicle provided by DOE-OCRWM for the shipment of sealed IHLW containers to the geologic repository.

\subsubsection{I7 Infrastructure Support for IS Solidified HLW and TRU}

From: 5

General infrastructure support needed to interim store solidified HLW and TRU waste. This will include but is not limited to fire protection, police, emergency preparedness, medical services, road services, telecommunications, radiological services, laboratory services, transportation and sewer. This includes land for siting facilities.

\subsubsection{I8 Raw Materials for IS Solidified HLW and TRU}

From: External

Chemicals, containers, utilities, replacement equipment, spare parts, supplies, etc. necessary for the interim storage of solidified HLW and TRU waste.

\subsubsection{I9 Solidified HLW and TRU Waste Production Information}

From: 1

Documentation supplied by production facilities certifying that containers comply with solidified HLW and TRU waste interim storage facility acceptance specifications and the HLW or TRU waste repository waste acceptance specifications.

\section{OUTPUTS:}

\subsubsection{O1 Cesium Product for Processing}

Cesium product delivered from the interim storage facility to a HLW immobilization facility. This interface is active only during phase 2 processing of tank wastes.

\subsubsection{O2 Cesium Product Transport Mechanism}

The ready-to-use cask and vehicle for on-site transport of cesium product from the Phase I LLW Immobilization Facility to the interim storage facility. The transport mechanism is provided by the Interim Store Solidified HLW and TRU Waste function (4.2.4.1).

\subsubsection{O3 Dispositioned Cs/Sr Capsules for Shipment}

To: External

$\mathrm{Cs} / \mathrm{Sr}$ capsules prepared to meet repository acceptance requirements, loaded into the shipping mechanism for shipment to the repository.

4.2.4.1 O4 Dispositioned Cs/Sr Capsules Transport Mechanism

The device(s) for on-site transport of dispositioned $\mathrm{Cs} / \mathrm{Sr}$ capsules from the capsule preparation system to 
the interim storage facility. The transport mechanism is provided by the Interim Store Solidified HLW and TRU Waste function (4.2.4.1).

\subsubsection{O5 DW Transferrable Resources}

Resources from Dispose Waste activities that have no further DW mission. These include valuable technology, work force, materials, equipment, facilities and infrastructure. Includes excess resources inventory information.

\subsubsection{O6 IHLW and ITRU Waste Transport Mechanism - Phase II}

The device(s) for onsite transport of immobilized HLW and TRU waste from the Phase II HLW immobilization facility to the interim storage facility. The transport mechanism is provided by the Interim Store Solidified HLW and TRU Waste function (4.2.4.1).

\subsubsection{O7 IHLW for Shipment}

To: External

Sealed containers of immobilized HLW derived from treatment of tank wastes (e.g., existing and new tank wastes). The containers of IHLW are placed in a shipping cask, that is loaded onto a shipping vehicle and shipped to the repository by DOE - OCRWM personnel. At the time of shipment to the repository, the waste will be certified to meet repository acceptance requirements.

\subsubsection{O8 IHLW Transport Mechanism - Phase I}

The device(s) for on-site transport of IHLW from the Phase I HLW immobilization facility to the interim storage facility to the interim storage facility. The transport mechanism is provided by the Interim Store Solidified HLW and TRU Waste function (4.2.4.1).

\subsubsection{O9 IS Solidified HLW and TRU Waste Dangerous Waste}

To: External

Solid waste generated within the Interim Store Solidified HLW and TRU Waste function that is classified as dangerous per EPA or State of Washington regulations.

\subsubsection{O10 IS Solidified HLW and TRU Waste Excess Facilities}

To: 4.1

Facilities that, having fulfilled their original purposes and completed the function/processes described in the interim store immobilized waste function, are now available and appropriate for reuse or deactivation. Excess facilities are transferred to Hanford Site Function 4.1; Deactivate Facilities. Reuse will be decided at the site level.

\subsubsection{O11 IS Solidified HLW and TRU Waste Non-Dangerous Solid Waste}

To: 5

Ordinary non-radioactive, non-dangerous solid waste generated within the Interim Store Solidified HLW and TRU Waste function, suitable for disposal in a sanitary landfill. 
Appendix B - Function 4.2.4.1

Solid waste generated from the Interim Store Solidified HLW and TRU Waste function that has been segregated, packaged, assayed, and certified for transfer to Hanford Site Function 4.3; Remedy Solid Waste, for further treatment or disposal. This includes mixed, and radioactive wastes.

\subsubsection{O13 IS Solidified HLW and TRU Waste Treated Gaseous Effluents}

To: External

Treated gaseous waste from functions associated with the interim storage of solidified HLW and TRU waste. Treated gaseous effluents are discharged to the atmosphere.

\subsubsection{O14 IS Solidified HLW and TRU Waste Treated Liquid Effluents}

Liquid effluents which meet interface acceptance criteria for discharge directly to the 200 Area Treated Effluent Disposal Facility (TEDF).

\subsubsection{O15 IS Solidified HLW and TRU Waste Untreated Liquid Effluents}

Generated liquid effluents which require treatment and meet interface acceptance criteria for discharge directly to the Liquid Effluent Retention Facility (LERF) and subsequent treatment in the Effluent Treatment Facility (ETF).

\subsubsection{O16 Solidified HLW and TRU Recertification Information}

Documentation certifying that the solidified HLW and TRU waste containers meet the repository acceptance criteria at the time of loading into repository shipping casks.

\subsubsection{O17 Solidified HLW and TRU Waste Storage Information}

Documentation supplied by the solidified HLW and TRU interim storage facility certifying that containers of solidified HLW or TRU Waste were stored in accordance with interim storage specifications and the applicable repository waste acceptance specifications. 


\section{FUNCTION ID NUMBER: $\quad 4.2 .4 .2$}

\section{FUNCTION TITLE: Dispose ILLW}

\section{FUNCTION DEFINITION:}

The Dispose ILLW Function transports sealed containers of immobilized low-level waste (ILLW) from the LLW Immobilization facility, places the containers in their designated storage locations, monitors containers for storage containment integrity, and eventually retrieves the containers, if necessary, from storage to prepare them for onsite disposal or converts the storage facility to a disposal facility. The Dispose ILLW Function furnishes shipping devices to the LLW Immobilization facility. The LLW Immobilization facility loads the devices with packages of ILLW provided by the Immobilize LLW system. The Dispose ILLW function collects the loaded shipping containers and transports them to the disposal area or the interim storage area as required.

Note: The identified hazardous waste constraints (i.e. 40CFR subpart 264, subpart 268) and dangerous waste constraints (i.e. WAC-173-303-630) should be reviewed for applicability based upon the regulatory status of the immobilized low-level waste.

\section{INPUTS:}

4.2.4.2 I1 ILAW for Interim Storage

From: 4.2 .3

Immobilized low-activity waste packages placed in the transport container and loaded onto the transport mechanism.

\subsubsection{I2 ILAW Non-Routine High-Level Solid Waste}

From: 4.2.3.3

Processing of tank wastes may generate secondary radioactive solid waste that meets the NRC's source-based definition of High-Level Waste. DOE anticipates that small quantities of such waste may be produced on a non-routine basis during privatization Part B operations, particularly during deactivation.

\subsubsection{I3 Infrastructure Support for Dispose ILLW}

From: 5

General infrastructure support needed to dispose ILLW. This will include but is not limited to fire protection, police, emergency preparedness, medical services, road services, telecommunications, radiological services, laboratory services, transportation and sewer. This includes land for siting facilities.

\subsubsection{I4 Raw Materials for Dispose ILLW}

From: External

Chemical, containers, utilities, replacement equipment, spare parts, supplies, etc. necessary for ILLW storage and disposal.

\section{OUTPUTS:}




\subsubsection{O1 Closed ILLW Sites}

To: External

The closed engineered disposal structures containing the immobilized LLW.

\subsubsection{O2 Dispose ILLW Dangerous Waste}

To: External

Solid waste generated within the Dispose ILLW function that is classified as dangerous per EPA or State of Washington regulations.

\subsubsection{O3 Dispose ILLW Non-Dangerous Solid Waste}

To: 5

Ordinary non-radioactive, non-dangerous solid wastes generated within the Dispose ILLW function, suitable for disposal in a sanitary landfill.

\subsubsection{O4 Dispose ILLW Prepared Solid Waste}

To: 4.3

Solid waste resulting from the disposal of ILLW and closing of the disposal sites. Solid waste items may include residues from sealing the engineered disposal structures, failed disposal and/or closure equipment, and contaminated tools. This includes mixed and radioactive solid wastes.

\subsubsection{O5 Dispose ILLW Treated Gaseous Effluents}

To: External

Gases resulting from ventilation of the engineered disposal structures.

\subsubsection{O6 Dispose ILLW Treated Liquid Effluents}

Liquid effluents which meet interface acceptance criteria for discharge directly to the 200 Area Treated Effluent Disposal Facility (TEDF).

\subsubsection{O7 Dispose ILLW Untreated Liquid Effluents}

Generated liquid effluents which require treatment and meet interface acceptance criteria for discharge directly to the Liquid Effluent Retention Facility (LERF) and subsequent treatment in the Effluent Treatment Facility (ETF).

\subsubsection{O8 ILAW Transport Mechanism}

A shielded transport mechanism for transport of ILAW containers from the ILAW immobilization facility to the ILAW disposal facility or interim storage. 


\section{FUNCTION ID NUMBER: 4.2 .4 .3}

\section{FUNCTION TITLE: Close Operable Units (Tanks)}

\section{FUNCTION DEFINITION:}

Closure ready tanks are deactivated and the operable units are closed per applicable regulations. The Operable Units include the tanks, ancillary equipment, and Past Practice Units (PPU), as defined in the Hanford Federal Facility Agreement and Consent Order.

\section{INPUTS:}

\subsubsection{I1 Closure-Ready Ancillary Equipment and Systems}

Ancillary equipment and systems from which sufficient waste has been retrieved to meet closure requirements.

\subsubsection{I2 Closure-Ready DSTs}

DSTs from which sufficient waste has been retrieved to meet closure requirements.

\subsubsection{I3 Closure-Ready SSTs}

From: 4.2.2.1

SSTs from which sufficient waste has been retrieved to meet closure requirements.

\subsubsection{I4 Infrastructure Support for Close Operable Units (Tanks)}

General infrastructure support needed to close operable units. This will include but is not limited to fire protection, police, emergency preparedness, medical services, road services, telecommunications, radiological services, laboratory services, transportation and sewer. This includes land for siting facilities.

\subsubsection{I5 Raw Materials for Close Operable Units (Tanks)}

From: External

Utilities, replacement equipment, spare parts, supplies, etc. necessary for closure of operable units (tanks).

\section{OUTPUTS:}

\subsubsection{O1 Close Operable Units (Tanks) Dangerous Waste}

To: External

Solid waste generated within the Close Operable Units (Tanks) function that is classified as dangerous per EPA or State of Washington regulations.

Ordinary non-radioactive, non-dangerous solid waste generated within the Close Operable Units (Tanks) function, suitable for disposal in a sanitary landfill. 
RCRA regulations require the removal of all waste from the tanks, and ancillary equipment to close as a tank system. If all the waste can not be removed from the operable units, then the units would either under go modified closure or be closed as a landfill. According to Condition II.K.3. of the Hanford Facility Resource Conservation and Recovery Act Permit (Hanford RCRA Permit), if dangerous waste concentration in TSD units that leave waste inplace are above MCTA Method B levels (residential-based scenario) but below MCTA Method C levels (industrial-based scenario) then a 'modified' closure option might be used (Ecology 1994). This option would not require a cover be placed over the waste left in place. Closure as a landfill would require a cover be placed over the waste left in place. Past Practice Units (PPU) associated with the tank system have closure requirements which are independent of the tank system but the PPU shall be closed as part of the Operable Unit.

A closure plan must be prepared and approved which will direct the final condition of the closed operable unit. If either a modified or landfill closure option is used, a post-closure permit application would have to be submitted to the regulators. This document would contain information on postclosure care and the final design of the landfill cover, if necessary."

\subsubsection{O4 COU (Tanks) Prepared Solid Waste}

Solid waste generated from the Close Operable Units (Tanks) function that has been segregated, packaged, assayed, and certified for transfer to Hanford Site Function 4.3; Remedy Solid Waste, for further treatment or disposal. This includes mixed, and radioactive wastes.

\subsubsection{O5 COU (Tanks) Treated Gaseous Effluents}

Treated gaseous waste from functions associated with closed operable units. Treated gaseous effluents are discharged to the atmosphere.

\subsubsection{O6 COU (Tanks) Treated Liquid Effluents}

Treated liquid effluents from the Close Operable Units (Tanks) function. 
WHC-SD-WM-FRD-020

Revision 1

\section{APPENDIX C}

\section{REQUIREMENTS ALLOCATION TABLES}

\section{C-1}


WHC-SD-WM-FRD-020

Revision 1

This appendix provides a cross-reference to identify the requirements allocated to the TWRS functions. Requirements may be one of two types: Constraints or Performance Requirements (see Appendices D and E). See special case for functions 4.2.3.3 and 4.2.3.4 on page 8 . 


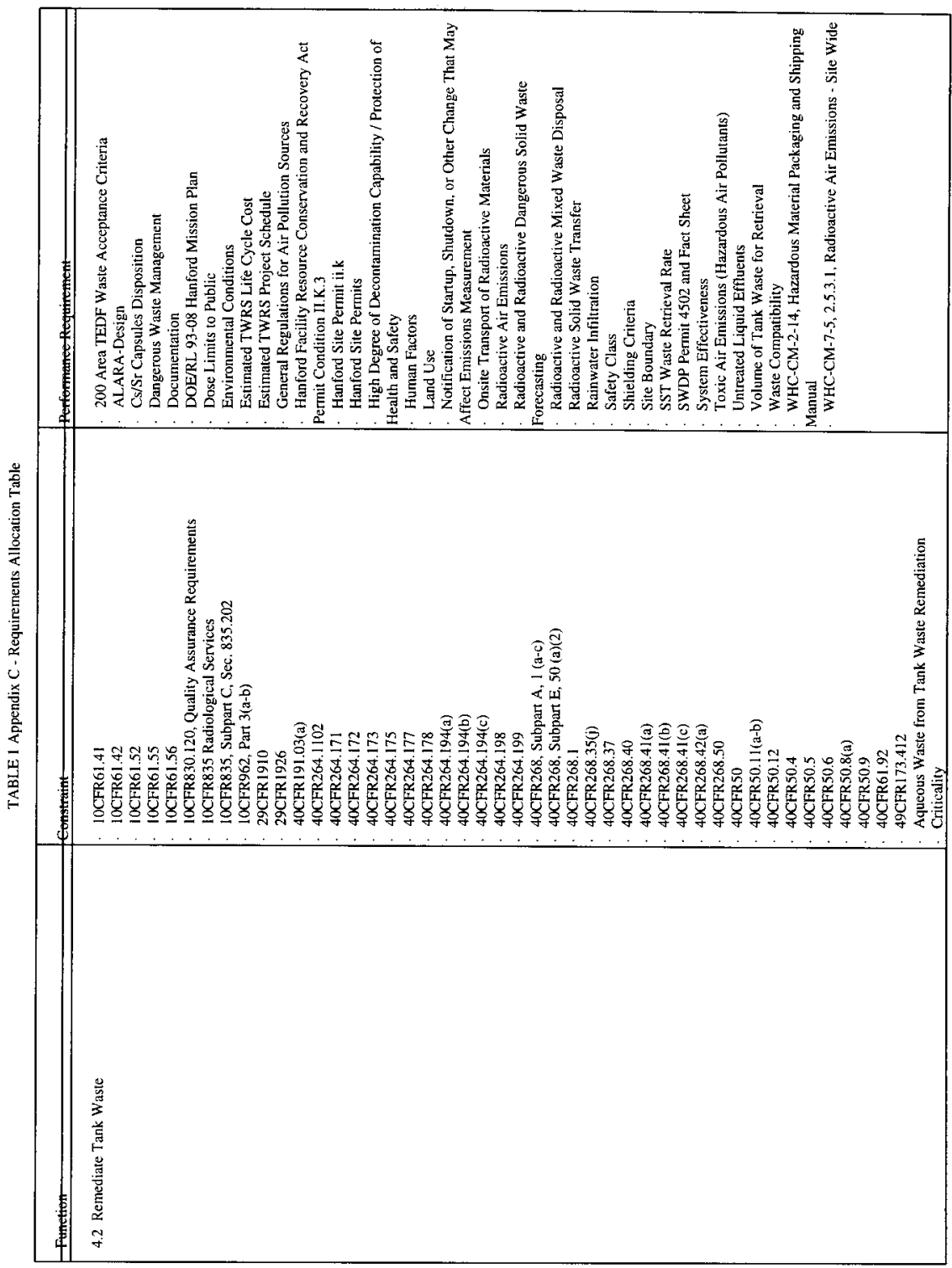




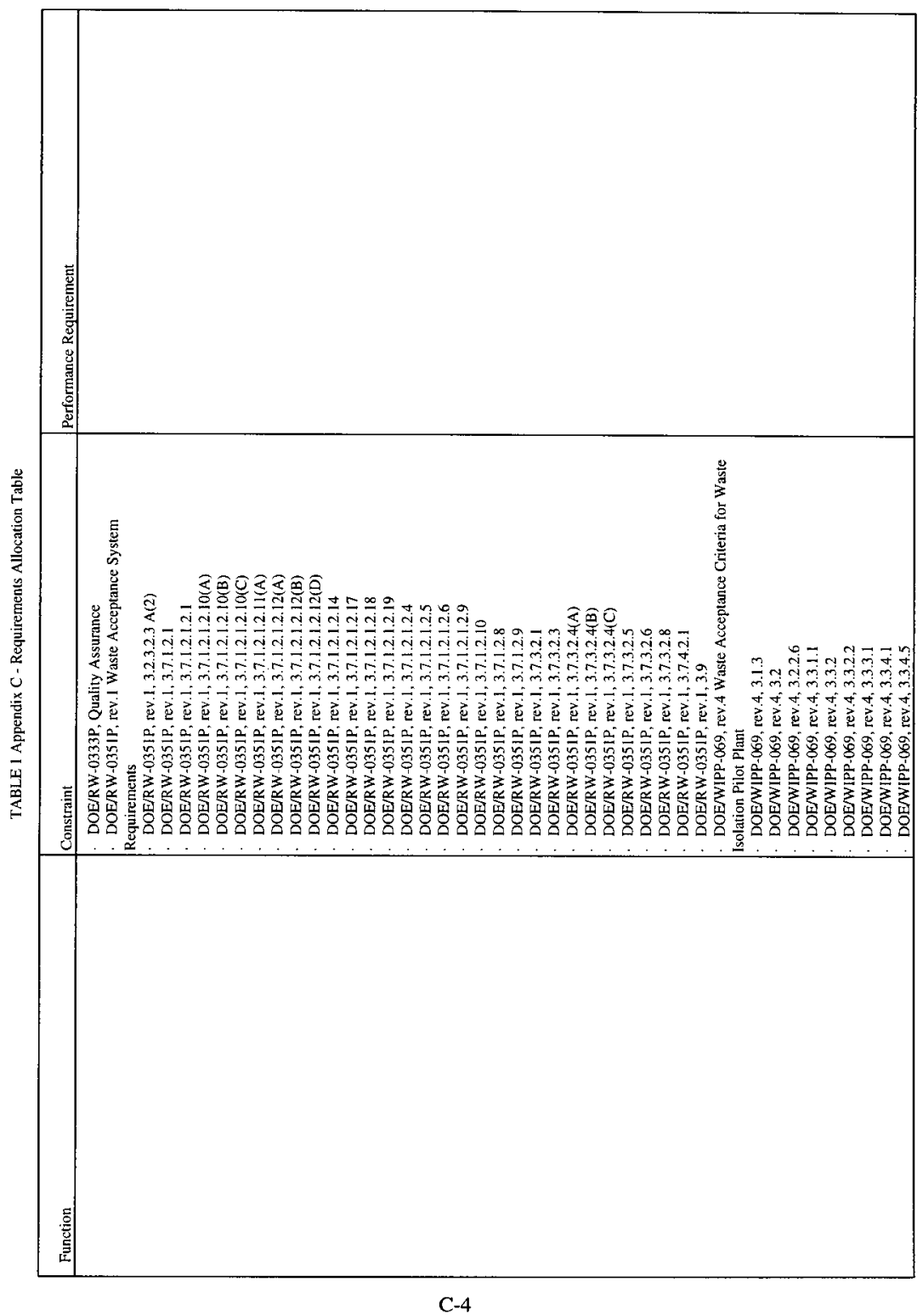




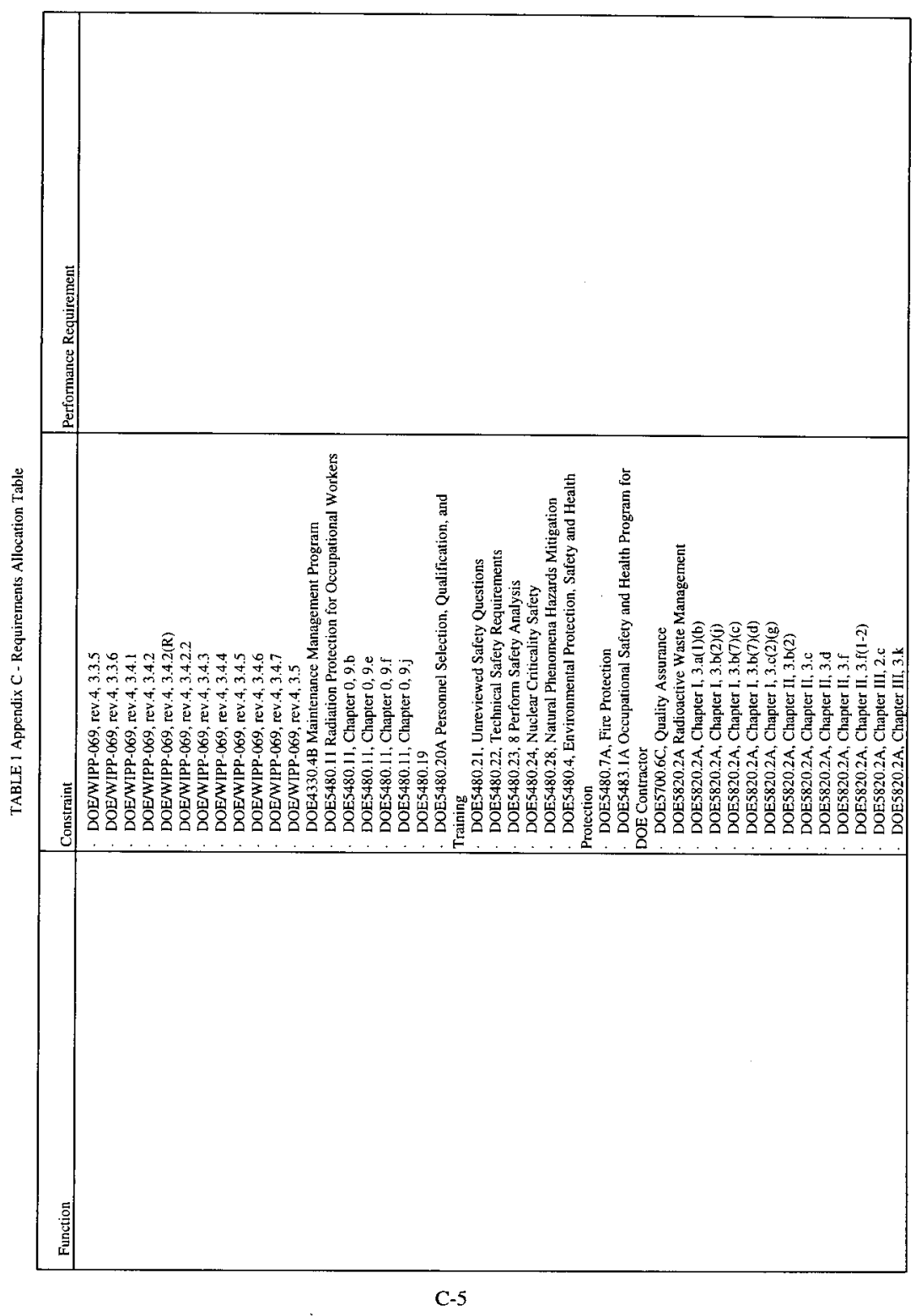




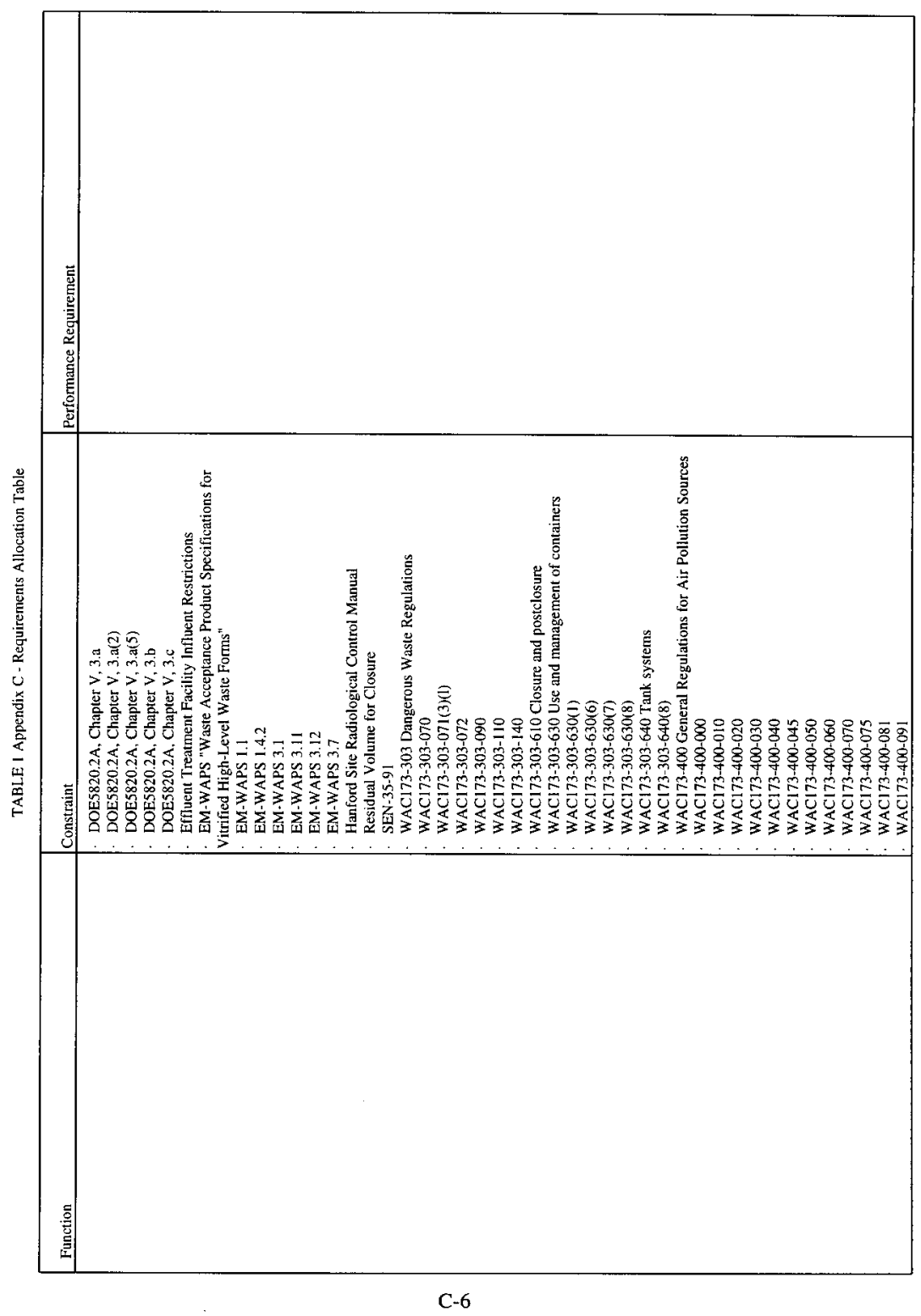




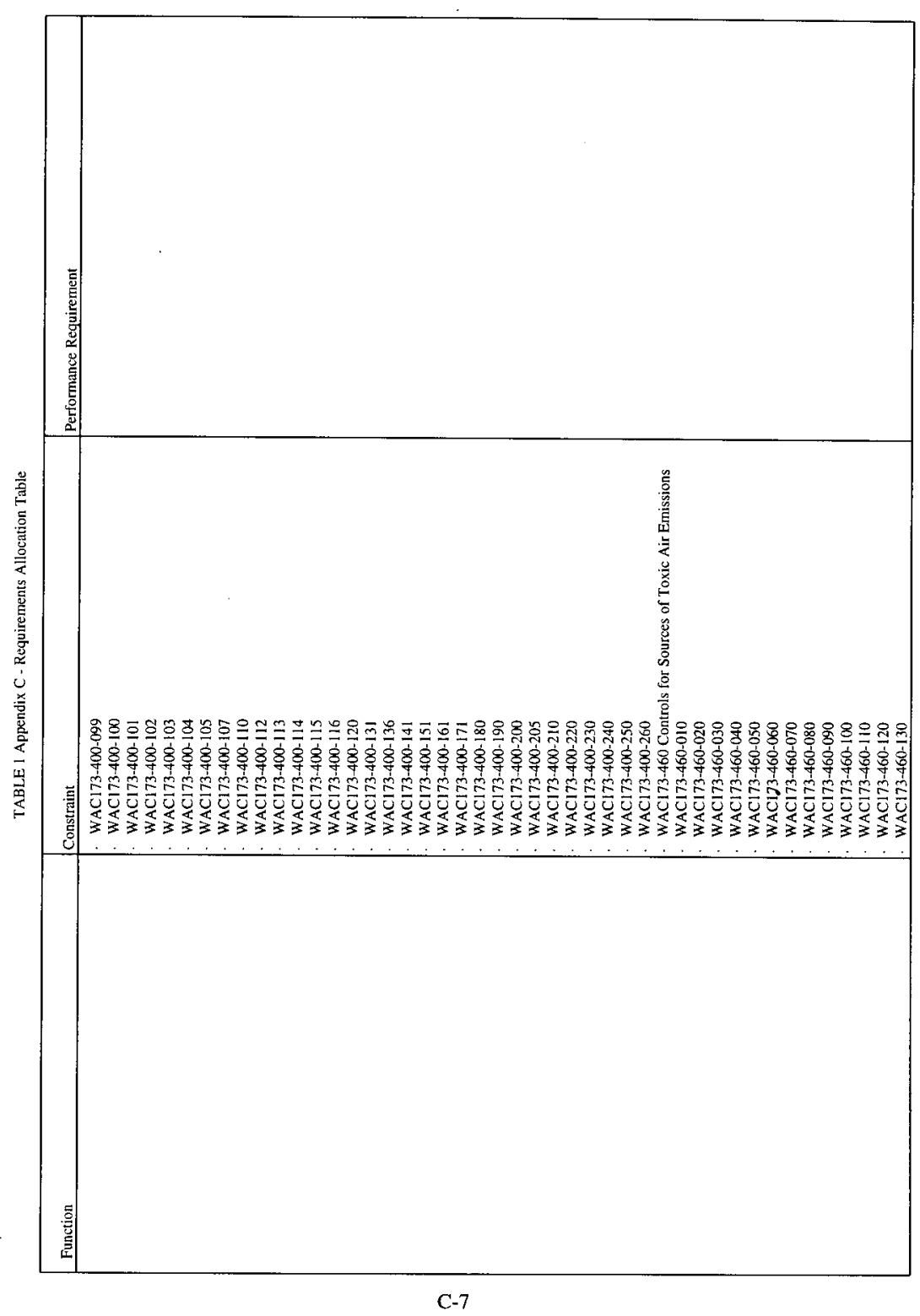




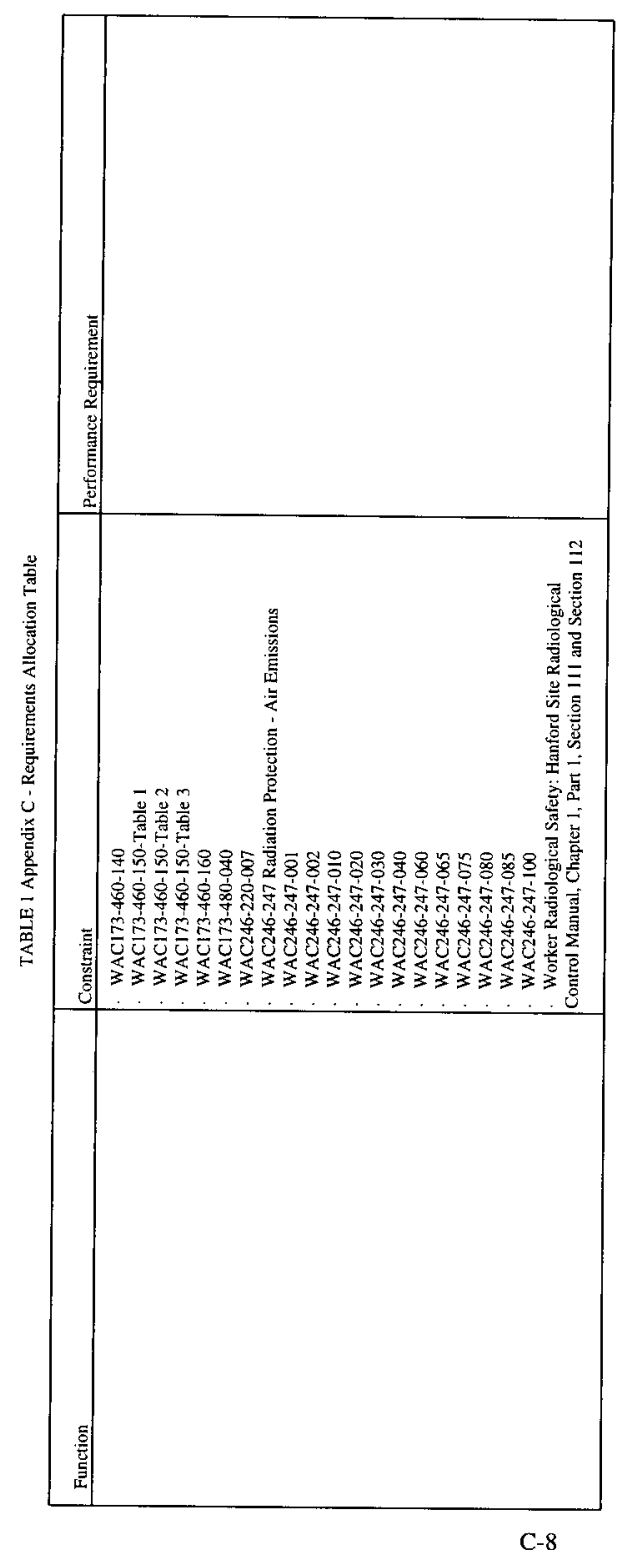




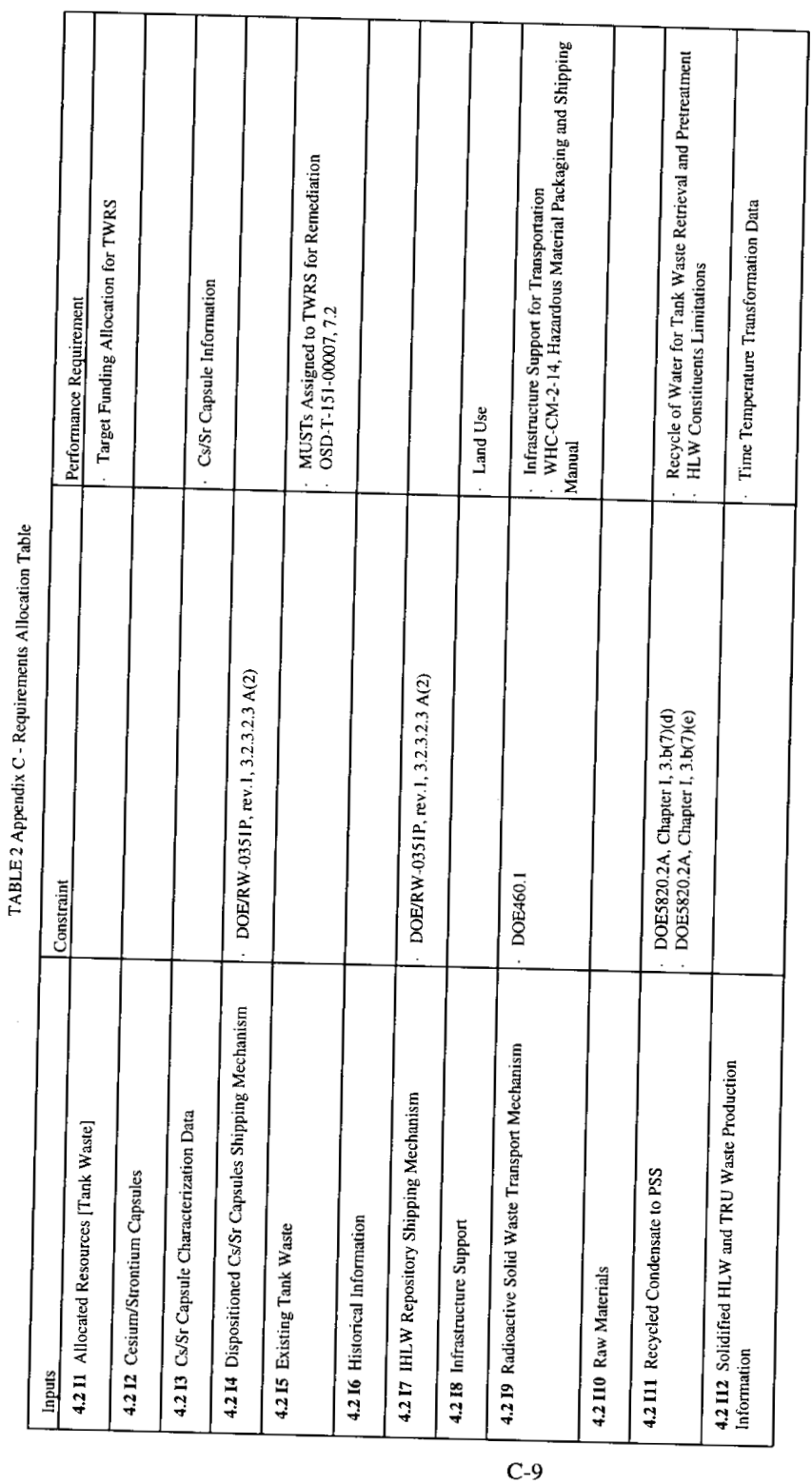


Revision 1

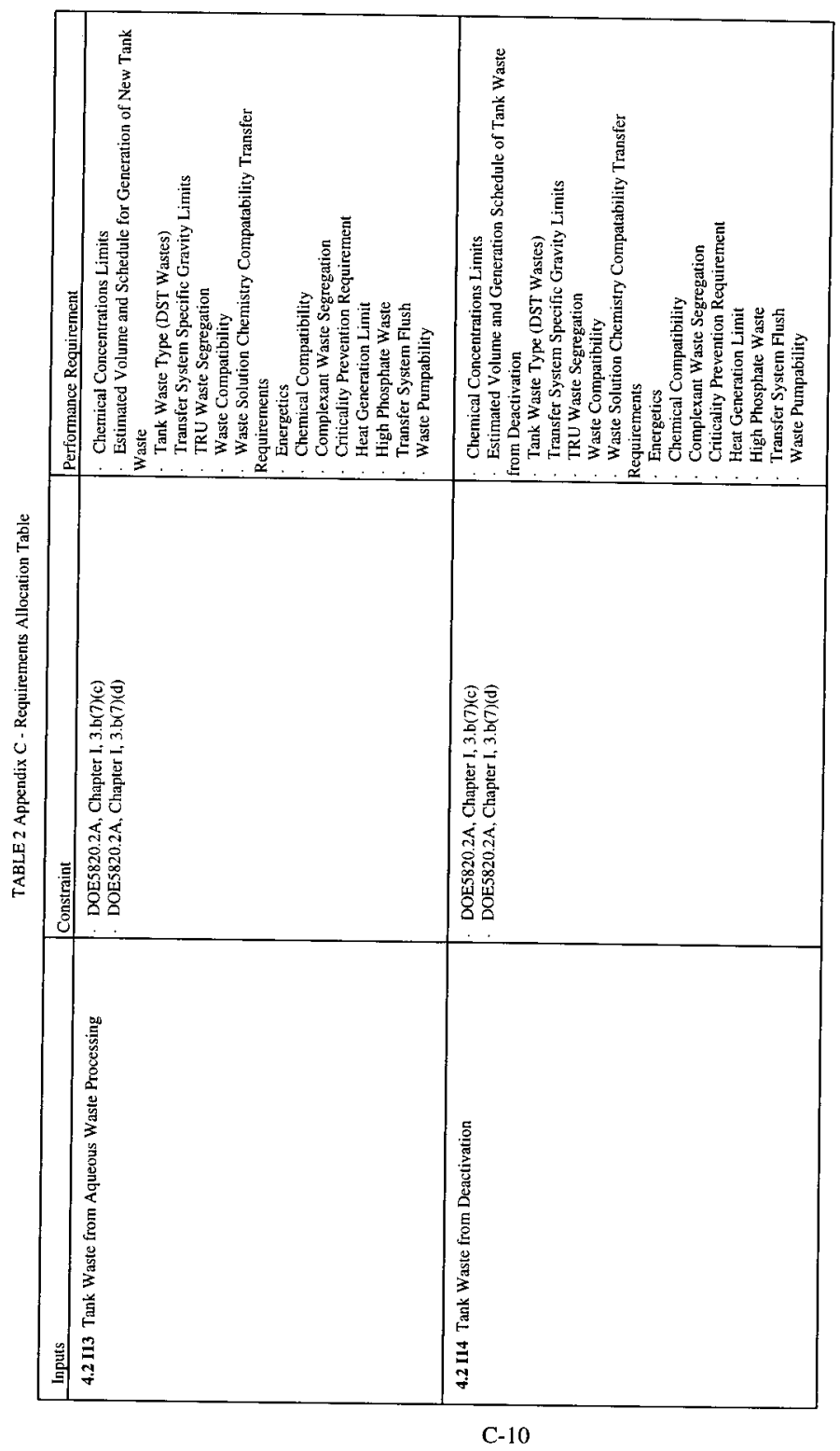




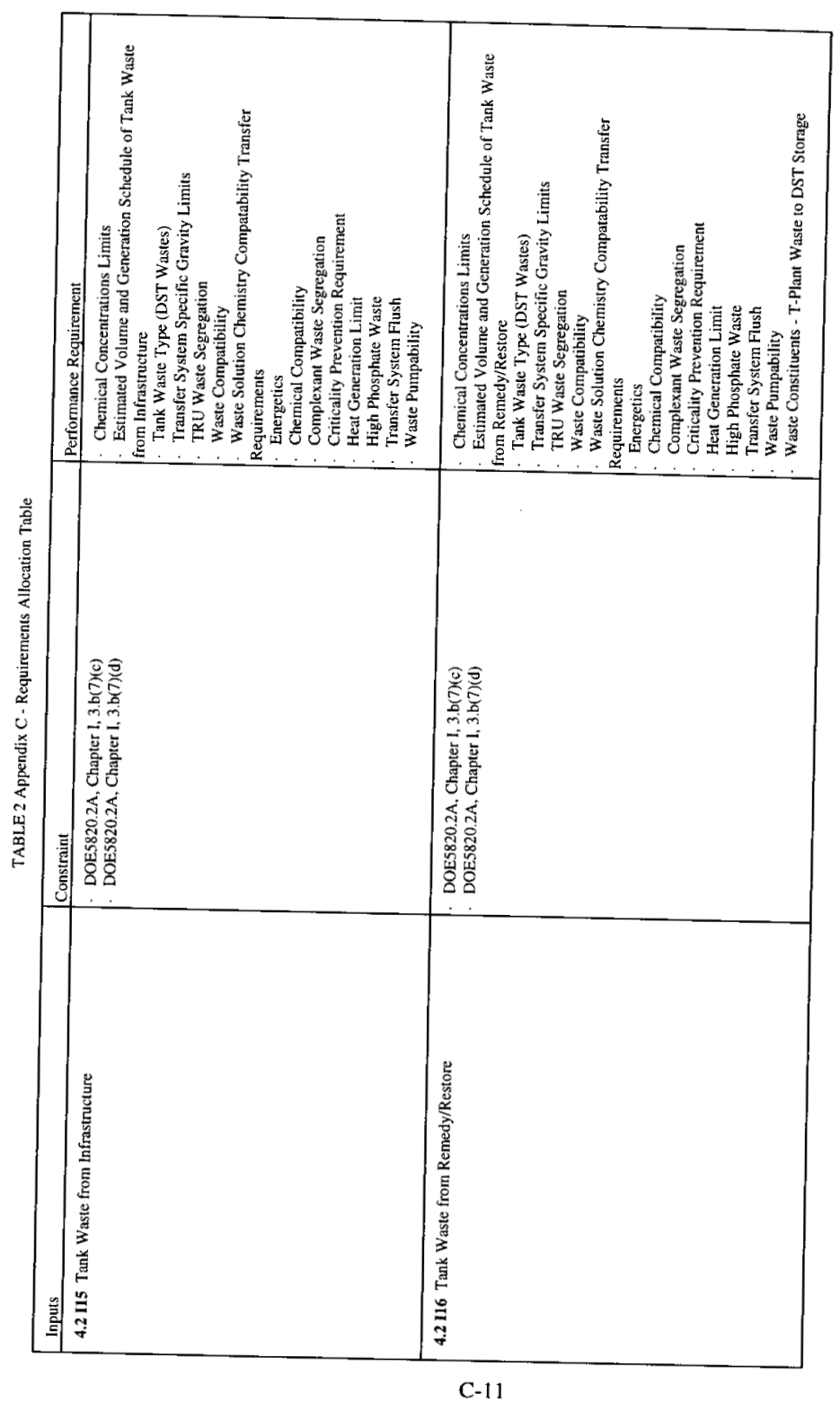


Revision 1

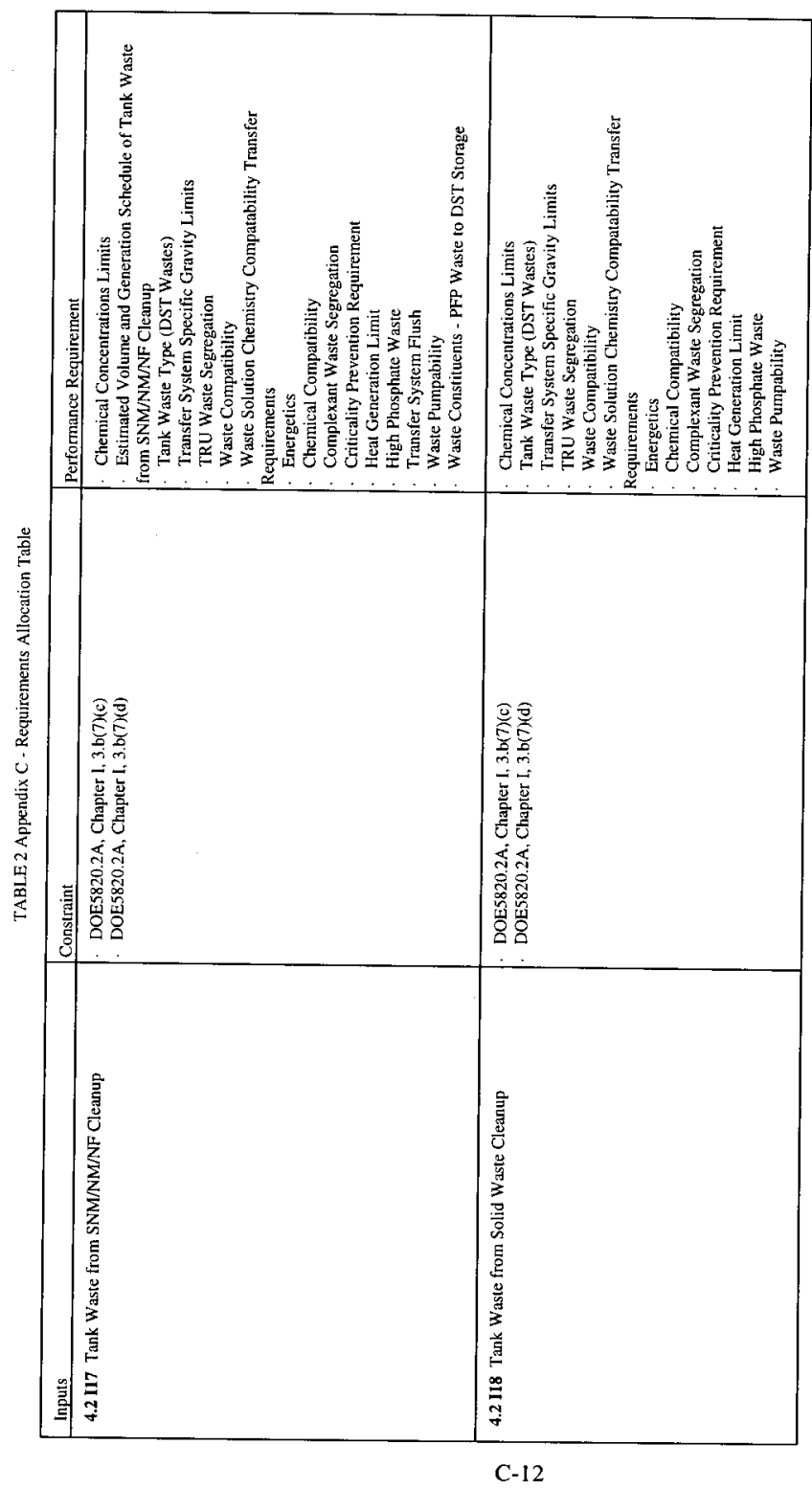




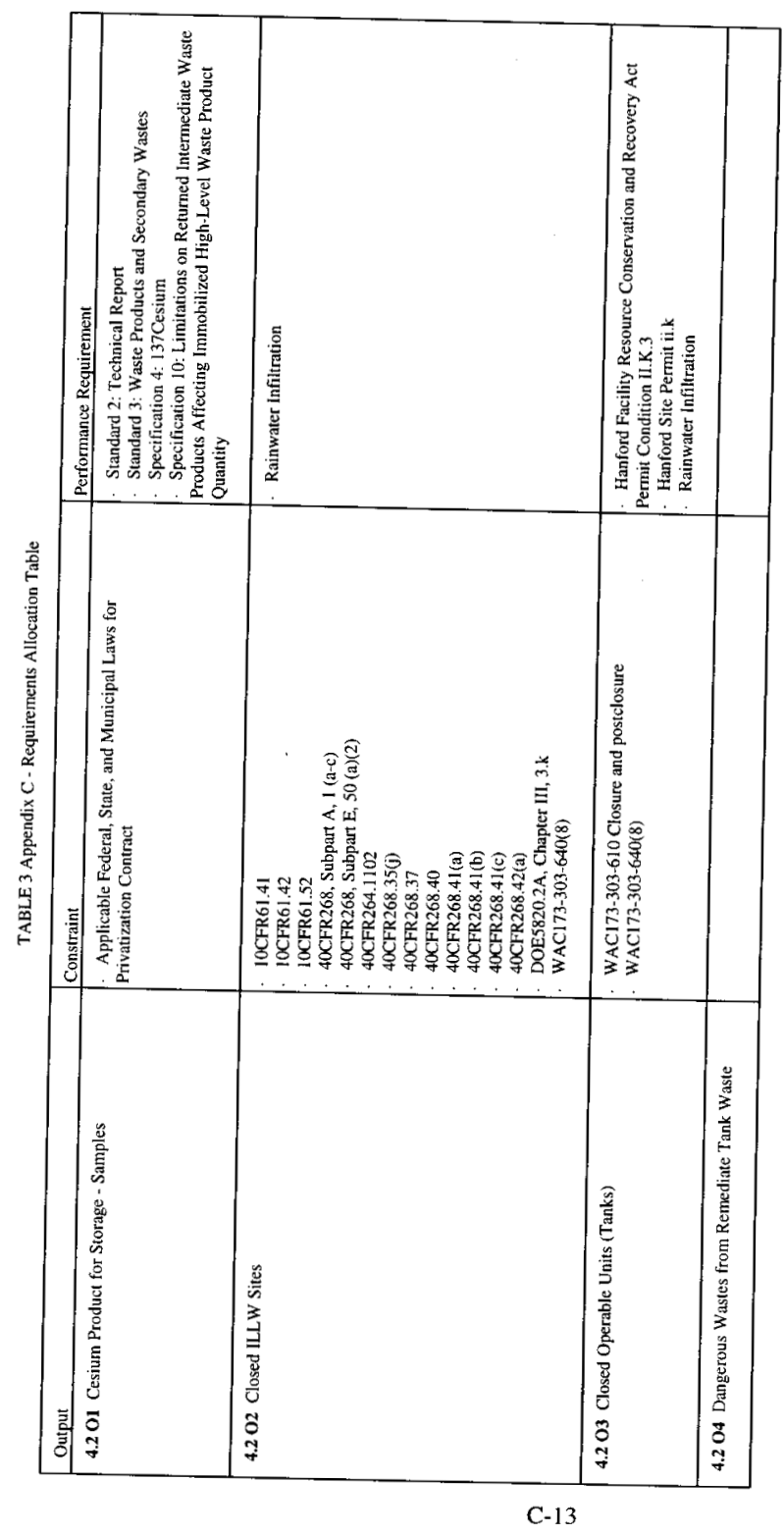




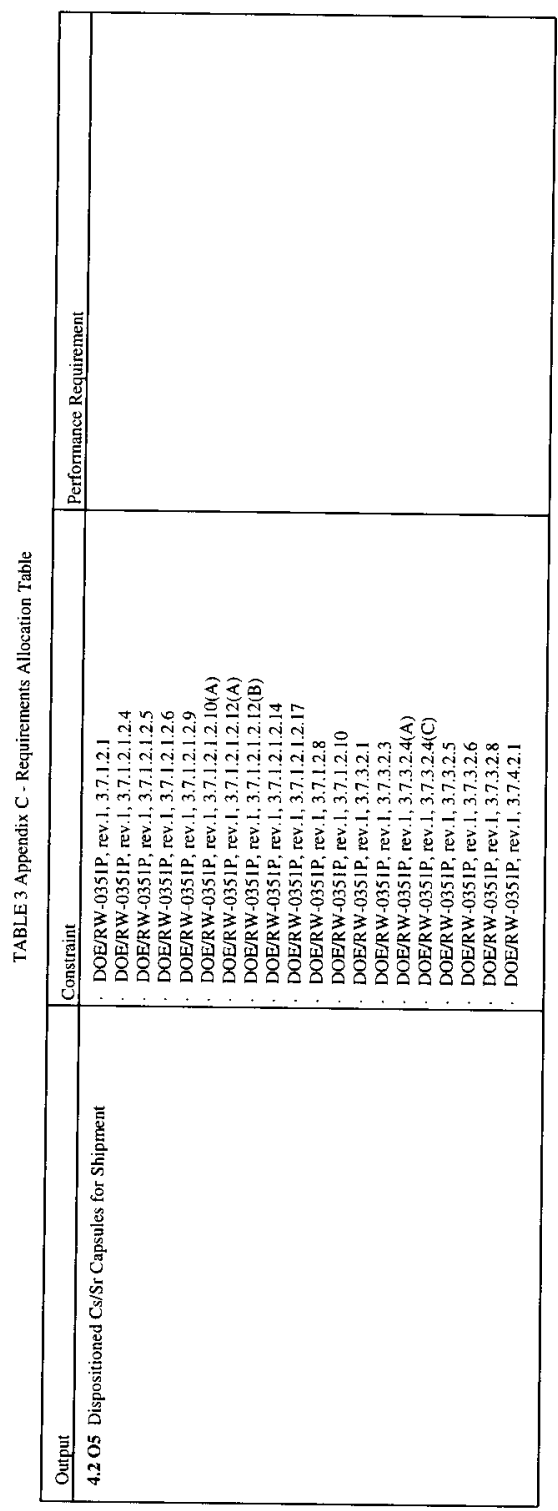

C-14 


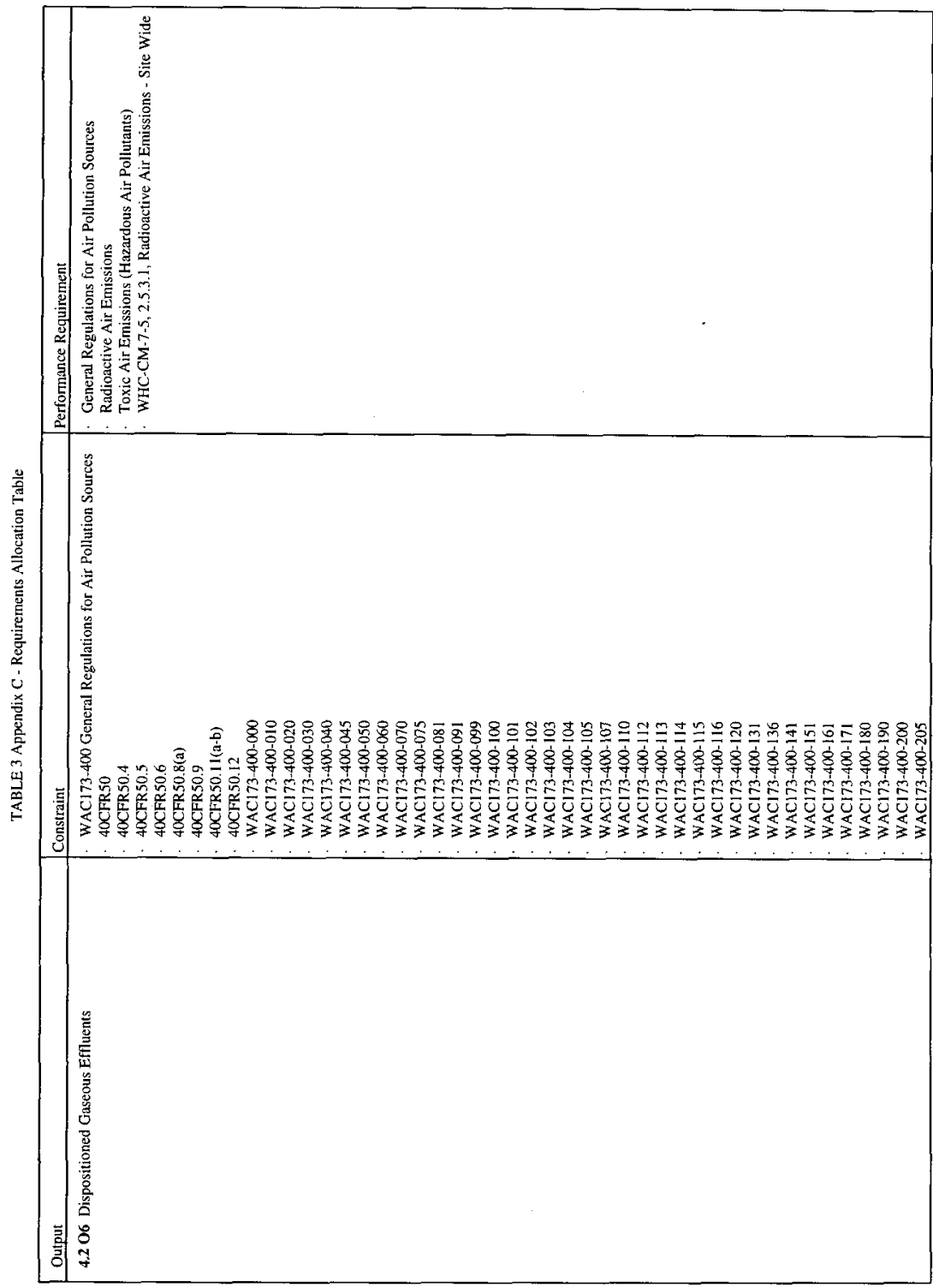




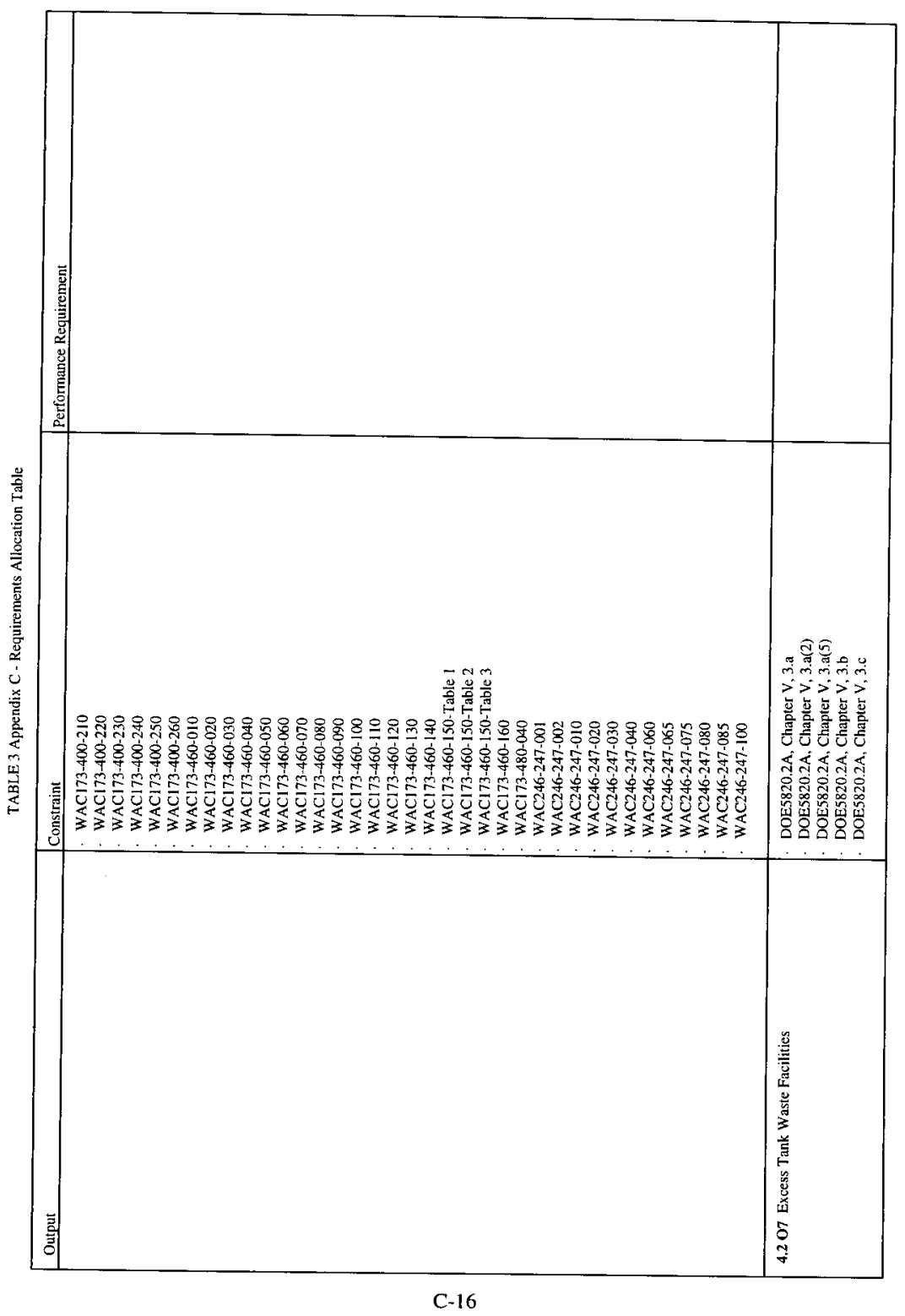




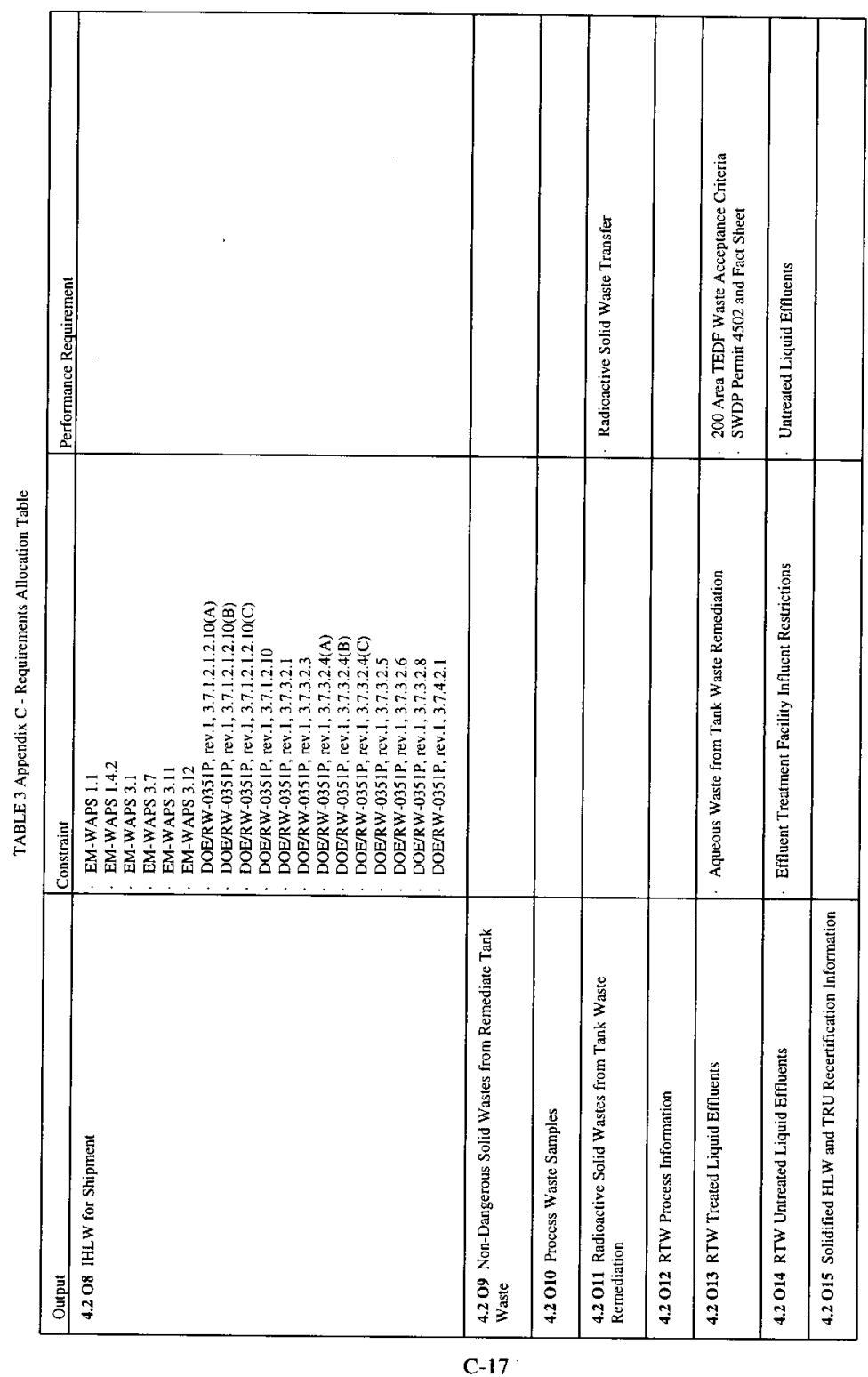




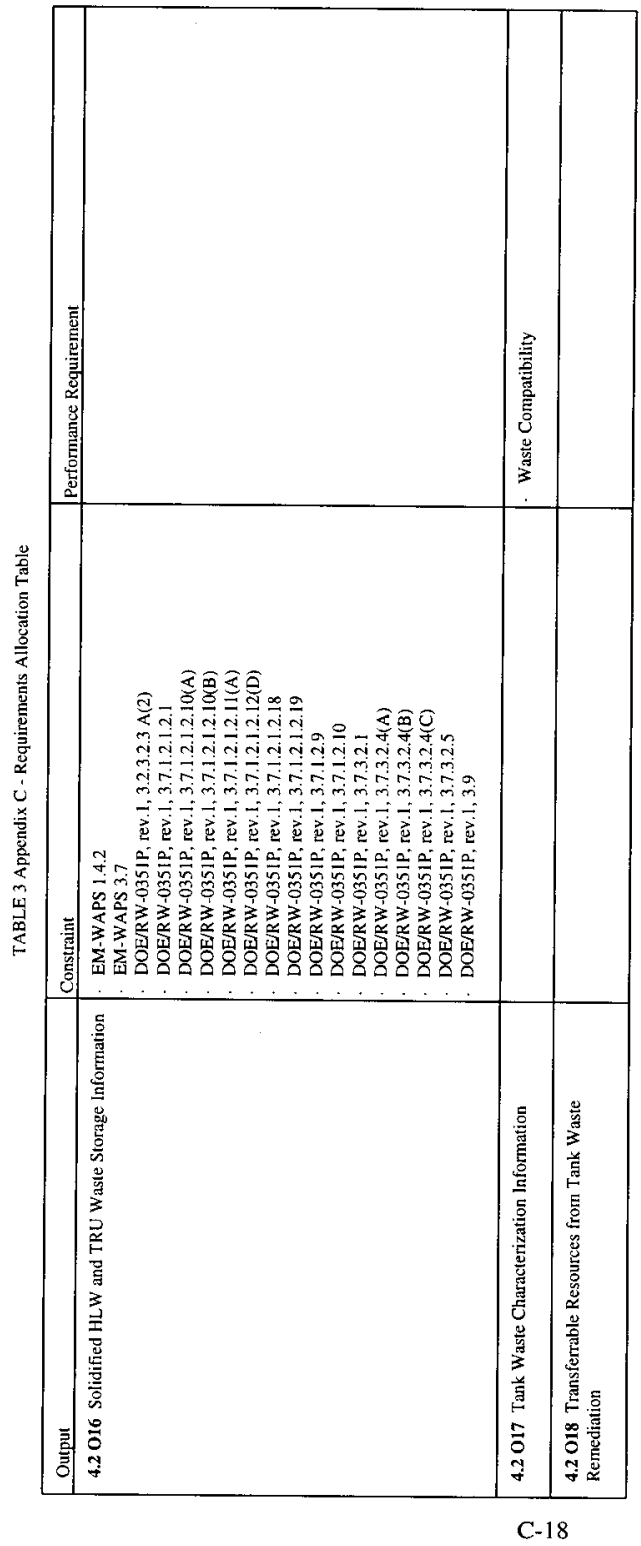


Revision I 
Revision 1

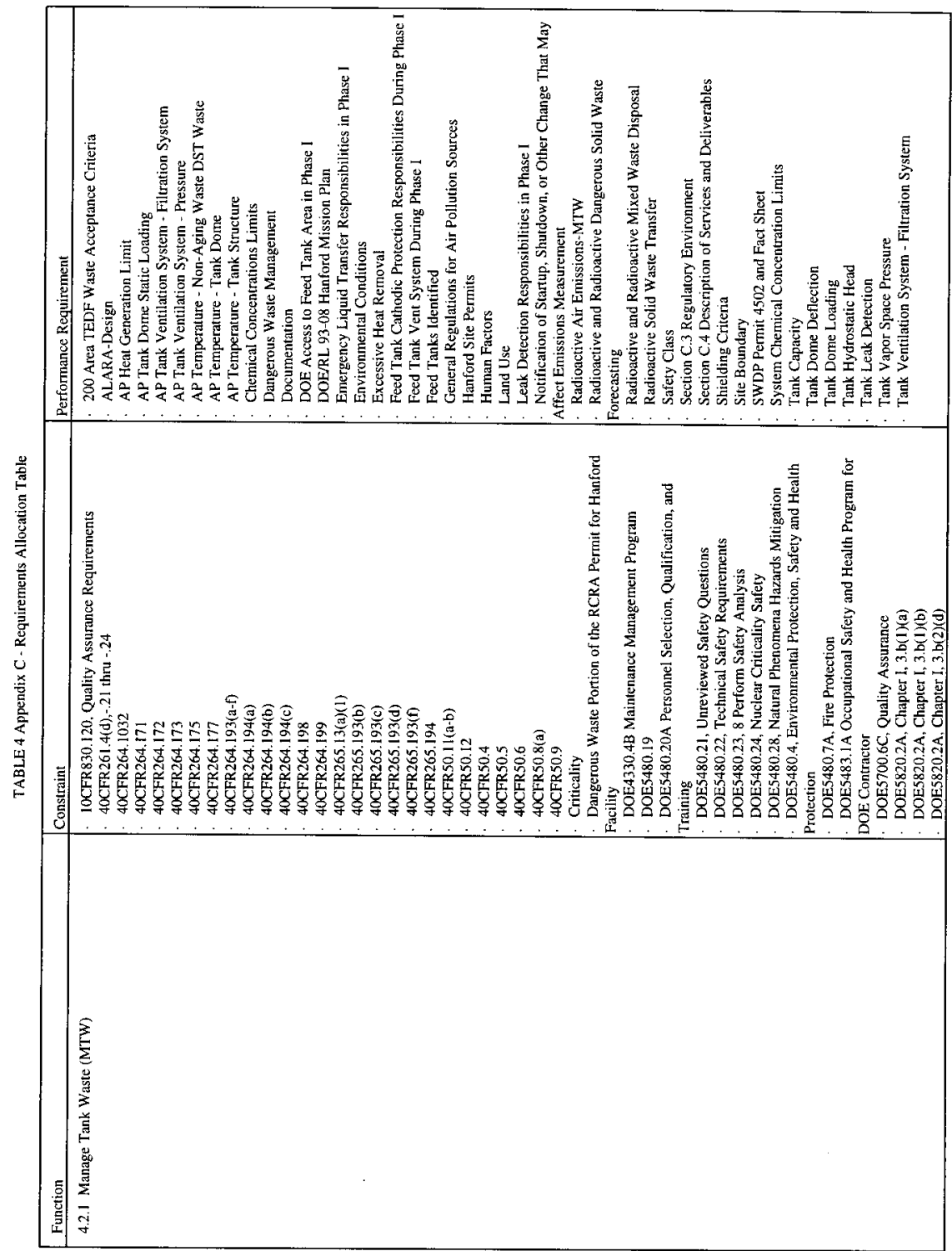




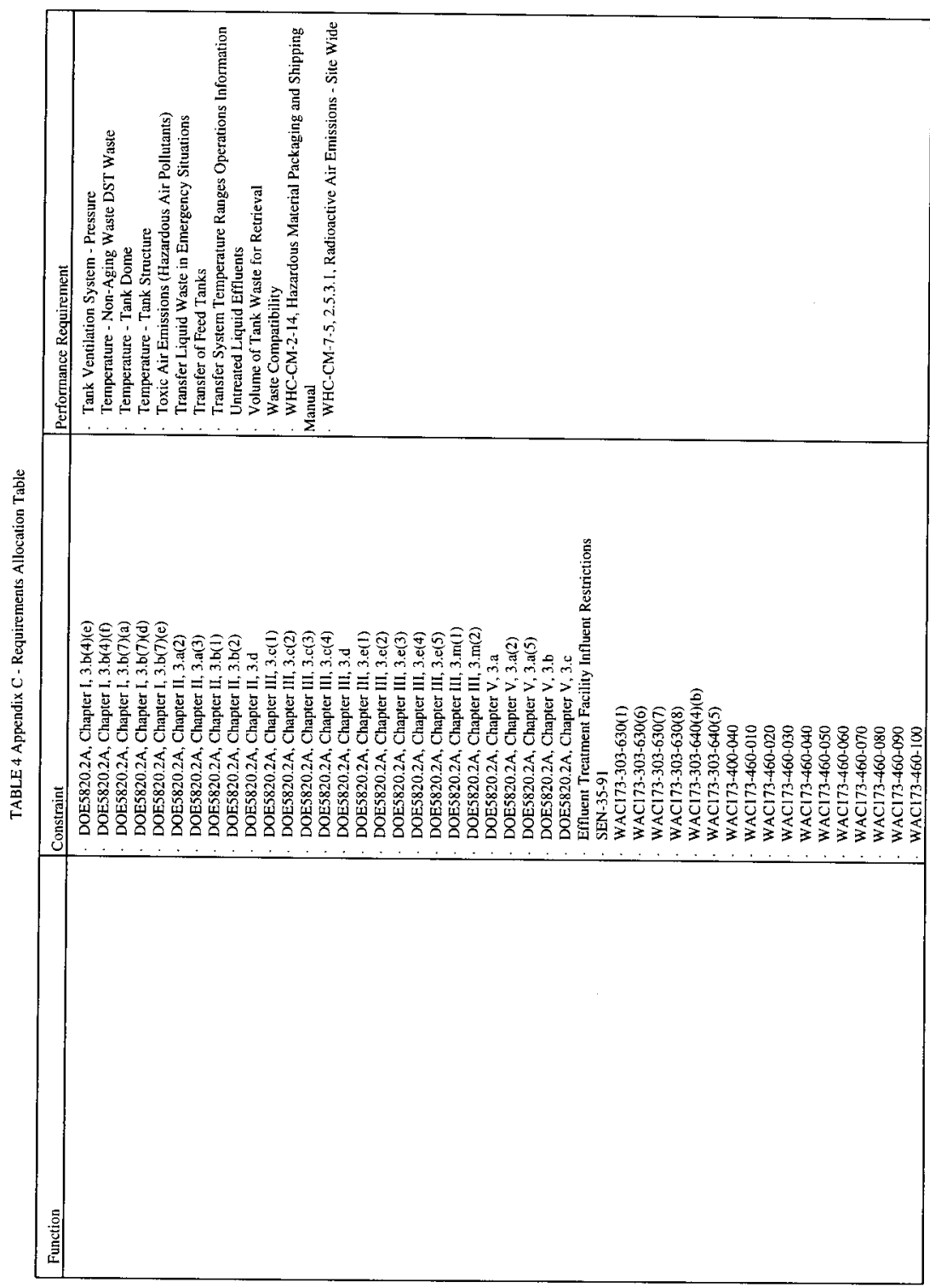


Revision 1

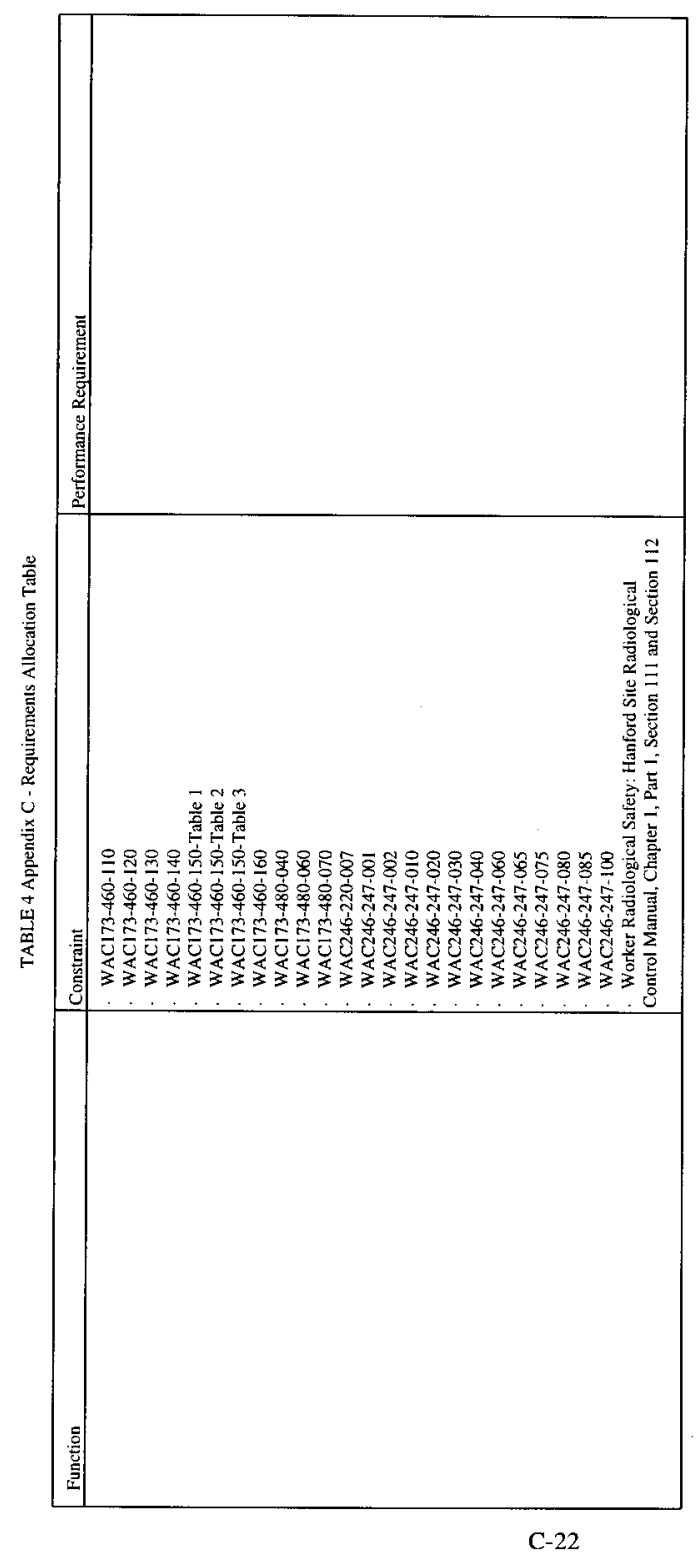




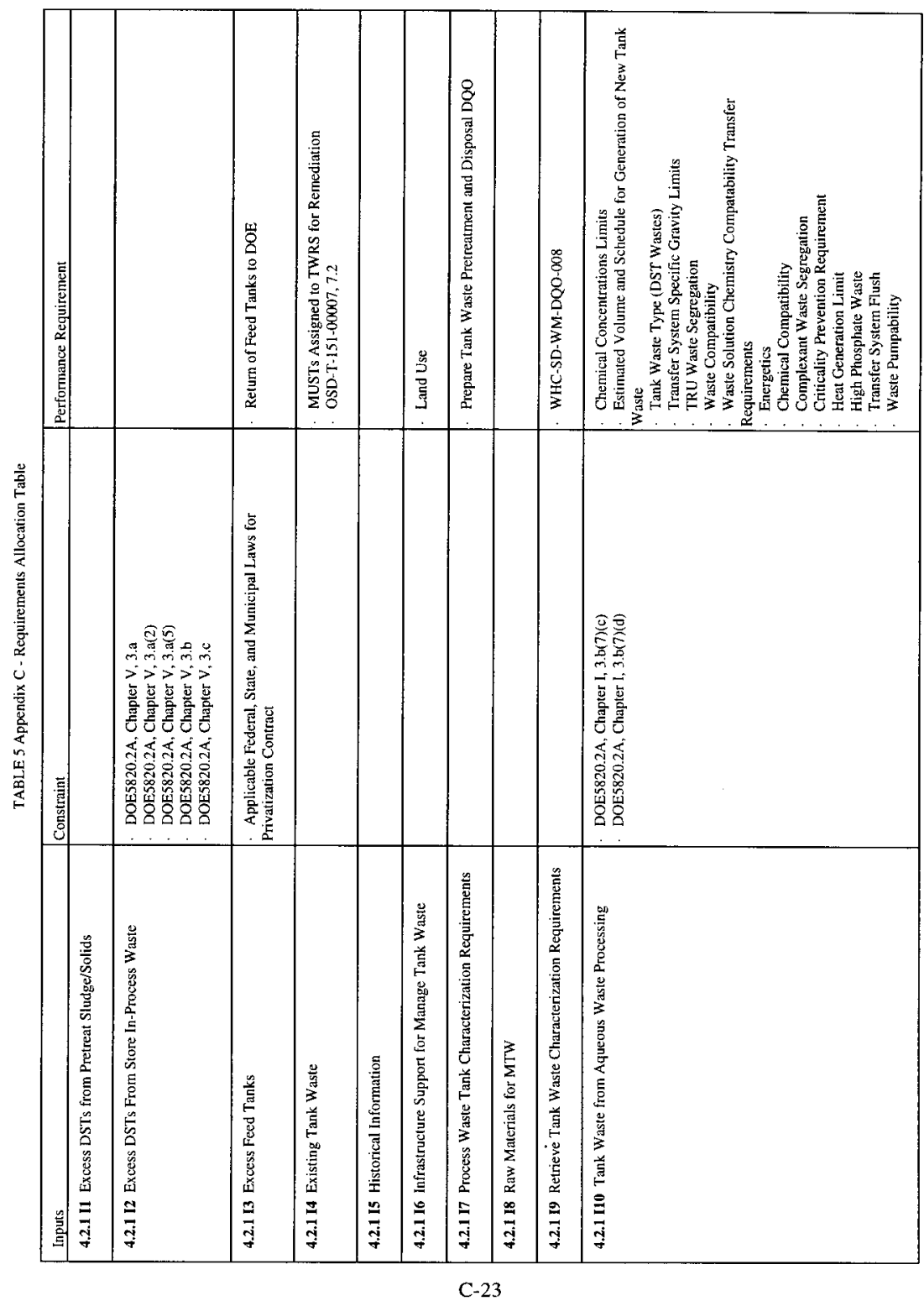




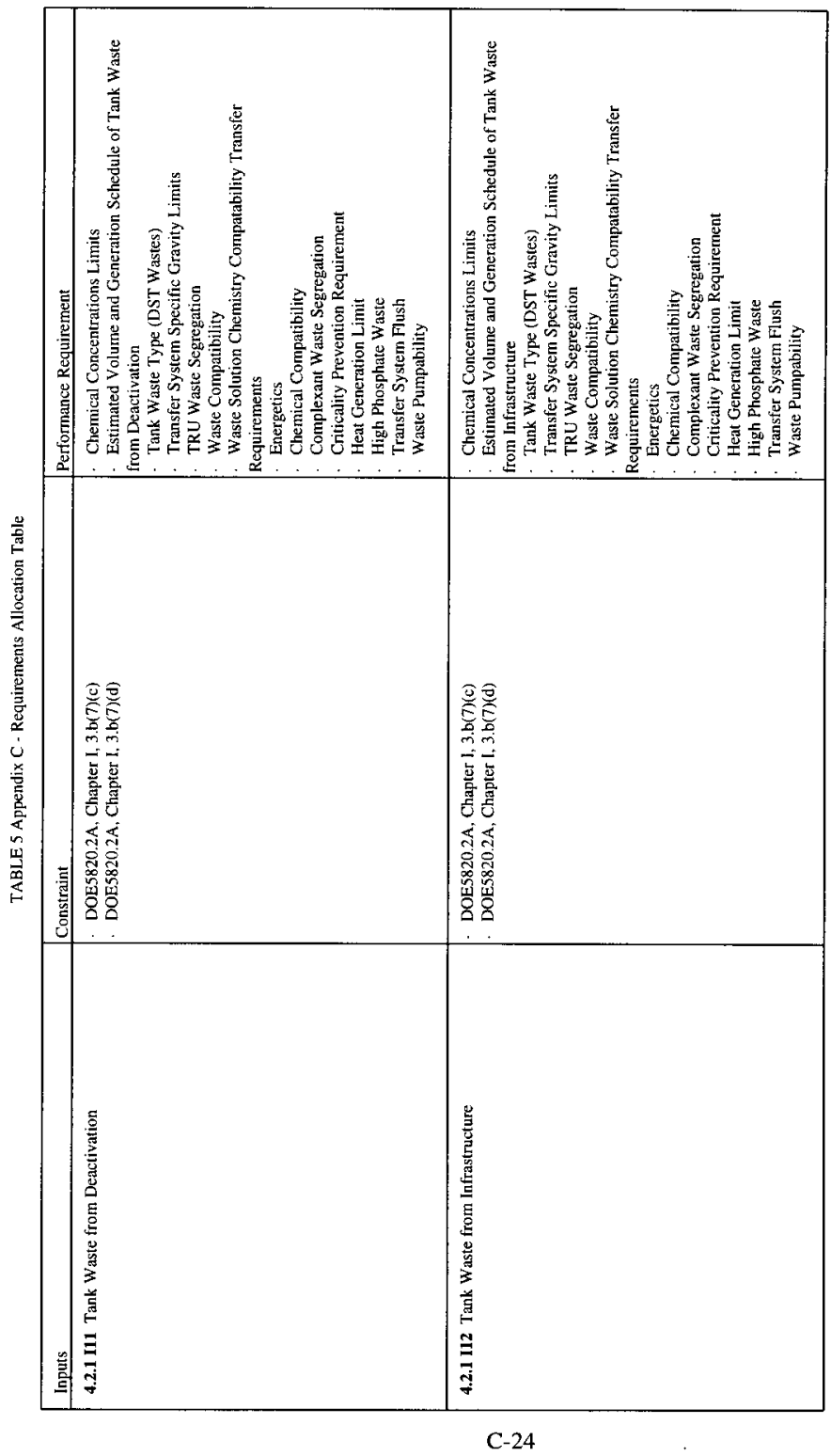




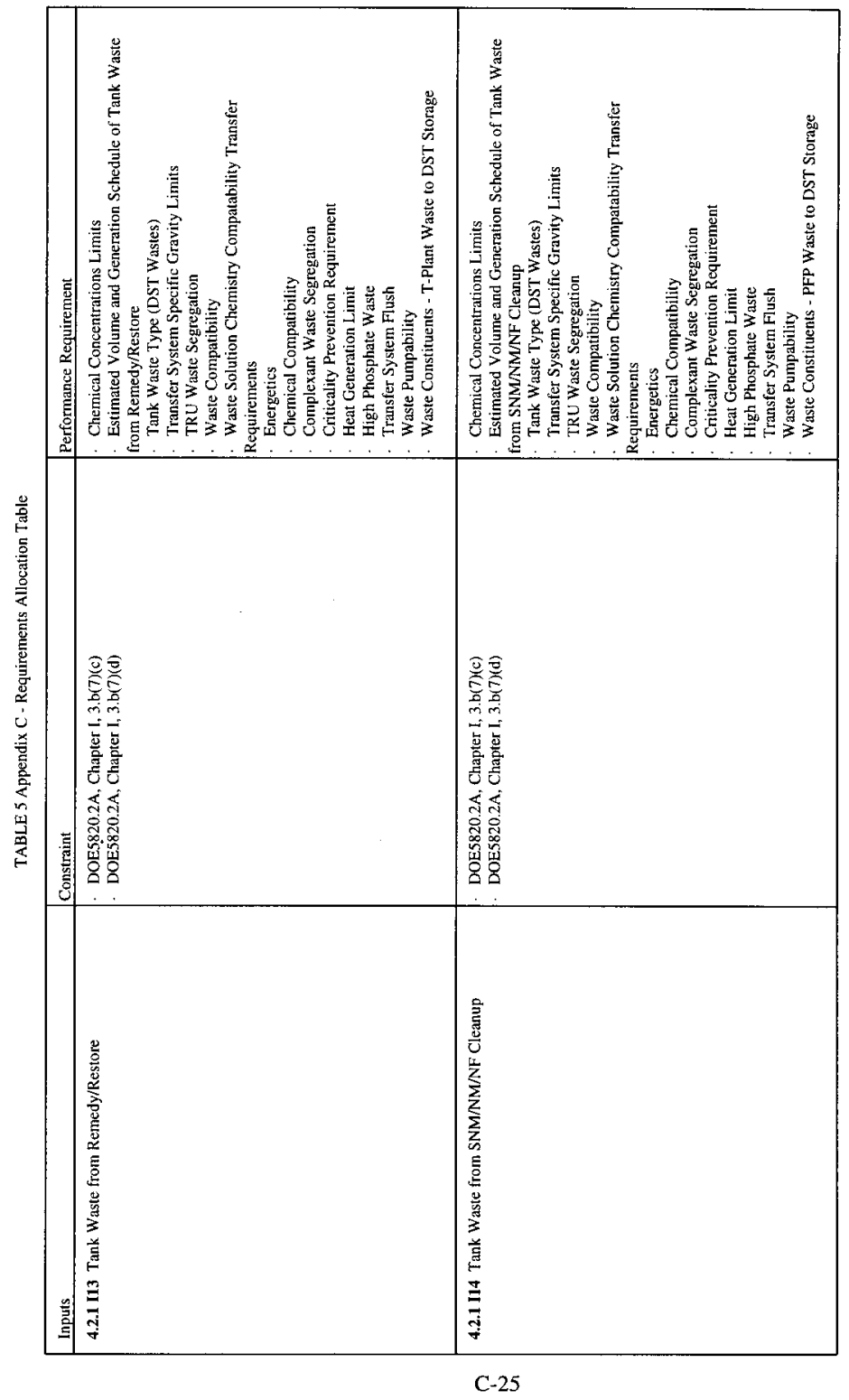




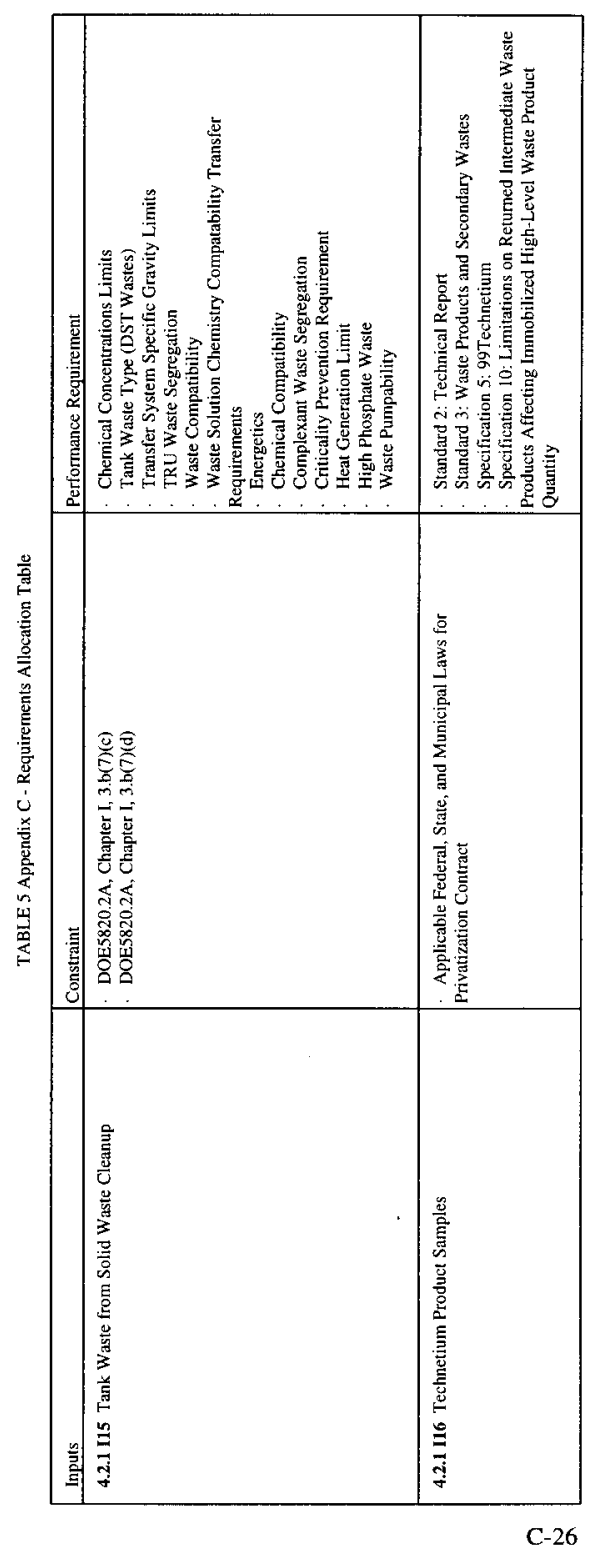




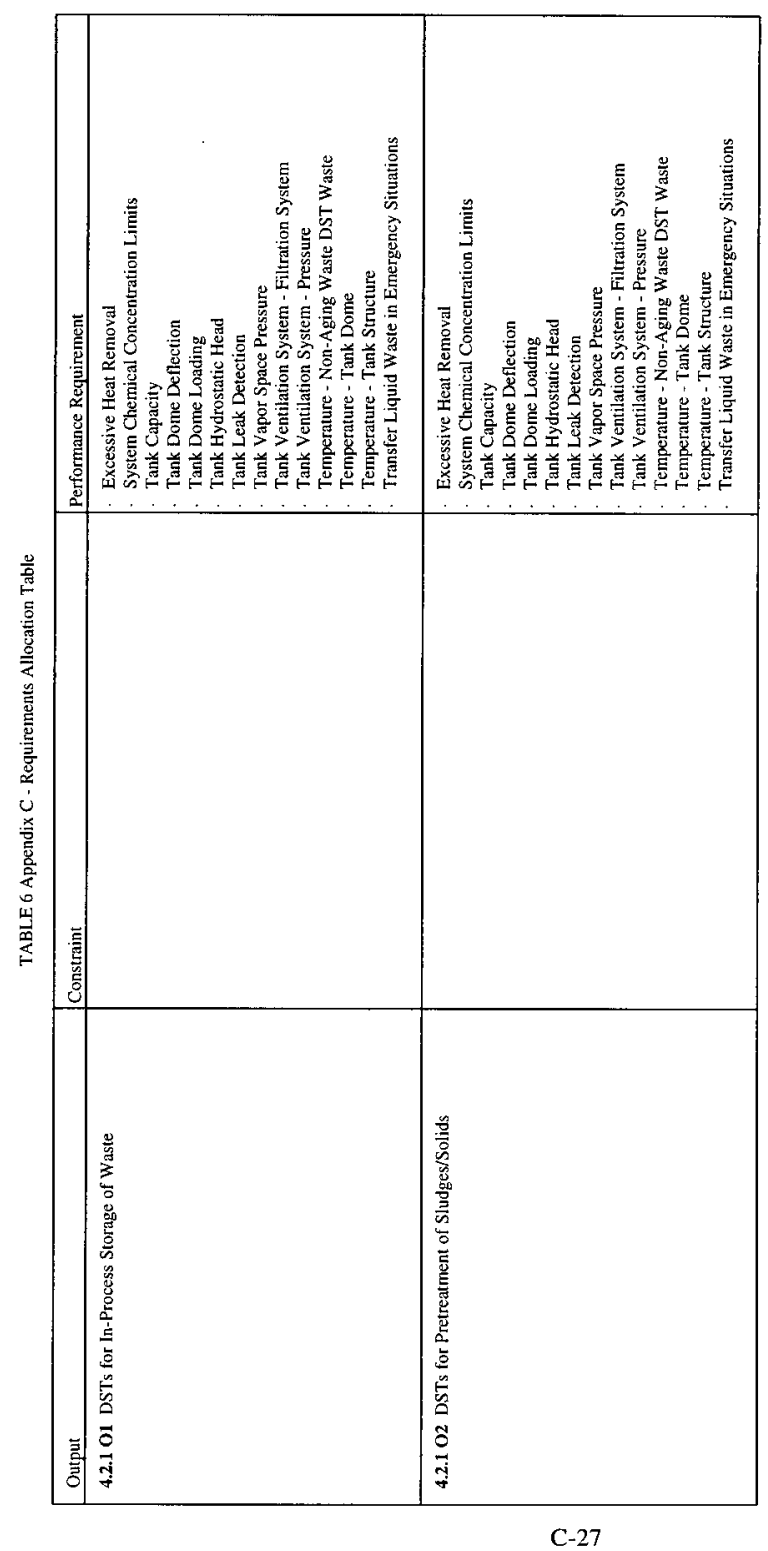


Revision 1

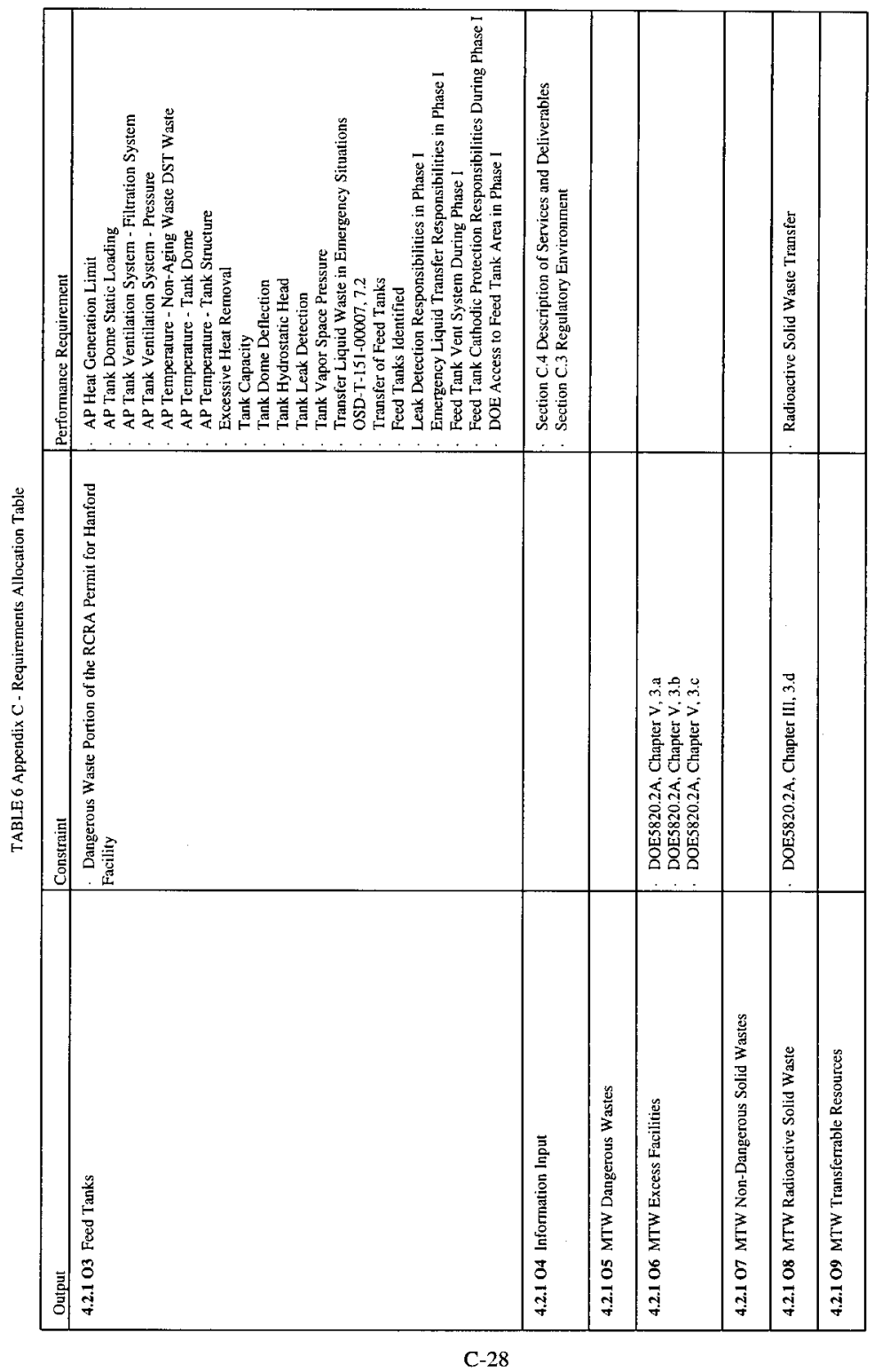




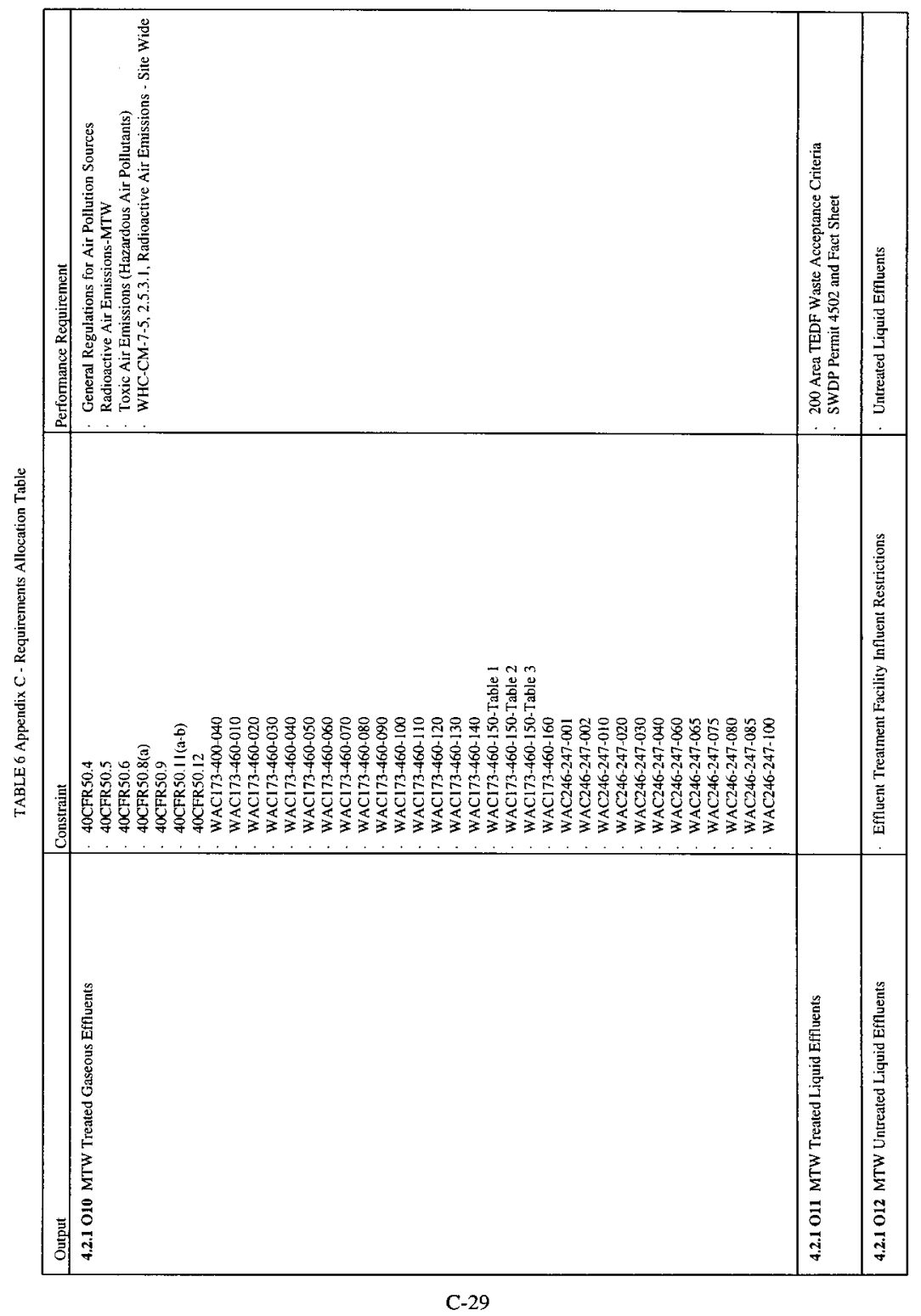




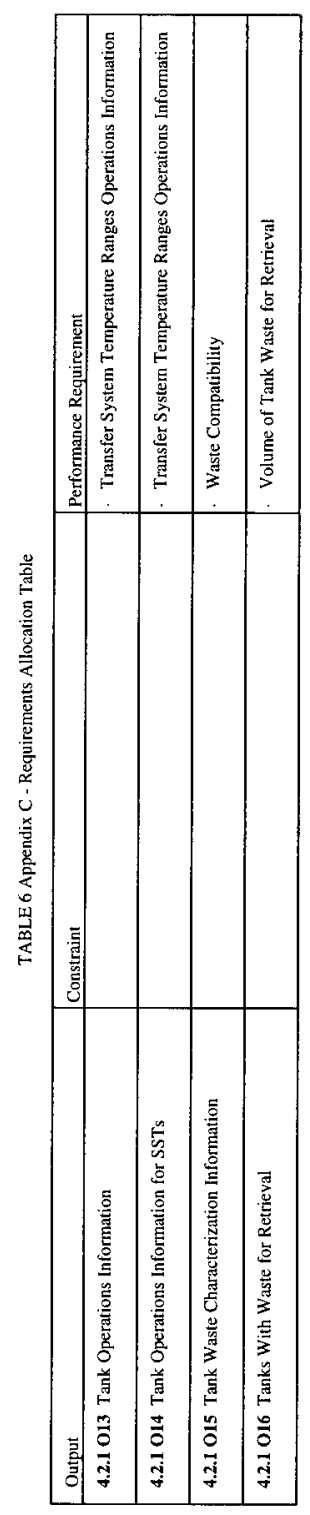

$$
\text { C-30 }
$$


Revision 1

C-31 


\section{Revision 1}

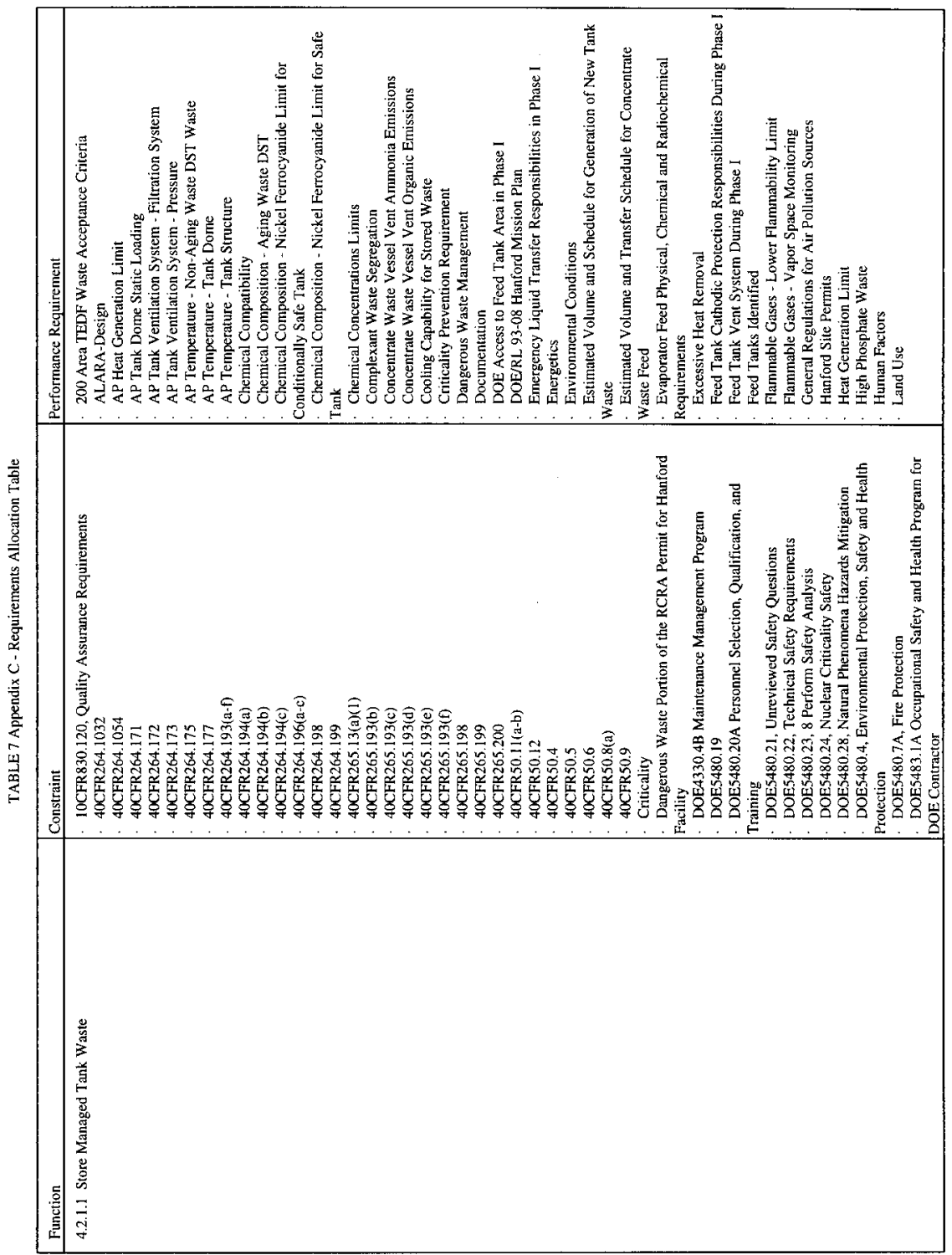




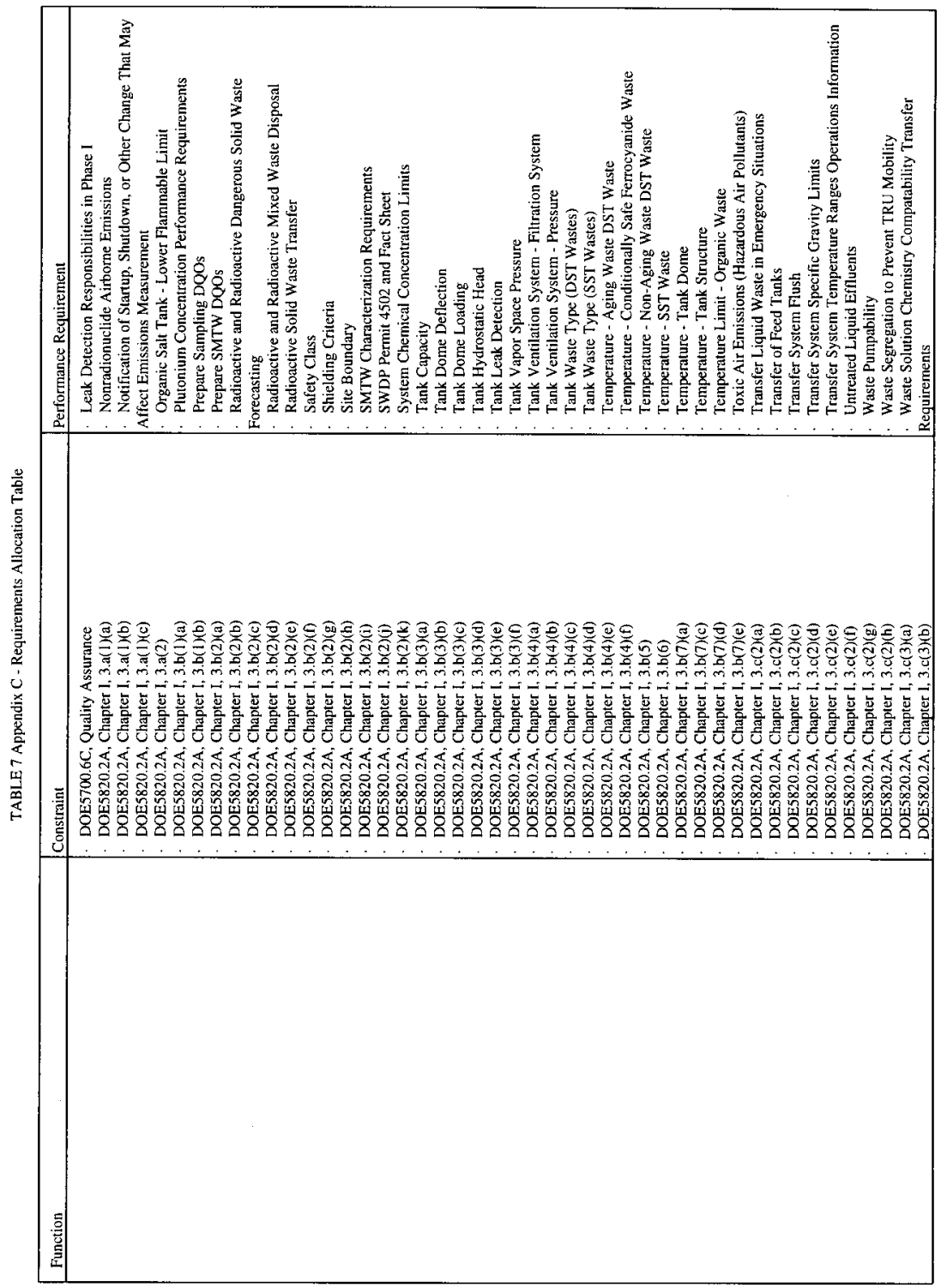




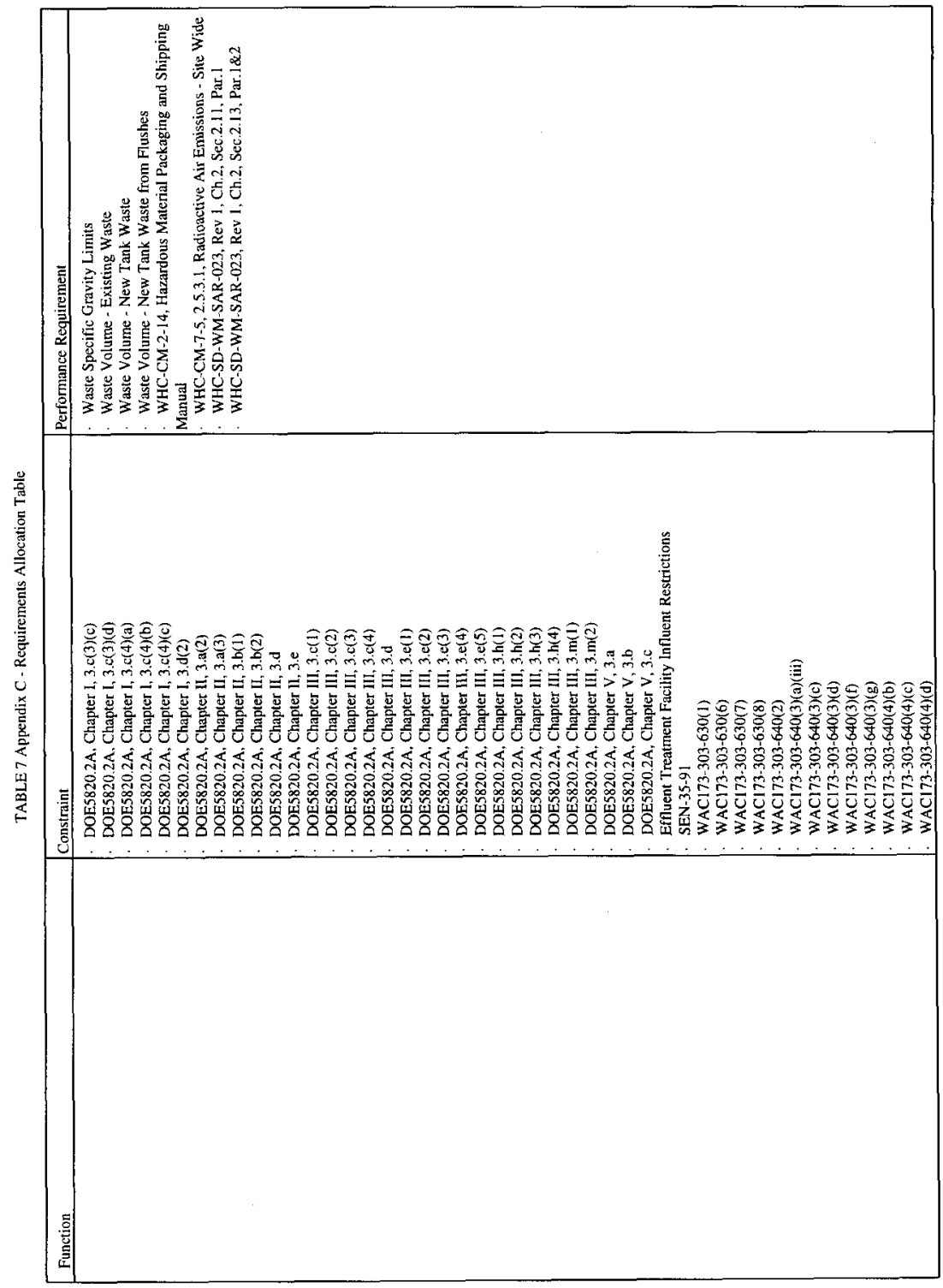




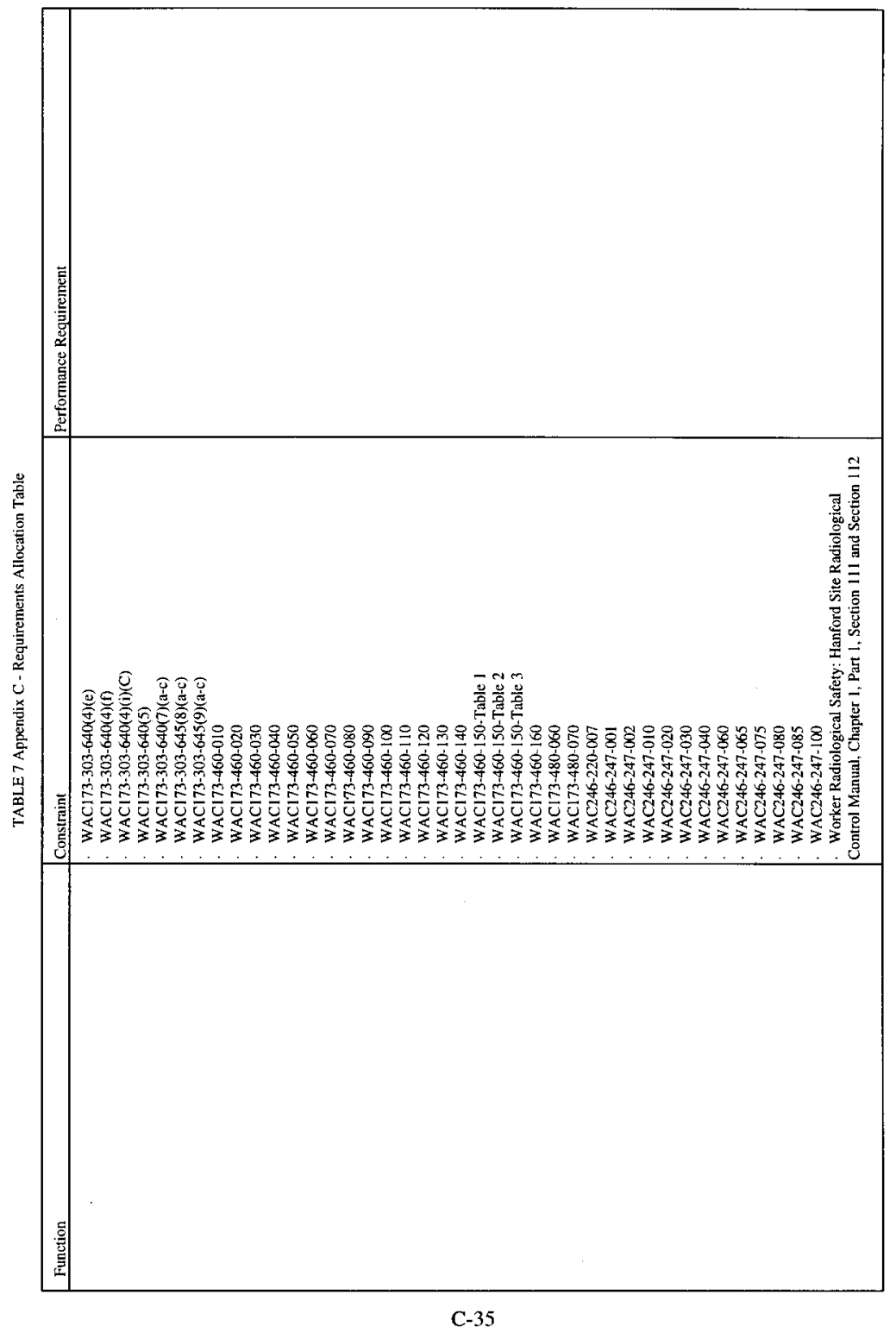


Revision 1

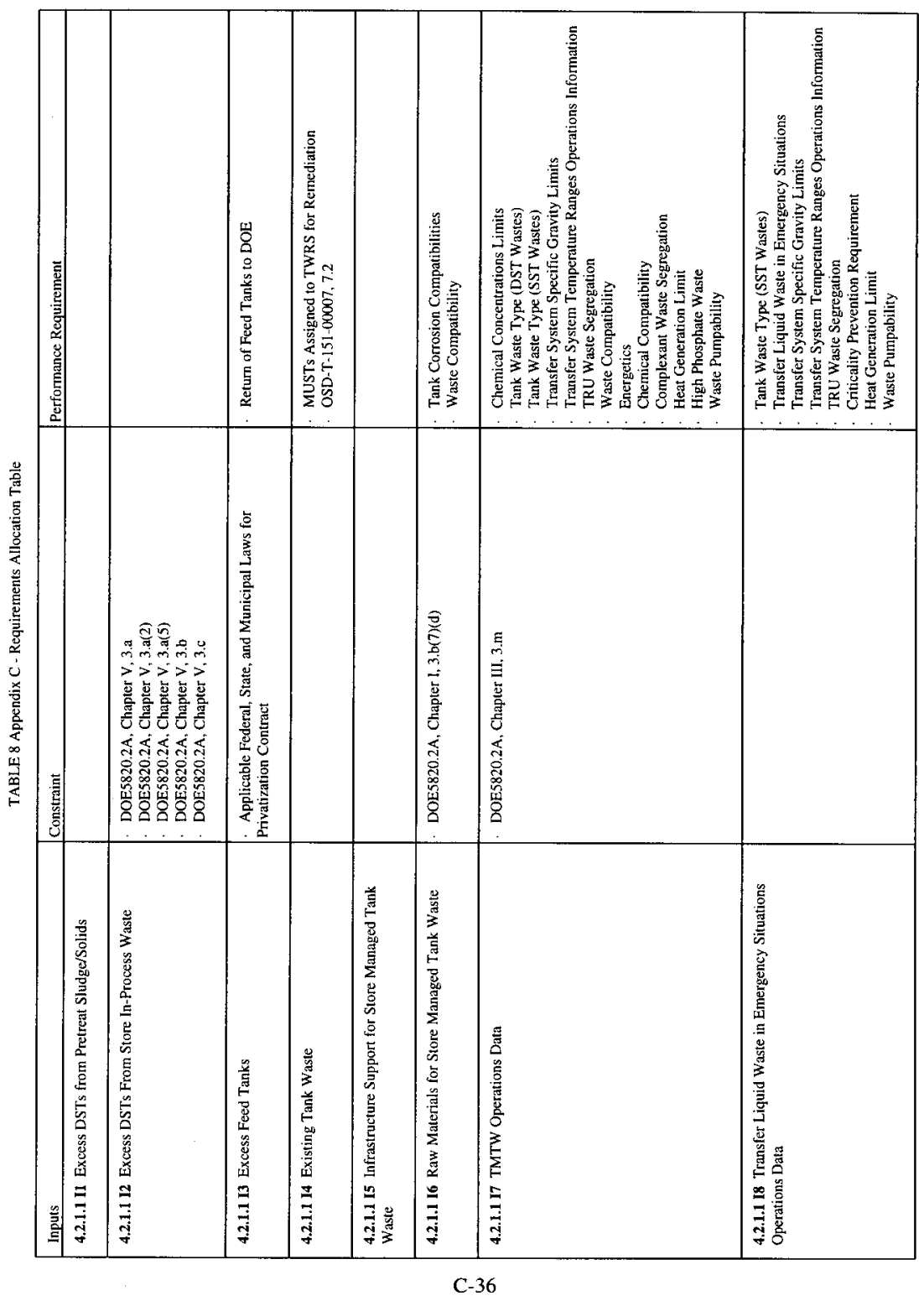




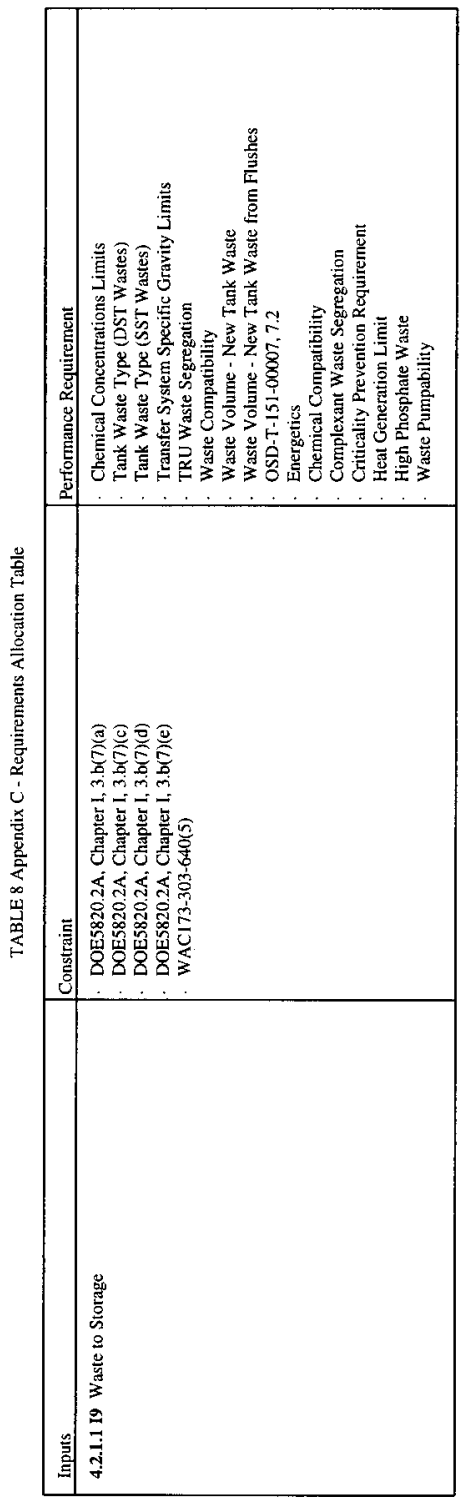




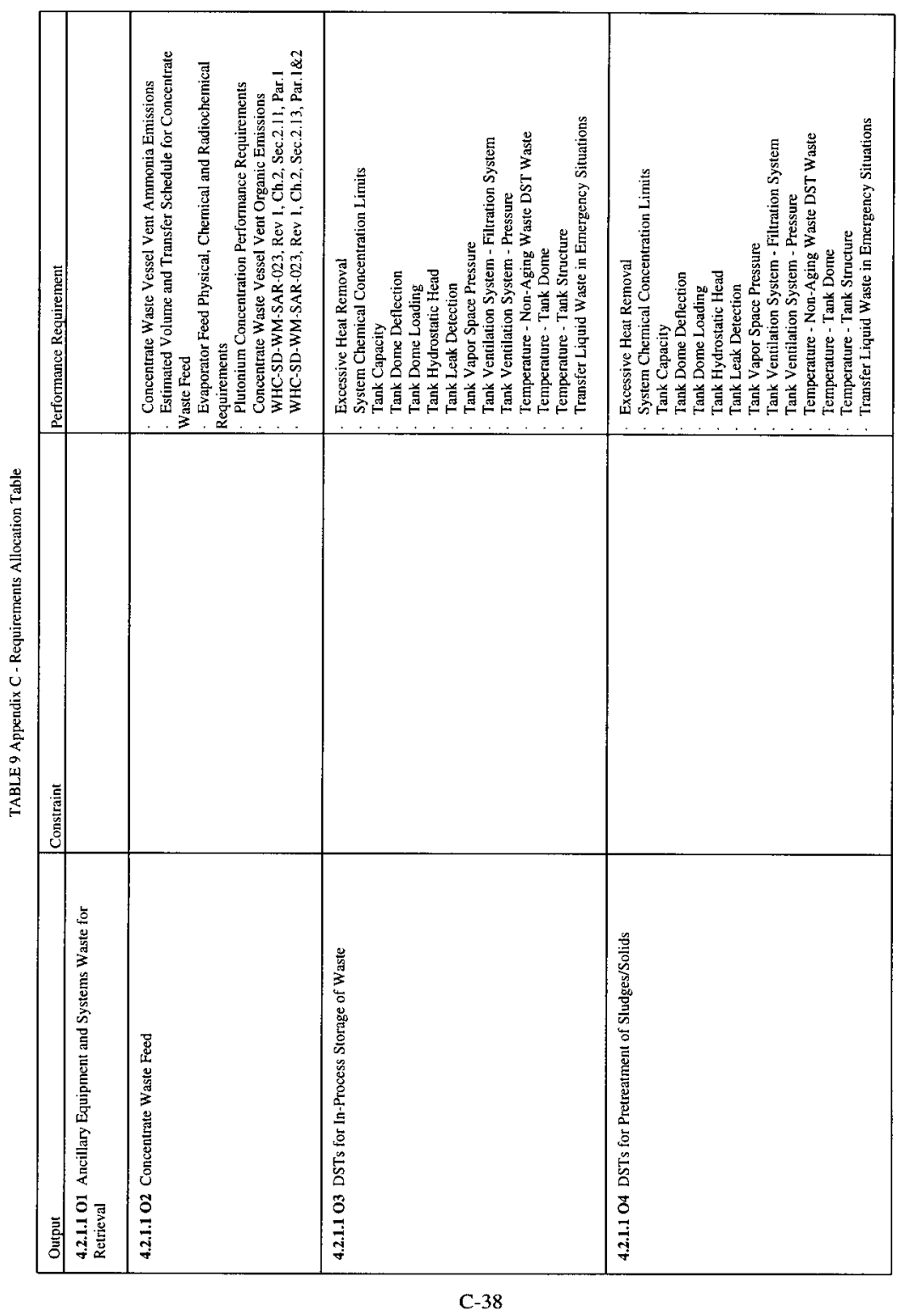




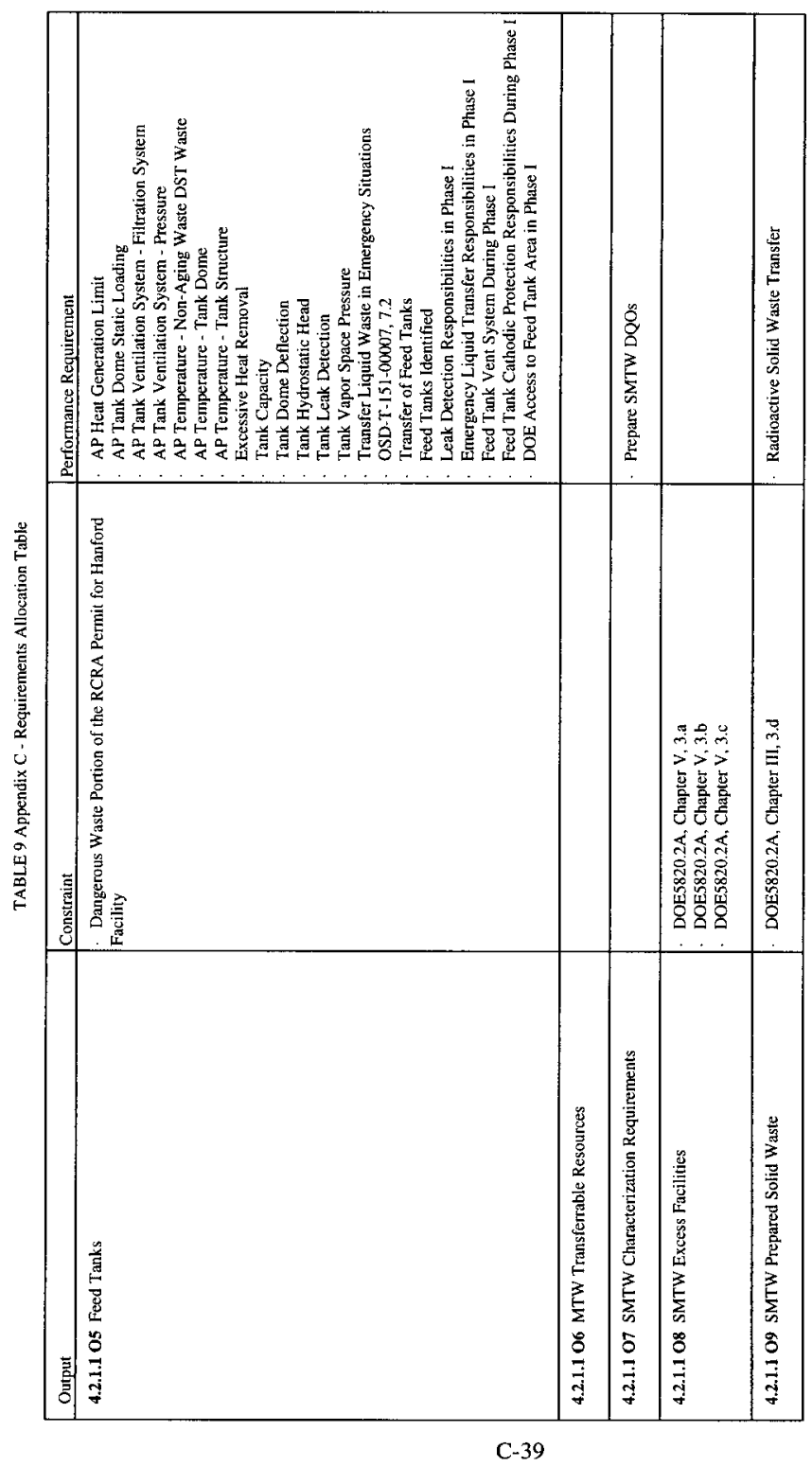




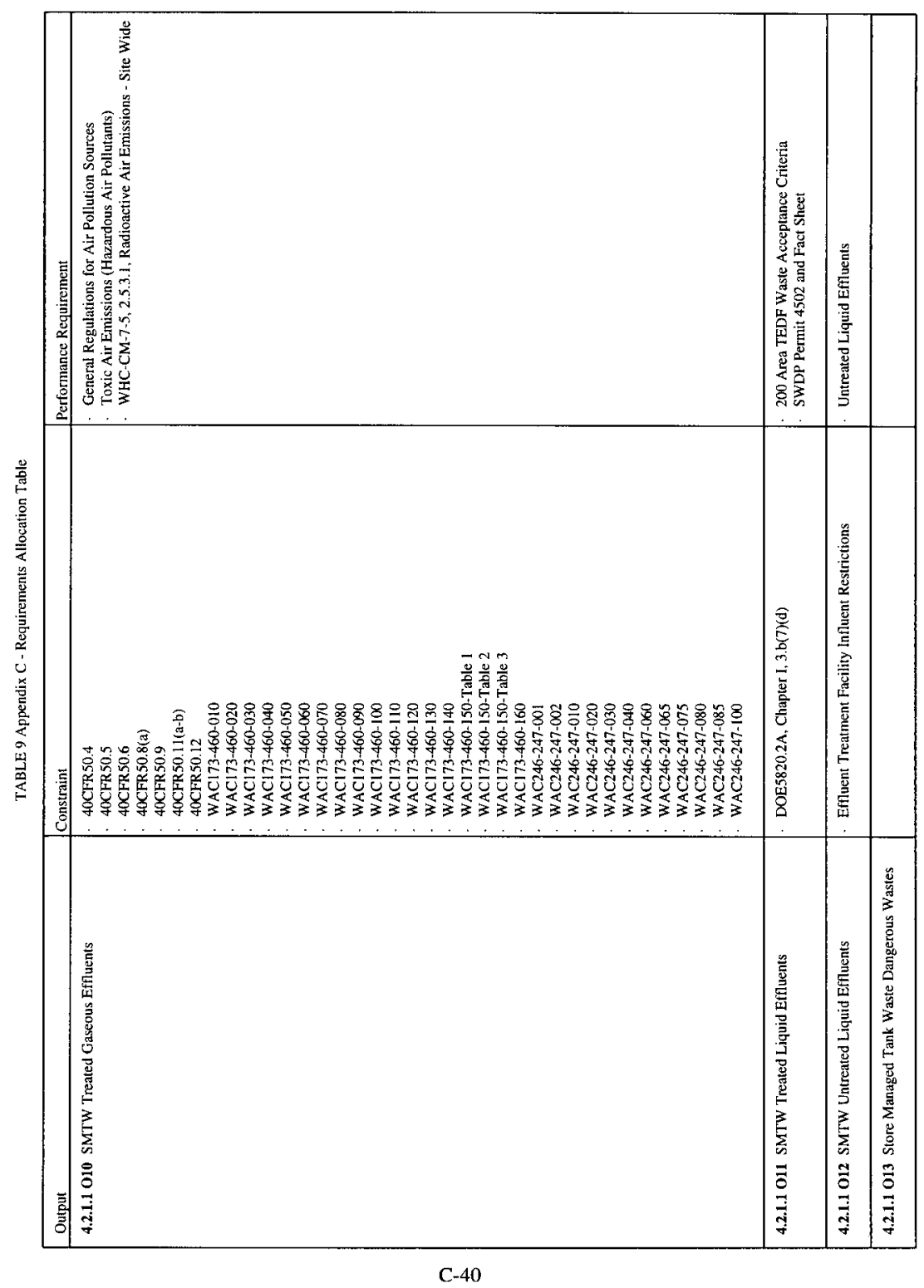




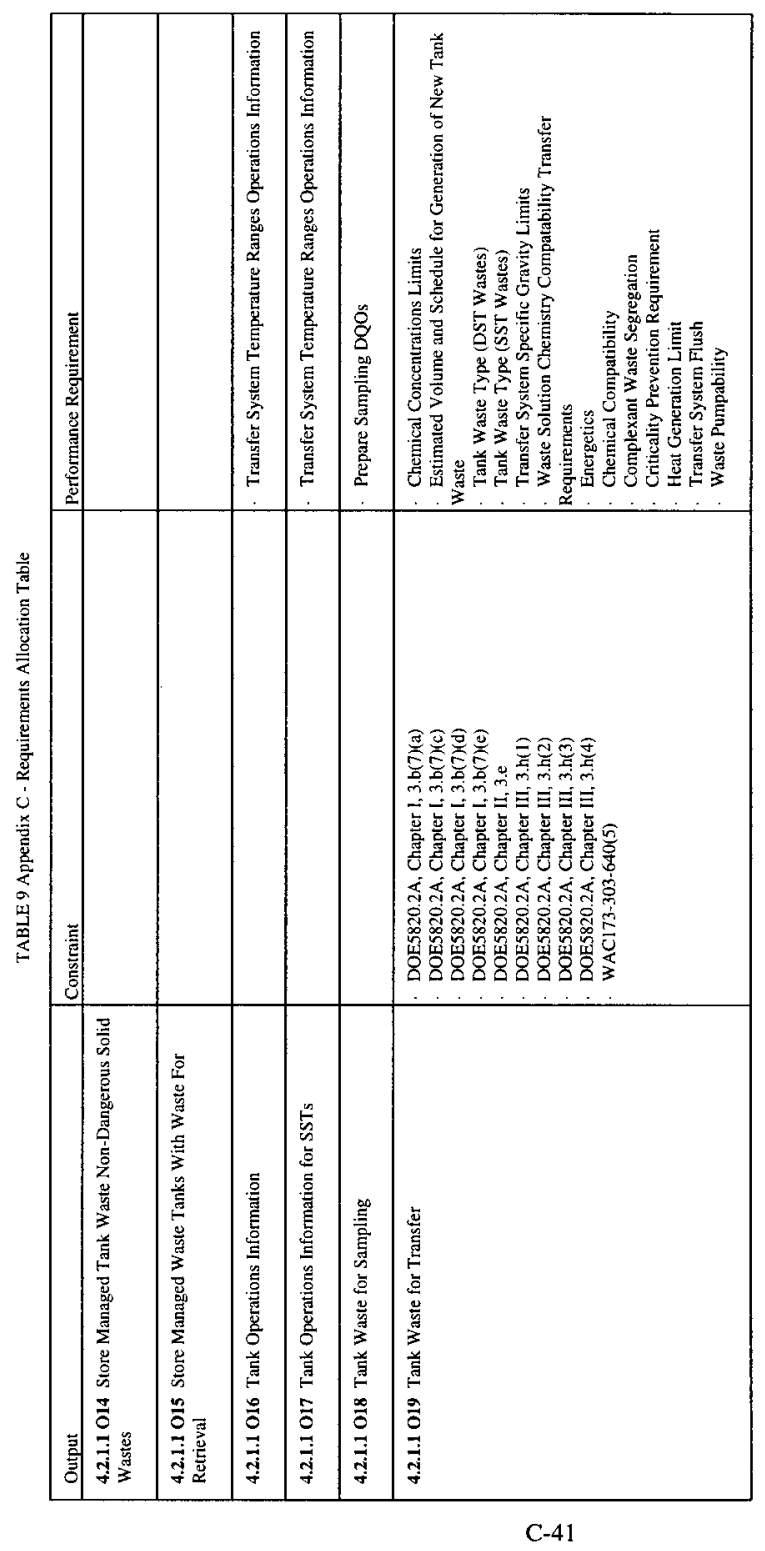


Revision 1 


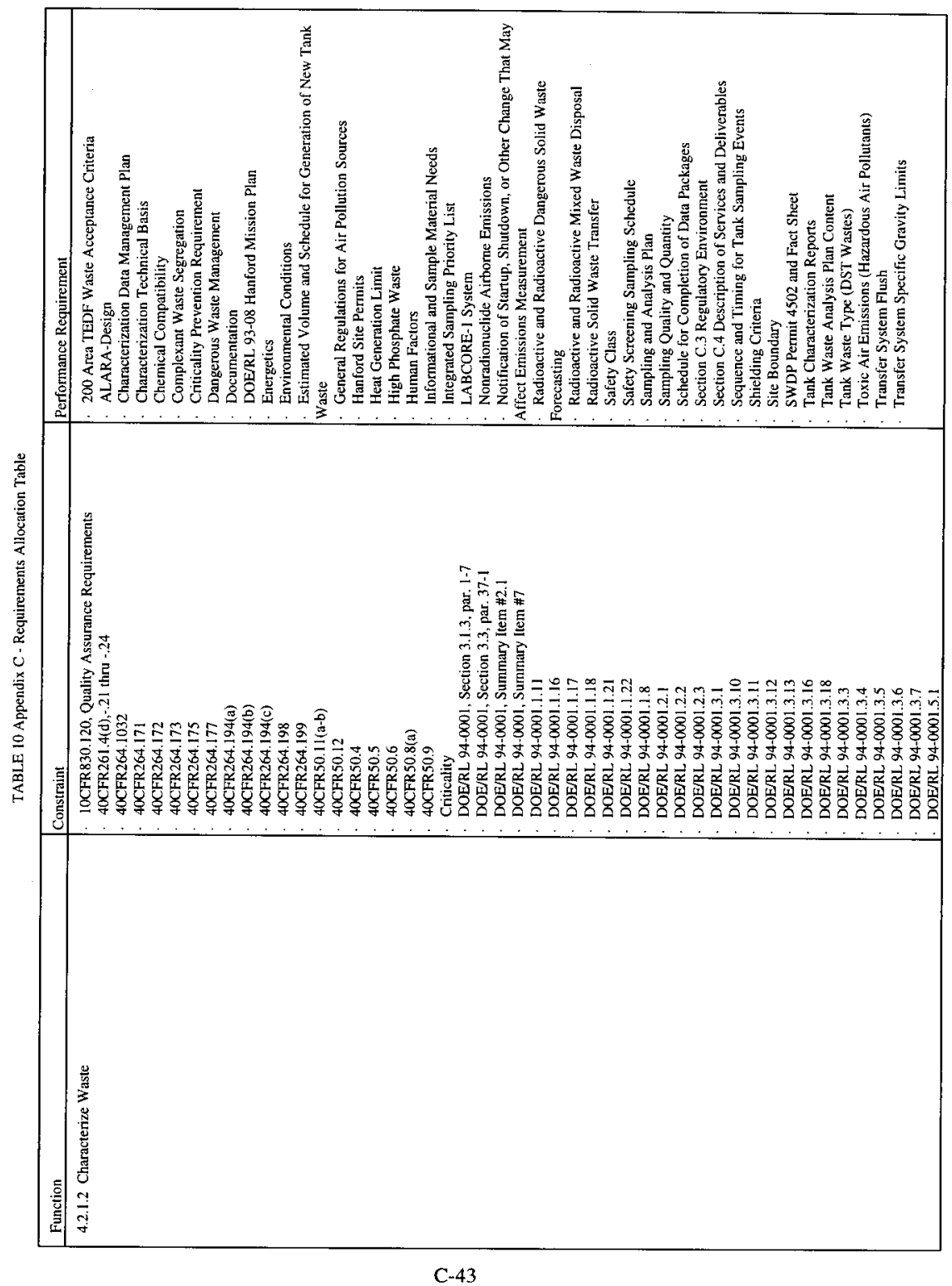




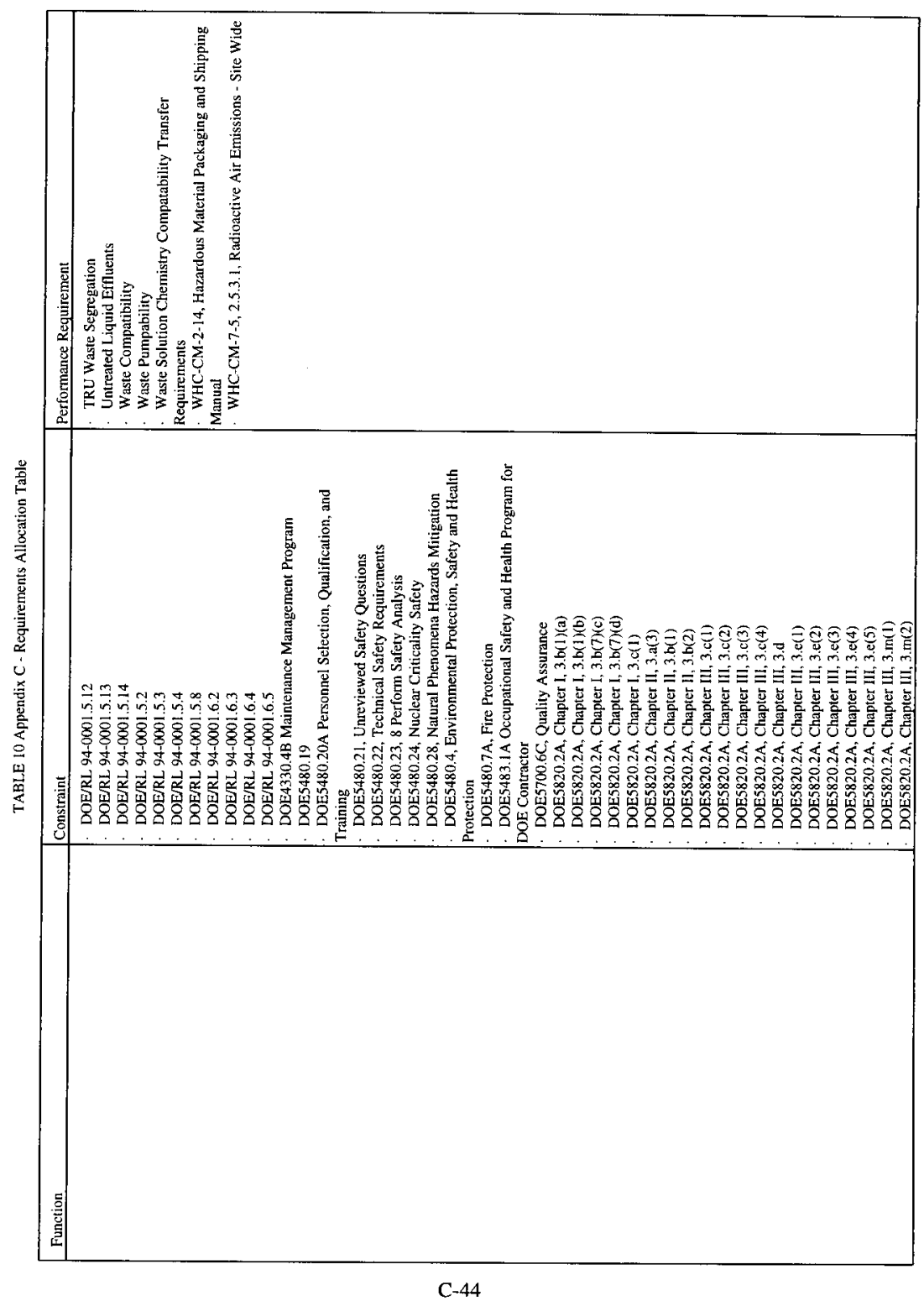




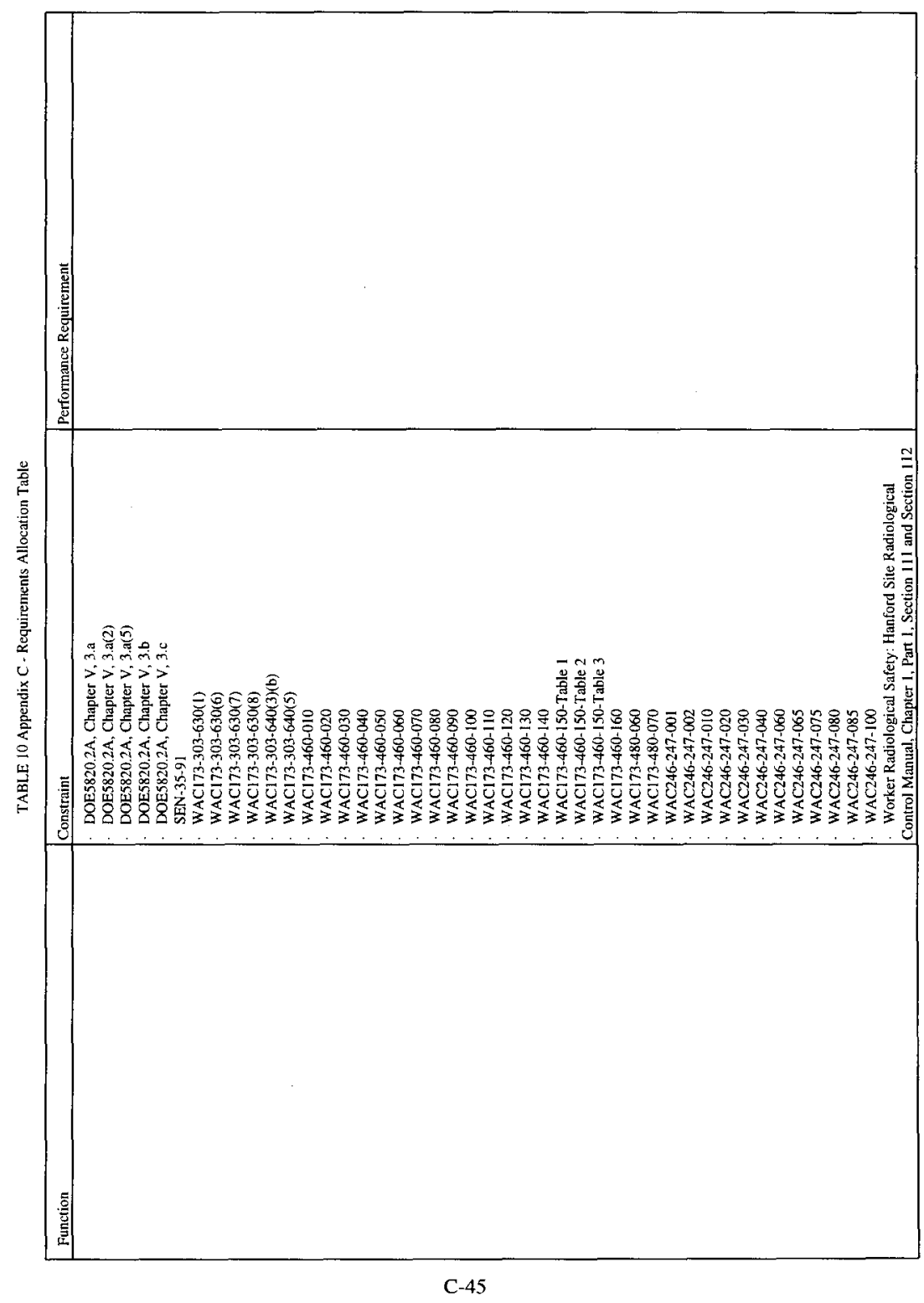


Revision 1

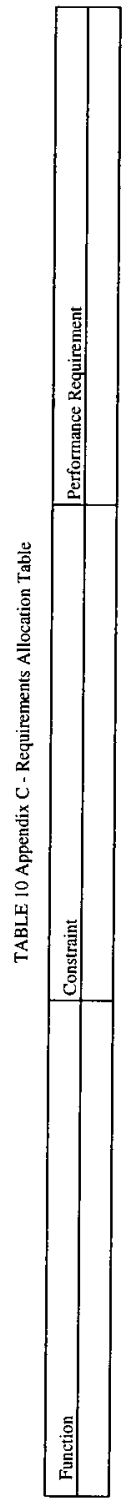

C-46 
Revision 1

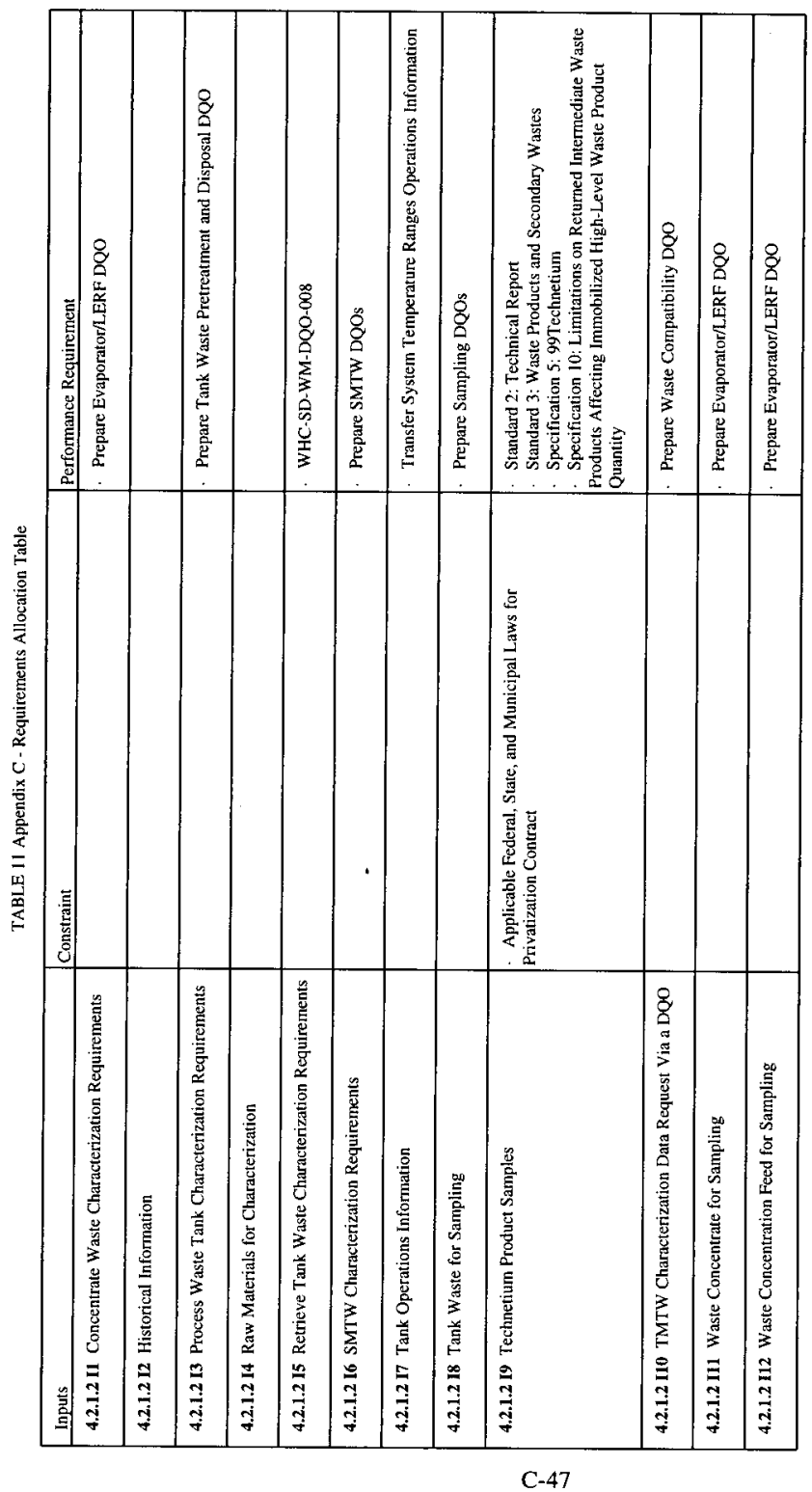




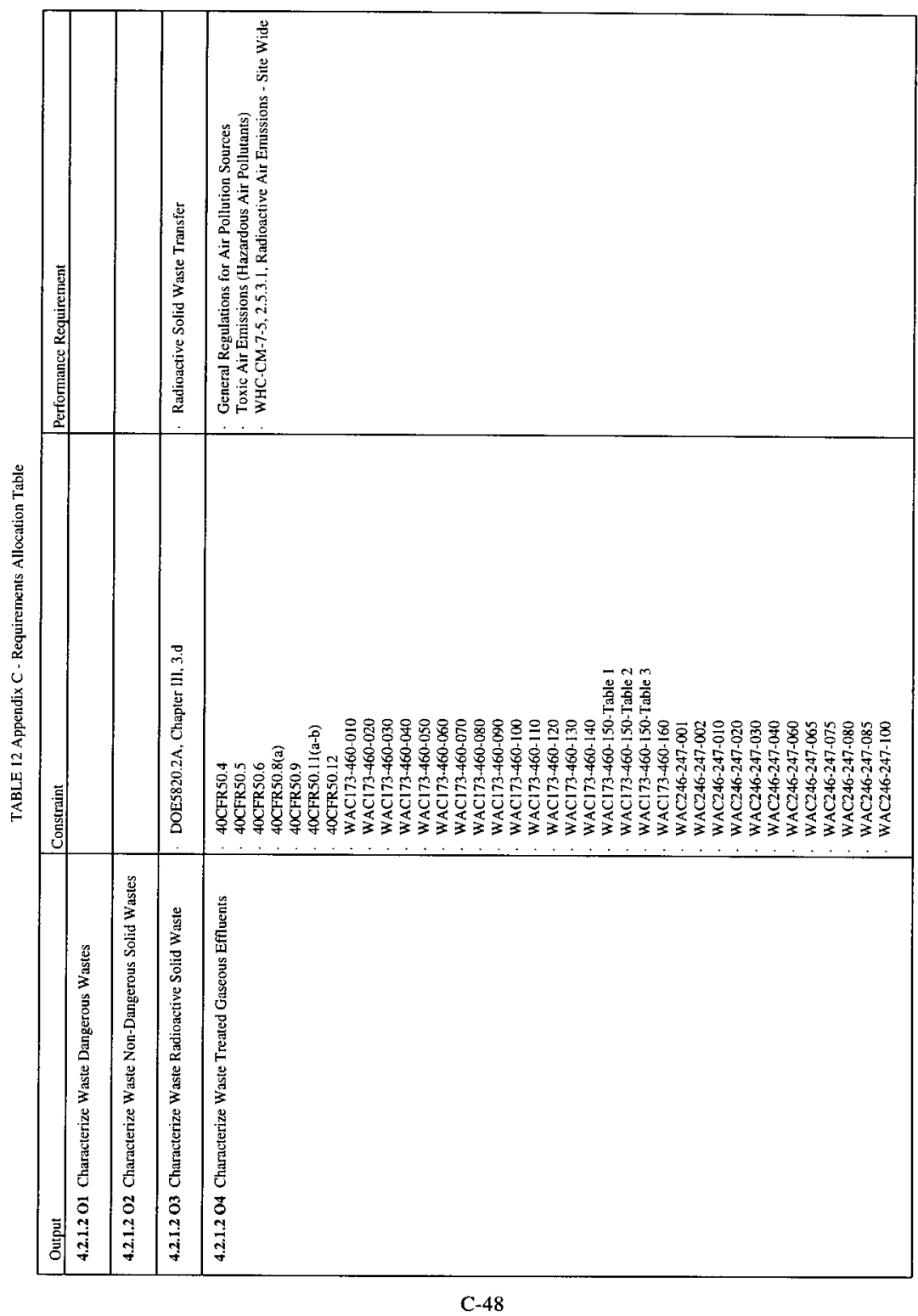


Revision 1

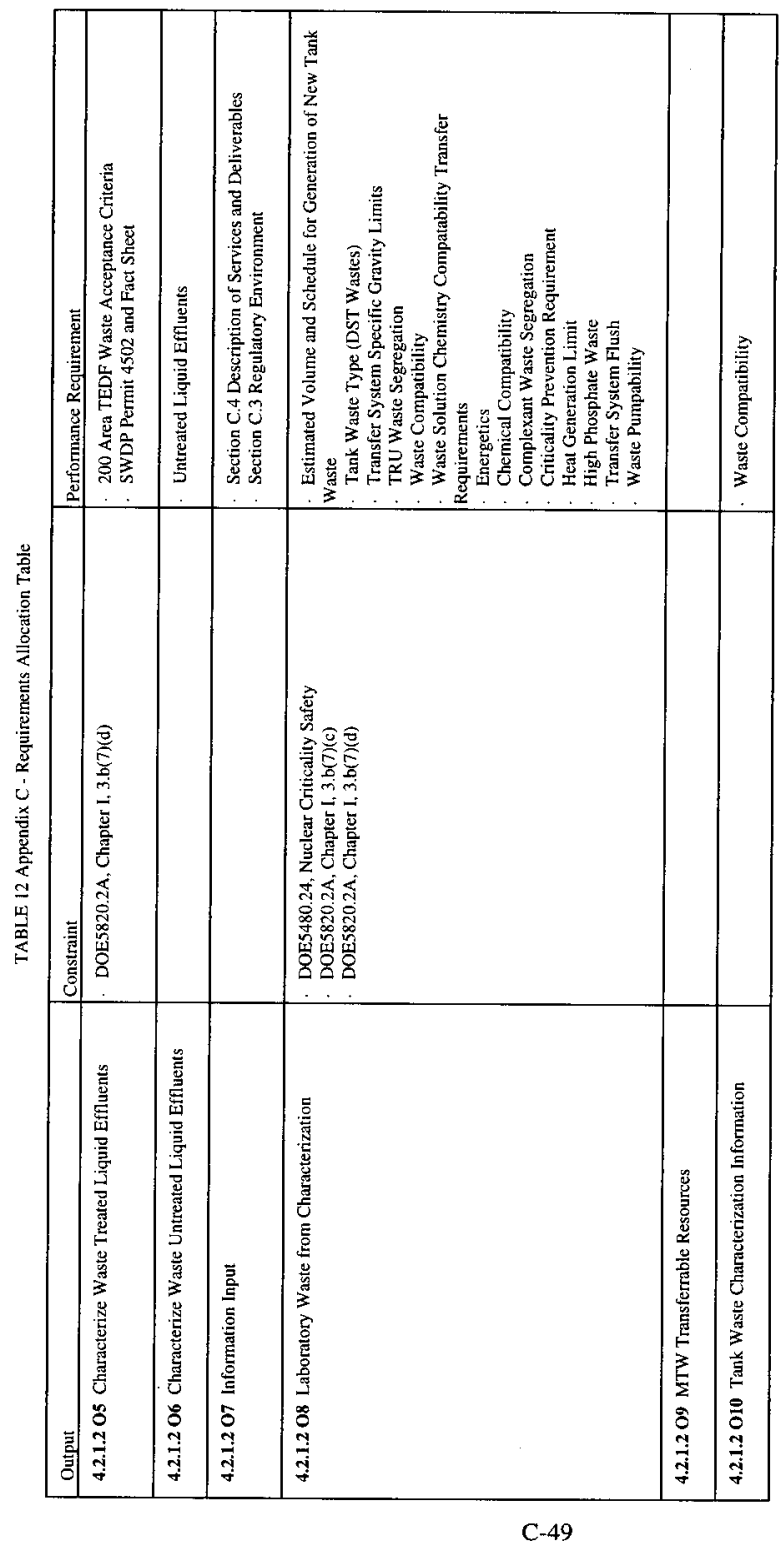


Revision 1 


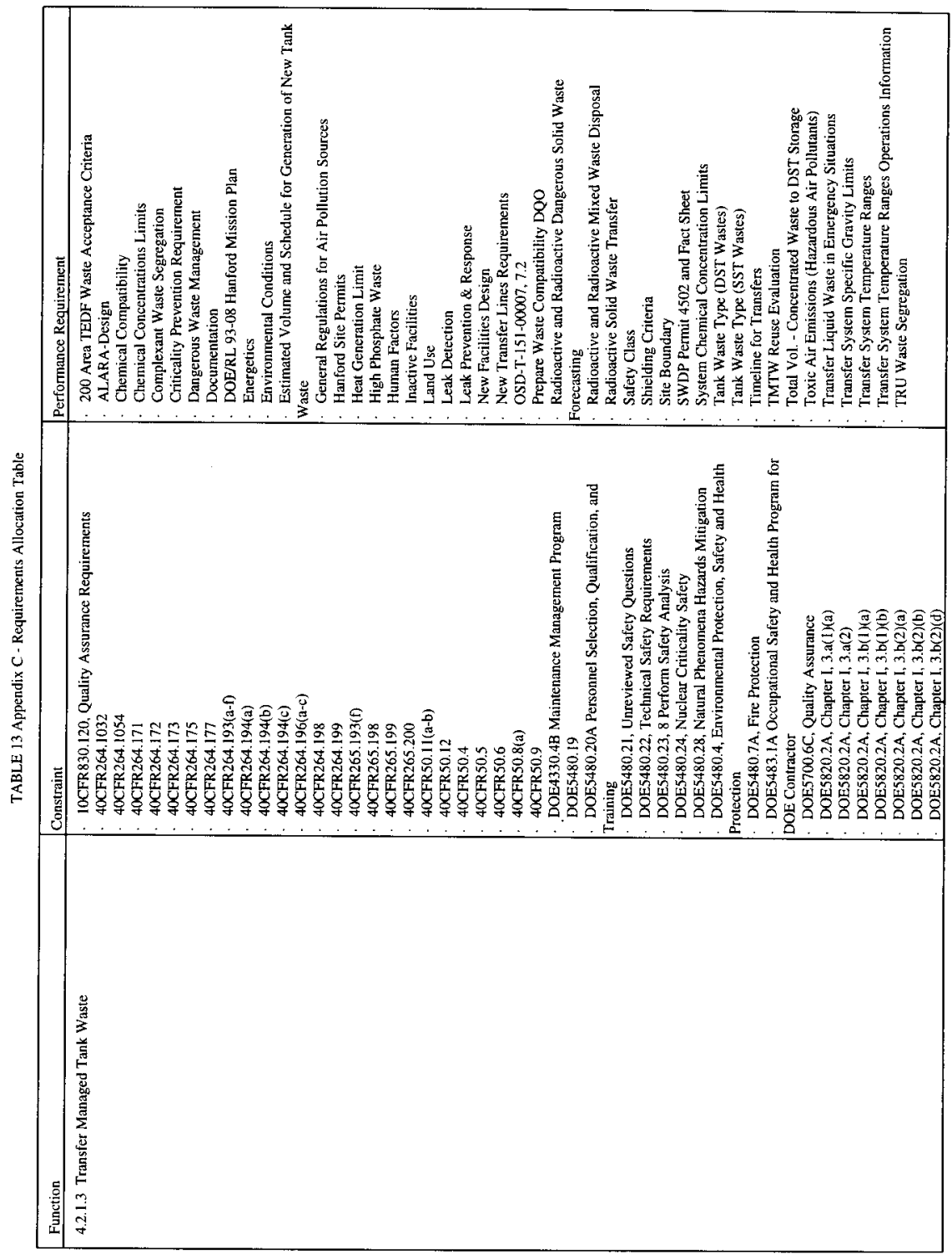




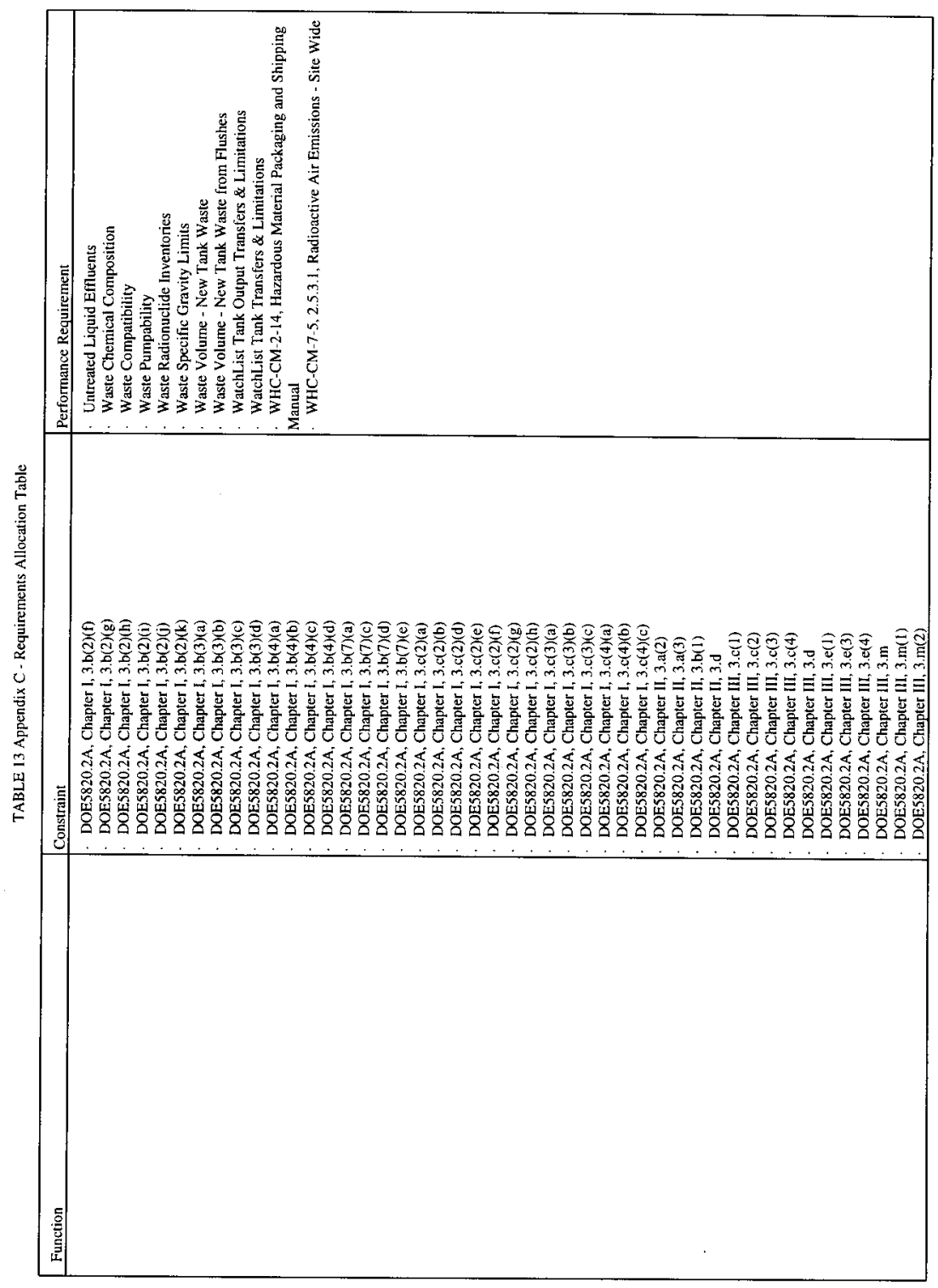




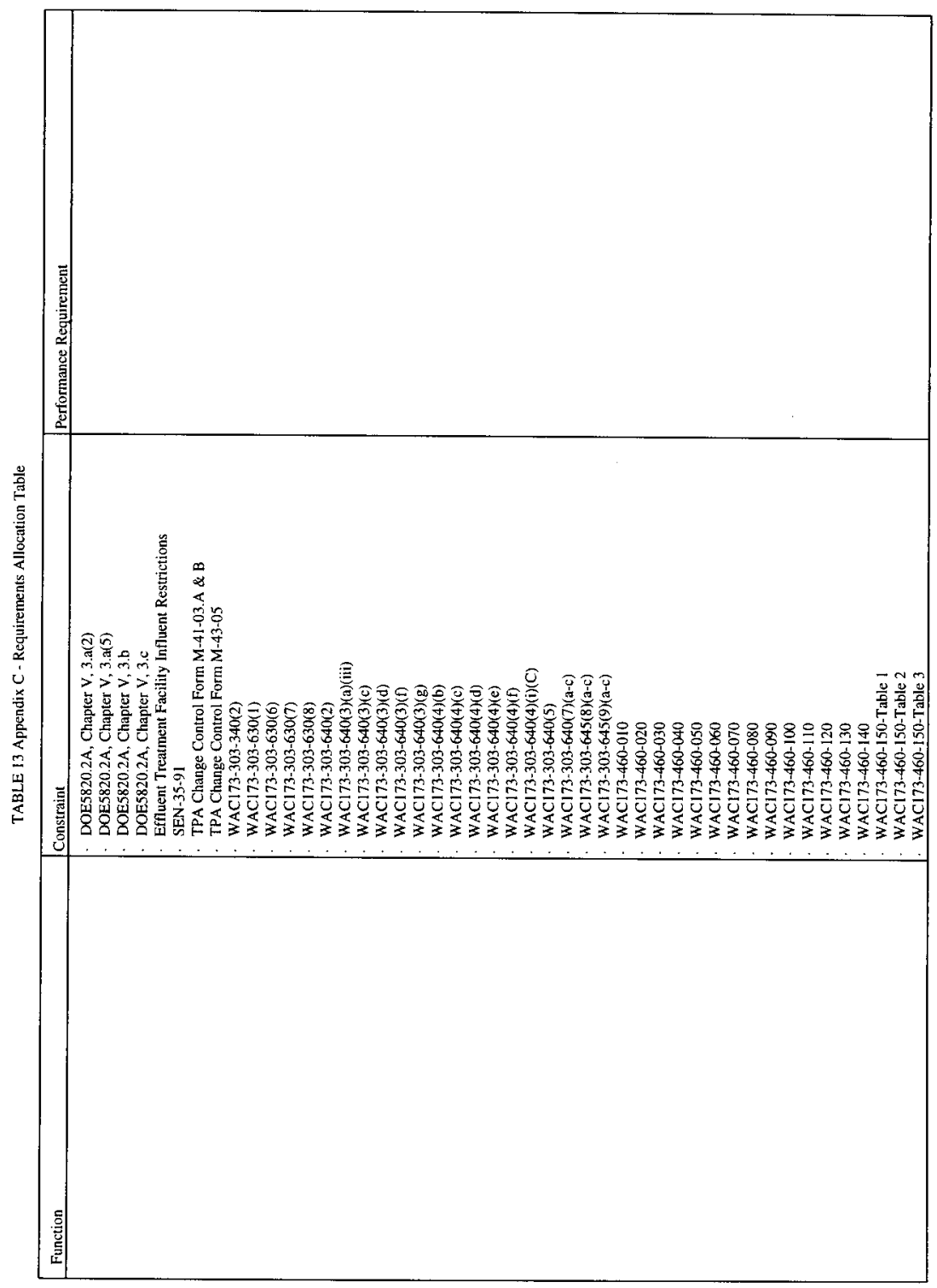




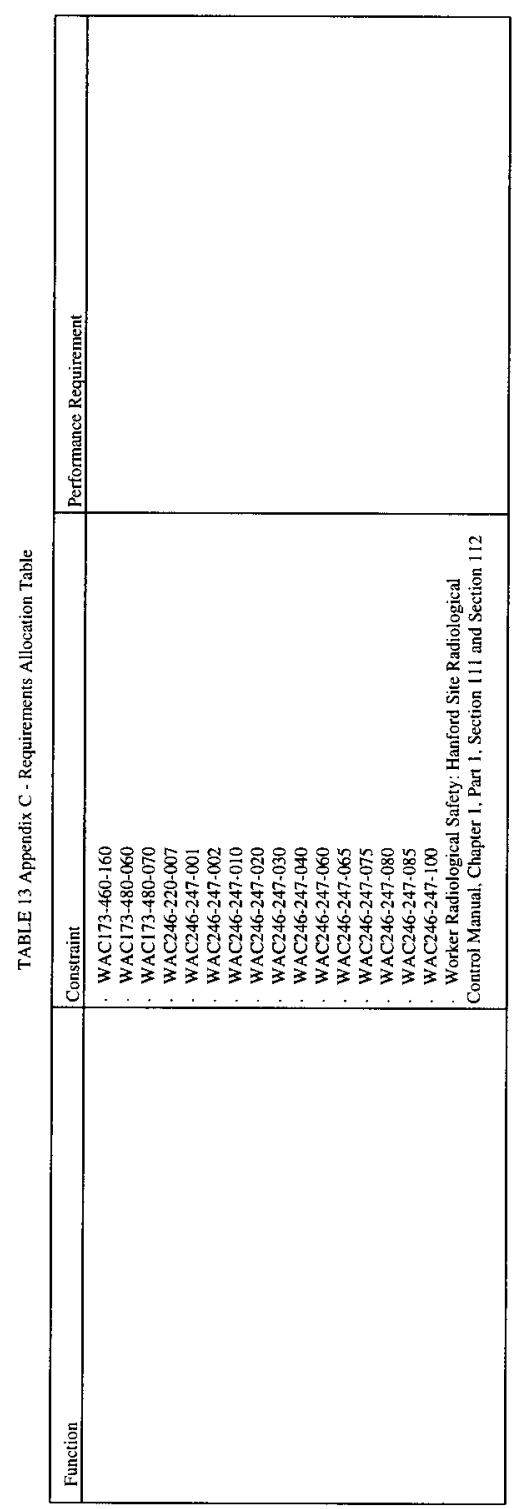




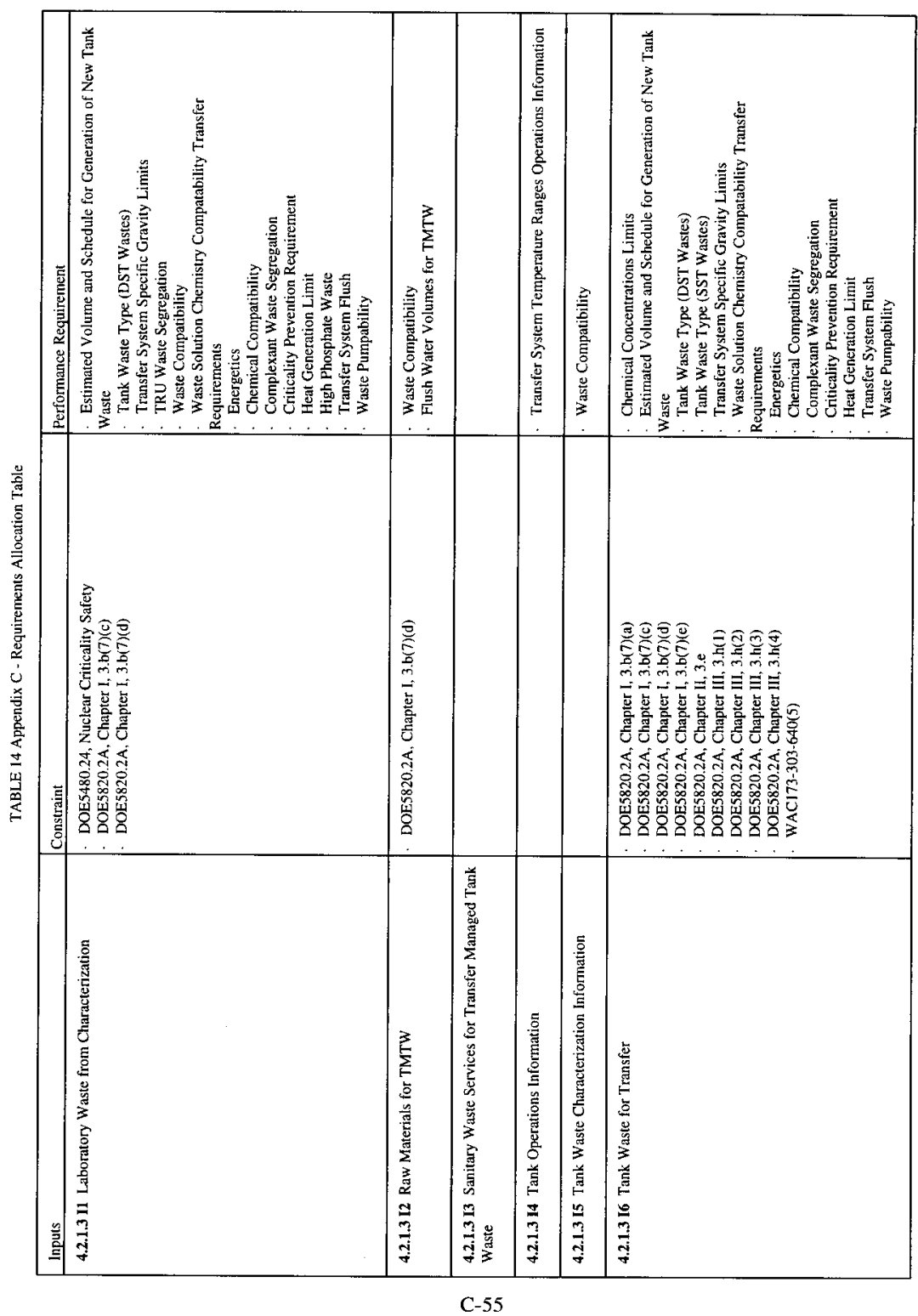


Revision 1

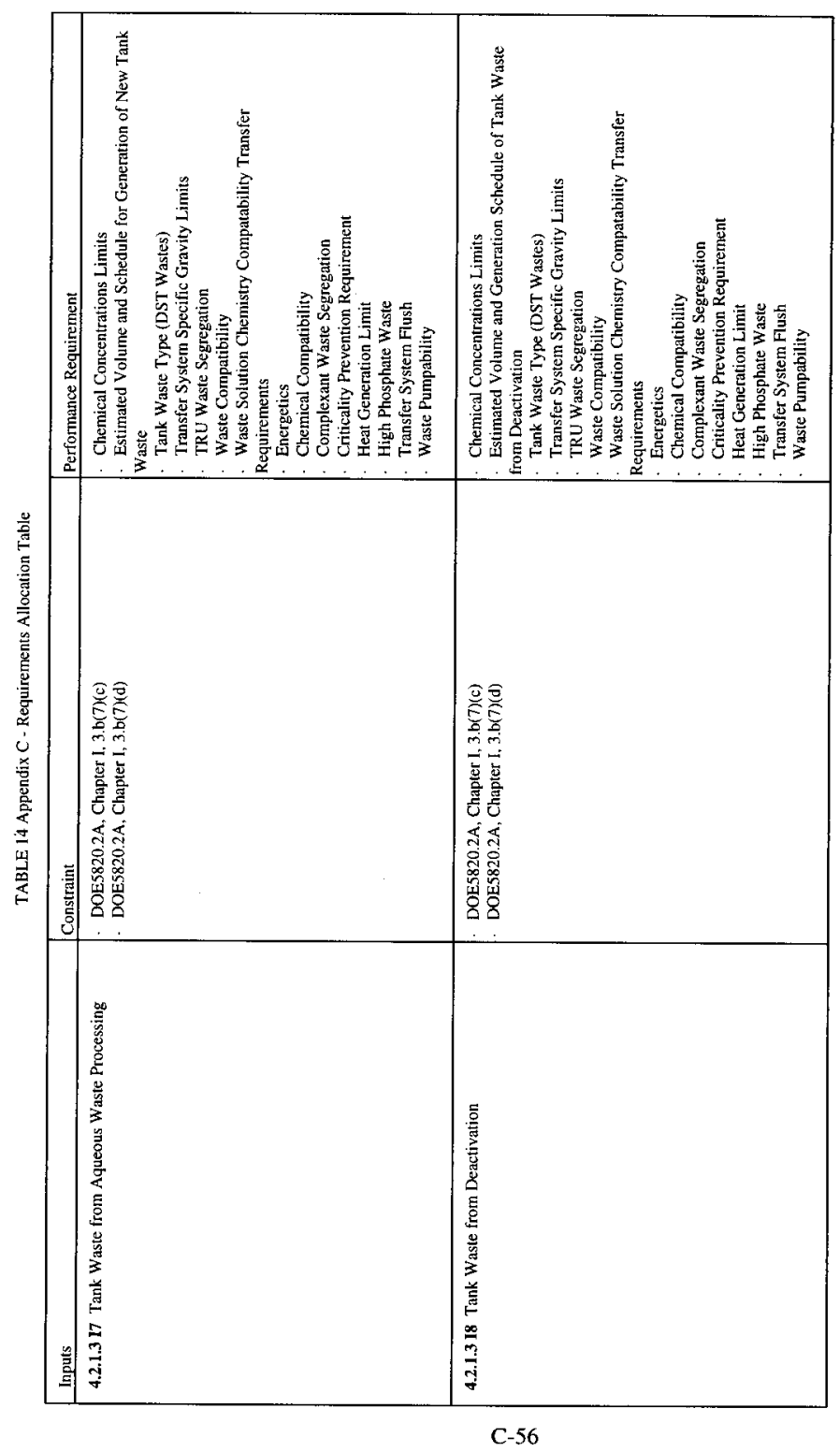


Revision 1

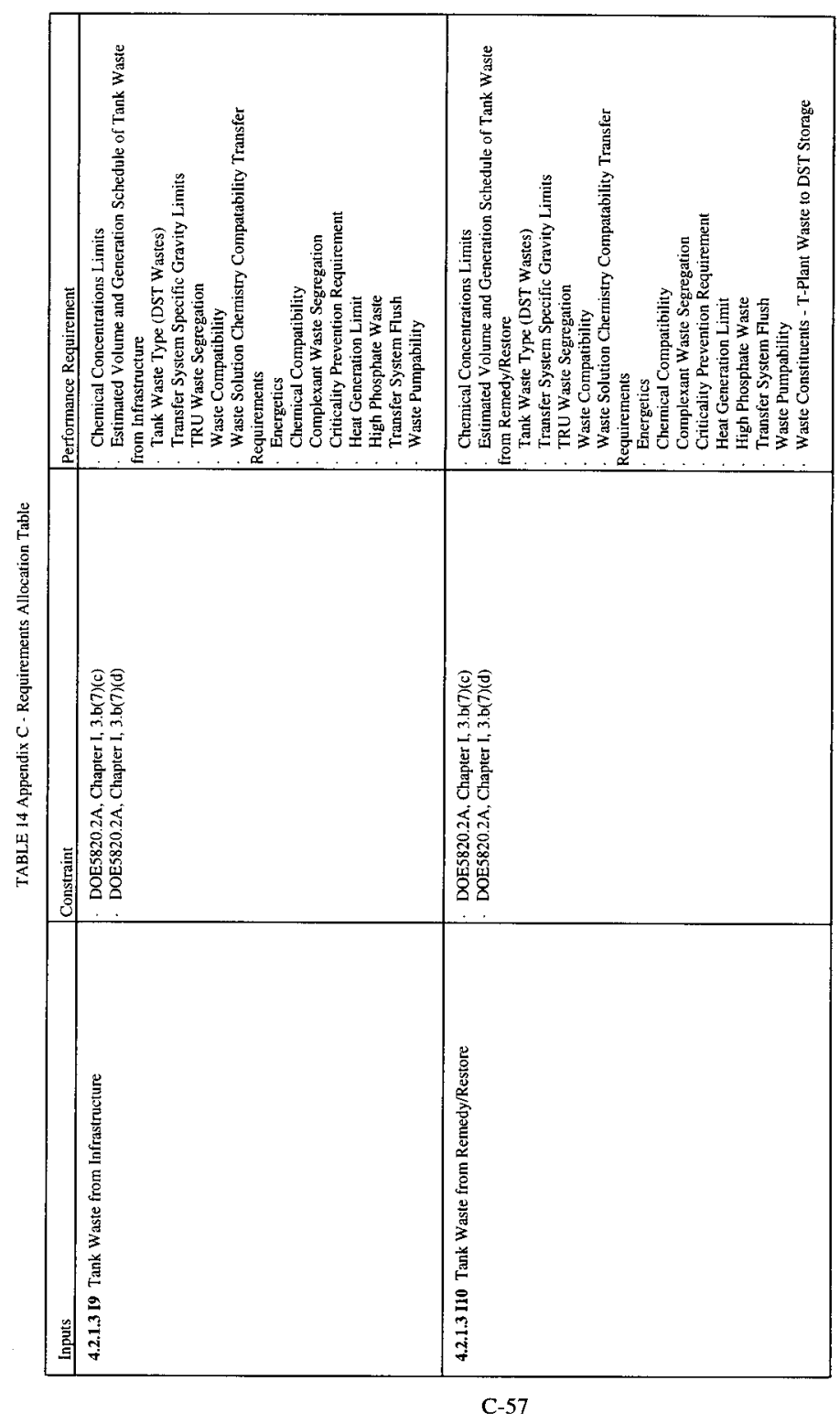




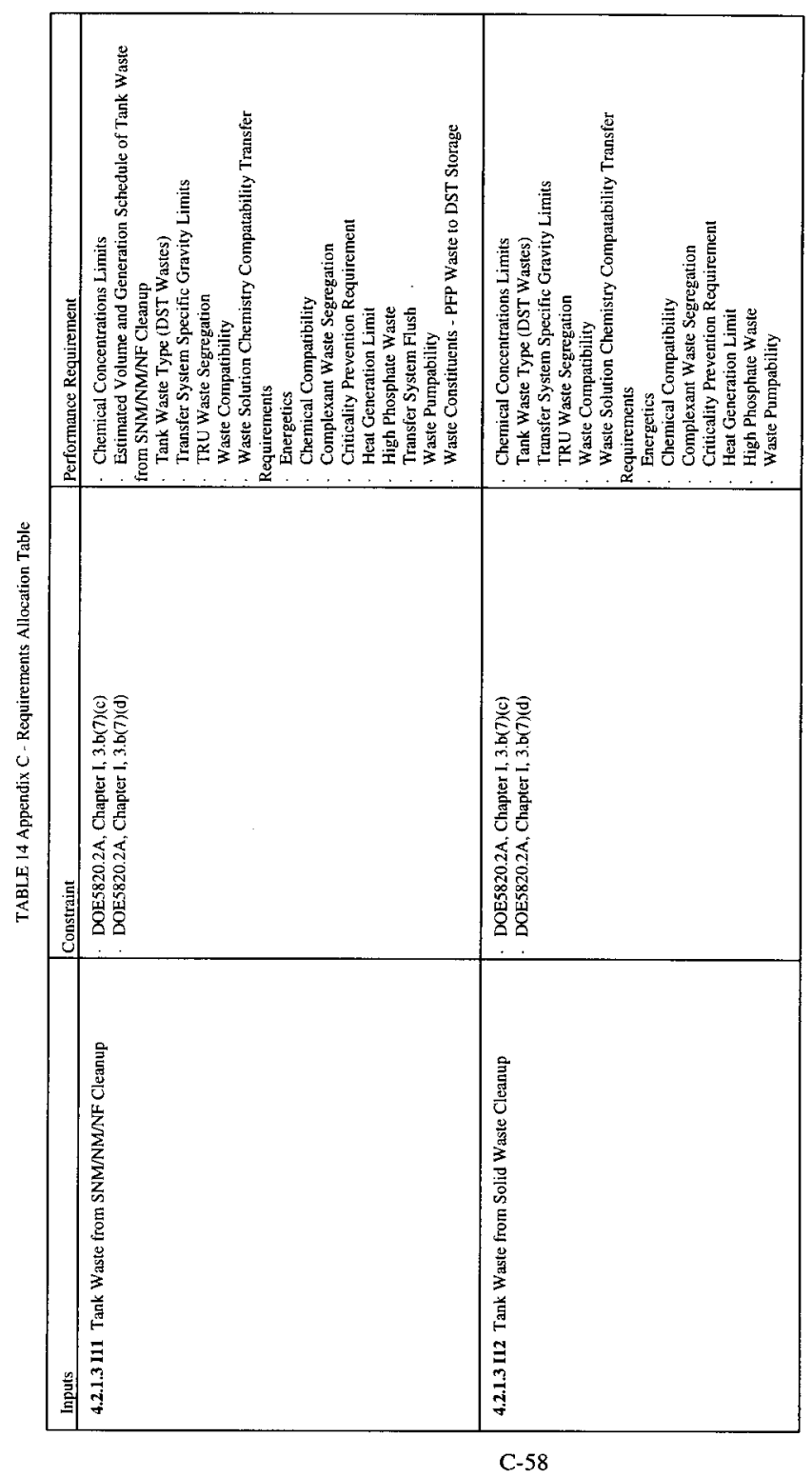




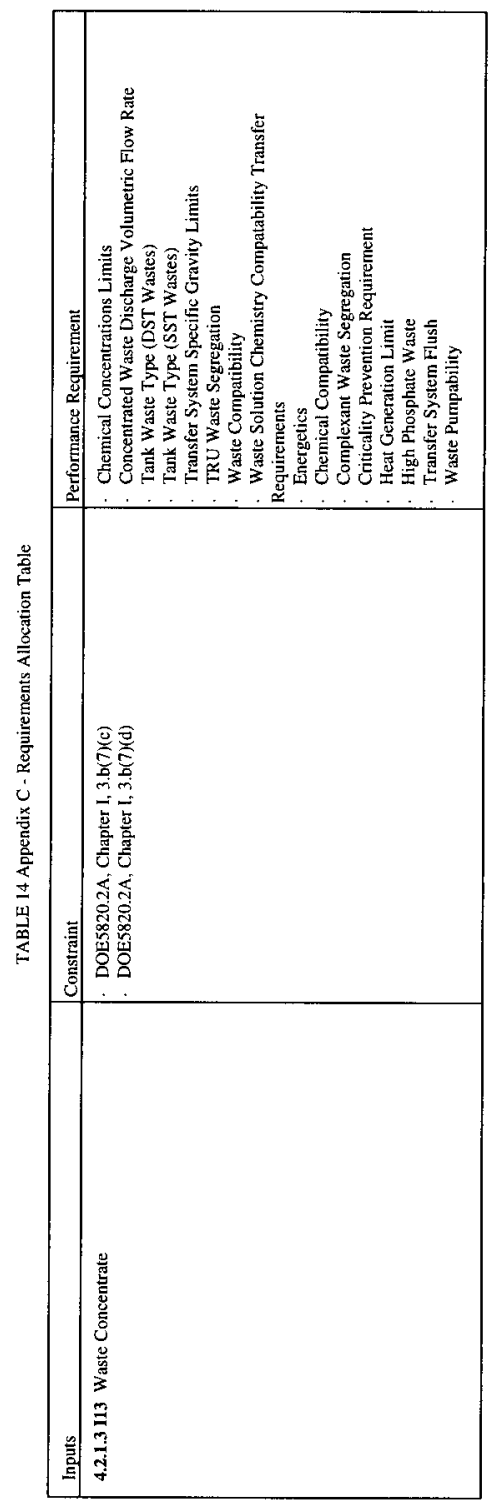


Revision 1

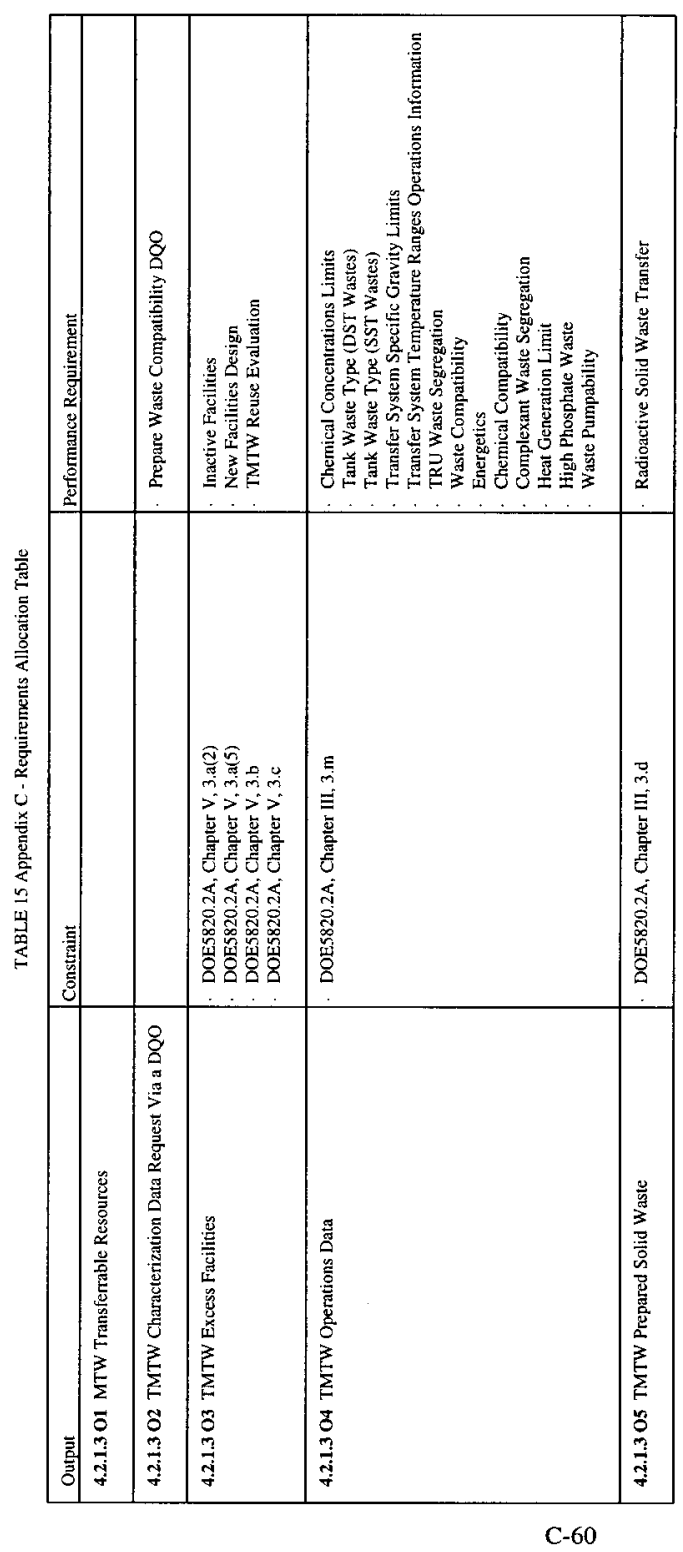


Revision 1

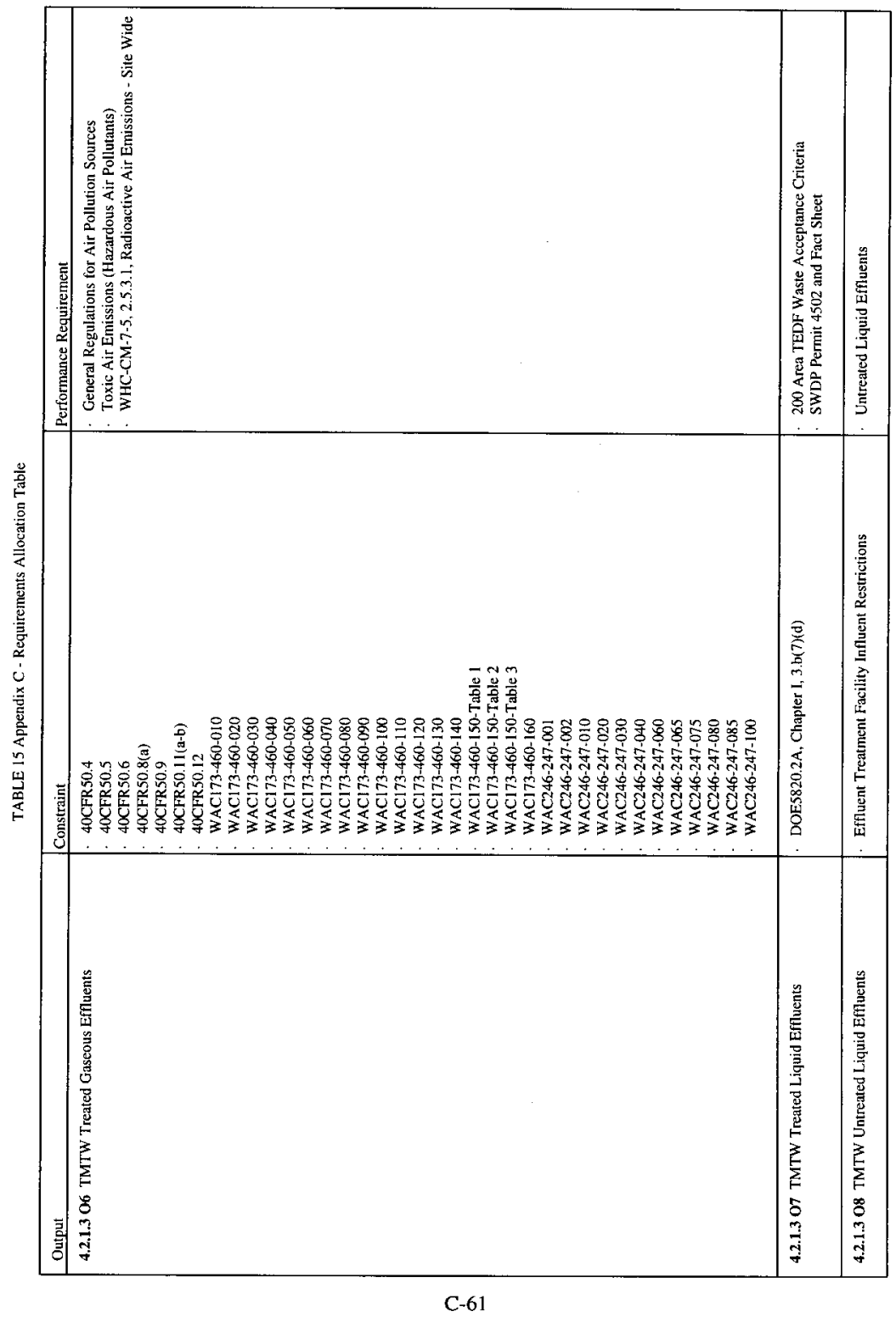


Revision 1

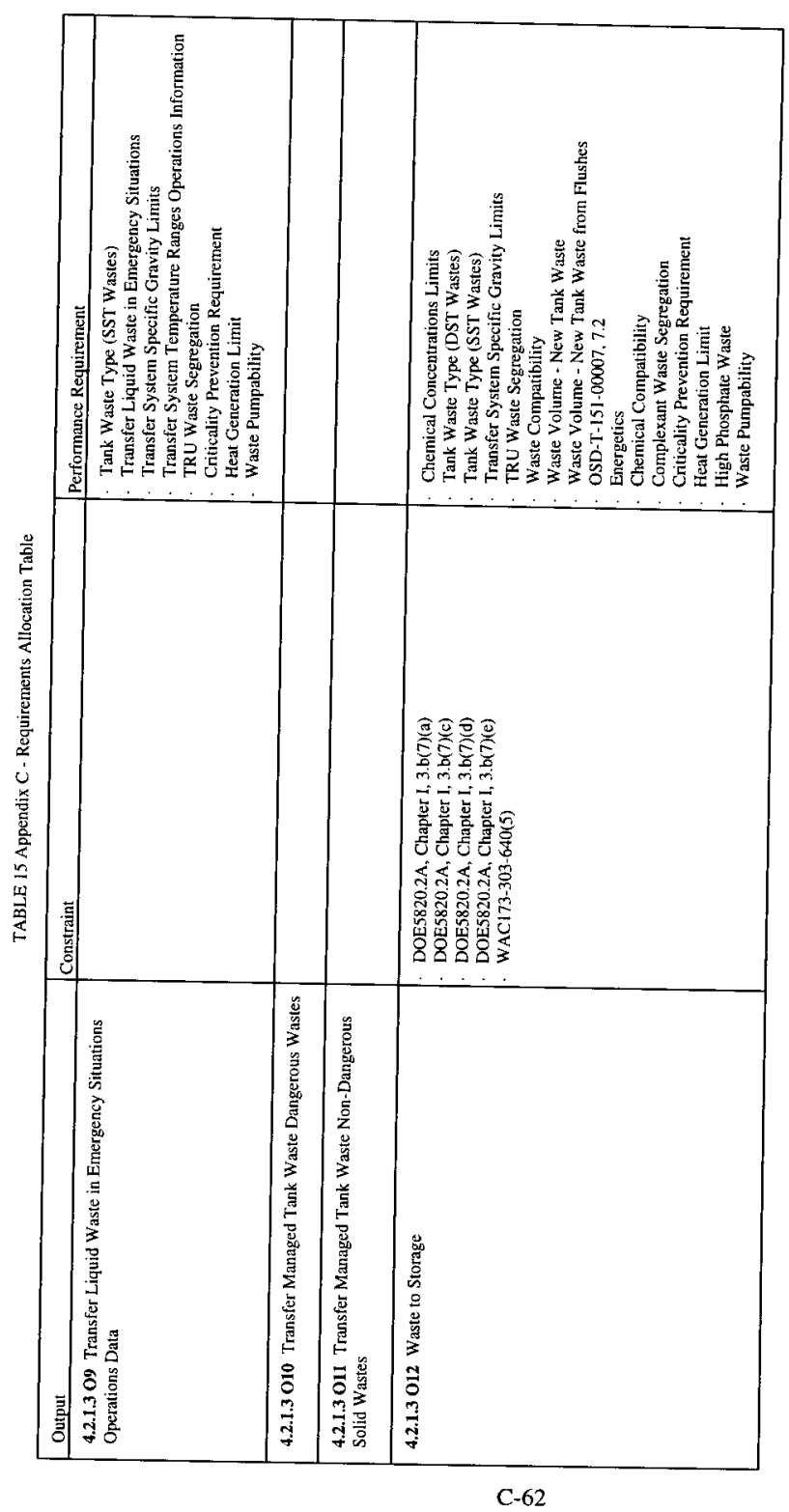


Revision 1

C-63 


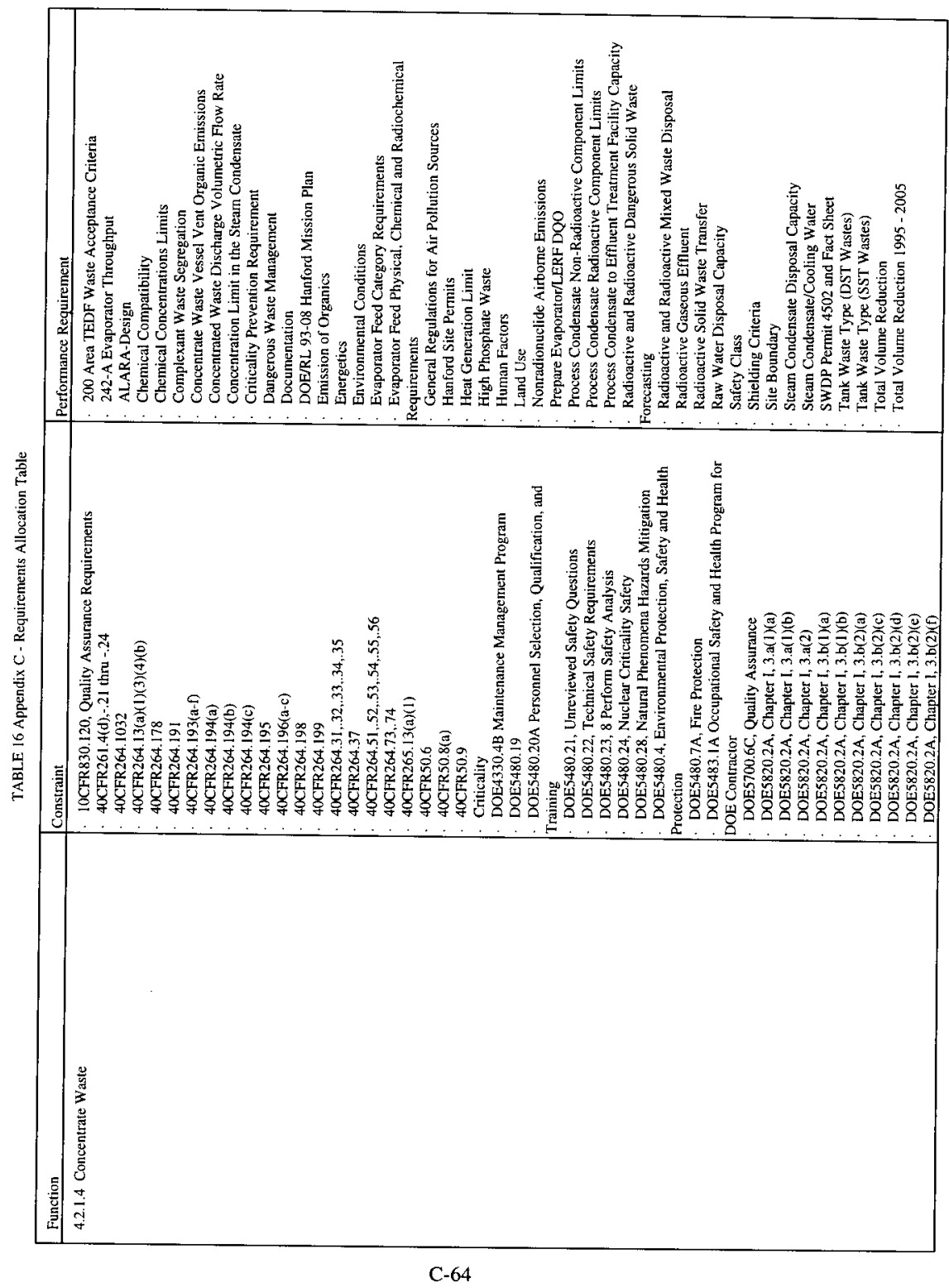




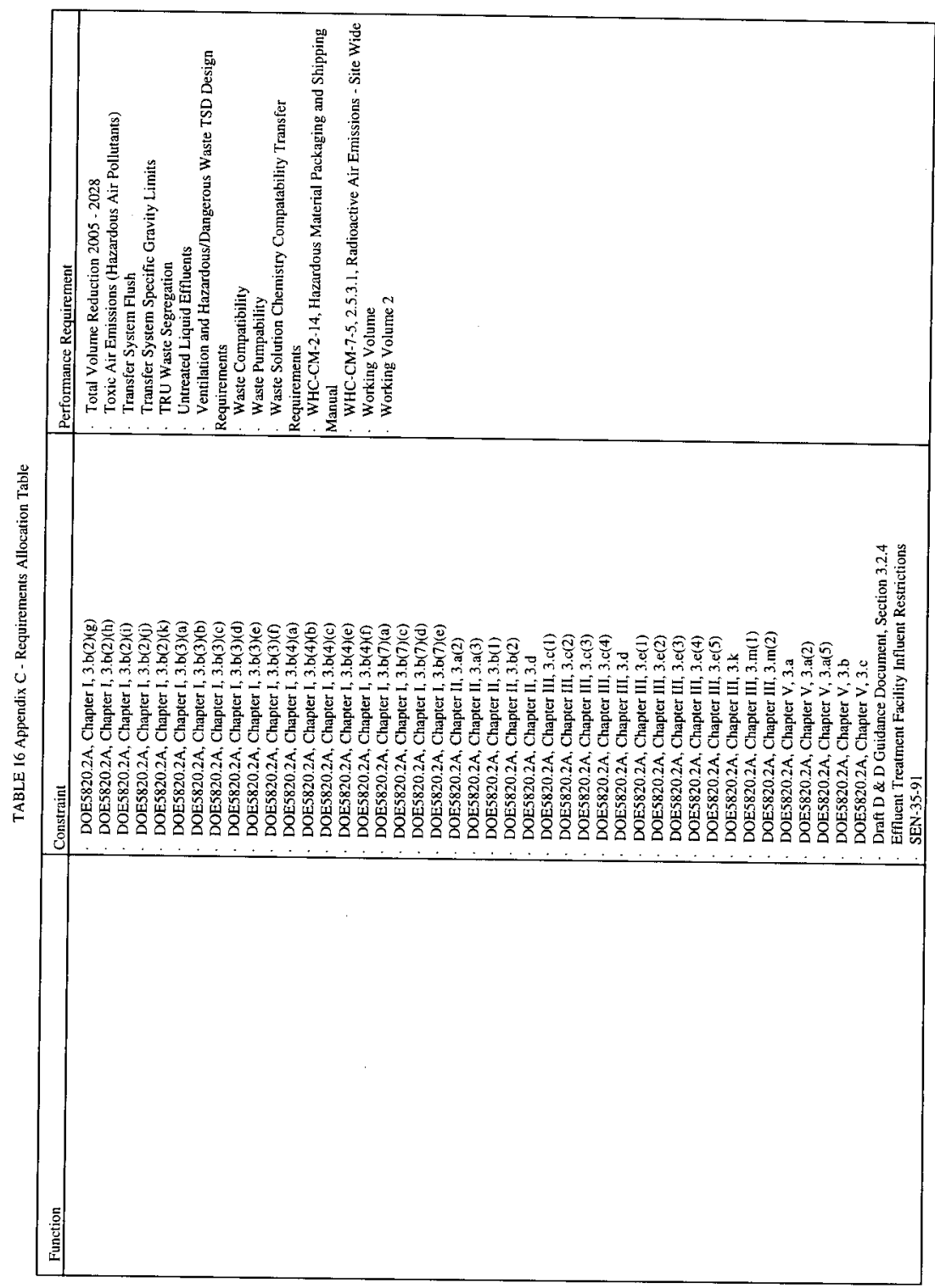




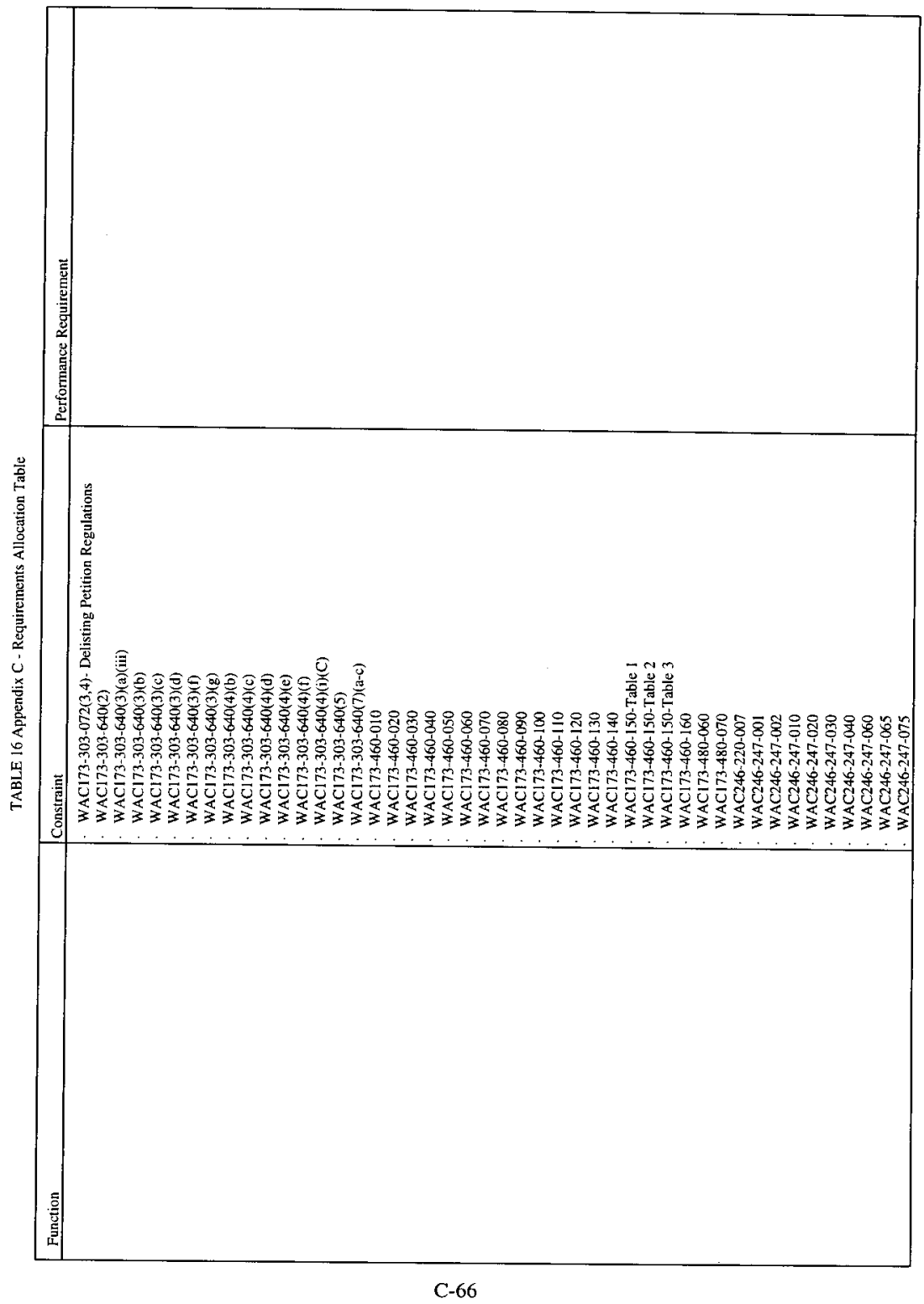


Revision 1

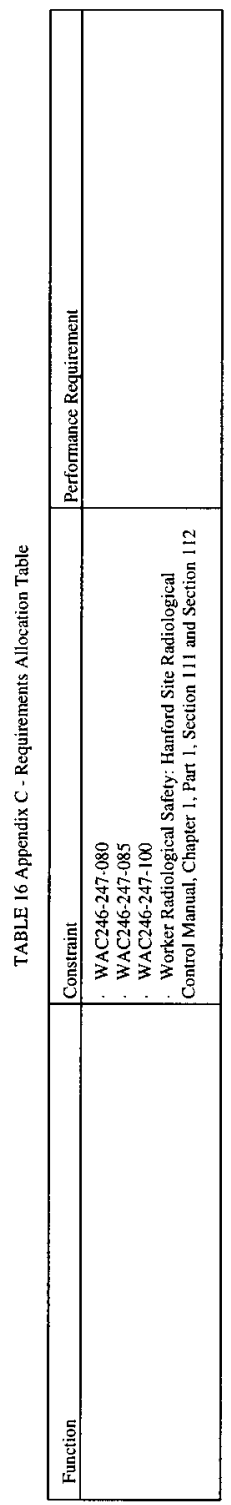




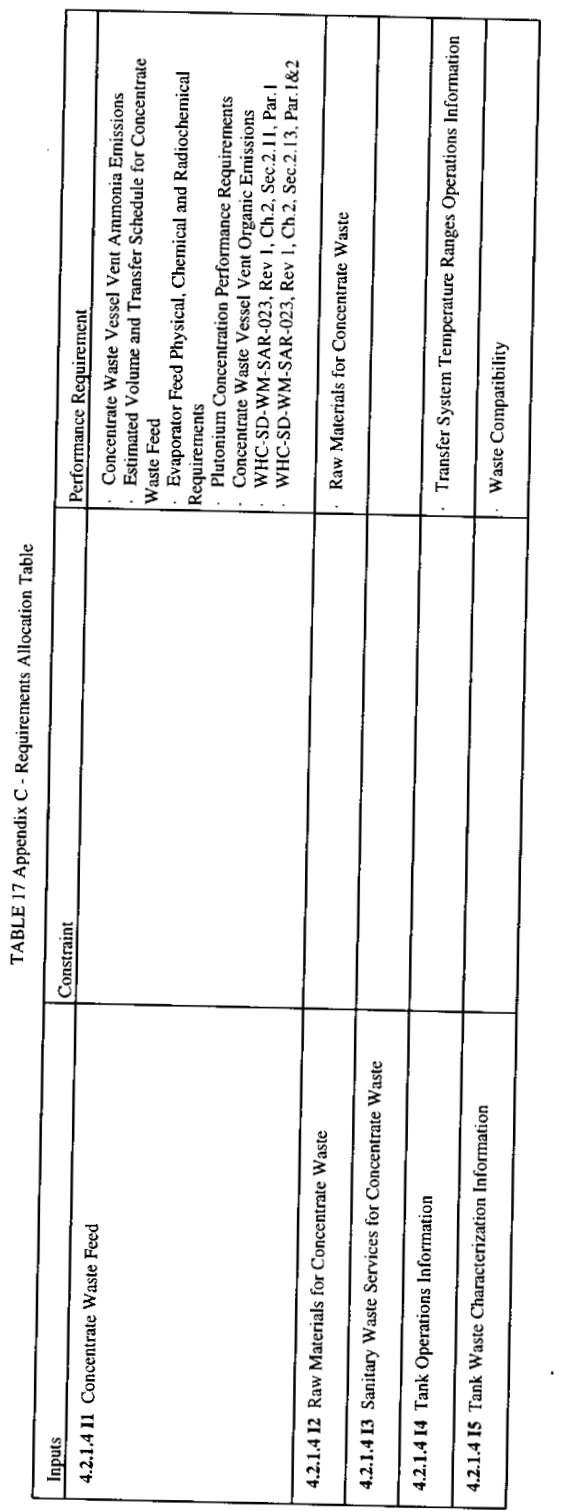




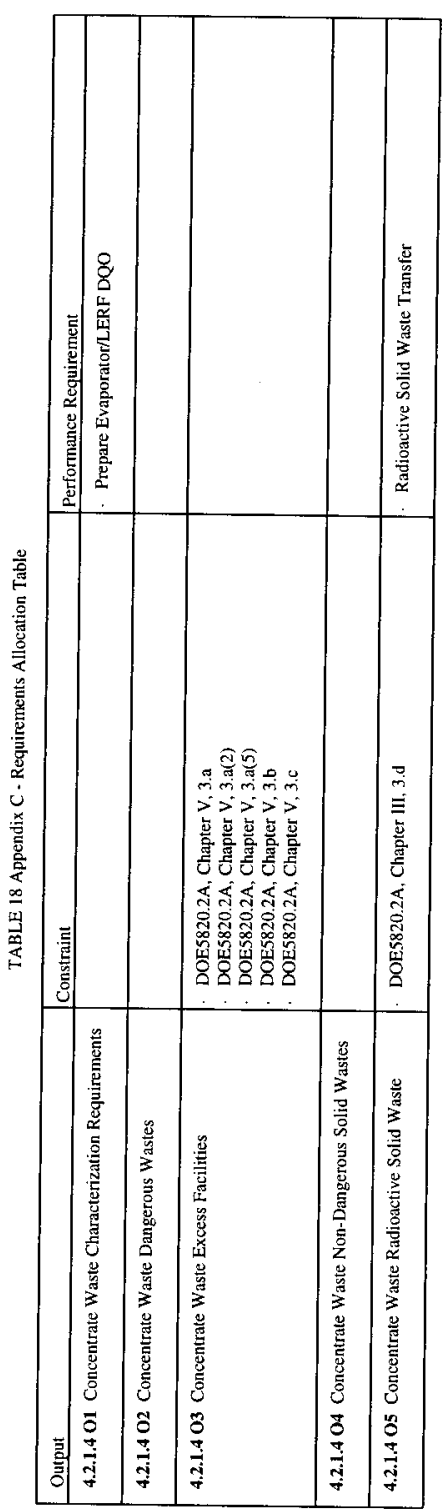




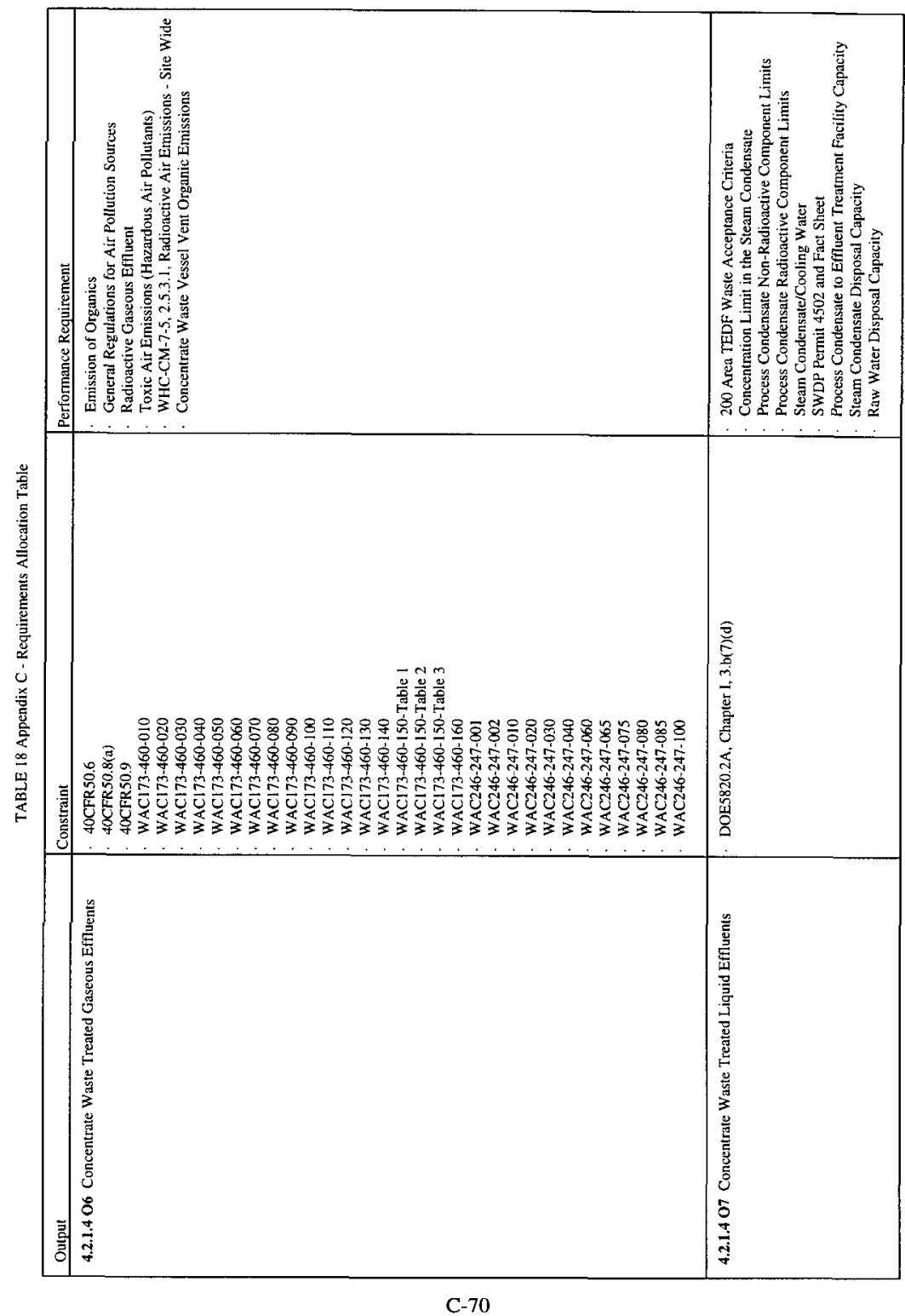




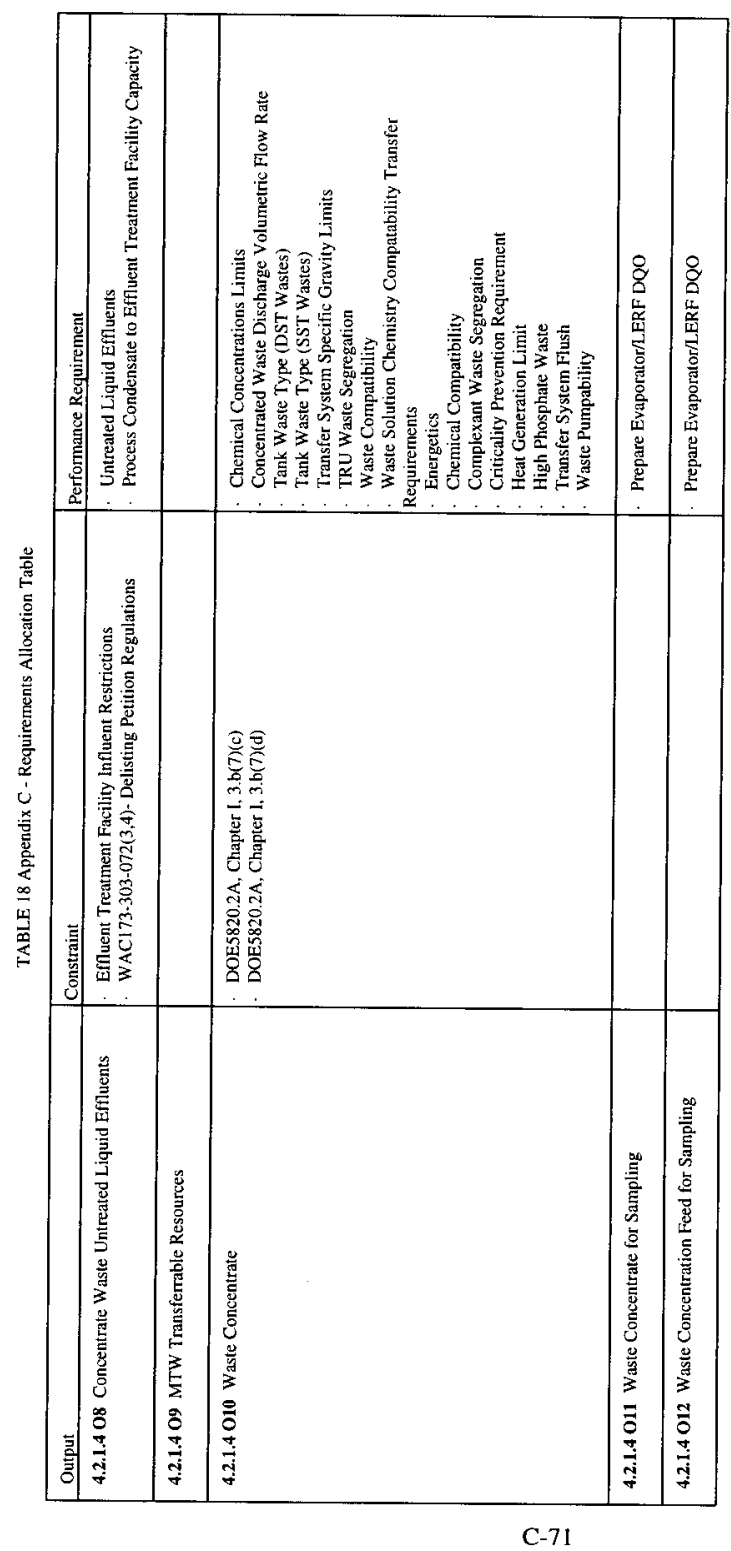


Revision 1

C-72 


\section{Revision 1}

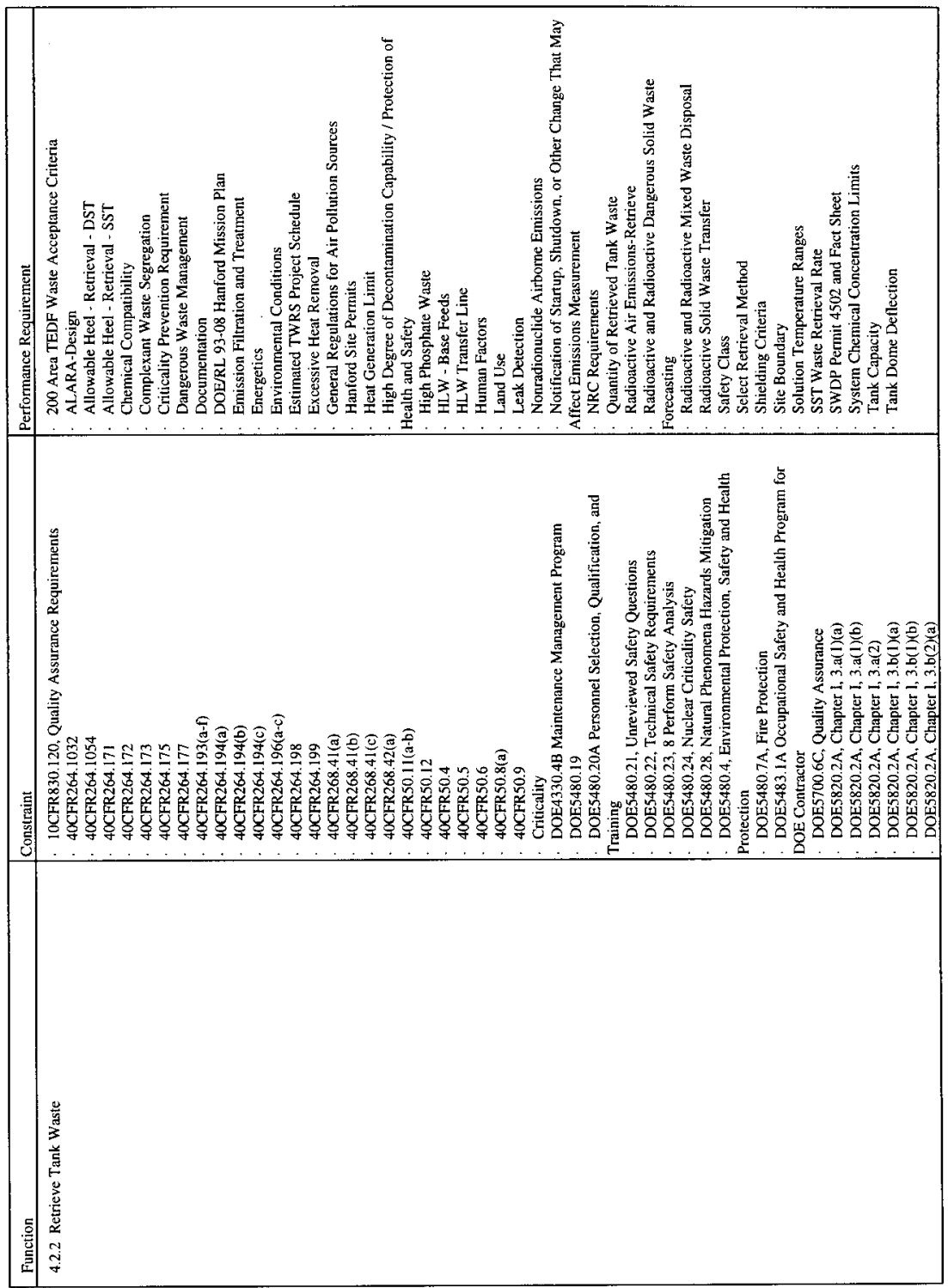




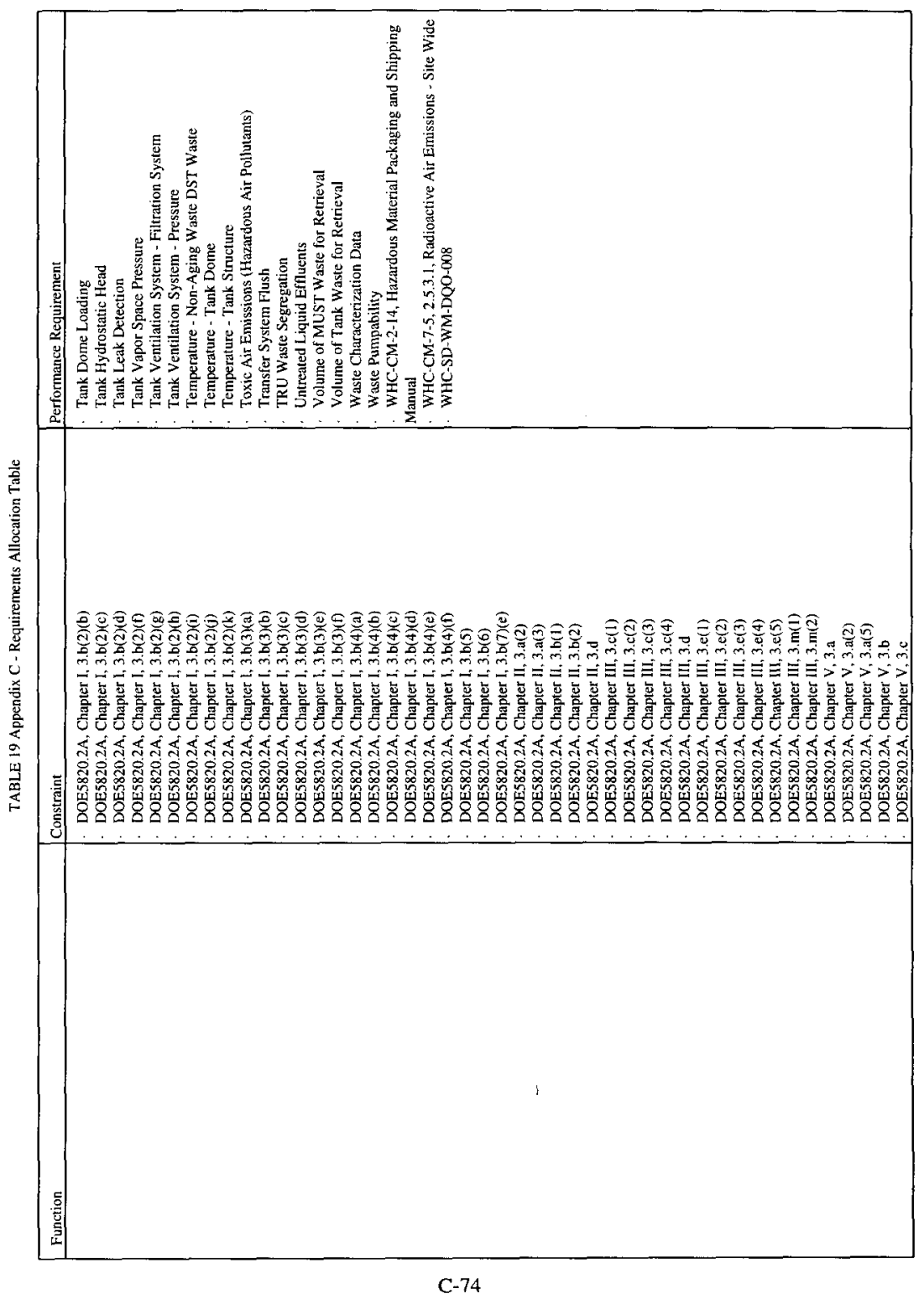




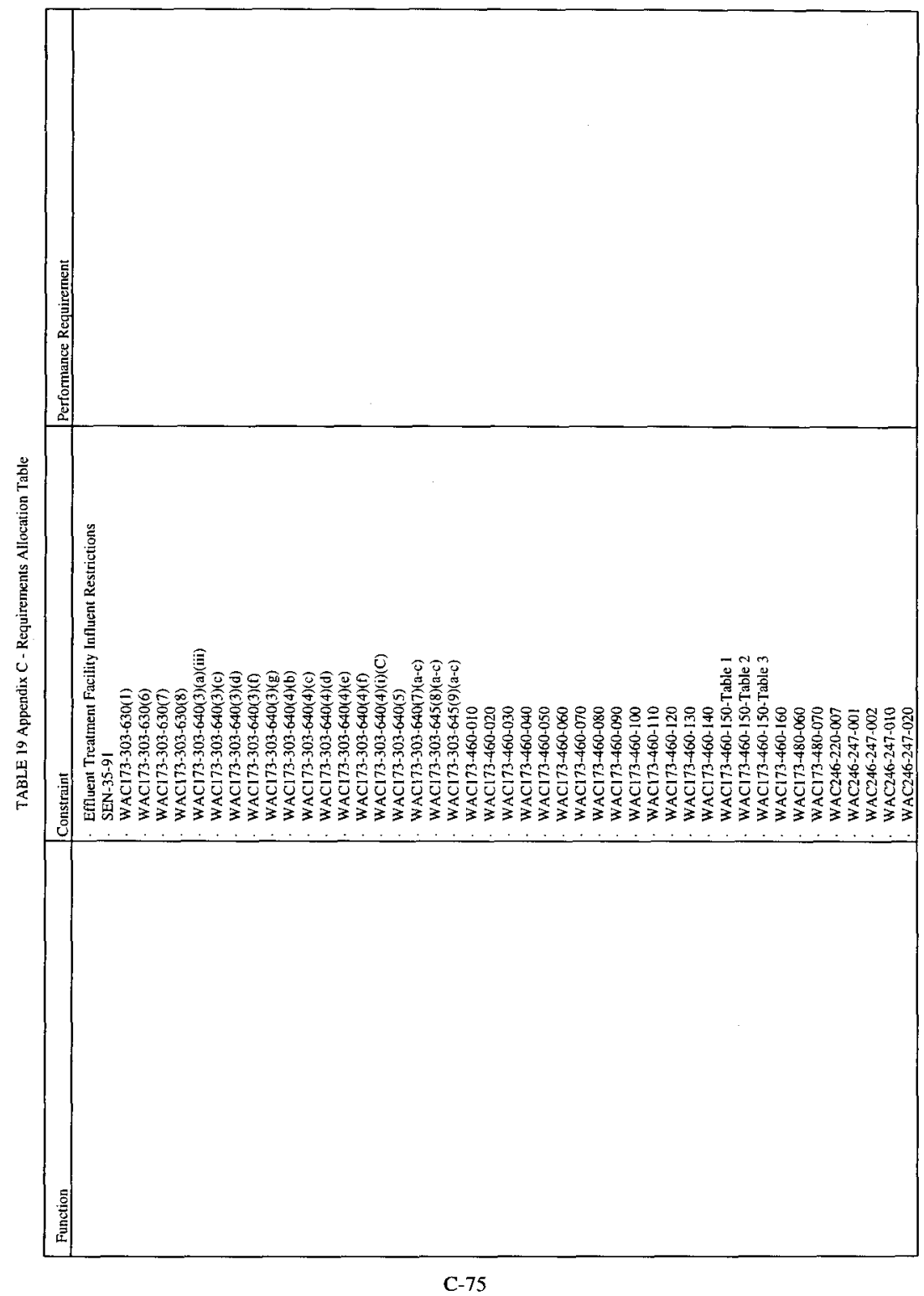


Revision 1

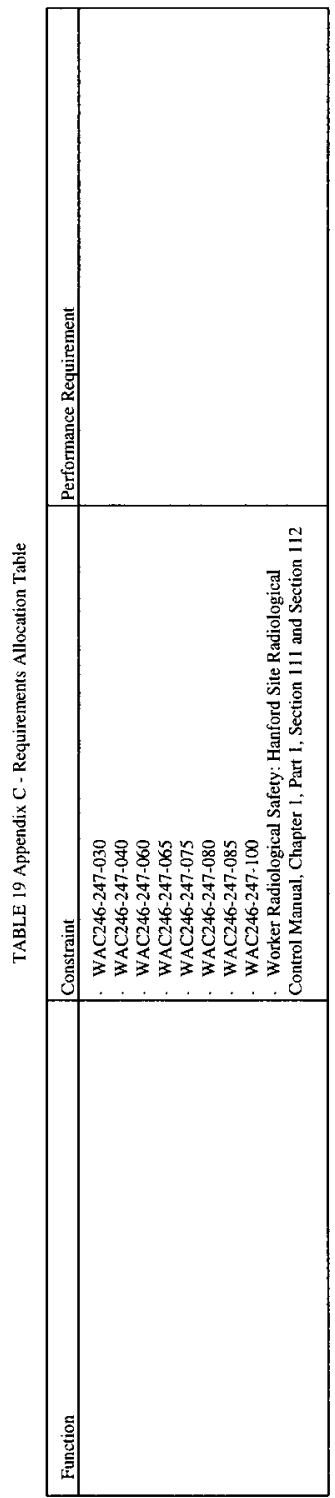




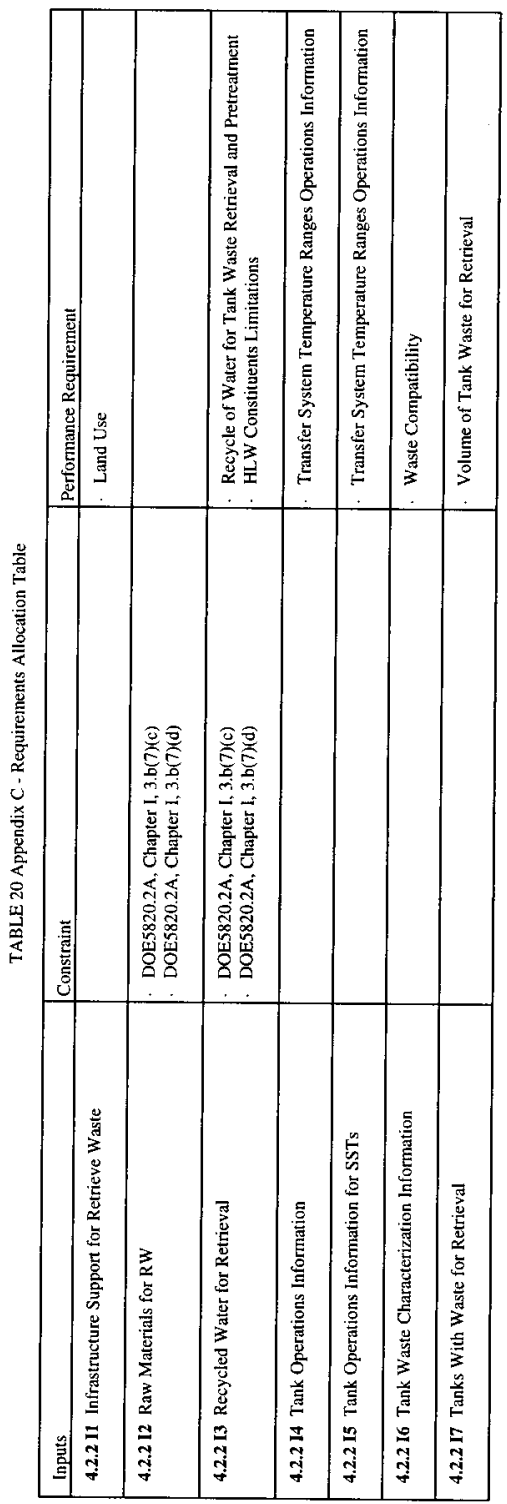




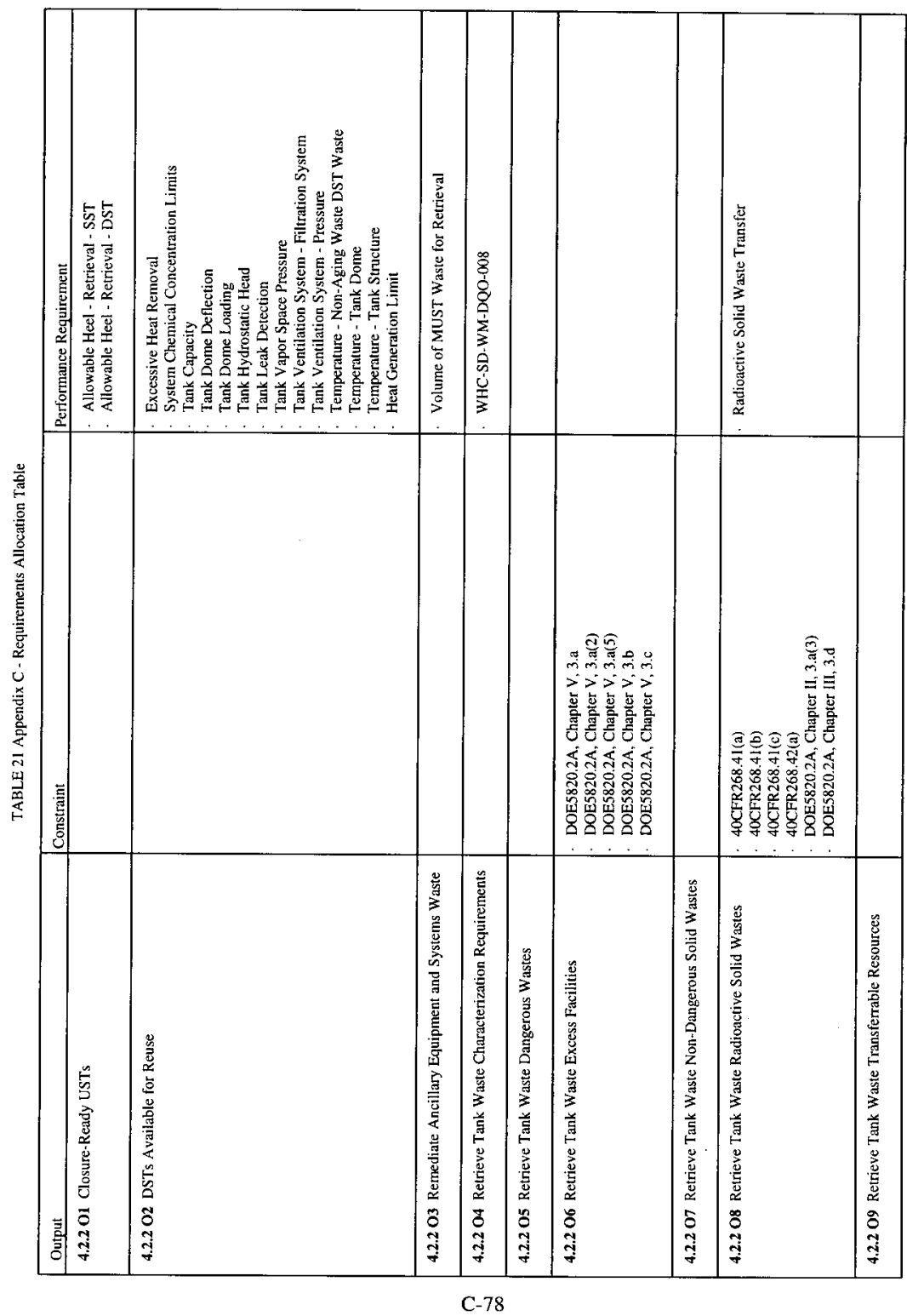


Revision 1

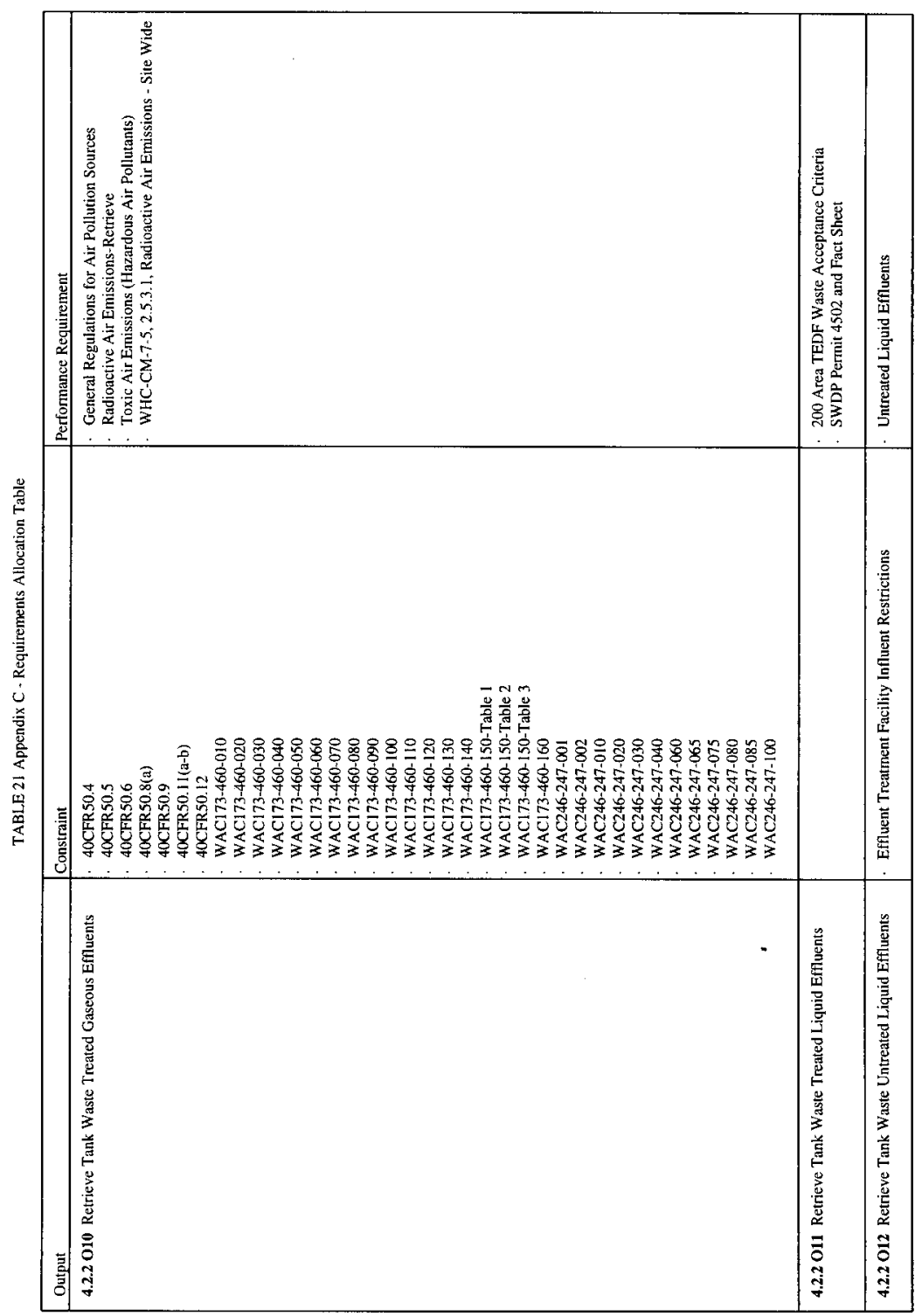

\section{C-79}


Revision 1

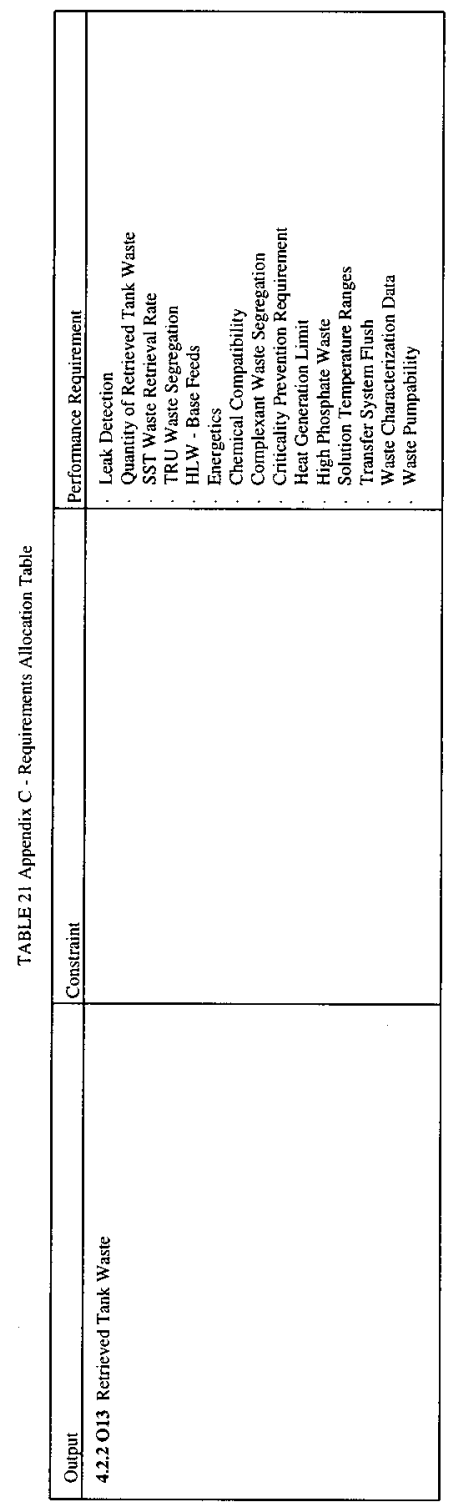


Revision 1

\section{C-81}




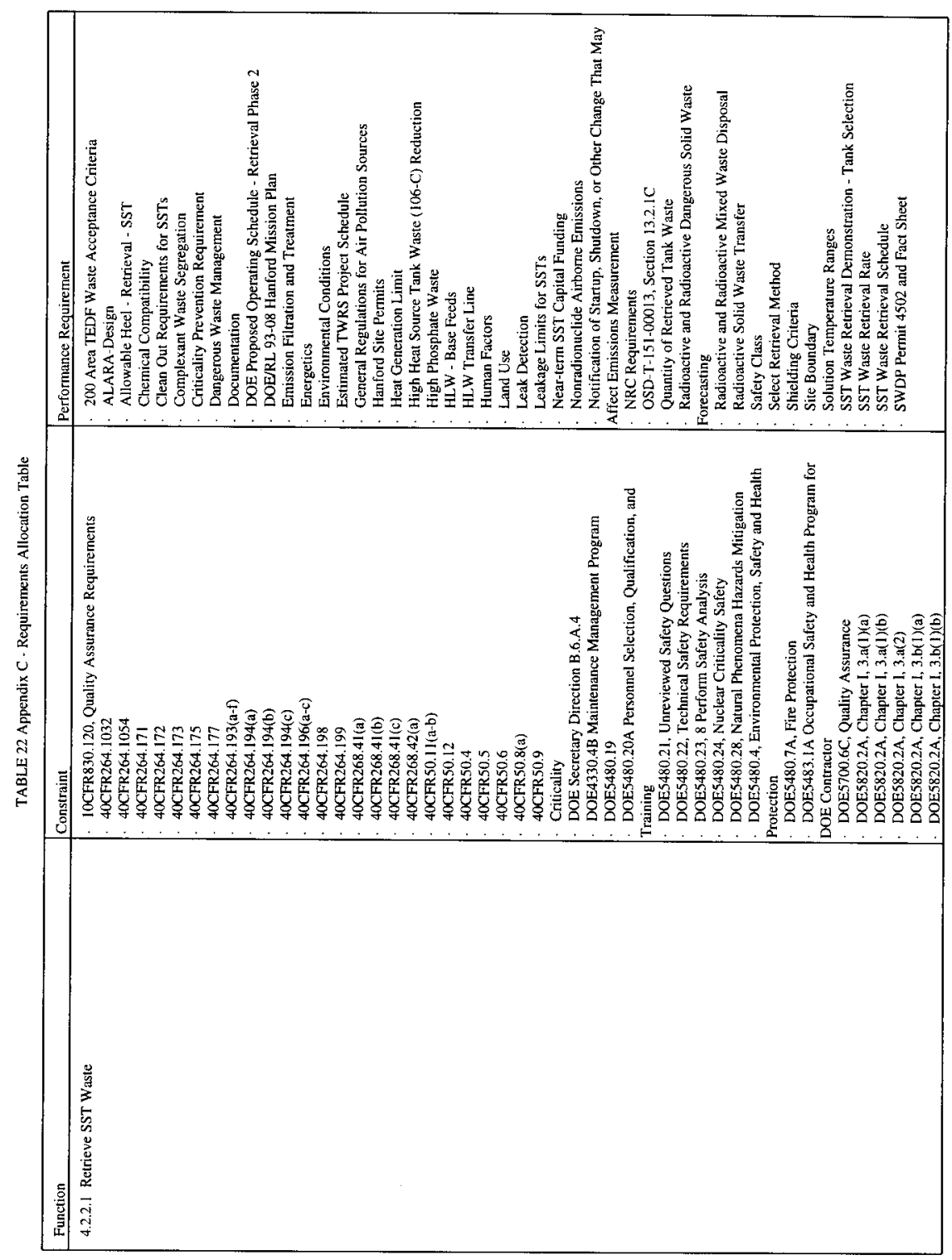




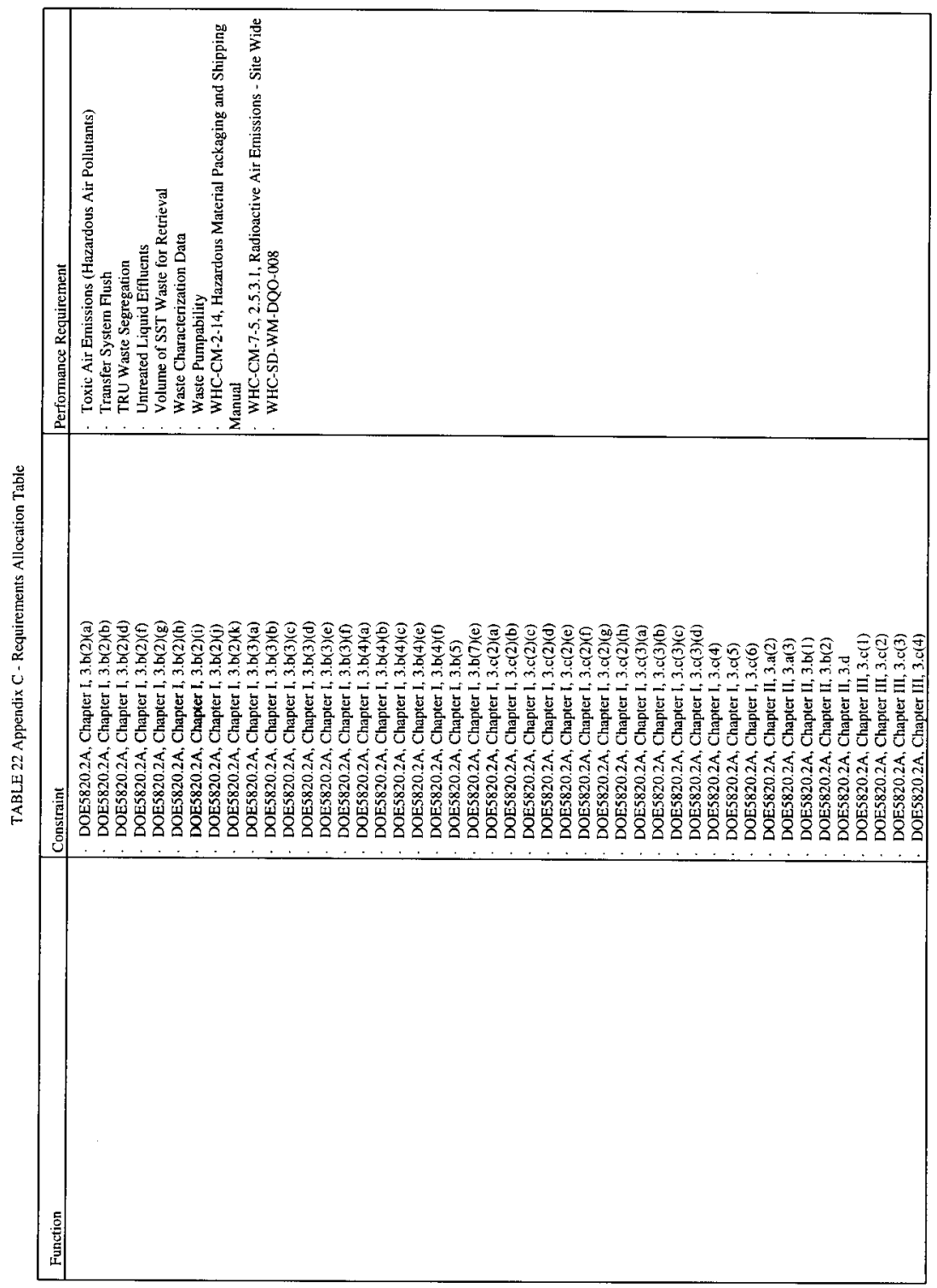




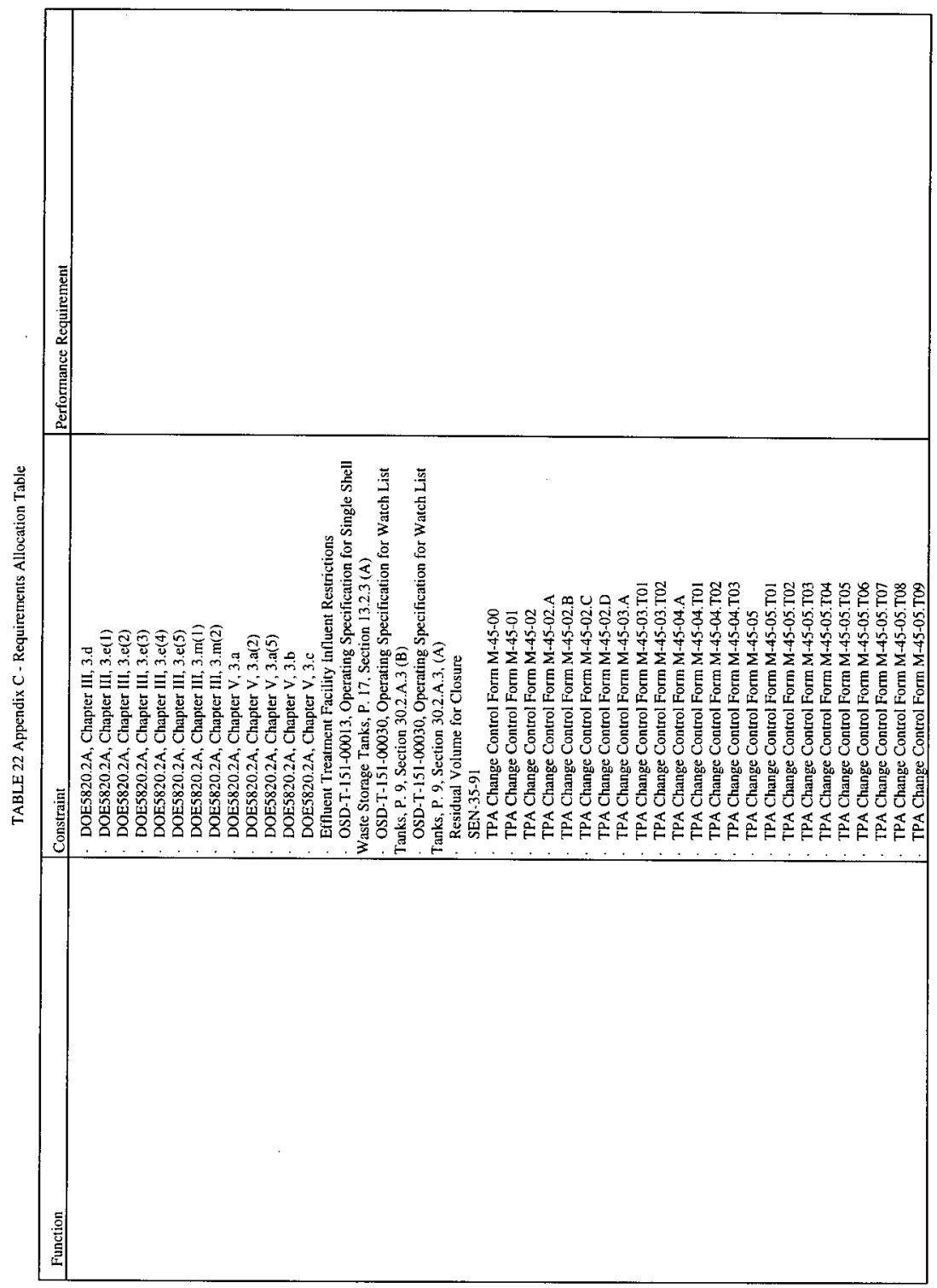




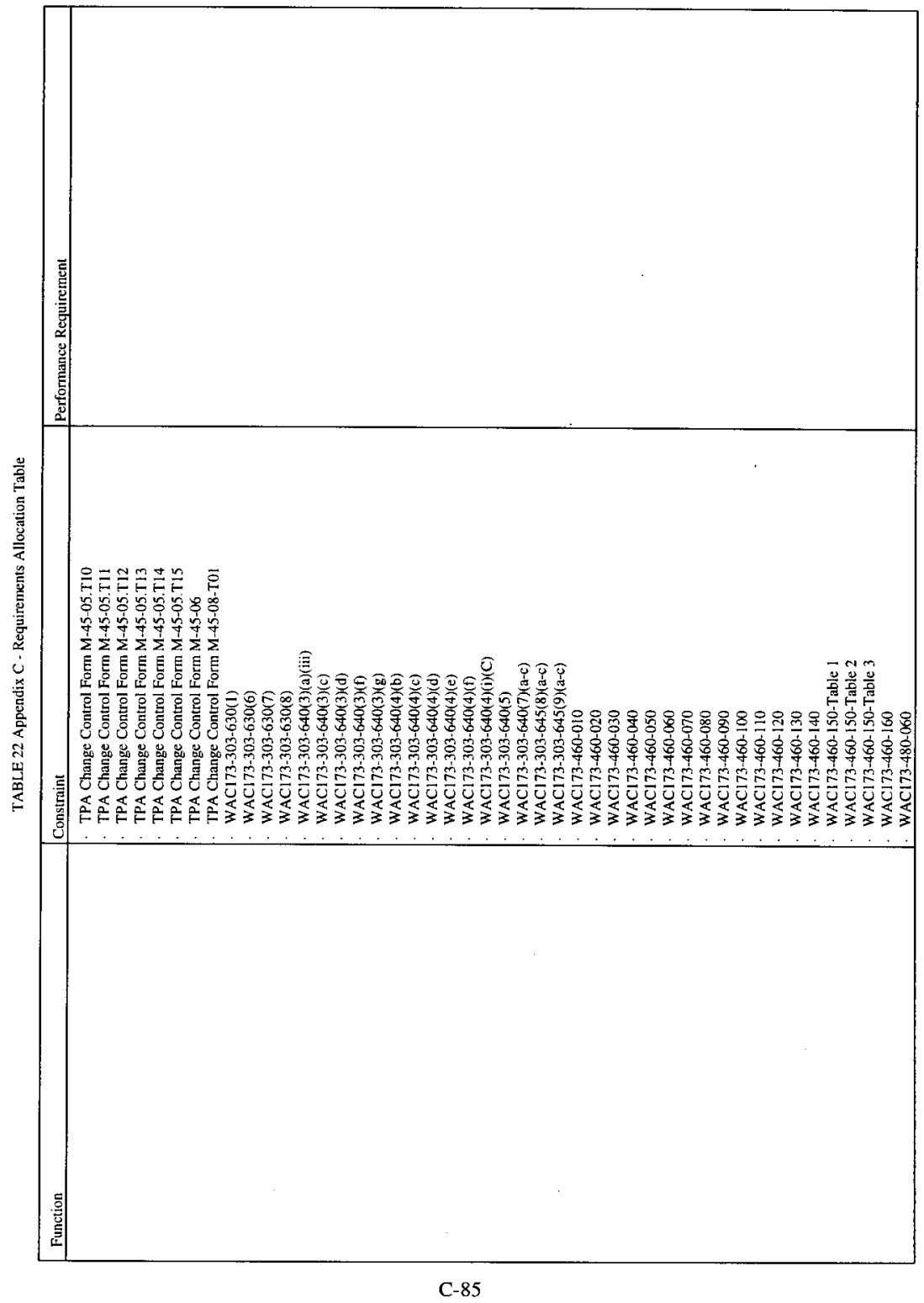




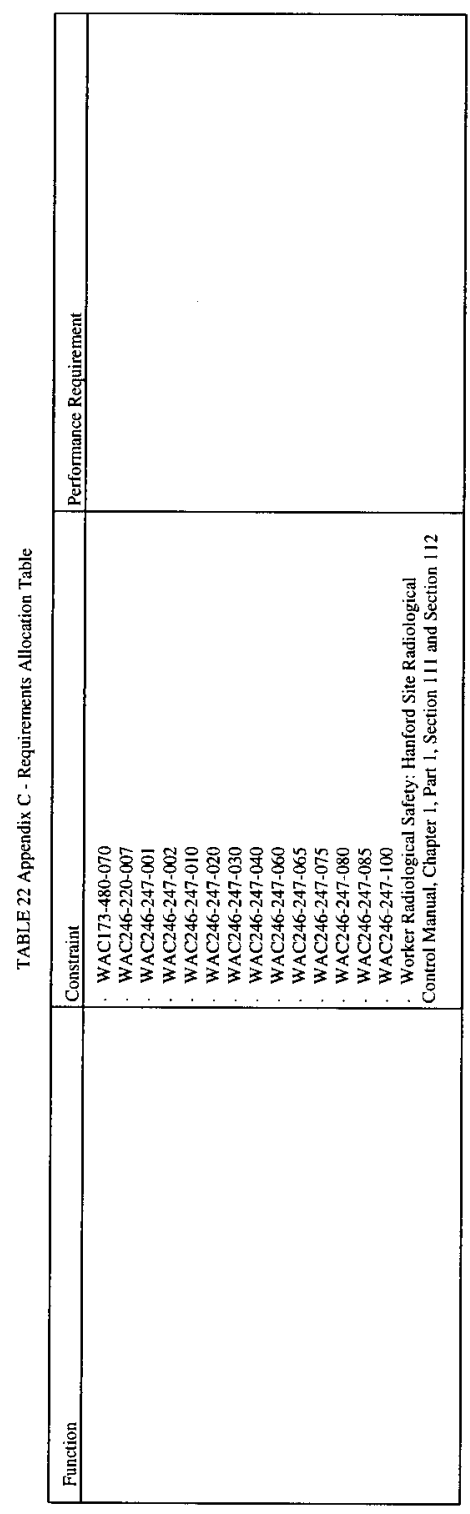




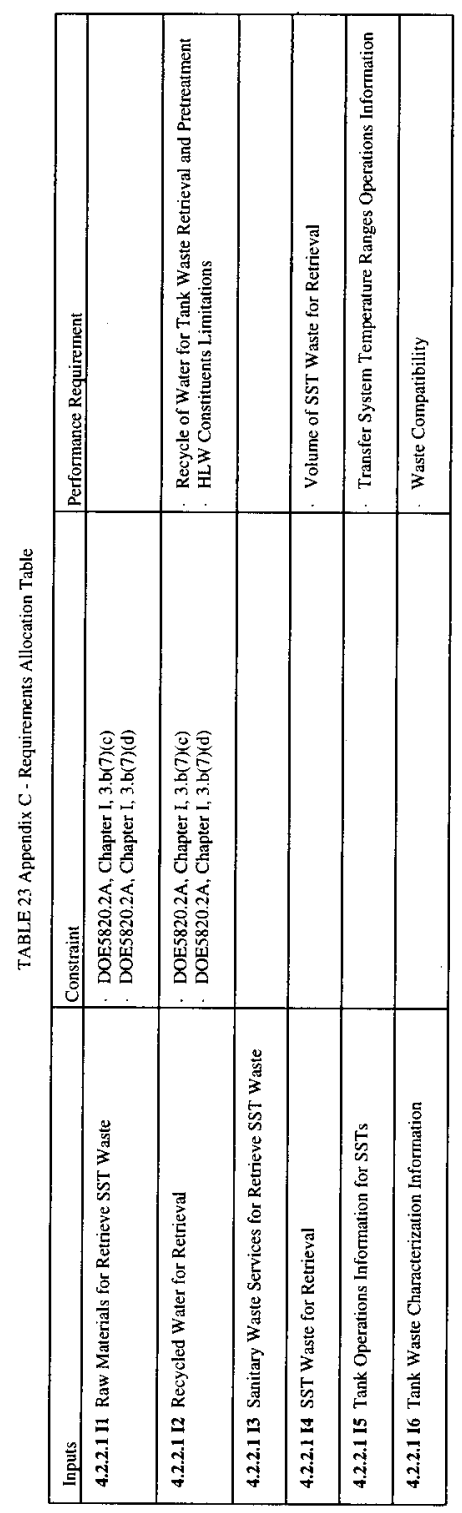


Revision 1

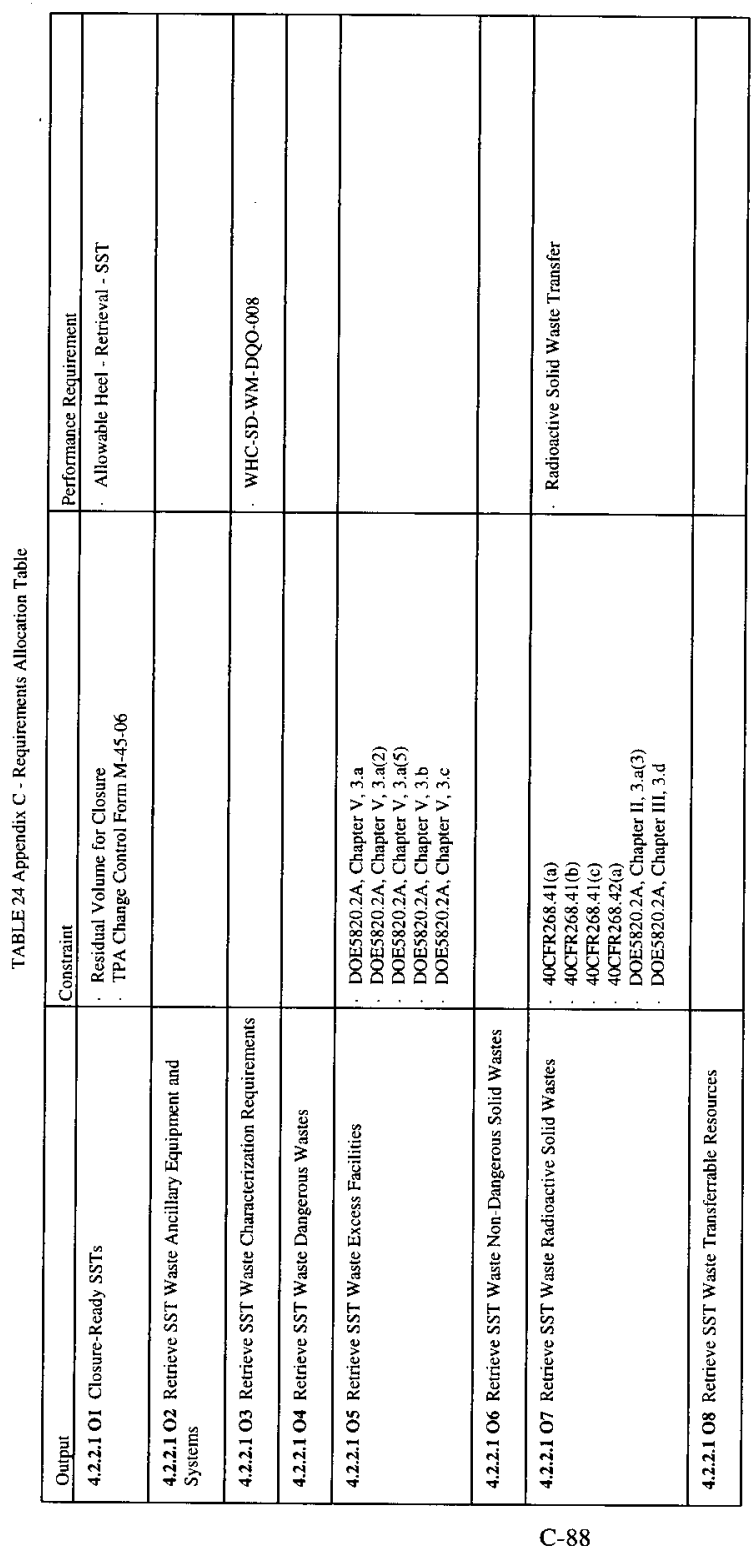


Revision 1

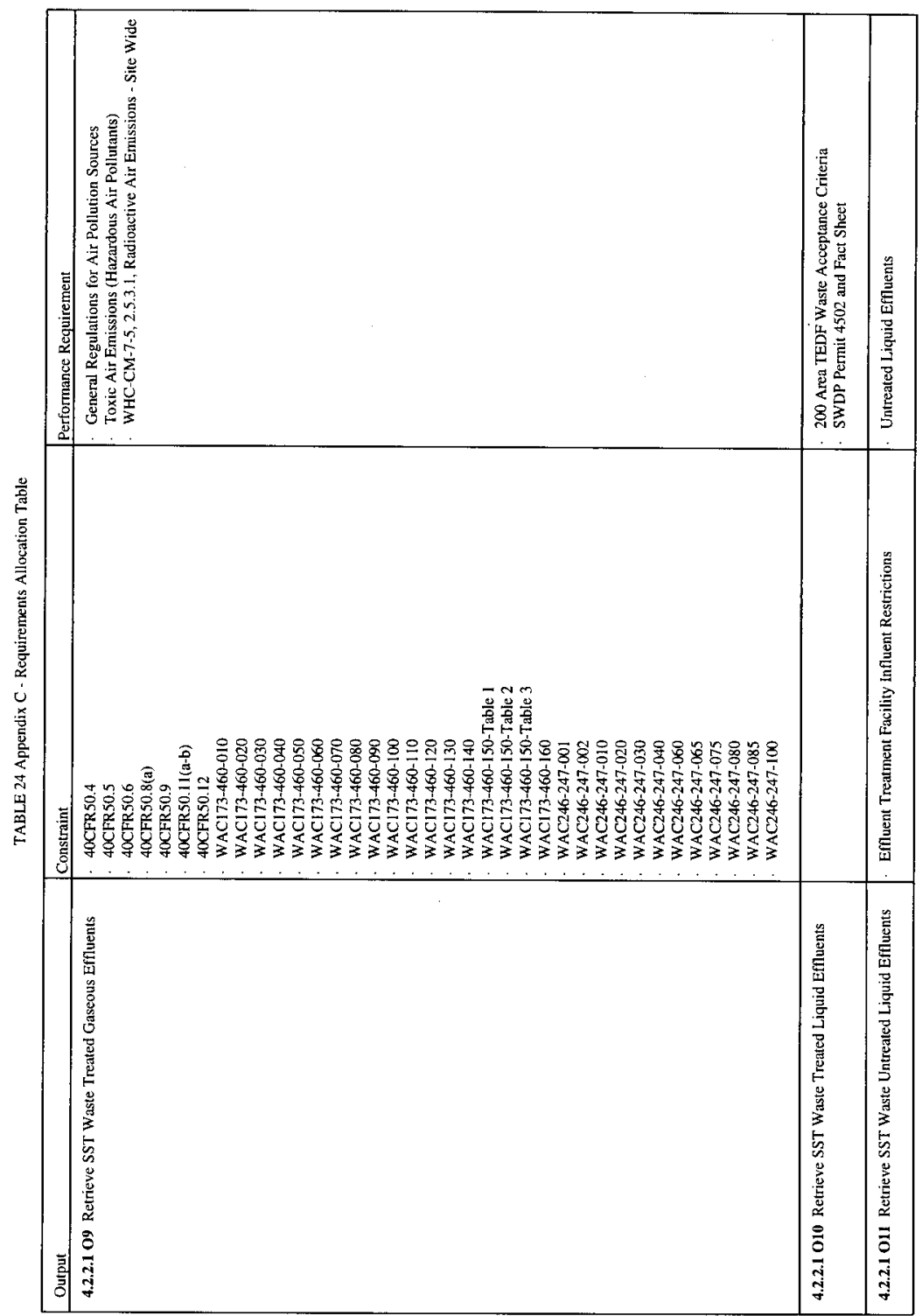




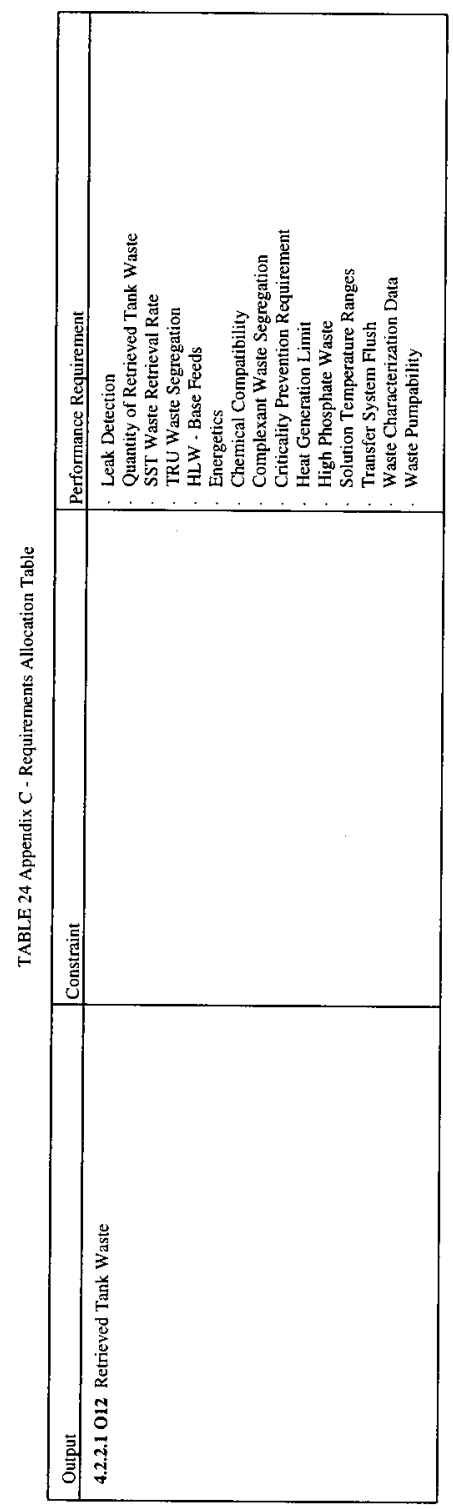


Revision 1 


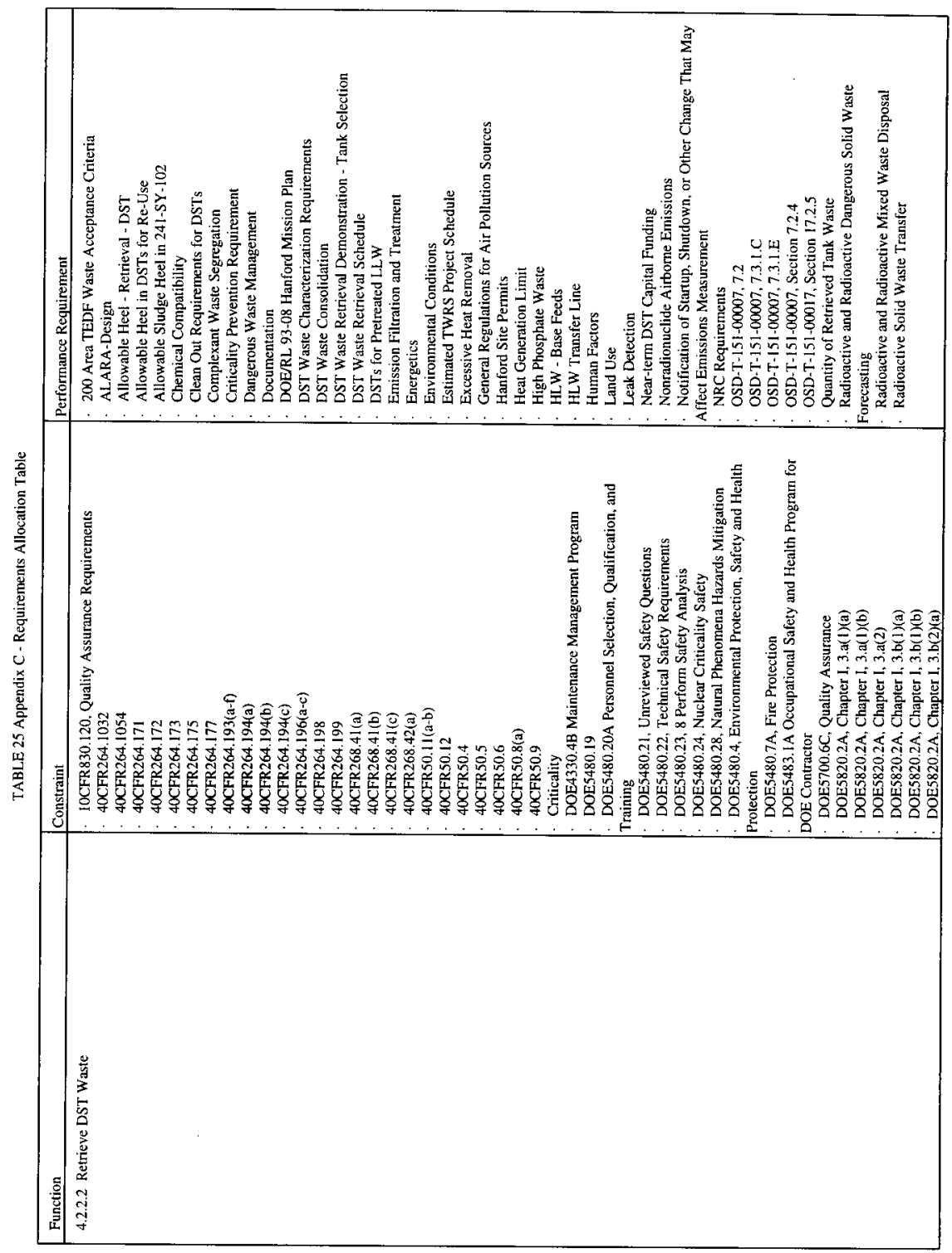


Revision 1

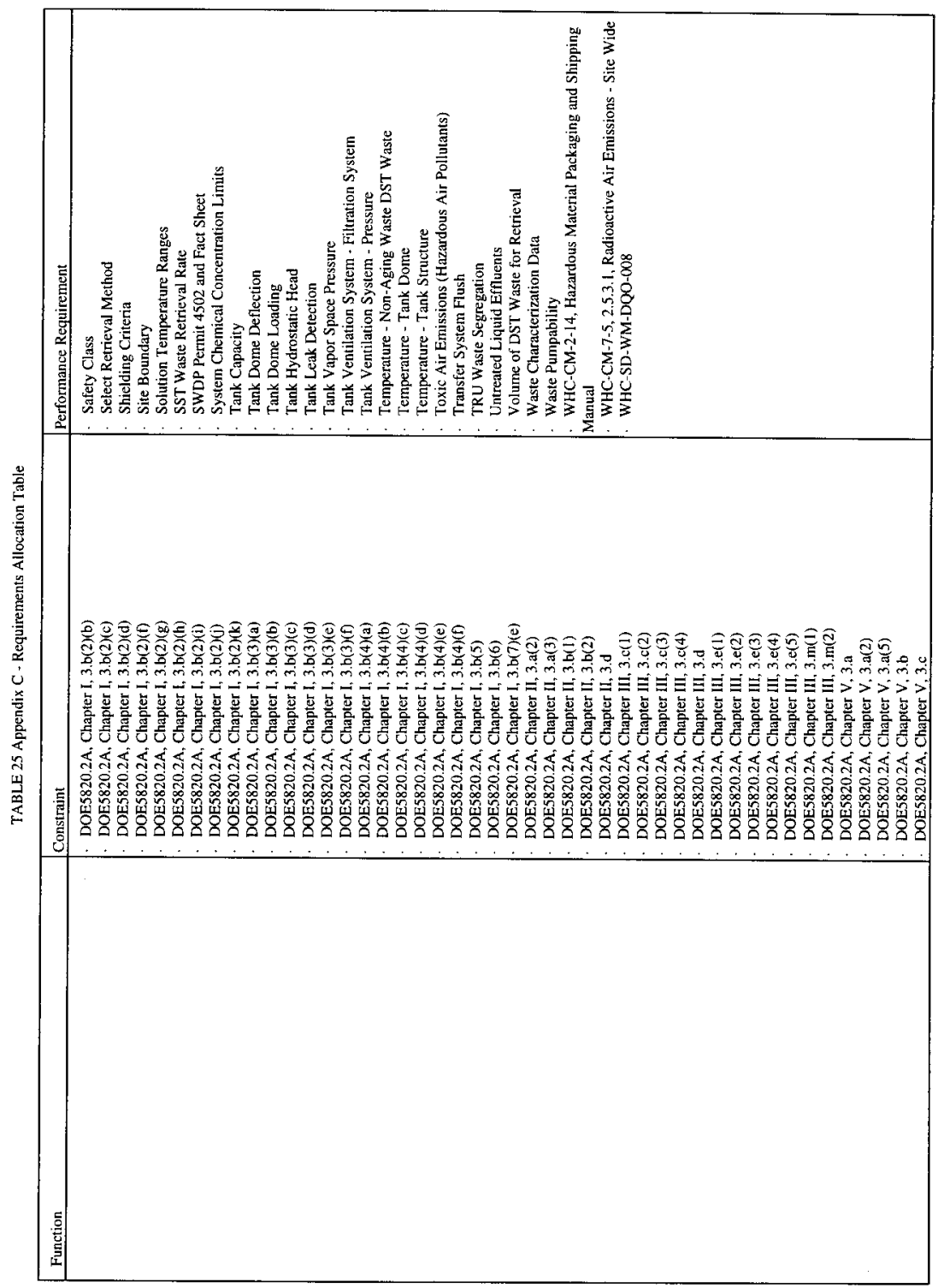




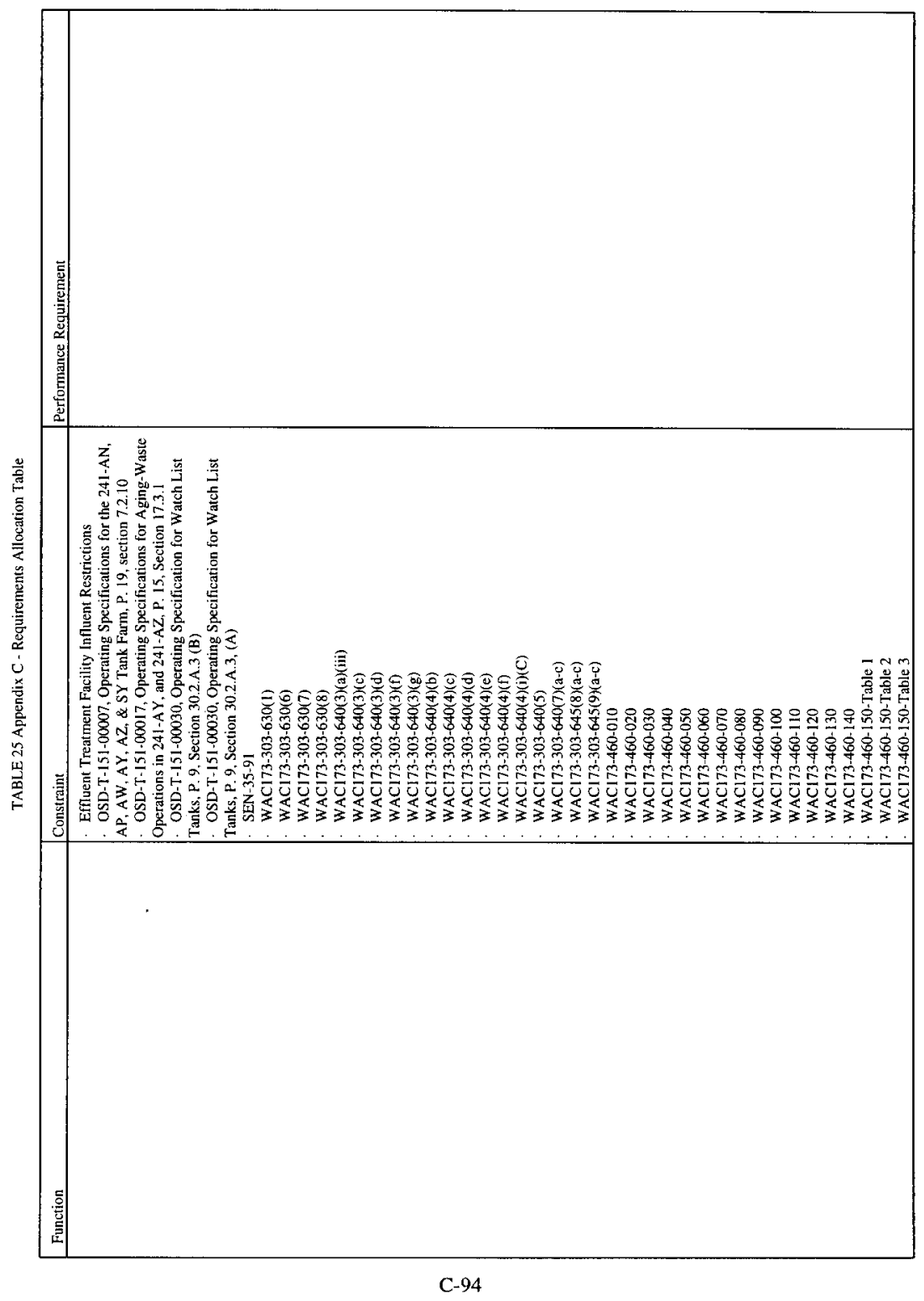




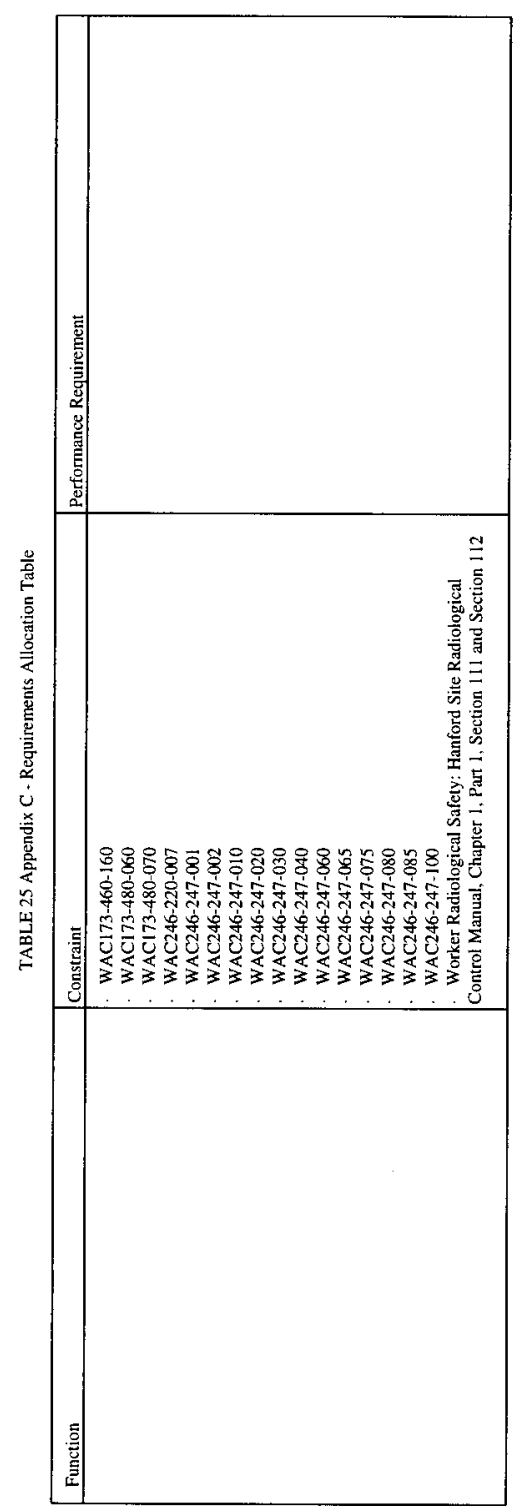


Revision 1

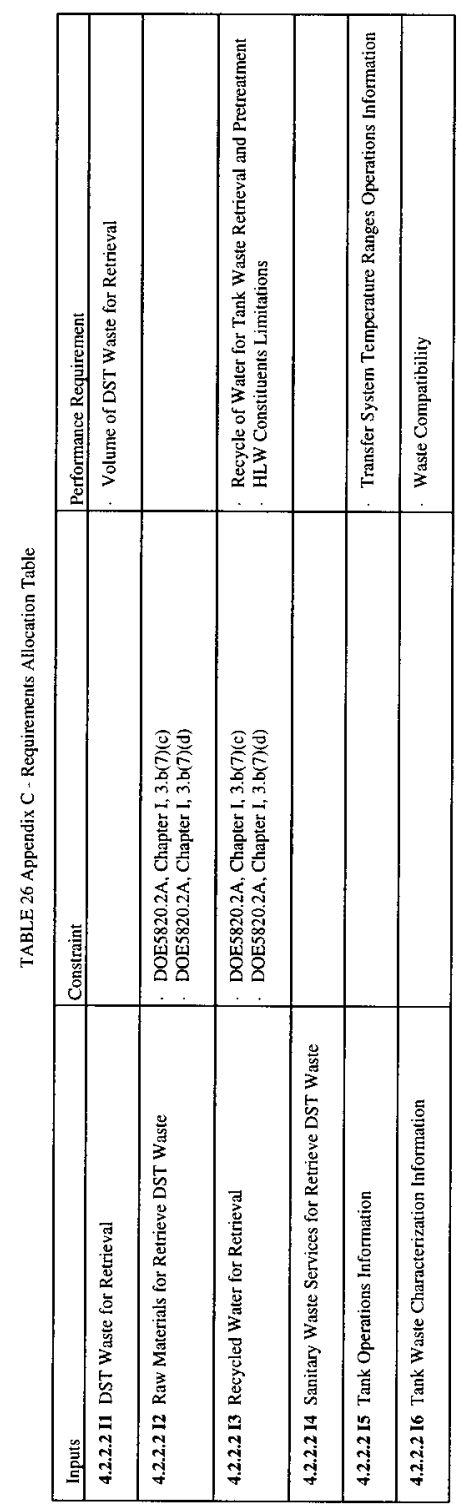


Revision I

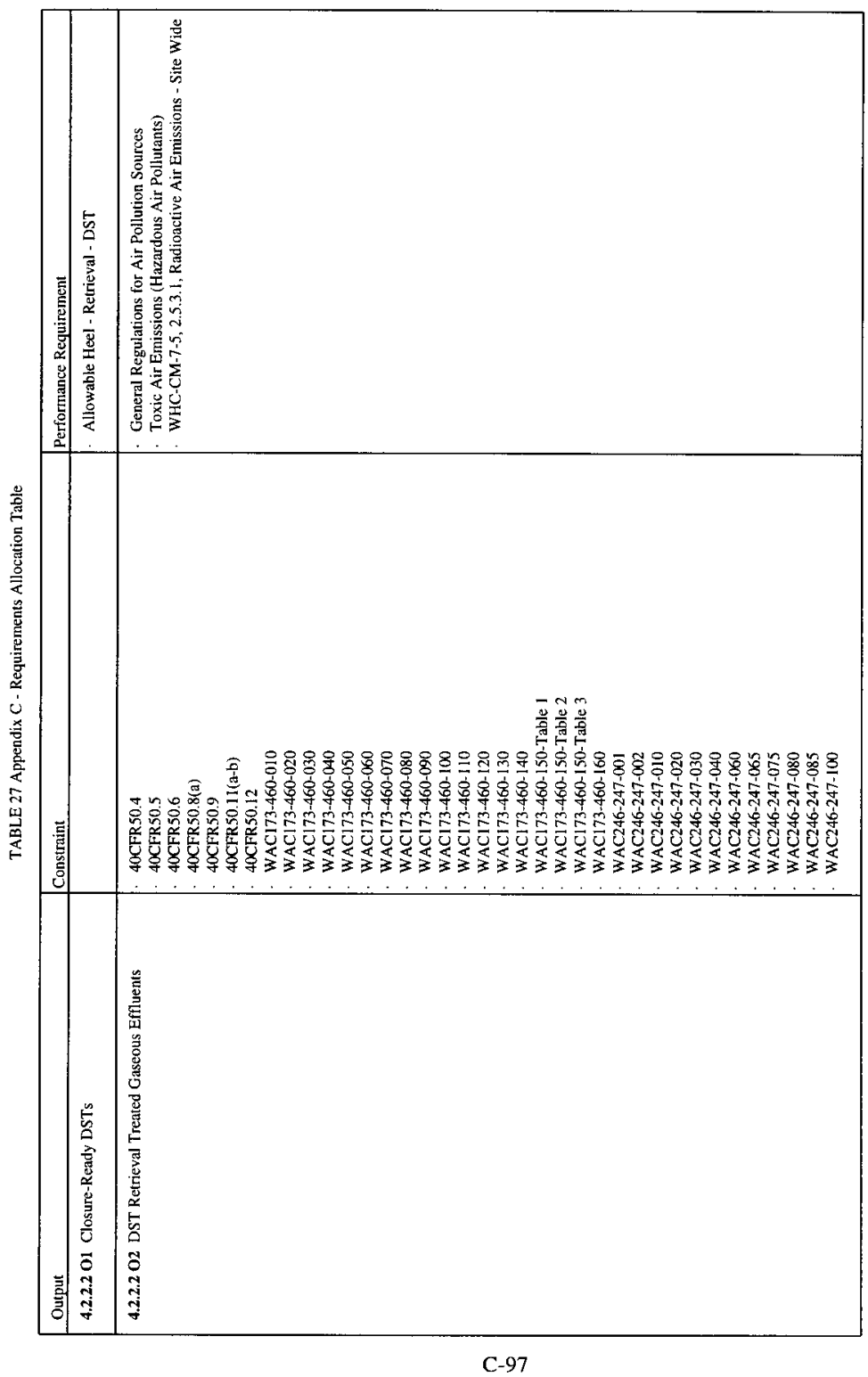




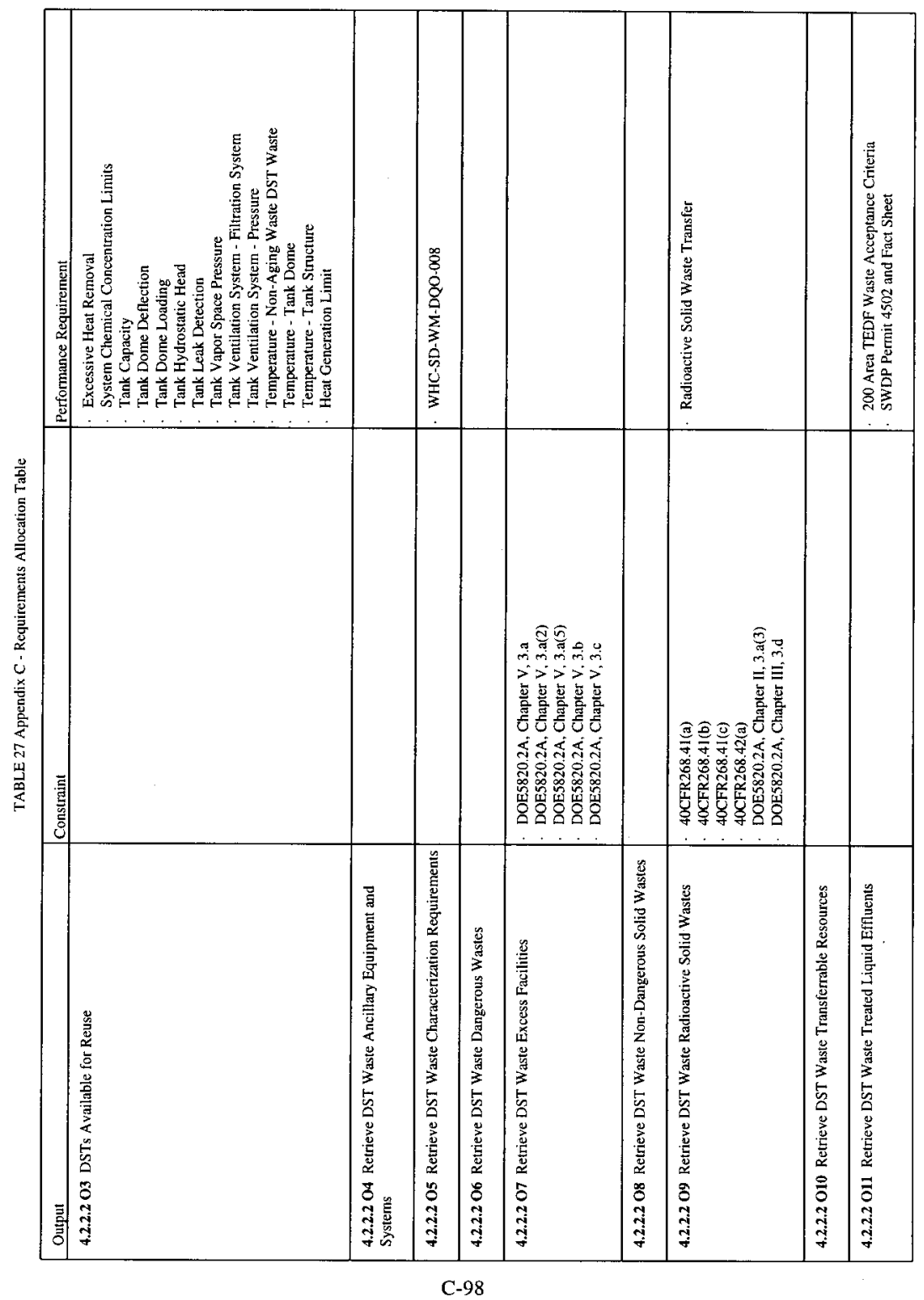




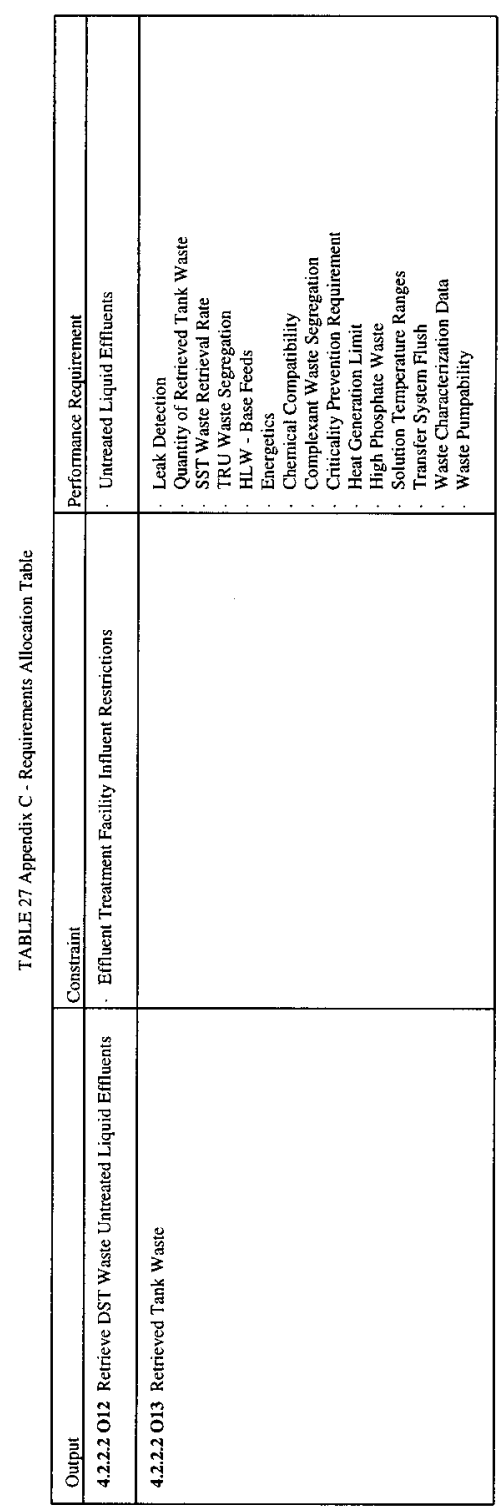


Revision 1 


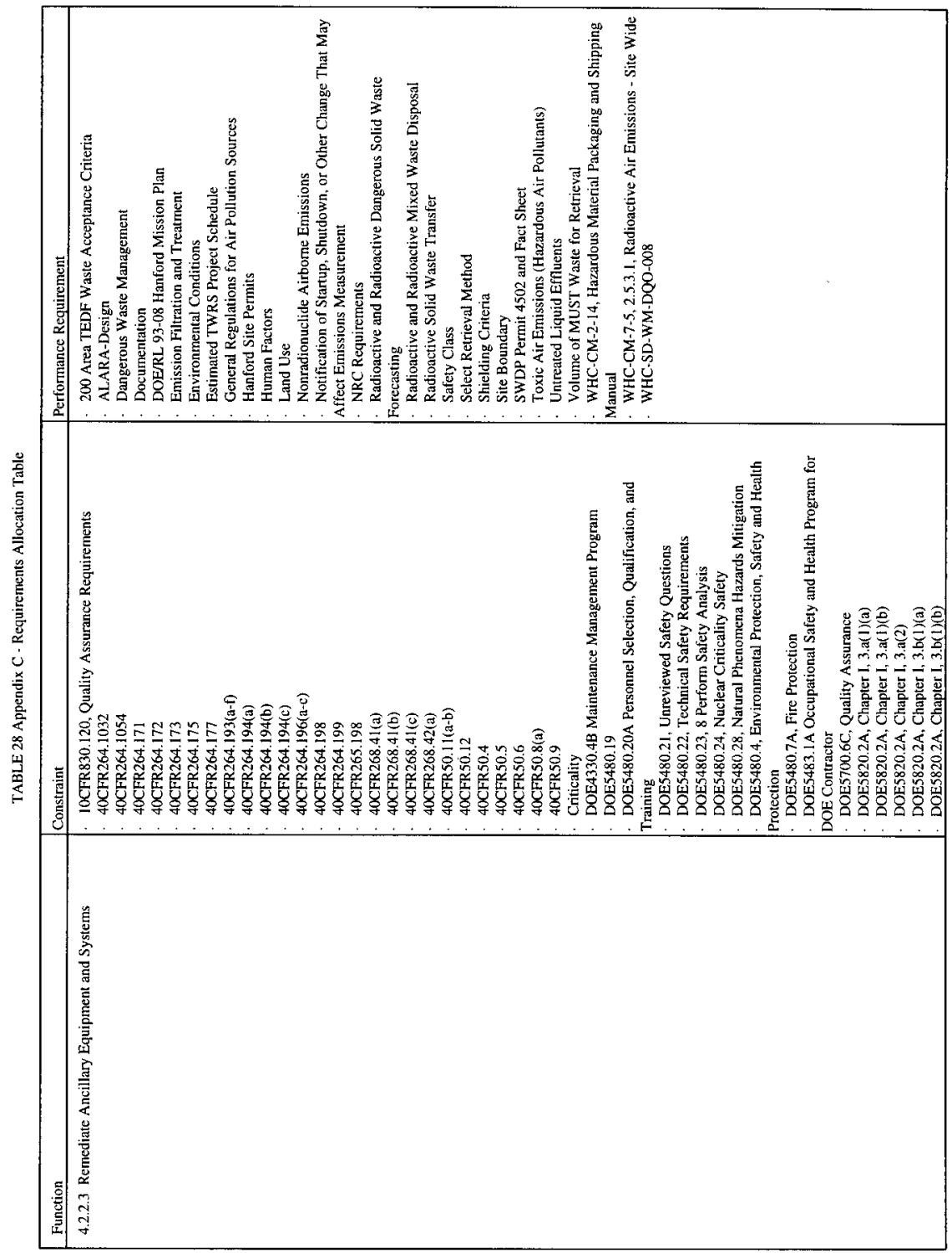




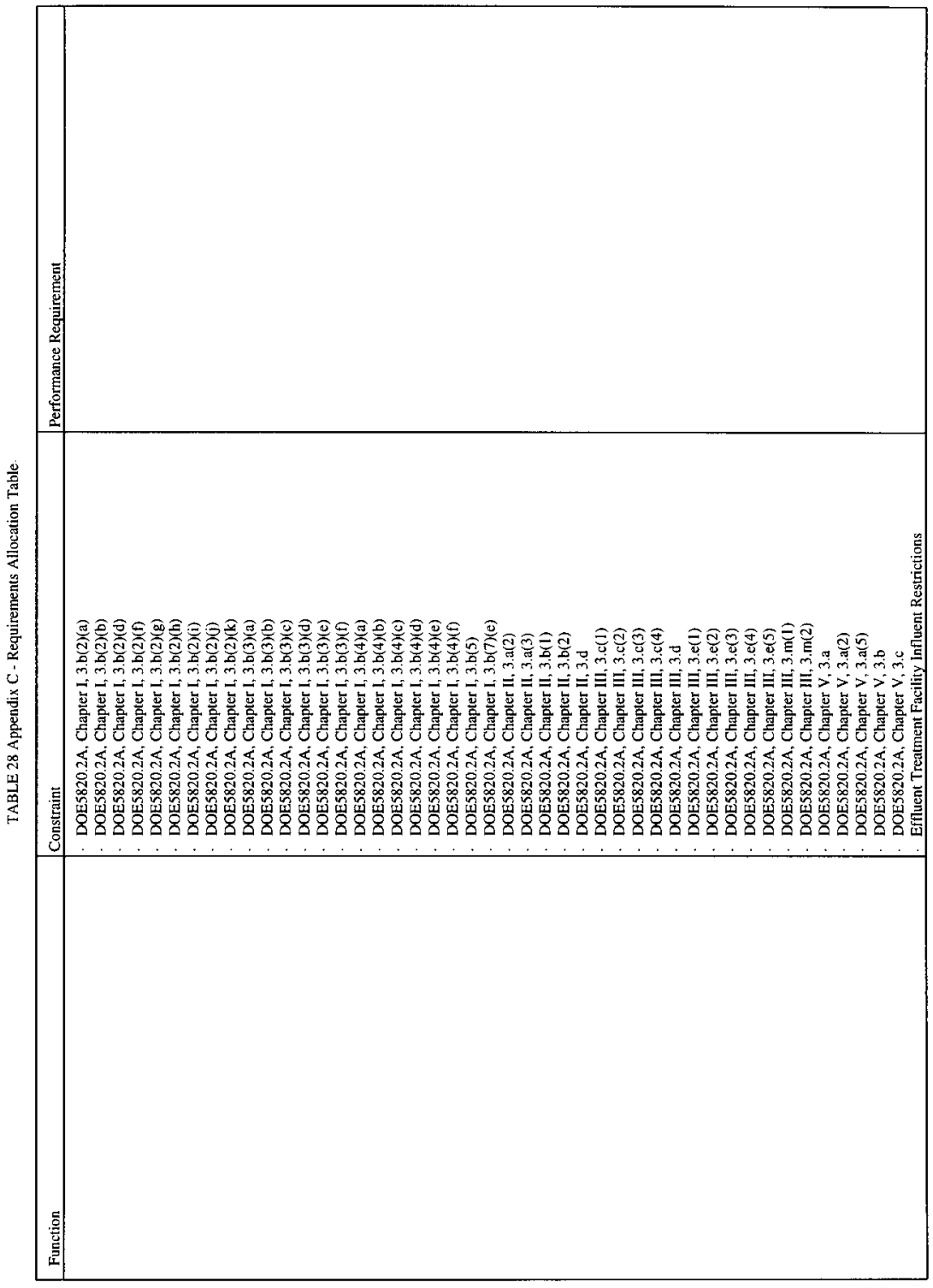

C-102 


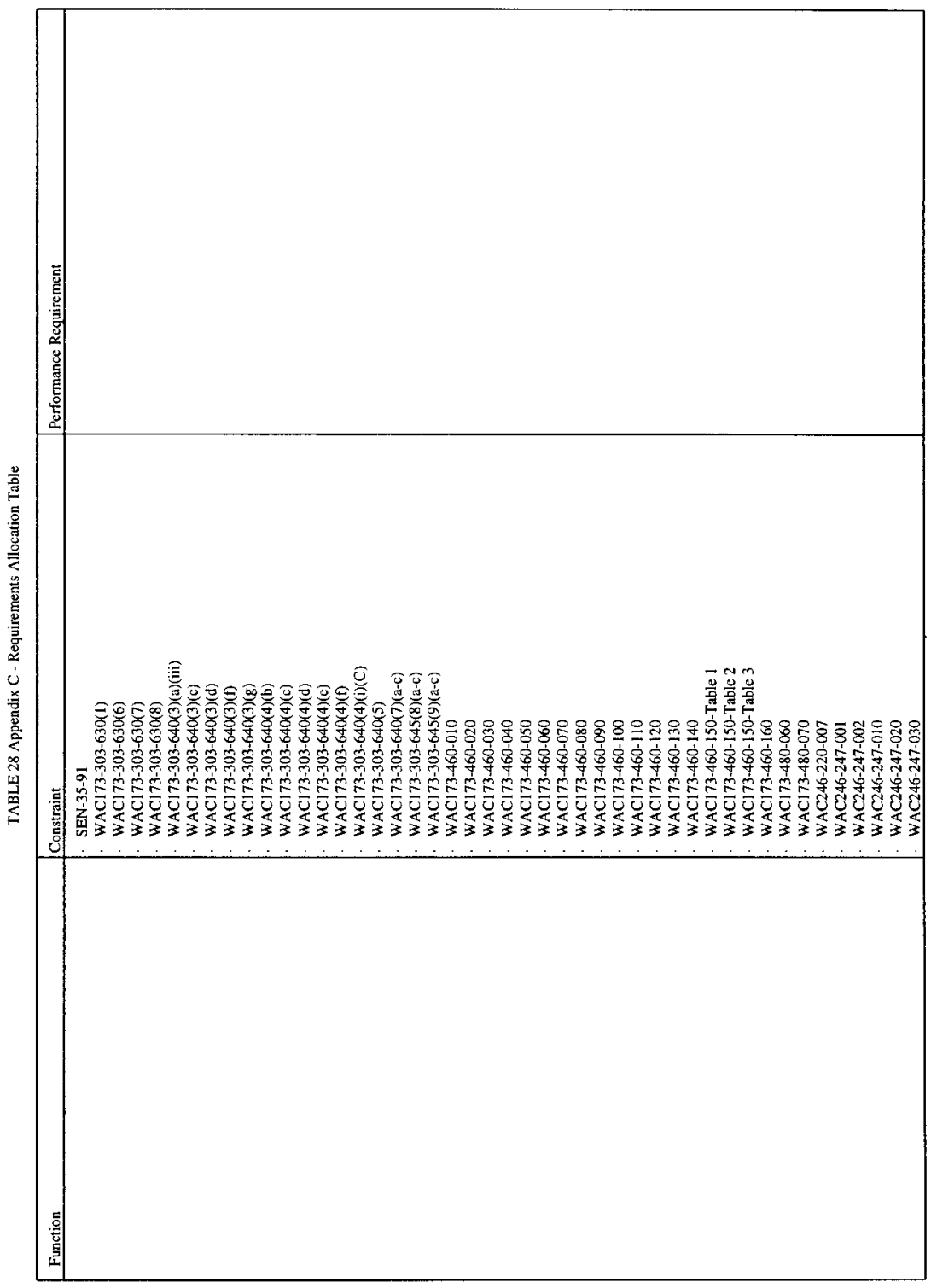


Revision 1

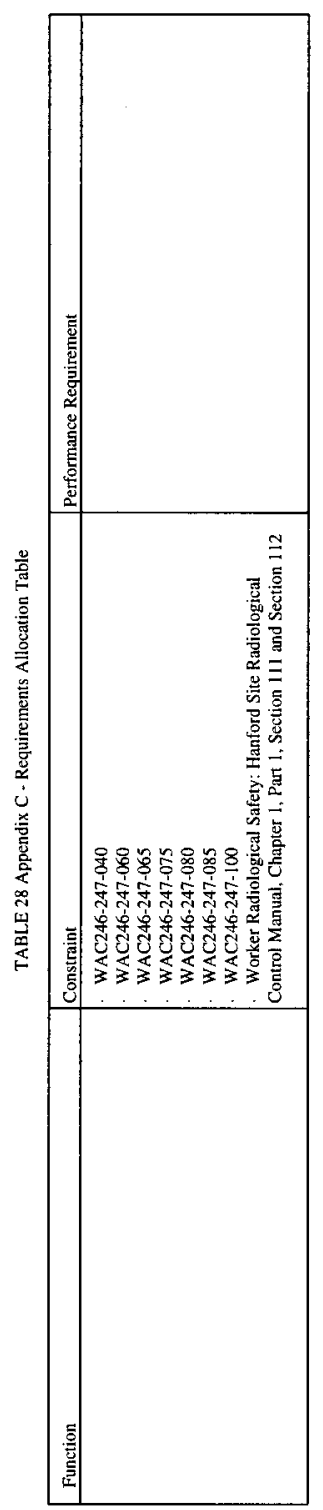




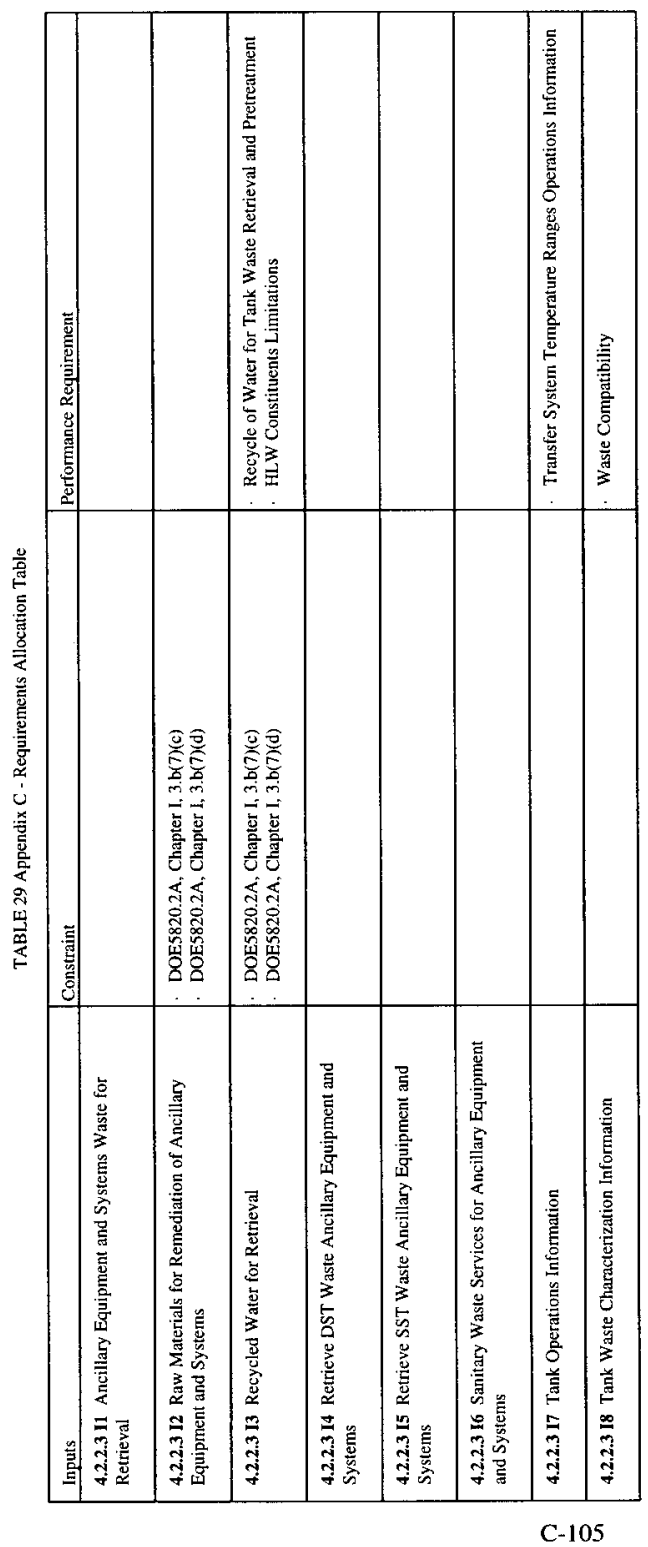




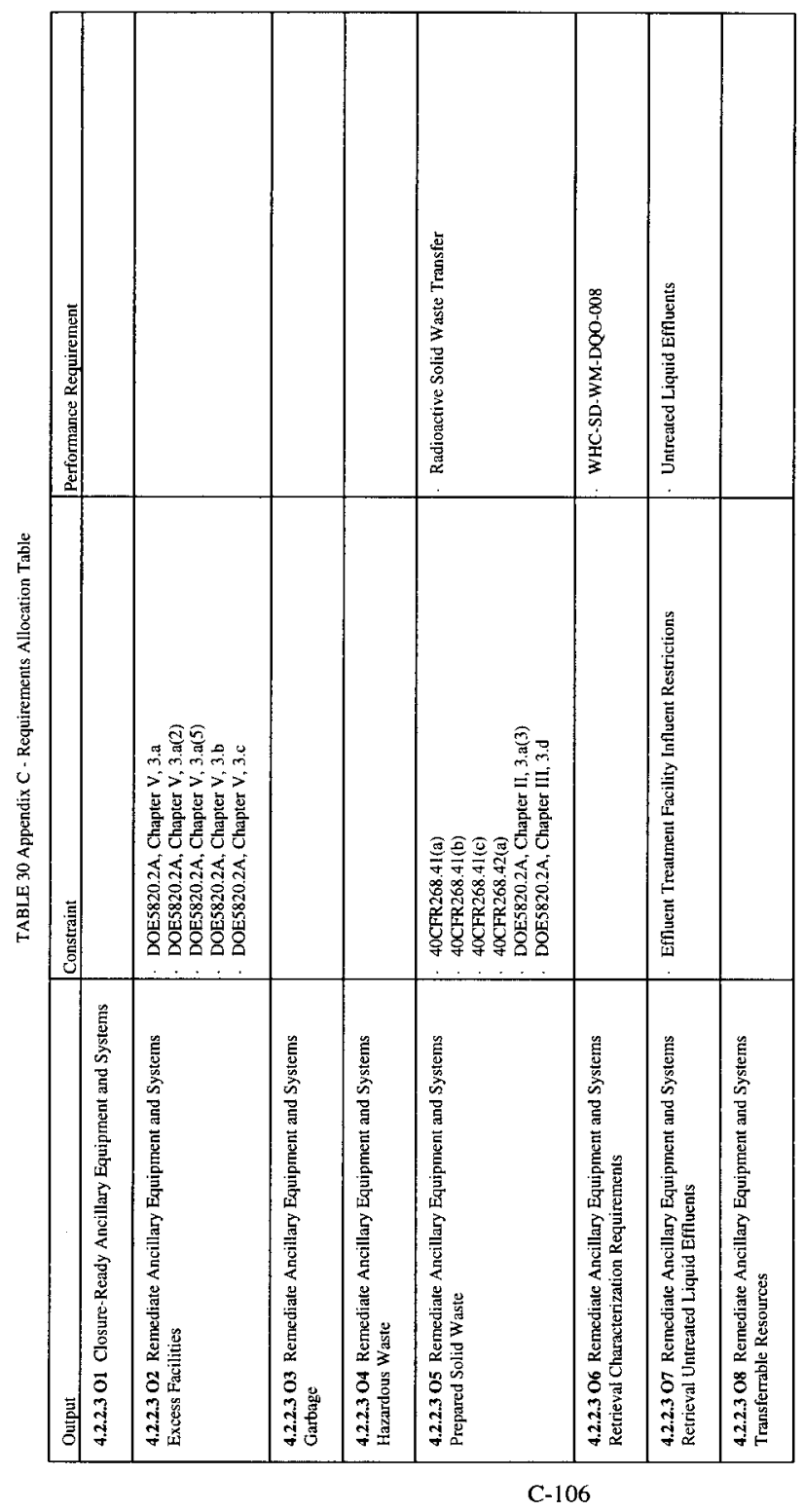




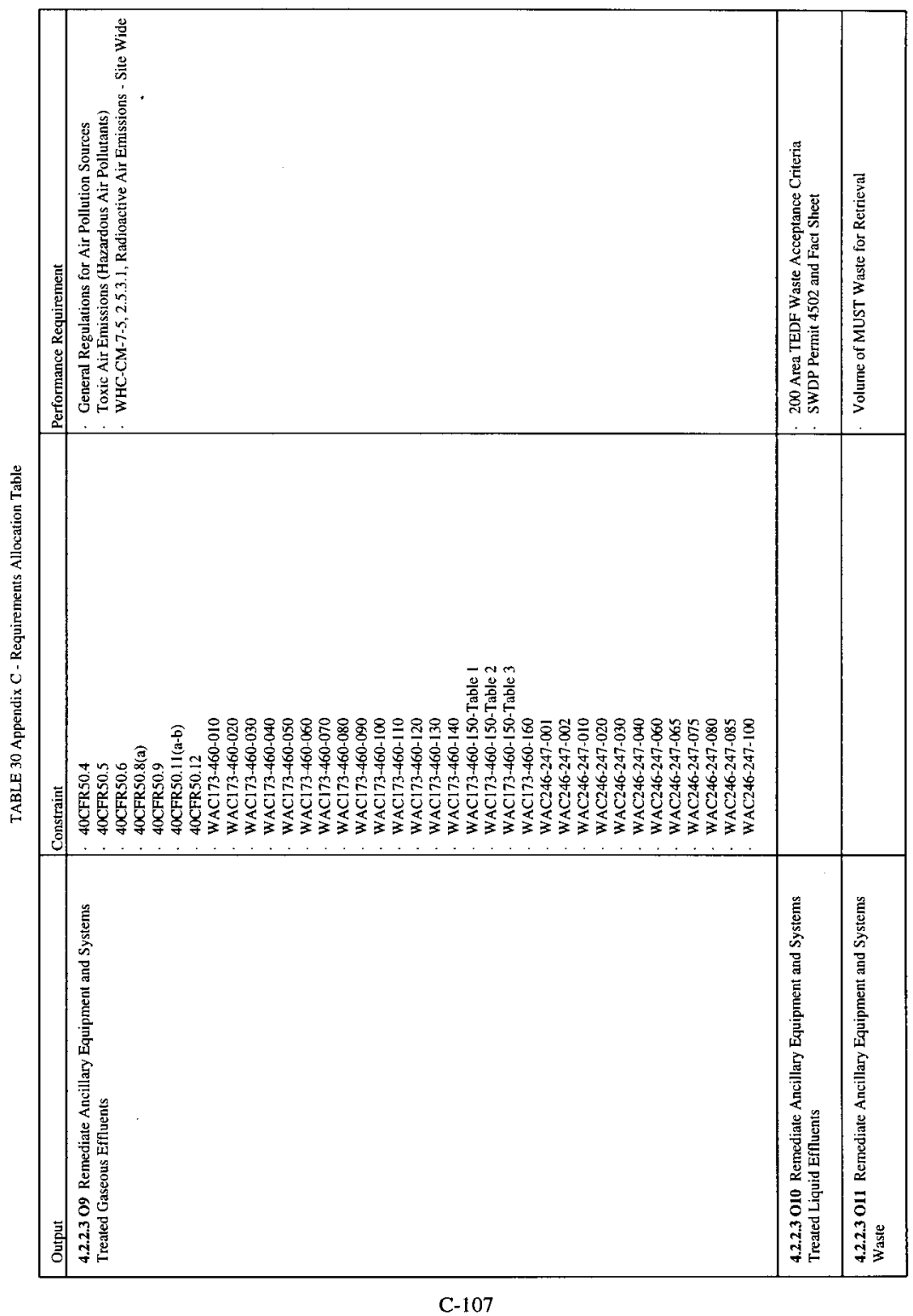




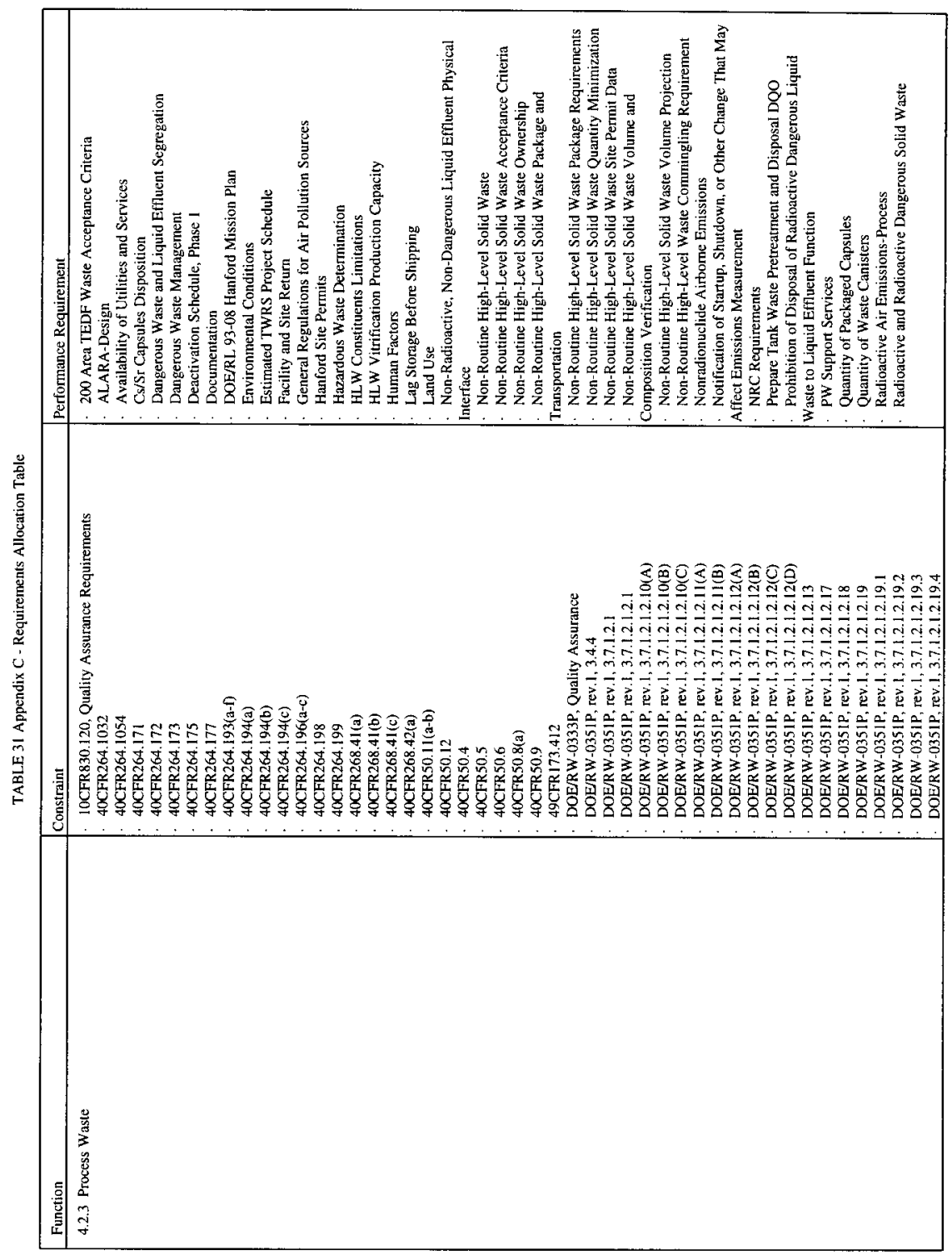




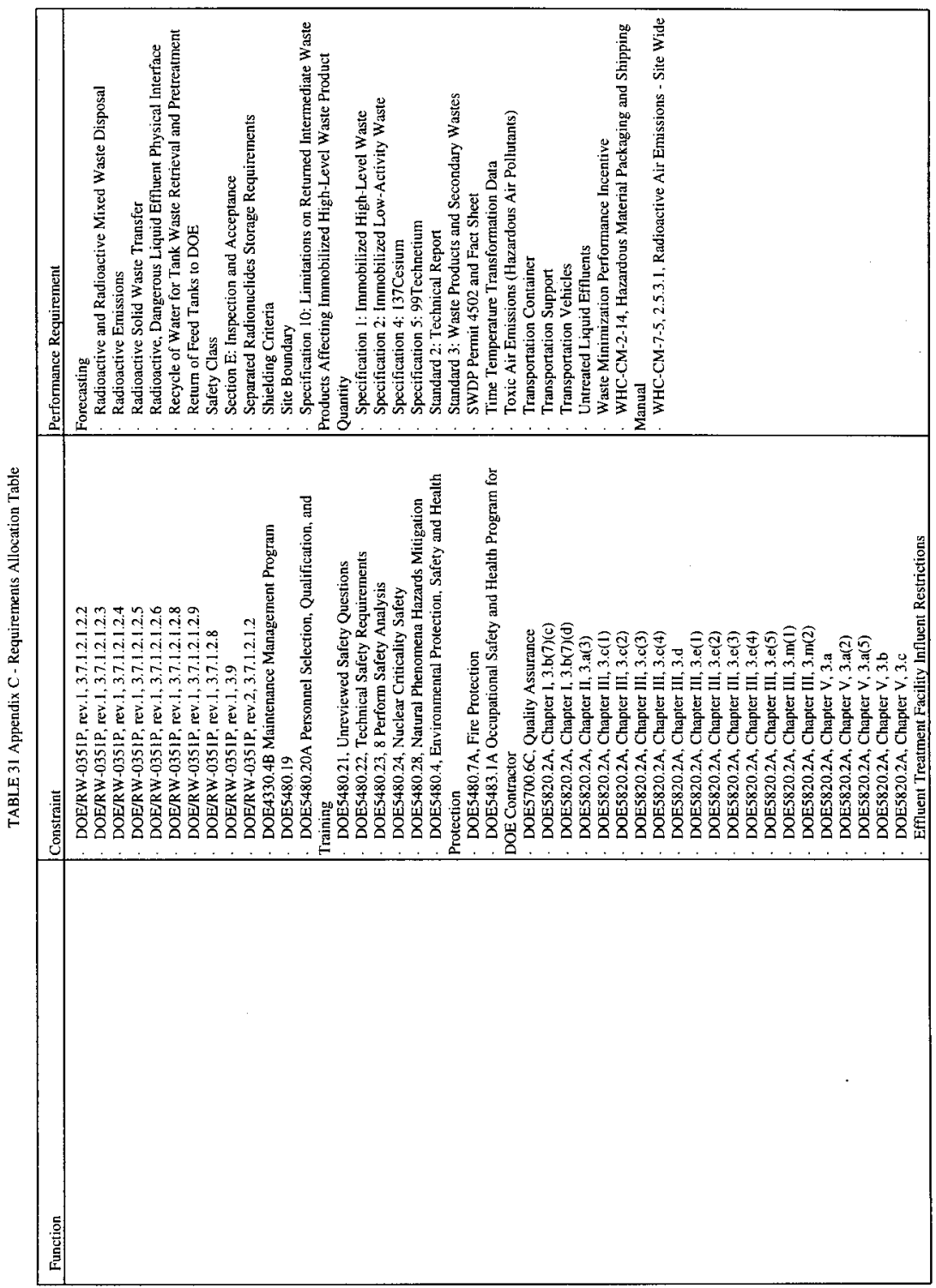




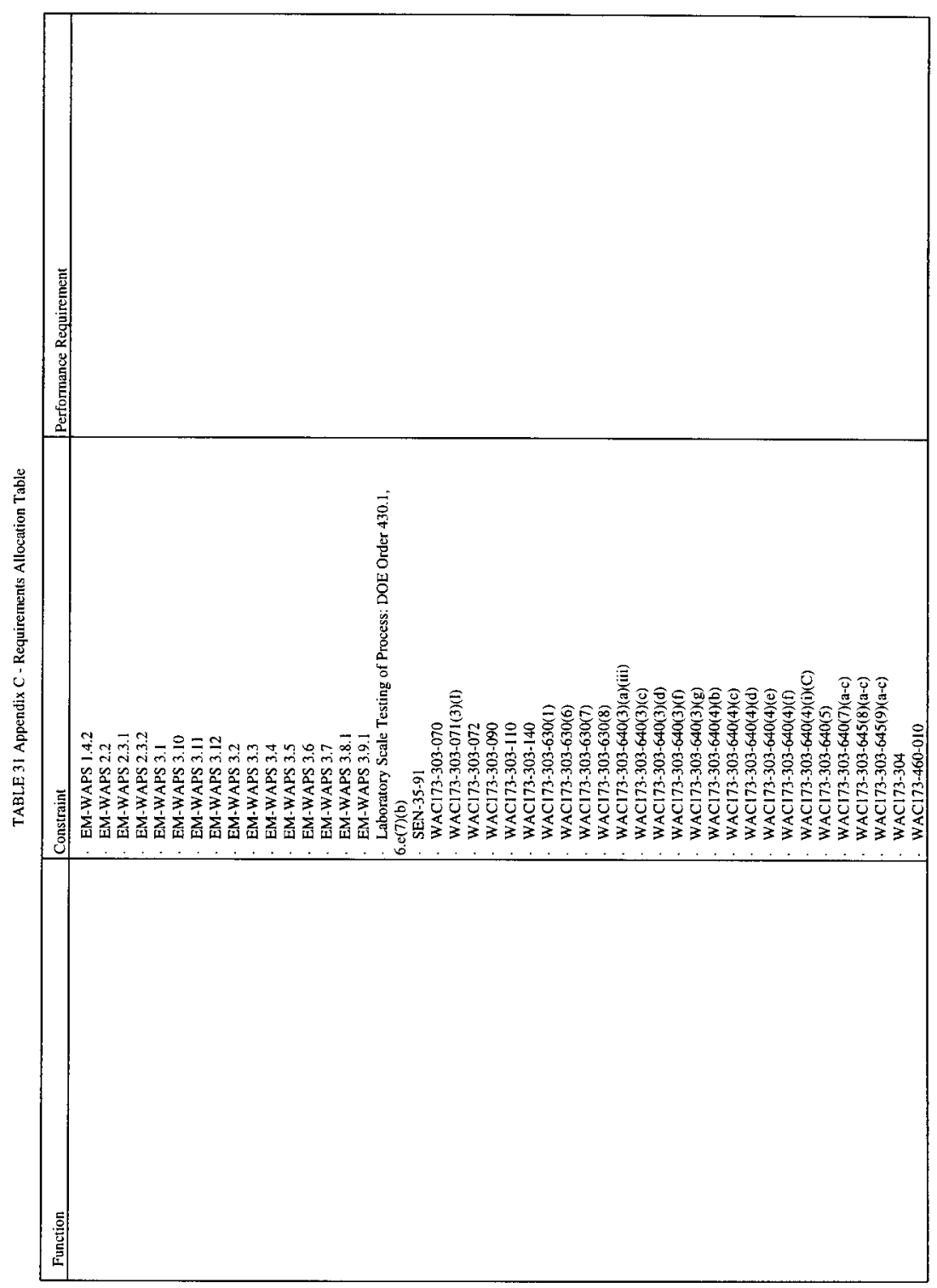




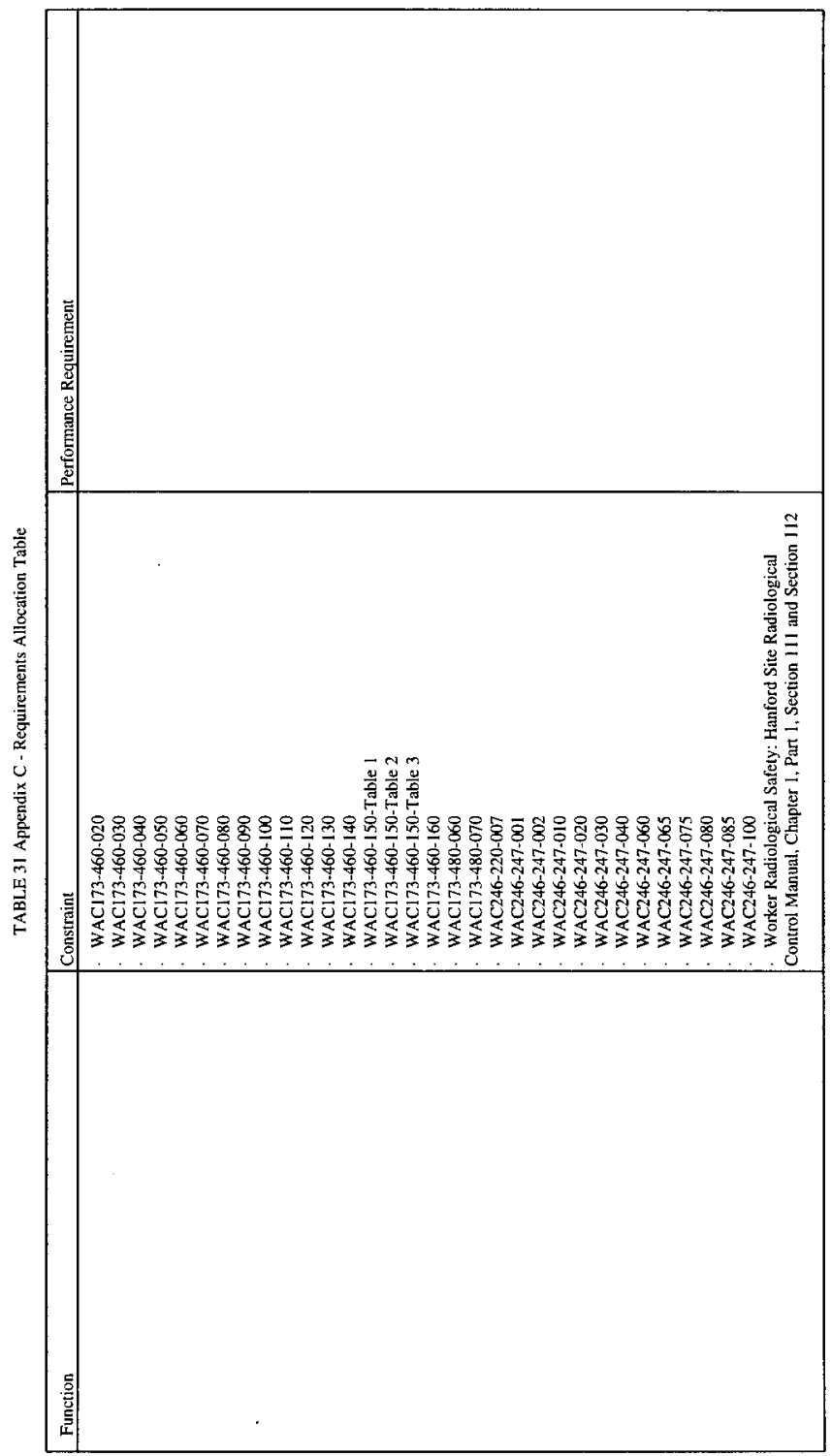

C-112 


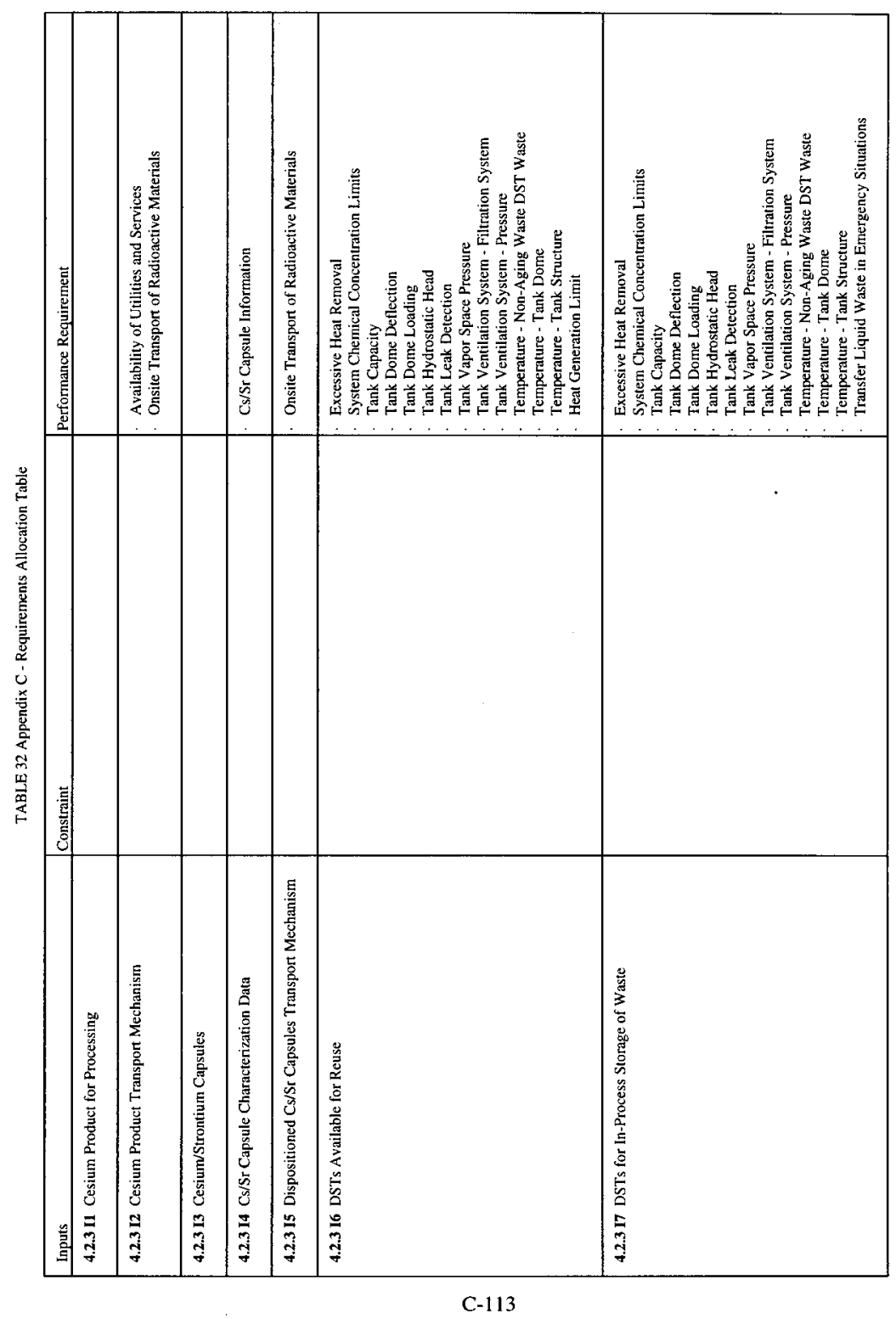


Revision 1

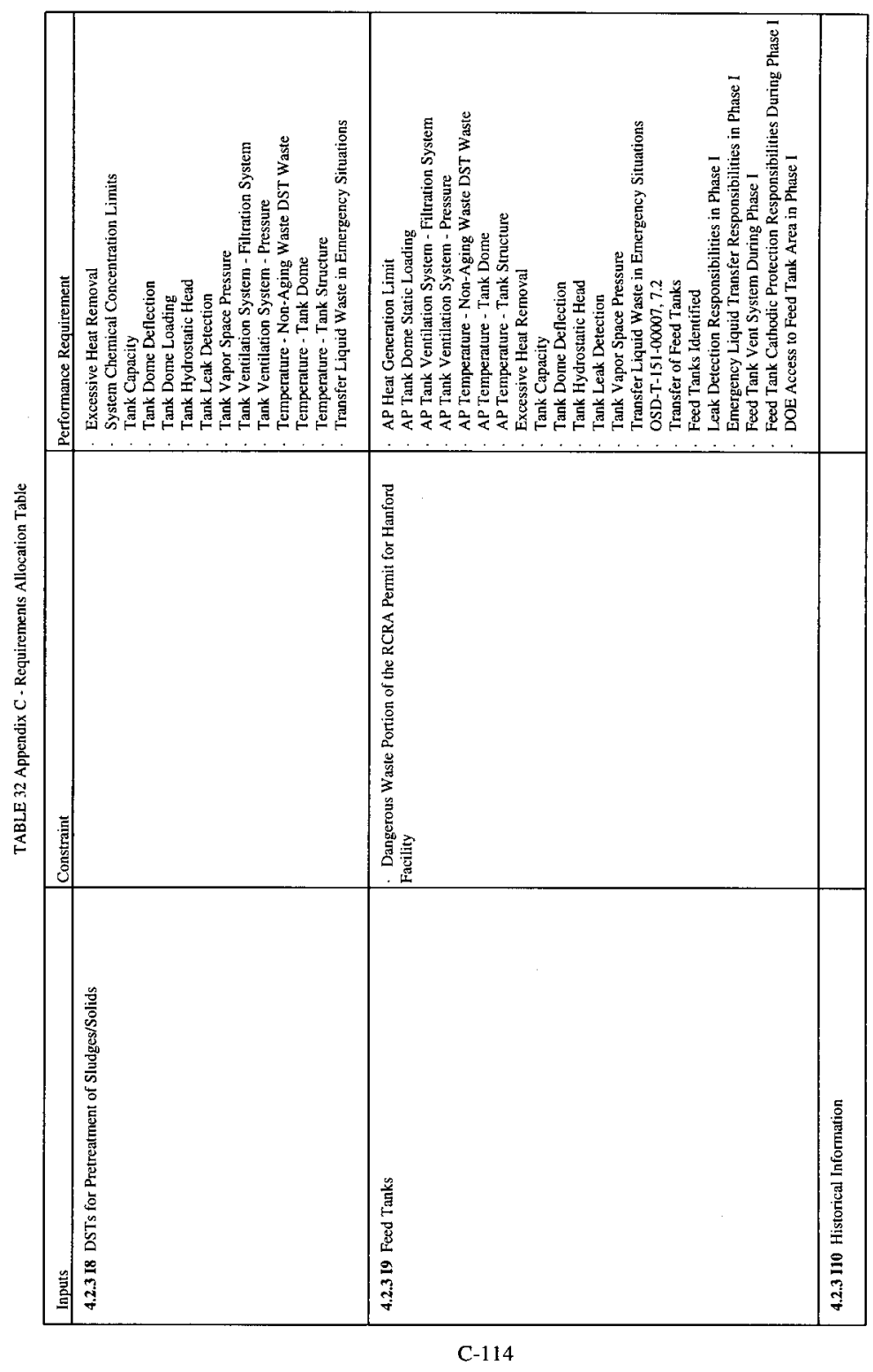




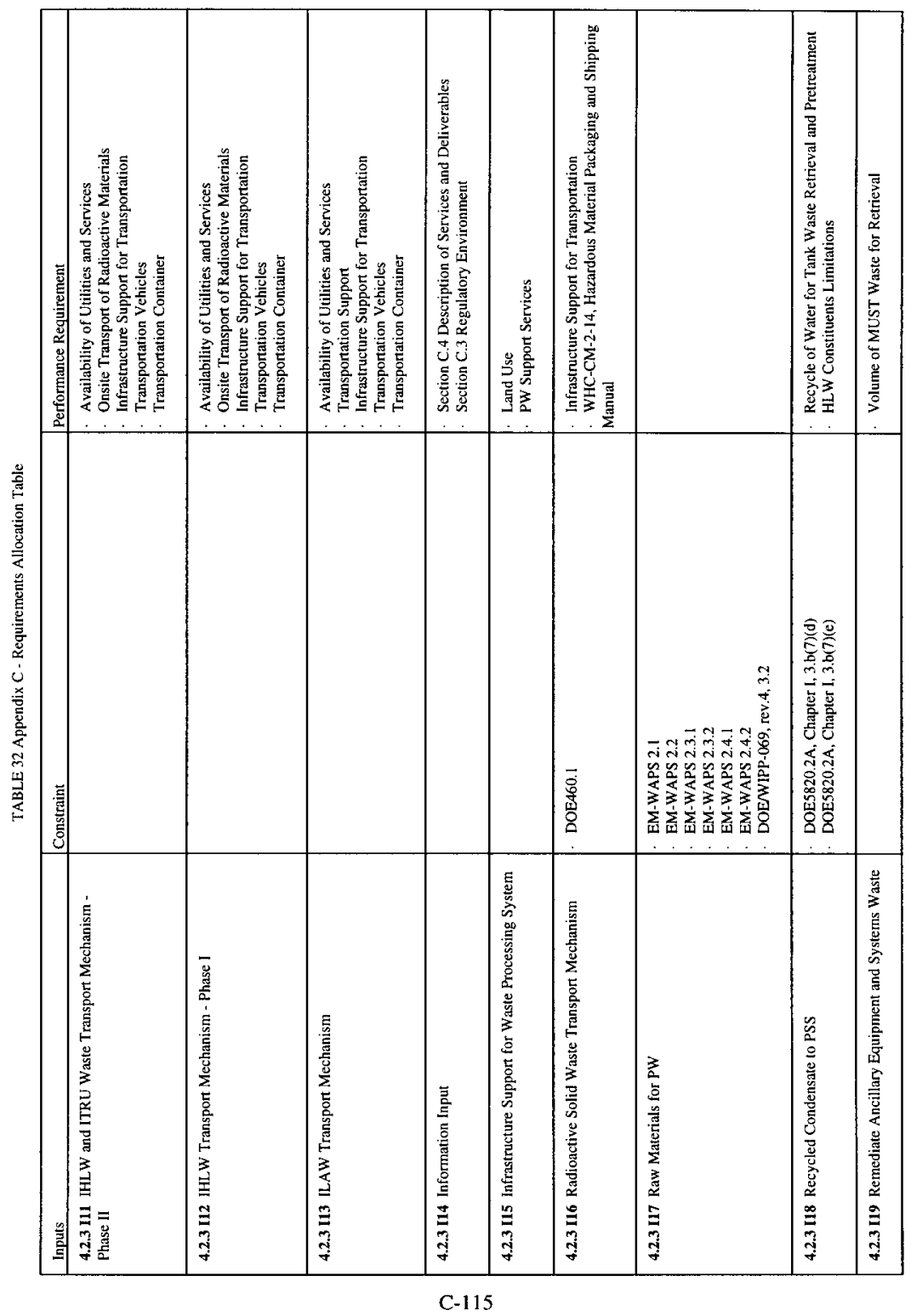




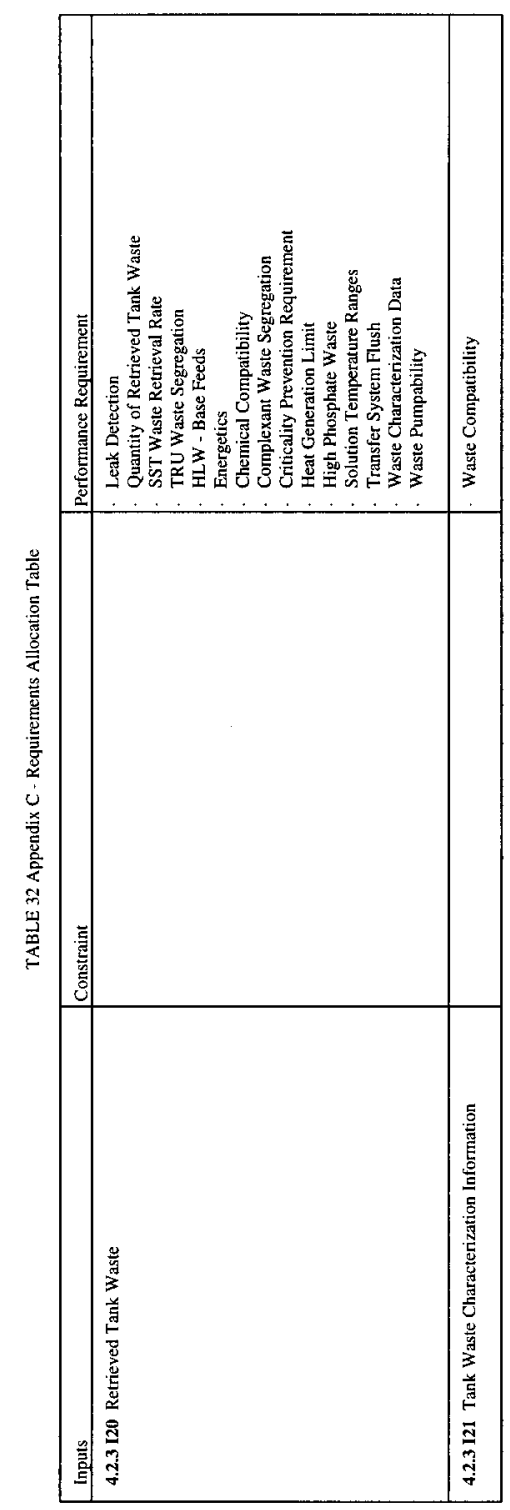




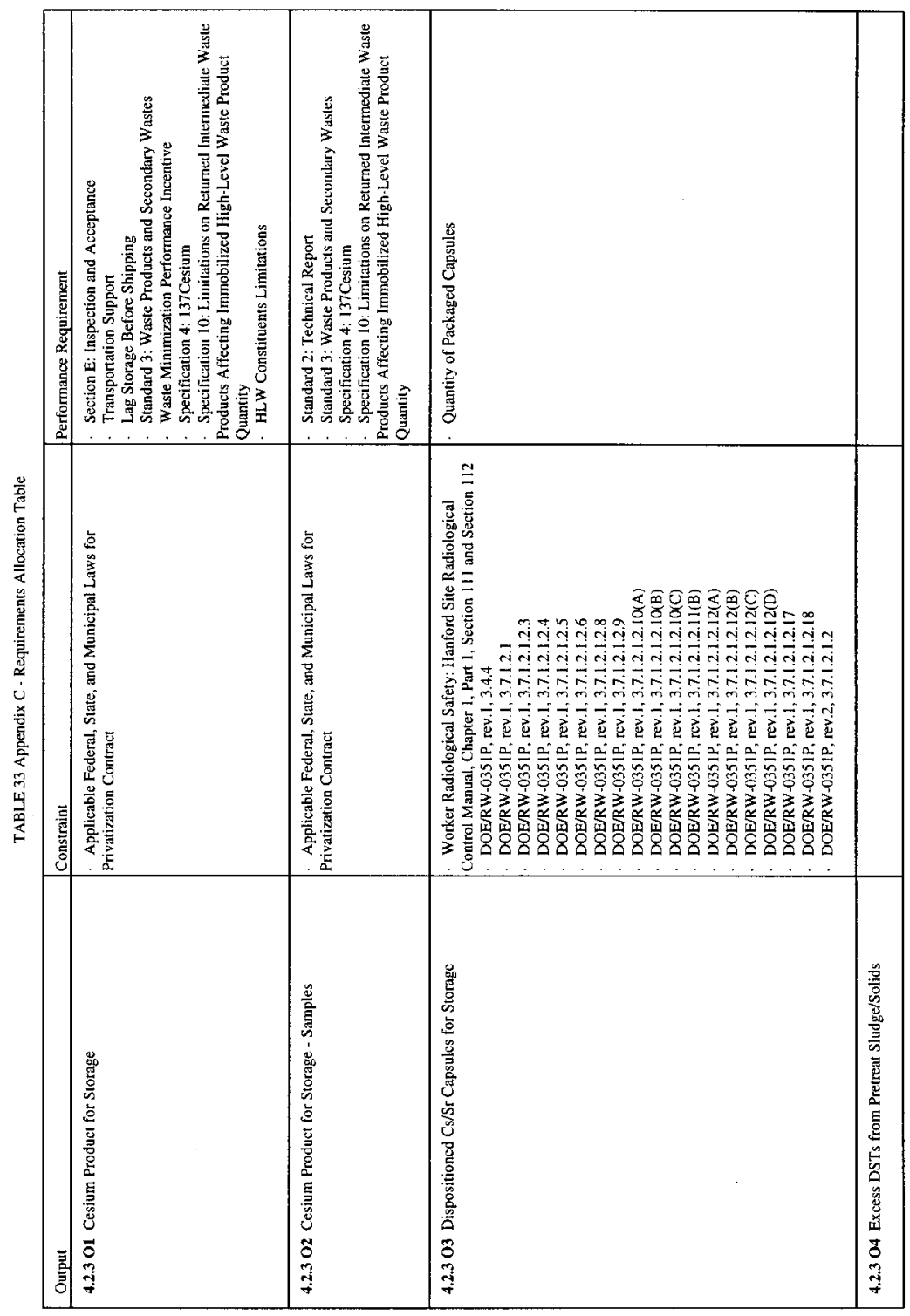




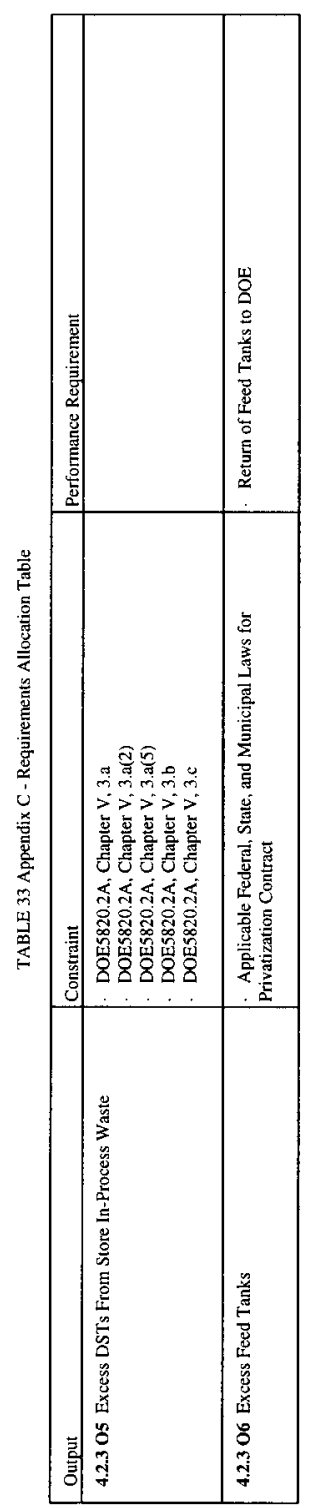




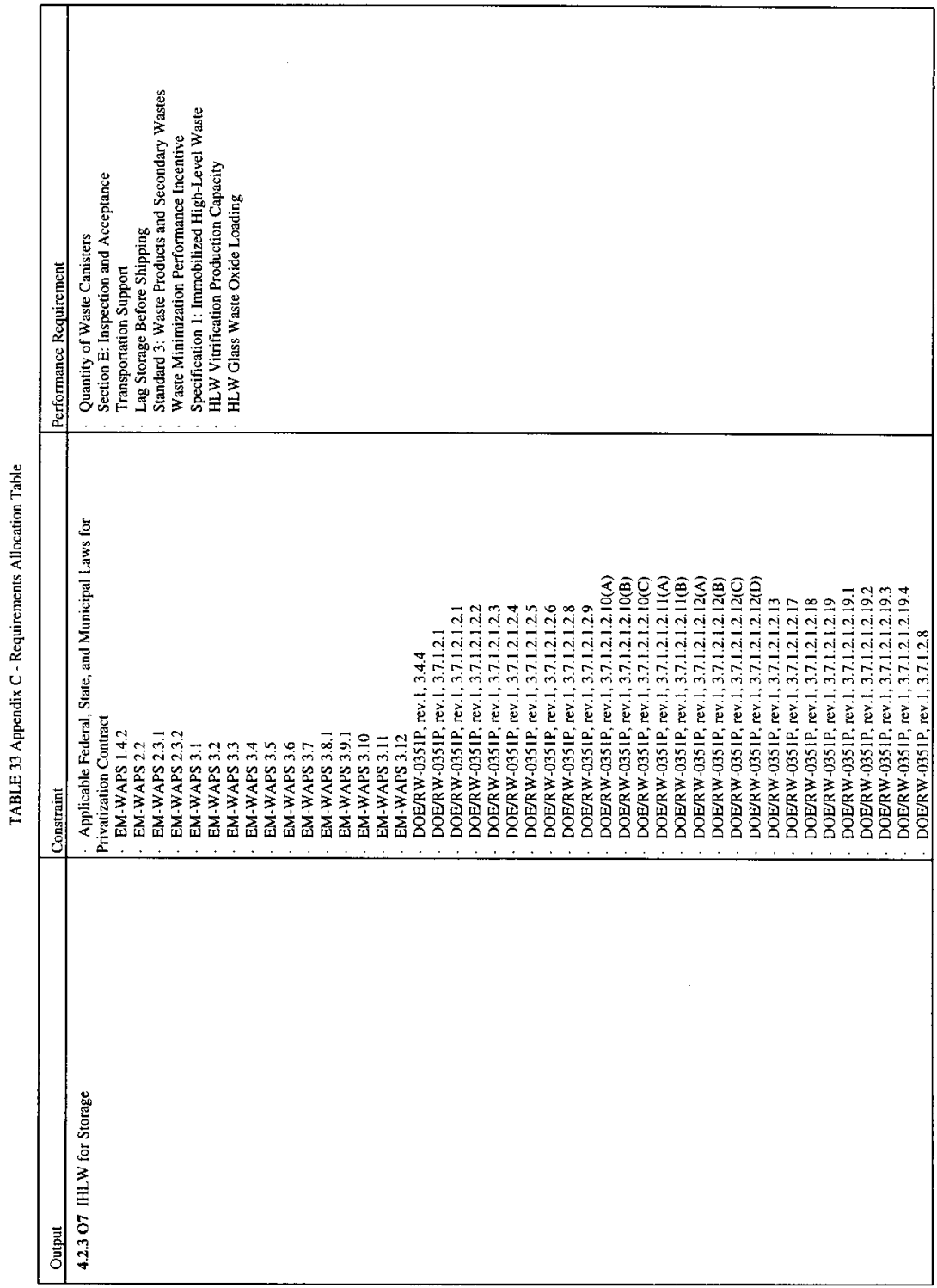




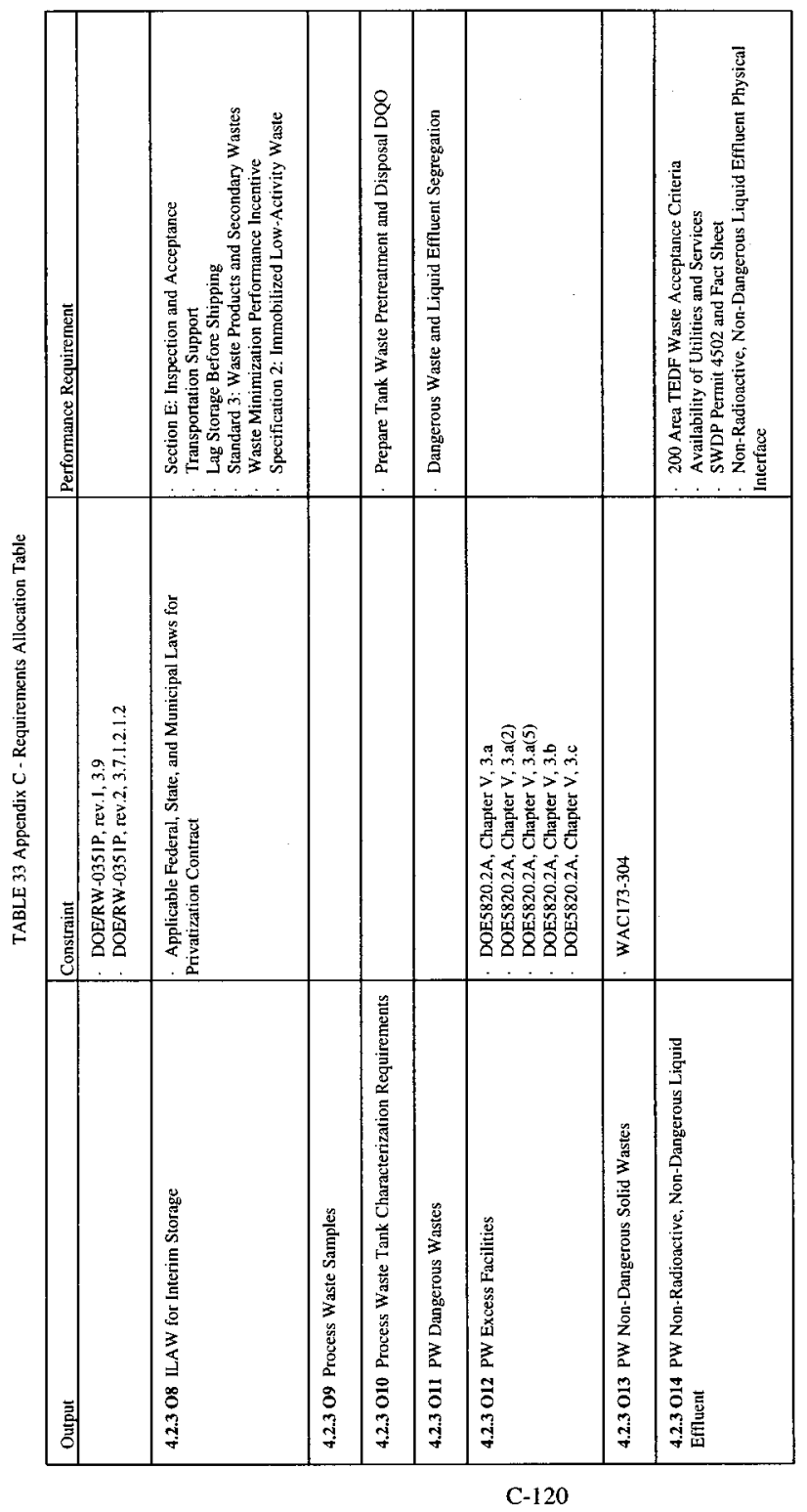




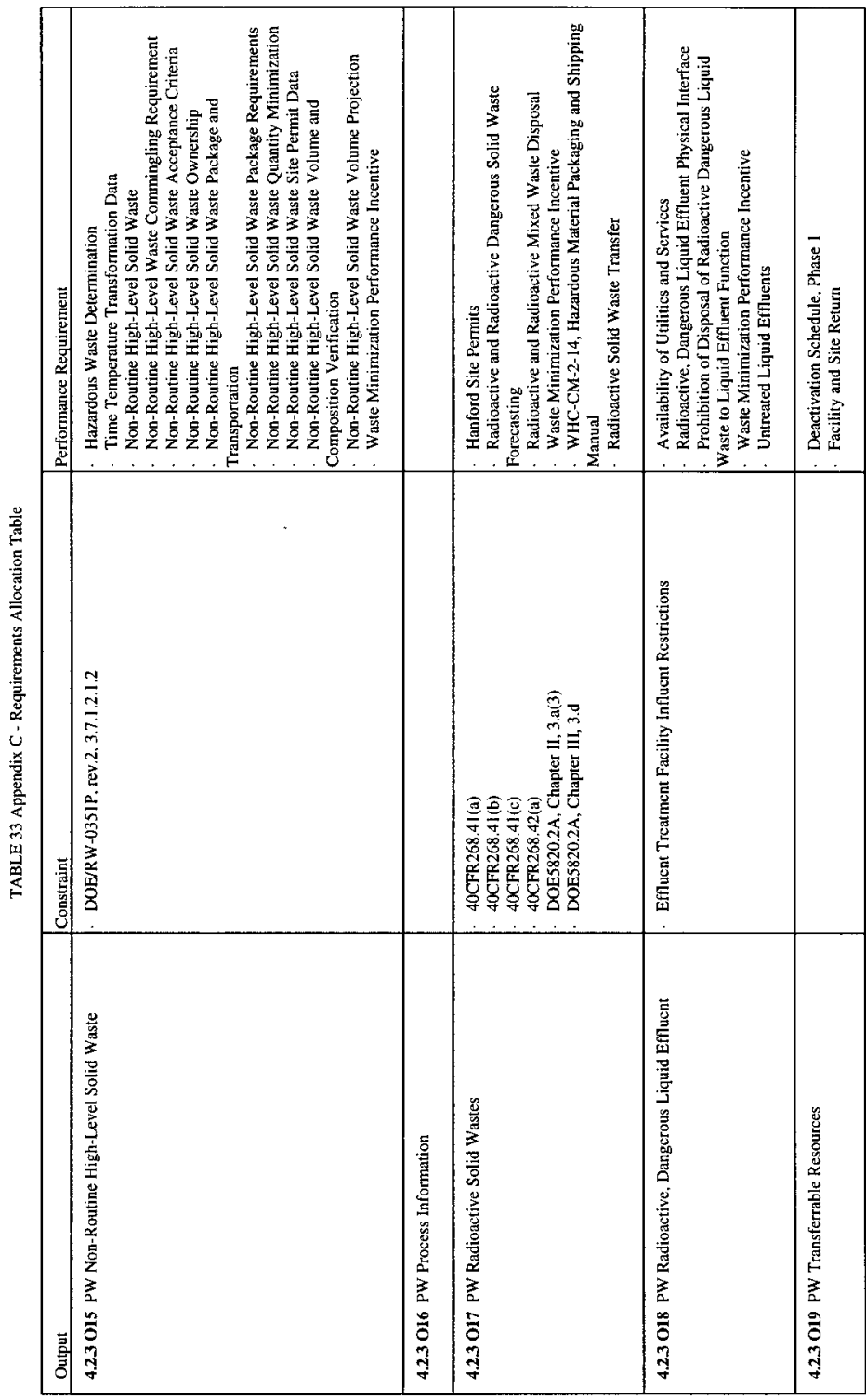

C- 121 
Revision 1

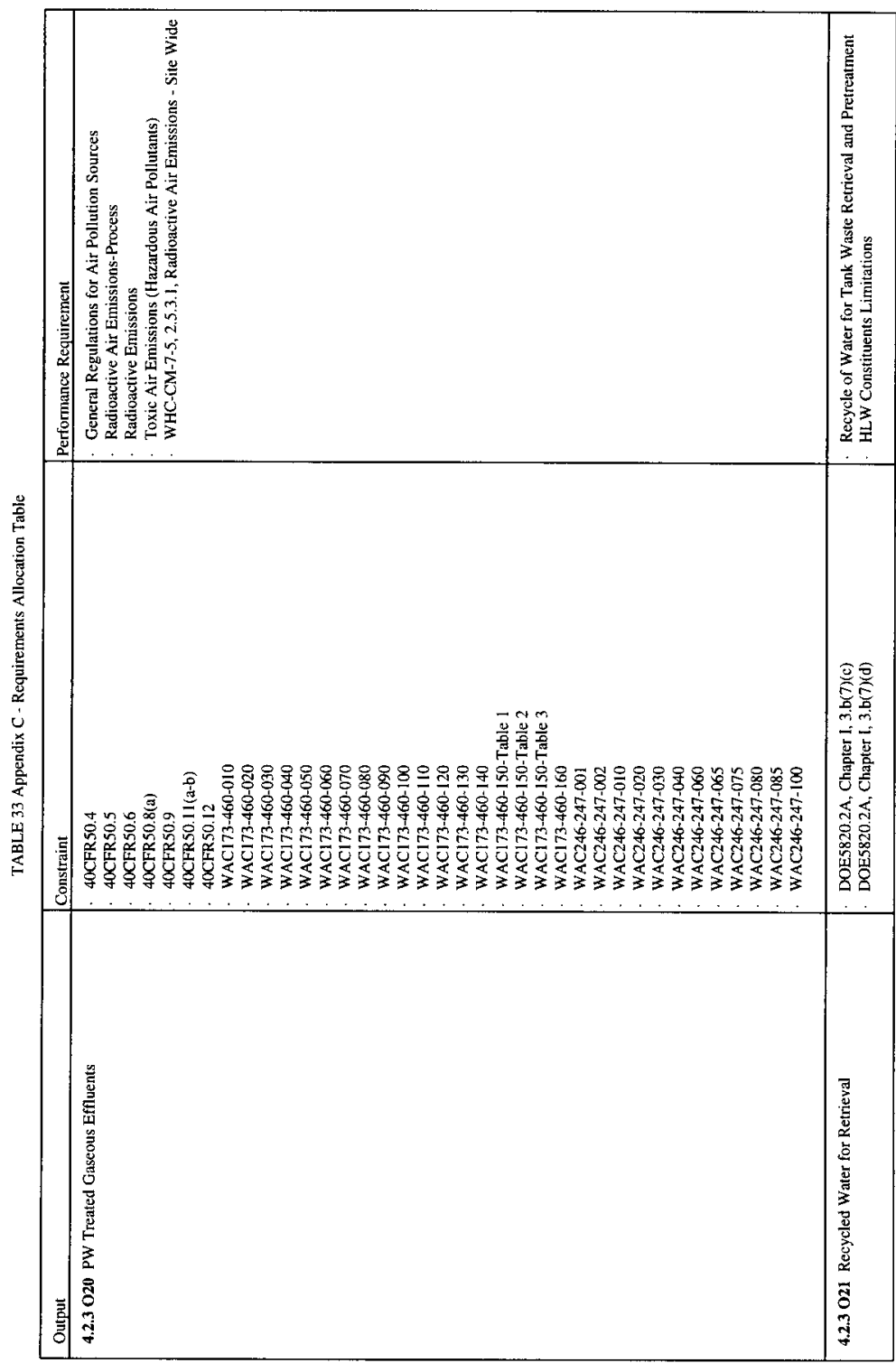

C- 122 


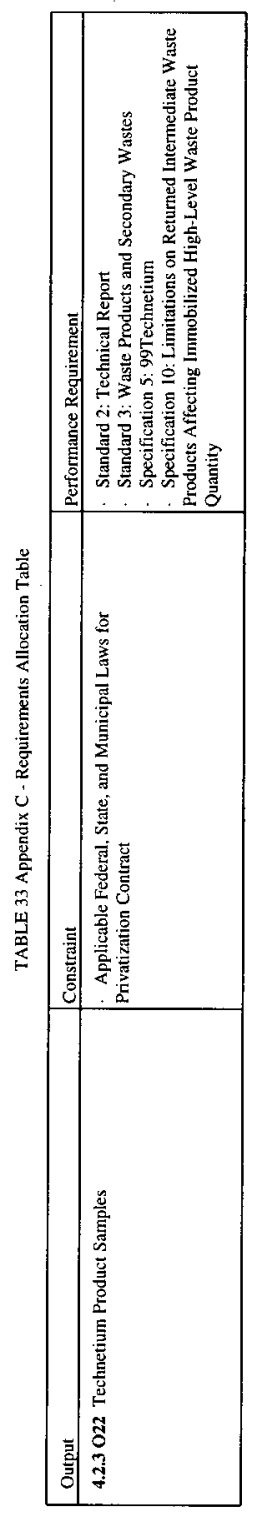


Revision 1 


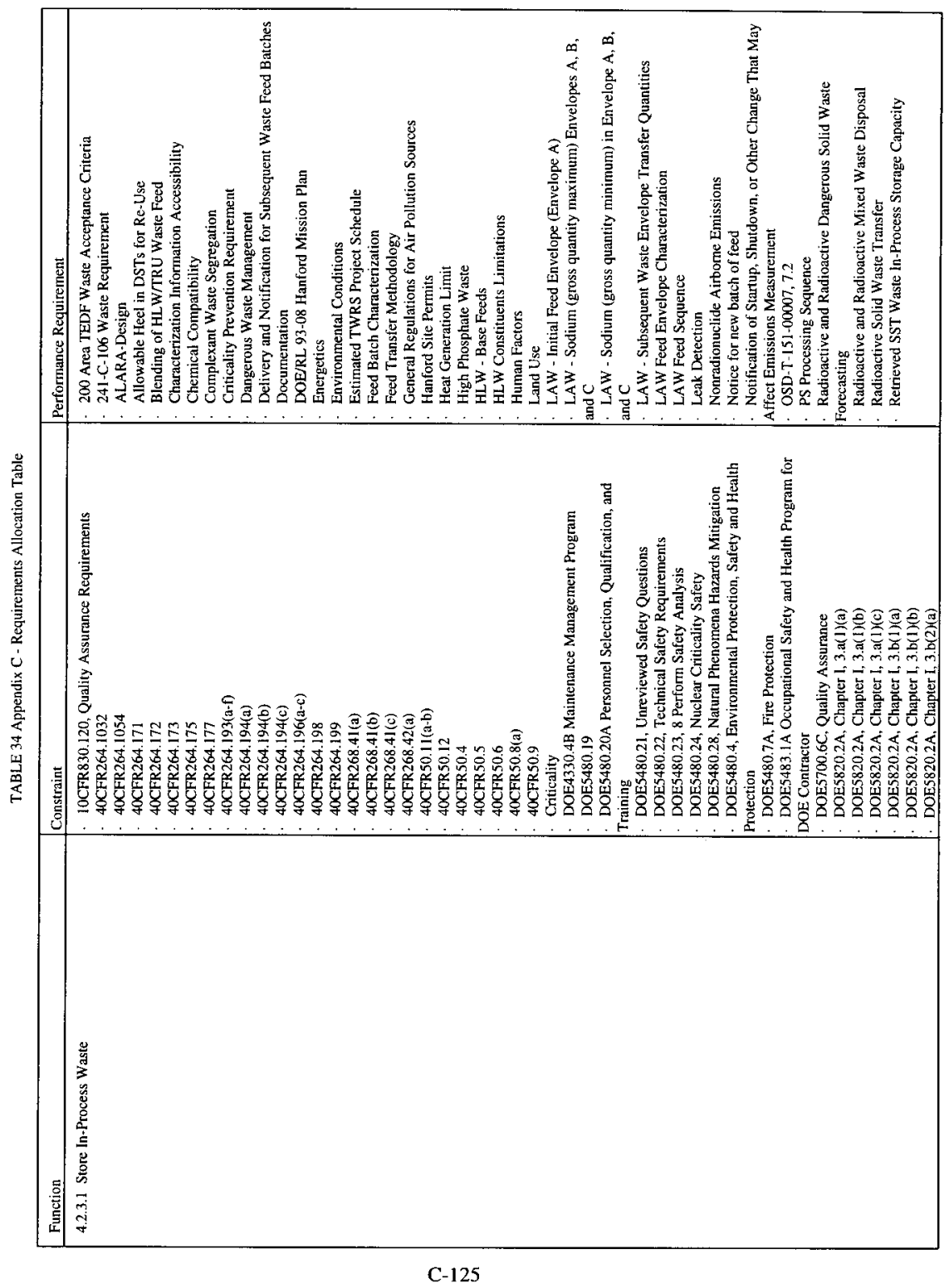




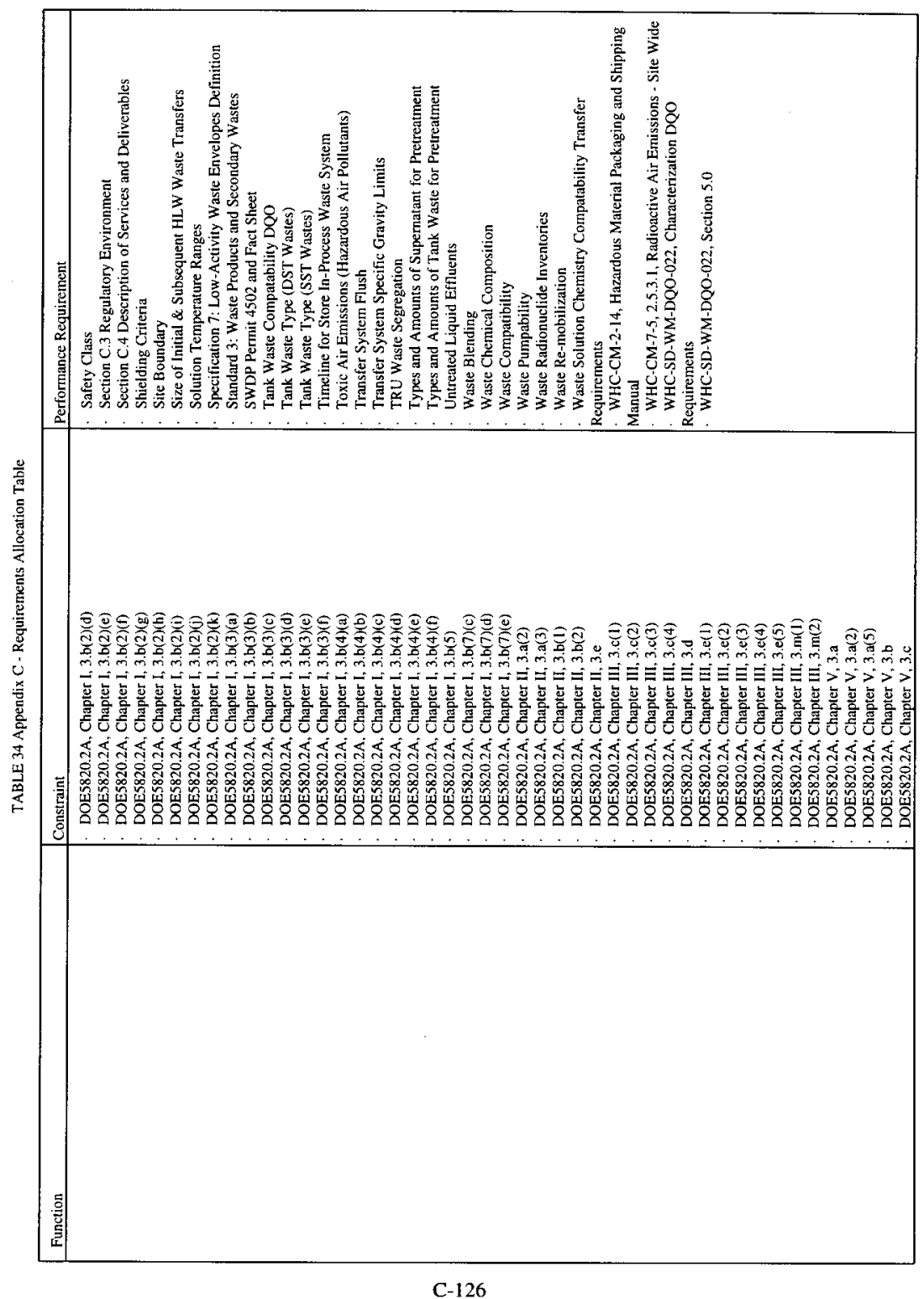




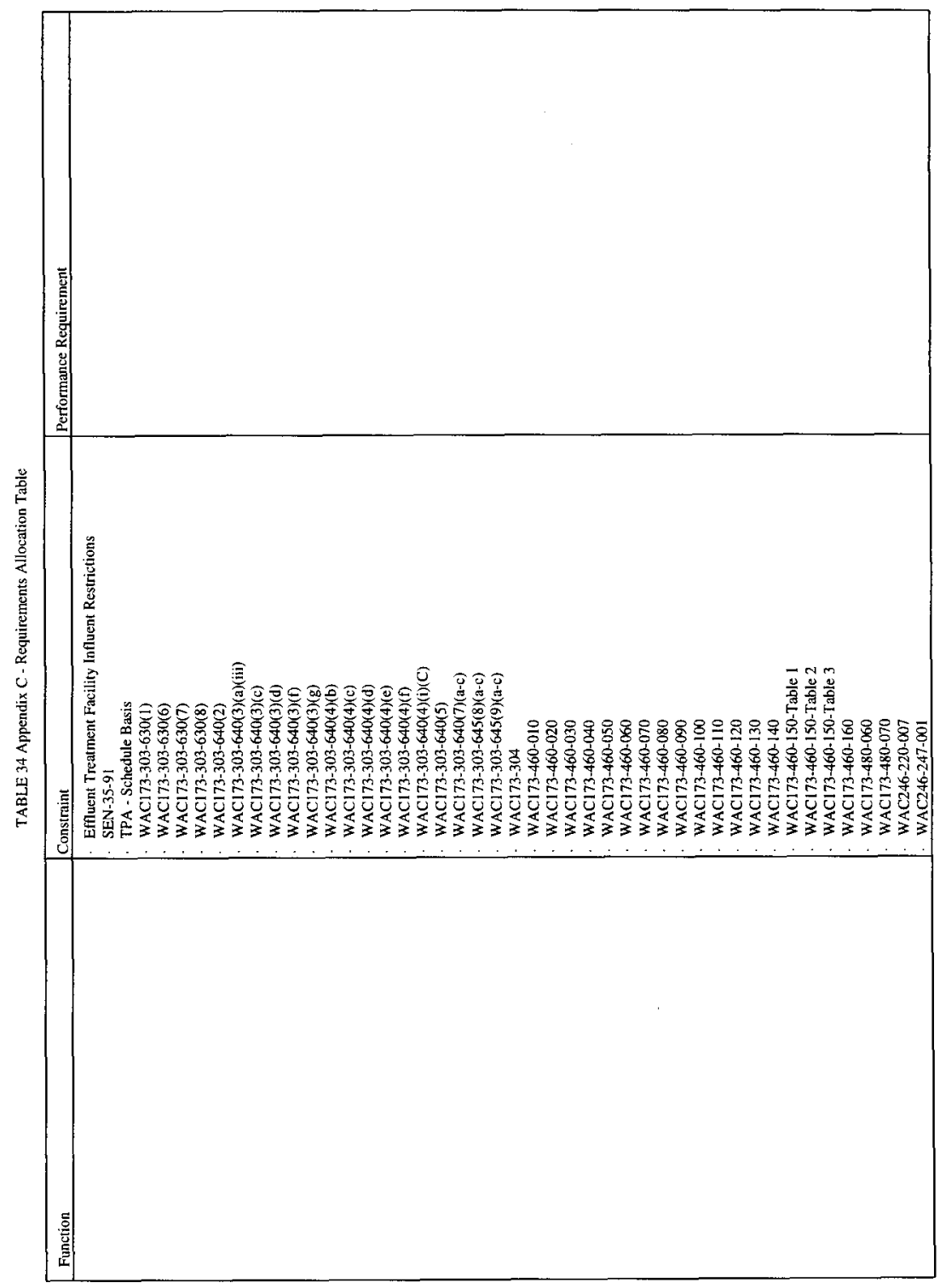


Revision 1

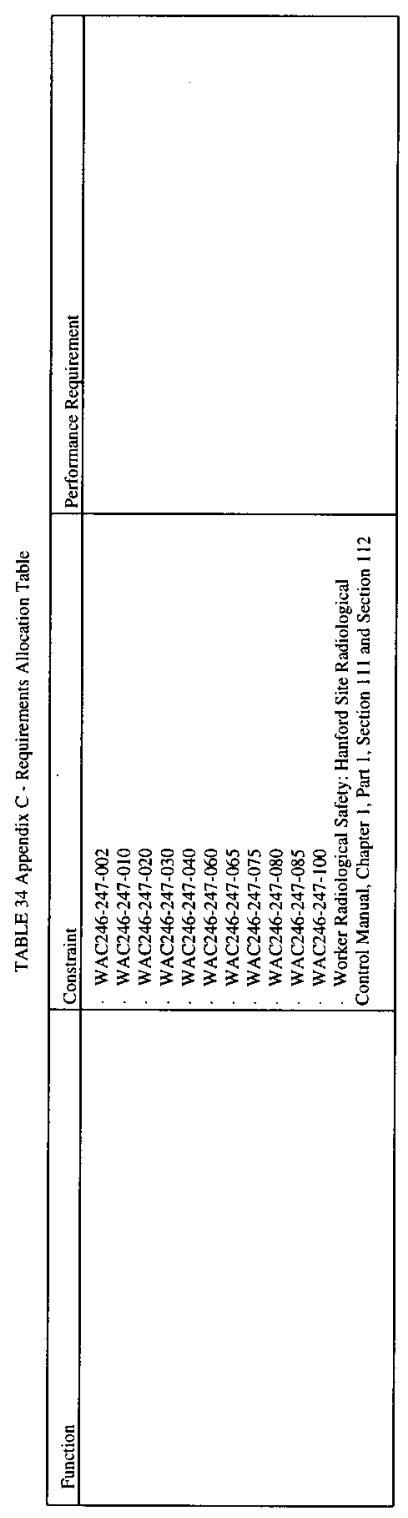

\section{C-128}




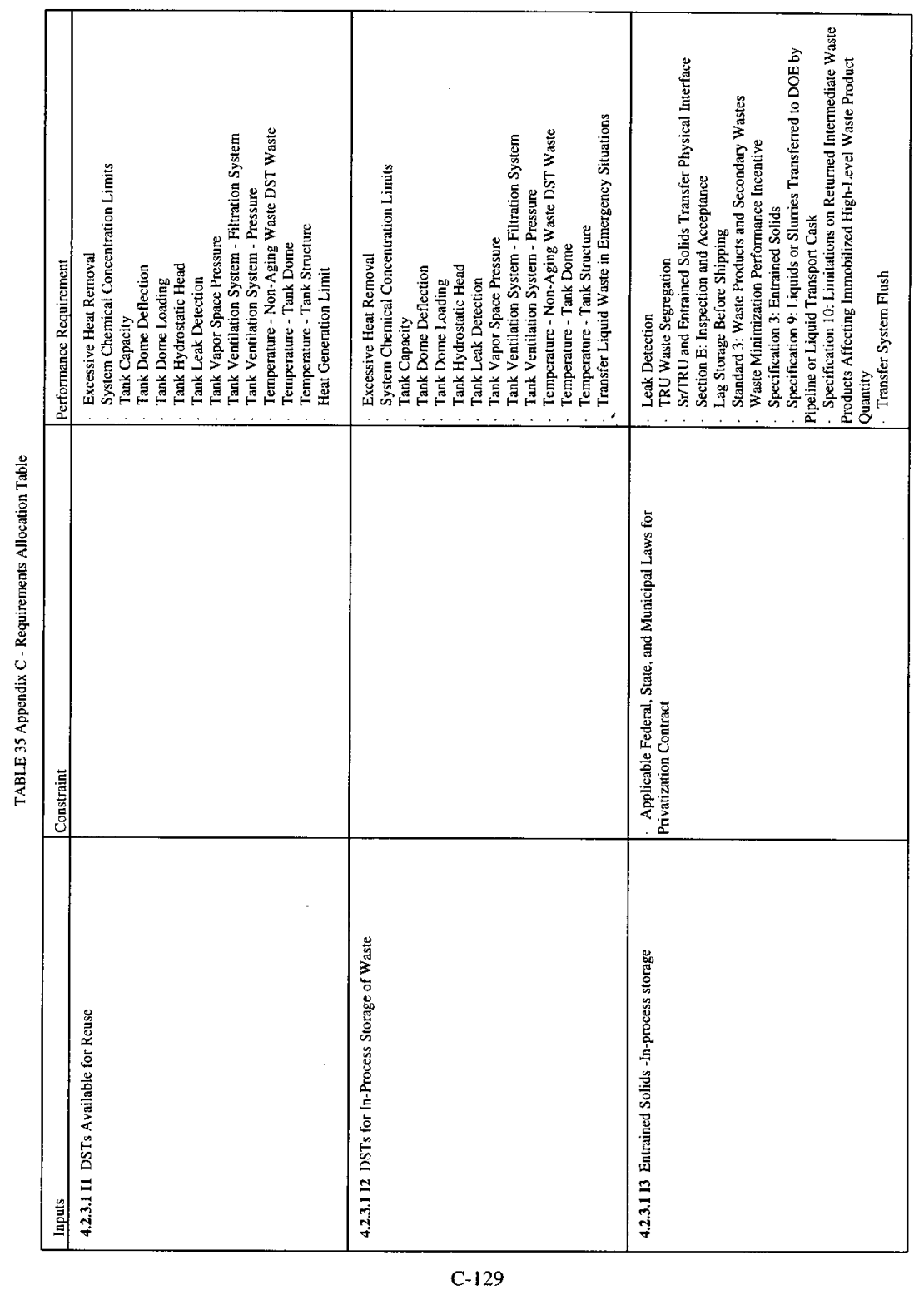




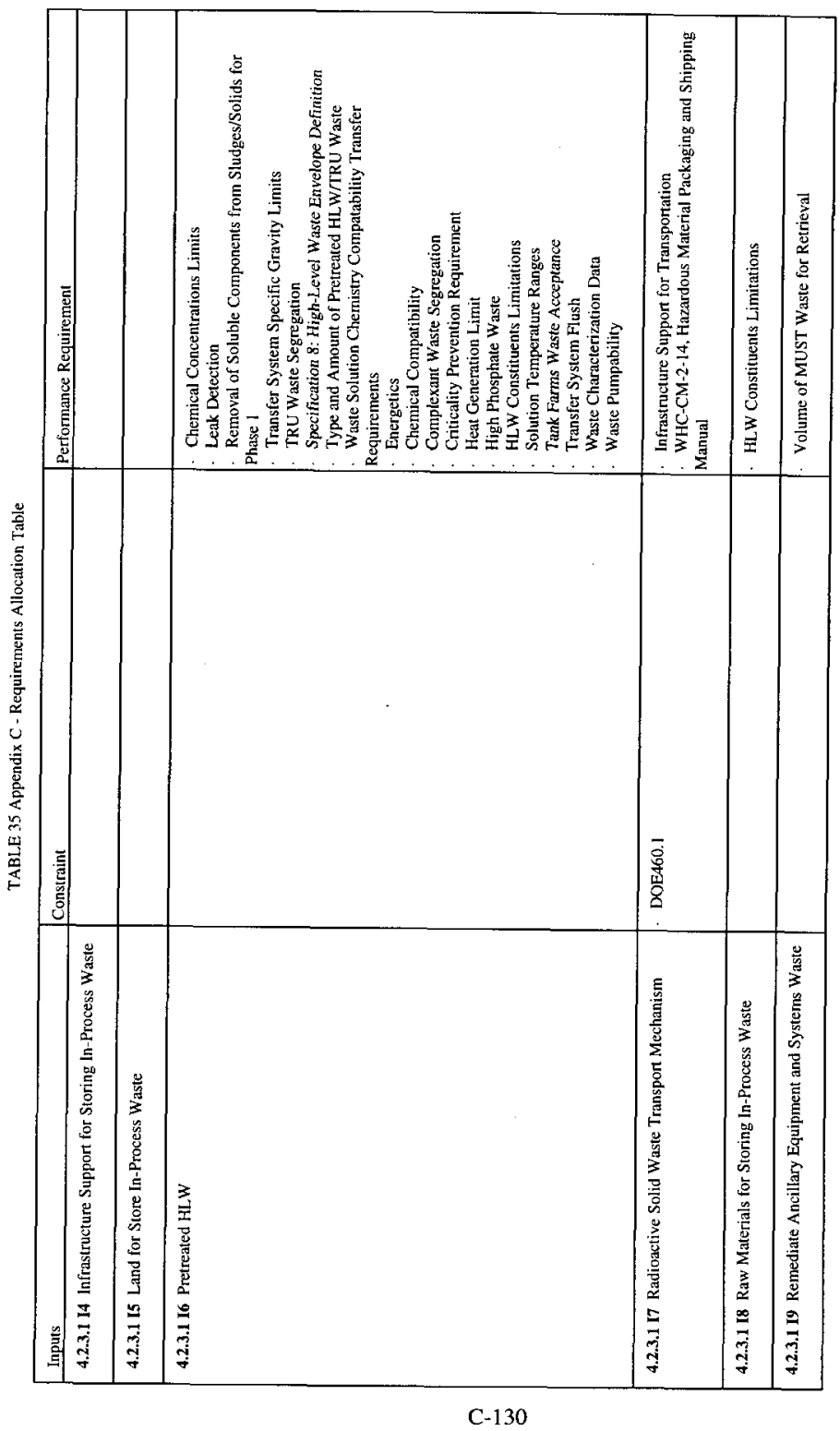


Revision 1

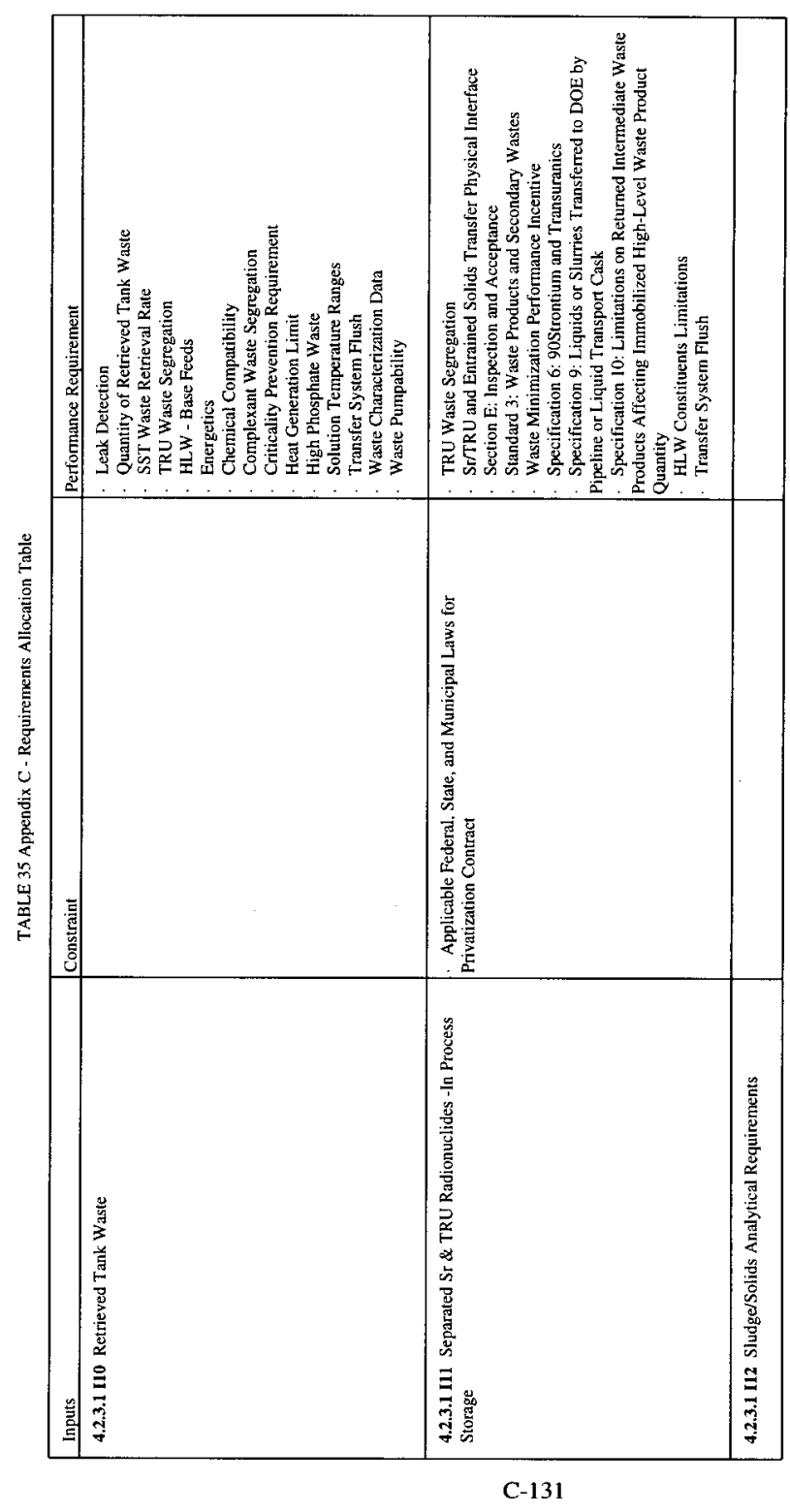


Revision 1

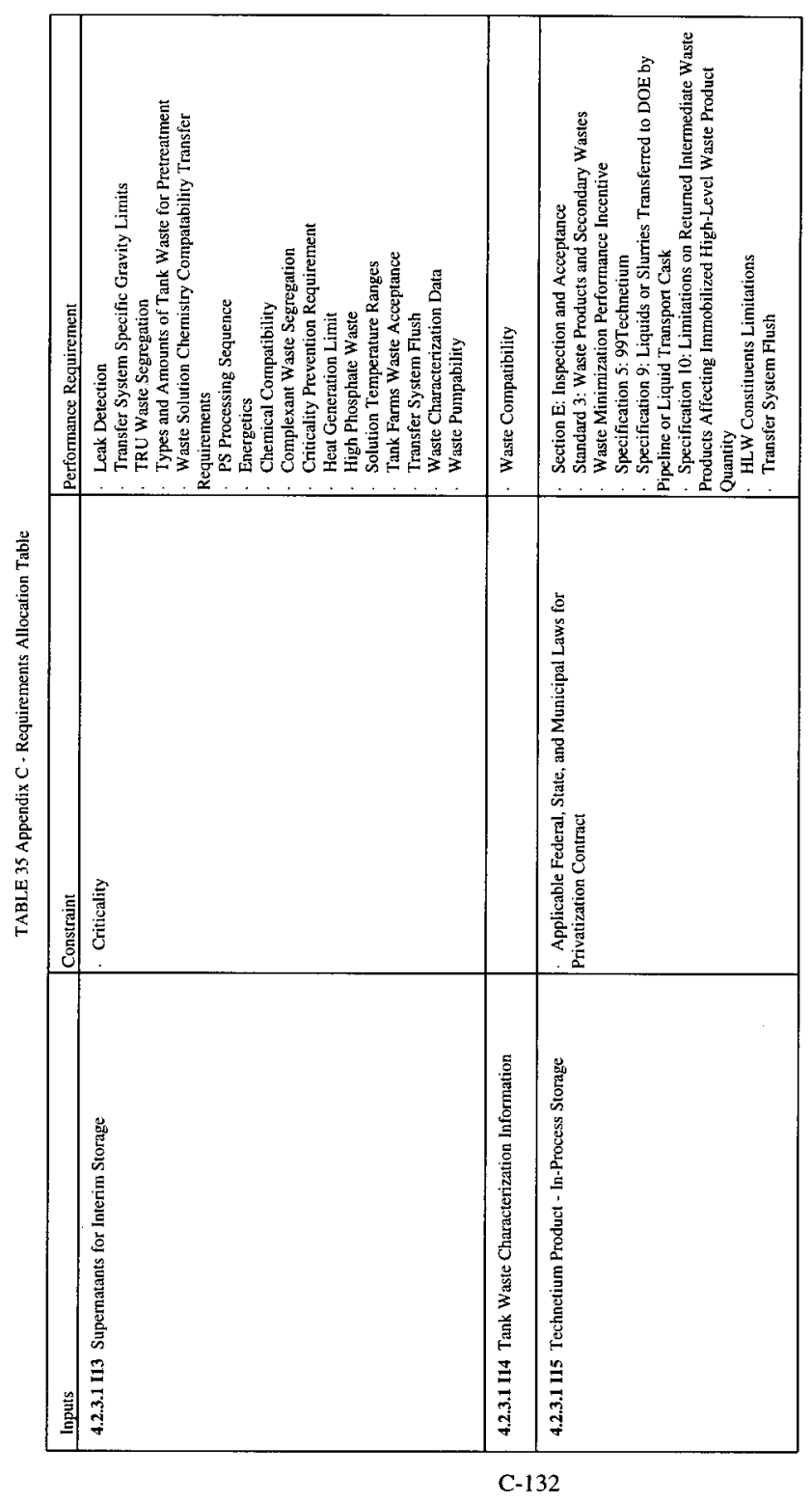


Revision 1

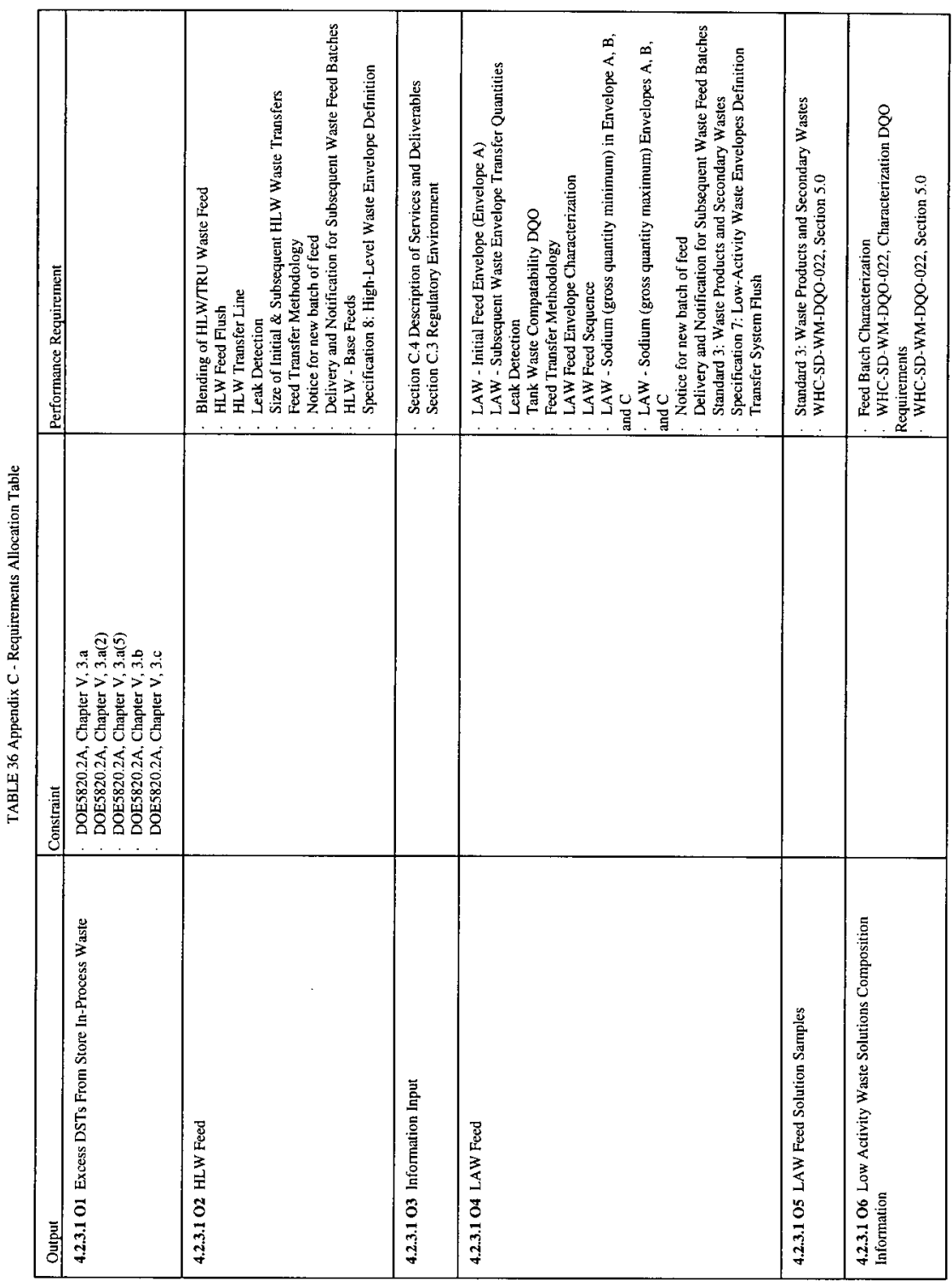

C-133 


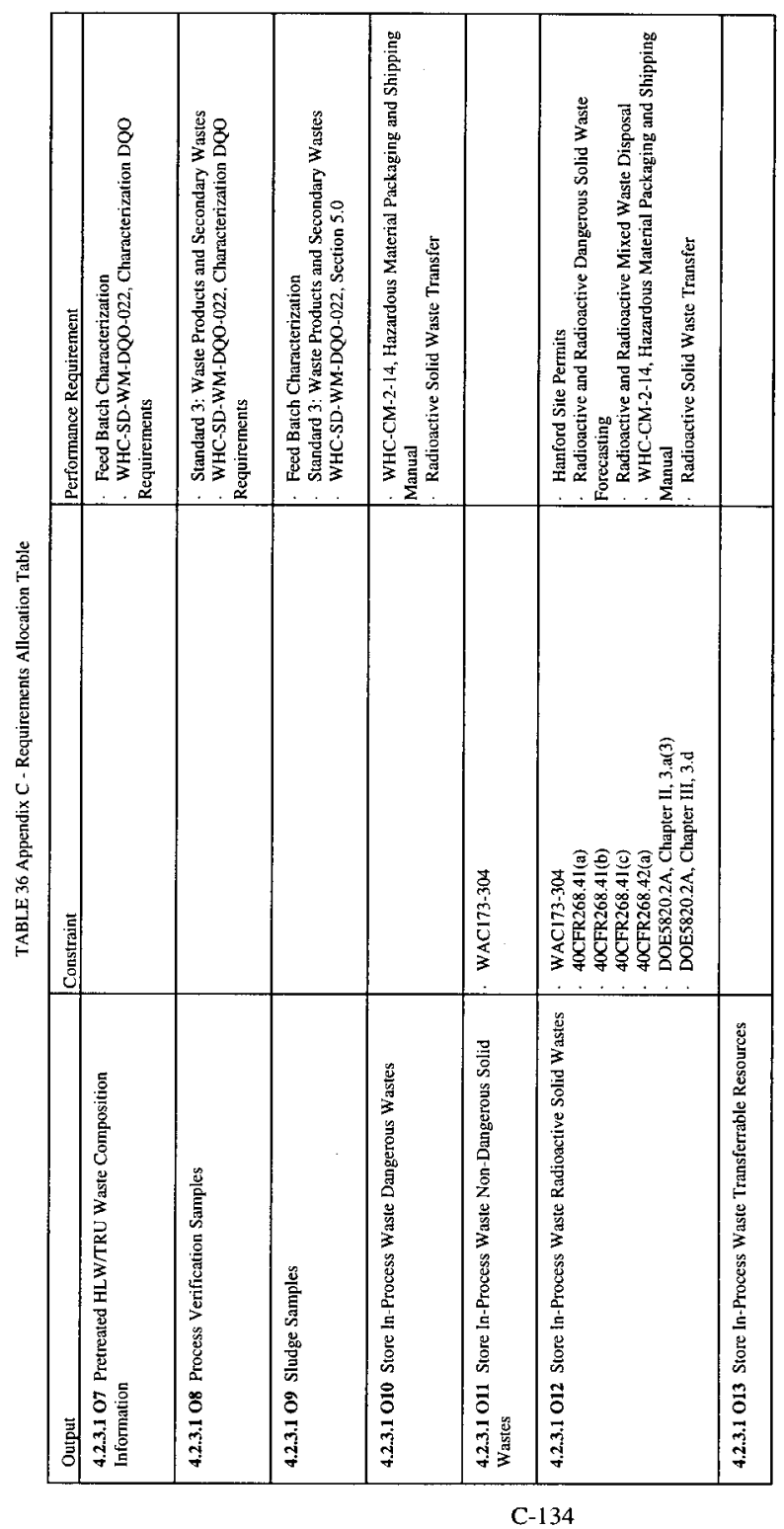




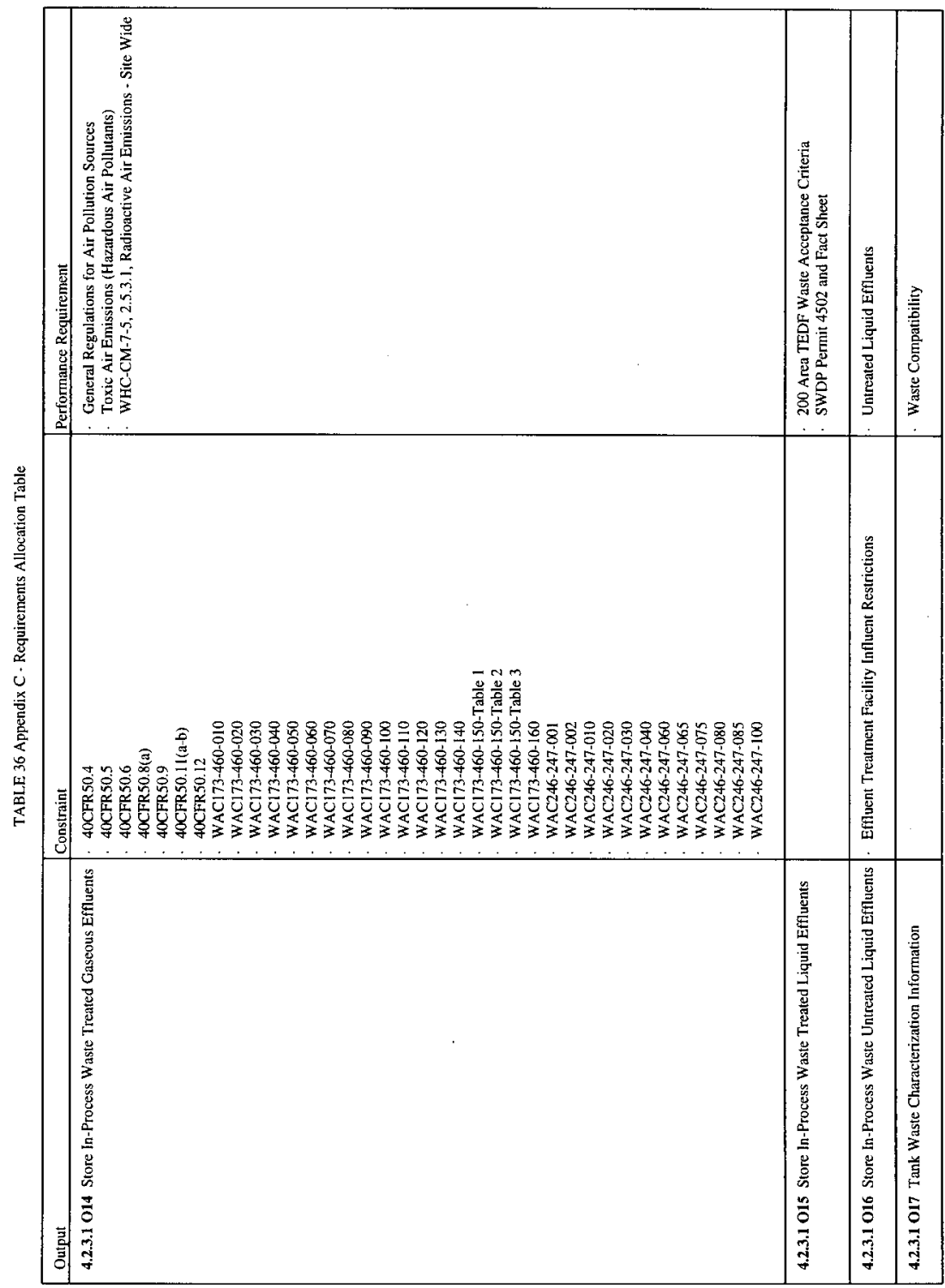

C-135 


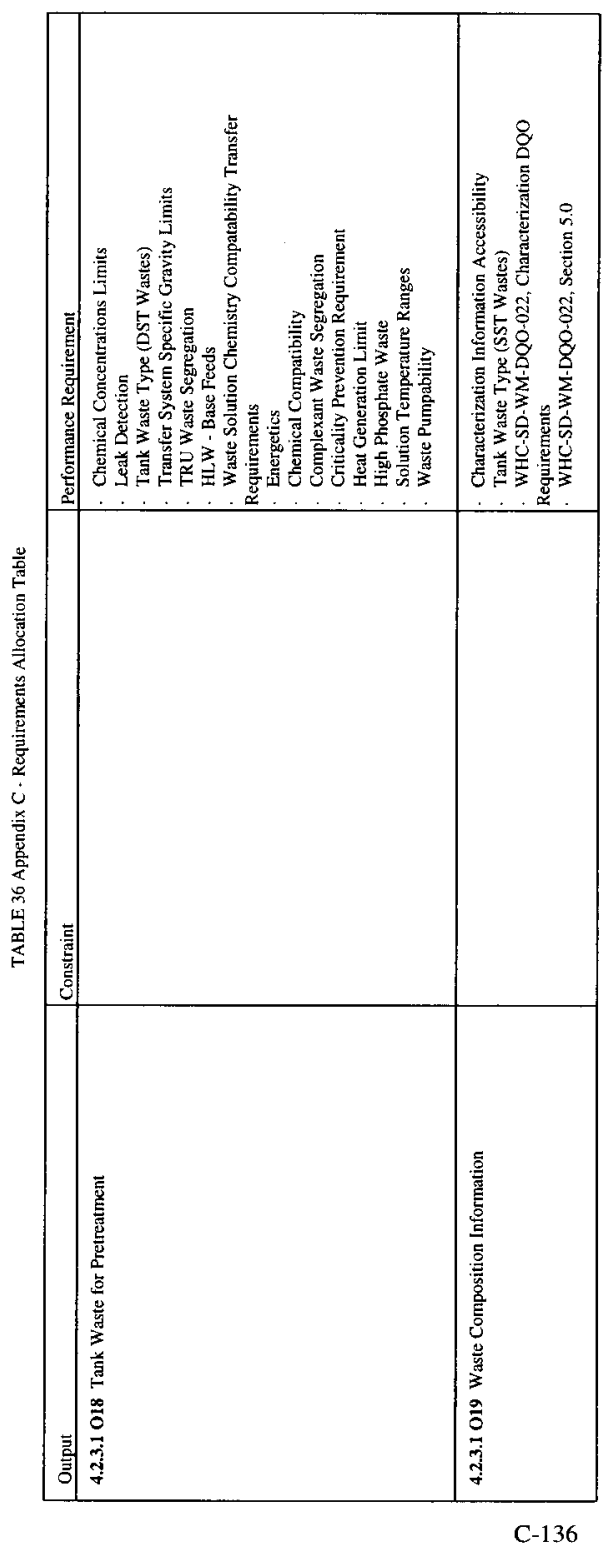


Revision 1 


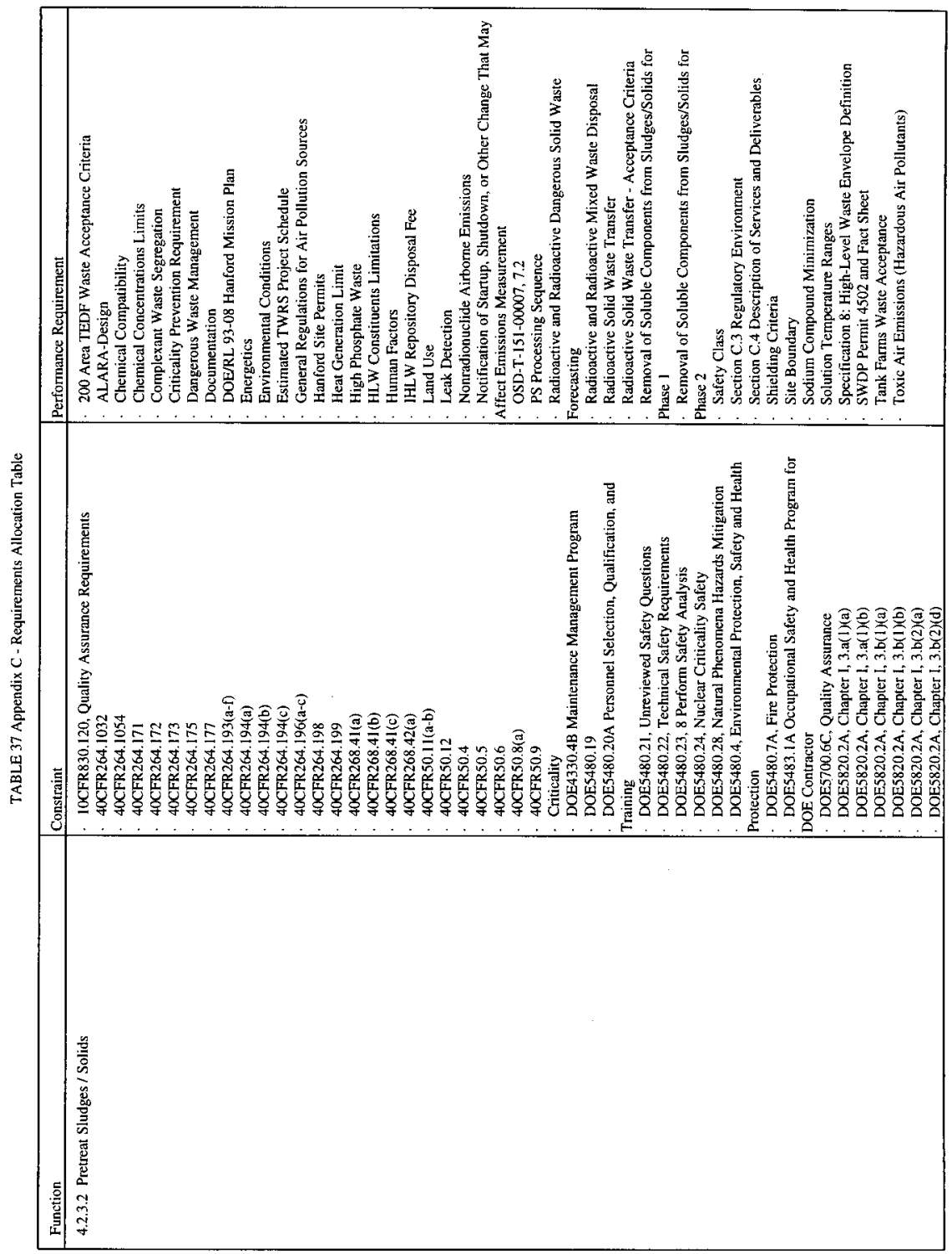




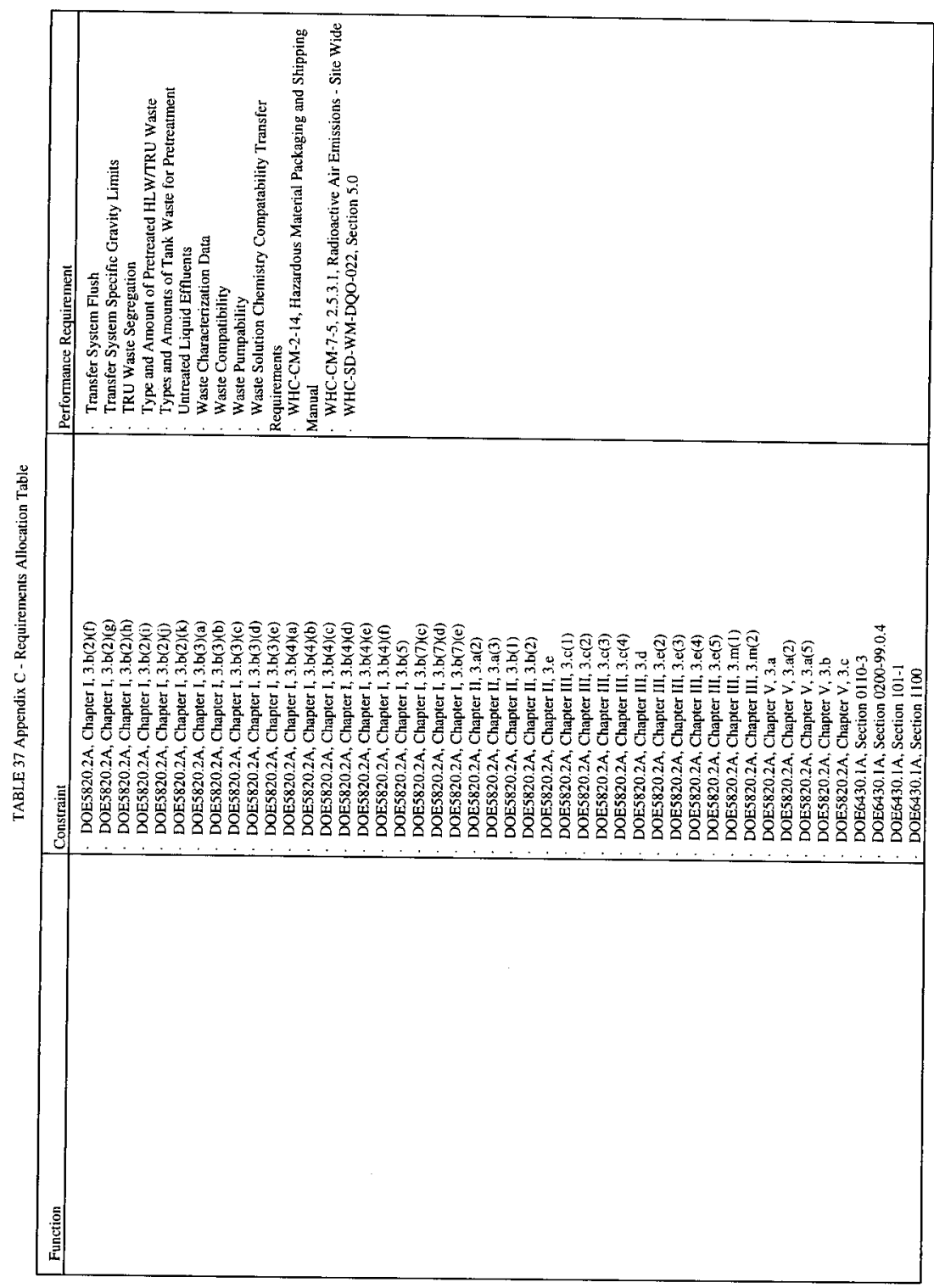




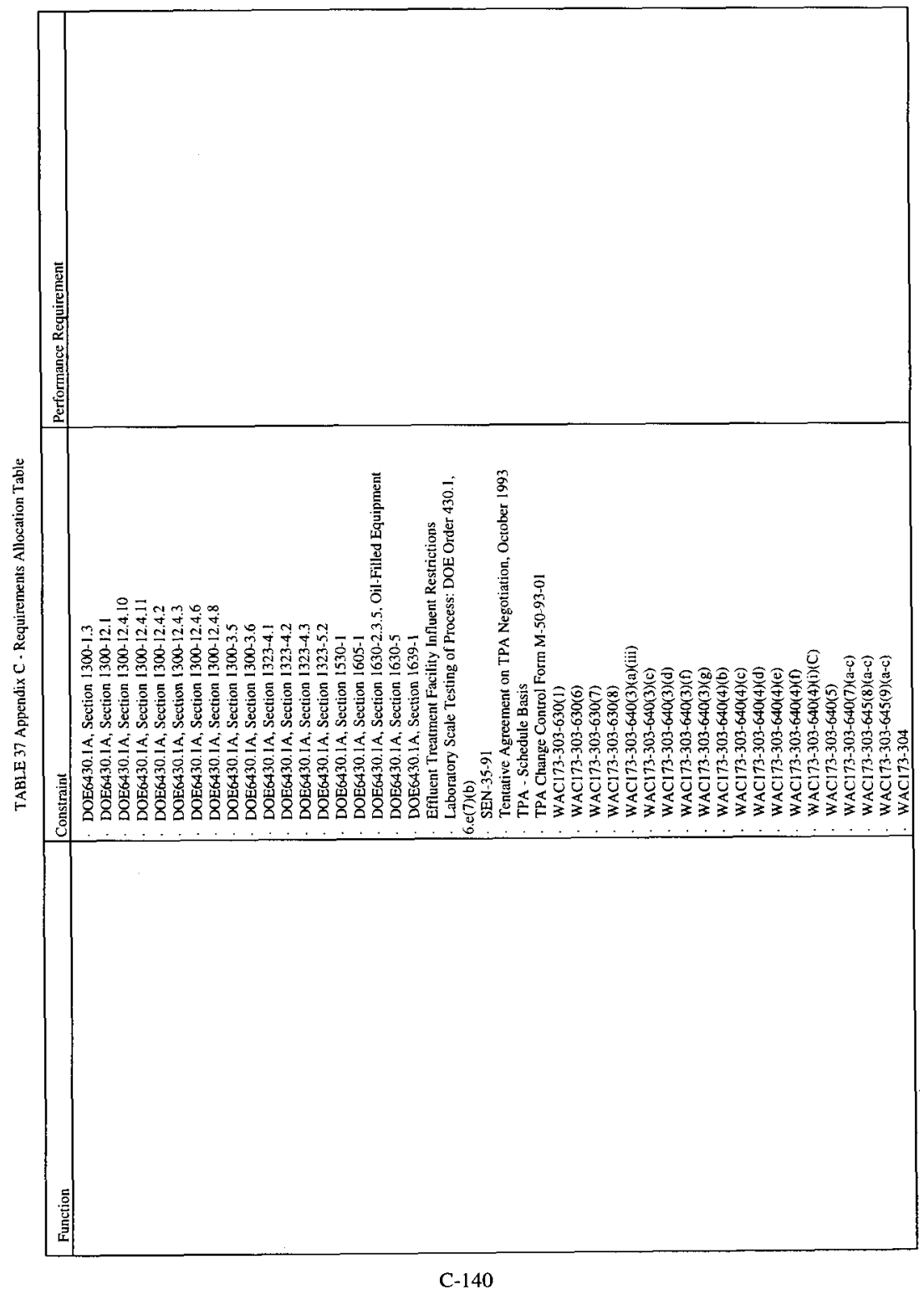




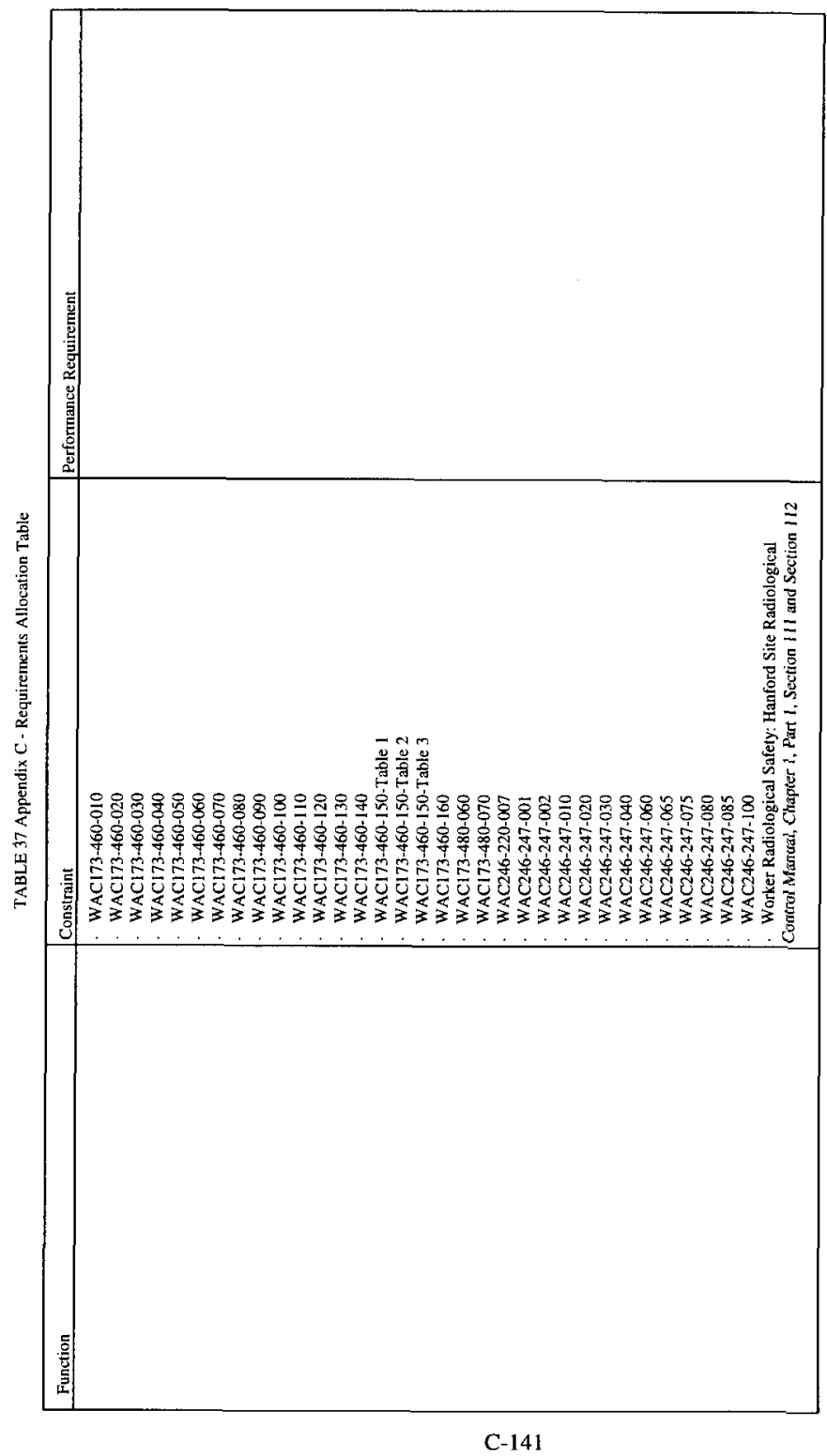


Revision 1

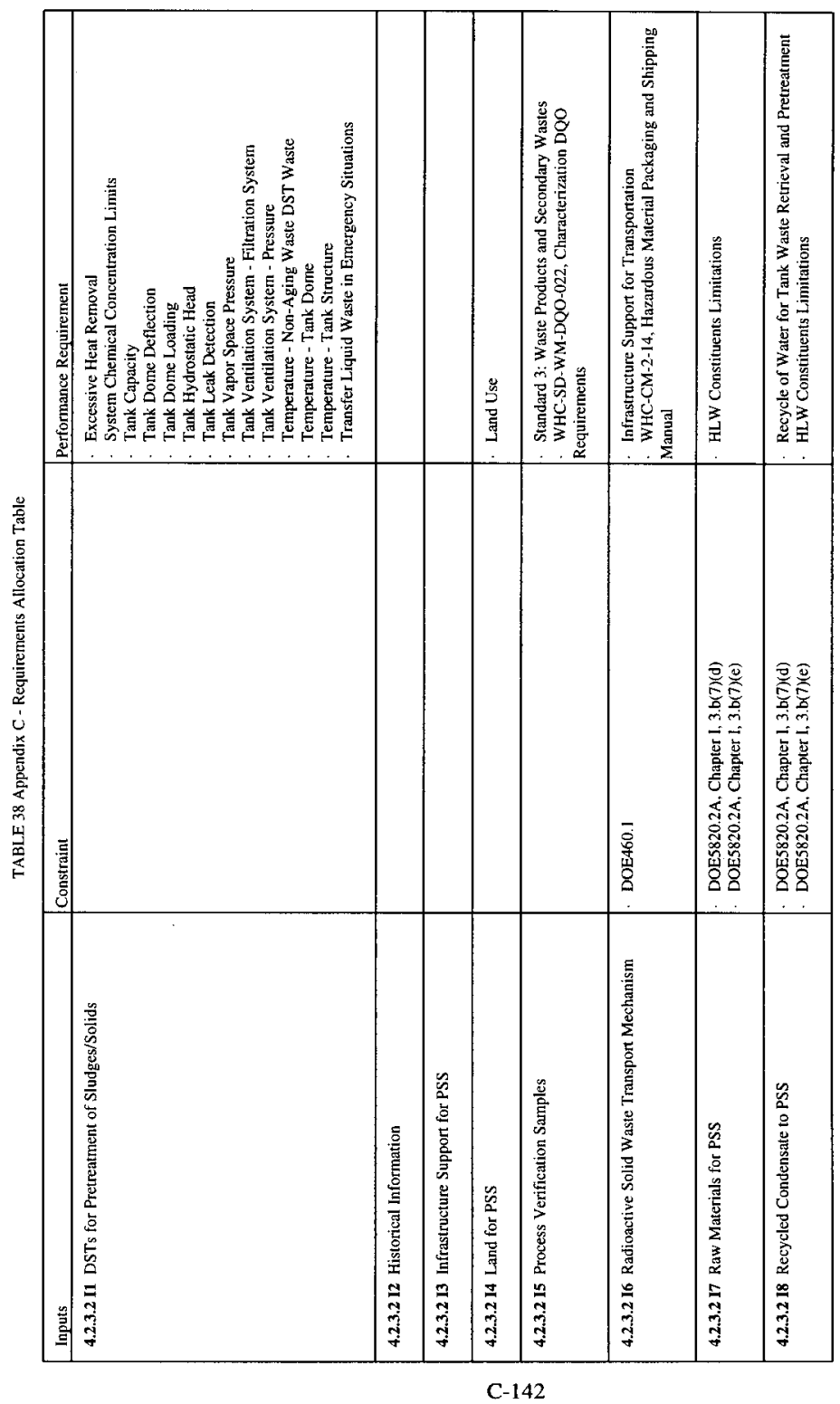




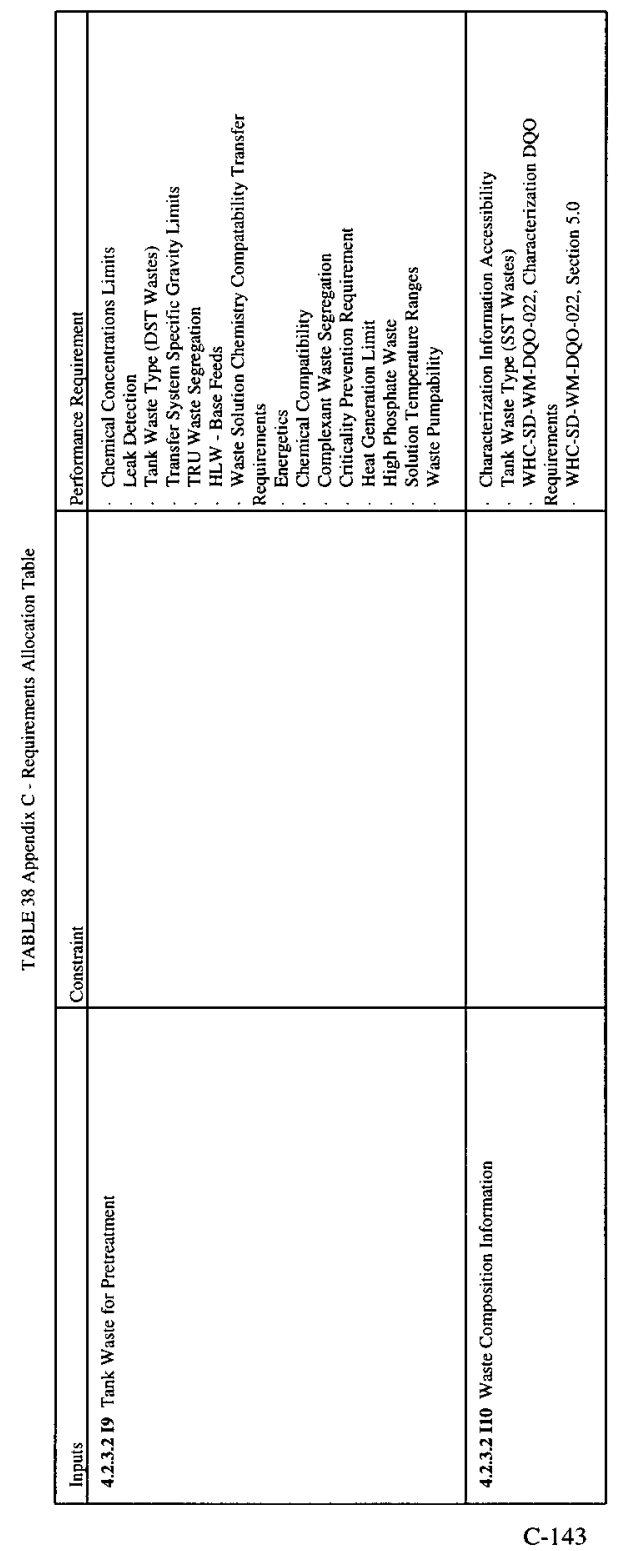




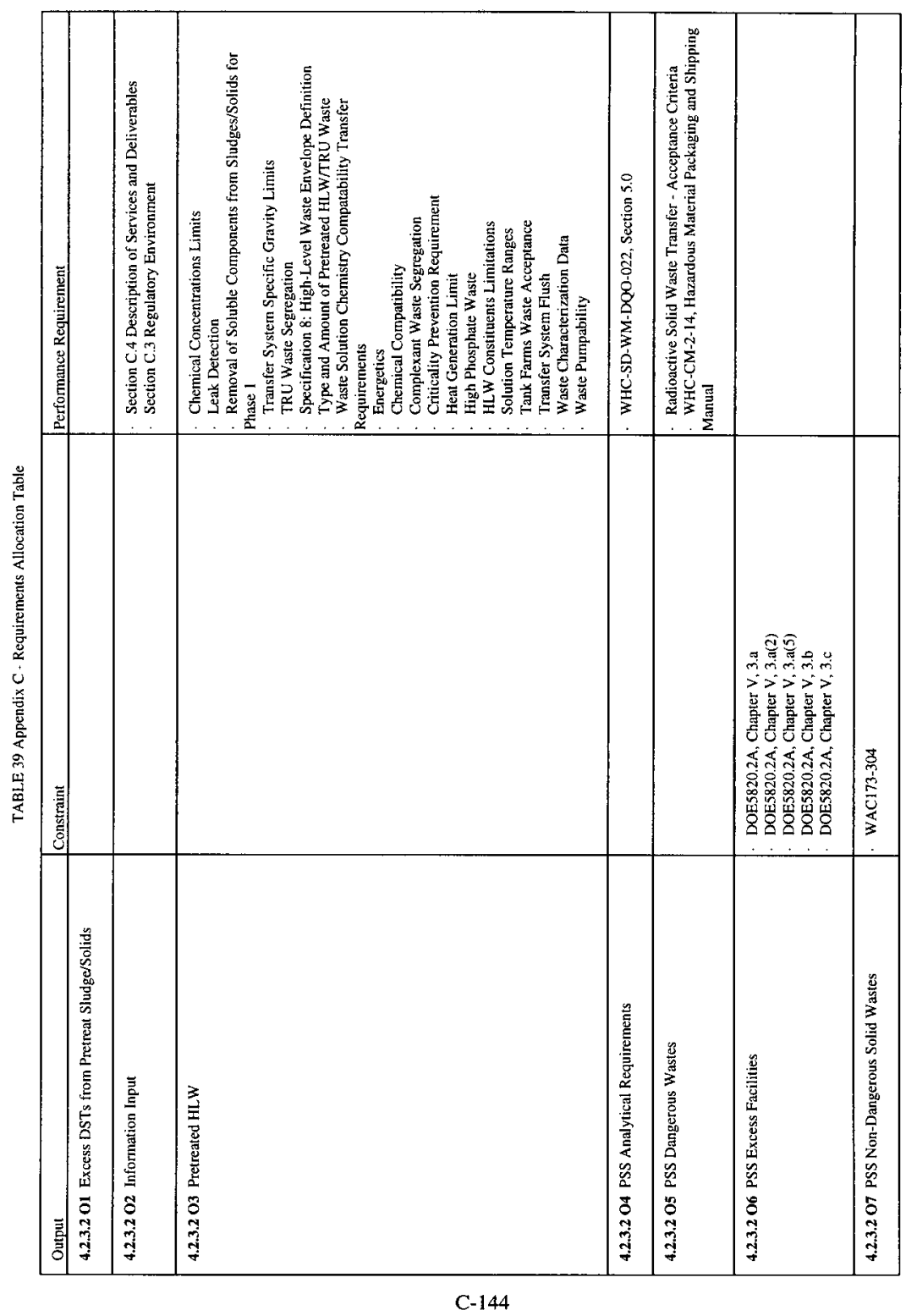




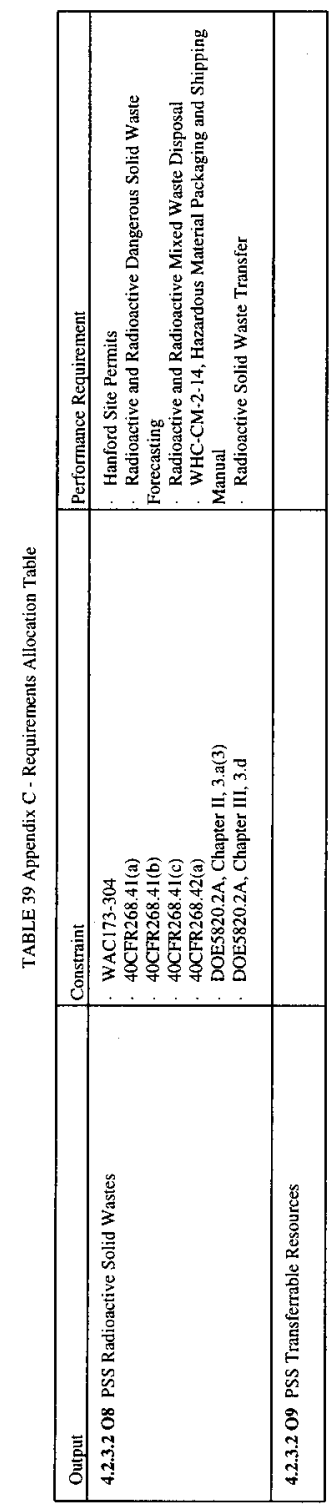




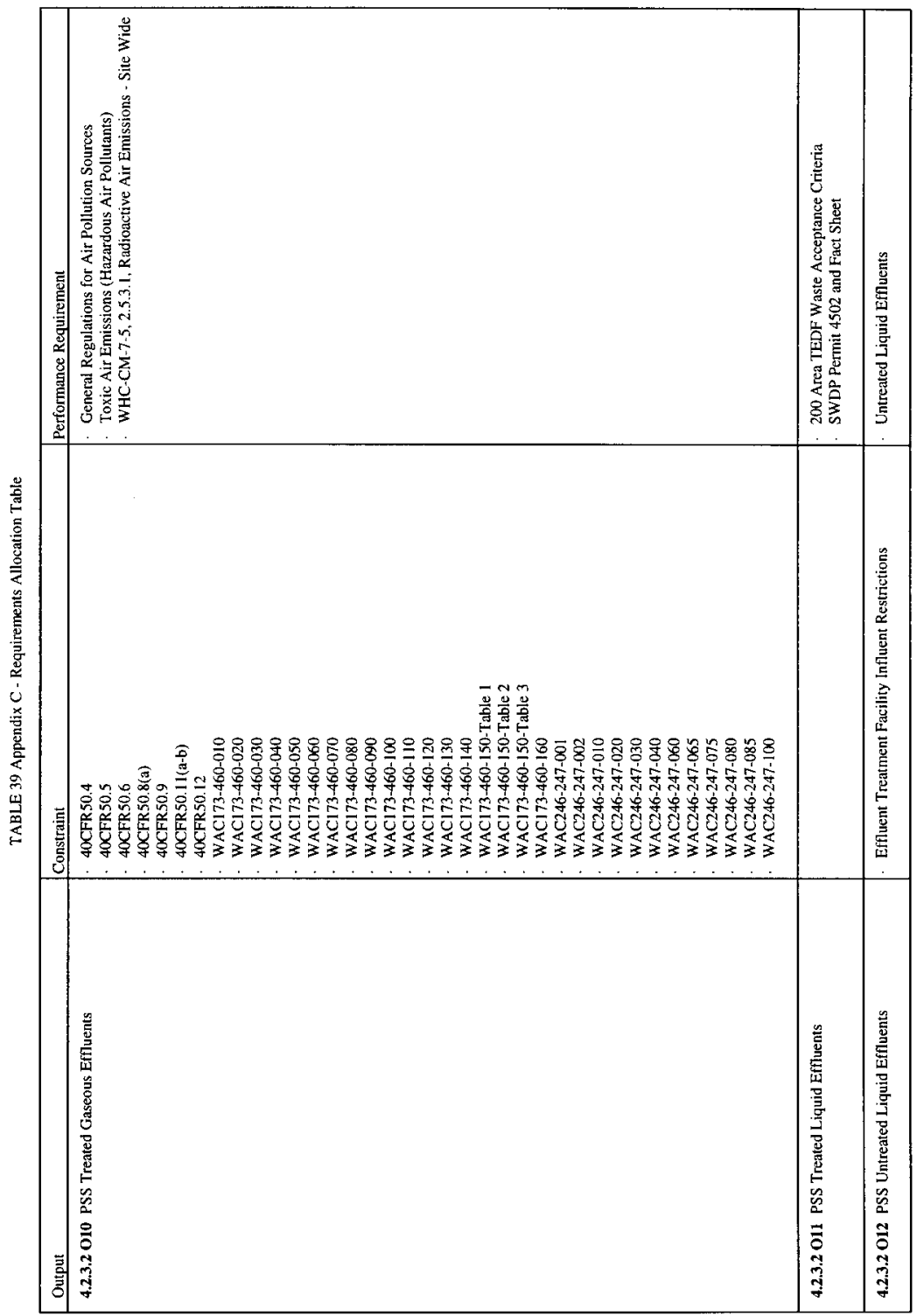




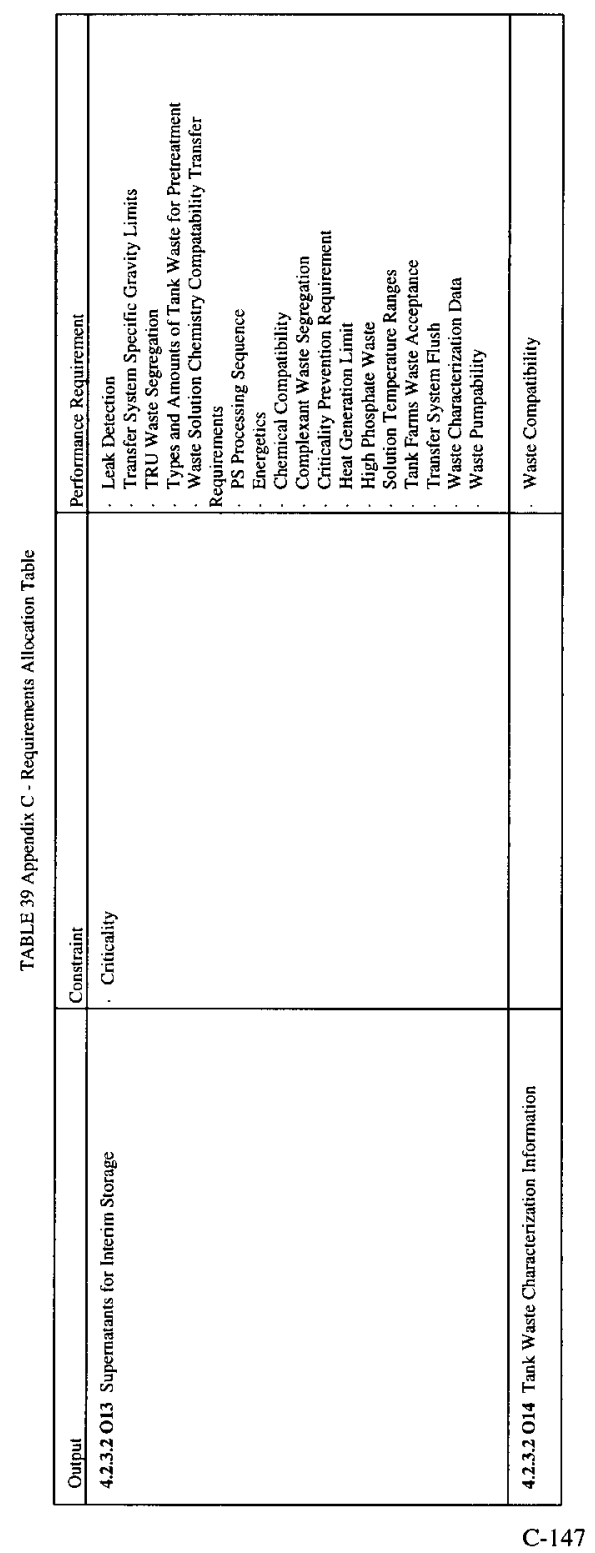


Revision 1 


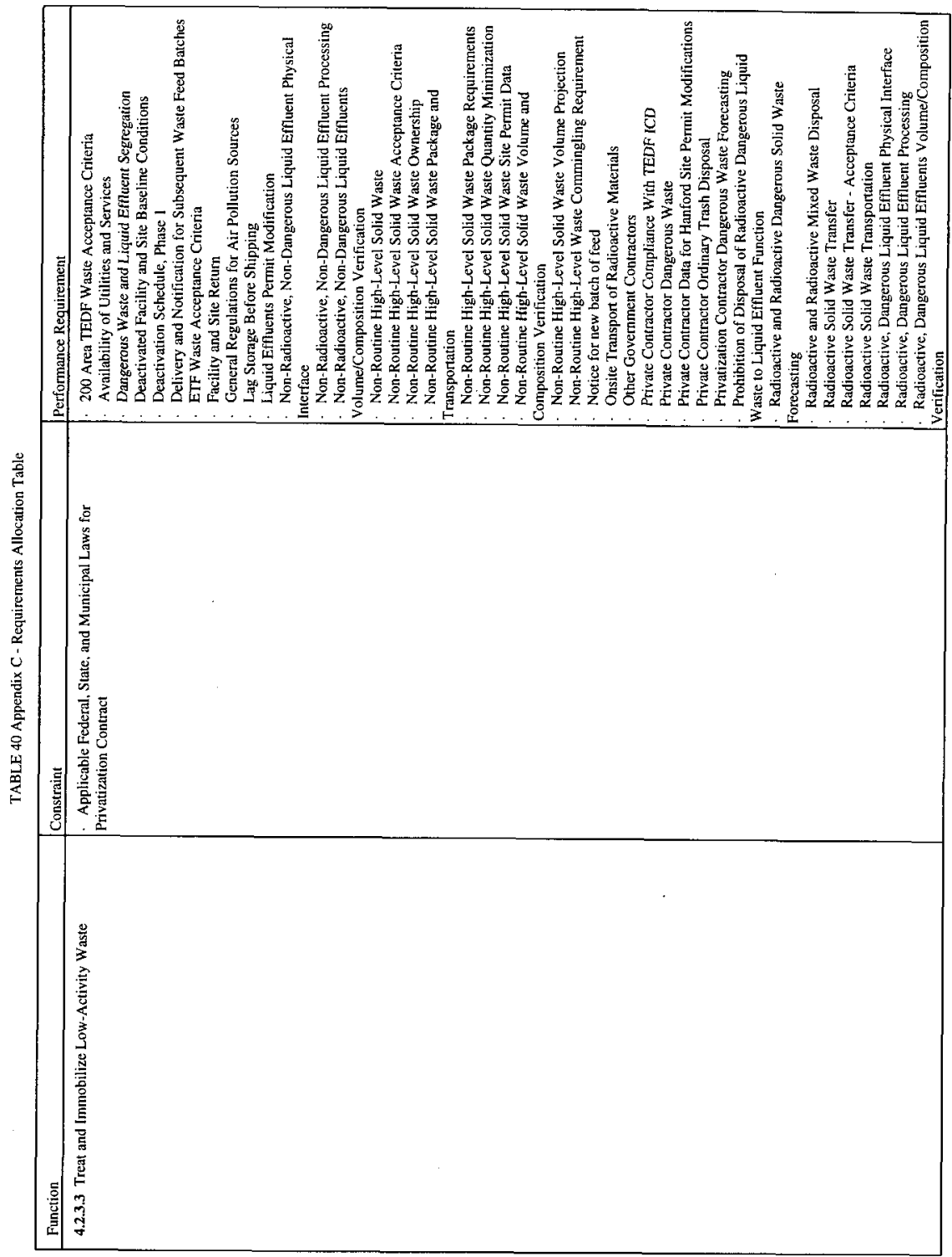

C-149 


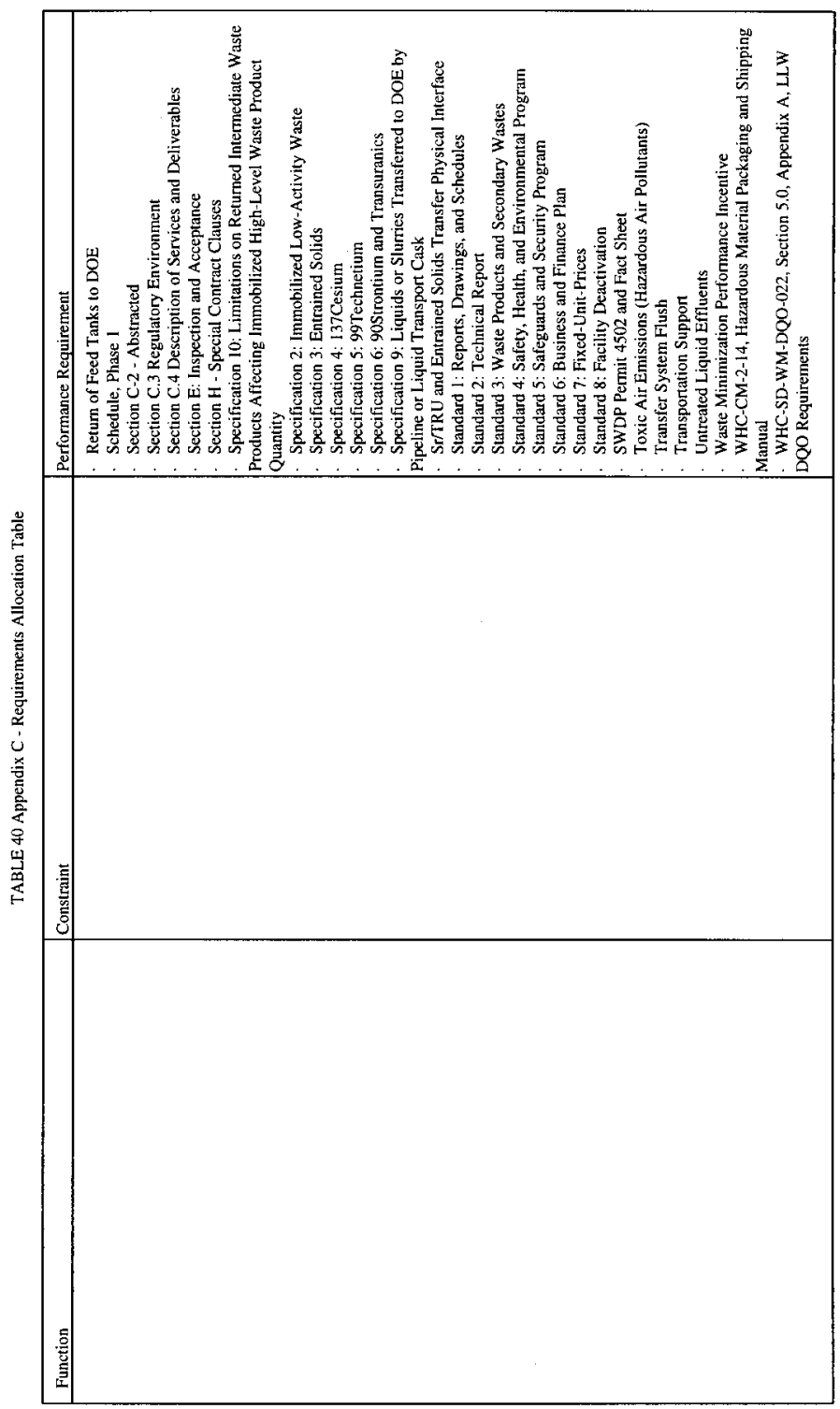




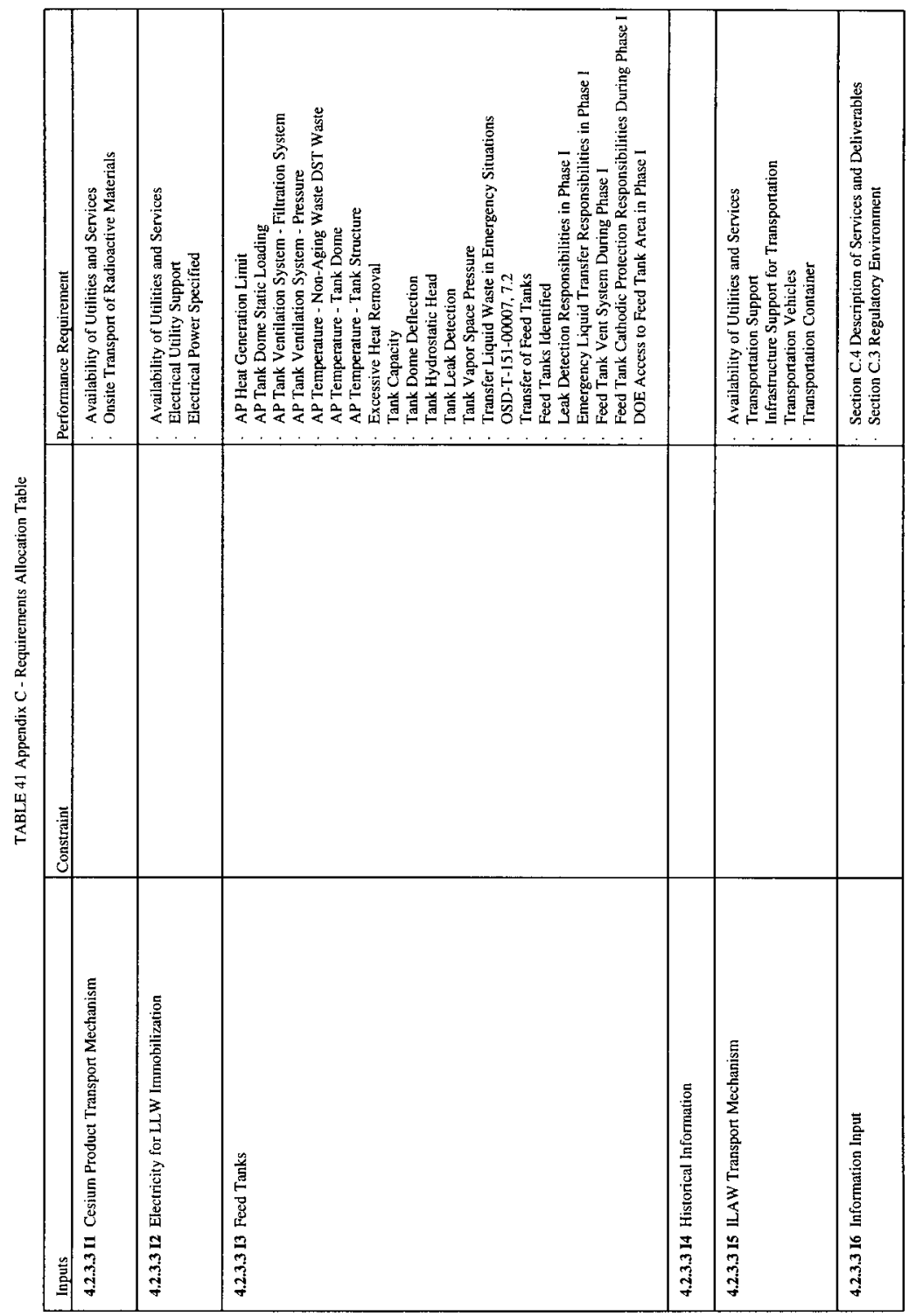

C-151 
Revision 1

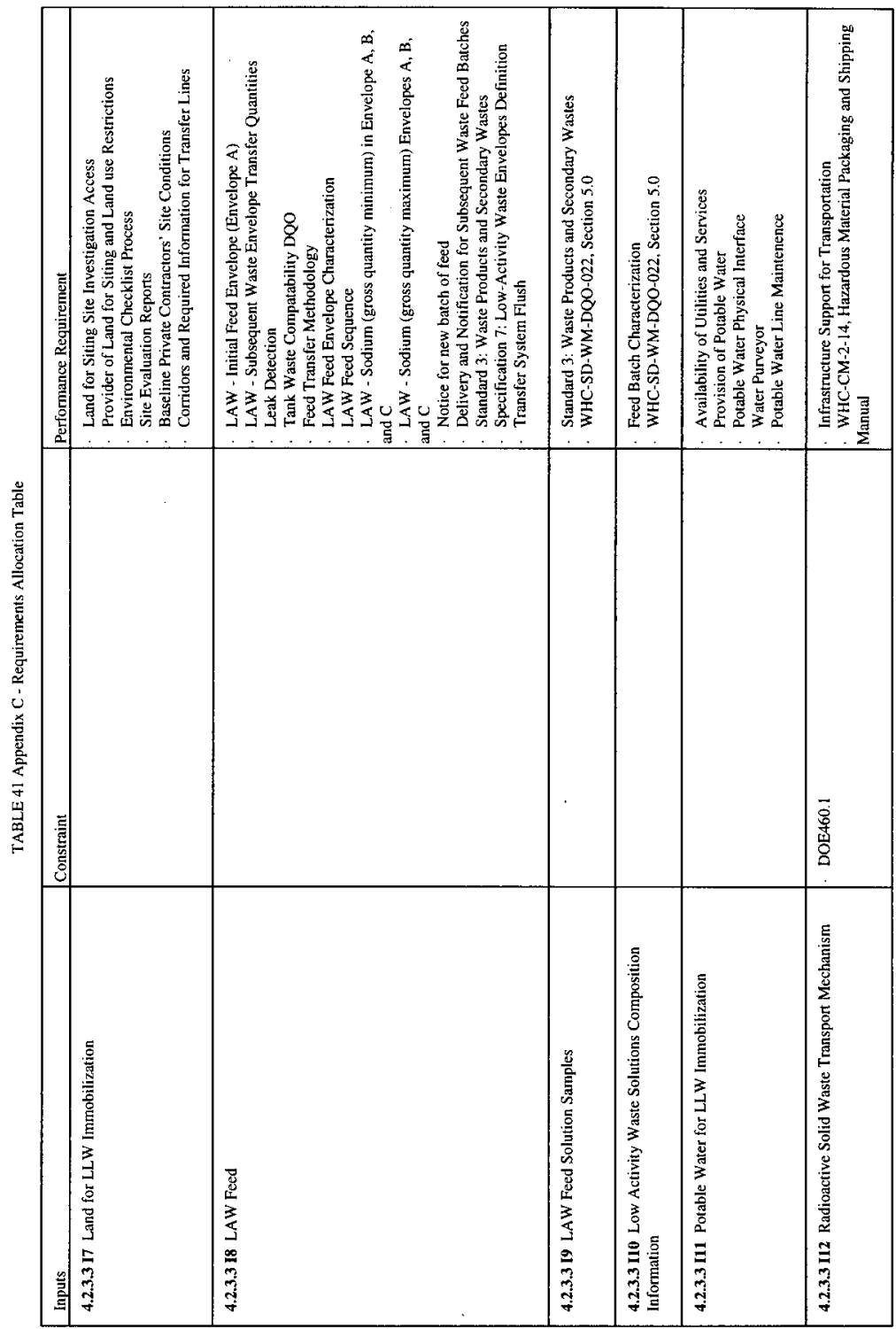

C-152 


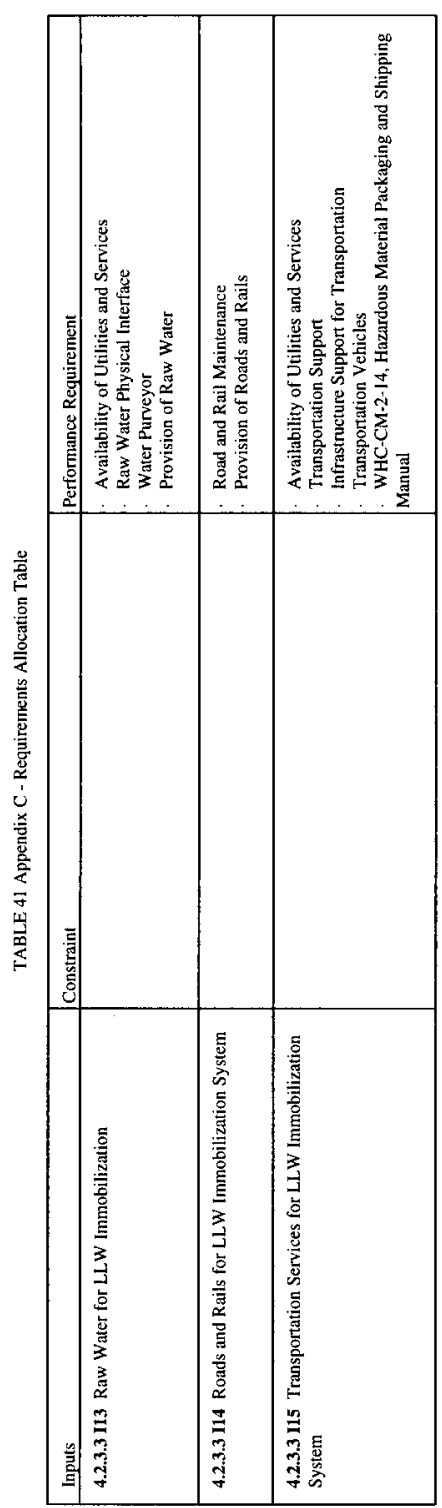




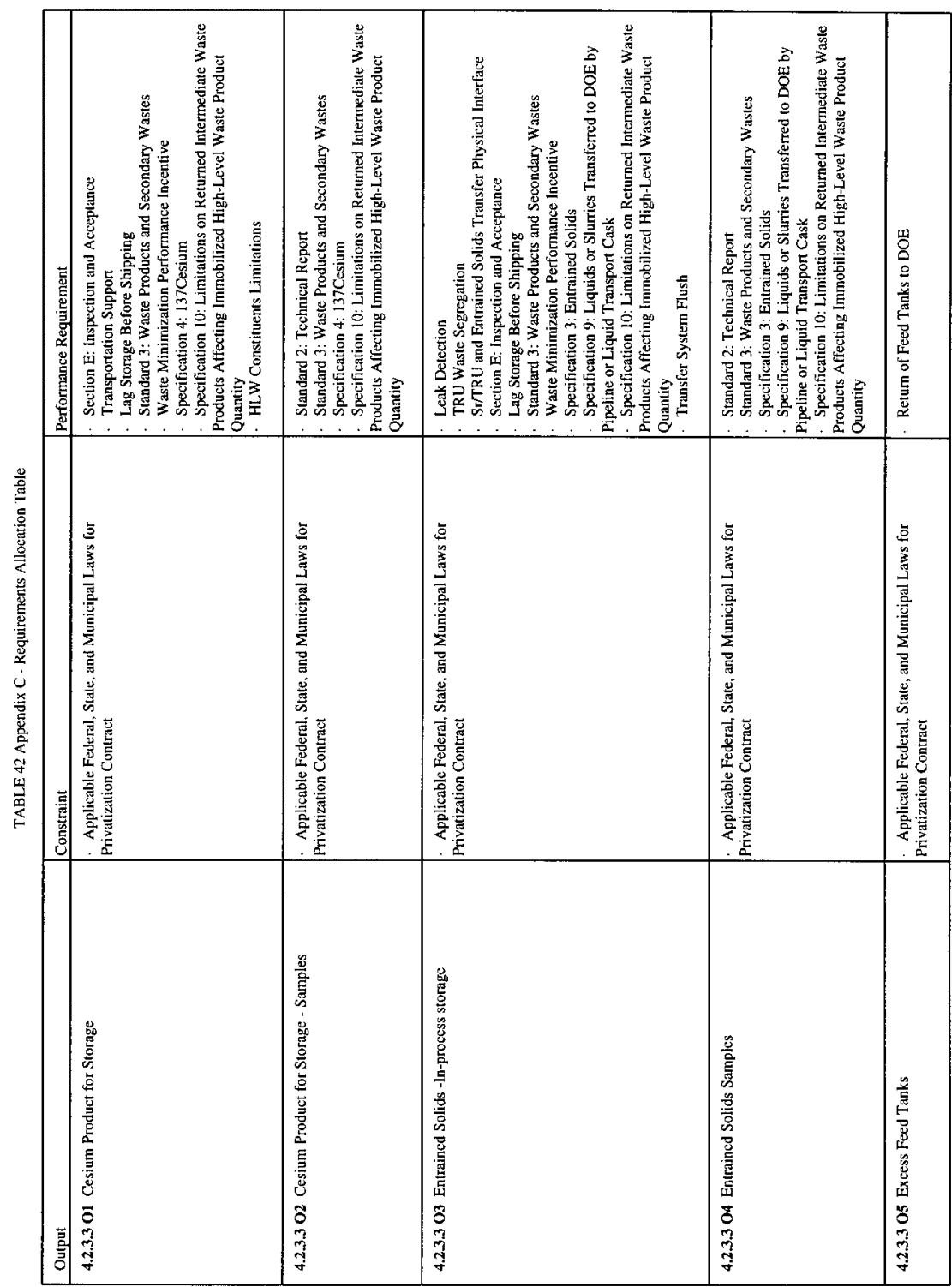




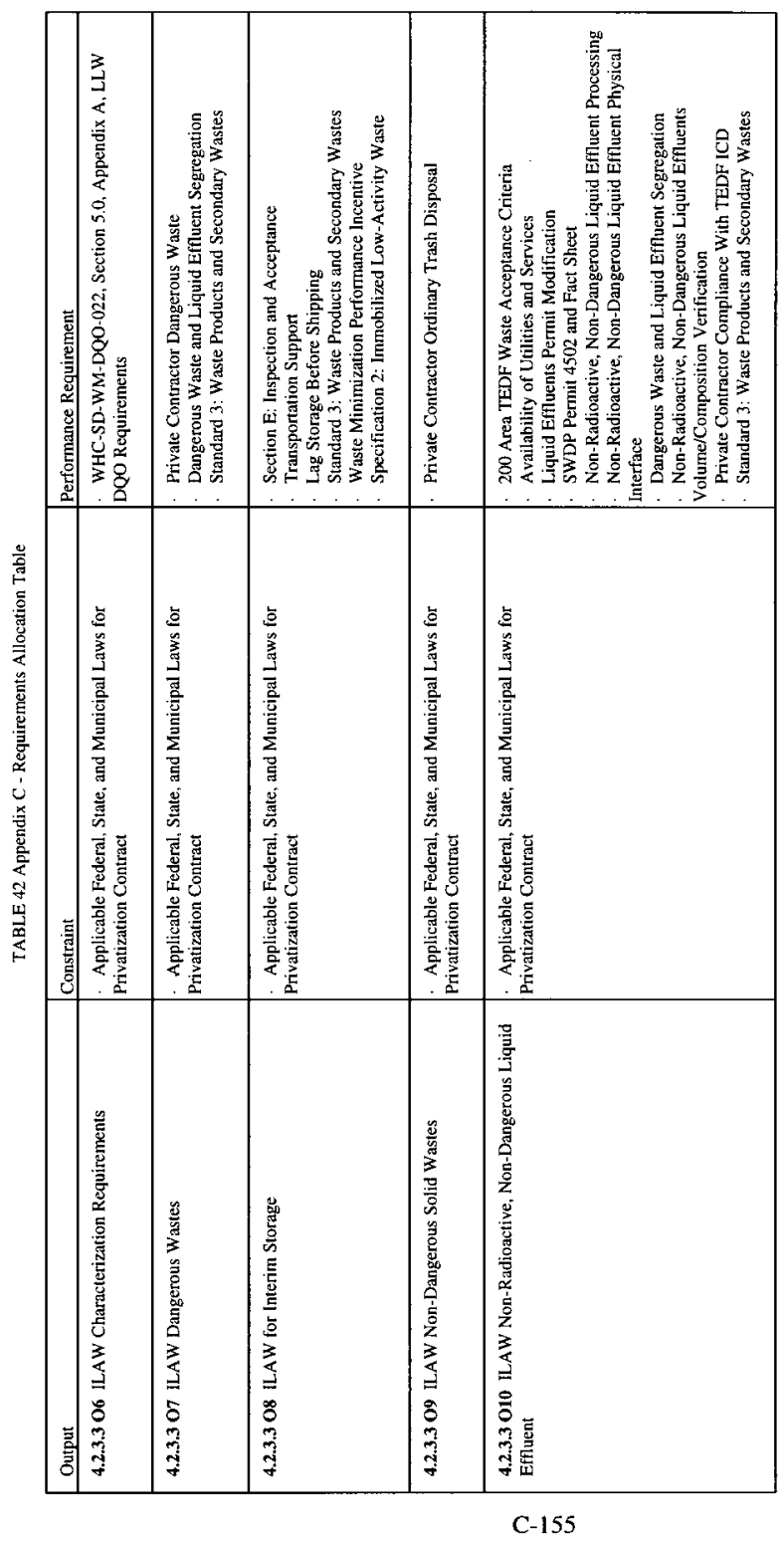




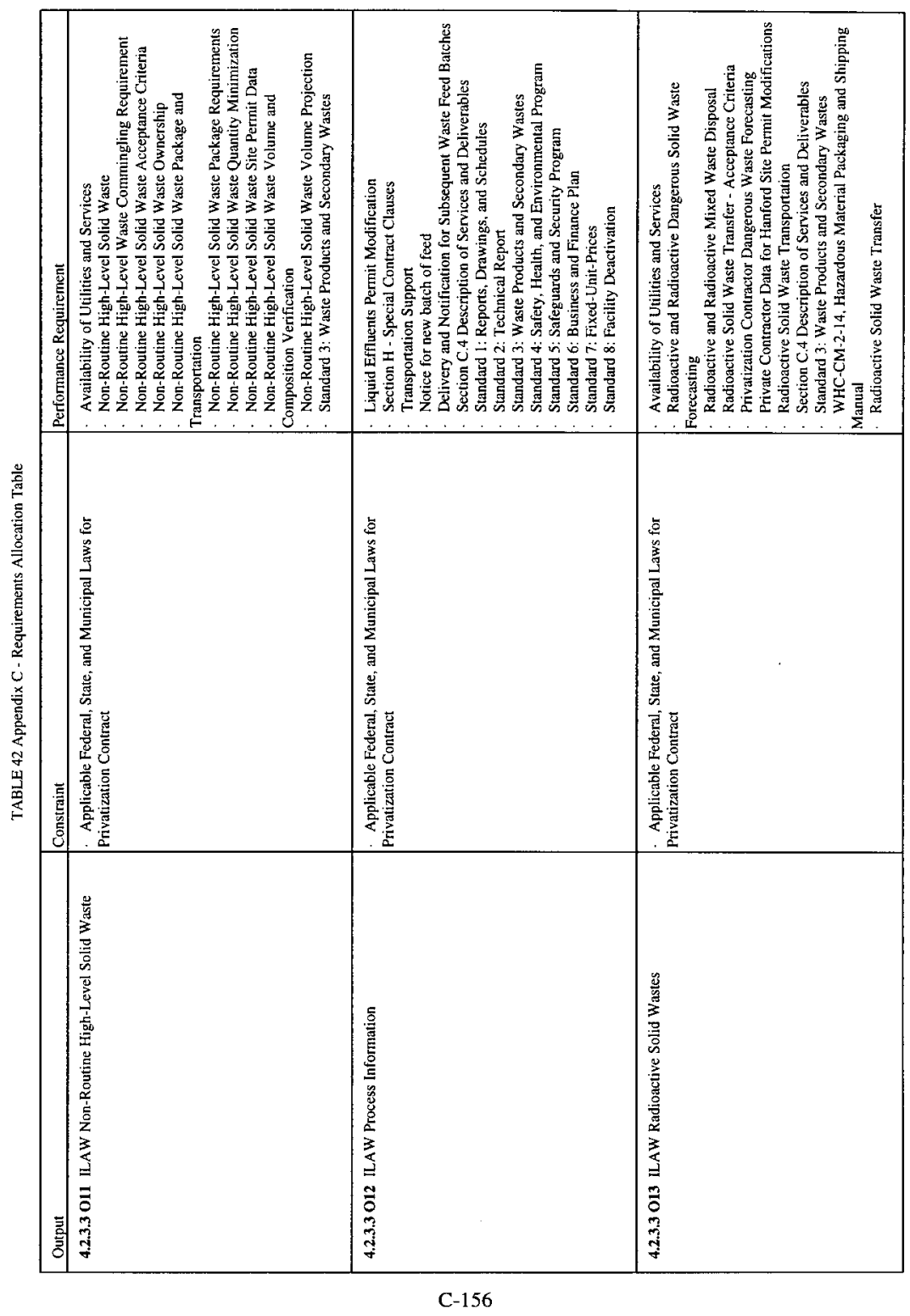




\section{Revision 1}

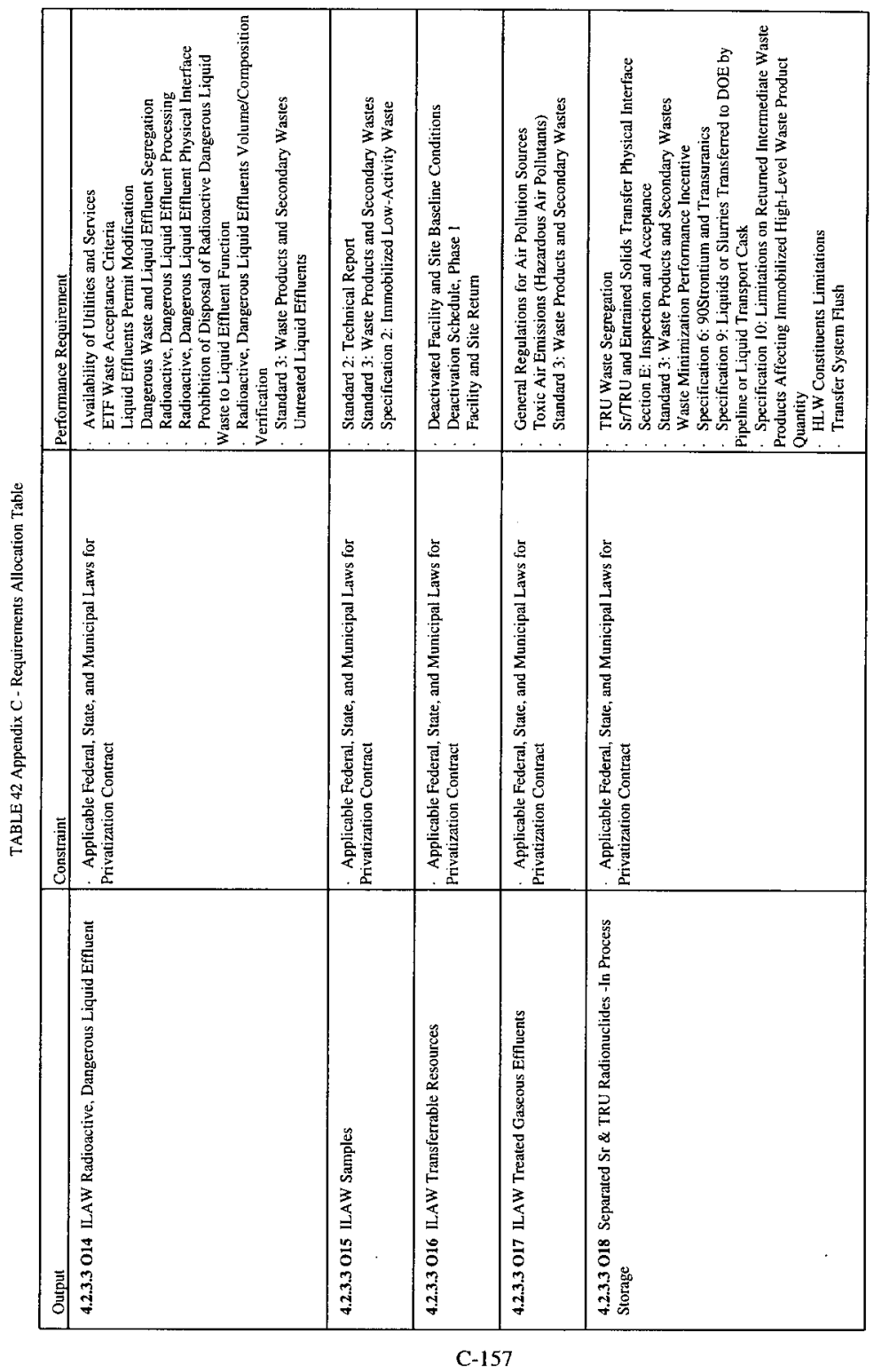




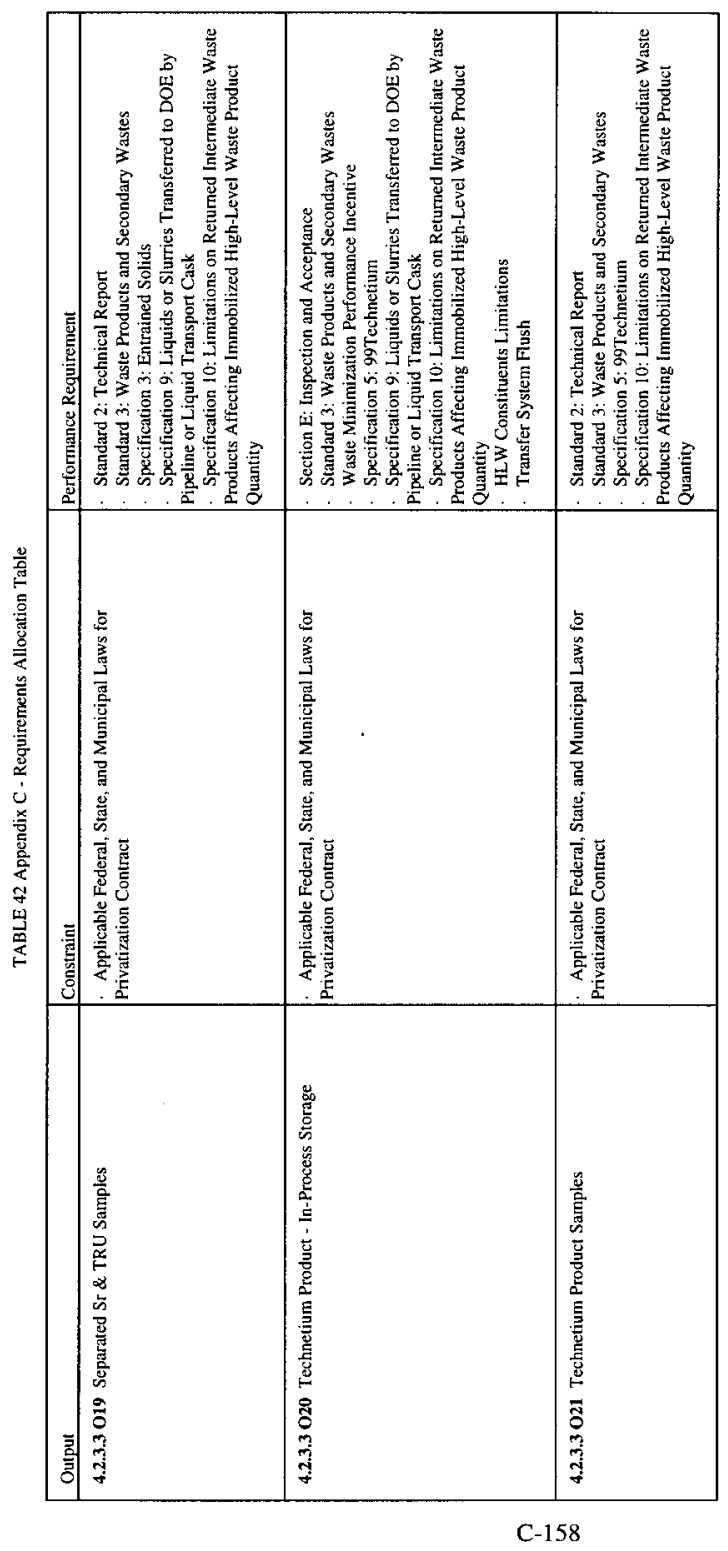


Revision 1

\section{C-159}




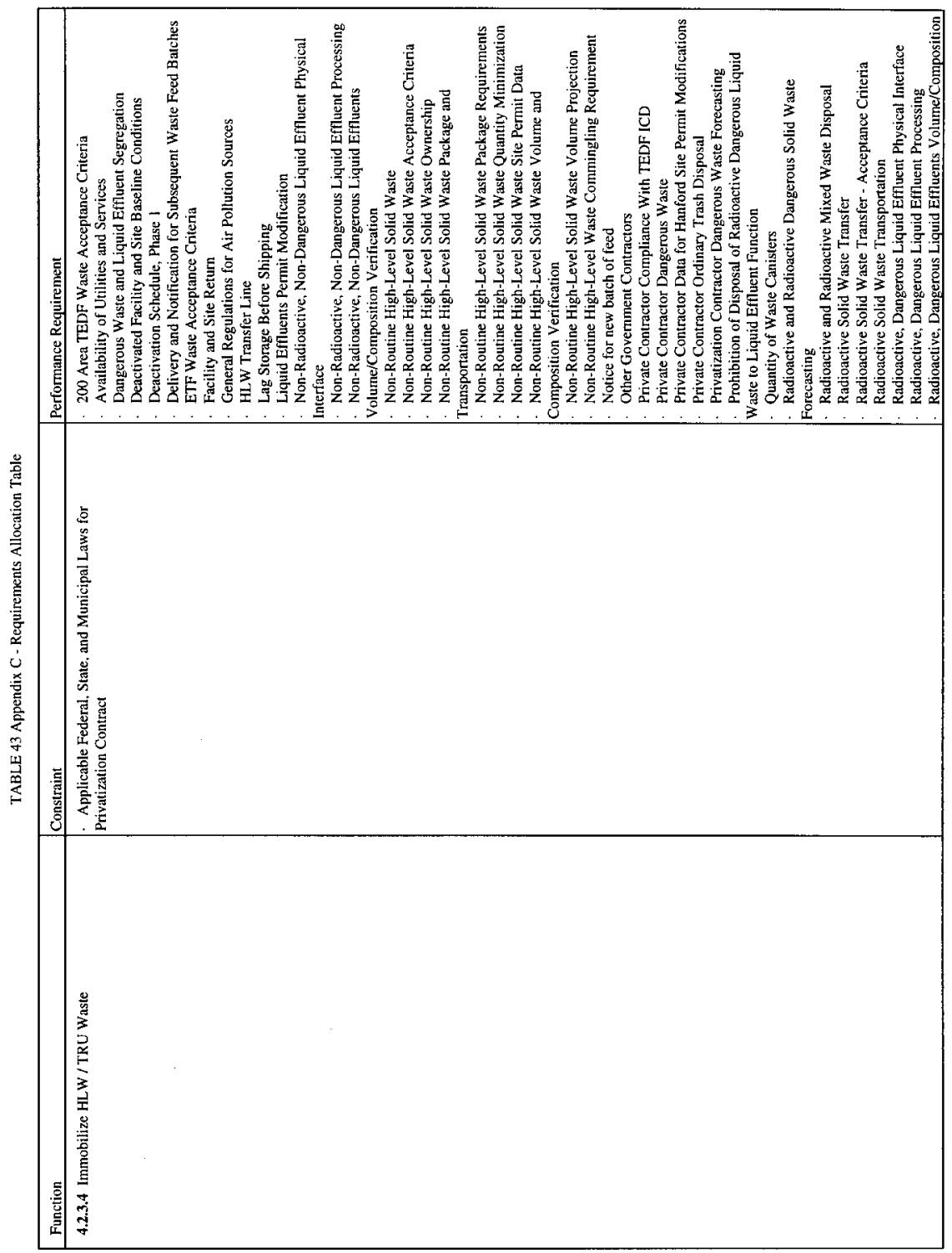




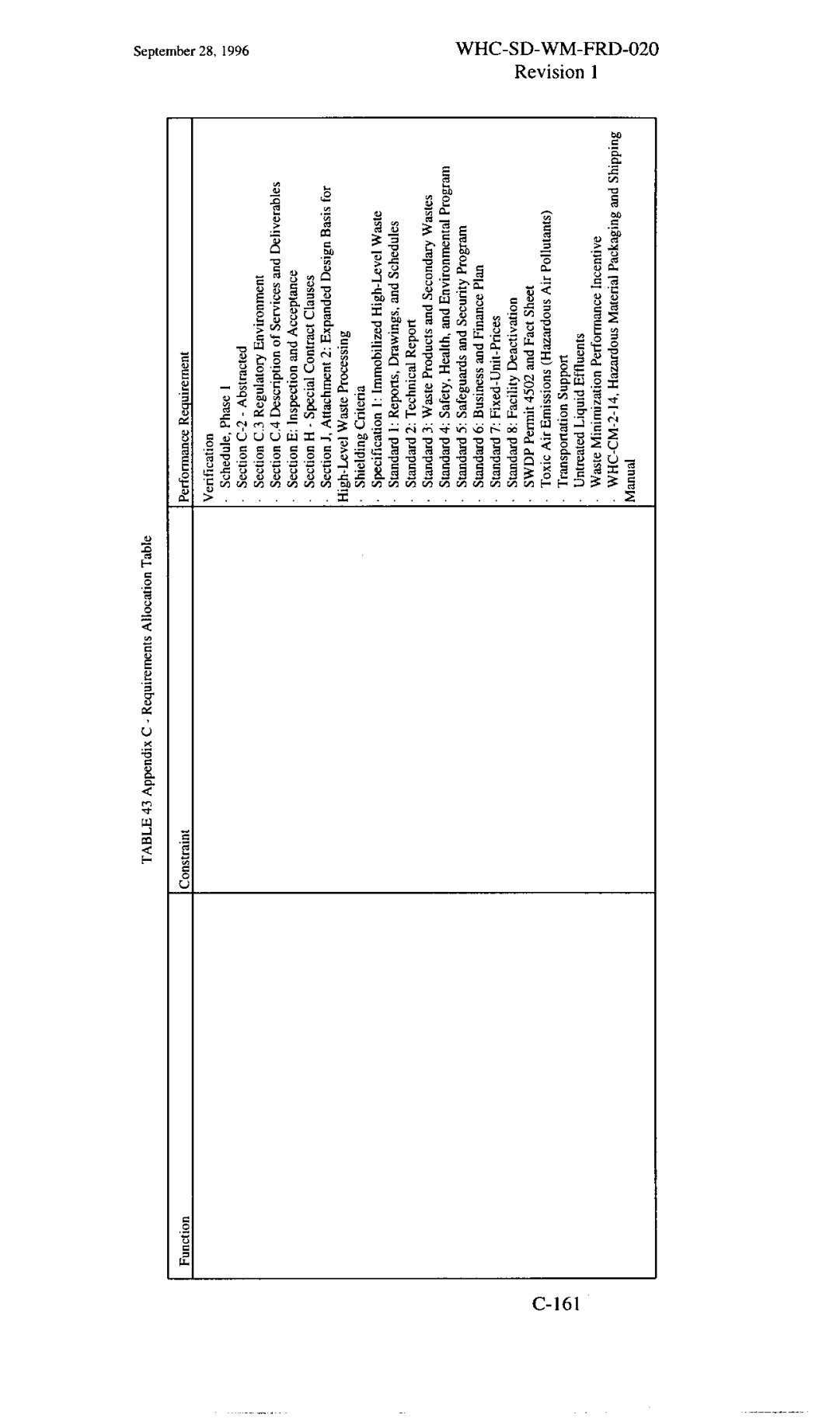


Revision 1

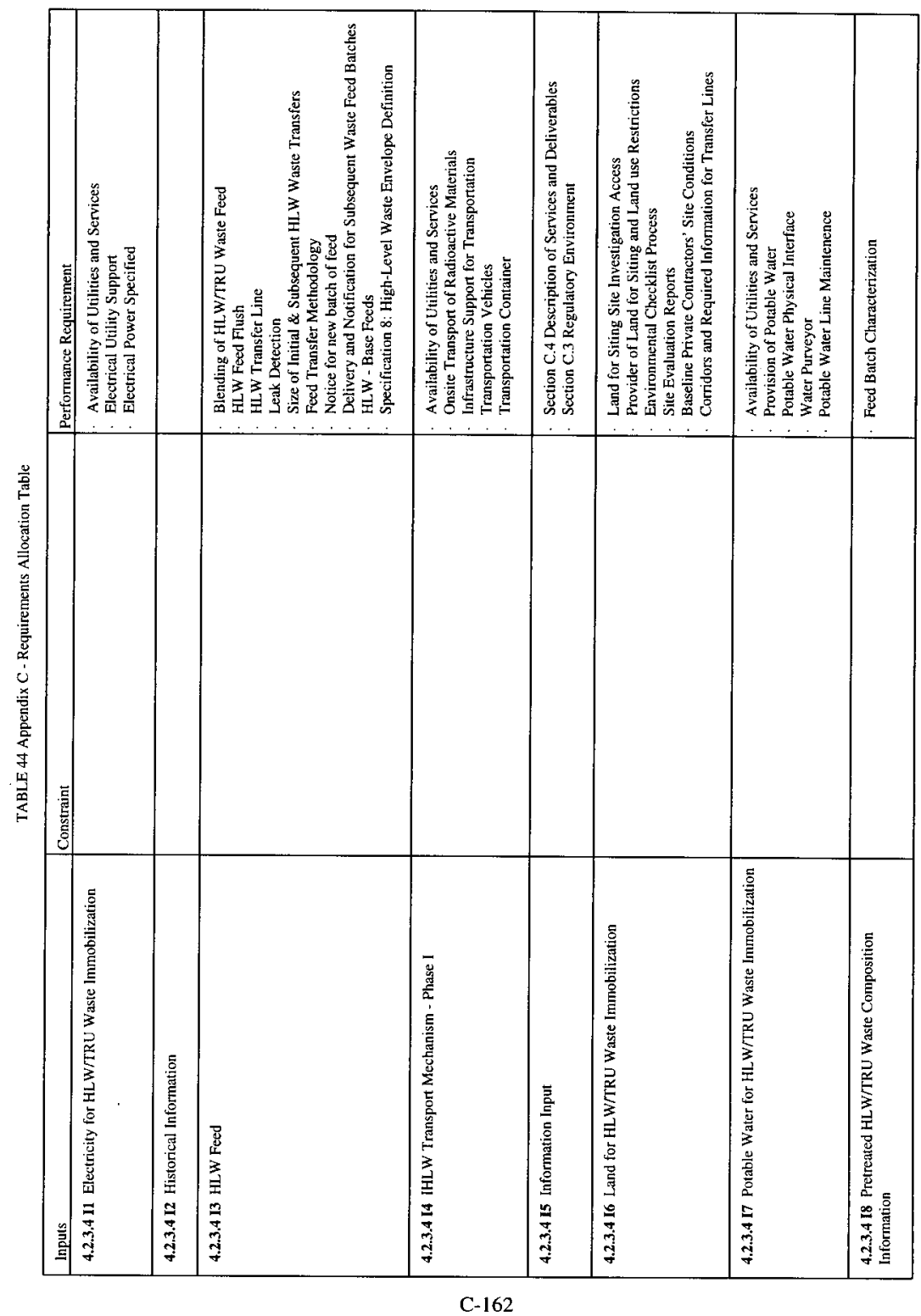




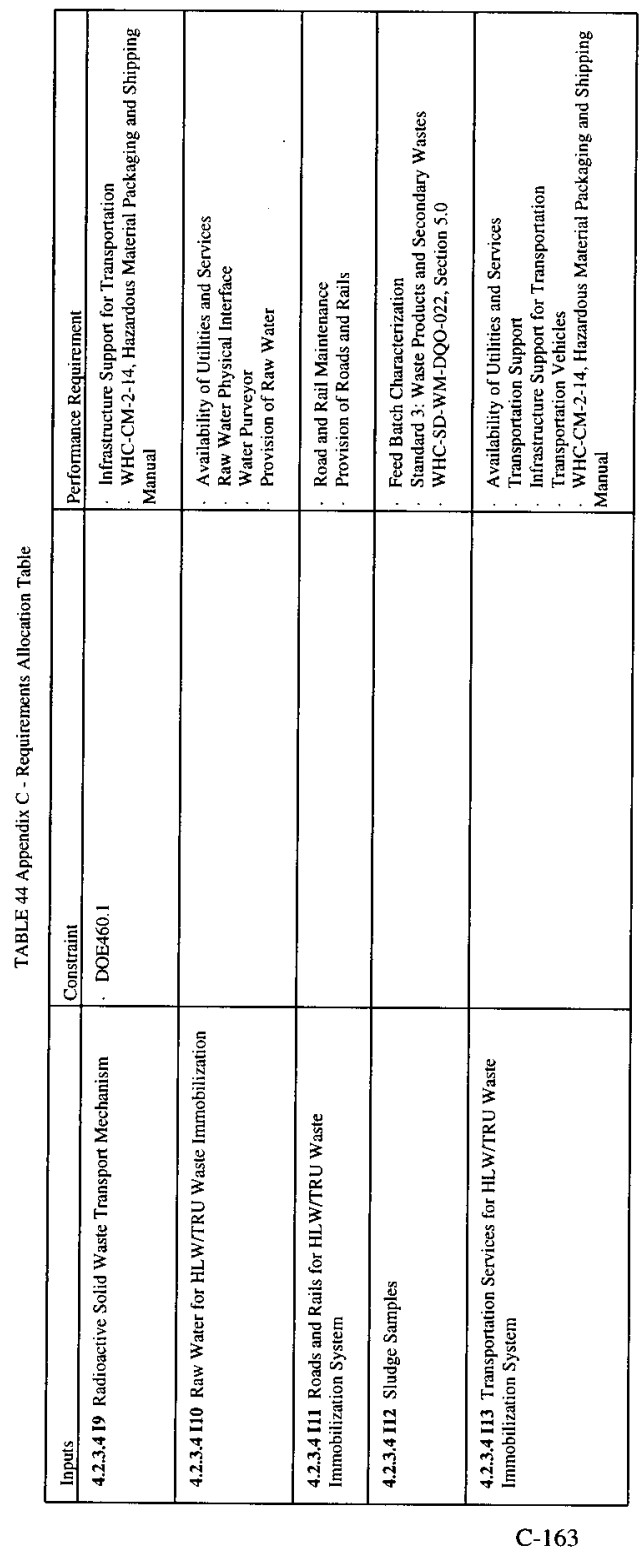


Revision 1

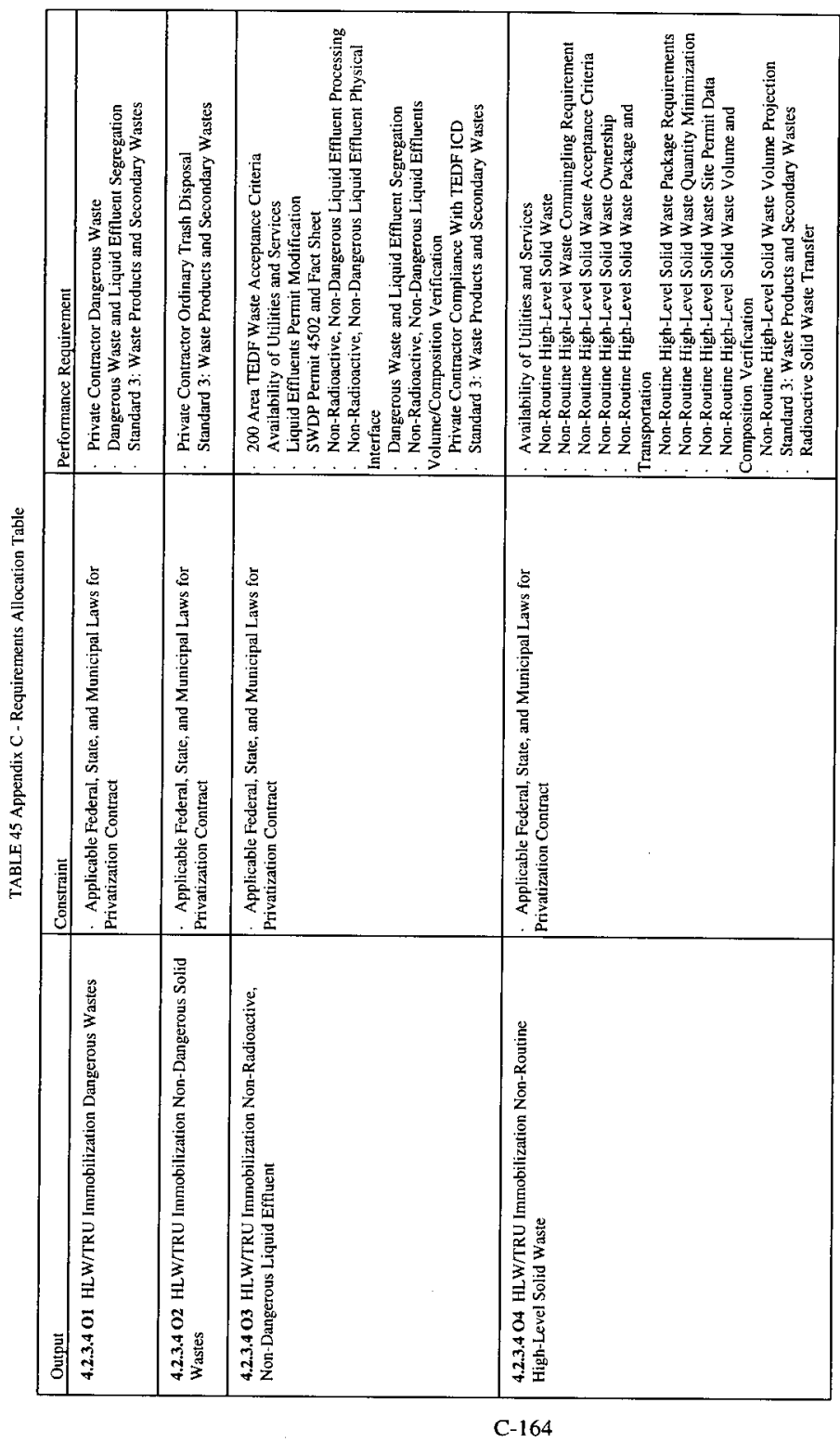




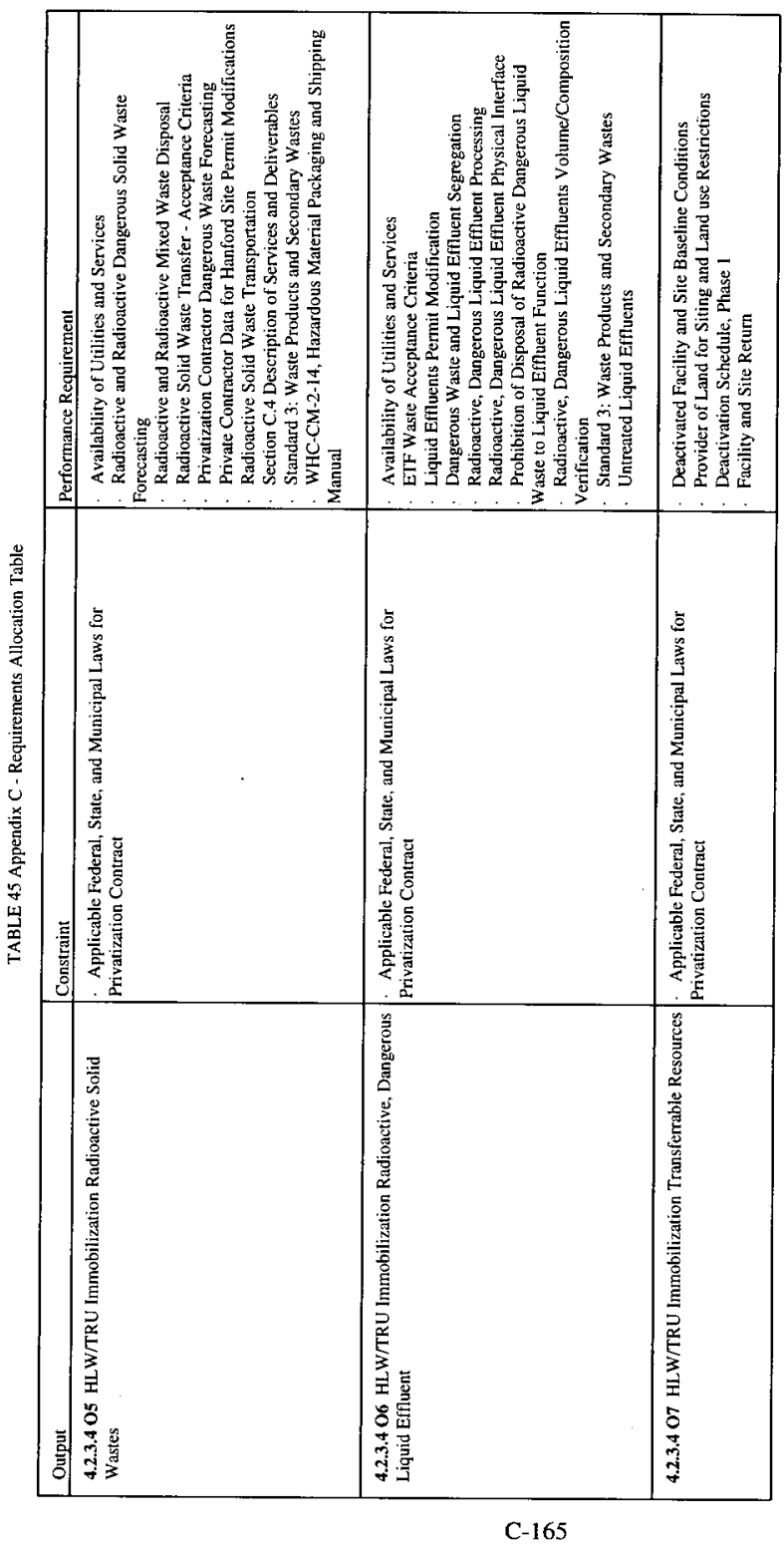


Revision 1

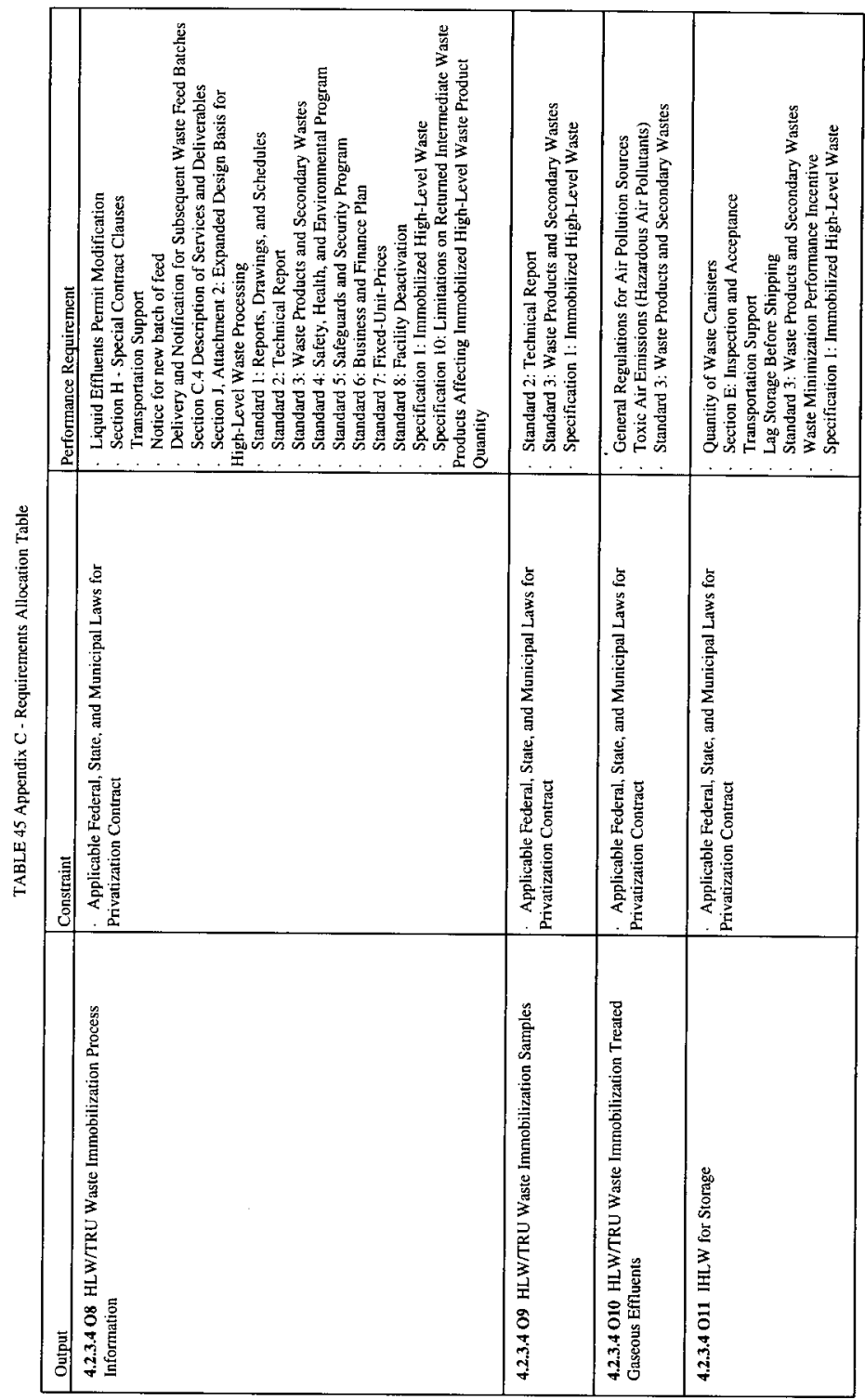

C-166 
Revision 1 


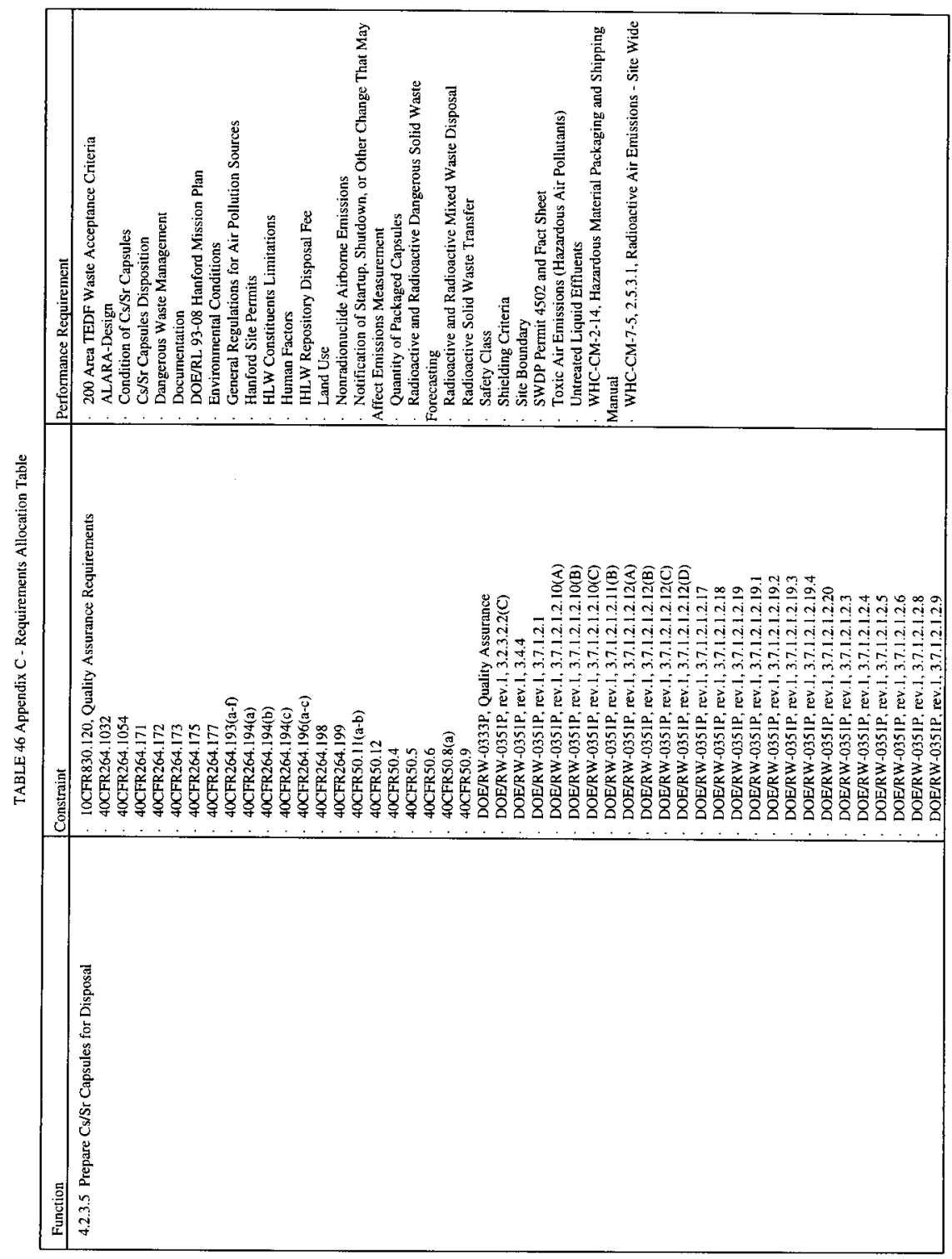




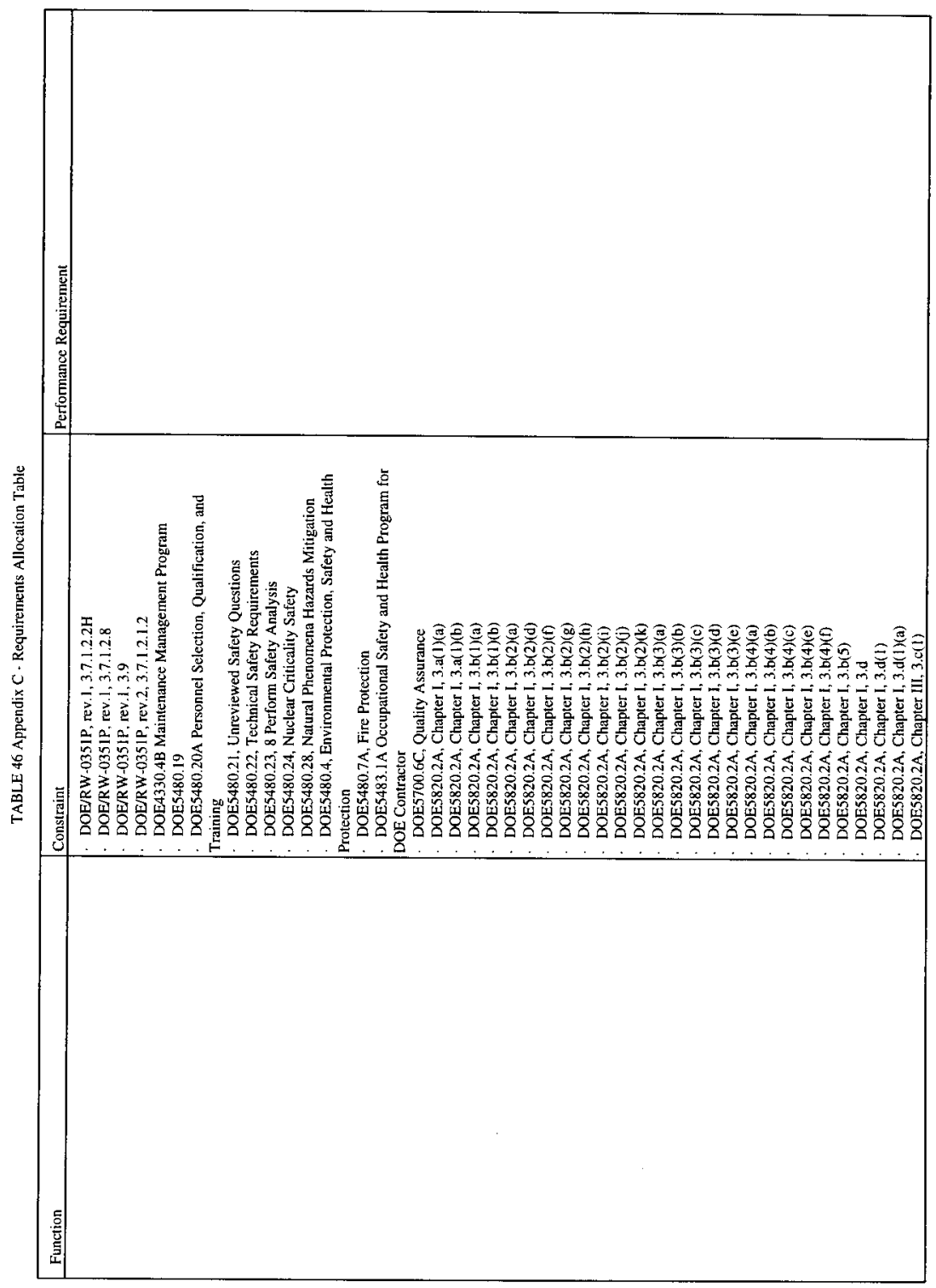




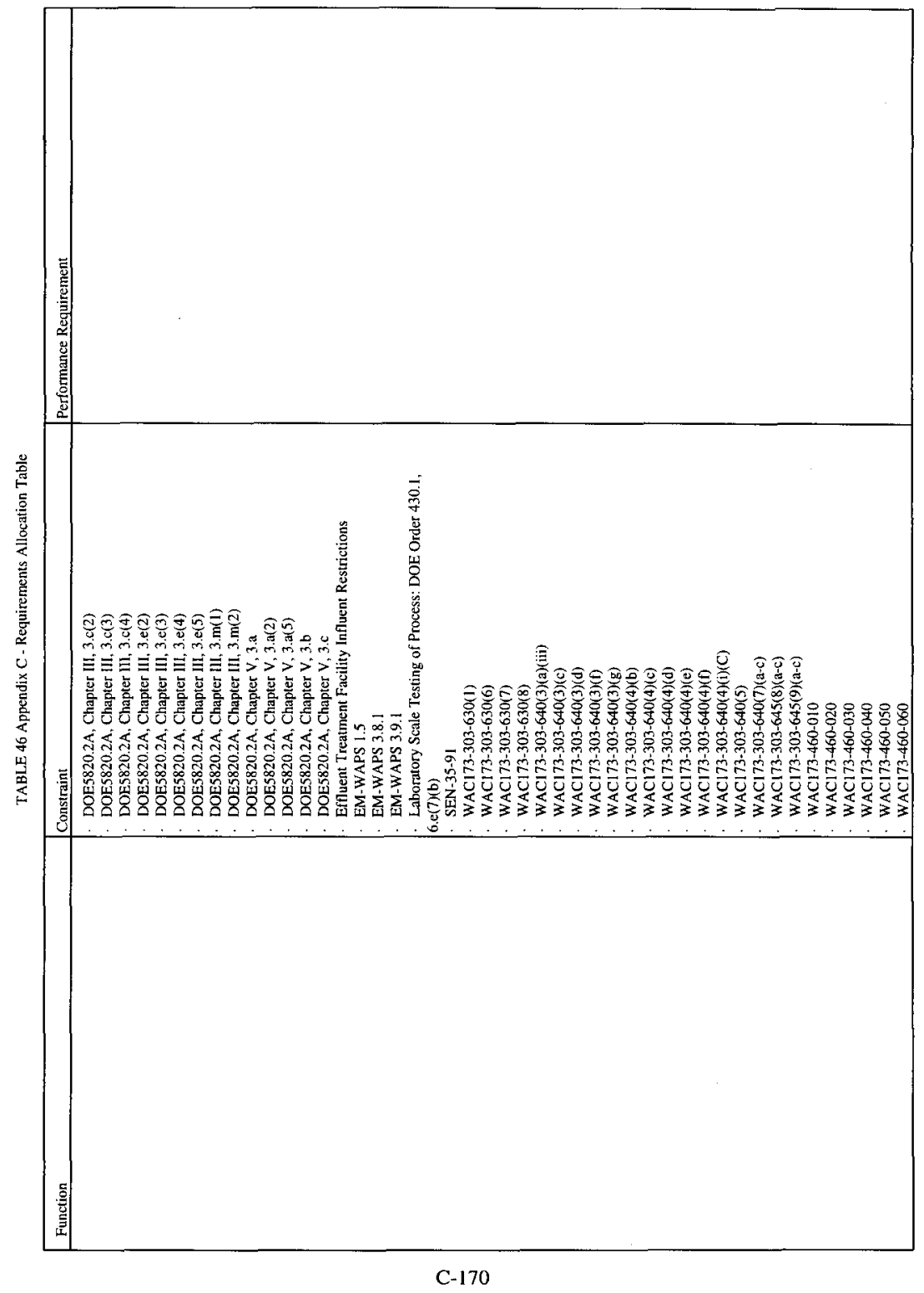




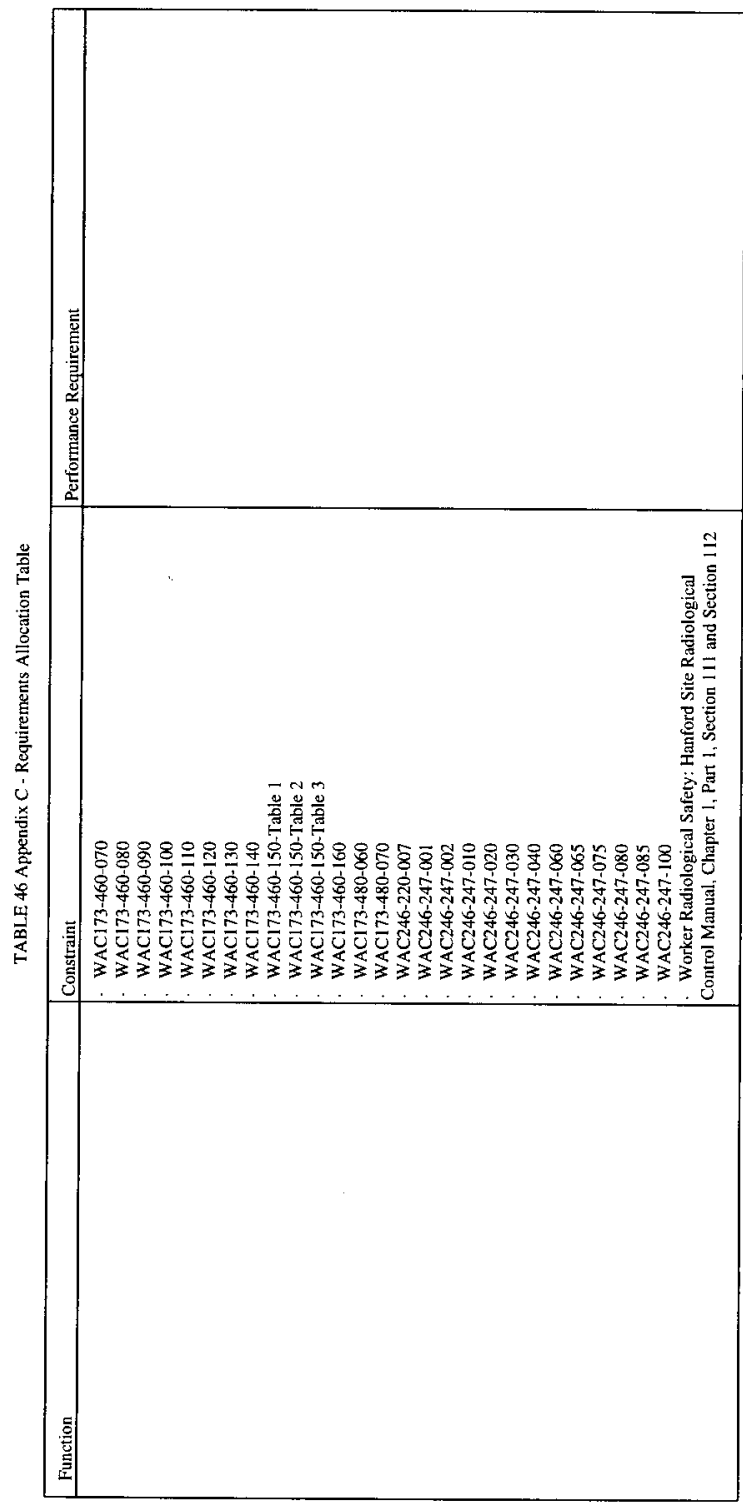

C-171 


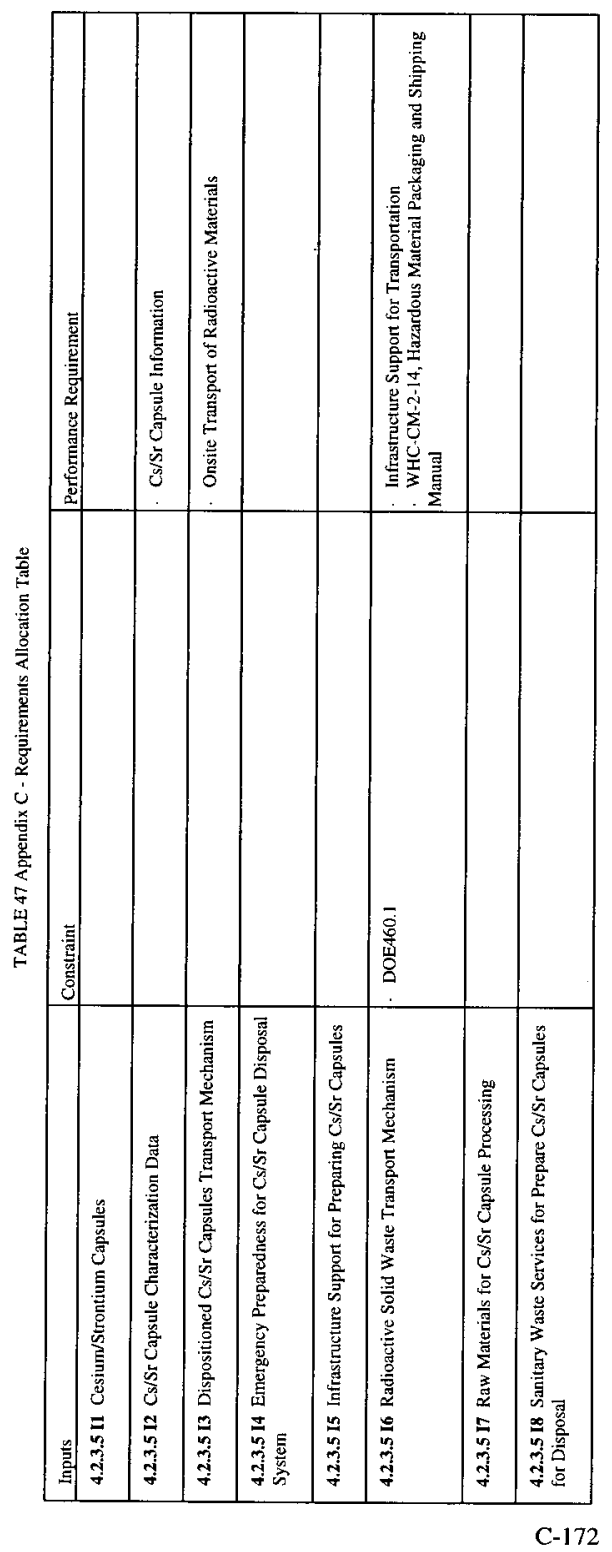




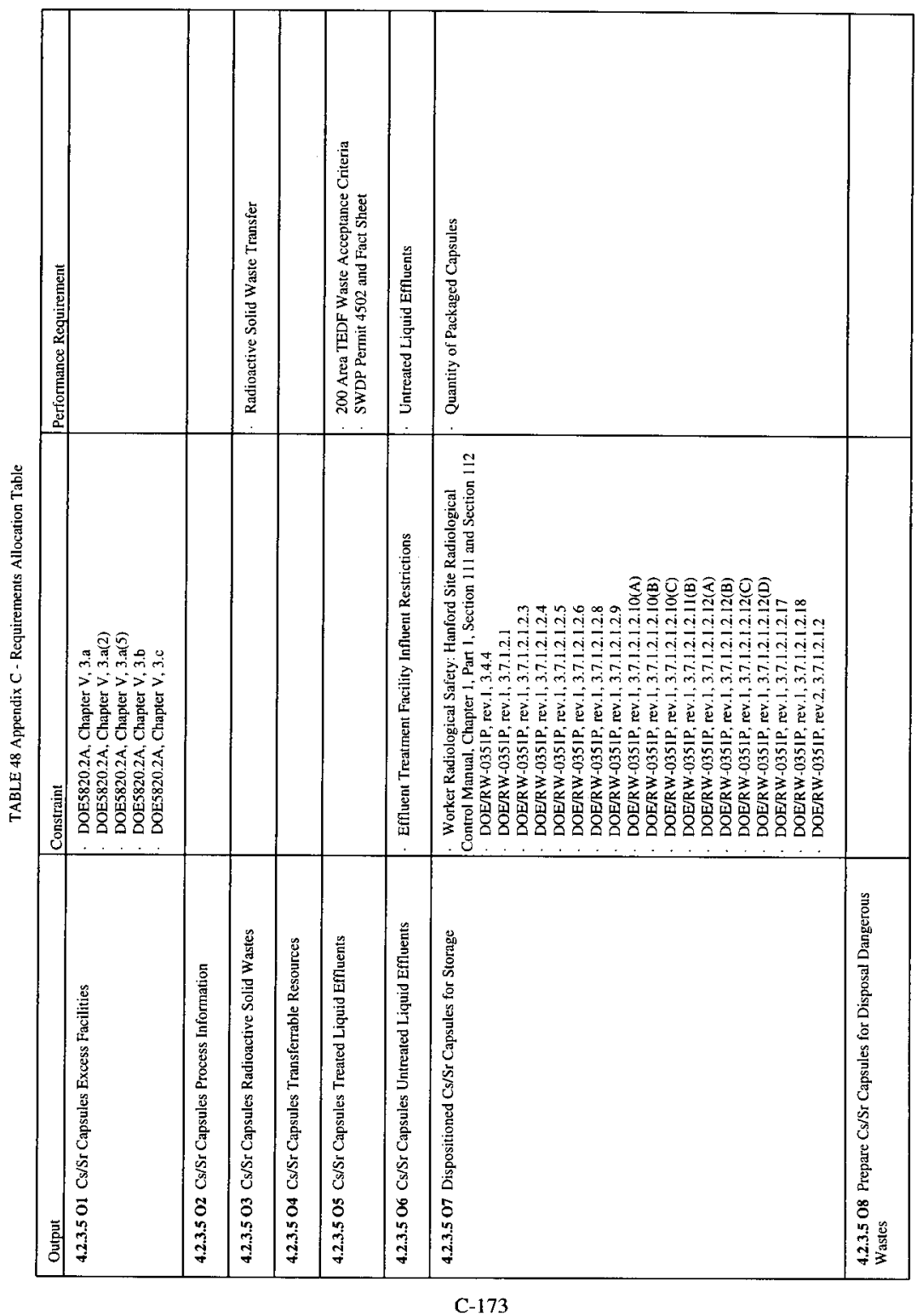




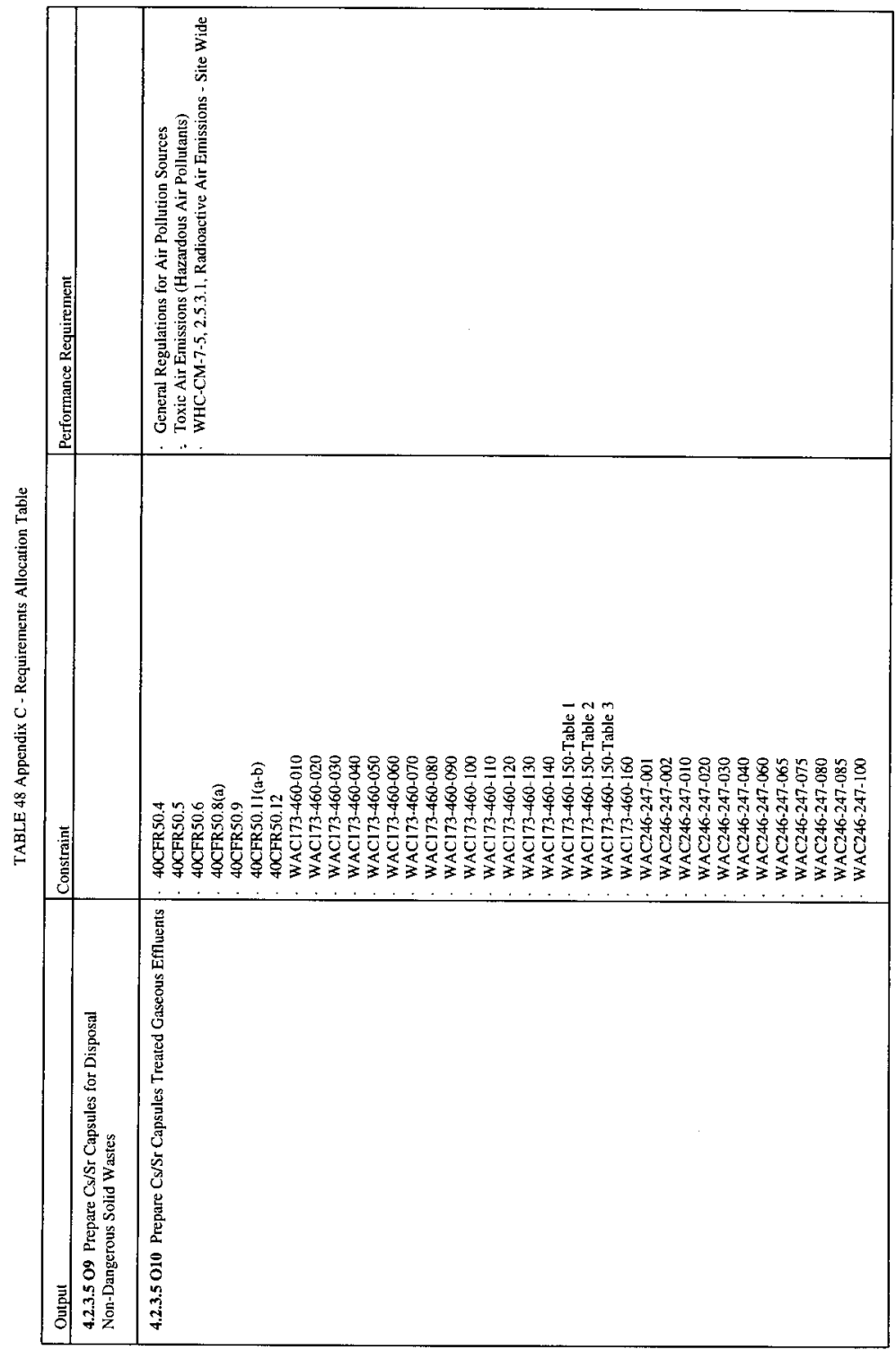


Revision 1 


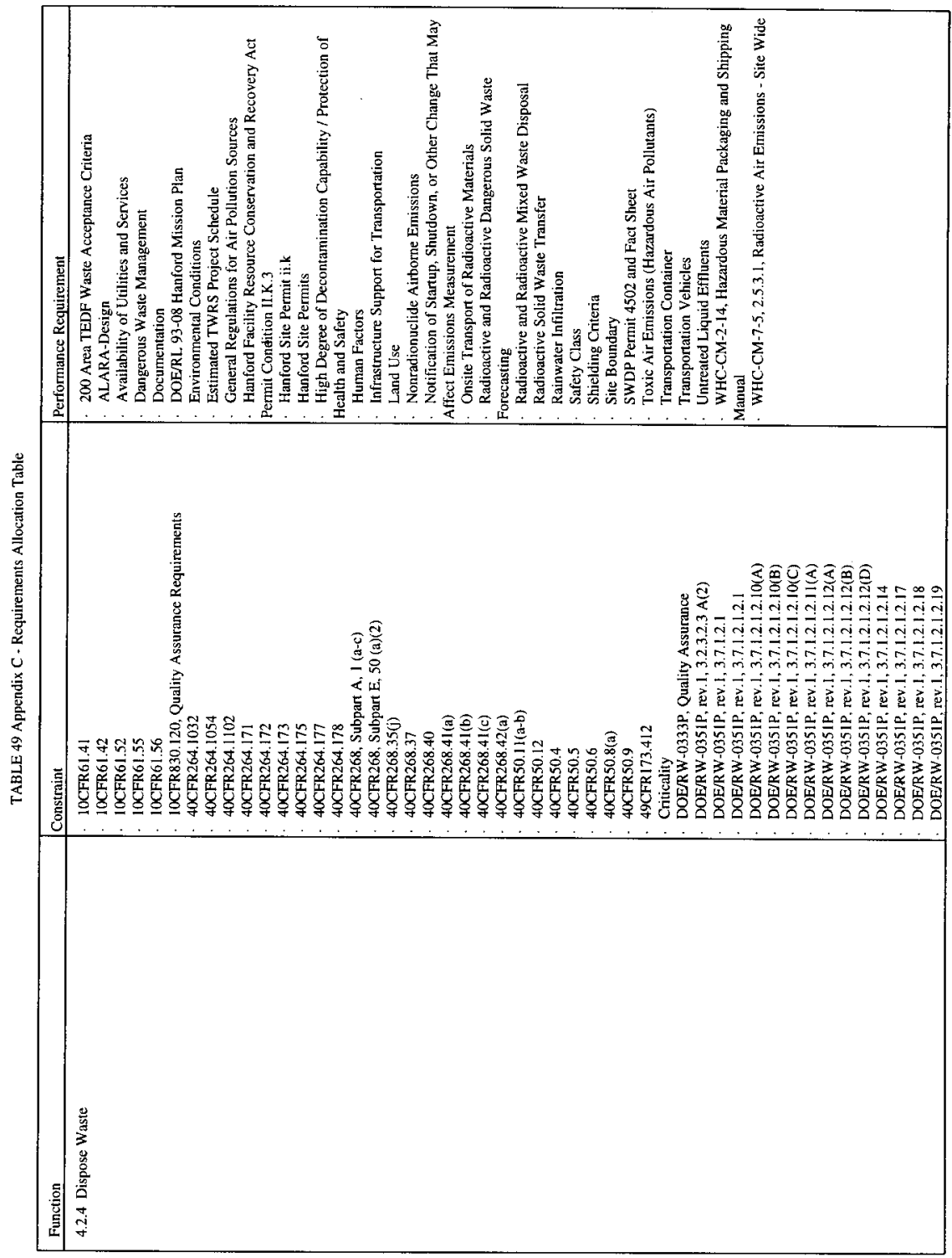




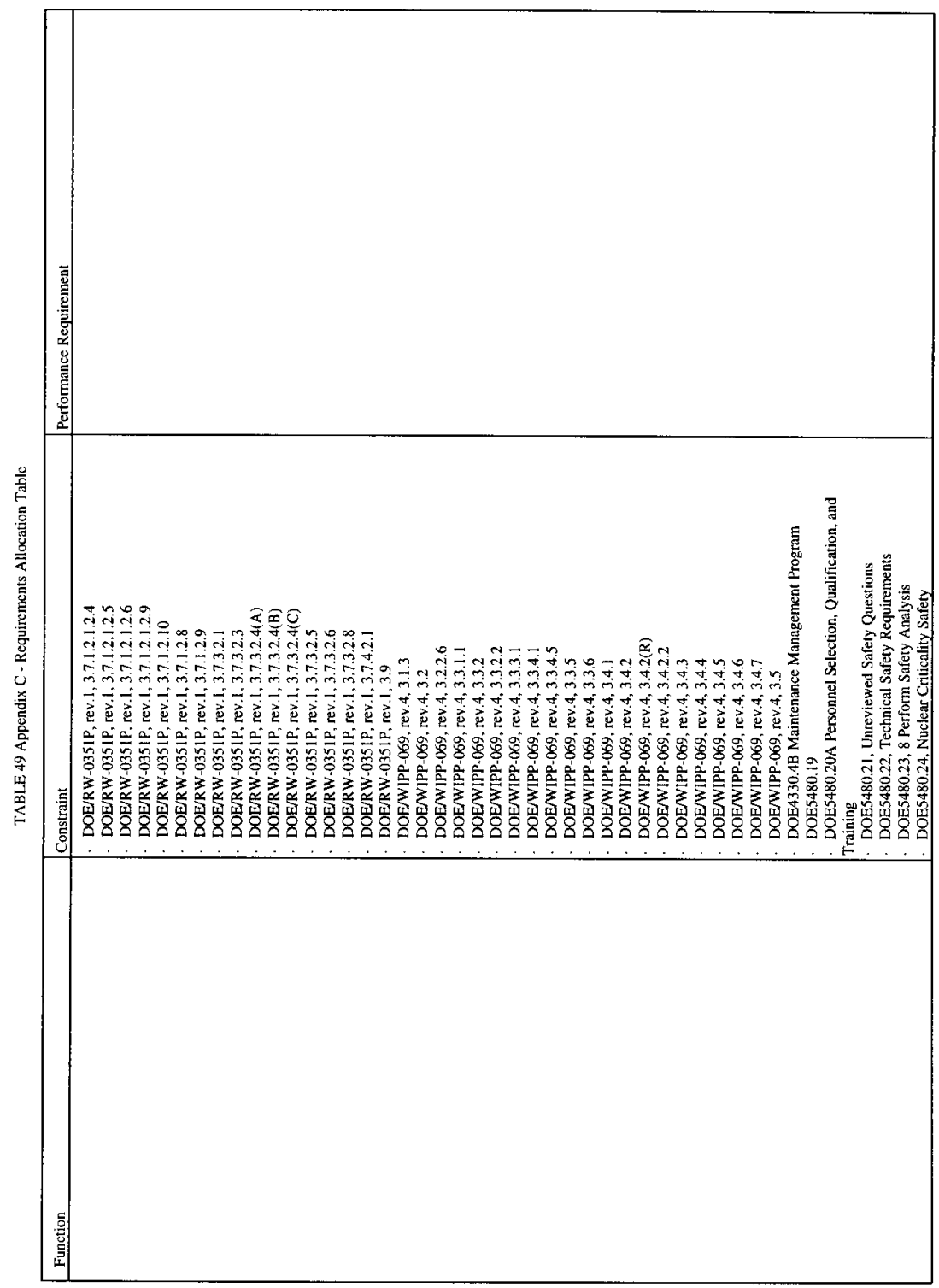




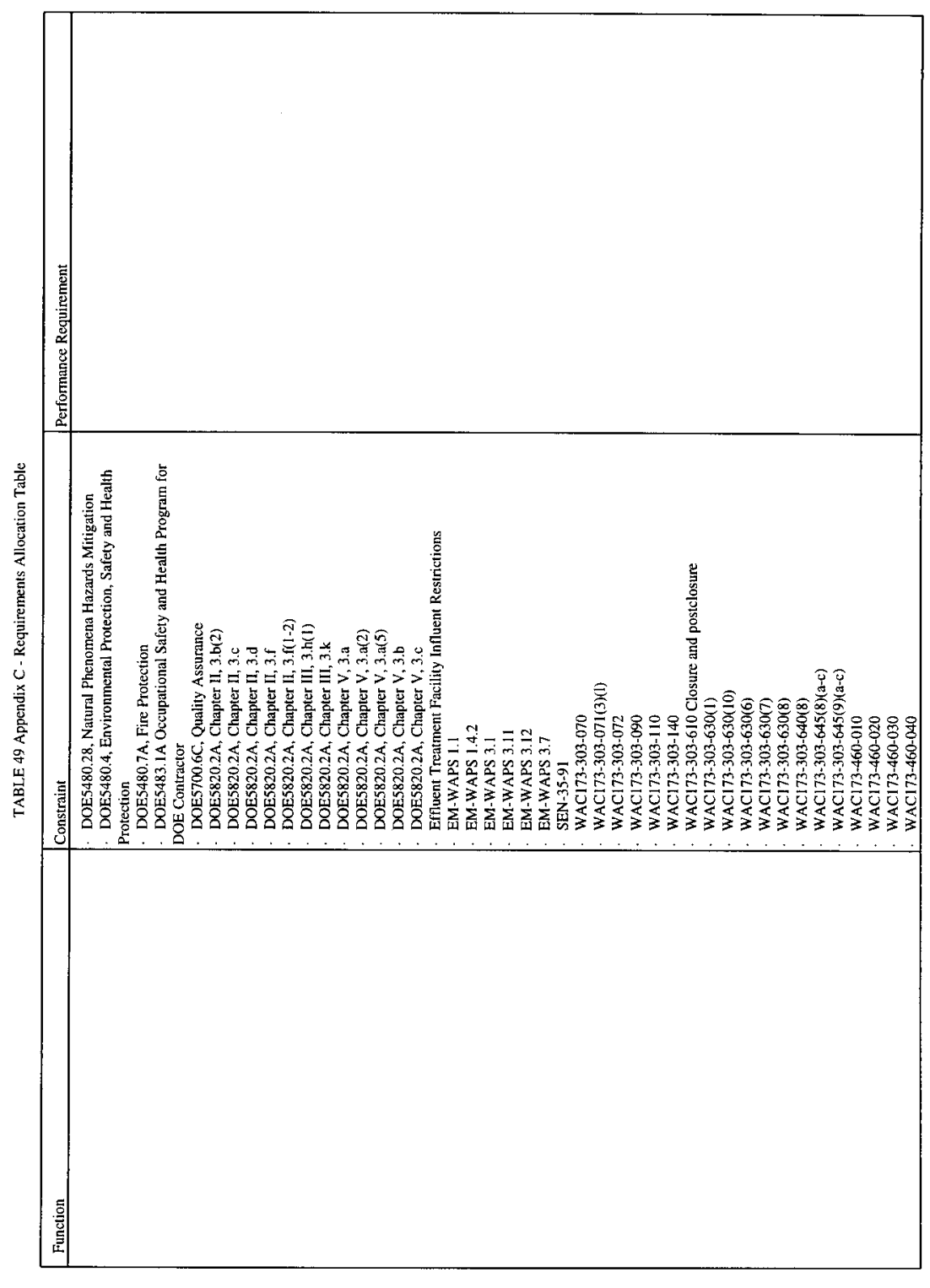




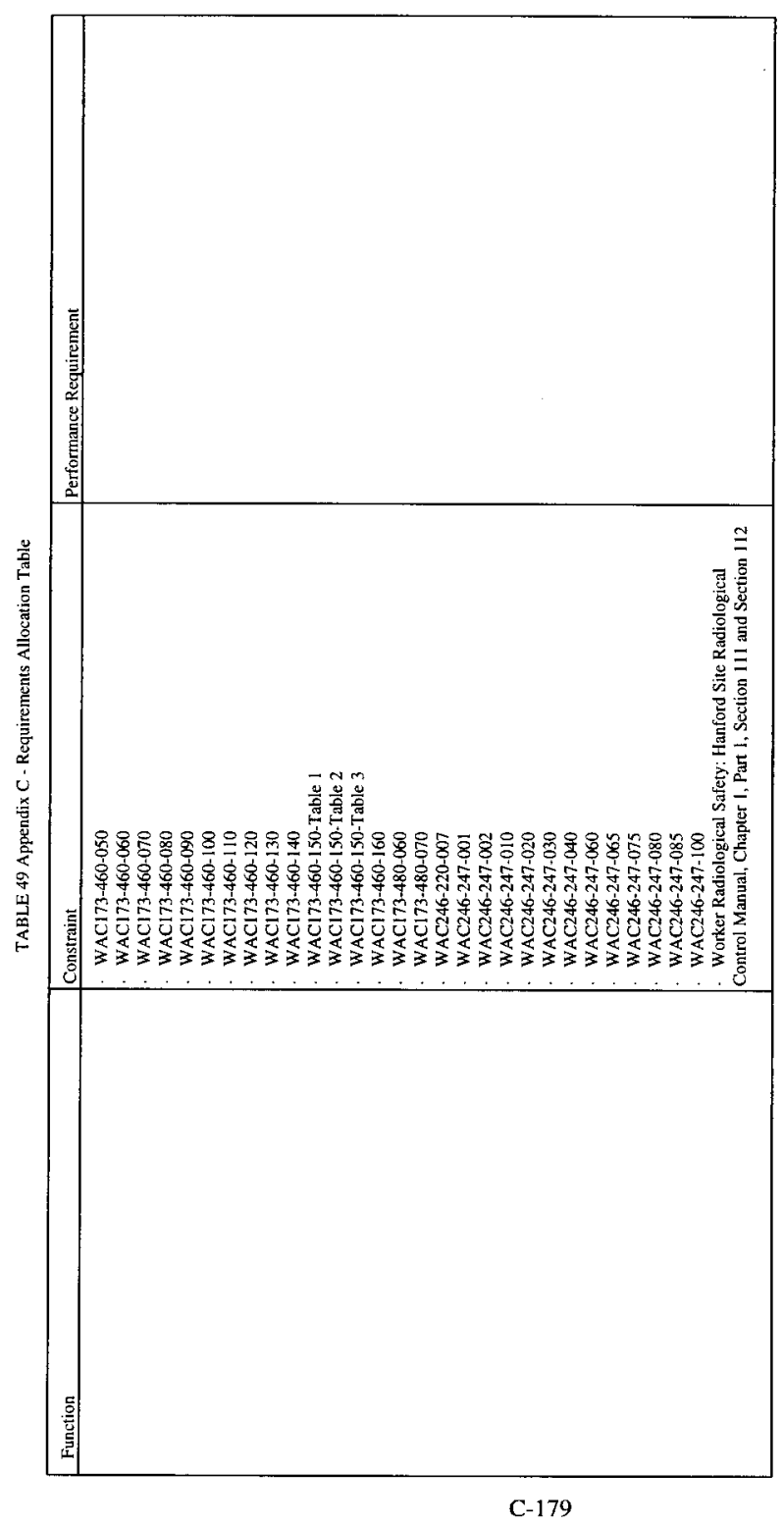




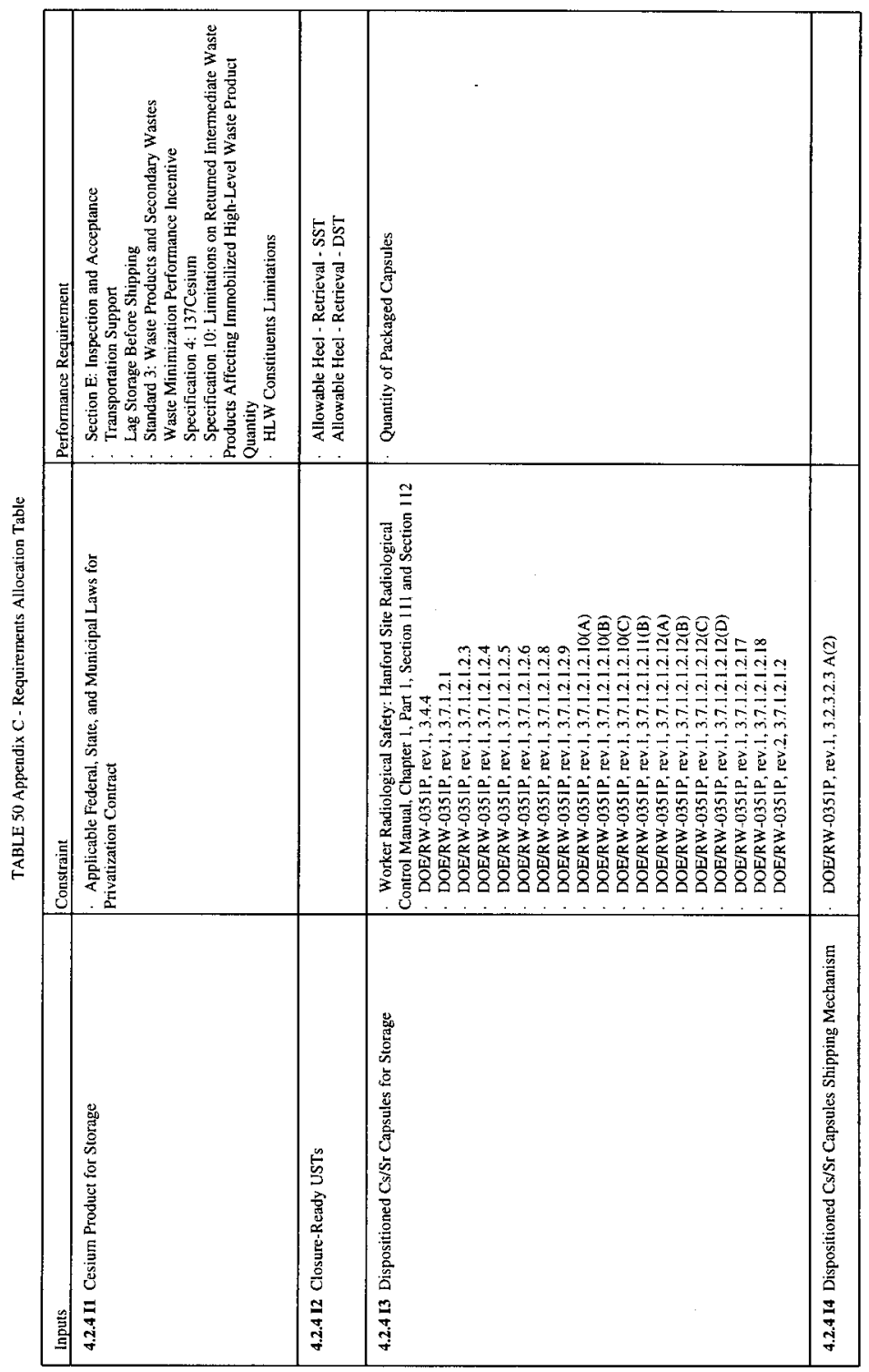




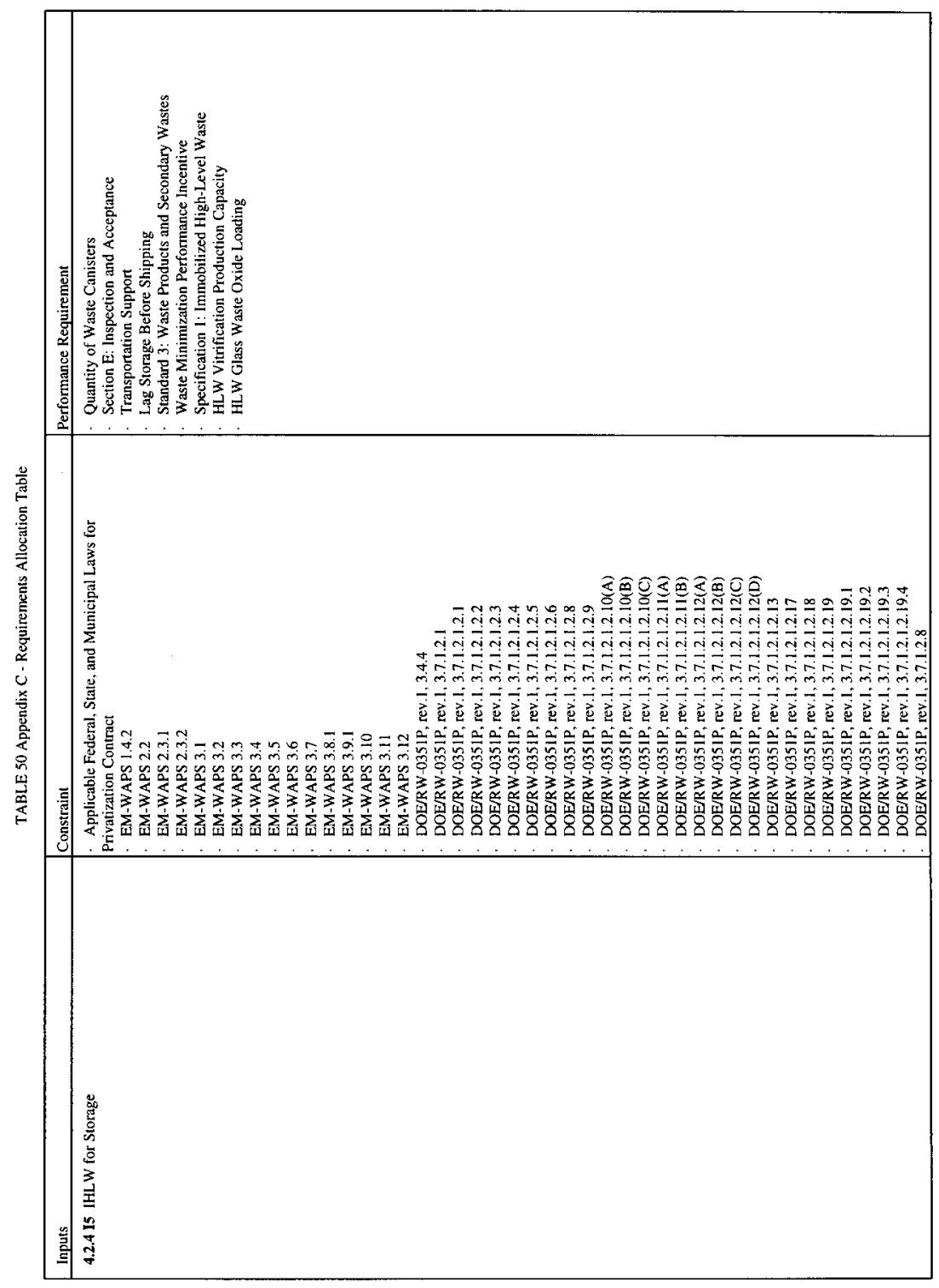




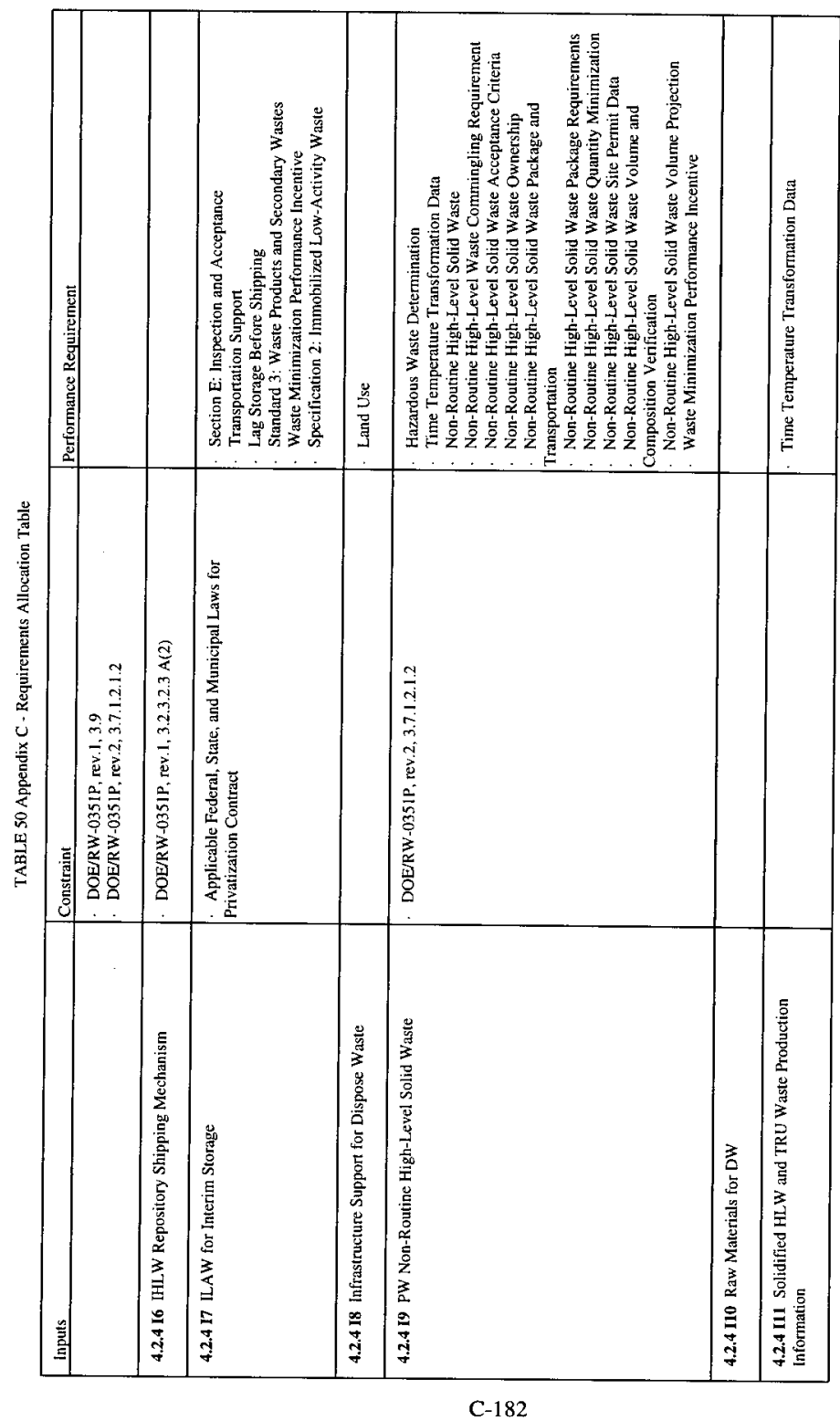




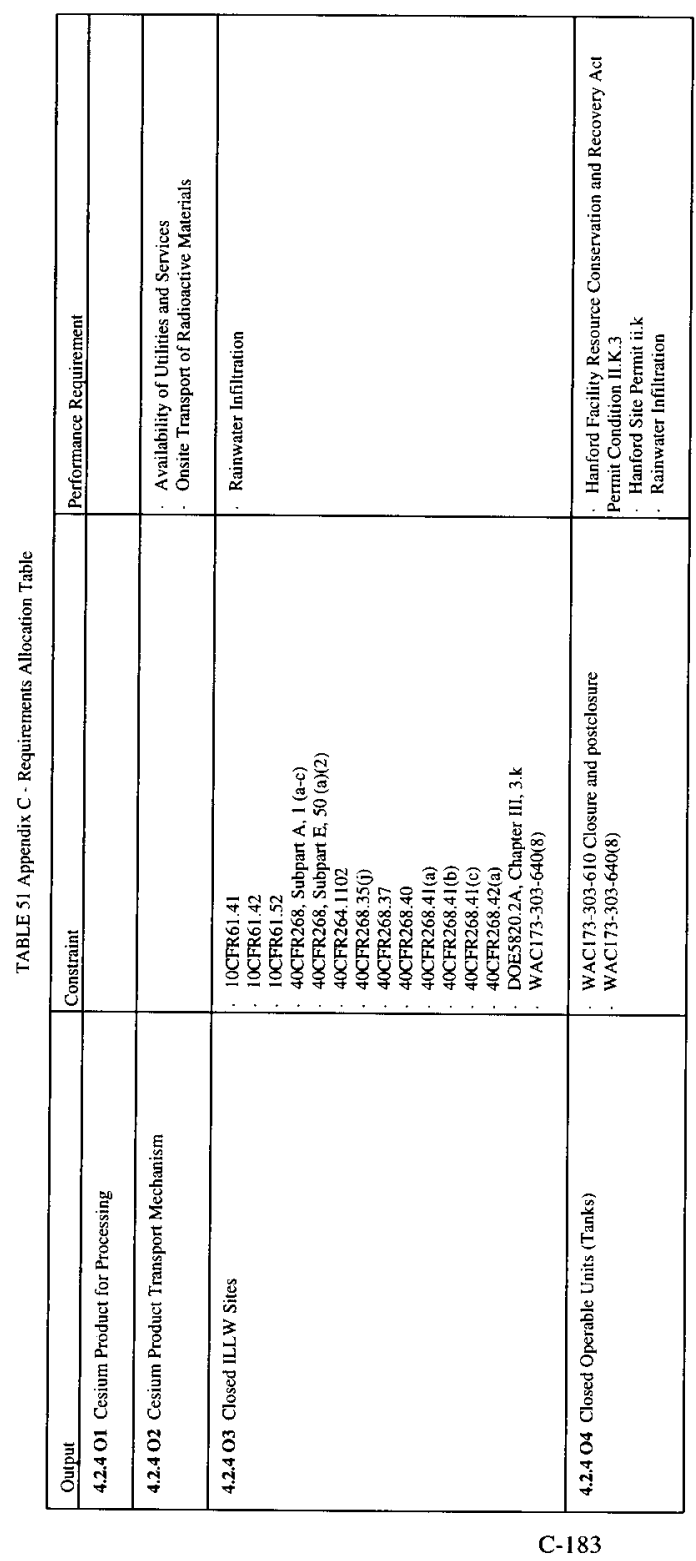




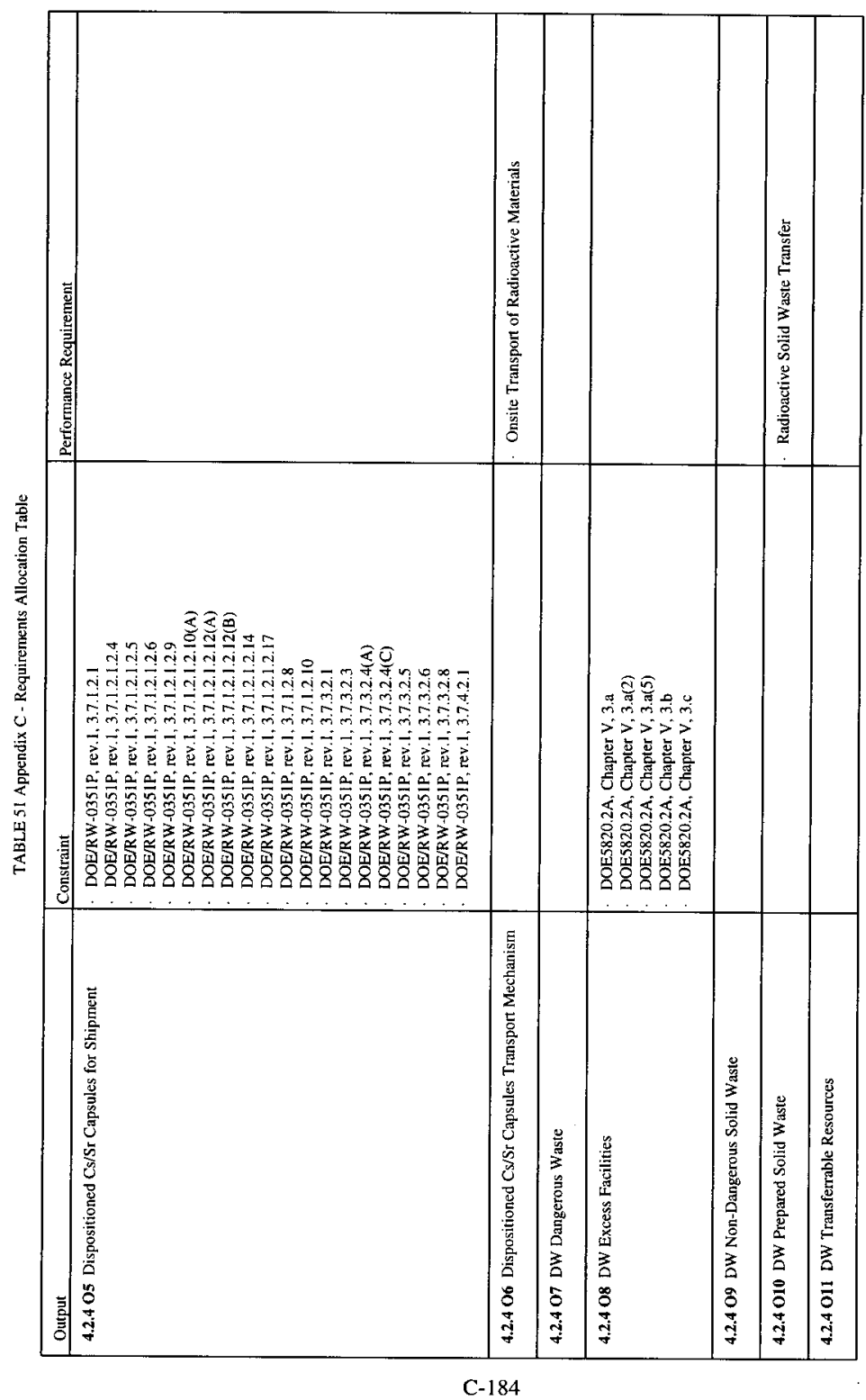


Revision 1

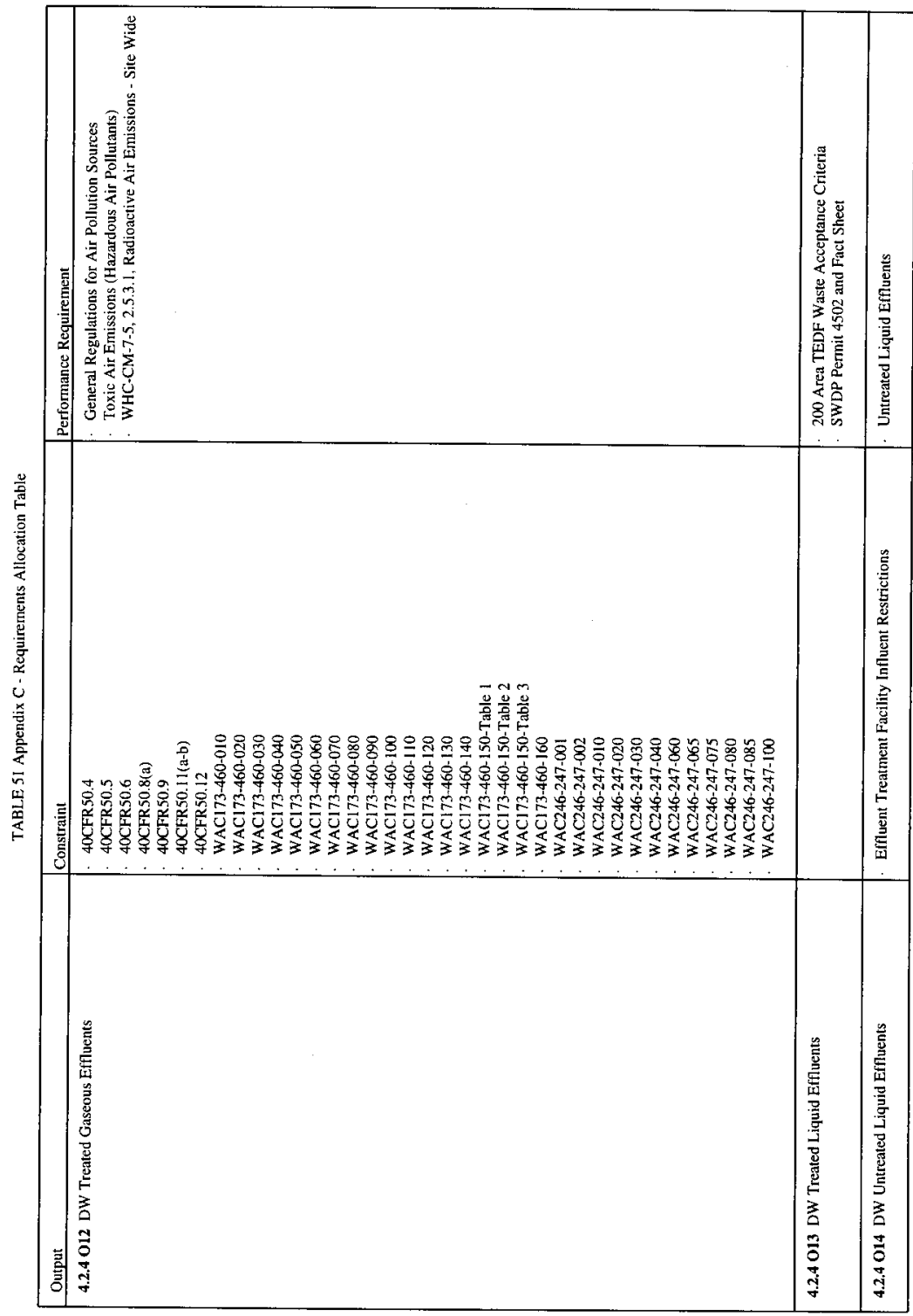




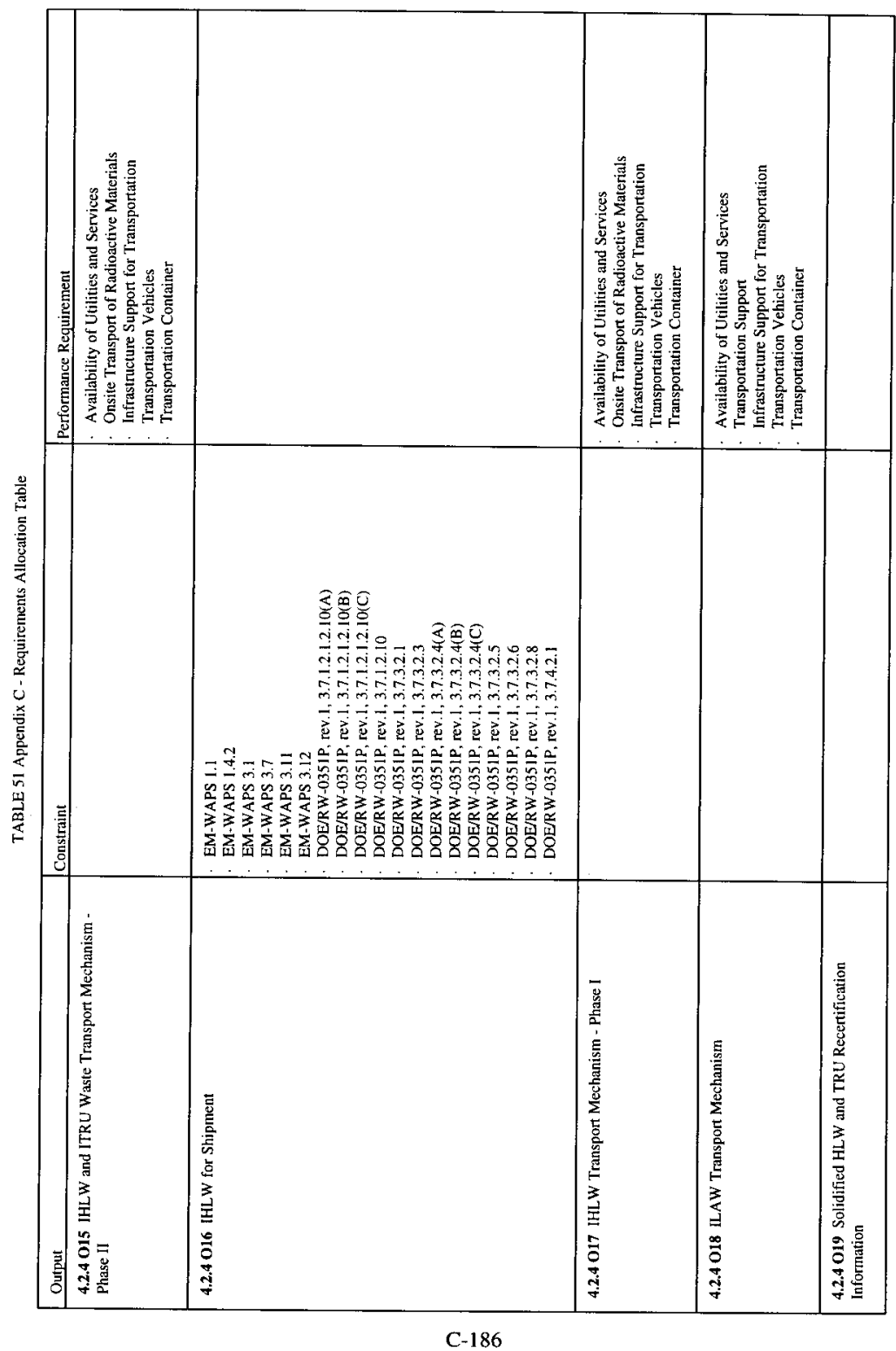




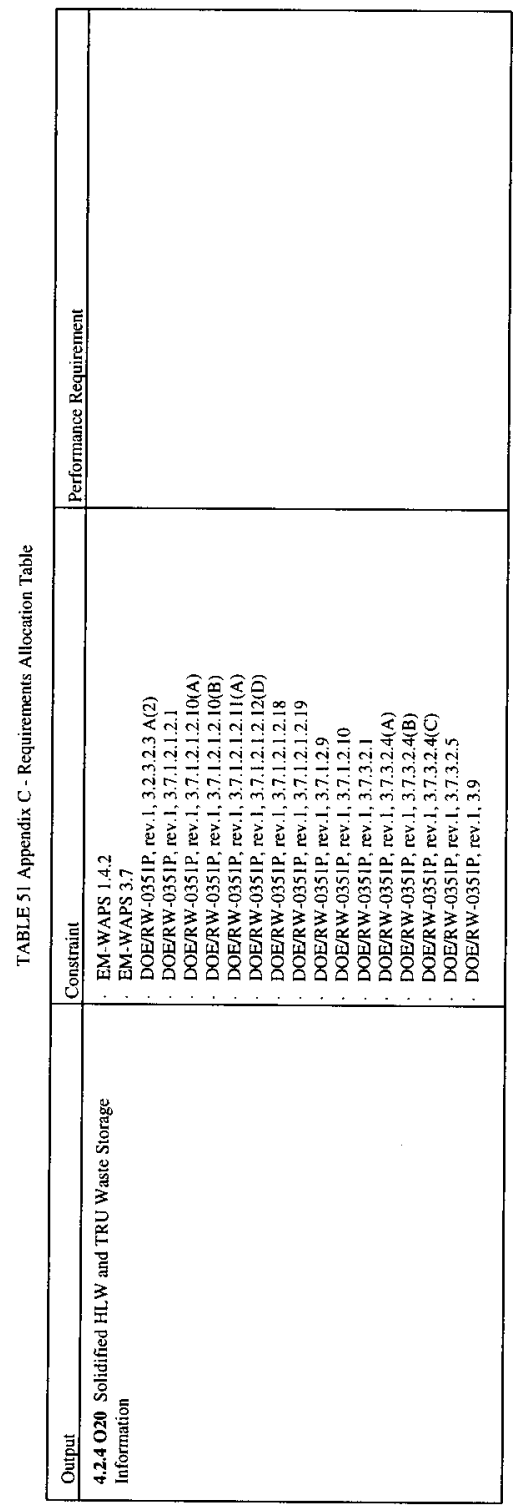


Revision 1 


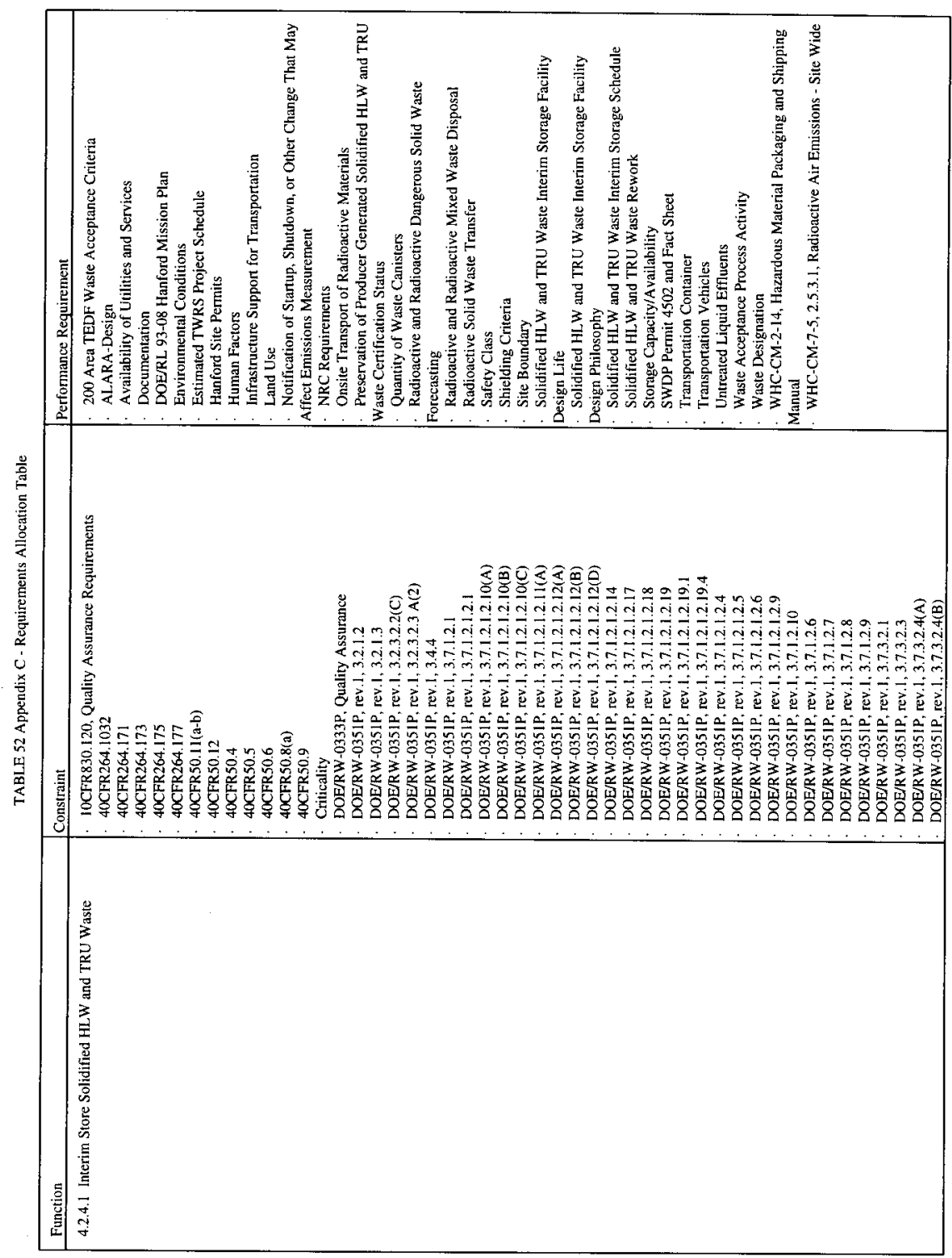




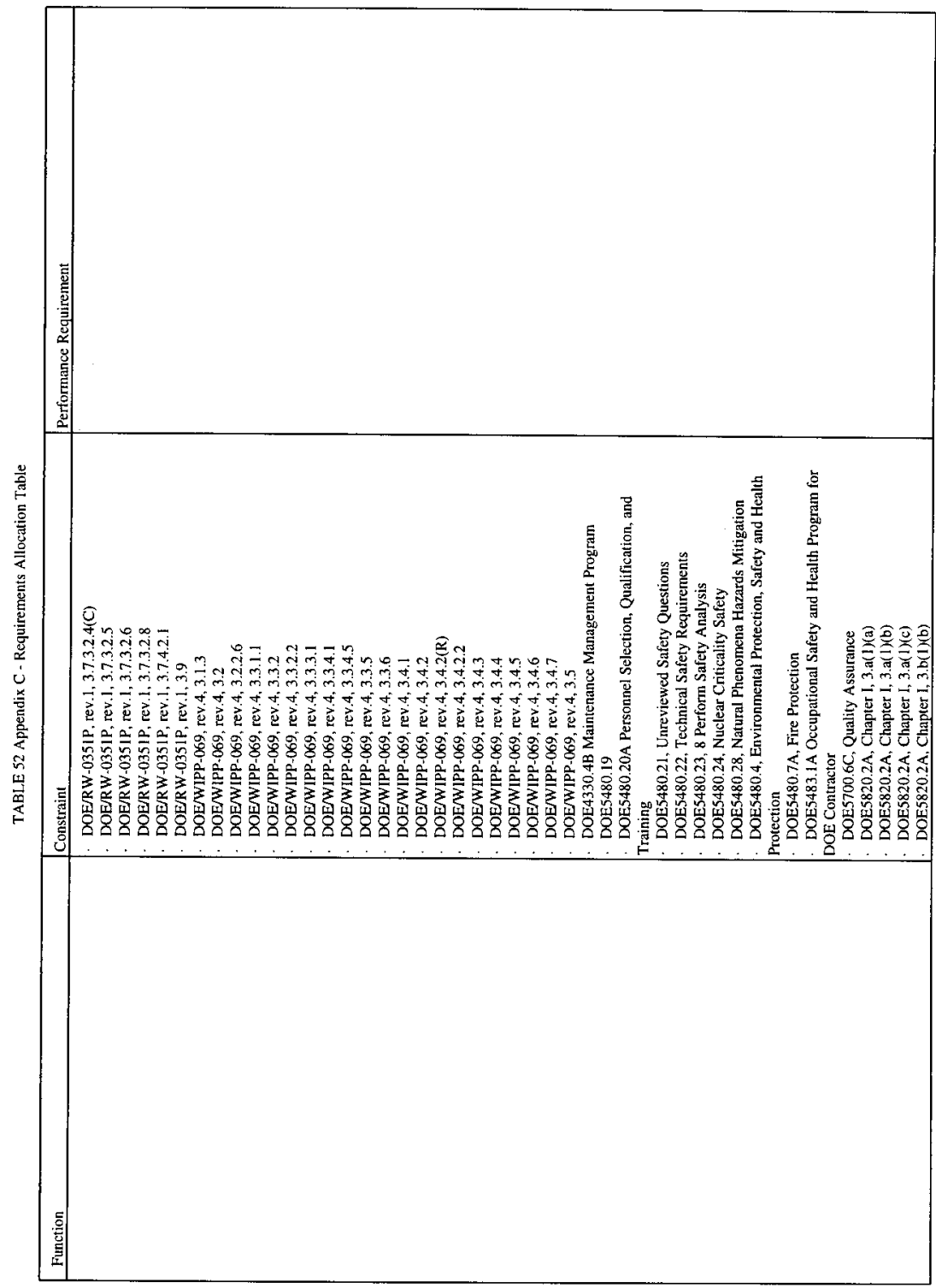




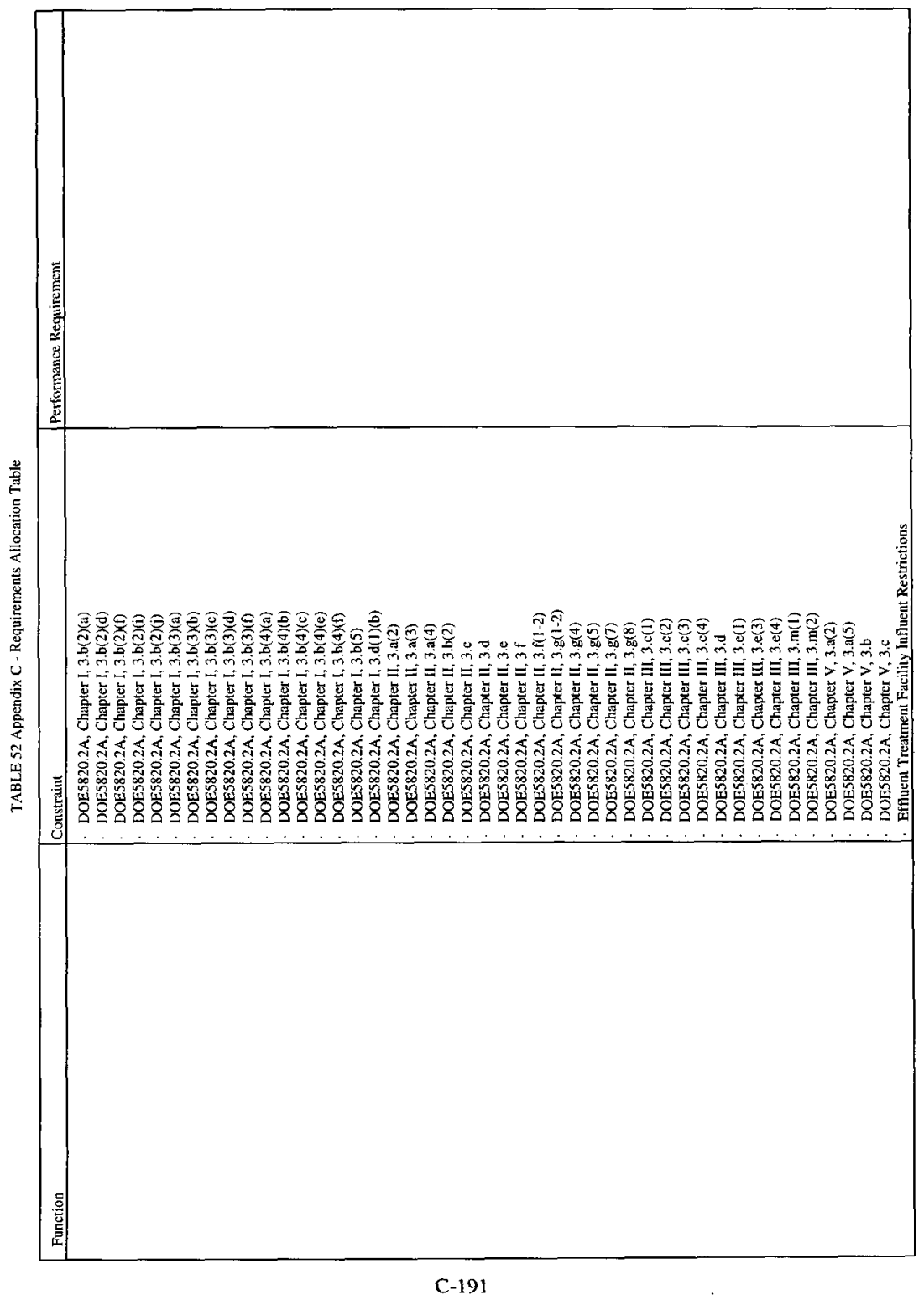




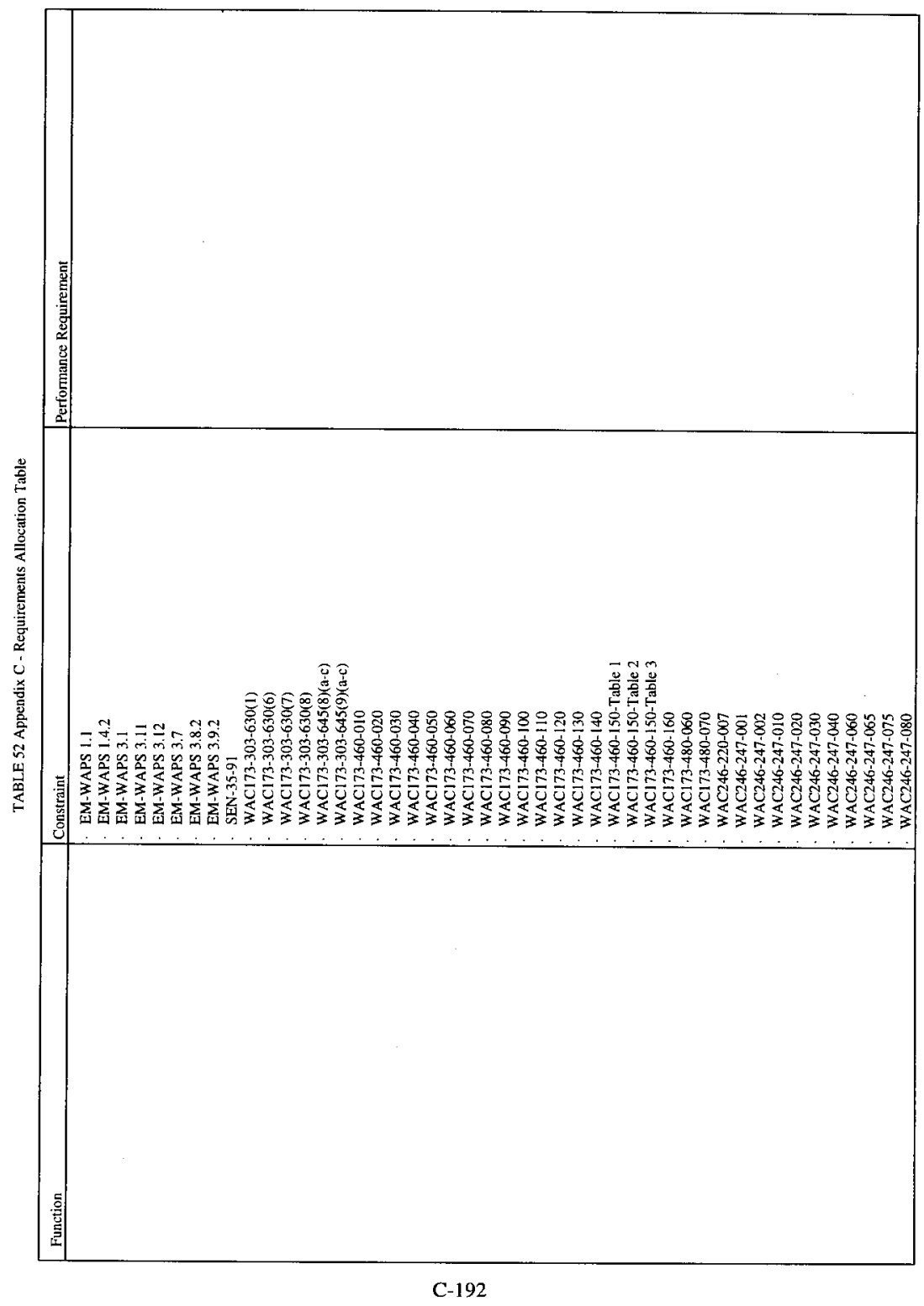


Revision 1

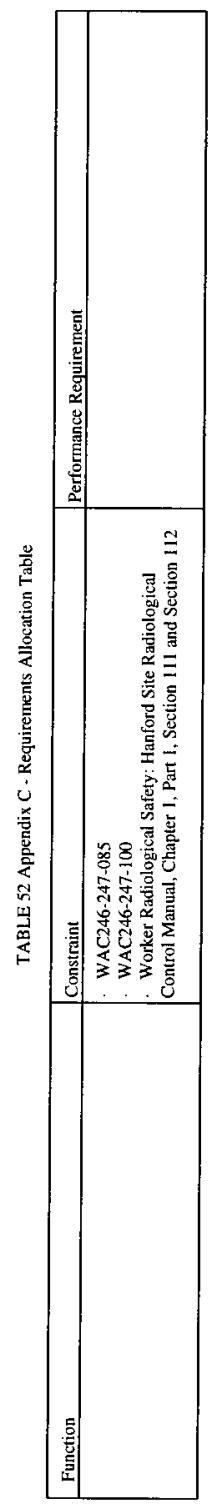

C- 193 
Revision 1

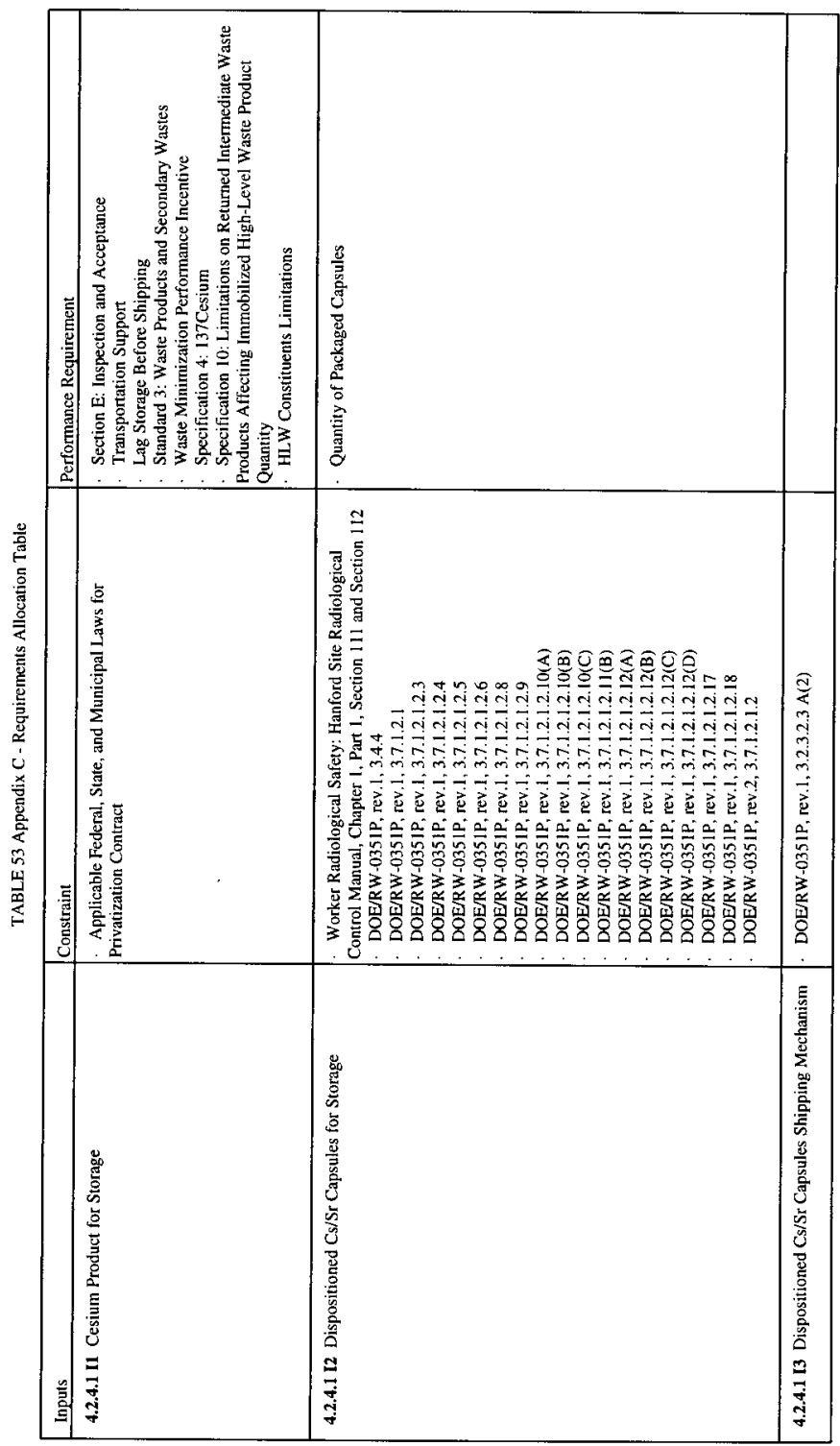

C-194 
Revision 1

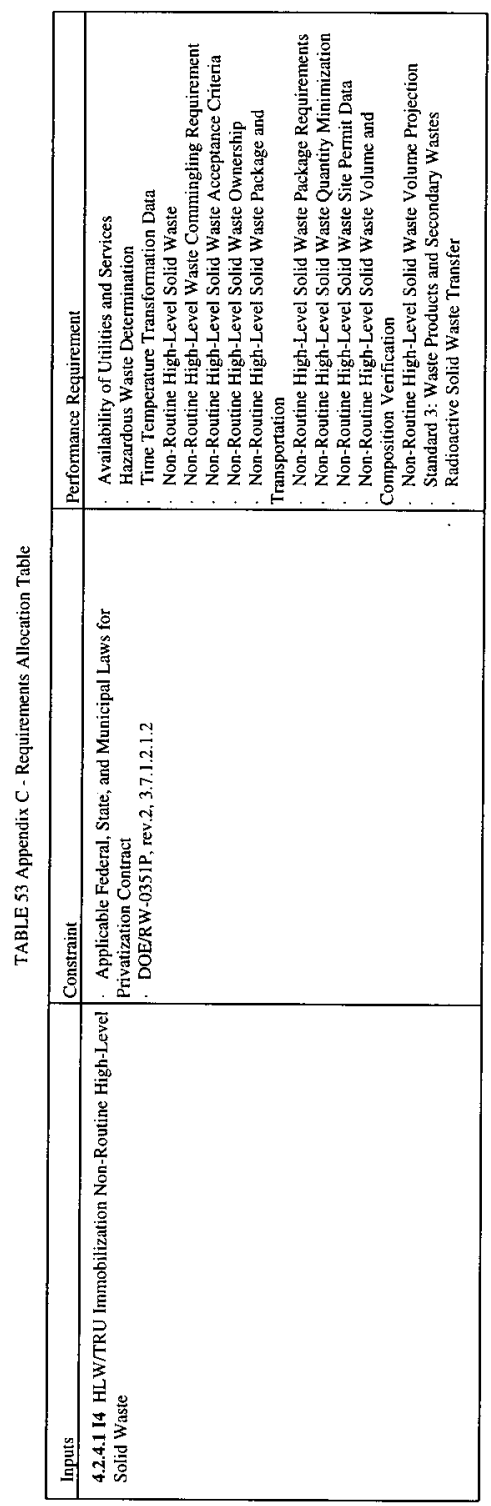

C-195 


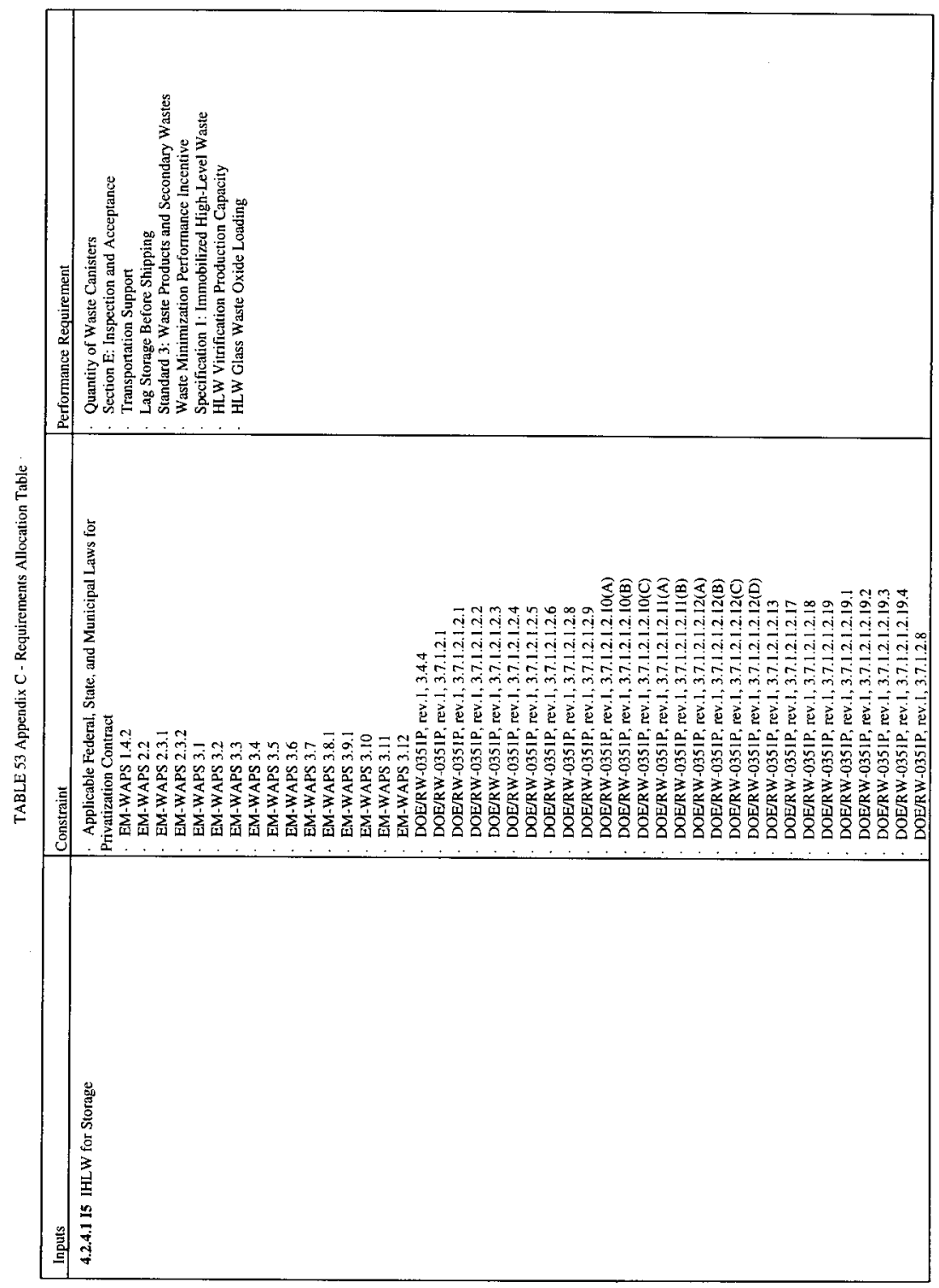




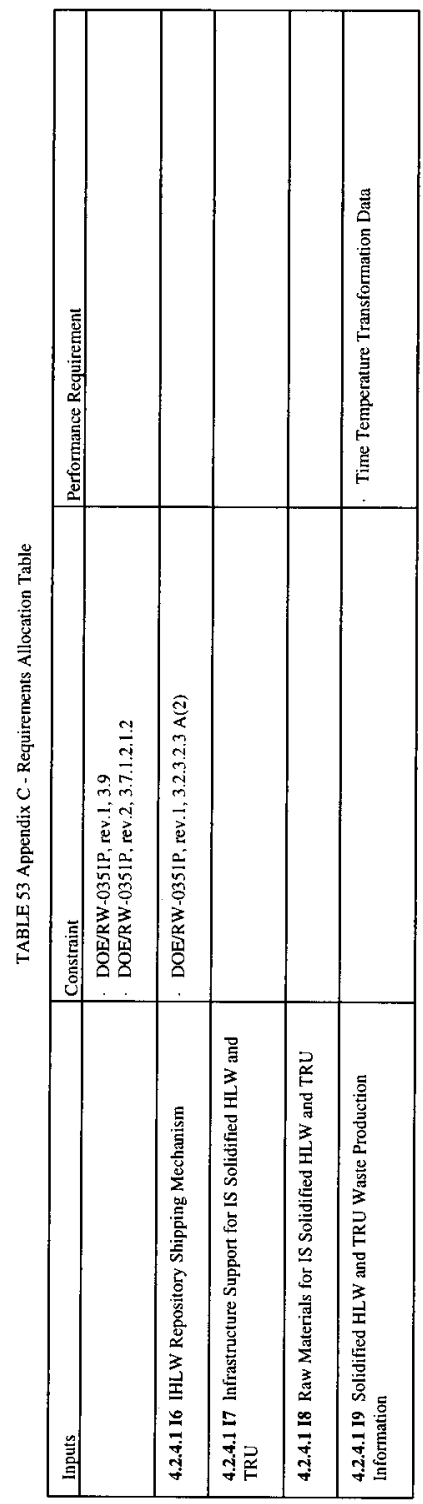




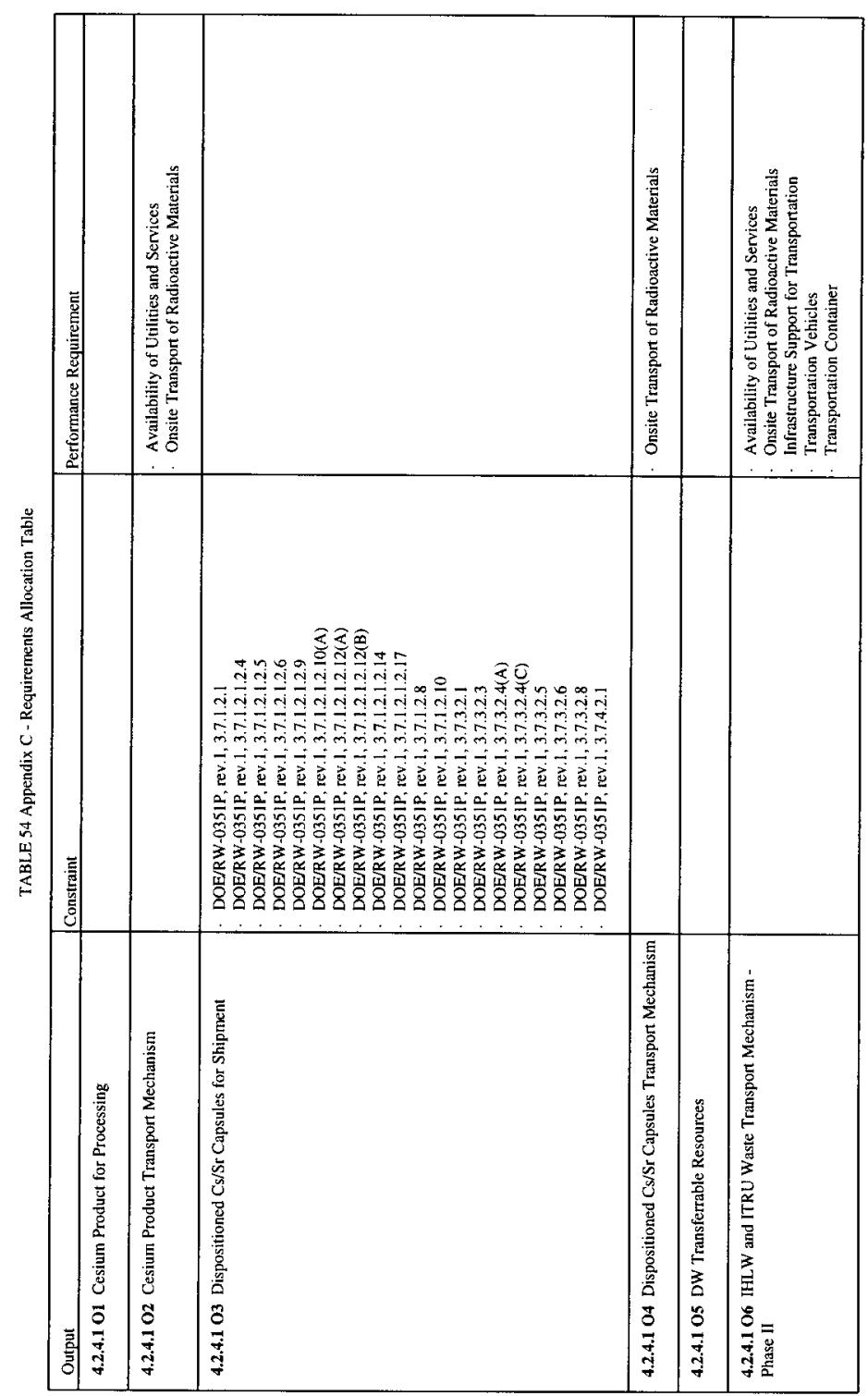

C-198 


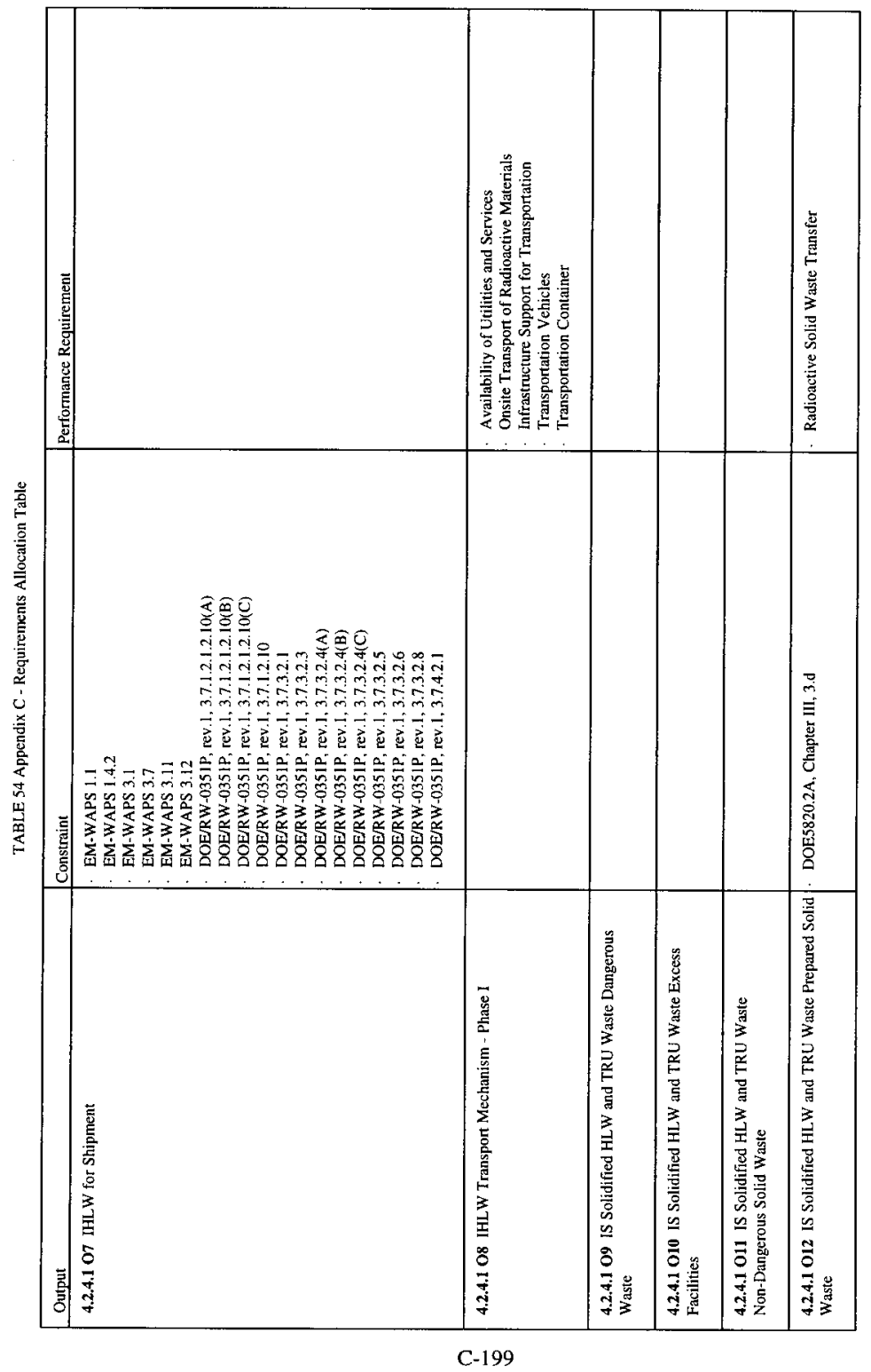




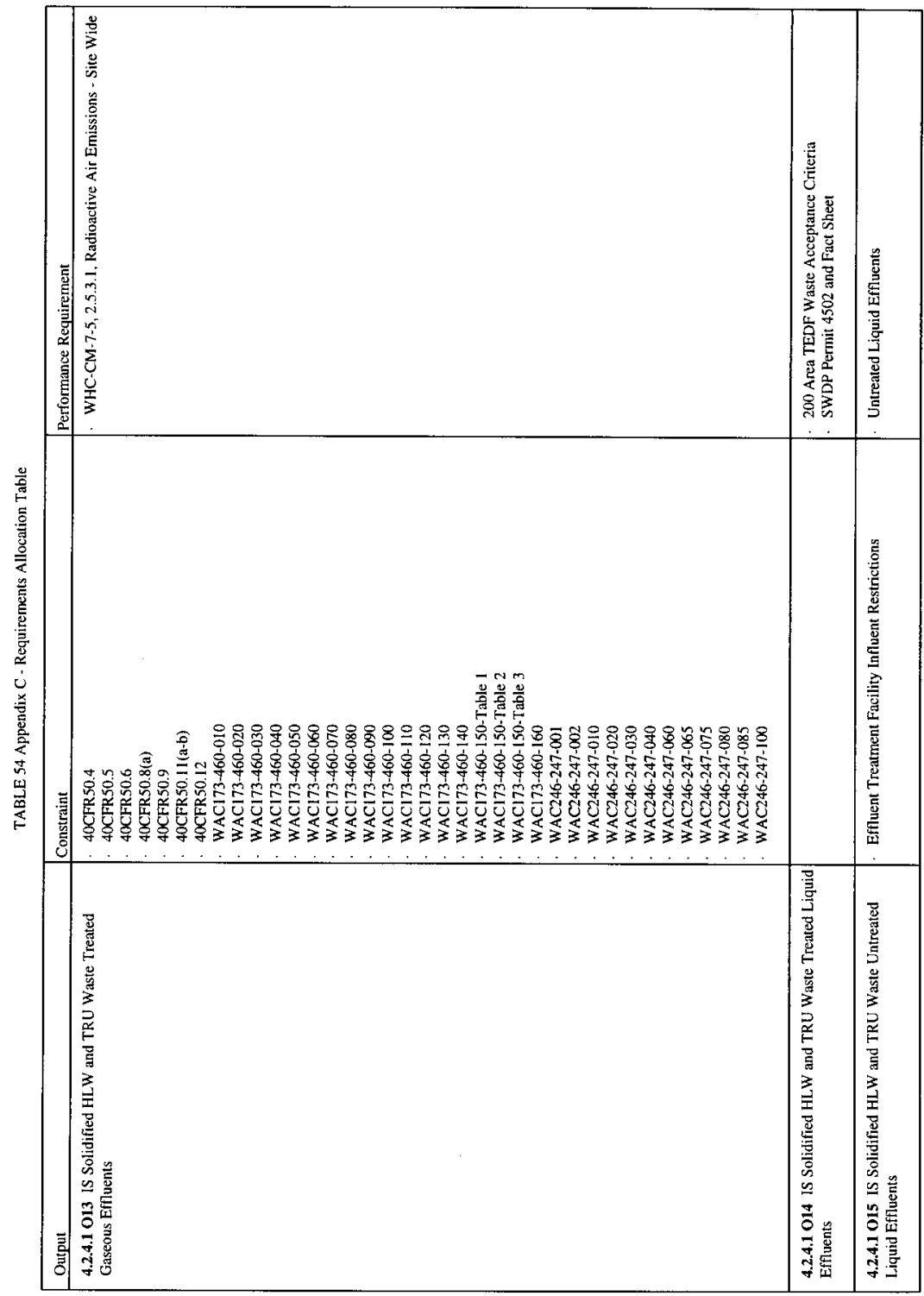




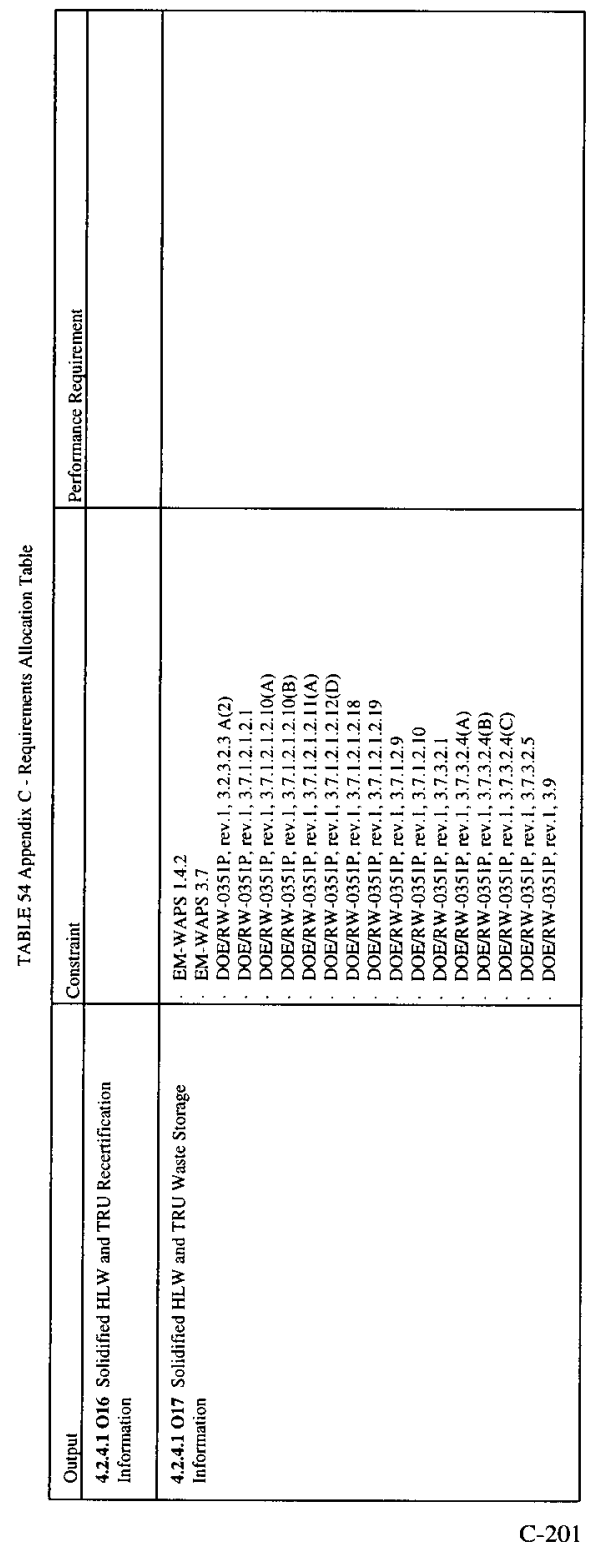


Revision 1 


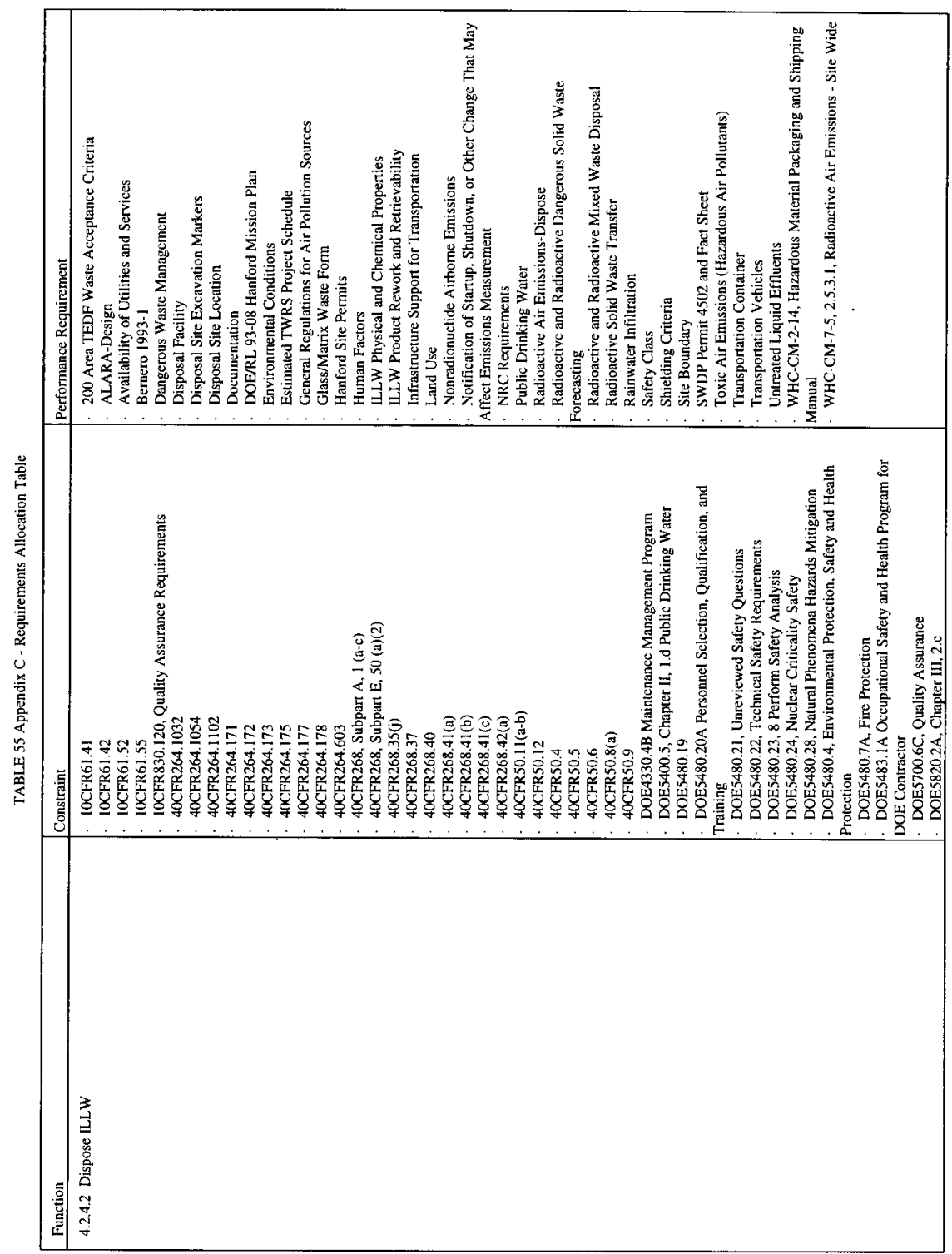




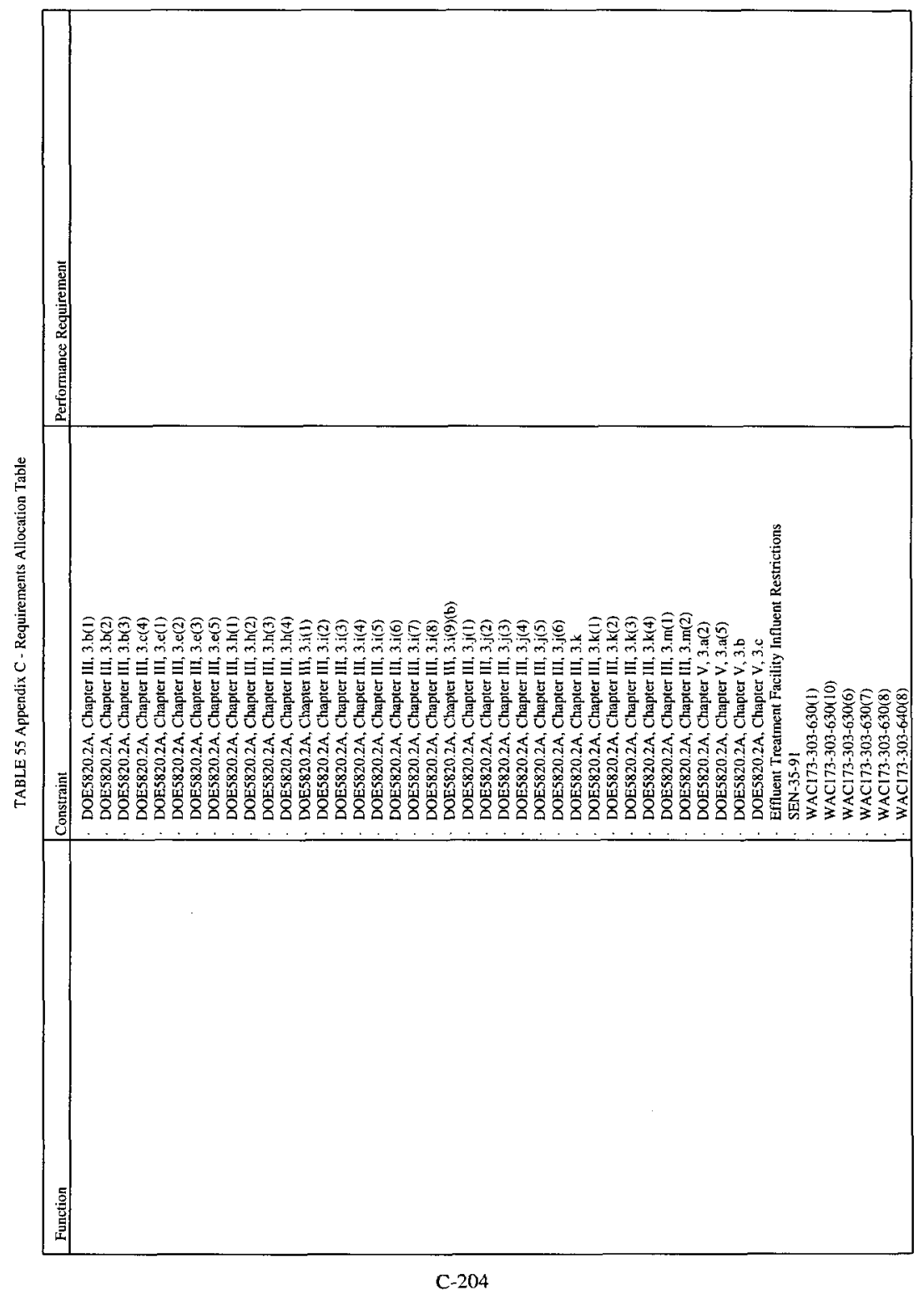




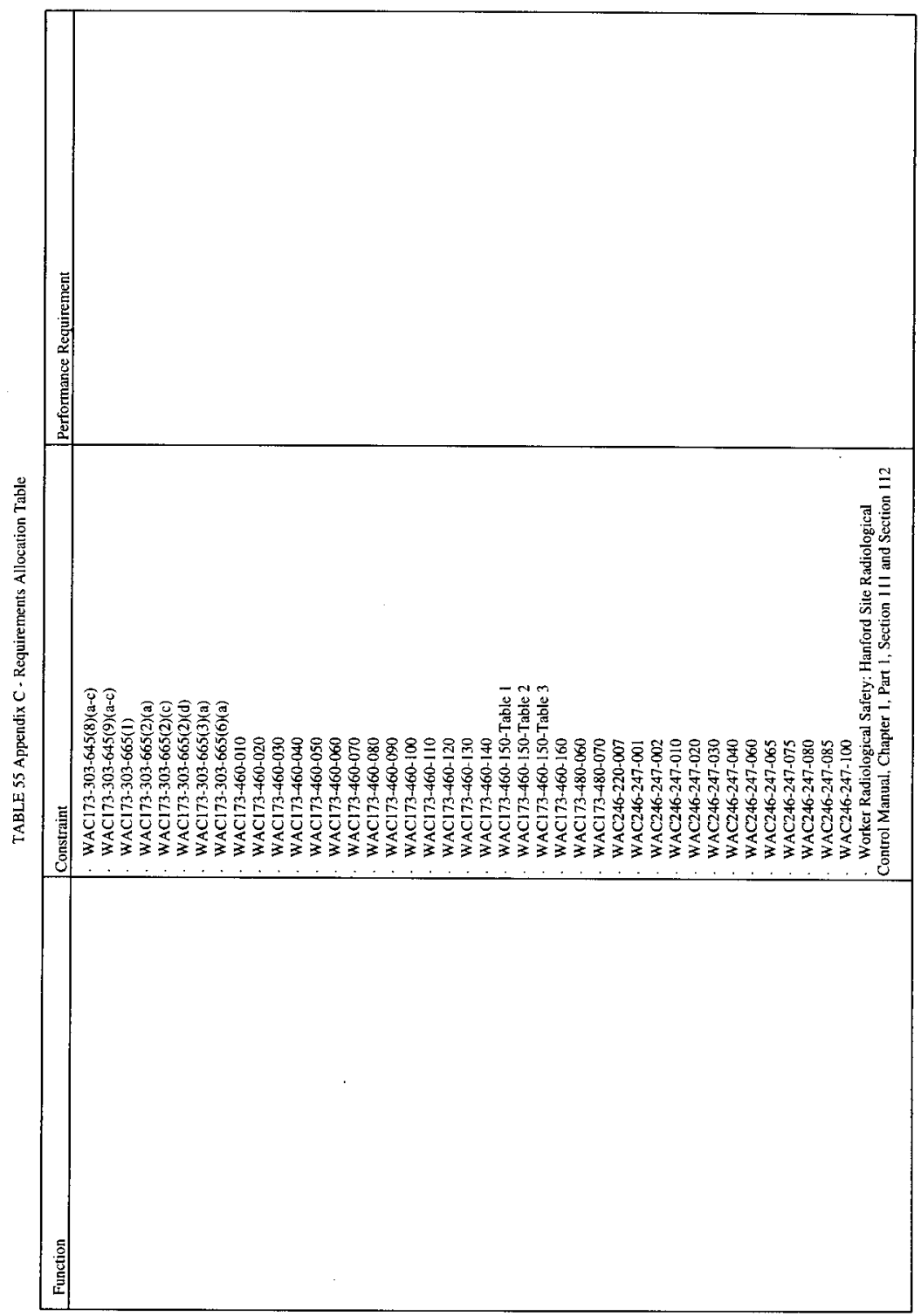




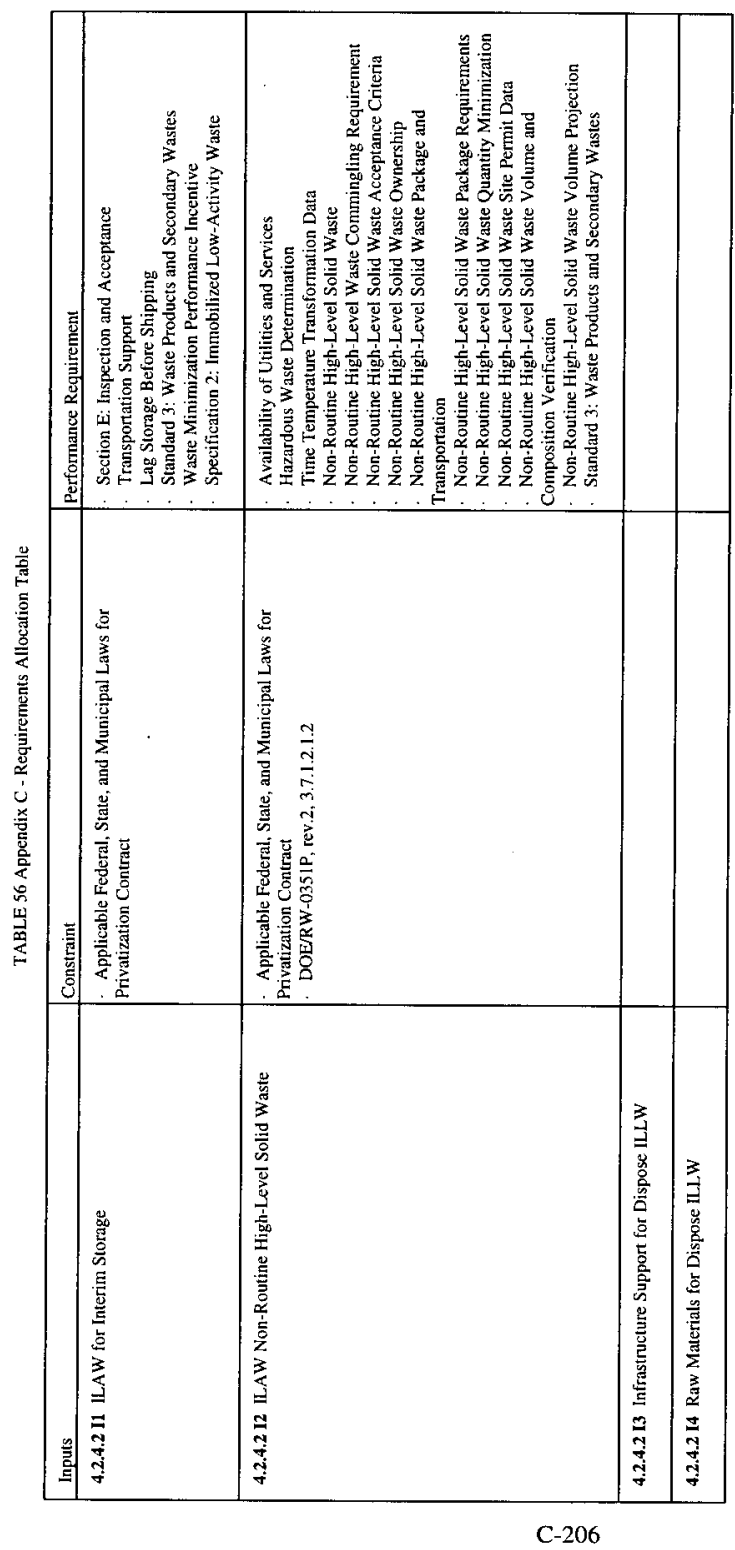




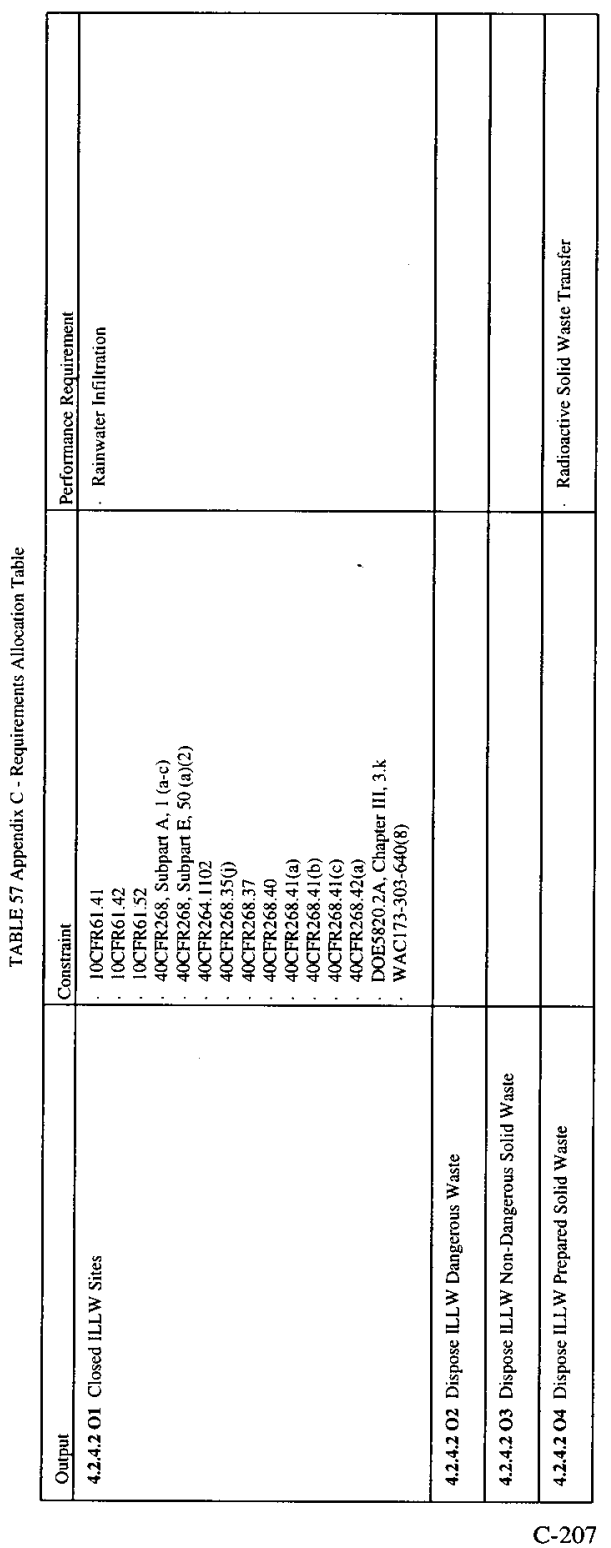


Revision 1

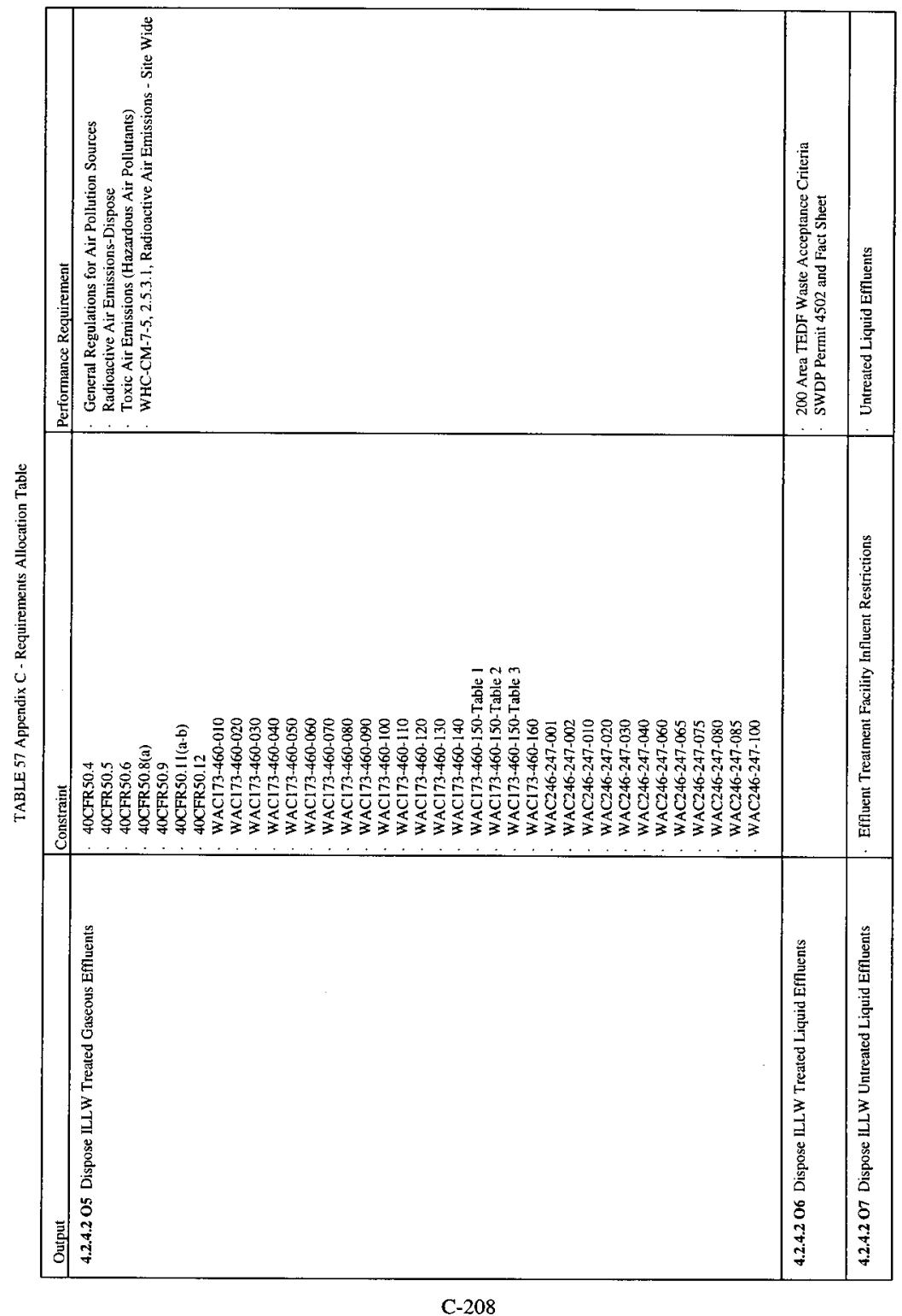


Revision 1

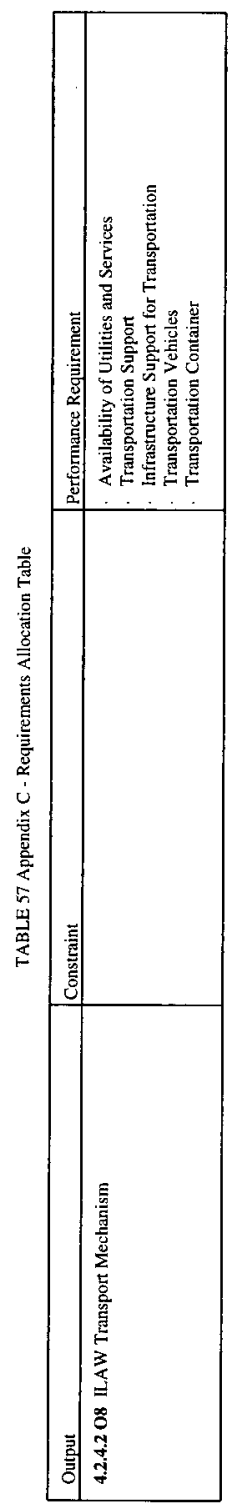




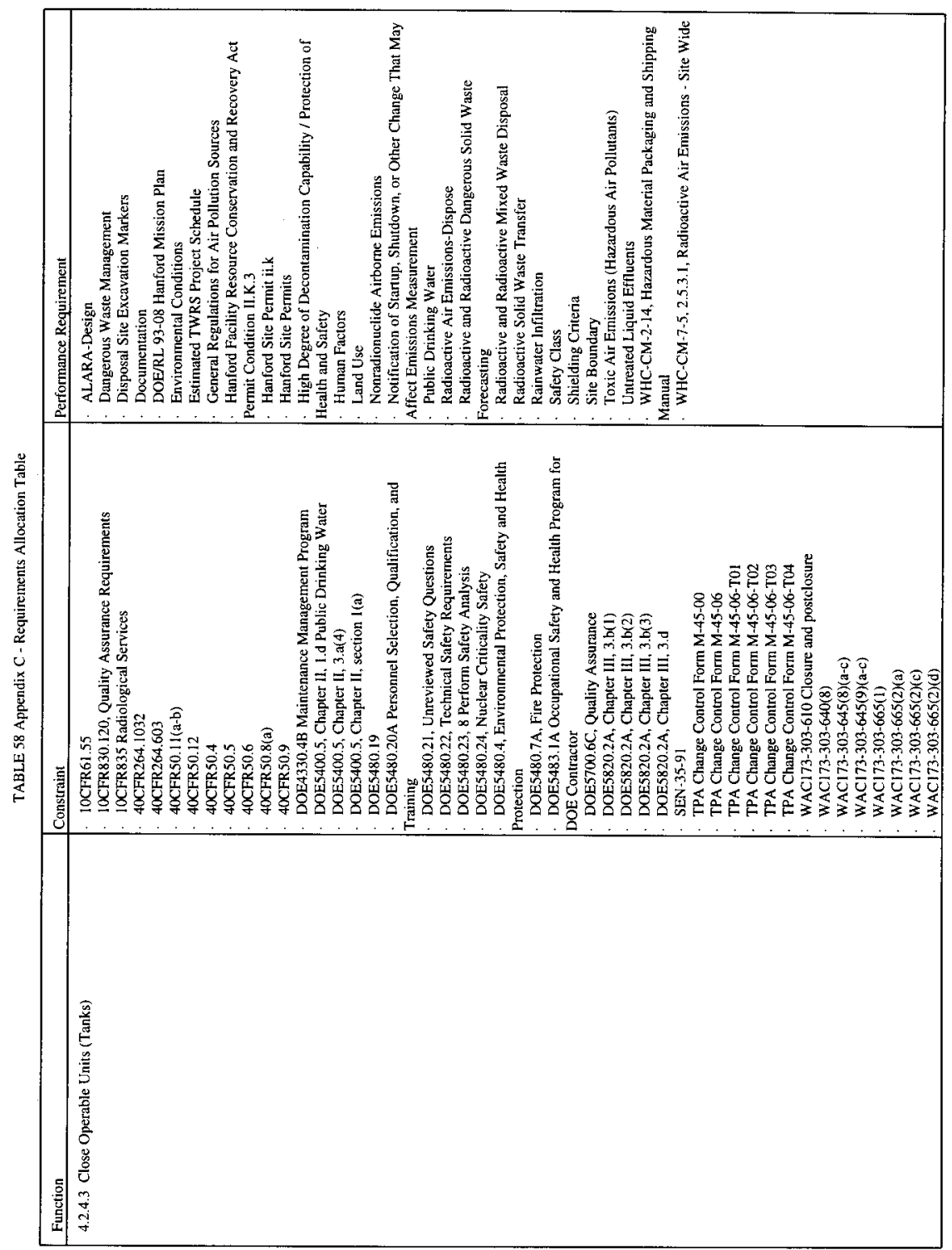




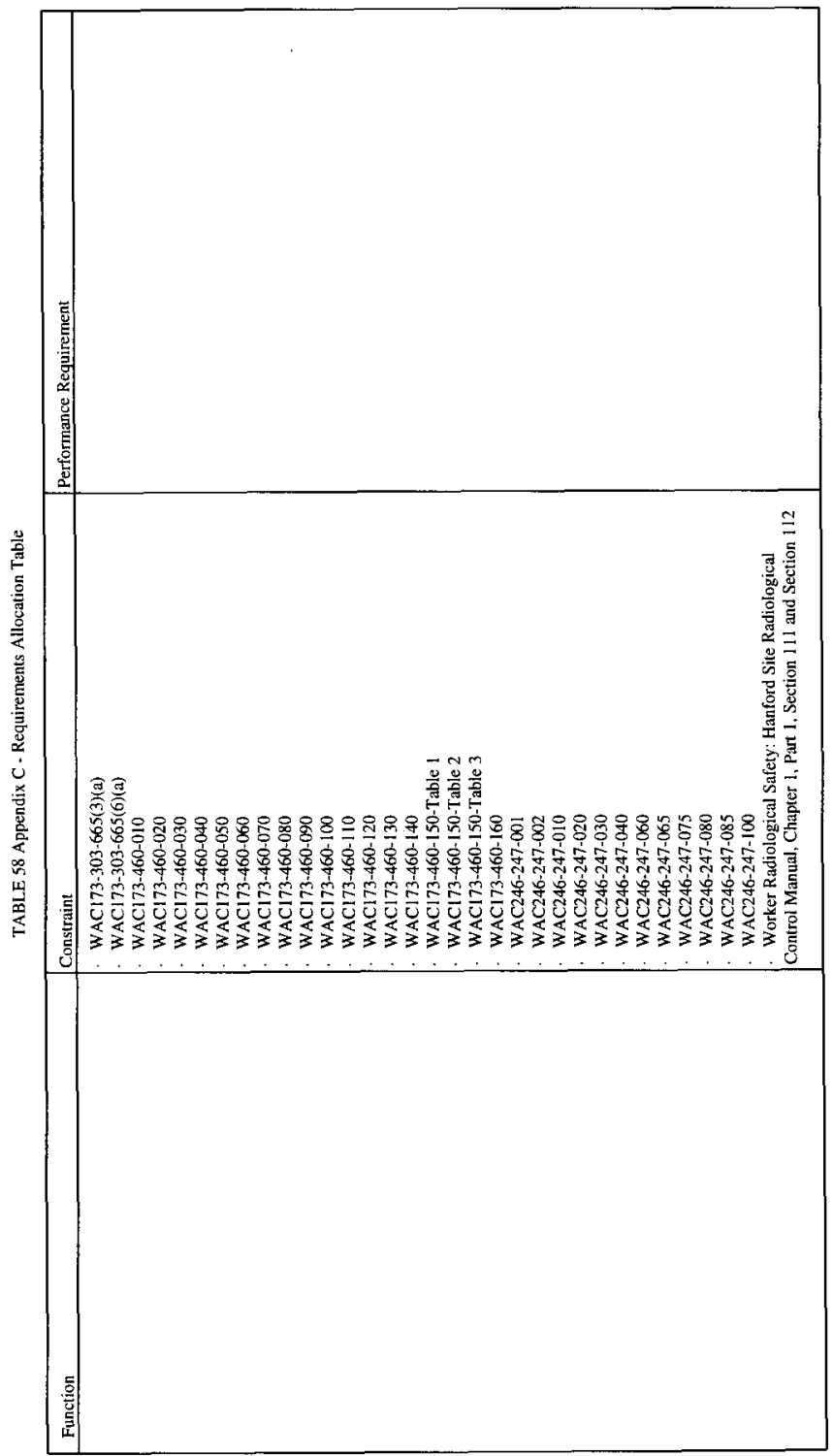

C-212 


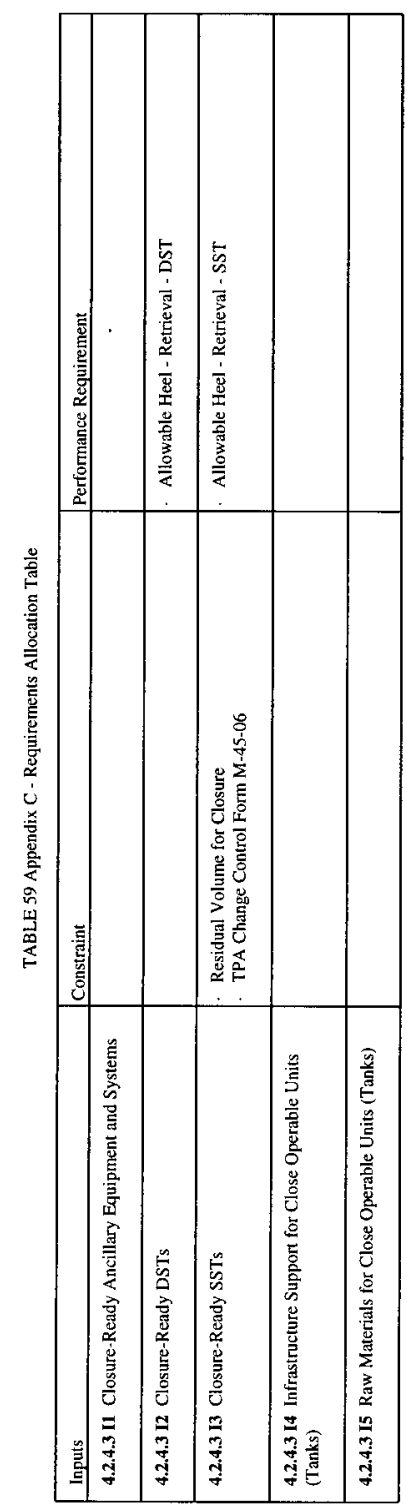




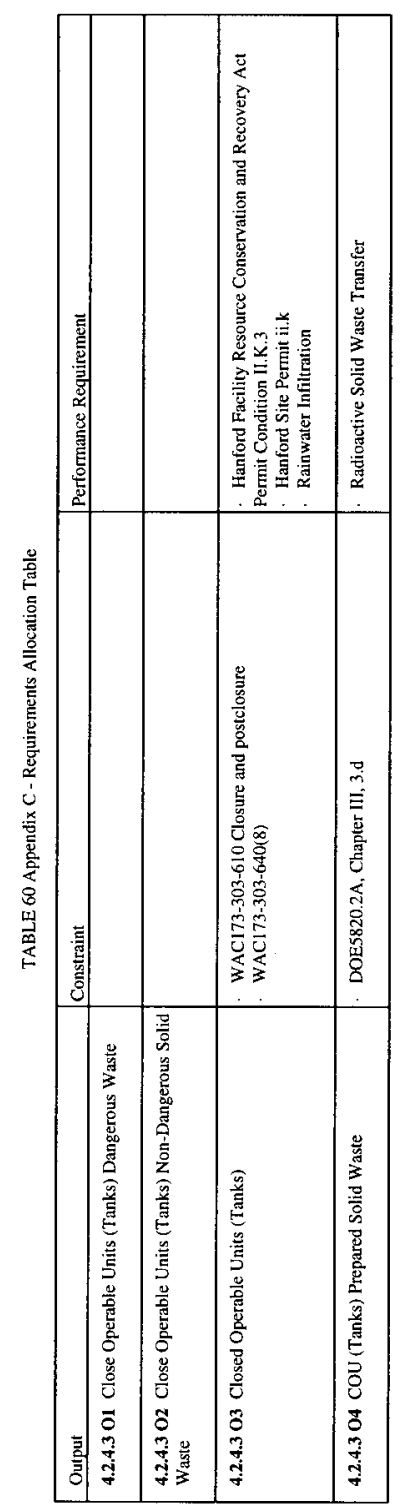


Revision 1

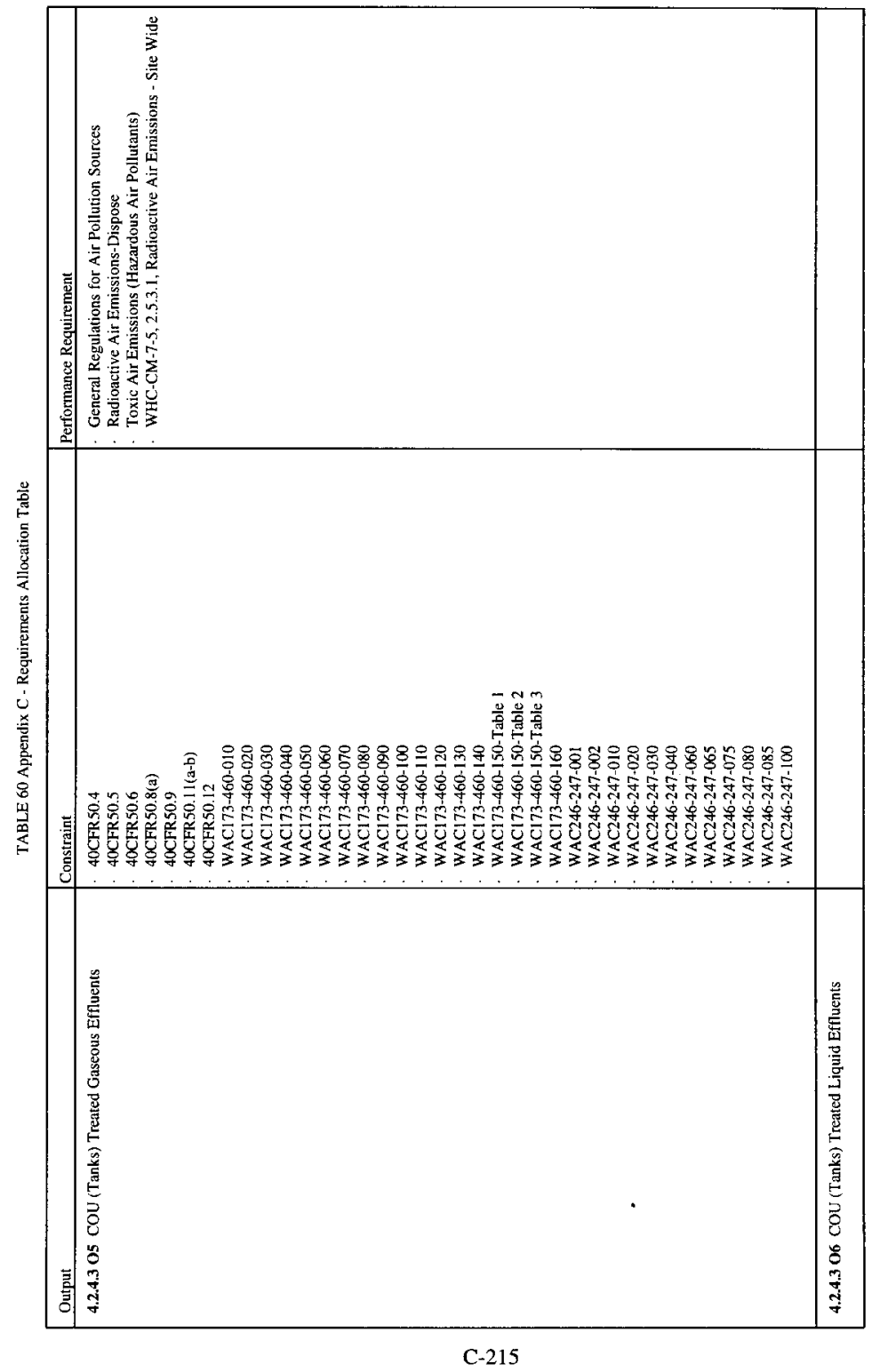


WHC-SD-WM-FRD-020

Revision 1

This page intentionally left blank. 
WHC-SD-WM-FRD-020

Revision 1

\section{APPENDIX D \\ CONSTRAINTS}

D-1 
WHC-SD-WM-FRD-020

Revision 1

This appendix lists, in alphanumeric order, applicable constraint documents or sections thereof. If a Constraint title is listed in Appendices $\mathrm{C}$ or $\mathrm{G}$, refer to this appendix for a description of the requirement. 


\section{CFR61.41}

Concentrations of radioactive material which may be released to the general environment in ground water, surface water, air, soil, plants, or animals must not result in an annual dose exceeding an equivalent of 25 millirems to the whole body, 75 millirems to the thyroid, and 25 millirems to any other organ of any member of the public. Reasonable effort should be made to maintain releases of radioactivity in effluents to the general environment as low as is reasonably achievable.

\section{CFR61.42}

Design, operation, and closure of the land disposal facility must ensure protection of any individual inadvertently intruding into the disposal site and occupying the site or contacting the waste at any time after active institutional controls over the disposal site are removed.

\section{CFR61.52}

(a)(1) Wastes designated as Class A pursuant to 61.55, must be segregated from other wastes by placing in disposal units which are sufficiently separated from disposal units for the other waste classes so that any interaction between Class $A$ wastes and other wastes will not result in the failure to meet the performance objectives in subpart $\mathrm{C}$ of this Part. This segregation is not necessary for Class $\mathrm{A}$ wastes if they meet the stability requirements in $61.56(\mathrm{~b})$ of this part.

(2) Wastes designated as Class $C$ pursuant to 61.55 , must be disposed of so that the top of the waste is a minimum of 5 meters below the top surface of the cover or must be disposed of with intruder barriers that are designed to protect against an inadvertent intrusion for a least 500 years.

(3) All wastes shall be disposed of in accordance with the requirements of paragraphs (a)(4) through (11) of this section.

(4) Wastes must be emplaced in a manner that maintains the package integrity during emplacement, minimizes the void spaces between packages, and permits the void spaces to be filled.

(5) Void spaces between waste packages must be filled with earth or other material to reduce future subsidence within the fill.

(6) Waste must be placed and covered in a manner that limits the radiation dose rate at the surface of the cover to levels that at a minimum will permit the licensee to comply with all provisions of 20.105 , or, for licensees implementing the provisions of $20.100120 .2401,20.1301$ and 20.1302 of this chapter at the time the license is transferred pursuant to 61.30 of this part.

(7) The boundaries and locations of each disposal unit (e.g., trenches) must be accurately located and mapped by means of a land survey. Near-surface disposal units must be marked in such a way that the boundaries of each unit can be easily defined. Three permanent survey marker control points, referenced to United States Geological Survey (USGS) or National Geodetic Survey (NGS) survey control stations, must be established on the site to facilitate surveys. The USGS or NGS control stations must provide horizontal and vertical controls as checked against USGS or NGS record files.

(8) A buffer zone of land must be maintained between any buried waste and the disposal site boundary and beneath the disposed waste. The buffer zone shall be of adequate dimensions to carry out environmental monitoring activities specified in 61.53(d) of this part and take mitigative measures if needed.

(9) Closure and stabilization measures as set forth in the approved site closure plan must be carried out as each disposal unit (e.g., each trench) is filled and covered.

(10) Active waste disposal operations must not have an adverse effect on completed closure and 
stabilization measures.

(11) Only wastes containing or contaminated with radioactive materials shall be disposed of at the disposal site.

(b) Facility operation and disposal site closure for land disposal facilities other than near-surface (reserved).

\section{CFR61.55}

(a)(1) Considerations. Determination of the classification of radioactive waste involves two considerations. First, consideration must be given to the concentration of long-lived radionuclides (and their shorter-lived precursors) whose potential hazard will persist long after such precautions as institutional controls, improved waste form, and deeper disposal have ceased to be effective. These precautions delay the time when long-lived radionuclides could cause exposures. In addition, the magnitude of the potential dose is limited by the concentration and availability of the radionuclide at the time of exposure. Second, consideration must be given to the concentration of shorter-lived radionuclides for which requirements on institutional controls, waste form, and disposal methods are effective.

(2) Classes of waste.

(i) Class A waste is waste that is usually segregated from other waste classes at the disposal site. The physical form and characteristics of Class $\mathrm{A}$ waste must meet the minimum requirements set forth in 61.56(a). If Class A waste also meets the stability requirements set forth in $61.56(\mathrm{~b})$, it is not necessary to segregate the waste for disposal.

(ii) Class B waste is waste that must meet more rigorous requirements on waste form to ensure stability after disposal. The physical form and characteristics of Class B waste must meet both the minimum and stability requirements set forth in 61.56 .

(iii) Class $\mathrm{C}$ waste is waste that not only must meet more rigorous requirements on waste form to ensure stability but also requires additional measures at the disposal facility to protect against inadvertent intrusion. The physical form and characteristics of Class $\mathrm{C}$ waste must meet both the minimum and stability requirements set forth in 61.56 .

(iv) Waste that is not generally acceptable for near-surface disposal is waste for which form and disposal methods must be different, and in general more stringent, than those specified for Class $\mathrm{C}$ waste. In the absense of specific requirements in this part, such waste must be disposed of in a geologic repository as defined in part 60 of this chapter unless proposals for disposal of such waste in a disposal site licensed pursuant to this part are approved by the Commission.

(3) Classification determined by long-lived radionuclides. If radioactive waste contains only radionuclides listed in Table 1, classification shall be determined as follows:

(i) If the concentration does not exceed 0.1 times the value in Table 1 , the waste is Class $\mathrm{A}$.

(ii) If the concentration exceeds 0.1 times the value in Table 1 but does not exceed the value in Table 1 , the waste is Class $\mathbf{C}$. (iii) If the concentration exceeds the value in Table 1, the waste is not generally acceptable for near-surface disposal.

(iv) For wastes containing mixtures of radionuclides listed in Table 1, the total concentration shall be determined by the sum of fractions rule described in paragraph $(a)(7)$ of this section.

Table 1

Concen-

tration

Radionuclide curies/per

cubic

meter 
C 14

C 14 in activated metal

Ni 59 in activated metal

$\mathrm{Nb} 94$ in activated metal

Tc 99

I 129

greater than five years

Pu 241

Cm 242
8 80

220

0.2

3

0.08

1/ Units are nanocuries per gram.

(4) Classification determined by short-lived radionuclides. If radioactive waste does not contain any of the radionuclides listed in Table 1, classification shall be determined based on the concentrations shown in Table 2. However, as specified in paragraph (a)(6) of this section, if radioactive waste does not contain any nuclides listed in either Table 1 or 2 , it is Class $\mathrm{A}$.

(i) If the concentration does not exceed the value in Column 1, the waste is Class A.

(ii) If the concentration exceeds the value in Column 1, but does not exceed the value in Column 2, the waste is Class $B$.

(iii) If the concentration exceeds the value in Column 2, but does not exceed the value in Column 3 , the waste is Class $\mathrm{C}$.

(iv) If the concentration exceeds the value in Column 3, the waste is not generally acceptable for near-surface disposal.

(v) For wastes containing mixtures of the nuclides listed in Table 2, the total concentration shall be determined by the sum of fractions rule described in paragraph (a)(7) of this section.

Table 2

$$
\begin{aligned}
& \text { Concentration, curies } \\
& \text { per cubic meter } \\
& \text { Radionuclide } \\
& \text { Col. } 1 \quad \text { Col. } 2 \quad \text { Col. } 3
\end{aligned}
$$

\begin{tabular}{|c|c|c|c|}
\hline than & \multicolumn{3}{|c|}{$700 \quad 01 / \quad 01 /$} \\
\hline H 3 & 40 & () $1 /$ & () $1 /$ \\
\hline Co 60 & 700 & () $1 /$ & () $1 /$ \\
\hline Ni 63 & 3.5 & 70 & 700 \\
\hline Ni 63 i & etal & & 7000 \\
\hline Sr 90 & 0.04 & 150 & 7000 \\
\hline Cs 137 & 1 & 44 & 4600 \\
\hline
\end{tabular}

Total of all nuclides with less

1/ There are no limits established for these radionuclides in Class $\mathbf{B}$ or $\mathbf{C}$ wastes. Practical considerations such as the effects of external radiation and internal heat generation on transportation, handling, and disposal will limit the concentrations for these wastes. These wastes shall be Class B unless the concentrations of other nuclides in Table 2 determine the waste to the Class $\mathrm{C}$ independent of these nuclides.

(5) Classification determined by both long- and short-lived radionuclides. If radioactive waste contains a 
mixture of radionuclides, some of which are listed in Table 1, and some of which are listed in Table 2, classification shall be determined as follows:

(i) If the concentration of a nuclide listed in Table 1 does not exceed 0.1 times the value listed in Table 1 , the class shall be that determined by the concentration of nuclides listed in Table 2.

(ii) If the concentration of a nuclide listed in Table 1 exceeds 0.1 times the value listed in Table 1 but does not exceed the value in Table 1, the waste shall be Class $C$, provided the concentration of nuclides listed in Table 2 does not exceed the value shown in Column 3 of Table 2.

(6) Classification of wastes with radionuclides other than those listed in Tables 1 and 2 . If radioactive waste does not contain any nuclides listed in either Table 1 or 2, it is Class A.

(7) The sum of the fractions rule for mixtures of radionuclides. For determining classification for waste that contains a mixture of radionuclides, it is necessary to determine the sum of fractions by dividing each nuclide"s concentration by the appropriate limit and adding the resulting values. The appropriate limits must all be taken from the same column of the same table. The sum of the fractions for the column must be less than 1.0 if the waste class is to be determined by that column. Example: A waste contains $\mathrm{Sr}-90$ in a concentration of $50 \mathrm{Ci} / \mathrm{m}$. and Cs- 137 in a concentration of $22 \mathrm{Ci} / \mathrm{m}$. Since the concentrations both exceed the values in Column 1, Table 2, they must be compared to Column 2 values. For $\mathrm{Sr}-90$ fraction $50 / 150=0.33$; for $\mathrm{Cs}-137$ fraction, $22 / 44=0.5$; the sum of the fractions $=0.83$. Since the sum is less than 1.0, the waste is Class B.

(8) Determination of concentrations in wastes. The concentration of a radionuclide may be determined by indirect methods such as use of scaling factors which relate the inferred concentration of one radionuclide to another that is measured, or radionuclide material accountability, if there is reasonable assurance that the indirect methods can be correlated with actual measurements. The concentration of a radionuclide may be averaged over the volume of the waste, or weight of the waste if the units are expressed as nanocuries per gram.

\section{CFR61.56}

(a) The following requirements are minimum requirements for all classes of waste and are intended to facilitate handling at the disposal site and provide protection of health and safety of personnel at the disposal site.

(1) Waste must not be packaged for disposal in cardboard or fiberboard boxes.

(2) Liquid waste must be solidified or packaged in sufficient absorbent material to absorb twice the volume of the liquid.

(3) Solid waste containing liquid shall contain as little free standing and noncorrosive liquid as is reasonably achievable, but in no case shall the liquid exceed $1 \%$ of the volume.

(4) Waste must not be readily capable of detonation or of explosive decomposition or reaction at normal pressures and temperatures, or of explosive reaction with water.

(5) Waste must not contain, or be capable of generating, quantities of toxic gases, vapors, or fumes harmful to persons transporting, handling, or disposing of the waste. This does not apply to radioactive gaseous waste packaged in accordance with paragraph (a)(7) of this section.

(6) Waste must not be pyrophoric. Pyrophoric materials contained in waste shall be treated, prepared, and packaged to be nonflammable.

(7) Waste in a gaseous form must be packaged at a pressure that does not exceed 1.5 atmospheres at 20

C. Total activity must not exceed 100 curies per container.

(8) Waste containing hazardous, biological, pathogenic, or infectious material must be treated to reduce to the maximum extent practicable the potential hazard from the non-radiological materials.

(b) The requirements in this section are intended to provide stability of the waste. Stability is intended to ensure that the waste does not structurally degrade and affect overall stability of the site through 
slumping, collapse, or other failure of the disposal unit and thereby lead to water infiltration. Stability is also a factor in limiting exposure to an inadvertent intruder, since it provides a recognizable and nondispersible waste.

(1) Waste must have structural stability. A structurally stable waste form will generally maintain its physical dimensions and its form, under the expected disposal conditions such as weight of overburden and compaction equipment, the presence of moisture, and microbial activity, and internal factors such as radiation effects and chemical changes. Structural stability can be provided by the waste form itself, processing the waste to a stable form, or placing the waste in a disposal container or structure that provides stability after disposal.

(2) Notwithstanding the provisions in 61.56(a) (2) and (3), liquid wastes, or wastes containing liquid, must be converted into a form that contains as little free standing and noncorrosive liquid as is reasonably achievable, but in no case shall the liquid exceed $1 \%$ of the volume of the waste when the waste is in a disposal container designed to ensure stability, or $0.5 \%$ of the volume of the waste for waste processed to a stable form.

(3) Void spaces within the waste and between the waste and its package must be reduced to the extent practicable.

\section{CFR830.120, Quality Assurance Requirements}

(a) General Rule. (1) A contractor responsible for a DOE nuclear facility shall:

(i) Conduct its work in accordance with the criteria of paragraph (c) of this section;

(ii) Develop and submit for approval by DOE a Quality Assurance Program (QAP) for the work; and

(iii) Implement the QAP, as approved and modified by DOE.

\section{CFR835 Radiological Services}

Radiological services shall be in accordance with the document "10 CFR 835".

\section{CFR835, Subpart C, Sec. 835.202}

Occupational exposure limits for general employees.

\section{Occupational Exposure}

(a) The occupational exposure to general employees resulting from DOE activities, other than planned special exposures under Sec. 835.204 and emergency exposure situations under Sec. 835.1302, shall be controlled so the following annual limits are not exceeded:

(1) A total effective dose equivalent of 5 rems ( 0.05 sievert);

(2) The sum of the deep dose equivalent for external exposures and the committed dose equivalent to any organ or tissue other than the lens of the eye of 50 rems ( 0.5 sievert);

(3) A lens of the eye dose equivalent of 15 rems ( 0.15 sievert); and

(4) A shallow dose equivalent of 50 rems ( 0.5 sievert) to the skin or to any extremity.

(b) All occupational exposure received during the current year shall be included when demonstrating compliance with Sec. 835.202(a). 
(c) Exposures from background, therapeutic and diagnostic medical radiation, and voluntary participation in medical research programs shall not be included in dose records or in the assessment of compliance with the occupational exposure limits.

\section{CFR962, Part 3(a-b)}

\section{[PART] 962.3 Byproduct material.}

(a) For purposes of this part, the term "byproduct material" "' means any radioactive material (except special nuclear material) yielded in or made radioactive by exposure to the radiation incident to the process of producing or utilizing special nuclear material.

(b) For purposes of determining the applicability of the Resource Conservation and Recovery Act (42 U.S.C. 6901 et seq.) to any radioactive waste substance owned or produced by the Department of Energy pursuant to the exercise of its atomic energy research, development, testing and production responsibilities under the Atomic Energy Act of 1954 (42 U.S.C. 2011 et seq.), the words "any radioactive material," "' as used in paragraph (a) of this section, refer only to the actual radionuclides dispersed or suspended in the waste substance. The nonradioactive hazardous component of the waste substance will be subject to regulation under the Resource Conservation and Recovery Act.

\section{CFR1910}

\section{CFR1926}

TBD

\section{CFR191.03(a)}

(a) Management and storage of spent nuclear fuel or high-level or transuranic radioactive wastes at all facilities regulated by the Commission or by Agreement States shall be conducted in such a manner as to provide reasonable assurance that the combined annual dose equivalent to any member of the public in the general environment resulting from:

(1) Discharges of radioactive material and direct radiation from such management and storage and (2) all operations covered by Part 190; shall not exceed 25 millirems to the whole body, 75 millirems to the thyroid, and 25 millirems to any other critical organ.

\section{CFR261.4(d), -.21 thru -.24}

(d) Samples. A sample of solid waste or a sample of water, soil, or air, which is collected for the sole purpose of testing to determine its characteristics or composition, is not subject to any requirements of this part or parts 262 through 268 or part 270 or part 124 of this chapter or to the notification requirements of section 3010 of RCRA, when: (i)the sample is being transported to a laboratory for the purpose of testing; or (ii)the sample is being transported back to the sample collector after testing;or 
(iii)the sample is being stored by the sample collector before transport to a laboratory for testing;or (iv)the sample is being stored in a laboratory before testing;or ( $v$ the sample is being stored in a laboratory after testing but before it is returned to the sample collector; or (vi)the sample is being stored temporarily in the laboratory after testing for a specific purpose (for example, until conclusion of a court case or enforcement action where further testing of the sample may be necessary). In order to qualify for the exemption in paragraphs (d)(1)(i) and (ii) of this section, a sample collector shipping samples to a laboratory and a laboratory returning samples to a sample collector must: (i)comply with U.S. DOT, USPS, or any other applicable shipping requirements; or (ii)comply with the following requirements if the sample collector determines that DOT,USPS, or other shipping requirements do not apply to the shipment of the sample: (A)assure the following information accompanies the sample: (1)the sample collector's name, mailing address, and telephone number; (2)the laboratory's name, mailing address, and telephone number; (3)the quantity of the sample; (4)the date of shipment;and (5)a description of the sample. (B)package the sample so that it does not leak, spill, or vaporize from its packaging. (3)this exemption does not apply if the laboratory determines that the waste is hazardous but the laboratory is no longer meeting any of the conditions stated in paragraph (d)(1) of this section.

-.21 Characteristic of ignitability. (a)a solid waste exhibits the characteristic of ignitability if a representative sample of the waste has any of the following properties: (1)it is a liquid, other than an aqueous solution containing less than 24 percent alcohol by volume and has a flash point less than $60 \mathrm{C}$ $(140 \mathrm{~F}$ ), as determined by a Pensky-Martens Closed Cup Tester, using the test method specified in ASTM Standard D-93-79 or D-93-80 (incorporated by reference), or a Setaflash Closed Cup Tester, using the test method specified in ASTM Standard D-3278-78 (incorporated by reference) or as determined by an equivalent test method approved by the Administrator under procedures set forth in parts 260.20 and 260.21. (2)it is not a liquid and is capable, under standard temperature and pressure, of causing fire through friction, absorption of moisture or spontaneous chemical changes and, when ignited, burns so vigorously and persistently that it creates a hazard. (3)it is an ignitable compressed gas as defined in 49 CFR 173.300 and as determined by the test methods described in that regulation or equivalent test methods approved by the Administrator under 260.20/.21. (4)it is an oxidizer as defined in $49 \mathrm{CFR}$ 173.151. (b)a solid waste that exhibits the characteristic of ignitability has the EPA Hazardous Waste Number of D001.

-.22 Characteristic of corrosivity. (a)a solid waste exhibits the characteristic of corrosivity if a representative sample of the waste has either of the following properties: (1)it is aqueous and has a $\mathrm{pH}$ less than or equal to 2 or greater than or equal to 12.5, as determined by a pH meter using Method 9040 in EPA Publication SW-846, as incorporated by reference in 260.11 of this chapter. (2)it is a liquid and corrodes steel (SAE 1020) at a rate greater than $6.35 \mathrm{~mm}(0.250 \mathrm{inch})$ per year at a test e test method specified in NACE Standard TM-01-69 as standardized in EPA Publication SW-846. (b)a solid waste that exhibits the characteristic of corrosivity has the EPA Hazardous Waste Number DO02.

-.23 Characteristic of reactivity. (a)a solid waste exhibits the characteristic of reactivity if a representative sample of the waste has any of the following properties: (1)it is normally unstable and readily undergoes violent change without detonating. (2)it reacts violently with water. (3)it forms potentially explosive mixtures with water. (4)when mixed with water, it generates toxic gases, vapors, or fumes in a quantity sufficient to present a danger to human health or the environment. (5)it is a cyanide or sulfide bearing waste which, when exposed to $\mathrm{pH}$ conditions between 2 and 12.5 , can generate toxic gases, vapors or fumes in a quantity sufficient to present a danger to human health or the environment. (6)it si capable of detonation or explosive reaction if it is subjected to a strong initiating source or if heated under confinement. (7)it is readily capable of detonation or explosive decomposition or reaction at standard temperature and pressure. (8)it is a forbidden explosive as defined in 49 CFR 173.51 of a Class 
A explosive as defined in 49 CFR 173.53 or a Class B explosive as defined in 49 CFR 173.88. (b)a solid waste that exhibits the characteristic of reactivity has the EPA Hazardous Waste Number of D003.

-.24 Toxicity characteristic. (a)a solid waste exhibits the characteristic of toxicity if, using the TCLP test method 1311 in EPA Publication SW-846, as incorporated by reference, the extract from a representative sample of the waste contains any of the contaminants listed in table 1 at the concentration equal to or greater than the respective value given in that table. Where the waste contains less than 0.5 percent filterable solids, the waste itself, after filtering using the methodology outlined in Method 1311, is considered to be the extract for the purpose of this section. (b)a solid waste that exhibits the characteristic of toxicity has the EPA Hazardous Waste Number specified in table 1 which corresponds to the toxic contaminant causing it to be hazardous.

Table 1-Maximum Concentration of Contaminants for the Toxicity Characteristic (See attachment.)

\section{CFR264.1032}

(a) The owner or operator of a facility with process vents associated with distillation, fractionation, thin-film evaporation, solvent extraction, or air or steam stripping operations managing hazardous wastes with organic concentrations of at least 10 ppmw shall either:

(1) Reduce total organic emissions from all affected process vents at the facility below $1.4 \mathrm{~kg} / \mathrm{h}(3 \mathrm{lb} / \mathrm{h})$ and $2.8 \mathrm{Mg} / \mathrm{yr}$ (3.1 tons/yr), or (2) Reduce, by use of a control device, total organic emissions from all affected process vents at the facility by 95 weight percent.

(b) If the owner or operator installs a closed-vent system and control device to comply with the provisions of paragraph (a) of this section the closed-vent system and control device must meet the requirements of [Section] 264.1033.

(c) Determinations of vent emissions and emission reductions or total organic compound concentrations achieved by add-on control devices may be based on engineering calculations or performance tests. If performance tests are used to determine vent emissions, emission reductions, or total organic compound concentrations achieved by add-on control devices, the performance tests must conform with the requirements of [Section] 264.1034(c).

(a) The owner or operator of a facility with process vents associated with distillation, fractionation, thin-film evaporation, solvent extraction, or air or steam stripping operations managing hazardous wastes with organic concentrations of at least $10 \mathrm{ppmw}$ shall either:

(1) Reduce total organic emissions from all affected process vents at the facility below $1.4 \mathrm{~kg} / \mathrm{h}(3 \mathrm{lb} / \mathrm{h})$ and $2.8 \mathrm{Mg} / \mathrm{yr}$ ( 3.1 tons/yr), or (2) Reduce, by use of a control device, total organic emissions from all affected process vents at the facility by 95 weight percent.

(b) If the owner or operator installs a closed-vent system and control device to comply with the provisions of paragraph (a) of this section the closed-vent system and control device must meet the requirements of [Section] 264.1033.

(c) Determinations of vent emissions and emission reductions or total organic compound concentrations achieved by add-on control devices may be based on engineering calculations or performance tests. If performance tests are used to determine vent emissions, emission reductions, or total organic compound concentrations achieved by add-on control devices, the performance tests must conform with the requirements of [Section] 264.1034(c).

(d) When an owner or operator and the Regional Administrator do not agree on determinations of vent emissions and/or emission reductions or total organic compound concentrations achieved by add-on control devices based on engineering calculations, the procedures in [Section] 264.1034(c) shall be used 
to resolve the disagreement.

\section{CFR264.1054}

(a) Except during pressure releases, each pressure relief device in gas/vapor service shall be operated with no detectable emissions, as indicated by an instrument reading of less than $500 \mathrm{ppm}$ above background, as measured by the method specified in [Section] 264.1063(c).

(b)(1) After each pressure release, the pressure relief device shall be returned to a condition of no detectable emissions, as indicated by an instrument reading of less than $500 \mathrm{ppm}$ above background, as soon as practicable, but no later than 5 calendar days after each pressure release, except as provided in [Section] 264.1059.

(2) No later than 5 calendar days after the pressure release, the pressure relief device shall be monitored to confirm the condition of no detectable emissions, as indicated by an instrument reading of less than $500 \mathrm{ppm}$ above background, as measured by the method specified in [Section] 264.1063 (c). (c) Any pressure relief device that is equipped with a closed-vent system capable of capturing and transporting leakage from the pressure relief device to a control device as described in [Section] 264.1060 is exempt from the requirements of paragraphs (a) and (b) of this section.

\section{CFR264.1102}

264.1102 Closure and post-closure care.

(a) At closure of a containment building, the owner or operator must remove or decontaminate all waste residues, contaminated containment system components (liners, etc.,) contaminated subsoils, and structures and equipment contaminated with waste and leachate, and manage them as hazardous waste unless 261.3(d) of this chapter applies. The closure plan, closure activities, cost estimates for closure, and financial responsibility for containment buildings must meet all of the requirements specified in subparts $\mathrm{G}$ and $\mathrm{H}$ of this part.

(b) If, after removing or decontaminating all residues and making all reasonable efforts to effect removal or decontamination of contaminated components, subsoils, structures, and equipment as required in paragraph (a) of this section, the owner or operator finds that not all contaminated subsoils can be practicably removed or decontaminated, he must close the facility and perform post-closure care in accordance with the closure and post-closure requirements that apply to landfills (264.310). In addition, for the purposes of closure, post-closure, and financial responsibility, such a containment building is then considered to be a landfill, and the owner or operator must meet all of the requirements for landfills specified in subparts $\mathrm{G}$ and $\mathrm{H}$ of this part.

\section{CFR264.13(a)(1)(3)(4)(b)}

-.13(a)(1)Before and owner or operator treats, stores, or disposes of any hazardous wastes, or nonhazardous wastes if applicable under 264.113 (d), he must obtain a detailed chemical and physical analysis of a representative sample of the wastes. At a minimum, the analysis must contain all the information which must be known to treat, store, or dispose of the waste in accordance with this part and part 268 of this chapter. (3)the analysis must be repeated as necessary to ensure that it is accurate and up to date. (4)(b)the owner or operator must develop and follow a written waste analysis plan which 
describes the procedures which he will carry out to comply with paragraph (a) of this section. He must keep this plan at the facility. At a minimum, the plan must specify: (1)the parameters for which each hazardous waste, or nonhazardous waste will be analyzed and the rationale for the selection of these parameters; (2)the test methods which will be used to test for these parameters; (3)the sampling method which will be used to obtain a representative sample of the waste to be analyzed; (4)the frequency with which the initial analysis of the waste will be reviewed or repeated to ensure that the analysis is accurate and up to date; and (5)for off-site facilities, the waste analyses that hazardous waste generators have agreed to supply.

\section{CFR264.171}

If a container holding hazardous waste is not in good condition (e.g., severe rusting, apparent structural defects) or if it begins to leak, the owner or operator must transfer the hazardous waste from this container to a container that is in good condition or manage the waste in some other way that complies with the requirements of this part.

\section{CFR264.172}

The owner or operator must use a container made of or lined with materials which will not react with, and are otherwise compatible with, the hazardous waste to be stored, so that the ability of the container to contain the waste is not impaired.

\section{CFR264.173}

(a) A container holding hazardous waste must always be closed during storage, except when it is necessary to add or remove waste.

(b) A container holding hazardous waste must not be opened, handled, or stored in a manner which may rupture the container or cause it to leak.

[Comment: Reuse of containers in transportation is governed by U.S. Department of Transportation regulations including those set forth in 49 CFR 173.28.]

\section{CFR264.175}

(a) Container storage areas must have a containment system that is designed and operated in accordance with paragraph (b) of this section, except as otherwise provided by paragraph (c) of this section.

(b) A containment system must be designed and operated as follows: (1) A base must underly the containers which is free of cracks or gaps and is sufficiently impervious to contain leaks, spills, and accumulated precipitation until the collected material is detected and removed; (2) The base must be sloped or the containment system must be otherwise designed and operated to drain and remove liquids resulting from leaks, spills, or precipitation, unless the containers are elevated or are otherwise protected from contact with accumulated liquids; (3) The containment system must have sufficient capacity to contain $10 \%$ of the volume of containers or the volume of the largest container, whichever is greater. Containers that do not contain free liquids need not be considered in this determination; (4) Run-on into the containment system must be prevented unless the collection system has sufficient excess capacity in 
addition to that required in paragraph (b)(3) of this section to contain any run-on which might enter the system; and (5) Spilled or leaked waste and accumulated precipitation must be removed from the sump or collection area in as timely a manner as is necessary to prevent overflow of the collection system.

[Comment: If the collected material is a hazardous waste under part 261 of this Chapter, it must be managed as a hazardous waste in accordance with all applicable requirements of parts 262 through 266 of this chapter. If the collected material is discharged through a point source to waters of the United States, it is subject to the requirements of section 402 of the Clean Water Act, as amended.]

(c) Storage areas that store containers holding only wastes that do not contain free liquids need not have a containment system defined by paragraph (b) of this section, except as provided by paragraph (d) of this section or provided that: (1) The storage area is sloped or is otherwise designed and operated to drain and remove liquid resulting from precipitation, or (2) The containers are elevated or are otherwise protected from contact with accumulated liquid. (d) Storage areas that store containers holding the wastes listed below that do not contain free liquids must have a containment system defined by paragraph (b) of this section: (1) FO20, FO21, FO22, FO23, FO26, and FO27.

\section{CFR264.177}

(a) Incompatible wastes, or incompatible wastes and materials (see appendix V for examples), must not be placed in the same container, unless [Section] 264.17(b) is complied with.

(b) Hazardous waste must not be placed in an unwashed container that previously held an incompatible waste or material.

[Comment: As required by [Section] 264.13, the waste analysis plan must include analyses needed to comply with [Section] 264.177. Also, [Section] 264.17(c) requires wastes analyses, trial tests or other documentation to assure compliance with [Section] 264.17 (b). As required by [Section] 264.73, the owner or operator must place the results of each waste analysis and trial test, and any documented information, in the operating record of the facility.]

(c) A storage container holding a hazardous waste that is incompatible with any waste or other materials stored nearby in other containers, piles, open tanks, or surface impoundments must be separated from the other materials or protected from them by means of a dike, berm, wall, or other device.

[Comment: The purpose of this section is to prevent fires, explosions, gaseous emission, leaching, or other discharge of hazardous waste or hazardous waste constituents which could result from the mixing of incompatible wastes or materials if containers break or leak.]

\section{CFR264.178}

At closure, all hazardous waste and hazardous waste residues must be removed from the containment system. Remaining containers, liners, bases, and soil containing or contaminated with hazardous waste or hazardous waste residues must be decontaminated or removed.

[Comment: At closure, as throughout the operating period, unless the owner or operator can demonstrate in accordance with [Section] 261.3(d) of this chapter that the solid waste removed from the containment system is not a hazardous waste, the owner or operator becomes a generator of hazardous waste and must manage it in accordance with all applicable requirements of parts 262 through 266 of this chapter]. 


\section{CFR264.191}

Assessment of existing tank system's integrity.

(a) For each existing tank system that does not have secondary containment meeting the requirements of Sec.264.193, the owner or operator must determine that the tank system is not leaking or is unfit for use. Except as provided in paragraph (c) of this section, the owner or operator must obtain and keep on file at the facility a written assessment reviewed and certified by an independent, qualified registered professional engineer, in accordance with Sec.270.11(d), that attests to the tank system's integrity by January 12,1988 .

(b) This assessment must determine that the tank system is adequately designed and has sufficient structural strength and compatibility with the waste(s) to be stored or treated, to ensure that it will not collapse, rupture, or fail. At a minimum, this assessment must consider the following:

(1) Design standard(s), if available, according to which the tank and ancillary equipment were constructed;

(2) Hazardous characteristics of the waste(s) that have been and will be handled;

(3) Existing corrosion protection measures;

(4) Documented age of the tank system, if available (otherwise, an estimate of the age); and

(5) Results of a leak test, internal inspection, or other tank integrity examination such that:

(i) For non-enterable underground tanks, the assessment must include a leak test that is capable of taking into account the effects of temperature variations, tank end deflection, vapor pockets, and high water table effects, and

(ii) For other than non-enterable underground tanks and for ancillary equipment, this assessment must include either a leak test, as described above, or other integrity examination, that is certified by an independent, qualified, registered professional engineer in accordance with Sec.270.11(d), that addresses cracks, leaks, corrosion, and erosion. (Note: The practices described in the American Petroleum Institute (API) Publication, Guide for Inspection of Refinery Equipment, Chapter XIII, 'Atmospheric and Low-Pressure Storage Tanks,' 4th edition, 1981, may be used, where applicable, as guidelines in conducting other than a leak test.)

(c) Tank systems that store or treat materials that become hazardous wastes subsequent to July 14,1986 , must conduct this assessment within 12 months after the date that the waste becomes a hazardous waste.

(d) If, as a result of the assessment conducted in accordance with paragraph (a), a tank system is found to be leaking or unfit for use, the owner or operator must comply with the requirements of Sec.264.196.

(Information collection requirements contained in paragraphs (a) through (d) were approved by the Office of Management and Budget under control number 2050-0050) (51 FR 25472, July 14, 1986; 51 FR 29430, Aug. 15, 1986)

\section{CFR264.193(a-f)}

(a) In order to prevent the release of hazardous waste or hazardous constituents to the environment, secondary containment that meets the requirements of this section must be provided (except as provided in paragraphs $(\mathrm{f})$ and $(\mathrm{g})$ of this section):

(1) For all new tank systems or components, prior to their being put into service; 
(2) For all existing tank systems used to store or treat EPA Hazardous Waste Nos. F020, F021, F022, F023, F026, and F027, within two years after January 12, 1987;

(3) For those existing tank systems of known and documented age, within two years after January 12, 1987 or when the tank system has reached 15 years of age, whichever comes later; (4) For those existing tank systems for which the age cannot be documented, within eight years of January 12, 1987; but if the age of the facility is greater than seven years, secondary containment must be provided by the time the facility reaches 15 years of age, or within two years of January 12, 1987, whichever comes later; and (5) For tank systems that store or treat materials that become hazardous wastes subsequent to January 12 , 1987 , within the time intervals required in paragraphs (a)(1) through (a)(4) of this section, except that the date that a material becomes a hazardous waste must be used in place of January 12, 1987.

(b) Secondary containment systems must be:

(1) Designed, installed, and operated to prevent any migration of wastes or accumulated liquid out of the system to the soil, ground water, or surface water at any time during the use of the tank system; and

(2) Capable of detecting and collecting releases and accumulated liquids until the collected material is removed.

(c) To meet the requirements of paragraph (b) of this section, secondary containment systems must be at a minimum:

(1) Constructed of or lined with materials that are compatible with the wastes(s) to be placed in the tank system and must have sufficient strength and thickness to prevent failure owing to pressure gradients (including static head and external hydrological forces), physical contact with the waste to which it is exposed, climatic conditions, and the stress of daily operation (including stresses from nearby vehicular traffic).

(2) Placed on a foundation or base capable of providing support to the secondary containment system, resistance to pressure gradients above and below the system, and capable of preventing failure due to settlement, compression, or uplift;

(3) Provided with a leak-detection system that is designed and operated so that it will detect the failure of either the primary or secondary containment structure or the presence of any release of hazardous waste or accumulated liquid in the secondary containment system within 24 hours, or at the earliest practicable time if the owner or operator can demonstrate to the Regional Administrator that existing detection technologies or site conditions will not allow detection of a release within 24 hours; and

(4) Sloped or otherwise designed or operated to drain and remove liquids resulting from leaks, spills, or precipitation. Spilled or leaked waste and accumulated precipitation must be removed from the secondary containment system within 24 hours, or in as timely a manner as is possible to prevent harm to human health and the environment, if the owner or operator can demonstrate to the Regional Administrator that removal of the released waste or accumulated precipitation cannot be accomplished within 24 hours.

[Note: If the collected material is a hazardous waste under part 261 of this chapter, it is subject to management as a hazardous waste in accordance with all applicable requirements of parts 262 through 265 of this chapter. If the collected material is discharged through a point source to waters of the United States, it is subject to the requirements of sections 301, 304, and 402 of the Clean Water Act, as amended. If discharged to a Publicly Owned Treatment Works (POTW), it is sub]ect to the requirements of section 307 of the Clean Water Act, as amended. If the collected material is released to the environment, it may be subject to the reporting requirements of 40 CFR part 302.]

(d) Secondary containment for tanks must include one or more of the following devices: (1) A liner (external to the tank); (2) A vault; (3) A double-walled tank; or (4) An equivalent device as approved by the Regional Administrator

(e) In addition to the requirements of paragraphs (b), (c), and (d) of this section, secondary containment 
systems must satisfy the following requirements: (1) External liner systems must be: (i) Designed or operated to contain 100 percent of the capacity of the largest tank within its boundary; (ii) Designed or operated to prevent run-on or infiltration of precipitation into the secondary containment system unless the collection system has sufficient excess capacity to contain run-on or infiltration. Such additional capacity must be sufficient to contain precipitation from a 25-year, 24-hour rainfall event. (iii) Free of cracks or gaps; and (iv) Designed and installed to surround the tank completely and to cover all surrounding earth likely to come into contact with the waste if the waste is released from the tank(s) (i.e., capable of preventing lateral as well as vertical migration of the waste). (2) Vault systems must be: (i) Designed or operated to contain 100 percent of the capacity of the largest tank within its boundary; (ii) Designed or operated to prevent run-on or infiltration of precipitation into the secondary containment system unless the collection system has sufficient excess capacity to contain run-on or infiltration. Such additional capacity must be sufficient to contain precipitation from a 25 -year, 24-hour rainfall event: (iii) Constructed with chemical-resistant water stops in place at all joints (if any): (iv) Provided with an impermeable interior coating or lining that is compatible with the stored waste and that will prevent migration of waste into the concrete; ( $v$ ) Provided with a means to protect against the formation of and ignition of vapors within the vault, if the waste being stored or treated: (A) Meets the definition of ignitable waste under [Section] 262.21 of this chapter; or (B) Meets the definition of reactive waste under [Section] 262.21 of this chapter, and may form an ignitable or explosive vapor. (vi) Provided with an exterior moisture barrier or be otherwise designed or operated to prevent migration of moisture into the vautt if the vault is subject to hydraulic pressure. (3) Double-walled tanks must be: (i) Designed as an integral structure (i.e., an inner tank completely enveloped within an outer shell) so that any release from the inner tank is contained by the outer shell. (ii) Protected, if constructed of metal, from both corrosion of the primary tank interior and of the external surface of the outer shell: and (iii) Provided with a built-in continuous leak detection system capable of detecting a release within 24 hours, or at the earliest practicable time, if the owner or operator can demonstrate to the Regional Administrator, and the Regional Administrator concludes, that the existing detection technology or site conditions would not allow detection of a release within 24 hours.

[Note: The provisions outlined in the Steel Tank Institute"s (STI) "Standard for Dual Wall Underground Steel Storage Tanks" "' may be used as guidelines for aspects of the design of underground steel double-walled tanks.]

(f) Ancillary equipment must be provided with secondary containment (e.g., trench, jacketing, double-walled piping) that meets the requirements of paragraphs (b) and (c) of this section except for: (1) Aboveground piping (exclusive of flanges, joints, valves, and other connections) that are visually inspected for leaks on a daily basis; (2) Welded flanges, welded joints, and welded connections, that are visually inspected for leaks on a daily basis; (3) Sealless or magnetic coupling pumps and sealless valves, that are visually inspected for leaks on a daily basis; and (4) Pressurized aboveground piping systems with automatic shut-off devices (e.g., excess flow check valves, flow metering shutdown devices, loss of pressure actuated shut-off devices) that are visually inspected for leaks on a daily basis.

\section{CFR264.194(a)}

(a) Hazardous wastes or treatment reagents must not be placed in a tank system if they could cause the tank, its ancillary equipment, or the containment system to rupture, leak, corrode, or otherwise fail. 


\section{CFR264.194(b)}

(b) The owner or operator must use appropriate controls and practices to prevent spills and overflows from tank or containment systems. These include at a minimum: (1) Spill prevention controls (e.g., check valves, dry disconnect couplings);

(2) Overfill prevention controls (e.g., level sensing devices, high level alarms, automatic feed cutoff, or bypass to a standby tank); and (3) Maintenance of sufficient freeboard in uncovered tanks to prevent overtopping by wave or wind action or by precipitation.

\section{CFR264.194(c)}

c) The owner or operator must comply with the requirements of 264.196 if a leak or spill occurs in the tank system.

\section{CFR264.195}

Inspections.

(a) The owner or operator must develop and follow a schedule and procedure for inspecting overfill controls.

(b) The owner or operator must inspect at least once each operating day:

(1) Aboveground portions of the tank system, if any, to detect corrosion or releases of waste;

(2) Data gathered from monitoring and leak detection equipment (e.g., pressure or temperature gauges, monitoring wells) to ensure that the tank system is being operated according to its design; and

(3) The construction materials and the area immediately surrounding the externally accessible portion of the tank system, including the secondary containment system (e.g., dikes) to detect erosion or signs of releases of hazardous waste (e.g., wet spots, dead vegetation). (Note: Section 264.15(c) requires the owner or operator to remedy any deterioration or malfunction he finds. Section 264.196 requires the owner or operator to notify the Regional Administrator within 24 hours of confirming a leak. Also, 40CFR part 302 may require the owner or operator to notify the National Response Center of a release.)

(c) The owner or operator must inspect cathodic protection systems, if present, according to, at a minimum, the following schedule to ensure that they are functioning properly:

(1) The proper operation of the cathodic protection system must be confirmed within six months after initial installation and annually thereafter; and

(2) All sources of impressed current must be inspected and/or tested, as appropriate, at least bimonthly (i.e., every other month). (Note: The practices described in the National Association of Corrosion Engineers (NACE) standard, 'Recommended Practice (RP-02-85) - Control of External Corrosion on Metallic Buried, Partially Buried, or Submerged Liquid Storage Systems,' and the American Petroleum Institute (API) Publication 1632, 'Cathodic Protection of Underground Petroleum Storage Tanks and Piping Systems,' may be used, where applicable, as guidelines in maintaining and inspecting cathodic protection systems.)

(d) The owner or operator must document in the operating record of the facility an inspection of those items in paragraphs (a) through (c) of this section. (Information collection requirements contained in paragraph (a) and (d) were approved by the Office of Management and Budget under control number 
2050-0050)

\section{CFR264.196(a-c)}

A tank system or secondary containment system from which there has been a leak or spill, or which is unfit for use, must be removed from service immediately, and the owner or operator must satisfy the following requirements:

(a) Cessation of use; prevent flow or addition of wastes. The owner or operator must immediately stop the flow of hazardous waste into the tank system or secondary containment system and inspect the system to determine the cause of the release.

(b) Removal of waste from tank system or secondary containment system. (1) If the release was from the tank system, the owner/operator must, within 24 hours after detection of the leak or, if the owner/operator demonstrates that it is not possible, at the earliest practicable time, remove as much of the waste as is necessary to prevent further release of hazardous waste to the environment and to allow inspection and repair of the tank system to be performed. (2) If the material released was to a secondary containment system, all released materials must be removed within 24 hours or in as timely a manner as is possible to prevent harm to human health and the environment.

(c) Containment of visible releases to the environment. The owner/operator must immediately conduct a visual inspection of the release and, based upon that inspection:

(1) Prevent further migration of the leak or spill to soils or surface water; and (2) Remove, and properly dispose of, any visible contamination of the soil or surface water.

\section{CFR264.198}

(a) Ignitable or reactive waste must not be placed in tank systems, unless: (1) The waste is treated, rendered, or mixed before or immediately after placement in the tank system so that: (i) The resulting waste, mixture, or dissolved material no longer meets the definition of ignitable or reactive waste under [Sections] 261.21 or 261.23 of this chapter, and (ii) Section 264.17(b) is complied with; or (2) The waste is stored or treated in such a way that it is protected from any material or conditions that may cause the waste to ignite or react; or (3) The tank system is used solely for emergencies.

(b) The owner or operator of a facility where ignitable or reactive waste is stored or treated in a tank must comply with the requirements for the maintenance of protective distances between the waste management area and any public ways, streets, alleys, or an adjoining property line that can be built upon as required in Tables 2-1 through 2-6 of the National Fire Protection Association'"s "Flammable and Combustible Liquids Code,',' (1977 or 1981), (incorporated by reference, see [Section] 260.11).

\section{CFR264.199}

(a) Incompatible wastes, or incompatible wastes and materials, must not be placed in the same tank system, unless [Section] 264.17(b) is complied with.

(b) Hazardous waste must not be placed in a tank system that has not been decontaminated and that previously held an incompatible waste or material, unless [Section] 264.17 (b) is complied with.

40CFR264.31,.32,.33,.34,.35 
-.31 Facilities must be designed, constructed, maintained, and operated to minimize the possibility of a fire, explosion, or any unplanned sudden or non-sudden release of hazardous waste or hazardous waste constituents to air, soil, or surface water which could threaten human health or the environment.

-.32 All facilities must be equipped with the following, unless it can be demonstrated that none of the hazards posed by waste handled at the facility could require a particular kind of equipment specified below: (a)an internal communications or alarm system capable of providing immediate emergency instruction to facility personnel; (b)a device, such as a telephone (immediately available at the scene of operations) or a hand-held two way radio, capable of summoning emergency assistance from local police departments, fire departments, or State or local emergency response teams; (c)portable fire extinguishers, fire control equipment; and (d)water at adequate volume and pressure to supply water hose streams, or foam producing equipment, or automatic sprinklers, or water spray systems.

-.33 All facility communications or alarm systems, fire protection equipment, spill control equipment, and decontamination equipment, where required, must be tested and maintained as necessary to assure its proper operation in time of emergency.

-.34 (a)Whenever hazardous waste is being poured, mixed, spread, or otherwise handled, all personnel involved in the operation must have immediate access to an internal alarm or emergency communication device, either directly or through visual or voice contact with another employee. (b)if there is ever just one emloyee on the premises while the facility is operating, he must have immediate access to a device, such as a telephone or a hand-held two way radio, capable of summoning external emergency assistance, unless the EPA has ruled that such a device is not required under 264.32.

-.35 The owner or operator must maintain aisle space to allow the unobstructed movement of personnel, fire protection equipment, spill control equipment, and decontamination equipment to any area of facility operation in an emergency.

\section{CFR264.37}

-.37 (a)the owner or operator must attempt to make arrangements to familiarize police, fire departments, and emergency response teams with the layout of the facility, properities of hazardous waste handled at the facility and associated hazards, places where facility personnel would normally be working, entrances to and roads inside the facility, and possible evacuation routes.

\section{CFR264.51,.52,.53,.54,.55,.56}

-.51 (a)each owner or operator must have a contingency plan for his facility. The contingency plan must be designed to minimize hazards to human health or the environment from fires, explosions, or any unplanned sudden or non-sudden release of hazardous waste or hazardous waste constituents to air, soil, or surface water.

-.52 (a)the contingency plan must describe the actions facility personnel must take to comply with 264.51 in response to fires, explosions, or any unplanned sudden or non-sudden release of hazardous waste or hazardous waste constituents to air, soil, or surface water at the facility; (b)the owner or operator has already prepared a spill prevention, control, and countermeasures plan in accordance with part 112 of this chapter; (c)the plan must describe arrangements agreed to by local police departments, fire 
departments, hospitals, contractors, and State and local emergency response teams to coordinate emergency services, pursuant to 264.37 ; (d)the plan must list names, addresses, and phone numbers of all persons qualified to act as emergency coordinator and this list must be kept up to date; (e)the plan must include a list of all emergency equipment at the facility where this equipment is required. This list must be kept up to date. In addition, the plan must include the location and physical description of each item on the list, and a brief outline of its capabilities; (f)the plan must include an evacuation plan for facility personnel where there is a possibility that evacuation could be necessary. The plan must describe signals to be used to begin evacuation, evacuation routes, and alternate evacuation routes.

$-.53 \mathrm{~A}$ copy of the contingency plan and all revisions to the plan must be (a)maintained at the facility; and (b)submitted to all local police departments, fire departments, hospitals, and State and local emergency response teams that may be called upon to provide emergency services.

-.54 The contingency plan must be reviewed, and immediately amended, whenever: (a)the facility permit is revised; (b)the plan fails in an emergency; (c)the facility changes in its design, construction, operation, maintenance, or other circumstances; (d)the list of emergency coordinators; (e)the list of emergency equipment changes.

-.55 At all times, there must be at least one employee either on the facility premeises or on call with the responsibility for coordinating all emergency response measures.

-.56 (a) whenever there is an imminent or actual emergency situation, the emergency coordinator must immediately: (1)activate internal facility alarms or communication systems, where applicable to notify all facility personnel; and (2)notify appropriate State or local agencies with designated response roles if their help is needed.(d)if the emergency coordinator determines that the facility has had a release, fire, or explosion which could threaten human health or the environment outside the facility, he must report his findings.

\section{CFR264.603}

A miscellaneous unit that is a disposal unit must be maintained in a manner that complies with [Section] 264.601 during the post-closure care period. In addition, if a treatment or storage unit has contaminated soils or ground water that cannot be completely removed or decontaminated during closure, then that unit must also meet the requirements of [Section] 264.601 during post-closure care. The post-closure plan under [Section] 264.118 must specify the procedures that will be used to satisfy this requirement.

\section{CFR264.73,.74}

-.73 (a)The owner or operator must keep a written operating record at his facility. (b)the following information must be recorded, as it becomes available: (1)a description and the quantity of each hazardous waste received, and the method and date of its treatment, storage or disposal; (2)the location of each hazardous waste within the facility and the quantity at each location; (3)records and results of waste analyses; (4)summary reports and details of all incidents that require implementing the contingency plan; (5)records and results of inspections; (6)monitoring,testing or analytical data and corrective actions where required; (7)for offsite facilities, notices to generators as specified in 264.12(b); and (8)all closure cost estimates under 264.142 and for disposal facilities, all post-closure cost estimates under 264.144. 
-.74 (a)all records, including plans, required under this part must be furnished upon request and made available at all reasonable times for inspection by any officer, employee, or representative of EPA who is duly designated by EPA. (b)the retention period for all records is extended automatically during the course of any unresolved enforcement action. (c)a copy of records of waste disposal locations and quantities must be submitted to the EPA and local land authority upon closure of the facility.

\section{CFR265.13(a)(1)}

(a)(1) Before an owner or operator treats, stores, or disposes of any hazardous wastes, or nonhazardous wastes if applicable under [Section] 265.113(d), he must obtain a detailed chemical and physical analysis of a representative sample of the wastes. At a minimum, the analysis must contain all the information which must be known to treat, store, or dispose of the waste in accordance with this part and part 268 of this chapter.

\section{CFR265.193(b)}

(b) Secondary containment systems must be:

(1) Designed, installed, and operated to prevent any migration of wastes or accumulated liquid out of the system to the soil, ground water, or surface water at any time during the use of the tank system; and (2) Capable of detecting and collecting releases and accumulated liquids until the collected material is removed.

\section{CFR265.193(c)}

(c) To meet the requirements of paragraph (b) of this section, secondary containment systems must be at a minimum:

(1) Constructed of or lined with materials that are compatible with the waste(s) to be placed in the tank system and must have sufficient strength and thickness to prevent failure due to pressure gradients (including static head and external hydrological forces), physical contact with the waste to which they are exposed, climatic conditions, the stress of installation, and the stress of daily operation (including stresses from nearby vehicular traffic);

(2) Placed on a foundation or base capable of providing support to the secondary containment system and resistance to pressure gradients above and below the system and capable of preventing failure due to settlement, compression, or uplift;

(3) Provided with a leak detection system that is designed and operated so that it will detect the failure of either the primary and secondary containment structure or any release of hazardous waste or accumulated liquid in the secondary containment system within 24 hours, or at the earliest practicable time if the existing detection technology or site conditions will not allow detection of a release within 24 hours;

(4) Sloped or otherwise designed or operated to drain and remove liquids resulting from leaks, spills, or precipitation. Spilled or leaked waste and accumulated precipitation must be removed from the secondary containment system within 24 hours, or in as timely a manner as is possible to prevent harm to human health or the environment, if removal of the released waste or accumulated precipitation cannot be accomplished within 24 hours. 
40CFR265.193(d)

(d) Secondary containment for tanks must include one or more of the following devices:

(1) A liner (external to the tank);

(2) A vault;

(3) A double-walled tank; or

(4) An equivalent device as approved by the Regional Administrator.

\section{CFR265.193(e)}

(e) In addition to the requirements of paragraphs (b), (c), and (d) of this section, secondary containment systems must satisfy the following requirements:

(1) External liner systems must be:

(i) Designed or operated to contain 100 percent of the capacity of the largest tank within its boundary;

(ii) Designed or operated to prevent run-on or infiltration of precipitation into the secondary containment system unless the collection system has sufficient excess capacity to contain run-on or infiltration. Such additional capacity must be sufficient to contain precipitation from a 25-year, 24-hour rainfall event;

(iii) Free of cracks or gaps; and

(iv) Designed and installed to completely surround the tank and to cover all surrounding earth likely to come into contact with the waste if released from the tank(s) (i.e., capable of preventing lateral as well as vertical migration of the waste).

(2) Vault systems must be:

(i) Designed or operated to contain 100 percent of the capacity of the largest tank within its boundary;

(ii) Designed or operated to prevent run-on or infiltration of precipitation into the secondary containment system unless the collection system has sufficient excess capacity to contain run-on or infiltration. Such additional capacity must be sufficient to contain precipitation from a 25-year, 24-hour rainfall event;

(iii) Constructed with chemical-resistant water stops in place at all joints (if any);

(iv) Provided with an impermeable interior coating or lining that is compatible with the stored waste and that will prevent migration of waste into the concrete;

(v) Provided with a means to protect against the formation of and ignition of vapors within the vault, if the waste being stored or treated:

(A) Meets the definition of ignitable waste under [Section] 262.21 of this chapter, or

(B) Meets the definition of reactive waste under [Section] 262.21 of this chapter and may form an ignitable or explosive vapor; and

(vi) Provided with an exterior moisture barrier or be otherwise designed or operated to prevent migration of moisture into the vault if the vault is subject to hydraulic pressure.

(3) Double-walled tanks must be:

(i) Designed as an integral structure (i.e., an inner tank within an outer shell) so that any release from the inner tank is contained by the outer shell:

(ii) Protected, if constructed of metal, from both corrosion of the primary tank interior and the external surface of the outer shell; and

(iii) Provided with a built-in, continuous leak detection system capable of detecting a release within 24 hours or at the earliest practicable time, if the owner or operator can demonstrate to the Regional Administrator, and the Regional Administrator concurs, that the existing leak detection technology or site conditions will not allow detection of a release within 24 hours.

Note: The provisions outlined in the Steel Tank Institute" s (STI) "Standard for Dual Wall Underground Steel Storage Tank"," may be used as guidelines for aspects of the design of underground steel 
double-walled tanks.

\section{CFR265.193(f)}

(f) Ancillary equipment must be provided with full secondary containment (e.g., trench, jacketing, double-walled piping) that meets the requirements of paragraphs (b) and (c) of this section except for: (1) Aboveground piping (exclusive of flanges, joints, valves, and connections) that are visually inspected for leaks on a daily basis;

(2) Welded flanges, welded joints, and welded connections that are visually inspected for leaks on a daily basis;

(3) Sealless or magnetic coupling pumps and sealless valves, that are visually inspected for leaks on a daily basis; and (4) Pressurized aboveground piping systems with automatic shut-off devices (e.g., excess flow check valves, flow metering shutdown devices, loss of pressure actuated shut-off devices) that are visually inspected for leaks on a daily basis.

\section{CFR265.194}

(a) Hazardous wastes or treatment reagents must not be placed in a tank system if they could cause the tank, its ancillary equipment, or the secondary containment system to rupture, leak, corrode, or otherwise fail.

(b) The owner or operator must use appropriate controls and practices to prevent spills and overflows from tank or secondary containment systems. These include at a minimum:

(1) Spill prevention controls (e.g, check valves, dry discount couplings);

(2) Overfill prevention controls (e.g, level sensing devices, high level alarms, automatic feed cutoff, or bypass to a standby tank); and

(3) Maintenance of sufficient freeboard in uncovered tanks to prevent overtopping by wave or wind action or by precipitation.

(c) The owner or operator must comply with the requirements of [Section] 265.196 if a leak or spill occurs in the tank system.

\section{CFR265.198}

(a) Ignitable or reactive waste must not be placed in a tank system, unless:

(1) The waste is treated, rendered, or mixed before or immediately after placement in the tank system so that:

(i) The resulting waste, mixture, or dissolved material no longer meets the definition of ignitable or reactive waste under [Sections] 261.21 or 261.23 of this chapter; and

(ii) Section 265.17(b) is complied with; or

(2) The waste is stored or treated in such a way that it is protected from any material or conditions that may cause the waste to ignite or react; or

(3) The tank system is used solely for emergencies.

(b) The owner or operator of a facility where ignitable or reactive waste is stored or treated in tanks must comply with the requirements for the maintenance of protective distances between the waste management area and any public ways, streets, alleys, or an adjoining property line that can be built upon as required in Tables 2-1 through 2-6 of the National Fire Protection Association"'s "Flammable and Combustible Liquids Code,",' (1977 or 1981), (incorporated by reference, see [Section] 260.11). 


\section{CFR265.199}

(a) Incompatible wastes, or incompatible waste and materials, must not be placed in the same tank system, unless [Section] 265.17(b) is complied with.

(b) Hazardous waste must not be placed in a tank system that has not been decontaminated and that previously held an incompatible waste or material, unless [Section] 265.17 (b) is complied with.

\section{CFR265.200}

In addition to performing the waste analysis required by [Section] 265.13 , the owner or operator must, whenever a tank system is to be used to treat chemically or to store a hazardous waste that is substantially different from waste previously treated or stored in that tank system; or treat chemically a hazardous waste with a substantially different process than any previously used in that tank system: (a) Conduct waste analyses and trial treatment or storage tests (e.g., bench-scale or pilot-plant scale tests); or

(b) Obtain written, documented information on similar waste under similar operating conditions to show that the proposed treatment or storage will meet the requirements of [Section] 265.194(a).

Note: Section 265.13 requires the waste analysis plan to include analyses needed to comply with [Sections] 265.198 and 265.199. Section 265.73 requires the owner or operator to place the results from each waste analysis and trial test, or the documented information, in the operating record of the facility.

\section{CFR268, Subpart A, 1 (a-c)}

(a) This part identifies hazardous wastes that are restricted from land disposal and defines those limited circumstances under which an otherwise prohibited waste may continue to be land disposed.

(b) Except as specifically provided otherwise in this part or Part 261 of this chapter, the requirements of this part apply to persons who generate or transport hazardous waste and owners and operators of hazardous waste treatment, storage, and disposal facilities.

(c) Restricted wastes may continue to be land disposed as follows:

(1) Where persons have been granted an extension to the effective date of a prohibition under Subpart $\mathrm{C}$ of this part or pursuant to Sec. 268.5 , with respect to those wastes covered by the extension;

(2) Where persons have been granted an exemption from a prohibition pursuant to a petition under Sec. 268.6, with respect to those wastes and units covered by the petition;

(3) Wastes that are hazardous only because they exhibit a hazardous characteristic, and which are otherwise prohibited from land disposal under this part, are not prohibited from land disposal if the wastes:

(i) Are disposed into a nonhazardous or hazardous injection well as defined in 40 CFR 144.6(a); and

(ii) Do not exhibit any prohibited characteristic of hazardous waste at the point of injection.

\section{CFR268, Subpart E, 50 (a)(2)}

(a) Except as provided in this section, the storage of hazardous wastes restricted from land disposal under Subpart C of this part of RCRA section 3004 is prohibited, unless the following conditions are met: 
(2) An owner/operator of a hazardous waste treatment, storage, or disposal facility stores such wastes in tanks or containers solely for the purpose of the accumulation of such quantities of hazardous waste as necessary to facilitate proper recovery, treatment, or disposal and:

(i) Each container is clearly marked to identify its contents and the date each period of accumulation begins;

(ii) Each tank is clearly marked with a description of its contents, the quantity of each hazardous waste received, and the date each period of accumulation begins, or such information for each tank is recorded and maintained in the operating record at that facility. Regardless of whether the tank itself is marked, an owner/operator must comply with the operating record requirements specified in Sec. 264.73 or Sec. 265.73 .

\section{CFR268.1}

[Section] 268.1 Purpose, scope and applicability.

(a) This part identifies hazardous wastes that are restricted from land disposal and defines those limited circumstances under which an otherwise prohibited waste may continue to be land disposed.

(b) Except as specifically provided otherwise in this part or part 261 of this chapter, the requirements of this part apply to persons who generate or transport hazardous waste and owners and operators of hazardous waste treatment, storage, and disposal facilities.

(c) Restricted wastes may continue to be land disposed as follows:

(1) Where persons have been granted an extension to the effective date of a prohibition under subpart $\mathrm{C}$ of this part or pursuant to [Section] 268.5, with respect to those wastes covered by the extension;

(2) Where persons have been granted an exemption from a prohibition pursuant to a petition under [Section] 268.6, with respect to those wastes and units covered by the petition;

(3) Wastes that are hazardous only because they exhibit a hazardous characteristic, and which are otherwise prohibited from land disposal under this part, are not prohibited from land disposal if the wastes:

(i) Are disposed into a nonhazardous or hazardous injection well as defined in 40 CFR 144.6(a); and

(ii) Do not exhibit any prohibited characteristic of hazardous waste at the point of injection.

(d) The requirements of this part shall not affect the availability of a waiver under section 121(d)(4) of the Comprehensive Environmental Response, Compensation, and Liability Act of 1980 (CERCLA).

(e) The following hazardous wastes are not subject to any provision of part 268 :

(1) Waste generated by small quantity generators of less than 100 kilograms of non-acute hazardous waste or less than 1 kilogram of acute hazardous waste per month, as defined in [Section] 261.5 of this chapter; (2) Waste pesticides that a farmer disposes of pursuant to [Section] 262.70;

(3) Wastes identified or listed as hazardous after November 8, 1984 for which EPA has not promulgated land disposal prohibitions or treatment standards.

(4) De minimis losses to wastewater treatment systems of commercial chemical product or chemical intermediates that are ignitable (D001), or corrosive (D002), and that contain underlying hazardous constituents as defined in [Section] 268.2 of this part, are not considered to be prohibited wastes. De minimis is defined as losses from normal material handling operations (e.g. spills from the unloading or transfer of materials from bins or other containers, leaks from pipes, valves or other devices used to transfer materials); minor leaks of process equipment, storage tanks or containers; leaks from well-maintained pump packings and seals; sample purgings; and relief device discharges.

(5) Land disposal prohibitions do not apply to laboratory wastes displaying the characteristic of ignitability (D001) or corrosivity (D002), that are commingled with other plant wastewaters under designated circumstances: ignitable and corrosive laboratory wastes containing underlying hazardous 


\section{ARCHITECTURE ID NUMBER: 1.9}

\section{ARCHITECTURE TITLE: Operable Unit (Tank) Closure System}

\section{ARCHITECTURE DEFINITION:}

New and existing equipment required to turnover TWRS SSTs, DSTs, MUSTs, and ancillary equipment for final disposition.

\section{ALTERNATIVES CONSIDERED:}

Closure alternatives will be evaluated in a supplement to the TWRS EIS. Alternatives that are tentatively to be evaluated are clean closure, modified closure, and landfill closure. Additionally, RCRA closure plans must be prepared and submitted to Ecology for the tank farm operable units, in accordance with WAC 173-303-610.

\section{a. Clean Closure of Operable Units}

All waste would be removed from the operable units prior to closure. The removed waste would be treated for disposal. The operable units would be closed as land fills, in accordance with applicable RCRA permits.

\section{b. Landfill Closure of Operable Units}

To the extent technically and economically practical, wastes would be removed from the operable units prior to closure. The removed wastes would be treated for disposal. The operable units would be closed as land fills, in accordance with applicable RCRA permits.

\section{c. Modified Closure of Operable Units}

Underground radioactive waste storage tanks are classified as treatment, storage and disposal (TSD) operable units. A TSD unit may be cleaned up to the level specified under method $\mathrm{C}$ of Chapter 173-340 WAC as a "modified closure." For modified closures, institutional controls will restrict access to the TSD unit for a minimum of five years following completion of closure. Periodic assessments of the TSD unit will determine the effectiveness of the closure. The periodic assessments shall include, as a minimum, a compliance monitoring plan that will address the assessment requirements on a unit by unit basis.

\section{RATIONALE FOR SELECTION:}

Washington Administrative Code, which addresses the non-radioactive component of residual waste in tank farm operable units, requires closure of TSD operable units to follow the requirements set forth in an approved closure plan. Requirements for disposal of the low-activity radioactive waste fraction of residual waste left in tank farm operable units are contained in DOE Order 5820.2A, Chapter III. No alternative can be selected until completion of assessment of environmental impacts and receipt of public input through the NEPA process. Selection of the alternative to be implemented will be documented in a Record of Decision, and authorized through issuance of approved closure plans by the Washington Department of Ecology. 
Appendix H - Architecture 1.9

\section{ENABLING ASSUMPTIONS:}

1. Residual waste will remain in tanks following waste retrieval operations from underground storage tanks (USTs). Closure will not remove additional waste from USTs, so tank farm operable units will be closed in place with residual waste. Retrieval will remove sufficient waste from USTs such that the waste residuals will be classified by the NRC as non-HLW, and therefore DOE (not NRC) will have regulatory authority for disposal of the radioactive waste component. Waste has leaked from many of the SSTs. Consequently soil beneath these SSTs, in all SST farms, is contaminated. Washing or excavation of soil to remove contaminants will not be undertaken, since to carry out such an operation tank shells would have to be removed, and to remove tank shells, retrieval would have to completely remove waste from the USTs. This is not included as part of the current retrieval baseline, and is not required by existing regulations, federal law, or the TPA.

\section{REQUIRED ANALYSES:}

1. An architecture evaluation has not been completed for closure of the tank farm operable units (i.e., SSTs, DSTs, and ancillary equipment). Alternatives for tank farm operable unit closure will be evaluated in a supplement to the TWRS EIS, and documented in a Record of Decision, under the NEPA process. An architecture selection for closure of the SST operable units will result from this process. A closure plan for the SST farm operable units will be negotiated with Ecology, based on the closure approach specified in the Record of Decision under the NEPA process. The DST operable units will remain in active service until 2028 to support the treatment and disposal of tank wastes. The closure planning process for the DST operable units will be initiated in the future.

\section{FUNCTIONS PERFORMED}

\subsubsection{Close Operable Units (Tanks)}




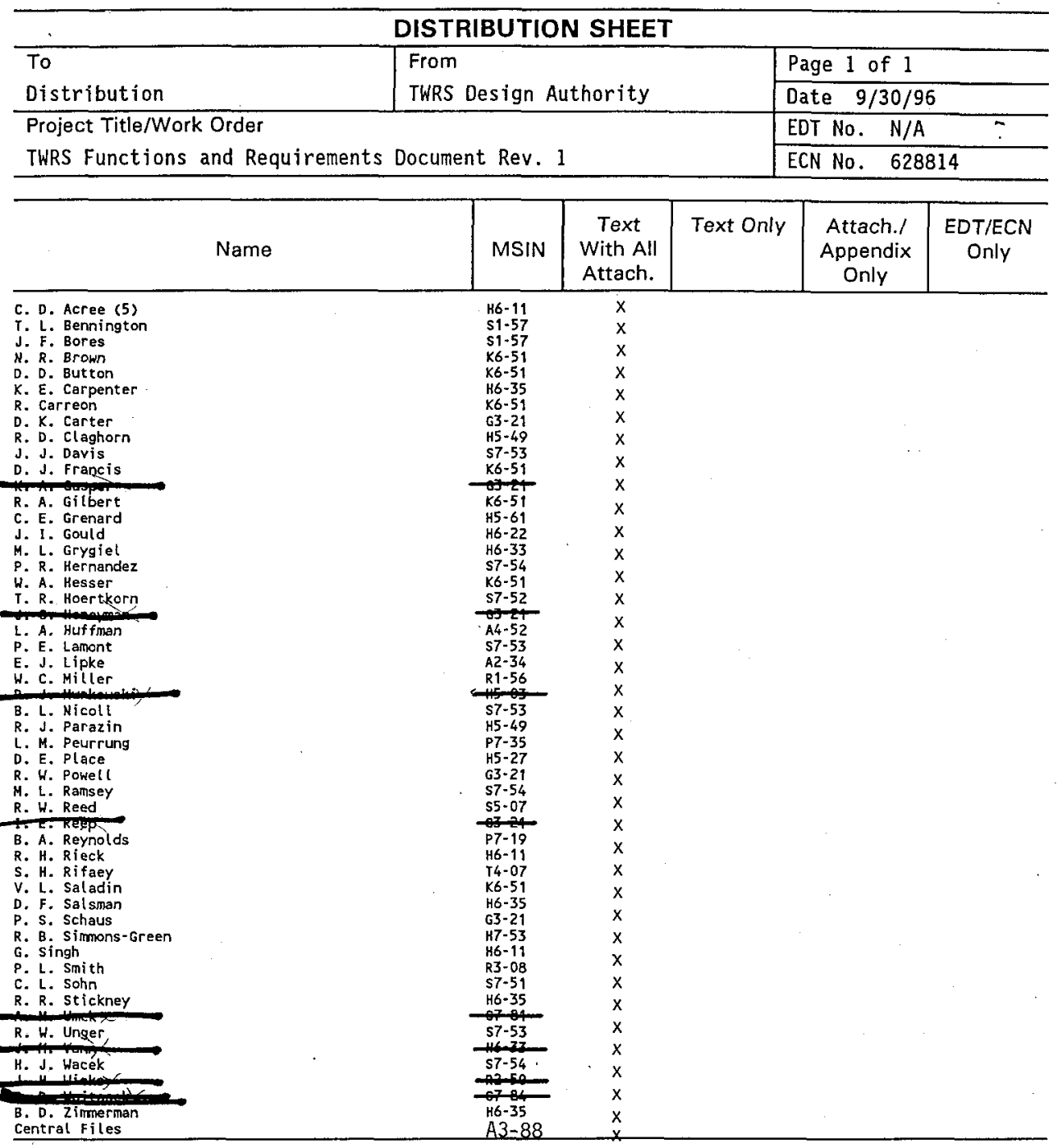


constituents from laboratory operations, that are mixed with other plant wastewaters at facilities whose ultimate discharge is subject to regulation under the CWA (including wastewaters at facilities which have eliminated the discharge of wastewater), provided that the annualized flow of laboratory wastewater into the facility"s headwork does not exceed one percent, or provided that the laboratory wastes' combined annualized average concentration does not exceed one part per million in the facility's headwork.

[51 FR 40638, Nov. 7, 1986; 52 FR 21016, June 4, 1987, as amended at 53 FR 27165, July 19, 1988; 53 FR 31212, Aug. 17, 1988; 54 FR 36970, Sept. 6, 1989; 55 FR 22686, June 1, 1990; 58 FR 29884, May $24,1993]$

\section{CFR268.35(j)}

(j) To determine whether a hazardous waste listed in [Section] 268.10, 268.11, and 268.12 exceeds the applicable treatment standards specified in [Sections] 268.41 and 268.43 , the initial generator must test a representative sample of the waste extract or the entire waste, depending on whether the treatment standards are expressed as concentrations in the waste extract or the waste, or the generator may use knowledge of the waste. If the waste contains constituents in excess of the applicable subpart $\mathrm{D}$ levels, the waste is prohibited from land disposal, and all requirements of part 268 are applicable, except as otherwise specified.

\section{CFR268.37}

(a) Effective August 9, 1993, the wastes specified in 40 CFR 261.21 as D001 (and is not in the High TOC Ignitable Liquids Subcategory), and specified in [Section] 261.22 as D002, that are managed in systems other than those whose discharge is regulated under the Clean Water Act (CWA), or that inject in Class I deep wells regulated under the Safe Drinking Water Act (SDWA), or that are zero dischargers that engage in CWA-equivalent treatment before ultimate land disposal, are prohibited from land disposal. CWA-equivalent treatment means biological treatment for organics, alkaline chlorination or ferrous sulfate precipitation for cyanide, precipitation/sedimentation for metals, reduction of hexavalent chromium, or other treatment technology that can be demonstrated to perform equally or greater than these technologies.

(b) Effective February 10, 1994, the wastes specified in 40 CFR 261.21 as D001 (and is not in the High TOC Ignitable Liquids Subcategory), and specified in [Section] 261.22 as D002, that are managed in systems defined in 40 CFR 144.6(e) and 146.6(e) as Class V injection wells, that do not engage in CWA-equivalent treatment before injection, are prohibited from land disposal.

\section{CFR268.40}

(a) A restricted waste identified in [Section] 268.41 may be land disposed only if an extract of the waste or of the treatment residue of the waste developed using the test method in appendix II of part 261 does not exceed the value shown in Table CCWE of [Section] 268.41 for any hazardous constituent listed in Table CCWE for that waste, with the following exceptions: D004, D008, K031, K084, K101, K102, P010, P011, P012, P036, P038, and U136. These wastes may be land disposed only if an extract of the waste or of the treatment residue of the waste developed using either the test method in 40 CFR part 261, appendix II, or the test method in appendix IX of this part, does not exceed the concentrations shown in Table CCWE of [Section] 268.41 for any hazardous constituent listed in Table CCWE for that 
waste.

(b) A restricted waste for which a treatment technology is specified under [Section] 268.42(a), or hazardous debris for which a treatment technology is specified under [Section] 268.45, may be land disposed after it is treated using that specified technology or an equivalent treatment method approved by the Administrator under the procedures set forth in [Section] 268.42(b). For waste displaying the characteristic of ignitability (D001) and reactivity (D003), that are diluted to meet the deactivation treatment standard in [Section] 268.42(a) Tables 1 and 2 (DEACT), the treater must comply with the precautionary measures specified in 40 CFR 264.17(b) and 265.17(b) of this chapter.

(c) Except as otherwise specified in [Section] 268.43(c), a restricted waste identified in [Section] 268.43 may be land disposed only if the constituent concentrations in the waste or treatment residue of the waste do not exceed the value shown in Table CCW of [Section] 268.43 for any hazardous constituents listed in Table CCW for that waste.

(d) If a treatment standard has been established in [Sections] 268.41 through 268.43 for a hazardous waste that is itself hazardous debris, the waste is subject to those standards rather than the standards for hazardous debris under [Section] 268.45 .

\section{CFR268.41(a)}

(a) Table CCWE identifies the restricted wastes and the concentrations of their associated constituents which may not be exceeded in the extract of a waste or waste treatment residual extracted using the test method in appendix I of this part for the allowable land disposal of such wastes. Compliance with these concentrations is required based upon grab samples.

\section{CFR268.41(b)}

(b) When wastes with differing treatment standards for a constituent of concern are combined for purposes of treatment, the treatment residue must meet the lowest treatment standard for the constituent of concern, except that mixtures of high and low zinc nonwastewater K061 are subject to the treatment standard for high zinc K061.

\section{CFR268.41(c)}

(c) The treatment standards for the constituents in F001-F005 which are listed in Table CCWE only apply to wastes which contain one, two, or all three of these constituents. If the waste contains any of these three constituents along with any of the other 26 constituents found in F001-F005, then only the treatment standards in [Section] 268.43 Table CCW are required.

\section{CFR268.42(a)}

(a) The following wastes in paragraphs (a)(1) and (a)(2) of this section and in Table 2 and Table 3 of this section must be treated using the technology or technologies specified in paragraphs (a)(1) and (a)(2) and Table 1 of this section.

(1) Liquid hazardous wastes containing polychlorinated biphenyls (PCBs) at concentrations greater than or equal to $50 \mathrm{ppm}$ but less than $500 \mathrm{ppm}$ must be incinerated in accordance with the technical 
requirements of $40 \mathrm{CFR} 761.70$ or burned in high efficiency boilers in accordance with the technical requirements of 40 CFR 761.60. Liquid hazardous wastes containing polychlorinated biphenyls (PCBs) at concentrations greater than or equal to $500 \mathrm{ppm}$ must be incinerated in accordance with the technical requirements of 40 CFR 761.70. Thermal treatment under this section must also be in compliance with applicable regulations in Parts 264, 265, and 266.

(2) Nonliquid hazardous wastes containing halogenated organic compounds (HOCs) in total concentration greater than or equal to $1,000 \mathrm{mg} / \mathrm{kg}$ and liquid HOC-containing wastes that are prohibited under [Section] 268.32(e)(1) of this part must be incinerated in accordance with the requirements of 40 CFR part 264, subpart $O$, or 40 CFR part 265 , subpart $O$. These treatment standards do not apply where the waste is subject to a part 268 , subpart D, treatment standard for a specific HOC (such as a hazardous waste chlorinated solvent for which a treatment standard is established under [Section] 268.41(a)).

(3) A mixture consisting of wastewater, the discharge of which is subject to regulation under either section 402 or section 307 (b) of the Clean Water Act, and de minimis losses of materials from manufacturing operations in which these materials are used as raw materials or are produced as products in the manufacturing process, and that meet the criteria of the D001 ignitable liquids containing greater than $10 \%$ total organic constituents (TOC) subcategory, is subject to the DEACT treatment standard described in Table 1 of this section. For purposes of this paragraph, de minimis losses include those from normal material handling operations (e.g., spills from the unloading or transfer of materials from bins or other containers, leaks from pipes, valves or other devices used to transfer materials); minor leaks from process equipment, storage tanks, or containers; leaks from well-maintained pump packings and seals; sample purgings; and relief device discharges.

\section{CFR268.50}

[Section] 268.50 Prohibitions on storage of restricted wastes.

(a) Except as provided in this section, the storage of hazardous wastes restricted from land disposal under subpart $\mathrm{C}$ of this part of RCRA section 3004 is prohibited, unless the following conditions are met:

(1) A generator stores such wastes in tanks, containers or containment buildings on-site solely for the purpose of the accumulation of such quantities of hazardous waste as necessary to facilitate proper recovery, treatment, or disposal and the generator complies with the requirements in [Section] 262.34 and parts 264 and 265 of this chapter.

(2) An owner/operator of a hazardous waste treatment, storage, or disposal facility stores such wastes in tanks, containers, or containment buildings solely for the purpose of the accumulation of such quantities of hazardous waste as necessary to facilitate proper recovery, treatment, or disposal and:

(i) Each container is clearly marked to identify its contents and the date each period of accumulation begins;

(ii) Each tank is clearly marked with a description of its contents, the quantity of each hazardous waste received, and the date each period of accumulation begins, or such information for each tank is recorded and maintained in the operating record at that facility. Regardless of whether the tank itself is marked, an owner/operator must comply with the operating record requirements specified in [Section] 264.73 or [Section] 265.73.

(3) A transporter stores manifested shipments of such wastes at a transfer facility for 10 days or less.

(b) An owner/operator of a treatment, storage or disposal facility may store such wastes for up to one year unless the Agency can demonstrate that such storage was not solely for the purpose of 
accumulation of such quantities of hazardous waste as are necessary to facilitate proper recovery, treatment, or disposal.

(c) A owner/operator of a treatment, storage or disposal facility may store such wastes beyond one year; however, the owner/operator bears the burden of proving that such storage was solely for the purpose of accumulation of such quantities of hazardous waste as are necessary to facilitate proper recovery, treatment, or disposal.

(d) If a generator"'s waste is exempt from a prohibition on the type of land disposal utilized for the waste (for example, because of an approved case-by-case extension under [Section] 268.5, an approved [Section] 268.6 petition, or a national capacity variance under subpart C), the prohibition in paragraph (a) of this section does not apply during the period of such exemption.

(e) The prohibition in paragraph (a) of this section does not apply to hazardous wastes that meet the treatment standards specified under [Sections] 268.41,268.42, and 268.43 or the treatment standards specified under the variance in [Section] 268.44, or, where treatment standards have not been specified, is in compliance with the applicable prohibitions specified in [Section] 268.32 or RCRA section 3004. (f) Liquid hazardous wastes containing polychlorinated biphenyls (PCBs) at concentrations greater than or equal to $50 \mathrm{ppm}$ must be stored at a facility that meets the requirements of 40 CFR 761.65 (b) and must be removed from storage and treated or disposed as required by this part within one year of the date when such wastes are first placed into storage. The provisions of paragraph (c) of this section do not apply to such PCB wastes prohibited under [Section] 268.32 of this part.

[51 FR 40642, Nov. 7, 1986; 52 FR 21017, June 4, 1987, as amended at 52 FR 25791, July 8, 1987; 54 FR 36972, Sept. 6, 1989; 57 FR 37281, Aug. 18, 1992]

\section{CFR50}

TWRS cumulative total organic emission rate from all affected process vents shall be maintained below 3 $\mathrm{lb} / \mathrm{h}$, or $3.1 \mathrm{ton} / \mathrm{yr}$. If this emission rate is exceeded, controls must be installed to reduce the total Site process vent emissions from all affected vents to below the emission rate limit or to reduce the total Site process vent organic emissions after primary recovery by 95 percent.

\section{CFR50.11(a-b)}

(a) The level of the national primary ambient air quality standard for nitrogen dioxide is 0.053 parts per million (100 micrograms per cubic meter), annual arithmetic mean concentration.

(b) The level of national secondary ambient air quality standard for nitrogen dioxide is 0.053 parts per million (100 micrograms per cubic meter), annual arithmetic mean concentration.

\section{CFR50.12}

National primary and secondary ambient air quality standards for lead and its compounds, measured as elemental lead by a reference method based on Appendix $G$ to this part, or by an equivalent method, are: 1.5 micrograms per cubic meter, maximum arithmetic mean averaged over a calendar quarter.

\section{CFR50.4}


The national primary ambient air quality standards for sulfur oxides measured as sulfur dioxide by the reference method described in appendix $A$ to this part, or by an equivalent method, are:

(a) 80 micrograms per cubic meter ( 0.03 p.p.m.)--annual arithmetic mean.

(b) 365 micrograms per cubic meter (0.14 p.p.m.)--Maximum 24-hour concentration not to be exceeded more than once per year.

\section{CFR50.5}

The national secondary ambient air quality standard for sulfur oxide measured as sulfur dioxide by the reference method described in appendix $A$ to this part, or by any equivalent method is 1,300 micrograms per cubic meter ( 0.5 p.p.m.) maximum 3-hour concentration not to be exceeded more than once per year.

\section{CFR50.6}

(a) The level of the national primary and secondary 24-hour ambient air quality standards for particulate matter is 150 micrograms per cubic meter $(\mathrm{g} / \mathrm{m} 3)$, 24-hour average concentration. The standards are attained when the expected number of days per calendar year with a 24-hour average concentration above $150 \mathrm{~g} / \mathrm{m} \mathrm{3}$, as determined in accordance with appendix $\mathrm{K}$ to this part, is equal to or less than one. (b) The level of the national primary and secondary annual standards for particulate matter is 50 micrograms per cubic meter $(\mathrm{g} / \mathrm{m} 3)$, annual arithmetic mean. The standards are attained when the expected annual arithmetic mean concentration, as determined in accordance with appendix $\mathrm{K}$ to this part, is less than or equal to $50 \mathrm{~g} / \mathrm{m} 3$.

(c) For the purpose of determining attainment of the primary and secondary standards, particulate matter shall be measured in the ambient air as PM 10 (particles with an aerodynamic diameter less than or equal to a nominal 10 micrometers) by:

(1) A reference method based on appendix $J$ and designated in accordance with part 53 of this chapter, or

(2) An equivalent method designated in accordance with part 53 of this chapter.

\section{CFR50.8(a)}

(a) The national primary ambient air quality standards for carbon monoxide are:

(1) 9 parts per million (10 milligrams per cubic meter) for an 8-hour average concentration not to be exceeded more than once per year and

(2) 35 parts per million ( 40 milligrams per cubic meter) for a 1-hour average concentration not to be exceeded more than once per year.

\section{CFR50.9}

(a) The level of the national primary and secondary ambient air quality standards for ozone measured by a 
reference method based on Appendix $D$ to this part and designated in accordance with part 53 of this chapter, is 0.12 part per million $(235 \mathrm{~g} / \mathrm{m} 3$ ). The standard is attained when the expected number of days per calendar year with maximum hourly average concentrations above 0.12 part per million $(235 \mathrm{~g} / \mathrm{m} 3)$ is equal to or less than 1 , as determined by Appendix $\mathbf{H}$.

\section{CFR61.92}

Standard: Emissions of radionuclides to the ambient air from Department of Energy facilities shall not exceed those amounts that would cause any member of the public to receive in any year an effective dose equivalent of $10 \mathrm{mrem} / \mathrm{yr}$.

\section{CFR173.412}

\section{ADDITIONAL DESIGN REQUIREMENTS FOR TYPE A PACKAGES}

In addition to meeting the general design requirements prescribed in 49CFR173.411, each Type A packaging shall be designed so that:

(a) The smallest overall external dimension of the package is not less than 10 centimeters ( 4 inches);

(b) The outside of the packaging incorporates a feature, such as a seal, that is not readily breakable, and that, while intact is evidence that the package has not been opened. In the case of packages shipped in exclusive use closed transport vehicles, the cargo compartment may be sealed instead of the individual packages;

(c) As far as practicable, the external surfaces are free from protrusions and are designed and finished so that they can be easily decontaminated;

(d) Containment and shielding would be maintained during transportation and storage in a temperature range of $-40 \mathrm{C}(-40 \mathrm{~F})$ to $70 \mathrm{C}(158 \mathrm{~F})$ with account being taken of the possibility of brittle fracture;

(e) It is able to withstand the effects of any acceleration, vibration, or vibration resonance that may arise during normal transportation, without any deterioration of the effectiveness of closing devices or of the integrity of the package as a whole and without loosening or unintentional release of nuts, bolts, or other securing devices even after repeated use;

(f) It includes a containment system securely closed by a positive fastening device that cannot be opened unintentionally or by pressure that may arise within the package during normal transport. Special form, as demonstrated in accordance with 49CFR173.469 may be considered as a component of the containment system;

(g) The materials of the packaging and any components or structures are physically and chemically compatible with each other and with the contents, taking into account the behavior of each under irradiation;

(h) For each component of the containment system account is taken, where applicable, of radiolytic decomposition of materials and the generation of gas by chemical reaction and radiolysis;

(i) The containment system will retain its radioactive contents under the reduction of ambient pressure to .25 kilograms per square centimeter ( 3.5 pounds per square inch);

(j) Each valve through which the radioactive contents could otherwise escape is protected against damage and unauthorized operation and, except for a pressure relief device, has an enclosure to retain any leakage;

(k) Any radiation shield that encloses a component of the packaging specified as part of the containment system will prevent the unintentional escape of that component from the shield; 
(1) Failure of any tie down attachment on the packaging under excessive load will not impair the ability of the package to meet other requirements of this subpart;

(m) When subjected to the tests specified in 49CFR173.461(a), the packaging will prevent:

(1) Loss or dispersal of the radioactive contents; and

(2) Any significant increase in the radiation levels recorded or calculated at the external surfaces for the condition before the test;

(n) Each packaging designed for liquids will:

(1) Meet the conditions prescribed in paragraph (m) of this section when subjected to the tests specified in 49CFR173.466 or evaluated against these tests by any of the methods authorized by 49CFR173.461(a);

(2) For any package with a liquid volume not exceeding 50 cubic centimeters ( 1.7 fluid ounces), have sufficient suitable absorbent material to absorb twice the volume of the liquid contents. The absorbent material shall be compatible with the package contents and suitably positioned to contact the liquid in the event of leakage; and

(3) For any package with a liquid volume exceeding 50 cubic centimeters ( 1.7 fluid ounces), either

(i) Have sufficient absorbent material as prescribed in paragraph (n) (2) of this section; or

(ii) Have a containment system composed of primary inner and secondary outer containment components designed to assure retention of the liquid contents within the secondary outer components in the event that the primary inner components leak; and

(o) Each package designed for compressed or uncompressed gasses other than tritium or argon-37 not exceeding 200 curies will be able to prevent loss of contents when the package is subjected to the tests prescribed in 49CFR 173.4666 or evaluated against these tests by any of the methods authorized by 49CFR173.461(a).

\section{Applicable Federal, State, and Municipal Laws for Privatization Contract}

The Privatization contractor shall determine and obey all applicable federal, state, and local laws whether they are specifically noted in the privatization request for proposal or not. These laws apply to both the functions as well as to the outputs generated from the function.

\section{Aqueous Waste from Tank Waste Remediation}

The manage aqueous waste function has the possibility of receiving two streams for effluent disposal. The first stream is process water that can be piped directly to Treated Effluent Disposal Facility (TEDF) with the acceptable criteria for that process water as defined in WHC-SD-WM-W049H-ICD-001 Rev. 0. The second process water stream can be transported ( $5000 \mathrm{gal}$ tankers available) or piped to the Effluent treatment facility. The ETF is a facility with a large amount of flexibility built into the operating design. The limitations for the ETF fall into three broad categories which are radiological, operational, and permitting.

The ETF is currently a radiological facility (but capable of being upgraded to a nuclear facility) and cannot receive greater than category 3 waste as defined in WHC-0931 within their 100,000 gallon holding/processing tank.

The operational limitations are that the facility can process 150 gallons/minute with a $72 \%$ operating efficiency. The current (9/95) demand from the 242 Evaporator which is the only existing stream to the ETF is estimated at 2 Million average gallons per year or approximately and average of $4 \mathrm{gal} / \mathrm{min}$ of the operating limit. The ETF can routinely handle with no modification to the facility up to 10 PPM 
suspended solids. Greater solid loading can be handled with simple modifications to filters and processing but should be evaluated on a case by case basis.

The current facility permit allows for treatment of spent solvents F01-F05 as identified in per 40 CFR 261. The initial conditions of the process stream must contain no suspendable organic matter and be fully characterized using test methods SW-846 "Test methods for evaluating Solid Waste: Physical and Chemical Methods". The ETF can accommodate a large variation in process water with minor and/or simple facility modifications therefore it is required that all process streams identify the contaminants and allo ETF to conduct engineering analyses to define the facilities capabilities and modifications required to treat the process stream. Refer to WHC-SD-ETF-001 for acceptance Criteria of the feed streams.

\section{Criticality}

The criticality safety program defined herein applies to all storing, retrieving, processing, transfer operations, transport and storage activities and waste form operations involving fissionable material quantities in excess of $3 \%$ of a minimum critical mass.

Designs shall incorporate sufficient factors of safety to require at least two unlikely, independent, and concurrent changes in process conditions before a criticality accident is possible. Protection shall be provided by either (a) the control of two independent process parameters (which is the preferred approach, if practical) or (b) a system of multiple (at least two) controls of a single parameter. In all cases, no single credible failure shall result in the potential for a criticality accident. The basis for selecting one approach over another shall be fully documented. New criticality safety evaluations (CSEs) and major revisions to existing CSEs shall provide this documentation; existing CSEs are not required to be revised just to provide this documentation.

\section{Dangerous Waste Portion of the RCRA Permit for Hanford Facility}

The Hanford Facility shall be operated in compliance with the Dangerous Waste Portion of the Resource Conservation and Recovery Act Permit for the Treatment, Storage, and Disposal of Dangerous Waste.

\section{DOE Secretary Direction B.6.A.4}

Initiate 106-C Accelerated Retrieval by October 1996 (accelerated 12 months ahead of baseline schedule) (TPA M-45-03A).

\section{DOE/RL 94-0001, Section 3.1.3, par. 1-7}

\subsubsection{PROVIDE SOUND TECHNICAL BASIS FOR SAMPLING AND ANALYSES}

A well-developed technical basis to support all sampling and analysis activities in the Tank Waste Remediation System Program does not exist. The purpose of this section is to describe how the TWRS Program will establish the technical basis upon which the program will make safety related, and other programmatic (retrieval, pretreatment and disposal) decisions. Some TWRS Programs, such as the Tank Safety Program, have a good understanding of what analyses are needed to resolve safety issues, however, the individiual TWRS Programs do not have a good understanding of: how much data are 
actually needed; how accurate the data must be; and how many samples must be collected to establish an acceptable level of risk for decision makers.

The need to establish the tehnical basis upon which the TWRS Characterization Program will proceed is critical. Without a sound technical basis one cannot determine the number of samples to be collected and analyzed to meet the TWRS Program objectives. Without knowing the number of samples to be collected, one cannot determine the number of sampling trucks and crews, the number of working shifts, the laboratory capacity, and other critical needs. Information which must be determined so that the technical basis can be established include: establishing the risk one is willing to take in making the wrong decision; and the definition of the accuracy, precision and detection limits for each analyte each TWRS program has identified as being important to their decisions. The types of risk vary with the program element. The risk to the disposal program elements, for example, are cost and schedule impacts if characterization data gathered are inadequate. At the other end, the risk of not knowing that a safety issue exists could be an increased chance of radiological releases.

There are various approaches or strategies which could be employed to establish the technical basis for characterization of the high-level nuclear waste tanks in order to resolve safety issues, and meet the needs of the TWRS Programs. Most of these strategies would lead to similar conclusions, albeit with different schedules. The large number of variables and uncertainties associated with a program as complex as TWRS will necessiate revision of the selected strategy as more knowledge is gained. Such is the case with the strategy selected for the DOE 93-5 Implementation Plan.

The 93-5 Implementation Plan strategy involves 3 parallel efforts: (1) a near term (6 to 8 months); (2) long term ( 3 years); and (3) establishing TWRS Program priorities. Figure 3 shows the elements of the 3 parallel efforts.

The near term effort involves establishing a FY 1994 priority listing of tanks to be core sampled. This priority list is attached at Appendix C (Tank Farm Sampling Schedule). This schedule includes those tanks which will be auger and core sampled. Using the Environmental Protection Agency's DQO process, the Characterization Program is assisting the other TWRS Program elements inidentifying critical data requirements including the suite of analyses required, precision, accuracy, detection levels of interest, the acceptable risk, etc. which will be required for each program to make decisions. The near term effort is focused primarilty on (1) resolving safety issues in compliance with the DNFSB's Recommendation 93-5; and (2) screening tanks to validate earlier decisions to put tanks on the Watch List. Based on the results of the screening analyses, further analyses will be conducted on each tank sampled to assess whether the tanks are "safe", "unsafe", or "conditionally safe". Data collected during the near term effort will form a database which will be used as an input to the DQO during the long term effort. Figure 4 shows the decision logic for the near term effort. Two or more core samples will be taken from each tank. The number of cores to be taken will be based on the number of risers which are available and readily accessible. The reason for this approach is that, in the near term, more samples cannot be taken than there are risers from which to take them; and the installation of additional risers or alternative sampling techniques will not be available in the near term. The data from the analyses of cores from each tank will be compared to the DQO to see if the DQO was met, or whether more data will be required to achieve the stated DQO. If additional samples are required to meet the DQO, furhter sampling of the tanks sampled during this period will be deferred until alternatives become available to allow additional sampling during the long term effort. In addition, as more information is made available through improved historical database analyses, improved databases and modeling, etc. reassessment of the near term DQOs will be needed. 
The long term effort involves using additional information as it becomes available to update the DQOs and the Tank Characterization Reports. The DQO process is being used toidentify data requirements of each TWRS Program during this effort. Extensive historical data analyses of the tank farms will be performed during the near term effort. The historical data includes process data, transfer records, and previous characterization data. The historical analysis will be used in part to segregate tanks into groups basedon chemical and physical similarities. The strategy will be to sample a few tanks within agroup. The optimum number of cores needed to desribe the vertical and horizontal homogenity will be determined using standard statistical models (e.g., the existing tanks 241-B-110 statistical model database and Heasler [1993]) and the most appropriate database developed during the near term effort. The database selected to predicted the number of samples from a specific group of tanks will match the group of tanks to be sampled. The data from the first few tanks sampled within a group will be compared to the DQO. Additional samples will be collected if necessary to meet the DQO. When the DQO has been met, the next tank within the group will then be sampled. The data from the analyses from this tank will be compared statistically to the data from previous tanks to validate the grouping. In addition, the data will be evaluated against the DQO and a determination will be made as to whether additional samples are needed. When the data indicates that the tank matches the grouping and meets the DQO, the next tank in the series will be sampled for the optimal number of samples and the previous steps will be repeated. The iterative process of sampling or resampling a tank, evaluating the aggregate data, comparing results to the $\mathrm{DQO}$, and collecting more samples and data will be repeated until the DQO has been met. The goal is to collect the optimum number of samples to meet the DQO and characterize the tanks to resolve safety issues.

The third parallel effort is establish TWRS Program priorities. Figure 3 depicts this effort. Sampling priorities have been established by Gasper (1993). But as methodology for estimating the number of cores to tak is improved, and the definition of bounding tanks becomes cleaer, the priority list will be revised. The revised priority list will be available in July 1994 . The revised priority list will establish the sampling schedule for all types of samples, and will be input to the continuing and iterative DQO processes for each of the TWRS Programs.

DOE/RL 94-0001, Section 3.3, par. 37-1

Up to date information on tank dome space vapors will be required prior to in-tank sampling to check for flammability for all rotary core sampling. Flammable gas meters will be used to show the atmosphere in flammable gas tanks is safe prior to in-tankactivities. In addition, vapor samples will be taken before core sampling to ensure that the requirements of the Clean Air Act permit are not exceeded during rotary core sampling. For flammable gas Unreviewed Safety Question (USQ) tanks, continuous head space gas monitoring for some period of time is required to determine if a flammability problem exists. Gas monitoring will be installed for all Watch List flammable gas tanks by April 1995.

\section{DOE/RL 94-0001, Summary Item \#2.1}

\section{Accelerated Saefty Related Characterization.}

Even though the primary goal of this plan is to accelerate characterization activities in support of the TWRS mission, a specific near-term task has been initiated to collect necessary characterization data to (1) ensure all tanks with safety issues are properly identified, and (2) resolve specific tank waste safety issues. This task is driven by a growing acceptance that waste historical records alone are too uncertain to 
allow an acceptable determination of whether a specific tank is safe, conditionally safe, or unsafe, and whether it belongs on the Watch List. This task commits TWRS to accomplish a comprehensive hazardous vapors, flammable gas, organic, ferrocyanides, and high heat safety screening sampling and analysis activity on each of the 177 HLW tanks within 3 years of date of acceptance of the Recommendation 93-5 (October 1996) and to complete safety-related sampling and analysis of all Watch List tanks within two years.

\section{DOE/RL 94-0001, Summary Item \#7}

\section{Change Control}

This section outlines the process for making changes to this document.

In summary, it is expected that the new Characterization Strategy, as implemented through the seven tasks of this Plan, will result in:

An acceptable determination of the safety issue status of each of the 177 Hanford HLW tanks; Sufficient data to allow resolution of any confirmed safety issue that may impact a specific tank

Operational sampling and analyses that will meet the quality, quantity, and timeliness needs of a Resource Conservation and Recovery Act (RCRA) permitted treatment, storage, and disposal (TSD) facility

Sufficient sample material and/or analytical data to support the design needs of the TWRS disposal programs.

These tasks should all occur within the three (3) year time period included within the DNFSB's Recommendation 93-5.

\section{DOE/RL 94-0001.1.11}

COMMITMENT 1.11: Develop and issue a field schedule for sampling that integrates all sampling activities (core, vapor, grab, auger, equipment availability, and crew training) for all tank sampling events for FY 1995 through FY 1996.

Deliverable: Approved schedule.

Due Date: June 1994

\section{DOE/RL 94-0001.1.16}

COMMITMENT 1.16: Complete Historical Tank Layering Models. This will develop sedimentation and tank layering models using detailed waste transaction analysis. The layering models will estimate the number of layers, volume of each layer, and the waste type of each layer for each tank.

Deliverable: Document.

Due Date: September 1994 


\section{DOE/RL 94-0001.1.17}

COMMITMENT 1.17: Complete historical tank content estimate reports for the northeast and southwest quadrants of tanks (covers $83 \%$ of thesingle-shell watch list tanks). These content estimates will be based on quantitative transactions analysis, layering models, nominal wastetype compositions, and historical sample data.

Deliverable: Documents for each quadrant.

Due Date: June 1994

\section{DOE/RL 94-0001.1.18}

COMMITMENT 1.18: Complete historical tank content estimate reports for remaining two quadrants of tanks (northwest and southeast).

Deliverable: Documents for each quadrant.

Due Date: March 1995

\section{DOE/RL 94-0001.1.21}

COMMTMENT 1.21: Complete DQOs for all TWRS program elements that may need data. Ten DQOs are scheduled to be completed in FY 1994, which encompass all the major customers of the Characterization Program. In addition, three of the less defined areas (e.g., pretreatment) will have developed working drafts. Others will be completed, published documents.

Deliverable:

1. Ferrocyanide Safety Issue DQO Report

2. C-103 Vapor DQO Draft Report

3. C-103 Dip Sample DQO Final Report

4. C-106 High Heat DQO Report

5. Organic Safety Issue DQO Report

6. Safety Screening Module DQO Report

7. Waste Compatibility DQO Report

8. In-tank Generic Vapor DQO Final Draft Report March 3, 1994

9. Vapor Rotary Core DQO Final Draft Report January 20, 1994
December 15, 1993

January 31,1994

December 16, 1994

December 20, 1994

January 31, 1994

January 31, 1994

February 28, 1994

D-37 
10. Hydrogen Generating DQO Final Draft Report April 29, 1994

11. Pretreatment DQO Draft Report August 22, 1994

12. HLW Immobilization DQO Draft Report September 6, 1994

13. LLW Immobilization DQO Draft Report September 21, 1994

\section{DOE/RL 94-0001.1.22}

COMMITMENT 1.22: Update field schedule for FY 1994 to incorporate new technical approach to maximize sampling.

Deliverable: Re-issue signed field schedule.

Due Date: February 1994

\section{DOE/RL 94-0001.1.8}

Issue QA Plan to cover all aspects of QA needs (sampling, development, equipment fabrication and laboratory).

Deliverable: WHC Document.

Due Date: February 1994

DOE/RL 94-0001.2.1

COMMITMENT 2.1: Complete DQOs for all six safety issues. Each DQO will be completed in time to support the necessary sampling and analysis scheduled (see Appendix C).

Deliverable: 6 documents.

Due Date: April 1994

\section{DOE/RL 94-0001.2.2}

COMMITMENT 2.2: Complete the safety screening DQO. This DQO documents what analysis needs to be performed to screen tanks to increase assurance that no safety issue tank has been missed.

Deliverable: Document.

Due Date: January 1994 


\section{DOE/RL 94-0001.2.3}

COMMITMENT 2.3: Complete sampling and analysis of all Watch List tanks per the DQOs established in commitments 2.1 and 2.2 .

Deliverable: Letter documenting completion.

Due Date: October 1995

\section{DOE/RL 94-0001.3.1}

COMMITMENT 3.1: Initiate construction of second and third rotary-mode core sampling trucks.

Deliverable: Commit funds and identify contractor.

Due Date: November 1993

\section{DOE/RL 94-0001.3.10}

Commitment 3.10: Complete qualification of two additional crews (one each for push and rotary trucks)

Deliverable: Letter documenting number of staff and date qualified.

Due Date: June 1994

\section{DOE/RL 94-0001.3.11}

COMMITMENT 3.11: Additional rotary-mode core sampling systems.

Fabricate and/or procure new core sampling trucks and support equipment as indicated by Characterization Program needs. Current planning entails developing one complete system, and procuring one additional base drill rig. A design specification document and drawings, based on the design of the rotary-mode core sampling system, will be prepared. Documentation to initiate fabrication of equipment will be issued. Equipment for the rotary-mode core sampling system includes a core sampling truck, nitrogen purge gas trailer, generator, support trailer, cask truck, and other ancillary equipment.

Deliverable: Transmittal of a letter documenting the operational availability of new rotary-mode core sampling system equipment.

Due Date: September 1994

DOE/RL 94-0001.3.12 
COMMITMENT 3.12: Hire, train, and qualify four additional rotary-mode crews.

Deliverable: Letter documenting number of staff and date qualified.

Due Date: October 1994

\section{DOE/RL 94-0001.3.13}

COMMITMENT 3.13: Deploy prototype cone penetrometer.

Technology development activities are being pursued which may result in the ability to provide some requested data outside of laboratory analysis. A cone penetrometer and a foil activation technique are being developed. The cone penetrometer is a deployment tool for commercially available sensors. A foil activation process is being tested to assess moisture and transuranic (TRU). Inaccuracies in the moisture measurements from core samples are incurred due to the use of a nitrogen gas flow in the rotary-mode core sampling system, which cause the drying of sample material (as it is contained in the sample) as well as potential drying of samples in hot cells. The present method provides conservative values (e.g., potentially lower moisture than in tank), and may result in unnecessary safety restrictions.

Deliverable: Letter documenting the deployment-ready status of the prototype core penetration.

Due Date: May 1995

\section{DOE/RL 94-0001.3.16}

COMMITMENT 3.16: Direct Drill Bit Temperature Monitoring. This will complete field deployment and testing of a direct drill bit temperature monitoring device. Sandia National Laboratories Albuquerque Office has completed the preliminary design and is developing a full size prototype for field deployment.

Deliverable: Field deployment of devise.

Due Date: January 1995

DOE/RL 94-0001.3.18

COMMITMENT 3.18: Develop means for measuring complete sample recovery. Complete engineering study of alternatives, select method and complete design/fabrication/testing of technique.

Deliverable: Completed design and testing.

Due Date: January 1995

\section{DOE/RL 94-0001.3.3}

COMMITMENT 3.3: Complete qualification of first push-mode crew. 
Deliverable: Letter documenting numbers of staff and date qualified.

Due Date: February 1994

\section{DOE/RL 94-0001.3.4}

COMMITMENT 3.4: Re-deploy push-mode core sampling.

Deliverable: A letter will be transmitted to the Characterization Program acknowledging the deployment-ready status of the push-mode core sampling system.

Due Date: March 1994

DOE/RL 94-0001.3.5

COMMITMENT 3.5: Complete training and qualification requirements for sampling cognizant engineers.

Deliverable: Letter documenting that cognizant engineers are available for sampling activities.

Due Date: February 1994

DOE/RL 94-0001.3.6

COMMITMENT 3.6: Restore rotary-mode sampling capability at the Hanford Site.

The rotary-mode hard salt cake sampler and all required support equipment will be approved and released for characterization sampling operations.

Deliverable: Transmittal of a letter documenting the completion of all actions necessary to implement the safe core sampling of the hard salt cake wastes

Due Date: March 1994

DOE/RL 94-0001.3.7

COMMITMENT 3.7: Complete qualification of first rotary-mode crews and vapor/grab/auger sampling crew.

Deliverable: Letter documenting number of staff and date qualified.

Due Date: March 1994 


\section{DOE/RL 94-0001.5.1}

COMMITMENT 5.1: Install Core Scanning System in Hot Cell.

The hot cell scanner is a WHC project to design and fabricate a multi-axis scanner platform to aid in deployment of various fiber optic excitation and spectroscopic probes (Raman, infrared). The scanner will support hot cell implementation of just-extruded waste tank core samples.

Deliverable: Install core scanning system in hot cell.

Due Date: September 1994

DOE/RL 94-0001.5.12

COMMITMENT 5.12: Upgrade INEL Laboratory to ready-to-serve mode.

Deliverable: Letter from INEL indicating ready-to-serve mode.

Due Date: October 1994

\section{DOE/RL 94-0001.5.13}

COMMITMENT 5.13: Upgrade LANL Laboratory to ready-to-serve mode. Long lead item is NEPA (started January 1994).

Deliverable: Letter from LANL indicating ready-to-serve mode.

Due Date: February 1995

\section{DOE/RL 94-0001.5.14}

COMMITMENT 5.14: Two PAS-1 transfer casks will be ready for use.

Deliverable: Letter acknowledging that two PAS-1 transfer casks are ready for use.

Due Date: January 1995

\section{DOE/RL 94-0001.5.2}

COMMITMENT 5.2: Complete Renovation of the 325 Building A Hot Cell.

Complete cleanout and renovation activities in the A Cell of the 325 Building High Level Radiochemistry Facility, Install hot cell related equipment. Begin installation and room modifications for a shielded 
inductively coupled plasma (ICP) instrument and glovebox. The setting of the shielded ICP will be completed in FY 1995.

Deliverable: Letter documenting completion of renovation of the A Hot Cell complex to be fully functional for tank waste core characterization work.

Due Date: September 1995

\section{DOE/RL 94-0001.5.3}

COMMITMENT 5.3: Issue a letter assessing the operability of the new extruder.

Determine the operability of the new sample extruder. Testing will be performed and will include testing in a mock-up facility, bench operations, and hot cell testing.

Deliverable: Letter report.

Due Date: $\quad$ March 1994

\section{DOE/RL 94-0001.5.4}

COMMITMENT 5.4: Cyanide Speciation - Complete Technology Transfer from PNL.

This activity provides for the development of new analytical methods and/or improvements to existing methods. Technical staff are responsible for investigating, developing, validating, documenting, and training personnel to formal procedures that detail analytical processes. These methods include, but are not limited to: cyanide speciation, hot cell gamma, and thermal conductivity.

Deliverable: Letter documenting completion.

Due Date: September 1994

\section{DOE/RL 94-0001.5.8}

COMMITMENT 5.8: Procure and receive two PAS-1 Transfer Casks.

Procure and receive two PAS-1 Transfer Casks onsite. The licensing revision required for use of the cask with core samples is not expected to be approved by the NRC until January 1995. In the interim, WHC will buy or lease additional Type A casks which will allow the shipment of small samples to off site labs beginning in October 1994.

Deliverable: Letter acknowledging receipt of two PAS-1 Transfer Casks.

Due Date: September 1994 
Appendix D - Constraints Definitions

\section{DOE/RL 94-0001.6.2}

A plan will be developed identifying implementation plans for improving data accessibility, data control, and data readability. These plans will be the basis for determining work scope in the outyears.

Deliverable: Issue internal WHC document

Date Due: May 1994

\section{DOE/RL 94-0001.6.3}

COMMITMENT 6.3: Initial Online Capability for an automated laboratory information management system ( LABCORE-1).

The first phases of the anticipated system (LABCORE-1) will be installed and implemented at the 222-S Laboratory to support SST analyses.

This task will result in development and installation of a Laboratory Information System (LIMS) in all site laboratories. MULTI LIMS software will manage the data which pertains to sample analysis tracking and the management aspects of the laboratory operations, work assignments, sample status, final reporting, personnel training and equipment status. Withthis capability WHC can assign to specif ic sample data the analysis request, chain-of-custody records, and laboratory analysis raw data (as appropriate) to provide summary laboratory reports.

Deliverable: Initial online capability for LABCORE-1 System.

Due Date: January 1994

\section{DOE/RL 94-0001.6.4}

COMMITMENT 6.4: Demonstrate offsite access to the Tank Characterization database.

Demonstration of read-only offsite access by regulators to three tanks worth of characterization data in the Tank Characterization database.

Deliverable: Letter documenting completion.

Due Date: January 1994

\section{DOE/RL 94-0001.6.5}

COMMITMENT 6.5: Complete data loading of 20 tanks of data in to the Tank Characterization database.

Load 20 tanks worth of characterization data in the Tank Characterization database. 
Appendix D - Constraints Definitions

Deliverable: Letter documenting completion.

Due Date: September 1994

\section{DOE/RW-0333P, Quality Assurance}

For facilities (and their products) that process materials for deep geologic disposal, the contractor shall comply with the requirements of DOE/RW-0333P (Quality Assurance).

\section{DOE/RW-0351P, rev.1 Waste Acceptance System Requirements}

Acceptance of HLW and SNF into the Civilian Radioactive Waste Management System (CRWMS) shall be in accordance with this document.

\section{DOE/RW-0351P, rev.1, 3.2.1.2}

SNF Receipt

(Purchaser/Producer) Until the SNF or HLW is accepted by WA, the Purchaser/Producer shall provide and pay the costs of interim storage for their respective sites. [NWPA Section 111(a)(5)]

\section{DOE/RW.0351P, rev.1, 3.2.1.3}

HLW Receipt

(WA) WA shall begin accepting HLW for disposal at the MGDS beginning in 2015. [Derived]

\section{DOE/RW-0351P, rev.1, 3.2.3.2.2(C)}

C. (WA) WA shall not accept in excess of 300 canisters of commercial HLW and 13,200 canisters of defense HLW for disposal at the first repository. [Derived] $<\mathrm{TBR}>$

\section{DOE/RW-0351P, rev.1, 3.2.3.2.3 A(2)}

WA-Transportation Interface Requirements

The types of interfaces between these two elements reflect transfer of both loaded and unloaded transportation cask subsystems and the documentation, reports and communications regarding loaded and unloaded transportation cask subsystems.

A. (WA) In support of the following requirements, WA shall arrange for a transportation cask system(s) and necessary Transportation System services to move SNF and/or HLW from the Purchaser's/Producer's site to [the CRWMS facility. [10CFR961.11 Article IV.B.2] 
(2) Producers shall be provided with a rail cask for delivery of defense HLW (from-Savannah River Site and from-Hanford) to the MGDS. [Derived]

\section{DOE/RW-0351P, rev.1, 3.4.4}

Test Plans and Procedures

(WA, Purchaser, Producer) Through test and evaluation, conformance of the system element's requirements shall be demonstrated as required in the verification matrix in Table 4-1. [CRD]

\section{DOE/RW-0351P, rev.1, 3.7.1.2.1}

\section{Waste Form Criteria}

A. (WA, Purchase, Producer) All radioactive waste (both SNF and HLW) accepted into the CRWMS for disposal at the MGDS shall be designed to meet the following criteria. Consistent with established agreements, DOE may be responsible for ensuring that certain waste types meet this requirement.

(1) (Purchaser, Producer) Radioactive waste shall be in solid form.

(2) (Purchaser, Producer) Particulate waste forms shall be consolidated (for example, by incorporation into an encapsulating matrix) to limit the availability and generation of particulates.

(3) (Purchaser, Producer) Combustible radioactive wastes shall be reduced to noncombustible form unless it can be demonstrated that a fire involving the waste packages containing combustibles will not adversely affect other waste packages, any structures, systems, and components important to safety, or the repository's ability for waste isolation.

B. (WA, Purchaser, Producer) The waste form shall not contribute to free liquids in the waste packages to an amount that could compromise the ability of the waste package to achieve the performance objectives related to containment of the waste form or result in spillage and spread of contamination in the event of waste package perforation during the period through permanent closure.

C. (WA, Purchaser, Producer) The waste form shall not contain explosive, pyrophoric, or chemically reactive materials in an amount that could compromise the repository's ability for waste isolation or the repository's ability to satisfy the performance objectives.

D. (WA, Purchaser, Producer) If the waste form does not meet the criteria specified in parts A, B, and $\mathrm{C}$, then the waste form shall not be accepted into the CRWMS. [Derived]

\section{DOE/RW-0351P, rev.1, 3.7.1.2.1.2.1}

\section{HLW Standard Form}

A. (Producer) The standard canistered HLW form 1 shall be borosilicate glass sealed inside an austenitic stainless steel canister(s) with a concentric neck and lifting flange. [Derived]

B. (Producer) The standard canistered HLW form shall meet the following criteria:

(1) (Producer) Total length shall be 3.000 meters $(+0.005,-0.020 \mathrm{~m}) .2$ [Derived]

(2) (Producer) Diameter shall be 61.0 centimeters $(+1.5,-1.0 \mathrm{~cm}) .2$ [Derived] 
(3) (Producer) Weight shall not exceed 2500 kilograms. [Derived]

(4) (Producer) Fill height shall be equivalent to at least $80 \%$ of the volume of the empty canister.

[Derived]

(5) (Producer) Total heat generation rate shall not exceed 1500 watts per canister at the year of shipment. [Derived]

(6) (Producer) Temperature shall not have exceeded 400 degrees $\mathrm{C}$ during storage to ensure the glass transition temperature has not been exceeded. [Derived]

(7) (Producer) Inert cover gas leak rate of the outermost closure shall be less than (10)-4 atm-cc/sec.

[Derived]

(8) (Producer) Canister shall be labeled with unique alphanumeric identifier as described in section

3.7.1.2.1.2.15. [10CFR60.135(b)(4)]

note:

1 Other standard HLW forms will be defined in subsequent revisions of the WA-SRD.

2 The minimum dimension may be measured prior to filling.

DOE/RW-0351P, rev.1, 3.7.1.2.1.2.10(A)

Removable Radioactive Contamination on Canister

A. (Producer) The levels of removable radioactive contamination of all external surfaces of each canistered waste form shall not exceed $220 \mathrm{dpm} / 100 \mathrm{~cm} 2$ for alpha radiation and $2200 \mathrm{dpm} / 100 \mathrm{~cm} 2$ for beta and gamma radiation. [Derived]

\section{DOE/RW-0351P, rev.1, 3.7.1.2.1.2.10(B)}

B. (Producer) The Producer shall inspect the canistered waste form and remove visible waste glass from the exterior surface of the canister prior to shipment. [Derived]

\section{DOE/RW-0351P, rev.1, 3.7.1.2.1.2.10(C)}

C. (Producer) The Producer shall report to DOE/OCRWM an estimate of the amount of canister material (particularly wall thickness) removed during decontamination of the canister surface. [Derived]

\section{DOE/RW-0351P, rev.1, 3.7.1.2.1.2.11(A)}

HLW Phase Stability and Integrity

A. (Producer) The Producer shall ensure the phase structure and composition of the canistered waste form are not degraded after initial cooldown by maintaining it below $400 * \mathrm{C}$ to ensure the glass transition temperature is not exceeded. [Derived]

DOE/RW-0351P, rev.1, 3.7.1.2.1.2.11(B) 
B. (Producer) The Producer shall provide the Time Temperature Transformation diagrams and data for the canistered waste form. [Derived]

\section{DOE/RW-0351P, rev.1, 3.7.1.2.1.2.12(A)}

Hazardous Waste Determination

(WA, Producer) WA shall require the Producer to determine if the HLW is hazardous as follows:

A. (Producer) The Producer shall determine, quantify, and report to DOE/OCRWM the presence of any hazardous waste listed in 40CFR261.31 through 40CFR261.33, in the waste or in any feed stream proposed for storage or disposal. The listed waste must be quantified in the WQR, or their absence must be certified in the WQR. [Derived]

\section{DOE/RW-0351P, rev.1, 3.7.1.2.1.2.12(B)}

B. (Producer) If no "listed hazardous wastes" are present in the waste or in any feed stream, the Producer shall perform the "Toxicity Characteristics Leaching Procedure" (TCLP) as described in 55 Federal Register 26986, 6/29/90, and other RCRA characteristics test(s) described in 40CFR261.20 through 261.24 as appropriate, using samples from production runs or prototypical specimens. Any modifications must have prior DOE/OCRWM approval. The method to be used must be described in the WCP and results documented in the WQR.

\section{DOE/RW-0351P, rev.1, 3.7.1.2.1.2.12(C)}

C. (Producer) Based on the results of A and B above, the Producer shall vertify in the WQR whether or not the waste is hazardous. [Derived]

\section{DOE/RW-0351P, rev.1, 3.7.1.2.1.2.12(D)}

D. (Producer) For hazardous wastes, the Producer shall prepare "Hazardous Waste Manifest" logs as required by 40 CFR262. These logs must be included in the Production Records and must accompany waste during shipment. [Derived]

\section{DOE/RW-0351P, rev.1, 3.7.1.2.1.2.13}

\section{Consistency Test}

A. (Producer) The Producer shall demonstrate control of waste form production by comparing (either directly or indirectly) melter batch production samples to the Environmental Assessment (EA) benchmark glass using the Product Consistency Test (PCT) or equivalent. [Derived] <TBR>

B. (Producer) For acceptance, the concentrations of lithium, sodium, and boron in the leachate, after 
normalization for the concentrations in the glass, shall be less than those of the benchmark glass.

[Derived] $\langle\mathrm{TBR}\rangle$

\section{DOE/RW-0351P, rev.1, 3.7.1.2.1.2.14}

\section{Canister Impact Characteristics}

(Producer) The canistered HLW shall be capable of withstanding a drop of 7 meters onto a flat, essentially unyielding surface without breaching or dispersing radionuclides. The test results shall include information on the measured canister leak rates and canister deformation after the drop test. [Derived] $\langle\mathrm{TBR}\rangle$

\section{DOE/RW-0351P, rev.1, 3.7.1.2.1.2.17}

Dose Rate at Shipment

(Producer) The canistered waste form shall not exceed a maximum surface gamma dose rate of 10E5 $\mathrm{rem} / \mathrm{hr}$ and a maximum neutron dose rate of $10 \mathrm{rem} / \mathrm{hr}$, at the year of shipment to the MGDS. [Derived]

\section{DOE/RW-0351P, rev.1, 3.7.1.2.1.2.18}

\section{HLW Condition at Delivery}

(Producer) At time of delivery, the HLW shall stand upright without support on a flat horizontal surface and properly fit into a right-circular, cylindrical cavity $(64 \mathrm{~cm}$ diameter and $3.01 \mathrm{~m}$ length). [Derived]

\section{DOE/RW-0351P, rev.1, 3.7.1.2.1.2.19}

Records

(WA, Producer) WA shall require the Producer to submit documentation to DOE/OCRWM to demonstrate compliance of the HLW form with this WA-SRD in accordance with the requirements of OCRWM QARD section 17. DOE-EM, as the cognizant organization within DOE for HLW form production, shall produce waste form production specifications, which describe the form and content of this document. As a minimum, this documentation will include a Waste Form Compliance Plan, a Waste Form Qualification Record, Production Records, and Storage and Shipping Records. [DOE/RW-0333P]

\section{DOE/RW-0351P, rev.1, 3.7.1.2.1.2.19.1}

\section{Waste Form Compliance Plan (WCP)}

(Producer) The WCP shall describe the Producer plan for demonstrating compliance with each requirement in the WA-SRD, including tests, analyses, and process controls to be performed by the 
Appendix D - Constraints Definitions

Producer. The WCP will also identify records that will be provided as evidence of compliance.

[DOE/RW-0333P]

DOE/RW-0351P, rev.1, 3.7.1.2.1.2.19.2

Waste Form Qualification Report (WQR)

(Producer) The WQR shall compile the results from waste form testing and analysis to demonstrate the ability of the Producer to comply with the WA-SRD. [DOE/RW-0333P]

\section{DOE/RW-0351P, rev.1, 3.7.1.2.1.2.19.3}

Production Record

(Producer) The Production Records shall describe the actual canistered waste form. [DOE/RW-0333P]

\section{DOE/RW-0351P, rev.1, 3.7.1.2.1.2.19.4}

Storage and Shipping Record

(Producer) The Storage and Shipping Record shall describe the physical attributes of each canistered waste form and identify any unexpected events, such as thermal excursions, which have occurred during storage. [DOE/RW-0333P]

\section{DOE/RW-0351P, rev.1, 3.7.1.2.1.2.2}

HLW Nonconforming Form

(Producer) The nonconforming canistered HLW form shall be any HLW that does not conform with the HLW characteristics in sections 3.7.1.2.1.2.1 and 3.7.1.2.1.2.4 through 3.7.1.2.1.2.18. [Derived]

The procedures for acceptance of nonconforming canistered HLW are described in sections 3.7.1.2.8 and 3.9 .

DOE/RW-0351P, rev.1, 3.7.1.2.1.2.20

HLW Annual Report

(Producer) Producer shall provide annual reports of waste generation and projections of quantities of vitrified HLW requiring disposal. [Derived]

DOE/RW-0351P, rev.1, 3.7.1.2.1.2.3 
Appendix D - Constraints Definitions

HLW Nonstandard Form

(Producer) The nonstandard canistered HLW form shall be any HLW with nonconforming conditions that have been reviewed and deemed acceptable into the CRWMS. Nonstandard canistered HLW may also be in a condition which requires special handling. [Derived]

The procedure for acceptance of nonstandard HLW is described in section 3.7.1.2.8A.

\section{DOE/RW-0351P, rev.1, 3.7.1.2.1.2.4}

\section{Criticality Safety for HLW}

(Producer) The Producer shall design a waste form to ensure that a nuclear criticality accident is not possible unless at least two unlikely, independent, and concurrent or sequential changes have occurred in the conditions essential to nuclear criticality safety. The waste form shall be designed for criticality safety under normal and accident conditions. The calculated effective multiplication factor (Keff) shall be sufficiently below unity to show at least a 5\% margin, after allowance for the bias in the method of calculation, the uncertainty in the experiments used to validate the method of calculation.

\section{DOE/RW-0351P, rev.1, 3.7.1.2.1.2.5}

Waste Form - Material Compatibility

(Producer) The contents of the canistered waste form shall not lead to internal corrosion of the canister such that there will be an adverse effect on normal handling during storage, and an abnormal occurrence such as a canister drop accident after exposure to temperatures up to the glass transition temperature. [Derived]

\section{DOE/RW-0351P, rev.1, 3.7.1.2.1.2.6}

Chemical Composition

A. (Producer) The Producer shall report to DOE/OCRWM the chemical composition and crystalline phase projections for the waste form. [Derived]

B. (Producer) The Producer shall report to DOE/OCRWM the oxide composition of the waste form for the oxides of elements present in concentrations greater than $0.5 \%$ by weight and the estimate of the error of the composition. [Derived]

\section{DOE/RW-0351P, rev.1, 3.7.1.2.1.2.8}

Radionuclide Inventory

(Producer) The Producer shall report to DOE/OCRWM the estimated total and individual canister inventory of radionuclides (in Curies) that have half-lives longer than 10 years and that are or will be 
Appendix D - Constraints Definitions

present in concentrations greater than $0.05 \%$ of the total radioactive inventory. The estimates shall be indexed to the year 2015. [Derived]

\section{DOE/RW-0351P, rev.1, 3.7.1.2.1.2.9}

Canister After Closure

(Producer) After closure, the canistered waste form shall not contain:

A. Free gas other than air, cover, and radiogenic gases with an immediate internal gas pressure no to exceed $150 \mathrm{kPa}(22 \mathrm{psia})$ at $25^{\circ} \mathrm{C}$. Cover gases shall be helium, argon, or other inert gases. [Derived]

B. Detectable amounts of organic materials. [Derived]

\section{DOE/RW-0351P, rev.1, 3.7.1.2.10}

Final Description of Waste

(Purchaser, Producer) Except as otherwise agreed to by DOE, the Purchaser/Producer shall describe in writing the material in each shipping lot 60 days prior to the scheduled DOE transportation of that shipping lot. [10CFR961.11 Article IV.A.2(b)]

\section{DOE/RW-0351P, rev.1, 3.7.1.2.2H}

Contract/Agreement

H. (DOE/RW, WA, Producer) The DOE/RW shall accept title to defense HLW. [Presidential Memo1985]

\section{DOE/RW-0351P, rev.1, 3.7.1.2.6}

Delivery Commitment Schedules

A. (Purchaser) Beginning January 1, 1992, the Purchasers shall submit to DOE the delivery commitment schedules (DCS) for all SNF the Purchasers wish to deliver to DOE beginning 63 months thereafter. The DCS should be in the format set forth in Appendix C of 10CFR961 as provided in OMB approved form number 1901-0260. [10CFR961.11 Article V.B.1]

B. (DOE/RW) DOE shall approve or disapprove of the Purchaser DCS within 3 months after receipt, and must notify the Purchaser in writing of the reasons for disapproval. DOE must request the Purchaser to submit a revised DCS within 30 days after receipt of DOE's disapproval. [1OCFR961.11 Article V.B.1]

C. (DOE/RW) DOE shall approve or disapprove the Purchaser revised DCS within 60 days after receipt. In the event of disapproval, DOE must advise the Purchaser in writing of the reasons and proposed schedules, and if the reasons and proposed schedules are not acceptable to the Purchaser, the parties must 
promptly try to negotiate mutually acceptable schedule(s). [1 OCFR961.11 Article V.B.2]

D. (DOE/RW, Purchaser) The Purchaser shall have the right to adjust the quantities of SNF and/or HLW plus or minus $20 \%$, and the delivery schedule up to 2 months, until the submission of the final delivery schedule. [10CFR961.11 Article V.B.2]

E. (DOE/RW) If the Purchaser fails to provide the annual forecast discussed in section 3.7.1.2.1.1.4A, DOE may, at its sole discretion, require a rescheduling of any DCS then in effect. [1OCFR961.11 Article IV.A.1(c)]

\section{DOE/RW-0351P, rev.1, 3.7.1.2.7}

Exchange Requests

A. (Purchaser) Not less than 6 months prior to the delivery date specified in the Purchaser approved DCS, the Purchaser shall be allowed to submit to DOE an exchange request as specified in 1OCFR961.11 Article V.E. [10CFR961.11 Article V.E]

B. (DOE/RW) DOE shall approve or disapprove the proposed exchange request within 30 days after receipt. In the event of disapproval, DOE must advise the Purchaser in writing of the reasons.

[10CFR961.11 Article V.E]

\section{DOE/RW-0351P, rev.1, 3.7.1.2.8}

Request for Nonstandard or Nonconforming Waste Delivery

A. (DOE/RW, Purchaser, Producer) Purchaser/Producer shall obtain delivery and procedure confirmation from DOE prior to delivery of other-than-standard waste (failed SNF and nonstandard SNF/HLW). DOE shall advise Purchaser/Producer within 60 days after receipt of confirmation request as to the technical feasibility of accepting of the other-than-standard waste on the currently agreed to schedule, and any schedule adjustment for such services. [10CFR961.11 Article VI.A.2(b)]

B. (Producer) Producer shall submit action plan for correction or disposition of nonconforming waste for verification and documented approval. The action plan must adequately identify and describe the nonconformance and any action to change or correct the existing nonconformance. The action plan must be signed by authorized personnel/organization. [DOE/RW-0333P]

\section{DOE/RW-0351P, rev.1, 3.7.1.2.9}

Final Delivery Schedules

A. (Purchaser) The Purchaser shall submit to DOE, not less than 12 months prior to delivery, final delivery schedule(s) (FDS) as specified in 1OCFR961.11 Appendix D. [10CFR961.11 Article V.Cl

B. (DOE/RW, Purchaser) DOE shall approve or disapprove a FDS within 45 days after receipt. In the event of disapproval, DOE must advise the Purchaser in writing of the reasons, and request a revised 
schedule. The Purchaser shall submit. the revised schedule within 30 days after receipt of DOE's notice of disapproval. [1OCFR961.11 Article V.C]

C. (DOE/RW) DOE shall approve or disapprove the revised FDS submitted by the Purchaser within 60 days after receipt If DOE disapproves the revised schedule, the reasons for disapproval must be provided in writing to the Purchaser, along with DOE's proposed schedule. If these are not acceptable to the Purchaser, the parties must promptly seek to negotiate mutually acceptable schedules. [1OCFR961.11 Article V.C]

\section{DOE/RW-0351P, rev.1, 3.7.3.2.1}

Shipping Records

(Purchaser, Producer) The Purchaser/Producer shall provide written documentation and certification:

A. (Purchaser, Producer) Of cask conditions and contents (including but not limited to SNF matrixed to the unique MPC identifier) prior to transfer to the receiving party in accordance with 1OCFR961.11 Article VI.B.2. [1OCFR71.5a] [1OCFR961.11 Article VI.B.2]

B. (Purchaser, Producer) That the transportation cask subsystem (including the MPC, if applicable) has been packaged to meet DOE, DOT, and NRC requirements, and to transfer care, custody and control of the shipment. [1OCFR40.13(c)(6)] [10CFR71.5a] [10CFR961.11 Article VI.B.2] [1OCFR961.11 Appendix E.B.6(c)] [49CFRI72.204(a)]

C. (Purchaser, Producer) Of the name of each radionuclide that is listed in 49CFRI73.435, in order of decreasing radiotoxicity, whose activity comprises $1 \%$ or greater of the total activity at the time of shipment. [Derived]

D. (Producer only) That the standard HLW form did not exceed 400 Degrees C to ensure the glass transition temperature was not exceeded. [Derived]

E. (Producer only) Of the hazardous waste classification for land disposal. [40CFR262]

F. (Purchaser) Of the sealing and inspection of the MPC welds. [1OCFR60.135(a)]

\section{DOE/RW-0351P, rev.1, 3.7.3.2.3}

Routine Determinations

(Purchaser, Producer) Prior to each shipment of licensed material, the Purchaser/Producer shall ensure the transportation cask with its contents satisfies the applicable requirements of 10CFR71.87.

[10CFR71.87]

DOE/RW-0351P, rev.1, 3.7.3.2.4(A) 
Title Transfer

A. (DOE/RW) Delivery and acceptance in writing by DOE of any SNF and/or HLW at a DOE facility shall constitute a transfer of title to DOE of the SNF and/or HLW. [NWPA Section 123] [10CFR961.11 Article I-101] [1OCFR961.11 Article II]

\section{DOE/RW-0351P, rev.1, 3.7.3.2.4(B)}

B. (DOE/RW, Producer) DOE/OCRWM shall accept HLW at a designated loading facility adjacent to the Producer's HLW facility. [DHLW: MOA between DP and RW, 1986] [CHLW: Derived] <TBR>

\section{DOE/RW-0351P, rev.1, 3.7.3.2.4(C)}

C. (DOE/RW, Purchaser, Producer) Title to SNF and/or HLW shall transfer to DOE at the Purchaser/Producer site. DOE shall be solely responsible for control of all I material upon transfer of title. DOE has the right to dispose, as it sees fit, of any SNF and/or HLW to which it has taken title. Purchasers/Producers shall have no claim against DOE or the Government for such SNF or HLW, nor shall the Government be obligated to compensate the Purchaser/Producer for such material. [Purchaser: 10CFR961.11 Article VII] [Producer: Derived]

\section{DOE/RW-0351P, rev.1, 3.7.3.2.5}

Observation by DOE

A. (DOE/RW, Purchaser, Producer) DOE/OCRWM may designate a representative(s) to observe the preparatory activities conducted at the Purchaser/Producer site. The Purchaser/Producer shall allow the designated representative(s) access to the site. [Purchaser: 1OCFR961.11 Article IV.A.2(a)] [Producer: Derived]

B. (DOE/RW, Purchaser, Producer) DOE/OCRWM shall verify the description of the SNF and/or HLW during MPC and transportation cask loading and prior to acceptance, in accordance with 1OCFR961.11 Appendices E and F. [10CFR961.11 Article VI.B.2]

C. (WA) WA shall have the capability to inspect, verify, and record the identification numbers, description, and characteristics of:

(1) SNF prior to loading into an MPC or a transportation cask

(2) HLW prior to loading into a transportation cask

(3) Loaded MPC prior to loading into a transportation cask.

[1OCFR961.11 Article VI.B.21 [CRD 3.2.1.1.A]

DOE/RW-0351P, rev.1, 3.7.3.2.6

Notification of Improperly Described Waste Prior to Acceptance into CRWMS 
(WA, Purchaser, Producer) If SNF and/or HLW is determined by WA to be improperly described prior to acceptance by DOE/OCRWM at the Purchaser/Producer site, WA shall promptly notify the Purchaser/Producer in writing. DOE/OCRWM reserves the right to refuse to accept improperly described waste. The Purchaser/Producer must not transfer title of improperly described SNF and/or HLW unless DOE/OCRWM agrees to accept title under other arrangements agreed to in writing by the parties. [Purchaser: 1OCFR961.11 Article VI.B.3(a)] [Producer: DOE/RW-0333P]

\section{DOE/RW-0351P, rev.1, 3.7.3.2.8}

Initial Inventory Reporting

(WA, Purchaser) A Material Balance Report (DOE/NRC Form-742) shall be completed and distributed reporting initial inventory. [10CFR72.76] [10CFR75.31] [10CFR75.32] [CRD 3.3.8.2C]

\section{DOE/RW-0351P, rev.1, 3.7.4.2.1}

Resolution of Improperly Described Waste After Acceptance into CRWMS

(WA, Purchaser, Producer) If subsequent to its acceptance, WA finds SNF and/or HLW is improperly described, WA shall promptly notify the Purchaser/Producer in writing of such a finding. In this event, the Purchaser/Producer must provide WA with a proper description within 30 days. In the event that the Purchaser/Producer fails to provide the proper description, DOE may hold in abeyance any and all further deliveries scheduled. [10CFR961.11 Article VI.B.3(b)] [DOE/RW-0333P]

\section{DOE/RW-0351P, rev.1, 3.9}

\section{QUALIFICATION/QUALITY ASSURANCE}

(WA, Purchaser, Producer) WA shall require the following of the Purchaser/Producer:

A. (Producer) The Producer shall establish, maintain, and execute a quality assurance program satisfying each of the applicable criteria of the DOE OCRWM Quality Assurance Requirements and Description (QARD), and satisfying any specific provisions which are applicable to WA activities. [DOE/RW-0333P]

B. (Producer) The Producer quality assurance program shall cover the activities from the time of waste form production through waste acceptance. [DOE/RW-0333P]

C. (Producer) The Producer shall prepare and maintain documentation sufficient to demonstrate canistered waste form compliance with the WA-SRD, WCP, and WQR as lifetime QA records. Copies of these records must be made available to the Federal Repository Operator at the time the repository is ready to begin accepting canistered waste forms from the Producer. Other documentation generated during preparation and implementation of the WCP and WQR must be collected and maintained as nonpermanent records. [DOE/RW-0333P]

D. (Purchaser, Producer) The Purchaser/Producer shall handle notification and disposition of 
Appendix D - Constraints Definitions

other-than-standard SNF and canisters of HLW in accordance with section 3.7.1.2.8. [1OCFR961.11 Article VI.A.2(b)][DOE/RW-0333P]

E. (Purchaser) The Purchaser shall have a quality assurance program approved by the Nuclear Regulatory Commission that satisfies the criteria in 10CFR50 Appendix B or other appropriate regulation. [1OCFR50 Appendix B] 
DOE/RW-0351P, rev.2, 3.7.1.2.1.2

HLW Specifications

(WA) WA shall accept standard and nonstandard HLW described in sections 3.7.1.2.1.2.1 and 3.7.1.2.1.2.3, respectively. [Derived]

Detailed design requirements are to be addressed in the WA Design Requirements Document.

\section{DOE/WIPP-069, rev.4 Waste Acceptance Criteria for Waste Isolation Pilot Plant}

Contractor waste certification shall be in accordance with this document.

\section{DOE/WIPP-069, rev.4, 3.1.3}

The RCRA regulations, as they apply to the WIPP, include Standards for the Owners/Operators of Treatment, Storage, or Disposal (TSD) facilities that are codified in 40 CFR Parts 264 and 265. These require the owner/operator to obtain a chemical and physical characterization of the waste, and ensure that the waste shipped to the facility is the waste specified on the shipping manifest. These RCRA requirements for the WIPP facility will be satisfied at the generator sites before transport of waste to the WIPP.

Sites may use process knowledge and/or sampling and analysis to characterize the hazardous component of their wastes. In addition, each site must characterize a statistically representative sample of its waste to demonstrate that it meets the requirements of the NMD. Sampling and analysis activities shall be detailed in the site Quality Assurance Project Plans, (QAPjP).

Waste generator and/or storage sites have the responsibility for collecting data that will be used to comply with the NMD. Headspace gas samples shall be collected and analyzed for total volatile organic compounds (VOCs) and toxic metals specified in the WAP contained in the WIPP RCRA Part B Permit Application.

For the waste generated or retrieved from storage during but not part of the test phase, the following criteria must be satisfied for a statistical population of packages:

- Real-time radiography or equivalent examination

- Radionuclide assay for total alpha activity

- Headspace analysis for inorganic and organic gases

- Visual examination of the waste

- Analysis of sludges for $\mathrm{pH}$ and major cations and anions.

\section{DOE/WIPP-069, rev.4, 3.2}

Waste containers for emplacement in the WIPP shall be noncombustible and meet all applicable requirements of 49 CFR /173.412 (Reference 14) for Type A packaging. Waste containers of various sizes, shown to meet Department of Transportation (DOT) Type A requirements by methods detailed in MLM 3245 (Reference 30) are acceptable at the WIPP. In addition, waste containers shall be used, 
handled and stored in a manner that is expected to maintain their Type A packaging specification from the time of certification to emplacement in the WIPP.

Remote-handled TRU waste containers shall be noncombustible and meet, as a minimum, the structural requirements and design conditions for Type A packaging as contained in 49 CFR/173.412. In addition, all RH-TRU waste containers shall be certified to the WIPP-approved specifications and shall be used, handled and stored in a manner that is expected to maintain their Type A packaging specification from the time of certification to emplacement in the WIPP.

\section{DOE/WIPP-069, rev.4, 3.2.2.6}

The maximum size of CH-TRU waste packages in the WIPP is limited by aces to the waste hoist and the size of the waste hoist cage. Existing packages of $\mathrm{CH}$-TRU waste that meet the criterion in Section 3.2.2.1 are:

- Standard 55-gal. (208-L) metal drum (DOT Spec. 17C and 17H)

- Standard 55-gal. (208-L) metal drum (DOT Spec. 6M)

- Rectangular metal box (74.4 X $50.5 \times 38.5$ in. LWH)

- Rectangular metal box ( $68 \times 54 \times 38.5$ in. LWH)

- Rectangular metal box ( 88 X 54 X 54 in. LWH)

- Rectangular metal box (71 X $57 \times 52.5$ in. LWH)

- Rectangular metal box (50.4 X $58.4 \times 72.4$ in. LWH)

- Rectangular metal box (4 X 4 X $7 \mathrm{ft}$. LWH)

- Standard waste box ( 37 in. high X 71 in. long OD/54.25 in. short OD X 45.06 in. side).

The TRUPACT-II limits the CH-TRU waste containers to 55-gallon drums, or SWBs. Other acceptable waste containers may be added in the future.

The RH-TRU waste package size is based on the handling of an overpacked RH canister in the WIPP transfer cask.

\section{DOE/WIPP-069, rev.4, 3.3.1.1}

Powders, ashes, and similar particulate waste materials shall be immobilized if more than 1 weight percent of the waste matrix in each package is in the form of particulate below 10 microns in diameter, or if more than 15 weight percent is in the form of particles below 200 microns in diameter.

\section{DOE/WIPP-069, rev.4, 3.3.2}

Liquid waste will not be placed in the WIPP. TRU waste for emplacement in the WIPP shall contain as little residual liquid as is reasonably achievable. All internal containers (e.g., bottles, cans, etc.) must be well-drained, but may contain residual liquids. As a guideline, residual liquid in well-drained containers will be restricted to approximately one percent of the volume of the internal container. In no case shall the total liquid equal or exceed one volume percent of the waste container (e.g., drum or SWB). Retrievably-Stored Waste Real-Time Radiography (RTR) or visual examination shall be used at DOE facilities to determine the presence and quantity of liquids in TRU wastes. Although some differences exist between the RTR equipment sensitivity at DOE sites, all facilities shall be able to certify TRU waste using RTR in accordance with the less than one volume percent liquid criterion for the external waste container. The RTR records shall include a description of the location of any liquid that is detected (e.g., between rigid 
liner and 55-gallon poly bag liner or within one gallon poly bottle) and an estimate of its volume.

\section{DOE/WIPP-069, rev.4, 3.3.2.2}

Waste for shipment in TRUPACT-II shall contain less than 1 volume percent of the waste container as liquids.

Same as TRUPACT-II requirements. (This requirement is anticipated based on initial negotiations with the NRC, but will not be finalized until review is complete and a $\mathrm{C}$ of $\mathrm{C}$ is issued.)

\section{DOE/WIPP-069, rev.4, 3.3.3.1}

\section{WIPP OPERATIONS AND SAFETY CRITERIA}

\section{Contact-Handled and Remote Handled Wastes}

Pyrophoric materials, other than radionuclides, shall be rendered safe by mixing them with chemically stable materials (e.g., concrete, glass) or shall be processed to remove their hazardous properties. Not more than one percent by weight of the waste in each waste container may be pyrophoric forms of radionuclides, and these shall be generally dispersed in the waste.

\section{DOE/WIPP-069, rev.4, 3.3.4.1}

Transuranic waste shall contain no explosives or compressed gases. 49 CFR Part 173 Subpart C (Reference 14) defines explosives and 49 CFR Part 173 Subpart G defines compressed gases.

\section{DOE/WIPP-069, rev.4, 3.3.4.5}

Documented procedures or RTR verifications are used to ensure that individual waste packages contain no pressurized vessels. Documented procedures are also used to exclude explosive items, compounds, or combination of materials that could form explosive compounds within the waste package. If such materials are present, they must be treated or diluted such that a detonation is not possible.

\section{DOE/WIPP-069, rev.4, 3.3.5}

\subsubsection{TRU MIXED WASTES}

\subsubsection{WIPP OPERATIONS AND SAFETY CRITERIA}

\section{Contact-Handled Waste}

Transuranic wastes shall contain no hazardous wastes unless they exist as co-contaminants with transuranics. Waste packages containing hazardous waste shall be identified with the appropriate DOT label. All TRU-contaminated corrosive, inactive, and ignitable materials shall be treated to remove the hazardous characteristic. Hazardous wastes to be reported are listed in 40 CFR 261, Subparts C and D 
(Reference 18).

Remote-Handled Waste

Transuranic wastes shall contain no hazardous wastes unless they exist as co-contaminants with transuranics. All TRU-contaminated corrosive, reactive, and ignitable materials shall be neutralized and rendered nonhazardous. Hazardous waste to be reported are listed in 40 CFR 261, Subparts C and D (Reference 18).

\subsubsection{TRANSPORTATION: WASTE PACKAGE REQUIREMENTS}

\section{TRUPACT-II Requirements}

Aqueous materials which have a pH less than 2 or more than 12.5 per 40 CFR 261.22(a)(1) are prohibited from the wastes (Reference 18).

RH Cask Requirements

Aqueous materials which have a pH less than 2 or more than 12.5 per 40 CFR 261.22(a)(1) (Reference 18) are prohibited from the wastes. (These are preliminary requirements based on meetings with the NRC and the SARP to be submitted for approval.)

\subsubsection{RCRA REQUIREMENTS}

RCRA - Waste Determination

Generators of TRU waste must determine whether their waste is regulated by RCRA as a hazardous waste. The determination is based on whether representative samples or process knowledge of the solid waste indicates that it is specifically identified or listed in 40 CFR Part 261 (Reference 18). Each hazardous waste must be assigned one or more of the applicable EPA hazardous waste codes. Only those waste codes included in the WIPP RCRA Part A Permit Application (Reference 19) can be managed at the WIPP. Wastes that exhibit the characteristics of Ignitability (DO01), Corrosivity (DO02), or Reactivity (DO03), as defined in 40 CFR 261 (Reference 18), will not be accepted at the WIPP.

WIPP RCRA Permit Aplication Reguirements and QAPjPs

The WAP included in the WIPP RCRA Part B Permit Application (Reference 20) specifles the waste analysis requirements applicable to the TRU mixed wastes to be shipped to WIPP. These include the specific sampling and analysis requirements specified in the NMD issued by the EPA. The QAPP (Reference 8) addresses analysis and sampling requirements to show compliance with the NMD criteria. The QAPjP establishes site-specific procedures for sampling and analytical protocols and QA/QC guidances for the WIPP Test Phase. The additional information required by 40 CFR 265.13 and 264.13 (Reference 18), such as test methods, sampling methods, frequency, and accuracy, are required to be addressed in the site-specific QAPjPs.

Waste generator and/or storage sites have the responsibility for sampling and analyzing headspace gases to demonstrate compliance with the waste characterization requirements in the NMD. The headspace gas samples shall be collected and analyzed in accordance with procedures specific in each site's QAPjP. The QAPP (Reference 8) contains a more detailed explanation of responsibilities for various 
Appendix D - Constraints Definitions

organizations involved in the waste characterization program. The waste characterization requirements of the NMD (Reference 23) are:

Headspace Gases

Flammability

See Section 3.4.7.3 for requirements.

Nonflammable VOCs (Comparability)

The NMD (Reference 23) mandates that any waste package that is sent to the WIPP must meet the requirement that the headspace concentration within a package does not exceed two times (2X) the maximum concentration for five nonflammable VOCS. This requirement is designed to ensure that the wastes to be emplaced in the WIPP are in fact similar to the wastes described in the NM-VP (Reference 22). The five nonflammable VOCs are:

Carbon Tetrachloride

Methviene Chloride

1,1,1-Trichioroethane

Trichloroethylene

1,1,2-Trichioro-1,2,2-trilluoroethane.

The five nonflammable compounds and their $2 \mathrm{X}$ maximum concentration limits are reported in the NMD (Reference 23) and the WAP in the WIPP RCRA Part B Permit Application (Reference 20), and the methodology for demonstrating compliance is presented in the QAPP (Reference 8).

Nonflammable VOCs (No-Migration Demonstration)

The NMD (Reference 23) mandates that any waste package that is sent to the WIPP must meet the requirement that the headspace concentration within a package does not exceed ten times $(10 \mathrm{X})$ the average concentration of three nonflammable VOCS.

(TWO of the five compounds listed above do not have to meet this requirement) The three nonflammable VOCs that must meet the requirement are:

Carbon Tetrachloride

Metbyiene Chloride

Trichloroethylene.

The three nonflammable compounds and their 10X average concentration are reported in the NMD (Reference 23) and the WAP in the WIPP RCRA Part B Permit Application (Reference 20), and the methodology for demonstrating compliance is presented in the QAPP (Reference 8).

\section{Sludges}

In addition to the headspace analyses specified above, sludges shall be analyzed for total VOCs and toxic metals specified in the WAP for the WIPP RCRA Part B Permit Application (Reference 20). Sampling and analysis procedures for VOCs and toxic metals in TRU sludges are being developed and, when 
Appendix D - Constraints Definitions

completed, the requirements will be included in the QAPP (Reference 8).

\subsubsection{PERFORMANCE ASSESSMENT CRITERIA}

No additional requirements.

\subsubsection{COMPLIANCE}

The types and quantities of hazardous wastes must be entered in the data package (Section 3.5.1.1). This information must be consistent with the acceptable EPA hazardous waste codes for WIPP as specified in the RCRA Part A Permit Application (Reference 19).

The basis for the identification of the hazardous wastes will be process knowledge supplemented with sampling.

\subsubsection{TECHNICAL JUSTIFICATION}

Transuranic mixed waste is defined as TRU waste that contains constituents considered hazardous in accordance with 40 CFR Part 261 (Reference 18). Because of the presence of hazardous constituents, the waste is subject to dual regulation under the AEA (Reference 21) and the RCRA (Reference 18). Dual regulation has made it necessary to make a RCRA hazardous waste determination for the purposes of manifesting for transportation, for reporting waste management activities, and for ensuring adequate health and safety programs. The DOE Order 5400.3 (Reference 33 ) requires the implementation of and compliance with the RCRA regulations.

Waste characterization data or other determinations made about the disposition of the waste shall be maintained for necessary audits.

\section{DOE/WIPP-069, rev.4, 3.3.6}

\subsubsection{SPECIFIC ACTIVITY OF WASTE}

\subsubsection{WIPP OPERATIONS AND SAFETY CRITERIA}

\section{Contact-Handled Waste}

For purposes of TRU waste certification, the lower limit of $>100$ nanocuries/gram $(\mathrm{nCi} / \mathrm{g})$ of TRU radionuclides in the waste shall be interpreted as $>100 \mathrm{nCi}$ per gram of waste matrix. The weight of added external shielding and the waste containers (including any rigid liners) shall be subtracted prior to performing the $\mathrm{nCi} / \mathrm{g}$ calculation. This is also applicable to wastes managed as TRU under the provisions of DOE Order 5820.2A (e.g., U-233 and Ra-226) (Reference 13).

\section{Remote-Handied Waste}

For purposes of TRU waste certification, the lower limit of $>100 \mathrm{nCi} / \mathrm{g}$ of TRU radionuclides in the waste shall be interpreted as $>100 \mathrm{nCi} / \mathrm{g}$ of waste matrix. The weight of added external shielding and the waste containers (including any rigid liners) shall be subtracted prior to performing the $\mathrm{nCi} / \mathrm{g}$ calculation. 


\section{Revision 1}

Appendix D - Constraints Definitions

The maximum activity concentration for a RH-TRU waste package shall not exceed 23 curies/liter.

The concentration may be averaged over the waste container.

\subsubsection{TRANSPORTATION: WASTE PACKAGE REQUIREMENTS}

TRUPACT-II Requirements

Same as WIPP Operations And Safety Criteria. Section 3.3.6.1.

\section{RH Cask Requirements}

Same as WIPP Operations And Safety Criteria, Section 3.3.6.1.

\subsubsection{RCRA REQUIREMENTS}

None.

\subsubsection{PERFORMANCE ASSESSMENT CRITERIA}

Same as WIPP Operations And Safety Criteria, Section 3.3.6.1.

\subsubsection{COMPLIANCE}

Documented evidence shall exist to show that the specific activity of any TRU waste package is greater than $100 \mathrm{nCi} / \mathrm{g}$ of waste and that the activity of RH-TRU waste does not exceed $23 \mathrm{Ci} /$ liter.

\subsubsection{TECHNICAL JUSTIFICATION}

The DOE Order 5820.2A "Radioactive Waste Management," Chapter II.3.a.(2), (Reference 13) states:

"The lower concentration limit for transuranic waste (>100 nCi/g of waste) shall apply to the contents of any single waste package at the time of assay. The mass of the waste container including shielding shall not be used in calculating specific activity of the waste."

The upper limit of RH-TRU waste activity arises from the WIPP Final Environmental Impact Statement (Reference 34).

\section{DOE/WIPP-069, rev.4, 3.4.1}

\subsubsection{WASTE PACKAGE WEIGHT}

\subsubsection{WIPP OPERATIONS AND SAFETY CRITERIA}

Contact-Handled Waste 
Appendix D - Constraints Definitions

All CH-TRU waste packages or package assemblies shall weigh no more than 21,000 pounds.

Remote-Handied Waste

All RH-TRU waste packages shall weigh no more than 8,000 pounds.

\subsubsection{TRANSPORTATION: WASTE PACKAGE REQUIREMENTS}

TRUPACT-II Requirements

The following weight limits shall apply for waste package assemblies transported in the TRUPACT-II package:

$1,000 \mathrm{lbs}$ per drum

$1,450 \mathrm{lbs}$ per drum overpacked in a SWB

4,000 lbs per SWB

7,265 lbs per TRUPACT-II payload

$19,250 \mathrm{lbs}$ per TRUPACT-II payload, including the weight of the TRUPACT-II.

Recent enhancements in the TRUPACT-II design have resulted in an average payload weight of approximately $6,200 \mathrm{lbs}$. The total weight of the top seven-pack of drums or SWB including error shall be less than or equal to the total weight including error of the lower seven-pack of drums or SWB. The DOT limit of $80,000 \mathrm{lbs}$ gross vehicle weight (GVW) must also be met.

RH Cask Requirements

To be determined.

\subsubsection{RCRA REQUIREMENTS}

None.

\subsubsection{PERFORMANCE ASSESSMENT CRITERIA}

None.

\subsubsection{COMPLIANCE}

For CH-TRU waste packages, documented evidence shall exist that the waste package has been weighed and the weight of the waste package or package assembly meets the requirements. The weight of the waste package cannot exceed the weight for which the waste package has been certified in accordance with 49 CFR 173.463 (Reference 14).

For RH-TRU waste, the canister weight may be calculated based on the weight of the empty canister plus the weight of waste that will be placed in the canister. The weight of the canister cannot exceed the weight for which the waste package has been certified in accordance with 49 CFR 173.463 (Reference 
14).

\subsubsection{TECHNICAL JUSTIFICAIION}

The CH-TRU waste handling system of the WIPP is limited by the capacity of the fork trucks that will transfer the CH-TRU waste materials on and off the waste hoist. These fork trucks have a rated lift capacity of 26,000 pounds. As this rated capacity must include an allowance for pallets and overpacks, estimated to be 5,000 pounds, a CH-TRU waste package may weigh a maximum of 21,000 pounds.

The WIPP has established a RH-TRU overpack gross weight limit of 10,000 pounds. It is estimated that a RH-TRU overpack may weigh 2,000 pounds, leaving a maximum gross weight of 8,000 pounds for the loaded RH canister.

The TRUPACT-II weight limits are based on the provisions of the TRUPACT-II SARP (Reference 9).

\section{DOE/WIPP-069, rev.4, 3.4.2}

Contact-Handled Waste

The fissile or fissionable radionuclide content of $\mathrm{CH}$-TRU waste packages shall be no greater than the following values, in Pu-239 fissile-gram equivalent:

- $200 \mathrm{~g}$ per 55-gallon $(0.21 \mathrm{~m} 3)$ drum

- $500 \mathrm{~g}$ per DOT $6 \mathrm{M}$ container

. $5 \mathrm{~g}$ per $\mathrm{ft} 3(0.028 \mathrm{~m} 3)$ in boxes, up to $350 \mathrm{~g}$ maximum.

The Pu-239 FGE shall be calculated using the methods detailed in Appendix 1.3.7 of the TRUPACT-II SARP (Reference 9).

\section{DOE/WIPP-069, rev.4, 3.4.2(R)}

Remote-Handled Waste

The fissile or fissionable radionuclide content of RH-TRU waste packages shall not exceed $600 \mathrm{~g}$ total (in Pu-239 FGE).

\section{DOE/WIPP-069, rev.4, 3.4.2.2}

The fissile or fissionable radionuclide content of CH-TRU waste in the TRUPACT-II, including two times the measurement error, shall be less than 200 grams for a 55-gallon drum or less than 325 grams for a SWB. The sum of the fissile equivalents of all waste packages in the entire payload quantity including two times the error may not exceed 325 grams. See the calculational methods detailed in Appendix 1.3.7 of the TRUPACT-II SARP for details.

\section{DOE/WIPP-069, rev.4, 3.4.3}

Waste Packages shall not exceed $1000 \mathrm{Ci}$ of Pu-239 equivalent activity (PE-Ci). 


\section{DOE/WIPP-069, rev.4, 3.4.4}

All RH-TRU waste packages shall have a surface dose rate at any point no greater than $1000 \mathrm{rem} / \mathrm{hr}$. Neutron contributions are limited to $270 \mathrm{mrem} / \mathrm{hr}$. Neutron contributions of greater than $20 \mathrm{mrem} / \mathrm{hr}$. to the total waste package dose rate shall be reported in the data package. At least $95 \%$ of the RH canisters must have dose rates of $<=100 \mathrm{rem} / \mathrm{hr}$, and no more than $5 \%$ of the RH canisters are allowed to have but $<=1000 \mathrm{rem} / \mathrm{hr}$ may be shipped to the WIPP.

\section{DOE/WIPP-069, rev.4, 3.4.5}

Removable surface contamination on waste packages or package assemblies to be emplaced in WIPP shall not be greater than 50 picocuries per $100 \mathrm{sq}$. cm for alpha-emitting radionuclides and 450 picocuries per $200 \mathrm{sq}$. $\mathrm{cm}$ for beta-gamma-emitting radionuclides. Fixation of surface contamination to meet the above criterion is not permitted.

\section{DOE/WIPP-069, rev.4, 3.4.6}

The thermal power generated by waste materials in any RH-TRU waste package shall not exceed 300 watts.

\section{DOE/WIPP-069, rev.4, 3.4.7}

Waste containers with waste that could potentially generate gases shall be vented.

\section{DOE/WIPP-069, rev.4, 3.5}

A data package with certification attesting to the fact that the waste package meets the requirements of these criteria shall be transmitted to the WIPP operator in advance of shipment. This data package/certification shall be based upon a QA program subject to audit and verification and shall proved information on the items specified below:

- Package identification number

- Package assemble identification number (if applicable)

- Date of waste package certification

-WAC exception number (if applicable)

- Waste generation site

- Date of package closure

- Maximum surface dose rate in $\mathrm{mrem} / \mathrm{hr}$ and specific neutron dose rate if greater than $20 \mathrm{mrem} / \mathrm{hr}$

- Weight (in kg)

- Container type

- Physical description of waste form (content code)

- Assay information, including PE-Ci, alpha Ci, and Pu-239 FGE content

- Radionuclide information including radionuclide symbol, quantity, and measure (in grams or Curies)

- Radioactive mixed waste (identity and quantity of listed wastes and those that exhibit the characteristics of a hazardous waste) 
- Weight and volume percent of organic materials content

- Measured or calculated thermal power (if over 0.1 watt/ft3)

- Shipment number

- Date of shipment

- Vehicle type

- TRUPACT-II number(s) (CH-TRU waste), or cask number (RH-TRU waste)

- Other information considered significant by the generator

- Name of certifying official who approved the waste package

- Name of person who certifies that the shipment meets the TRUPACT-II TRAMPAC

A hard copy of the signed and dated Certification Statement, certifying that the waste content and packaging are in accordance with the WIPP WAC and that the waste is unclassified, shall be maintained on file at each site for WACCC audits.

The specific data format for the transmittal of this information is contained in Appendix B of this document.

\subsubsection{TRANSPORTATION: WASTE PACKAGE REQUIREMENTS}

TRUPACT-II Requirements

The documentation required for the certification of an individual waste package or a group of waste packages for an individual TRUPACT-II is given in Section 13.0 of Appendix 1.3.7 of the TRUPACT-II SARP. The format of these tables is not mandatory, however, all listed parameters must be included in any site documentation. This documentation may be computer generated based on the site's waste data base.

RH Cask Requirements

To be determined.

\subsubsection{RCRA REQUIREMENTS}

A generator must prepare a specific hazardous waste manifest in accordance with the EPA requirements of $40 \mathrm{CFR} / 262.20$ through 262.23. A generator must also sign the certification on the manifest that indicates that the generator has a program in place to reduce the volume and toxicity of the waste generated. Identification numbers that link each RCRA-regulated waste container and its waste data package must also accompany the manifest. The identification numbers must be attached to the waste profile documentation. The Land Disposal Restriction (LDR) Certification required by the 40 CFR 268 must also accompany the manifest and data package.

\section{DOE4330.4B Maintenance Management Program}

The Maintenance management program for all DOE property be consistent with this Order and that all DOE property be maintained in a manner which promotes operational safety, worker health, environmental protection and compliance, property preservation, and cost-effectiveness while meeting the programmatic mission.

Structures, systems, and components that are important to safe operation shall be subject to a maintenance program in order to meet or exceed their design requirements throughout their life.

Periodic inspection of structures, systems, components, and equipment be performed to determine deterioration or technical obsolescence which threaten performance and/or safety.

\section{DOE460.1}


Appendix D - Constraints Definitions

Packaging and Transportation Safety

Onsite hazardous materials transfers shall comply with the Hazardous Materials Regulations, or the siteor facility-specific cognizant Operations or Field Office approved Transportation Safety Document that describes the methodology and compliance process to meet equivalent safety for any deviation from the Hazardous Materials Regulations. For multiple-tenant DOE sites, safety documents for several contractor organizations may be combined into a single document. DOE-operated sites (specifically, Morgantown and Pittsburgh Energy Technology Centers) may approve their own Transportation Safety Documents. Approved Transportation Safety Documents shall be in effect no later than 1 year from incorporation of this Order into the contractor's contracts.

\title{
DOE5400.5, Chapter II, 1.d Public Drinking Water
}

1(d) Taken together, site waste handling operations and all WHC site operations shall not affect public drinking water supply systems operated by DOE, its contractor(s), or a public or private entity in a manner to cause persons consuming the water to receive an effective dose equivalent greater than 4 mrem in a year. Combined radium-226 and radium-228 shall not exceed $5 \times 10-9$ micro $\mathrm{Ci} / \mathrm{ml}$, and gross alpha activity (including radium-226 but excluding radon and uranium) shall not exceed $1.5 \times 10-8 \mathrm{micro} \mathrm{i} / \mathrm{ml}$. The enabling assumption for TWRS Disposal operations is that the Low Level Waste disposal site public drinking water pathway does not receive any contribution from other site disposal facilities. TWRS LLW disposal operations shall be conducted so that a person consuming 2 liters of groundwater per day at the site boundary will not receive more than $4 \mathrm{mrem} /$ year EDE, nor will concentrations of radium and gross alpha in the groundwater exceed $5 \times 10-9 \mathrm{micro} \mathrm{Ci} / \mathrm{ml}$ and $1.5 \times 10-8 \mathrm{micro} \mathrm{Ci} / \mathrm{ml}$, respectively.

\section{DOE5400.5, Chapter II, 3.a(4)}

(a)(4) To prevent the buildup of radionuclide concentrations in sediments, liquid process waste streams containing radioactive material in the form of settleable solids may be released to natural waterways if the concentration of radioactive material in the solids present in the waste stream does not exceed $5 \mathrm{pCi}(0.2$ $\mathrm{Bq}$ ) per gram above background level, of settleable solids for alpha-emitting radionuclides or $50 \mathrm{pCi}$ (2 Bq) per gram above background level, of settleable solids for beta-gamma-emitting radionuclides.

DOE5400.5, Chapter II, section 1(a)

DOE Order 5400.5

RADIATION PROTECTION OF THE PUBLIC AND THE ENVIRONMENT

\author{
CHAPTER II
}

\section{REQUIREMENTS FOR RADIATION PROTECTION OF THE PUBLIC AND THE ENVIRONMENT}

1. PUBLIC DOSE LIMITS. Dose limits for members of the public are presented in this chapter. The primary public dose limits include consideration of all exposure modes from all DOE activities (including remedial actions). The primary dose limit is expressed as an effective dose equivalent, a term developed by the ICRP for their risk-based system, which requires the weighted summation of doses to various 
organs of the body. Additional public dose limits are established by EPA regulations for exposures to several selected sources or exposure modes (pathways or conditions). Public dose limits promulgated by EPA for selected exposure modes are sometimes expressed as dose equivalents, which do not include risk-based weighting or summation of doses to various organs, and sometimes expressed as effective dose equivalent. DOE must also comply with legally applicable requirements (e.g., 40 CFR Parts 61, 191, and 192 and 10 CFR Parts 60 and 72), including administrative and procedural requirements. Except for those provided in paragraph II.1a(4), administrative and procedural requirements of legally applicable regulations are not addressed in this Order. Such legally applicable regulations must be consulted for provisions not addressed in this Order.

a. DOE Public Dose Limit--All Exposure Modes, All DOE Sources of Radiation. Except as provided by II.1a(4), the exposure of members of the public to radiation sources as a consequence of all routine DOE activities shall not cause, in a year, an effective dose equivalent greater than 100 mrem ( $1 \mathrm{mSv})$. Dose evaluations should reflect realistic exposure conditions (see II.6b).

(1) Dose Components. The limit of $100 \mathrm{mrem}(1 \mathrm{mSv})$ effective dose equivalent in a year specified in paragraph II.1a is the sum of the effective dose equivalent (or deep dose equivalent, if dosimeter data are used) from exposures to radiation sources external to the body during the year plus the committed effective dose equivalent from radionuclides taken into the body during the year.

(2) Exposure Modes. Other than for sources specifically excepted, doses to members of the public from all exposure modes that could contribute significantly to the total dose shall be considered for evaluation. Requirements and methods for performing the evaluations are discussed in paragraph II.6.

(3) Application. The public dose limits in paragraph 11.1 a apply to doses from exposures to radiation sources from routine activities, including remedial actions and naturally occurring radionuclides released by DOE processes and operations. The dose limits also apply to the doses to individuals who are exposed to radiation or contamination by radionuclides at properties subsequent to remedial action and release of the property. Limits for radon and its decay products in air are provided in terms of Working Levels and concentrations in air and are addressed independently (Chapter IV and Figure III-1). In addition, DOE operators are required to report DOE-related effective dose equivalent contributions of 10 mrem $(0.10 \mathrm{mSv})$ or more in a year (see paragraph II.7).

(a) Doses from Sources Other than DOE Man-Made or Enhanced Natural Radionuclides. Except for medical sources, consumer products, residual fallout from past nuclear accidents and weapons tests, and naturally occurring radiation sources, DOE operators shall make a reasonable effort to be aware of the existence of other than DOE man-made sources of radiation which, combined with the DOE sources, might present a potential for exceeding contributions of $10 \mathrm{mrem}(0.1 \mathrm{mSv})$ effective dose equivalent in a year. Reasonable efforts shall be made to limit dose to members of the public, from multiple sources of radiation, to $100-\mathrm{mrem}(1 \mathrm{mSv})$ effective dose equivalent, or less, in a year. $\mathrm{EH}-1$ and the appropriate Headquarters Program Offices shall be notified if the 100-mrem in a year dose limit cannot be achieved.

(b) Doses Not Included in Evaluations. The public dose limits do not apply to doses from medical exposures, consumer products, and generally do not apply to doses from naturally occurring radiation sources or from exposures due to accident conditions, where controls of exposures cannot be maintained. The policy and requirements relating to protective actions following the uncontrolled release of radionuclides are set forth in the DOE 5500 series of directives. Requirements for planning to prevent or mitigate accidents and their effects are presented in DOE 5480.5 and DOE 5480.6. 
(c) Doses from Underground Nuclear Weapons Tests. The unanticipated release of radioactive material due to venting or seepage from underground nuclear weapons is considered to be an accident. However, the release of radioactive material that results from planned sampling or reentry following an underground nuclear weapons test is not an accidental condition, and shall be controlled in accordance with this standard.

(4) Exceptions. Unusual circumstances could affect a DOE activity in such a manner that the potential public dose could exceed an effective dose equivalent of 100 mrem $(1 \mathrm{mSv})$ in a year.

(a) Temporary Increases of Dose Limit. If avoidance of the higher exposures is impracticable, the Manager of the DOE Field Office, in coordination with their Program Office, may request, from EH-1, specific authorization for a temporary public dose limit higher than $100 \mathrm{mrem}(1 \mathrm{mSv})$, but not to exceed $500 \mathrm{mrem}(5 \mathrm{mSv})$, for the year. The temporary higher dose limit derives from ICRP recommendations (ICRP Publication 45) for a principal stochastic dose limit of $100 \mathrm{mrem}(1 \mathrm{mSv})$ effective dose equivalent in a year for exposures to the public, and a subsidiary dose limit of $500 \mathrm{mrem}$ ( 5 $\mathrm{mSv}$ ) effective dose equivalent in a year, for some years, if the dose averaged over a lifetime does not exceed the principal limit of $100 \mathrm{mrem}(1 \mathrm{mSv})$ effective dose equivalent per year. The specific sources excepted in paragraph II.1a(3)(b) are also excepted for II.1 a(4)(a).

\section{DOE5480.11 Radiation Protection for Occupational Workers}

The contractor radiation protection program for occupational workers shall include the requirements of, and be in accordance with, this Order.

\section{DOE5480.11, Chapter 0, 9.b}

b. The exposure of an Occupational worker to radiation resulting from routine DOE activities shall not cause the limiting values for assessed dose specified herein and summarized in Figure 1 to be exceeded. Continued exposure of any worker over a substantial portion of a working lifetime at or near the limiting values for assessed dose to individual workers should be avoided. (Note: Natural background and therapeutic and diagnostic medical exposures are not to be included in dose records or in assessment of dose against limiting values.)

(1) Stochastic Effects. The limiting value of annual effective dose equivalent from both internal and external sources received in any year by an occupational worker is 5 rem ( 0.05 sievert).

(2) Non-Stochastic Effects. The limiting value of annual dose equivalent received in any year by an Occupational worker, for individual organs and tissue is $15 \mathrm{rem}(0.15$ sievert $)$ to the lens of the eye or 50 rem $(0.5$ sievert) to any other organ, tissue (including the skin of the whole body), or extremity of the body.

(3) Unborn Child. The limiting value of annual dose equivalent received by the unborn child from the period of conception to birth (entire gestation period) as a result of occupational exposure of a female occupational worker, who has notified her employer in writing that she is pregnant, is $0.5 \mathrm{rem}(0.005$ sievert). Efforts should be made to avoid substantial variation above the uniform monthly exposure rate that would satisfy this limiting value. If the dose to the unborn child is determined to have already exceeded $0.5 \mathrm{rem}(0.005$ sievert) by the time a worker notifies her employer in writing of her pregnancy, the worker shall not be assigned to tasks where additional occupational exposure is likely. The limiting value of dose equivalent to the unborn and the assignment of female workers (who have declared pregnancy in writing to their employer) to tasks where additional occupational exposure is not likely 
does not create a basis for discrimination and should be achieved in conformance with the provisions of Title VII of the Civil Rights Act of 1964 [See Environmental Protection Agency (1) - pages 2829 and 2832 of Federal Register, Vol. 52, No. 17, 1987!!.

\section{DOE5480.11, Chapter 0, 9.e}

e. The effective dose equivalent received by any member of the public resulting from exposure during direct onsite access at a DOE facility shall not exceed a limiting value of 0.1 rem $(0.001$ sievert $)$ per year from the committed effective dose equivalent from internal irradiation plus the effective dose equivalent from any external irradiation. In addition, exposures shall not cause a dose equivalent to any tissue (including the skin and the lens of the eye) to exceed 5 rem ( 0.05 sievert) per year for any member of the public. Guidance for entry during emergency conditions is provided in paragraph $9 \mathrm{p}$ of this Order.

\section{DOE5480.11, Chapter 0, 9.f}

(f)(1) The annual effective dose equivalent to an individual shall be determined by summing the annual effective dose equivalents from internally deposited radionuclides and from external exposure to radioactive material and/or radiation generating devices resulting from DOE activities. When in-vivo and/or in-vitro measurements confirm the retention of radionuclides in the body, with respect to evaluating conformance with the limiting value for occupational exposure, the annual effective dose equivalent due to all radionuclides retained in the body from these intakes shall be assessed for as long as the annual effective dose equivalent is $10 \mathrm{mrem}$ or greater. Exposures to the skin, extremities, and lens of the eye are not included in the determination of the annual effective dose equivalent. For uniform external irradiation of the whole body, a weighting factor $(\mathrm{Wt})$ equal to one may be used. This whole body dose is to be measured in accordance with the provisions in paragraph $9 \mathrm{~g}(1)$. Non-uniform external and internal irradiation values of Wt for organs and tissues are defined in paragraph $8 \mathrm{e}(12)$. (2) Non-Uniform Exposure to Skin. For non-uniform exposures to skin from $x$ rays, beta radiation, or skin contamination, one of the following assessments shall be made and recorded:

(a) When the area of skin exposed is $>100 \mathrm{~cm} 2$ the maximum value of dose averaged over any area of $100 \mathrm{~cm} 2$ is to be assessed, recorded, and included in the annual skin (shallow) dose equivalent.

(b) When the area of skin exposed is $>10 \mathrm{~cm} 2$ but $<100 \mathrm{~cm} 2$ the dose equivalent to that tissue is to be determined by:

$$
\mathrm{H}=\mathrm{fD}
$$

where: $D$ is the maximum dose averaged over a $1 \mathrm{~cm} 2$ of skin and $f$ is the fraction of skin exposed compared to $100 \mathrm{~cm} 2$. In no case shall an " $\mathrm{fl}$ of $<0.1$ be used. This value of dose is to be recorded and included in the annual skin (shallow) dose equivalent.

(c) When the area of skin exposed is $<10 \mathrm{~cm} 2$ the maximum value of dose averaged over any $1 \mathrm{~cm} 2$ is to be assessed and recorded in the individual"'s occupational exposure history as a special entry but is not to be included in the annual skin (shallow) dose equivalent.

(3) Emergency or Accidental Exposures. When an occupational worker has been exposed to radiation in excess of the limits specified in this Order as a result of an unplanned or accidental situation, the decision to allow the worker to return to work in a radiological area shall be made by operating management based on advice from health physics and medical personnel and the concurrence of the worker and shall be subject to the approval of the DOE field organization manager. The dose received in an unplanned or accidental situation is to be documented in the radiation exposure record of the exposed individual 
pursuant to paragraph $9 \mathrm{~m}(2)$ and reported pursuant to DOE 5484.1. The operating contractor is to verify to the head of the responsible field organization that the conditions under which the emergency or accidental exposures were received have been eliminated. The resumption of operations following an emergency or accidental exposure in excess of the occupational limits specified in this Order shall be subject to the approval of the head of the responsible field organization. Investigations and reporting shall be conducted pursuant to DOE 5484.1 and DOE 5000.3.

(4) Air and Water Concentration Guides.

(a) Air. Derived air concentration (DAC) values for control of the workplace are given in Attachment 1 . They were derived from the ICRP Publication 30 values for committed effective dose equivalent values, translated to conventional U.S. units of rem and curie. The ICRP Publication 23 recommended annual inhalation volume for male workers ( $40 \mathrm{hr} / \mathrm{wk}, 50 \mathrm{wk} / \mathrm{yr}$ ) was assumed to be $2400 \mathrm{~m} \mathrm{3}$. The DAC values or other air concentration values shall not be used for the calculation of internal dose equivalent received by a worker except for unusual circumstances where bioassay data is unavailable or inadequate. (b) Water. Concentrations of radionuclides in drinking water in controlled areas shall not exceed the standards given in 40 CFR Part 141.

(5) Quality Factors. The dose equivalent limits specified in this chapter are expressed in terms of rem; this requires that the absorbed dose (expressed in rads) be multiplied by an appropriate quality factor (Q). The quality factors to be used for determining dose equivalent in rem are shown in Figures 2 and 3.

\section{RADIATION TYPE}

X-rays, gamma rays, positrons, electrons (including tritium beta particles)

Neutrons, $<=10 \mathrm{keV}$

Neutrons, $>10 \mathrm{keV}$

Protons and singly-charged particles of unknown energy with rest mass greater than one atomic mass unit

Alpha particles and multiple-charged particles (and particles of unknown charge) of unknown energy

\section{QUALITY FACTOR (Q)*}

* Where spectral data is sufficient to identify the energy of the neutrons, the $Q$ values in Figure 3 may be used.

Figure 2 Quality Factors

$\begin{array}{ccc}\begin{array}{c}\text { NEUTRON ENERGY } \\ \text { MeV }\end{array} & \text { Q[bar] } & \begin{array}{c}\text { NEUTRON } \\ \text { FLUX DENSITY } \\ \mathrm{cm}-2 \mathrm{~S}-1\end{array} \\ \begin{array}{c}2.5 \times 10-8 \text { (thermal) } \\ 1 \times 10-7\end{array} & 2 & 680 \\ 1 \times 10-6 & 2 & 680 \\ 1 \times 10-5 & 2 & 560 \\ \end{array}$




$\begin{array}{llll}1 \times 10-4 & 2 & 580 \\ 1 \times 10-3 & 2 & 680 \\ 1 \times 10-2 & 2.5 & 700 \\ 1 \times 10-1 & 7.5 & 115 \\ 5 \times 10-1 & 11 & 27 \\ 1 & 11 & 19 \\ 2.5 & 9 & 20 \\ 5 & 8 & 16 \\ 7 & 7 & 17 \\ 10 & 6.5 & 17 \\ 14 & 7.5 & 12 \\ 20 & 8 & 11 \\ 40 & 7 & 10 \\ 60 & 5.5 & 11 \\ 1 \times 102 & 4 & 14 \\ 2 \times 102 & 3.5 & 13 \\ 3 \times 102 & 3.5 & 11 \\ 4 \times 102 & 3.5 & 10\end{array}$

Mean quality factors, $\mathrm{Q},{ }^{*}$ and values of neutron flux density which, in 40 hours, result in a maximum dose equivalent of 100 mrem.

* Maximum value of $\mathrm{Q}$ in a 30 -cm dosimetry phantom.

Figure 3 Quality Factors for Neutrons

\section{DOE5480.11, Chapter 0, 9.j}

j. Radiation exposure rates in controlled workplace areas should be reduced to as low as reasonably achievable levels by proper facility design and control. The primary means for maintaining exposures as low as reasonably achievable are to be through physical controls, e.g., confinement, ventilation, remote handling, and shielding. Administrative controls and procedural requirements are to be considered supplemental means to achieve control.

(1) Design. During the design of facilities, the following objectives shall be applied:

(a) Optimization. Optimization principles, as discussed in ICRP Publication 37, are to be utilized in developing and justifying facility design and physical controls.

(b) External Radiation Exposure. The design objectives for personnel exposure from external sources of radiation in continuously occupied controlled areas are ALARA and not exceeding 0.5 mrem ( 5 microsieverts) per hour on average. The design objectives for exposure rates for potential exposure to a radiation worker where occupancy is generally not continuous are ALARA and not exceeding 20 percent of the applicable standard in paragraphs $9 \mathrm{~b}(1)$ and (2).

(c) Internal Radiation Exposure. As a design objective, exposure of personnel to inhalation of airborne radioactive materials is to be avoided under normal operating conditions to the extent reasonably achievable. This will normally be accomplished by confinement and ventilation.

(d) Maintenance. Decontamination, and Decommissioning. Ease of maintenance and decontamination and decommissioning is to be considered in facility design and selection of materials.

(2) Control. During routine operations, the combination of design and control procedures shall provide that, with respect to the radiological workplace, the anticipated magnitude of the prospective committed 
Appendix D - Constraints Definitions

effective dose equivalent from intakes plus any effective dose equivalent from external exposure will not exceed 5 rem ( 0.05 sievert) in a year, and the anticipated magnitude of the committed dose equivalent to any organ or tissue from intakes plus any dose equivalent from extemal exposure will not exceed 50 rems ( 0.5 sievert) in a year. Compliance with these requirements shall be demonstrated through appropriate workplace monitoring pursuant to the provisions of paragraph $9 \mathrm{~g}(3)$.

\section{DOE5480.19}

\section{Conduct of Operations Requirements for DOE Facilities}

It is the policy of the Department that the conduct of operations at DOE facilities be managed with a consistent and auditable set of requirements, standards, and responsibilities. Effective implementation and control of operating activities are primarily achieved by establishing written standards in Operations, periodically monitoring and assessing performance, and holding personnel accountable for their performance. The Conduct of Operation Manual includes specific areas that must be considered.

\section{DOE5480.20A Personnel Selection, Qualification, and Training}

Management and operating contractors shall:

1. Implement the requirements of DOE5480.20A as they apply to the facility and the position;

2. Prepare and submit a Training Implementation Matrix to the Operations Office Manager for review and approval;

3. Prepare and submit procedures which establish the requirements for granting exceptions to specific training or qualification requirements for an individual to the Operations Office Manager for review and approval;

4. Provide written requests for certification extensions to the Operations Office Manager for approval;

5. Prepare and submit an assessment of the need for a simulator to the Operations Office Manager for review and approval (Category $\mathrm{A}$ test and research reactors only); and

6. Perform periodic systematic evaluations of training and qualification programs.

\section{DOE5480.21, Unreviewed Safety Questions}

In accordance with this Order, a contractor authorized to operate DOE nuclear facilities shall:

1) Perform all safety evaluations required by paragraph (b) of this section to determine whether a situation involves USQ;

2) Prior to implementation of a proposed action, obtain PSO approval for situations determined to involve a USQ or a Technical Safety Requirements (TSR) change; and

3) Develop and implement procedures to govern the need for, and the performance of, safety evaluations under this section.

DOE5480.22, Technical Safety Requirements 
In accordance with this Order, a contractor responsible for the operation of a DOE nuclear facility shall:

1) prepare Technical Safety Requirements for the facility;

2) submit the Technical Safety Requirements to the PSO for approval; and

3) operate the facility in accordance with the Technical Safety Requirements as approved by the PSO including any modificatin by the PSO.

\section{DOE5480.23, 8 Perform Safety Analysis}

8. REQUIREMENTS. A contractor, as designated in writing by the PSO, who is responsible for the design, construction, or operation of DOE nuclear facilities shall be required to perform a safety analysis that develops and evaluates the adequacy of the safety basis for each such facility. The safety basis to be analyzed shall include management, design, construction, operation, and engineering characteristics necessary to protect the public, workers, and the environment from the safety and health hazards posed by the nuclear facility or nonfacility nuclear operations. All contractors shall be held responsible for adhering to assumptions and commitments set forth in the safety analysis. Contractors shall be required to prepare, and shall submit to DOE for its approval, SARs documenting safety analyses for each DOE nuclear facility under their cognizance. Contractors responsible for conducting one or more nonfacility nuclear operations are required to maintain up to date analyses of the safety of such operations and analyses documented in a form that is auditable by DOE. Attachment I provides guidance in greater detail than the requirements of this Order.

a. Graded Approach for the Level of Analysis.

(1) Justification for the level of analyses and documentation for each hazard considered shall be provided as part of the plan and schedule submitted in accordance with paragraph $9(\mathrm{~b})(2)$ of this Order. The level of analysis and documentation for each facility must be commensurate with:

(a) The magnitude of the hazards being addressed;

(b) The complexity of the facility and/or systems being relied on to maintain an acceptable level of risk; and

(c) The stage or stages of the facility life cycle for which DOE approval is sought.

(2) This application of the graded approach is specific for the SAR.

b. Scope and Content of Safety Analysis Reports.

(1) SARs shall define the safety basis, document the logic of its derivation, demonstrate adherence to the safety basis, and justify its adequacy.

(2) Each SAR required by this Order shall include thorough documentation of the assumptions employed in the safety analysis. 
(3) A SAR shall include the results of the safety analysis that identifies the dominant contributors to the risk of the facility so that these vulnerabilities can be better managed. The safety analysis report shall address the following topics:

(a) Executive summary;

(b) Applicable statutes, rules, regulations and Departmental Orders;

(c) Site characteristics;

(d) Facility description and operation, including design of principal structures, components, all systems, engineered safety features, and processes;

(e) Hazard analysis and classification of the facility;

(f) Principal health and safety criteria;

(g) Radioactive and hazardous material waste management;

(h) Inadvertent criticality protection;

(i) Radiation protection;

(j) Hazardous material protection;

(k) Analysis of normal, abnormal, and accident conditions, including design basis accidents; assessment of risks; consideration of natural and manmade external events; assessment of contributory and casual events, mechanisms, and phenomena; and evaluation of the need for an analysis of beyond-design-basis accidents; however, the SAR is to exclude acts of sabotage and other malevolent acts since these actions are covered under security protection of the facility.

(1) Management, organization, and institutional safety provisions;

(m) Procedures and training;

(n) Human factors;

(o) Initial testing, inservice surveillance, and maintenance;

(p) Derivation of TSRs;

(q) Operational safety;

(r) Quality assurance;

(s) Emergency preparedness;

(t) Provisions for decontamination and decommissioning; and 
(u) Applicable Facility design codes and standards.

c. Hazard Classification for Nuclear Facilities and Operations. Contractors shall be required to perform a hazard analysis of their nuclear activities and classify their processes, operations, or activities in accordance with the following requirements:

(1) Classification Categories. The consequences of unmitigated releases of radioactive and/or hazardous material shall be evaluated and classified by the following hazard categories:

(a) Category 1 Hazard. The hazard analysis shows the potential for significant off site consequences.

(b) Category 2 Hazard. The hazard analysis shows the potential for significant onsite consequences.

(c) Category 3 Hazard. The hazard analysis shows the potential for only significant localized consequences.

(2) Inventory of Hazardous Materials. The hazard analysis shall be based on an inventory enveloping all radioactive and nonradioactive hazardous materials that are stored, utilized, or may be formed within a nuclear facility.

(3) Evaluation of Potential Releases. The hazard analysis shall identify energy sources or processes that might contribute to the generation or uncontrolled release of hazardous materials. The hazard analysis shall estimate the consequences of accidents in which the facility or process and/or materials in the inventory are assumed to interact, react, or be released in a manner to produce a threat or challenge to the health and safety of individuals on site and off site.

(4) Submission of Hazard Analysis to DOE. The hazard analysis shall be submitted to DOE for approval in accordance with the safety analysis plan and schedule required by paragraph $9(\mathrm{~b})(2)$ of this Order.

d. Document Control. Contractors with the primary responsibility for the design, construction, operation, or decommissioning of DOE nuclear facilities must maintain such document control as may be necessary to ensure that all users of SARs and their supporting documentation designated by DOE or the contractor as authorized users, including DOE line management and the Department's safety oversight groups, have current editions.

\section{DOE5480.24, Nuclear Criticality Safety}

The contractor criticality safety program for nuclear facilities shall include the requirements of, and be in accordance with, this Order.

\section{DOE5480.28, Natural Phenomena Hazards Mitigation}

The TWRS facilities and equipment shall comply with the DOE Order 5480.28, "Natural Phenomena Hazards Mitigation" policy of the DOE to design, construct, and operate DOE facilities so that workers, 
the general public, and the enviroment are protected from the impacts of natural phenomena hazards on DOE facilities. The seismic guidance of the National Earthquake Hazards Reduction Program (NEHRP) contained in the Interagency Committee of Seismic Safety in Construction (ICSSC), reports (RP-1 and RP-3), shall be used. Recent evaluations under the NEHRP studies have found that the standards used by DOE for DESIGN and evaluation of buildings to by "substantially equivalent" to the NEHRP provisions required by the Executive Order (E.O.) on Seismic Safety (E.O. 12699 dated 1-5-90) and substantially more conservative for levels of design beyond those judged acceptable for life safety.

\section{DOE5480.4, Environmental Protection, Safety and Health Protection}

The Purpose of this Order is to specify and provide requirements for the application of the mandatory environmental protection, safety, and health (ES\&H) standards applicable to all Department of Energy (DOE) and DOE contractor operations, to provide a listing of reference ES\&H standards; and to identify the sources of the mandatory and reference ES\&H standards. This Order shall be followed during facility design, construction, operation, modification, and decommissioning.

\section{DOE5480.7A, Fire Protection}

In accordance with this Order and, as required by the PSO or the Heads of Field Organizations and directed by the Contracting Officer, contractors shall be required to:

1) Provide and maintain a level of fire protection to meet the objectives of paragraph 4 , and the criteria of paragraph 9.

2) Provide and maintain a system to ensure that the requirements of the DOE fire protection program are documented and incorporated in the plans and specifications for all new facilities and for major modifications of existing facilities. This includes review and comment by a qualified fire protection engineer of plans, specifications and test procedures and results for fire protection features.

3) Assist DOE in coordinating fire safety assessments at those facilities included in the survey program, establish action plans for compliance with recommendations resulting from the assessments, and forward compliance plans, exemption requests, and other requested data to DOE field organizations.

4) Establish and maintain a list of facilities for which the contractor has fire protection assessment responsiblity.

5) Conduct fire protection assessments of facilities according to the scope and frequency established by this Order.

6) Provide fire protection technical assistance to $D O E$.

7) Submit requests for exemptions and fire safety equivalencies to the Head of the Field Organization for those facilities where compliance with specific program elements is not attainable and where an acceptable level of safety has been achieved.

8) Maintain or have access to an adequate fire protection staff, including a qualified fire protection 
engineer(s). Continuing education and training should be provided to maintain and enhance the level of competency of the fire protection staff.

\section{DOE5483.1A Occupational Safety and Health Program for DOE Contractor}

The Contractor shall comply with the DOE Order 5483.1 A to ensure that the required occupational safety and health programs are functioning satisfactorily. (Note: This order was cancelled January 1995 and will be replaced with DOE Order 440.1 "Worker Protection Management" after transition is complete and after appropriate supercedure analysis is complete.)

\section{DOE5700.6C, Quality Assurance}

For non-nuclear operations and activities the contractor shall comply with the requirements of DOE5700.6C. This Order establishes quality assurance requirements for the DOE.

\section{DOE5820.2A Radioactive Waste Management}

The contractor management of radioactive and mixed waste and contaminated facilities shall include the requirements of, and be in accordance with, this Order.

\section{DOE5820.2A, Chapter I, 3.a(1)(a)}

(a) Design objectives for new facilities will assure protection of the public and operating personnel from hazards associated with normal high-level waste operations, accident conditions, and the effects of natural phenomena. Other objectives are compliance with DOE policies regarding nuclear safety, quality assurance, fire protection, pollution control, and safeguards and security protection for high-level waste and protection of essential operations from the effects of potential accidents.

\section{DOE5820.2A, Chapter I, 3.a(1)(b)}

(b) Designs for new storage and treatment facilities shall meet the requirements of DOE 6430.1, applicable EM Orders and 40 CFR 264.

\section{DOE5820.2A, Chapter I, 3.a(1)(c)}

(c) Designs for new storage facilities shall incorporate features to facilitate retrieval capability.

\section{DOE5820.2A, Chapter I, 3.a(2)}

(2) Design Review for Existing Facilities. Uniform requirements for the preparation of safety analysis reports for high-level waste operations, detailed in DOE $5481.1 \mathrm{~B}$, include the review of existing operational facilities based on current technical criteria. When hazards are identified that should be 
eliminated, controlled, or mitigated, appropriate upgrading, actions in accordance with paragraph 3a(1) above, shall be identified and implemented according to the requirements of DOE 5481.1B.

\section{DOE5820.2A, Chapter I, 3.b(1)(a)}

(a) Liquid and solidified high-level waste shall be characterized consistent with radiation protection requirements to determine its hazardous components, per 40 CFR 261 and 40 CFR 264. Characterization shall satisfy requirements of paragraph $3 \mathrm{~b}(1)(\mathrm{b})$ and may reflect knowledge of waste generating processes, laboratory testing results, and/or the results of periodic sampling and analysis. Examples of required information are chemical composition, physical properties, radionuclide concentrations, and $\mathrm{pH}$.

\section{DOE5820.2A, Chapter I, 3.b(1)(b)}

(b) Waste characteristics and compatibility information shall be documented in a safety analysis report (see DOE 5481.1B) and be used as a basis for designing new facilities.

DOE5820.2A, Chapter I, 3.b(2)(a)

(b)(2)(a) All new high-level waste handling, transfer, and storage facilities (e.g., tanks, bins, pipelines, and capsules) shall be doubly contained.

\section{DOE5820.2A, Chapter I, 3.b(2)(b)}

(b)(2)(b) Singly contained pipelines may be used routinely for liquid waste that has a total radioactivity concentration of less than $0.05 \mathrm{Ci} / \mathrm{gal}(4.9 \times 10 / 11 \mathrm{~Bq} / \mathrm{m} 3)$. They may be used on a temporary basis for higher activity waste, if appropriate design and administrative controls are in place to mitigate adverse effects from a pipeline failure.

\section{DOE5820.2A, Chapter I, 3.b(2)(c)}

(b)(2)(c) Leaking waste storage systems shall not be used to receive waste unless secondary containment is maintained (e.g., liquid level maintained below leak point) and it can be shown with the support of formal documentation (e.g., Safety Analysis Reports, Operational Safety Requirements, Operating Standards) that temporary operation can be performed without releasing radioactive liquid to the environment.

\section{DOE5820.2A, Chapter I, 3.b(2)(d)}

(b)(2)(d) Secondary containment systems shall be capable of containing liquids that leak into them from the primary system and shall be equipped with transfer capability to retrieve the leaked liquid.

Secondary containment systems for solidified high-level waste shall provide for physical isolation of the waste from the environment. 


\section{DOE5820.2A, Chapter I, 3.b(2)(e)}

(b)(2)(e) To the extent practical, waste shall be segregated by type (sludge, salt, high activity, and low activity) to make accessibility for future processing easier.

\section{DOE5820.2A, Chapter I, 3.b(2)(f)}

(b)(2)(f) Where required, ventilation and filtration systems shall be provided to maintain radionuclide releases within the guidelines specified in DOE 5481.1B and applicable EM Orders. Ventilation systems shall be provided where the possibility exists for generating flammable and explosive mixtures of gases (e.g., hydrogen/air or organic/air).

\section{DOE5820.2A, Chapter I, 3.b(2)(g)}

(b)(2)(g) Facilities using cathodic corrosion protection systems shall include engineered features that protect against abnormal conditions such as stray currents or system failure. The cathodic protection systems shall be calibrated annually, and all sources of impressed current shall be inspected and/or tested at least every other month.

\section{DOE5820.2A, Chapter I, 3.b(2)(h)}

(h) Engineering controls shall be incorporated to provide liquid volume inventory data and to prevent spills, leaks, and overflows from tanks or containment systems. Examples are level-sensing devices, liquid level alarms, and maintenance of sufficient freeboard. The high-level waste shall be stored at pressures lower than those of ancillary systems (e.g., cooling water).

\section{DOE5820.2A, Chapter I, 3.b(2)(i)}

(b)(2)(i) Nuclear criticality safety considerations and controls shall be evaluated for normal operations and, before any significant operational changes are made, to protect against an uncontrolled nuclear criticality incident (e.g., dissolution of sludges for removal from tank).

\section{DOE5820.2A, Chapter I, 3.b(2)(j)}

(b)(2)(j) Each facility shall utilize remote maintenance features and other appropriate techniques to minimize personnel radiation exposure in accordance with DOE 5481.1B.

\section{DOE5820.2A, Chapter I, 3.b(2)(k)}

(b)(2)(k) Upon loss and subsequent recovery of normal electrical power, high-level waste transfer equipment shall not have the capability to restart without active operator action. 


\section{DOE5820.2A, Chapter I, 3.b(3)(a)}

$b(3)$ (a) Monitoring and leak detection capability shall be incorporated in the engineering systems (e.g., liquid level sensing devices and alarms for high-level waste liquid systems) to provide rapid identification of failed containment, and measurement of abnormal temperatures. The following, at a minimum, shall be monitored; temperature; pressure; radioactivity in ventilation exhaust; and liquid effluent streams associated with high-level waste facilities. Where the possibility exists for the generation of flammable and explosive mixtures of gases, monitoring shall be conducted. For facilities storing liquid high-level waste, the following should also be monitored: liquid levels; sludge volume; tank chemistry; condensate and cooling water.

\section{DOE5820.2A, Chapter I, 3.b(3)(b)}

$b(3)(b)$ Leak detection systems (e.g., conductivity probes) shall be designed and operated so that they will detect the failure of the primary containment boundary, the occurrence of waste release, or accumulated liquid in the secondary containment system.

\section{DOE5820.2A, Chapter I, 3.b(3)(c)}

b(3)(c) A method for periodically assessing waste storage system integrity (e.g., coupons for corrosion testing, photographic and periscopic inspections, leak detectors, liquid level devices) shall be established, documented, and reported as required in the Waste Management Plan.

\section{DOE5820.2A, Chapter I, 3.b(3)(d)}

$\mathrm{b}(3)$ (d) Electrical monitoring and leak detection devices essential to safe operations shall be provided with backup power, as appropriate, to ensure operability under emergency conditions.

\section{DOE5820.2A, Chapter I, 3.b(3)(e)}

b(3)(e) Surface water systems associated with the high-level waste storage area shall be monitored according to applicable National Pollution Discharge Elimination System permits and EM Order requirements.

\section{DOE5820.2A, Chapter I, 3.b(3)(f)}

$\mathrm{b}(3)(\mathrm{f})$ A system of ground water or vadose zone monitoring wells meeting the Resource Conservation and Recovery Act requirements per 40 CFR 264 shall be installed, as a minimum, around clusters of liquid waste storage tanks.

DOE5820.2A, Chapter I, 3.b(4)(a) 
(4) Contingency Actions.

(a) A tank or secondary containment system from which there has been a leak or a spill to the surrounding soil, or which is otherwise unfit for use, shall be removed from service until conditions can be evaluated fully.

\section{DOE5820.2A, Chapter I, 3.b(4)(b)}

(b) Upon detection of released radioactive materials, steps shall be taken to prevent further migration of the release to soil or surface water. Major contamination in the soil shall be removed or stabilized unless compliance with this requirement would cause greater harm to human health or the environment.

\section{DOE5820.2A, Chapter I, 3.b(4)(c)}

(c) If a release results from a spill and the integrity of the system is not damaged, the system may be returned to service as soon as action to correct the condition is completed.

\section{DOE5820.2A, Chapter I, 3.b(4)(d)}

(d) For emergency situations involving liquid high-level waste, spare capacity with adequate heat dissipation capability shall be maintained to receive the largest volume of liquid contained in any one tank. Adequate transfer pipelines also shall be maintained in operational condition. Interconnected tank farms with adequate transfer capabilities and spare capacity may be considered as a single tank farm for purposes of this requirement.

\section{DOE5820.2A, Chapter I, 3.b(4)(e)}

(e) A schedule and procedure shall be developed for monitoring, surveillance, and calibration checks. The frequency of these activities shall be based on the potential rate of equipment deterioration and the possibility of an environmental or human health incident, assuming that a malfunction from equipment failure or human error is not detected between checks. Schedules, procedures, and performance requirements shall be documented in the operating and maintenance documentation.

\section{DOE5820.2A, Chapter I, 3.b(4)(f)}

(f) Each high-level waste facility shall have response procedures for credible emergencies, as identified in the Safety Analysis Reports.

\section{DOE5820.2A, Chapter I, 3.b(5)}

b. Storage Operations - Doubly Contained Systems.

(5) Training. 
(a) Operator training and qualification standards shall be developed and an up-to-date record of training status shall be maintained.

(b) Worker safety training must comply with the requirements of DOE 5480.1B and applicable EM Orders.

\section{DOE5820.2A, Chapter I, 3.b(6)}

b. Storage Operations - Doubly Contained Systems.

(6) Quality Assurance. Consistent with DOE Order 5700.6B, high-level waste operations shall be conducted in accordance with applicable requirements of the American National Standards Institute/American Society of Mechanical Engineers Nuclear Quality Assurance-1 and other appropriate national consensus standards. (See Attachment 1, page 5, paragraph 48).

\section{DOE5820.2A, Chapter I, 3.b(7)(a)}

(b)(7)(a) For the purpose of economy and enhancing the safety of high-level waste storage, processing programs shall be developed and implemented at the generating site to reduce the quantity of waste being sent to storage, and techniques (e.g., evaporation) shall be implemented to reduce further the waste volume in storage.

\section{DOE5820.2A, Chapter I, 3.b(7)(c)}

(b)(7)(c) The chemistry of liquid high-level waste shall be adjusted to control corrosion within design limits for the storage system.

This DOE requirement is not invoked for Functions 4.2.3.4 and 4.2.3.5.

\section{DOE5820.2A, Chapter I, 3.b(7)(d)}

(b)(7)(d) Treatment reagents shall not be placed in a tank system without proven effective mitigative action if they could cause the tank, its ancillary equipment, or the containment system to rupture, leak, or otherwise fail.

This DOE requirement is not invoked for Functions 4.2.3.4 and 4.2.3.5.

\section{DOE5820.2A, Chapter I, 3.b(7)(e)}

(e) Waste generation and waste management systems that significantly change the chemical and physical forms of the waste shall be technically assessed to assure compatibility and retrievability. 
Appendix D - Constraints Definitions

This DOE requirement is not invoked for Functions 4.2.3.4 and 4.2.3.5.

\section{DOE5820.2A, Chapter I, 3.c(1)}

(c)(1) Waste Characterization. The contents of singly contained tank systems shall be characterized consistent with radiation protection requirements and the needs associated with safe storage to determine its hazardous components consistent with 40 CFR 261, 40 CFR 264, and State requirements.

Characterization may reflect knowledge of waste generating processes, laboratory testing results, and/or the results of periodic sampling and analysis.

\section{DOE5820.2A, Chapter I, 3.c(2)(a)}

(c)(2)(a) Singly contained tank systems shall not be used to store fresh high-level waste from fuel reprocessing operations except under emergency conditions as determined by the Operations Office Manager.

\section{DOE5820.2A, Chapter I, 3.c(2)(b)}

(c)(2)(b) Storage and transfer operations shall be conducted within the limits defined in the Safety Analysis Reports according to DOE 5481.1B.

\section{DOE5820.2A, Chapter I, 3.c(2)(c)}

(c)(2)(c) Engineered systems shall be incorporated to provide waste volume inventory data, consistent with the nature of the specific waste stored in singly contained tanks. Examples are surface level sensing devices and interstitial liquid level sensing devices.

\section{DOE5820.2A, Chapter I, 3.c(2)(d)}

(c)(2)(d) Singly contained pipelines: (see paragraph $3 b(2)(b)$ ).

\section{DOE5820.2A, Chapter I, 3.c(2)(e)}

(c)(2)(e) Where active ventilation is required, systems shall be provided to maintain radionuclide releases at the point of discharge within the guidelines specified in applicable EH Orders for offsite concentrations and DOE 5480.1B for onsite dose commitment considerations.

\section{DOE5820.2A, Chapter I, 3.c(2)(f)}

(c)(2)(f) Nuclear criticality safety (see paragraph $3 b(2)(i))$. 
Appendix D - Constraints Definitions

DOE5820.2A, Chapter I, 3.c(2)(g)

(c) (2) (g) Each facility shall use remote maintenance features and other appropriate techniques to maintain personnel radiation exposure as low as reasonably achievable.

DOE5820.2A, Chapter I, 3.c(2)(h)

$(c)(2)(h)$ Electrical power loss (see paragraph $3 b(2)(k))$.

DOE5820.2A, Chapter I, 3.c(3)(a)

(c)(3)(a) Monitoring and surveillance capability shall exist to provide liquid volume, waste inventory data, and identification of failed containment.

DOE5820.2A, Chapter I, 3.c(3)(b)

(c)(3)(b) A method for periodically assessing waste storage tank integrity (e.g., coupons, photographic inspections, leak detectors, liquid level devices) shall be established and documented.

DOE5820.2A, Chapter I, 3.c(3)(c)

(c)(3)(c) Emergency power (see paragraph $3 b(3)(d))$.

DOE5820.2A, Chapter I, 3.c(3)(d)

(c)(3)(d) Monitoring wells (see paragraph 3b(3)(f)).

DOE5820.2A, Chapter I, 3.c(4)

(c)(4) Contingency Action.

(a) A contingency action plan shall be maintained to respond to spills or leaks and other credible emergencies as identified in the Safety Analysis Reports.

(b) Leak mitigation (see paragraph $3 b(4)(b)$ ).

(c) For emergency situations involving pumpable liquid in singly contained tanks, appropriate equipment (e.g., pumps) shall be maintained to provide removal of liquid.

DOE5820.2A, Chapter I, 3.c(4)(a)

(c)(4)(a) A contingency action plan shall be maintained to respond to spills or leaks and other credible 
emergencies as identified in the Safety Analysis Reports.

DOE5820.2A, Chapter I, 3.c(4)(b)

(c)(4)(b) Leak mitigation (see paragraph 3b(4)(b)).

\section{DOE5820.2A, Chapter I, 3.c(4)(c)}

(c)(4)(c) For emergency situations involving pumpable liquid in singly contained tanks, appropriate equipment (e.g., pumps) shall be maintained to provide removal of liquid.

DOE5820.2A, Chapter I, 3.c(5)

(c)(5) Training. (See paragraphs $3 b(5)(a)$ and (b)).

DOE5820.2A, Chapter I, 3.c(6)

(c)(6) Quality Assurance. (See paragraphs 3b(6)(a)).

\section{DOE5820.2A, Chapter I, 3.d}

(d) Disposal. New and readily retrievable waste shall be processed and the high-level waste fraction disposed of in a geologic repository according to the requirements of the Nuclear Waste Policy Act of 1982 (Public Law 97-425) as amended. Options for permanent disposal of other waste, such as single shell tank waste, shall be evaluated and include such methods as in-place stabilization as well as retrieval and processing, as required for new and readily retrievable waste. Analytic predictions of disposal system performance shall be prepared and incorporated in the National Environmental Policy Act process.

(1) New and Readily Retrievable. New and readily retrievable existing high-level waste shall be processed to a final immobilized form in facilities such as the Defense Waste Processing Facility and the Hanford Waste Vitrification Plant preparatory to permanent disposal in a deep geologic repository.

(a) Waste acceptance specifications and criteria based upon the requirements outlined in $10 \mathrm{CFR} 60.113$, 10 CFR 60.131(b)(7), 10 CFR 60.135, 10 CFR 71.8, and 40 CFR 191 shall be developed for high-level waste forms prior to startup of facilities that generate the disposal waste form. Specifications and criteria shall be approved by RW-20 and DP-12 for Defense Programs high-level waste forms and by RW-20 and NE-20 for West Valley Demonstration Project product. As examples, specifications and criteria for the Defense Waste Processing Facility vitrified high-level waste form are documented in DOE/RW-0125; those for the West Valley Demonstration Project high-level waste form are documented in DOE/RW-0136.

(b) Interim storage for solidified high-level waste awaiting transport to the designated geologic repository shall comply with applicable requirements in paragraph 36 . 
(2) Other Waste. High-level waste that is not readily retrievable shall be monitored periodically in site. Field offices shall reevaluate the safety of such waste to determine the need for corrective measures as necessary. Options for permanent disposal of singly contained tank waste shall be evaluated and include such methods as in-place stabilization as well as retrieval and processing, as required for new and readily retrievable waste in paragraph $3 \mathrm{~d}(1)$.

\section{DOE5820.2A, Chapter I, 3.d(1)}

(d)(1) New and Readily Retrievable. New and readily retrievable existing high-level waste shall be processed to a final immobilized form in facilities such as the Defense Waste Processing Facility and the Hanford Waste Vitrification Plant preparatory to permanent disposal in a deep geologic repository.

\section{DOE5820.2A, Chapter I, 3.d(1)(a)}

(d)(1)(a) Waste acceptance specifications and criteria based upon the requirements outlined in $10 \mathrm{CFR}$ 60.113, 10 CFR 60.131(b)(7), 10 CFR 60.135, 10 CFR 71.8, and 40 CFR 191 shall be developed for high-level waste forms prior to startup of facilities that generate the disposal waste form. Specifications and criteria shall be approved by RW-20 and DP-12 for Defense Programs high-level waste forms and by RW-20 and NE-20 for West Valley Demonstration Project product. As examples, specifications and criteria for the Defense Waste Processing Facility vitrified high-level waste form are documented in DOE/RW-0125; those for the West Valley Demonstration Project high-level waste form are documented in DOE/RW-0136.

\section{DOE5820.2A, Chapter I, 3.d(1)(b)}

(d)(1)(b) Interim storage for solidified high-level waste awaiting transport to the designated geologic repository shall comply with applicable requirements in paragraph $3 \mathrm{~b}$.

\section{DOE5820.2A, Chapter I, 3.d(2)}

(d)(2) Other Waste. High-level waste that is not readily retrievable shall be monitored periodically in site. Field offices shall reevaluate the safety of such waste to determine the need for corrective measures as necessary. Options for permanent disposal of singly contained tank waste shall be evaluated and include such methods as in-place stabilization as well as retrieval and processing, as required for new and readily retrievable waste in paragraph $3 \mathrm{~d}(1)$.

\section{DOE5820.2A, Chapter II, 3.a(2)}

(a)(2) The lower concentration limit for transuranic waste (>100 nCi/g of waste) shall apply to the contents of any single waste package at the time of assay. The mass of the waste container including shielding shall not be used in calculating the specific activity of the waste.

DOE5820.2A, Chapter II, 3.a(3) 
(a)(3) Radioactive wastes with quantities of transuranic radionuclides in concentrations of $100 \mathrm{nCi} / \mathrm{g}$ of waste or less shall be considered to be low-level waste, and shall be managed according to the requirements of Chapter III of this Order.

\section{DOE5820.2A, Chapter II, 3.a(4)}

(a)(4) Mixed transuranic waste:

(a) Mixed transuranic waste meeting the requirements of the Waste Isolation Pilot Plant-Waste Acceptance Criteria shall be sent to the Waste Isolation Pilot Plant.

(b) The Data Package prepared by the generators for the Waste Isolation Pilot Plant shall include information on the kinds and quantities of hazardous components contained in a waste package in accordance with applicable Resource Conservation and Recovery Act regulations.

(c) The determination whether the transuranic waste exhibits any hazardous characteristics or contains listed hazardous components may be based on knowledge of the waste generating process when the performance of a chemical analysis would significantly increase the radiation hazard to personnel.

\section{DOE5820.2A, Chapter II, 3.b(1)}

(b)(1) Technical and administrative controls shall be directed to reducing the gross volume of waste generated and/or the amount of radioactivity requiring disposal. Transuranic waste reduction efforts shall be based on the implementation of techniques such as process modification, process optimization, materials substitution, decontamination, assay of suspect waste, and new technology development. Volume reduction techniques, such as incineration, compaction, extraction, and shredding, shall be implemented wherever cost effective and practical. Treatment facilities shall be permitted by the appropriate regulatory authority.

\section{DOE5820.2A, Chapter II, 3.b(2)}

(b)(2) Transuranic waste shall be assayed or otherwise evaluated to determine the kinds and quantities of transuranic radionuclides present prior to storage. Additionally, hazardous waste components shall be estimated or analyzed, whichever is appropriate.

\section{DOE5820.2A, Chapter II, 3.c}

(c) Transuranic Waste Certification.

(1) Transuranic waste shall be certified, pursuant to the Waste Isolation Pilot Plant-Waste Acceptance Criteria, placed in interim storage, and sent to the Waste Isolation Pilot Plant when it becomes operational.

(2) Uncertified transuranic waste shall not be sent to the Waste Isolation Pilot Plant except by special 
permission granted in response to a formal, documented request to the Waste Isolation Pilot Plant-Waste Acceptance Criteria Certification Committee and the Waste Isolation Pilot Plant Waste Operations.

(3) All transuranic waste certification sites shall prepare a certification plan which describes how the waste meets each waste acceptance criterion described in the WIPP-DOE-069 (see Attachment 1, page 3, paragraph 18).

(4) Each certification plan shall define controls and other measures to ensure that each element of the certification plan is performed adequately as described. Requirements for these quality assurance activities are described in the WIPP-DOE-120 (see Attachment 1, page 2, paragraph 19).

(5) Certification plans, including associated quality assurance plans, shall be submitted for review, comment, and approval by the Waste Isolation Pilot Plant-Waste Acceptance Criteria Certification Committee.

6) The Waste Isolation Pilot Plant-Waste Acceptance Criteria Certification Committee shall submit certification and associated quality assurance plans to the state of New Mexico"'s Environmental Evaluation Group for review and comment prior to granting formal approval of such plans.

(7) The Environmental Evaluation Groups"'s comments on certification and associated quality assurance plans shall be resolved between the affected site and the Waste Isolation Pilot Plant-Waste Acceptance Criteria Certification Committee prior to granting formal approval of the plans.

(8) Approved certification and associated quality assurance plans shall be implemented by the generating sites using specific, written operational procedures.

(9) Certification activities conducted under approved plans and procedures shall be audited periodically, in accordance with a written audit program plan on a continuing basis by the Waste Isolation Pilot Plant-Waste Acceptance Criteria Certification Committee. An Environmental Evaluation Group representative may accompany the Waste Isolation Pilot Plant-Waste Acceptance Criteria Certification Committee audit team as an observer during site audits. The Waste Isolation Pilot Plant-Waste Acceptance Criteria Certification Committee may grant certifying authority to the site following successful completion of an audit.

(10) The Waste Isolation Pilot Plant-Waste Acceptance Criteria Certification Committee shall issue a formal audit report to the responsible field organization following the completion of an audit. The audit report shall describe the activities of the Waste Isolation Pilot Plant-Waste Acceptance Criteria Certification Committee audit team and include a record of any findings, observations, and recommendations. Corrective actions taken as a result of a finding shall be verified on subsequent audits. The Waste Isolation Pilot Plant-Waste Acceptance Criteria Certification Committee shall institute a tracking system to ensure timely resolution of findings, observations, recommendations, and the resultant corrective actions.

(11) Failure to resolve and close out previous audit findings and recommendations or sending noncomplying waste to the Waste Isolation Pilot Plant when judged by the Waste Acceptance Criteria Certification Committee to be a serious violation, shall result in suspension of certifying authority, pending satisfactory resolution. 


\section{DOE5820.2A, Chapter II, 3.d}

(d)(1) Newly generated transuranic waste shall be placed in noncombustible packaging that meets DOT requirements.

(2) All Type A transuranic waste containers shall be equipped with a method to prevent pressure buildup. Acceptable pressure-relief devices include permeable gaskets, vent clips, and filtered vents.

(3) The waste packages shall be marked, labeled, and sealed in accordance with the Waste Isolation Pilot Plant-Waste Acceptance Criteria, EPA, and DOT requirements, as defined in the WIPP-DOE-O69, 40 CFR 262, Subpart C, and 49 CFR 172, Subparts D, E, and 49 CFR 173, Subpart I, where applicable, prior to shipping.

\section{DOE5820.2A, Chapter II, 3.e}

(e) Temporary Storage at Generating Sites. The following activities shall be performed to assure the safe storage of transuranic wastes consistent with the requirements of applicable Resource Conservation and Recovery Act regulations:

(1) Transuranic waste shall be segregated or otherwise clearly identified to avoid the commingling of transuranic waste streams with high-level waste or low-level waste.

(2) Certified transuranic waste shall not be commingled with noncertified transuranic waste and shall be stored in a manner unlikely to alter its certification status.

(3) Transuranic waste in storage areas shall be protected from unauthorized access.

(4) Transuranic wastes in storage shall be monitored periodically to ensure that the wastes are not releasing their radioactive and/or hazardous constituents.

(5) Transuranic waste storage facilities shall be designed, constructed, maintained, and operated to minimize the possibility of fire, explosion, or accidental release of radioactive and/or hazardous components of the waste to the environment.

(6) Facilities which store transuranic waste shall have a contingency plan designed to minimize the adverse impacts of fire, explosion, or accidental release of hazardous components of the waste to the environment.

(7) Transuranic waste shall be stored in such a way so as to maintain radiation exposures as low as reasonably achievable.

\section{DOE5820.2A, Chapter II, 3.f}

(f) Transportation/Shipping to the Waste Isolation Pilot Plant.

(1) Transuranic waste shipments shall comply with the provisions of DOE and DOE regulations, pursuant to DOE 1540.1 .

(2) Transuranic waste shipments by truck shall be by a DOE-controlled carrier system. All transuranic 
Appendix D - Constraints Definitions

waste shall be transported in certified Type B packaging.

(3) Shipping papers shall provide the information required by DOT ( 49 CFR 172, Subpart C), the Waste Isolation Pilot Plant Data Package (WIPP DOE-157), and, as necessary, the manifest required by EPA (40 CFR 261, and 262).

(4) Distribution of the shipping papers shall be as follows:

(a) Shipper - one copy (or more);

(b) Carrier - one copy; and

(c) Waste Isolation Pilot Plant - two copies.

A copy of the papers will be returned by the Waste Isolation Pilot Plant to the shipper after emplacement of the waste at the Waste Isolation Pilot Plant.

(5) Appropriate EPA and State authorizations/permits shall be obtained for the transport system, as applicable.

(6) Placarding of shipments shall be carried out, as required by the regulations of DOT (contained in 49 CFR 172, Subpart F).

(7) All shipments of transuranic waste shall be in or on "exclusive use" vehicles, as defined in 49 CFR 173. Shipments shall be made as expeditiously as possible and shall be tracked from origin to destination using a real-time tracking communications system. Deviations from "preferred routes," delays and other irregularities detected by the system shall be investigated by the responsible traffic manager and a report sent to the Waste Isolation Pilot Plant within 90 days.

(8) The Albuquerque Operations Office shall develop a transuranic waste transportation management and operations plan which addresses, but is not limited to, the following considerations:

(a) Communication between transport vehicle and traffic management;

(b) Shipment tracking in transit;

(c) Security;

(d) Emergency notification/response;

(e) Shipment routing;

(f) Shipment notification as appropriate;

(g) Driver training and qualifications;

(h) Vehicle maintenance and inspection;

(i) State surveillance and inspection; and 
(j) Inspection and recertification of transport packagings.

\section{DOE5820.2A, Chapter II, 3.f(1-2)}

(f)(1) Transuranic waste shipments shall comply with the provisions of DOE and DOE regulations, pursuant to DOE 1540.1 .

(2) Transuranic waste shipments by truck shatl be by a DOE-controlled carrier system. All transuranic waste shall be transported in certified Type $B$ packaging.

\section{DOE5820.2A, Chapter II, 3.g(1-2)}

(g) (1-2) Interim Storage.

(1) Interim storage sites have been designated for storage of:

(a) Waste certified by off site generators;

(b) Waste certified by on site generators;

(c) Waste certified by interim storage personnel; and

(d) Uncertified waste received from on site and/or off site generators that is awaiting processing and certification.

(2) New interim storage facilities shall be sited, designed, constructed, and operated consistent with the requirements of applicable Resource Conservation and Recovery Act regulations and in a manner which satisfactorily addresses the following considerations at a minimum:

(a) Proximity to ground water and areas of seismic activity or flood plains shall be identified, and potential impacts shall be evaluated.

(b) The facility shall be designed and operated to minimize the run on and run off of precipitation. The run off control system shall provide for collecting and sampling run off, which may come in contact with the waste packages, prior to releasing the water for discharge.

(c) An environmental monitoring system shall be provided to detect any release and migration of major radioactive and hazardous components. Background levels of primary radioactive and hazardous waste components shall be determined.

(d) The storage facility design shall minimize the possibility for the unauthorized entry of persons.

(e) Incompatible wastes types shall be placed in separate packages and stored in segregated areas to prevent accidental ignition or chemical reaction.

(f) Waste storage facilities shall be designed and operated to minimize the exposure of personnel to radiation and chemicals.

(g) The storage facility operator shall inspect or verify routinely the condition of waste packages at the storage site for deterioration that may threaten human health or cause release of hazardous or radioactive components to the environment.

(h) The storage facility operator shall prepare plans that identify and describe how the site will be closed at the end of its active life. These plans shall address sampling, testing, and monitoring for major radioactive and hazardous waste components in soil and groundwater.

(i) Sites that use underground storage tanks for the storage of transuranic waste shall comply with the requirements of the Resource Conservation and Recovery Act, as applicable.

(j) Permits shall be acquired, as necessary, from appropriate regulatory entities for all the interim storage facility activities listed above. 
Appendix D - Constraints Definitions

\section{DOE5820.2A, Chapter II, 3.g(4)}

(g)(4) Certified waste shall be stored in a manner unlikely to alter the certification of the waste package.

\section{DOE5820.2A, Chapter II, 3.g(5)}

(g)(5) Operators of interim storage facilities shall receive data package information (see Attachment 1 , page 2, paragraphs 18 and 20) for each waste package from the generator. The operator shall store the waste generator"s data and shall use the data to prepare a new Data Package at the time of shipment to the Waste Isolation Pilot Plant.

\section{DOE5820.2A, Chapter II, 3.g(7)}

(g)(7) Waste that has been certified by a generator and shipped to an interim storage site shall be reshipped to the Waste Isolation Pilot Plant by the interim storage site in the following manner:

(a) The generator/certifier shall be identified as the generator/certifier and shipping originator.

(b) The interim storage site shall be identified as the reshipper.

(c) The shipping originator is responsible for certifiability of the waste form, waste package content, waste container procurement documentation, related Data Package information, and proper marking, labeling and placarding of the shipment. The shipping originator is responsible for any problems or discrepancies relating to the above-mentioned items that may occur during shipment to or emplacement at the Waste Isolation Pilot Plant.

(d) The reshipper is responsible for complete data package assembly, transmittal, proper marking, labeling, placarding, verifying the adequacy of the exterior condition of the container (e.g., no significant deterioration, bulging) and for proper shipment loading. The reshipper shall perform radiation dose rate and contamination surveys on each package. The reshipper is responsible for any problems or discrepancies involving the items mentioned above.

\section{DOE5820.2A, Chapter II, 3.g(8)}

(g)(8) The interim storage site is the shipping originator for stored waste certified at that site. Agreements may need to be developed between offsite waste generators and interim storage site operators/certifiers to define clearly their respective responsibilities.

\section{DOE5820.2A, Chapter III, 2.c}

c. DOE-low-level waste shall be disposed of on the site at which it is generated, if practical, or if on-site disposal capability is not available, at another DOE disposal facility.

\section{DOE5820.2A, Chapter III, 3.b(1)}

$b(1)$ Field organizations with disposal sites shall prepare and maintain a site specific radiological performance assessment for the disposal of waste for the purpose of demonstrating compliance with the performance objectives stated in paragraph 3a. 


\section{DOE5820.2A, Chapter III, 3.b(2)}

b(2) Each field organization shall, for each DOE reservation within its cognizance, prepare and maintain an overall waste management systems performance assessment supporting the combination of waste management practices used in generation reduction, segregating, treatment, packaging, storage, and disposal. Background and guidance on waste management systems performance assessment is provided in Attachment 1, page 3, paragraph 21

\section{DOE5820.2A, Chapter III, 3.b(3)}

b(3) Where practical, monitoring measurements to evaluate actual and prospective performance should be made at locations as required, within and outside each facility and disposal site. Monitoring should also be used to validate or modify the models used in performance assessments.

\section{DOE5820.2A, Chapter III, 3.c(1)}

c(1) Technical and administrative controls shall be directed to reducing the gross volume of waste generated and/or the amount of radioactivity requiring disposal. Waste reduction efforts shall include consideration of process modification, process optimization, materials substitution and decontamination.

\section{DOE5820.2A, Chapter III, 3.c(2)}

c(2) Waste Generation Reduction. All DOE-low-level waste generators shall establish auditable programs (goals, incentives, procedures, and reports) to assure that the amount of low-level waste generated and/or shipped for disposal is minimized.

\section{DOE5820.2A, Chapter III, 3.c(3)}

c(3) Waste Segregation. Each DOE-low-level waste generator shall separate uncontaminated waste from low-level waste to facilitate cost effective treatment and disposal.

\section{DOE5820.2A, Chapter III, 3.c(4)}

c(4) Waste Minimization. Each DOE-low-level waste generator preparing a design for a new process or process change shall incorporate principles into the design that will minimize the generation of low-level waste.

\section{DOE5820.2A, Chapter III, 3.d}

d(1) Low-level waste shall be characterized with sufficient accuracy to permit proper segregation, treatment, storage, and disposal. This characterization shall ensure that, upon generation and after 
processing, the actual physical and chemical characteristics and major radionuclide content are recorded and known during all stages of the waste management process.

(2) Waste characterization data shall be recorded on a waste manifest, as required by paragraph $3 \mathrm{~m}$, and shall include:

(a) The physical and chemical characteristics of the waste.

(b) Volume of the waste (total of waste and any solidification or absorbent media).

(c) Weight of the waste (total of waste and any solidification or absorbent media).

(d) Major radionuclides and their concentrations.

(e) Packaging date, package weight, and external volume.

(3) The concentration of a radionuclide may be determined by direct methods or by indirect methods such as use of scaling factors which relate the inferred concentration of one radionuclide to another that is measured, or radionuclide material accountability, if there is reasonable assurance that the indirect methods can be correlated with actual measurements.

\section{DOE5820.2A, Chapter III, 3.e(1)}

e(1) Waste shipped from one field organization to another for treatment, storage or disposal shall be done in accordance with the requirements established by the operations office having responsibility for operations of the receiving facility.

\section{DOE5820.2A, Chapter III, 3.e(2)}

e(2) Waste acceptance criteria shall be established for each low-level waste treatment, storage, and disposal facility, andsubmitted to the cognizant field organization.

\section{DOE5820.2A, Chapter III, 3.e(3)}

e(3) Generators of waste shall implement a low-level waste certification program to provide assurance that the waste acceptance criteria for any low-level waste treatment, storage, or disposal facility used by the generator are met. Generators and facilities receiving the waste are jointly responsible for assuring compliance with waste acceptance criteria. Generators are financially responsible for actions required due to nonconformance.

\section{DOE5820.2A, Chapter III, 3.e(4)}

e(4) Generator low-level waste certification programs shall be subject to a periodic audit by operators facilities to which the waste is sent by the generator. 


\section{DOE5820.2A, Chapter III, 3.e(5)}

e(5) The waste acceptance criteria for storage, treatment, or disposal facilities shall address the following issues:

(a) Allowable quantities/concentrations of specific radioisotopes to be handled, processed, stored or disposed of;

(b) Criticality safety requirements (waste forms and geometries);

(c) Restrictions regarding low-level waste classified for security reasons;

(d) External radiation and internal heat generation;

(e) Restrictions on the generation of harmful gases, vapors, or liquids in waste;

(f) Chemical and structural stability of waste packages, radiation effects, microbial activity, chemical reactions, and moisture;

(g) Restrictions for chelating and complexing agents having the potential for mobilizing radionuclides; and

(h) Quantity of free liquids.

\section{DOE5820.2A, Chapter III, 3.h(1)}

(h)(1) Low-level waste shall be stored by appropriate methods, to achieve the performance objectives stated in paragraph $3 \mathrm{a}$.

DOE5820.2A, Chapter III, 3.h(2) 
(h)(2) Records shall be maintained for all low-level waste that enters and leaves the storage facility, (see paragraph 3m).

\section{DOE5820.2A, Chapter III, 3.h(3)}

(h)(3) The development and operation of a waste storage facility shall be supported by the following documentation (two or more of these may be combined for convenience):

(a) An analysis which identifies the need for the storage facility;

(b) A Construction Design Report, including projected waste planned for storage; construction and operating cost estimates;

(c) A Safety Analysis Report and appropriate National Environmental Policy Act documentation; and

(d) Operational procedures and plans.

\section{DOE5820.2A, Chapter III, 3.h(4)}

(h)(4) Storage of waste to allow for nuclides to decay or storage of wastes until they can be disposed of by approved methods are acceptable.

\section{DOE5820.2A, Chapter III, 3.i(1)}

(i)(1) Low-level waste shall be disposed of by methods appropriate to achieve the performance objectives stated in paragraph $3 \mathrm{a}$, consistent with the disposal site radiological performance assessment in paragraph $3 b$.

\section{DOE5820.2A, Chapter III, 3.i(2)}

(i)(2) Engineered modifications (stabilization, packaging, burial depth, barriers) for specific waste types and for specific waste compositions (fission products, induced radioactivity, uranium,thorium, radium) for each disposal site shall be developed through the performance assessment model (see paragraph $3 b(1)$ ). In the course of this process, site specific waste classification limits may be developed if operationally useful in determining how specific wastes should be stabilized and packaged for disposal.

\section{DOE5820.2A, Chapter III, 3.i(3)}

(i)(3) An Oversight and Peer Review Panel of DOE, contractor, and other specialists in performance assessments will be selected by DP-12, with participation by EH-1 and operations office representatives. Through consultation and review, this panel shall ensure consistency and technical quality around the DOE complex in the development and application of performance assessment models that include site 
specific geohydrology and waste composition.

\section{DOE5820.2A, Chapter III, 3.i(4)}

(i)(4) Disposition of waste designated as greater-than-class C, as defined in 10 CFR 61.55, must be handled as special cases. Disposal systems for such waste must be justified by a specific performance assessment through the National Environmental Policy Act process and with the concurrence of DP-12 for all DP-1 disposal facilities and of NE-20 for those disposal facilities under the cognizance of NE-1.

\section{DOE5820.2A, Chapter III, 3.i(5)}

- (i)(5) The following are additional disposal requirements intended either to improve stability of the disposal site or to facilitate handling and provide protection of the health and safety of personnel at the disposal site:

(a) Waste must not be packaged for disposal in cardboard or fiberboard boxes, unless such boxes meet DOE requirements and contain stabilized waste with a minimum of void space. For all types of containers, void spaces within the waste and between the waste and its packaging shall be reduced as much as practical.

(b) Liquid wastes, or wastes containing free liquid, must be converted into a form that contains as little freestanding and noncorrosive liquid as is reasonably achievable, but, in no case, shall the liquid exceed 1 percent of the volume of the waste when the waste is in a disposal container, or 0.5 percent of the volume of the waste processed to a stable form.

(c) Waste must not be readily capable of detonation or of explosive decomposition or reaction at normal pressures and temperatures, or of explosive reaction with water.

(d) Waste must not contain, or be capable of generating, quantities of toxic gases, vapors, or fumes harmful to persons transporting, handling, or disposing of the waste. This does not apply to radioactive gaseous waste packaged as identified in paragraph $3 \mathrm{i}(5)(\mathrm{e})$.

(e) Waste in a gaseous form must be packaged at a pressure that does not exceed 1.5 atmospheres at $20 \mathrm{C}$. 
(f) Waste must not be pyrophoric. Pyrophoric materials contained in waste shall be treated, prepared, and packaged to be nonflammable.

\section{DOE5820.2A, Chapter III, 3.i(6)}

(i)(6) Waste containing amounts of radionuclides below regulatory concern, as defined by Federal regulations, may be disposed without regard to radioactivity content.

\section{DOE5820.2A, Chapter III, 3.i(7)}

(i)(7) Disposal Site Selection.

(a) Disposal site selection criteria (based on planned waste confinement technology) shall be developed for establishing new low-level waste disposal sites.

(b) Disposal site selection shall be based on an evaluation of the prospective site in conjunction with planned waste confinement technology, and in accordance with the National Environmental Policy Act process.

(c) The disposal site shall have hydrogeologic characteristics which, in conjunction with the planned waste confinement technology, will protect the groundwater resource.

(d) The potential for natural hazards such as floods, erosion, tornadoes, earthquakes, and volcanoes shall be considered in site selection.

(e) Site selection criteria shall address the

impact on current and projected populations, land use resource development plans and nearby public facilities, accessibility to transportation routes and utilities, and the location of waste generation.

DOE5820.2A, Chapter III, 3.i(8)

(i)(8) Disposal Facility and Disposal Site Design. 


\section{Revision 1}

(a) Design criteria shall be established prior to selection of new disposal facilities, new disposal sites, or both. These design criteria shall be based on analyses of physiographic, environmental, and hydrogeological data to assure that the policy and requirements of this Order can be met. The criteria shall be also based on assessments of projected waste volumes, waste characteristics, and facility and disposal site performance.

(b) Disposal units shall be designed consistent with disposal site hydrology, geology, and waste characteristics and in accordance with the National Environmental Policy Act process.

DOE5820.2A, Chapter III, 3.i(9)(b)

(i)(9)(b) Permanent identification markers for disposal excavations and monitoring wells shall be emplaced.

DOE5820.2A, Chapter III, 3.j(1)

(j)(1) Field organizations shall develop site-specific comprehensive closure plans for new and existing operating low level waste disposal sites. The plan shall address closure of disposal sites within a 5-year period after each is filled and shall conform to the requirements of the National Environmental Policy Act process. Performance objectives for existing disposal sites shall be developed on a case-by-case basis as part of the National Environmental Policy Act process.

\section{DOE5820.2A, Chapter III, 3.j(2)}

(j)(2) During closure and post closure, residual radioactivity levels for surface soils shall comply with existing DOE decommissioning guidelines.

\section{DOE5820.2A, Chapter III, 3.j(3)}

(j)(3) Corrective measures shall be applied to new disposal sites or individual disposal units if conditions occur or are forecasted that could jeopardize attainment of the performance objectives of this Order.

\section{DOE5820.2A, Chapter HI, 3.j(4)}

(j)(4) Inactive disposal facilities, disposal sites, and disposal units shall be managed in conformance with the Resource Conservation and Recovery Act, the Comprehensive Environmental Response, Compensation, and Liability Act, and the Superfund Amendments and Reauthorization Act, or, if mixed waste is involved, may be included in permit applications for operation of contiguous disposal facilities. 
Appendix D - Constraints Definitions

\section{DOE5820.2A, Chapter III, 3.j(5)}

(j)(5) Closure plans for new and existing operating low-level waste disposal facilities shall be reviewed and approved by the appropriate field organization.

\section{DOE5820.2A, Chapter III, 3.j(6)}

(j)(6) Termination of monitoring and maintenance activity at closed facilities or sites shall be based on an analysis of site performance at the end of the institutional control period.

\section{DOE5820.2A, Chapter III, 3.k}

k(1) Each operational or non-operational low-level waste treatment, storage, and disposal facility shall be monitored by an environmental monitoring program that conforms with DOE 5484.1 and, at a minimum, meet the requirements of paragraph $3 \mathrm{~K}(2)$ through $3 \mathrm{~K}(4)$.

(2) The environmental monitoring program shall be designed to measure:

(a) operational effluent releases;

(b) migration of radionuclides;

(c) disposal unit subsidence; and

(d) changes in disposal facility and disposal site parameters which may affect long-term site performance.

(3) Based on the characteristics of the facility being monitored, the environmental monitoring program may include, but not necessarily be limited to, monitoring surface soil, air, surface water, and, in the subsurface, soil and water, both in the saturated and the unsaturated zones.

(4) The monitoring program shall be capable of detecting changing trends in performance sufficiently in advance to allow application of any necessary corrective action prior to exceeding performance objectives. The monitoring program shall be able to ascertain whether or not effluents from each treatment, storage, or disposal facility or disposal site meet the requirements of applicable EH Orders.

\section{DOE5820.2A, Chapter III, 3.k(1)}

$\mathrm{k}$ (1) Each operational or non-operational low-level waste treatment, storage, and disposal facility shall be monitored by an environmental monitoring program that conforms with DOE 5484.1 and, at a minimum, meet the requirements of paragraph $3 \mathrm{~K}(2)$ through $3 \mathrm{~K}(4)$. 


\section{Revision 1}

Appendix D - Constraints Definitions

\section{DOE5820.2A, Chapter III, 3.k(2)}

$k(2)$ The environmental monitoring program shall be designed to measure:

(a) operational effluent releases;

(b) migration of radionuclides;

(c) disposal unit subsidence; and performance.

(d) changes in disposal facility and disposal site parameters which may affect long-term site

\section{DOE5820.2A, Chapter III, 3.k(3)}

$\mathbf{k}(3)$ Based on the characteristics of the facility being monitored, the environmental monitoring program may include, but not necessarily be limited to, monitoring surface soil, air, surface water, and, in the subsurface, soil and water, both in the saturated and the unsaturated zones.

\section{DOE5820.2A, Chapter III, 3.k(4)}

$\mathbf{k}(4)$ The monitoring program shall be capable of detecting changing trends in performance sufficiently in advance to allow application of any necessary corrective action prior to exceeding performance objectives. The monitoring program shall be able to ascertain whether or not effluents from each treatment, storage, or disposal facility or disposal site meet the requirements of applicable EH Orders.

\section{DOE5820.2A, Chapter III, 3.m}

m. Records and Reports.

(1) Each field organization shall develop and maintain a record keeping system that records the following: a historical record of waste generated, treated, stored, shipped, disposed of, or both, at the facilities under its cognizance. The data maintained shall include all data necessary to show that the waste was properly classified, treated, stored, shipped, and/or disposed of. The data maintained in the system shall be based on the data recorded on waste manifests.

(2) Waste Manifest. Records shall be kept and accompany each waste package from generator through final disposal. The manifest shall contain data necessary to document the proper classification, and assist in determining proper treatment, storage, and disposal of the waste. Waste manifests will be kept as permanent records. At a minimum, the following data will be included:

(a) Waste physical and chemical characteristics,

(b) Quantity of each major radionuclide present, 


\section{Revision 1}

Appendix D - Constraints Definitions

(c) Weight of the waste (total of waste and any solidification or absorbent media),

(d) Volume of the waste (total of waste and any solidification or absorbent media), and

(e) Other data necessary to demonstrate compliance with waste acceptance criteria.

\section{DOE5820.2A, Chapter III, 3.m(1)}

$m$ (1) Each field organization shall develop and maintain a record keeping system that records the following: a historical record of waste generated, treated, stored, shipped, disposed of, or both, at the facilities under its cognizance. The data maintained shall include all data necessary to show that the waste was properly classified, treated, stored, shipped, and/or disposed of. The data maintained in the system shall be based on the data recorded on waste manifests.

\section{DOE5820.2A, Chapter II, 3.m(2)}

$\mathrm{m}$ (2) Waste Manifest. Records shall be kept and accompany each waste package from generator through final disposal. The manifest shall contain data necessary to document the proper classification, and assist in determining proper treatment, storage, and disposal of the waste. Waste manifests will be kept as permanent records. At a minimum, the following data will be included:

(a) Waste physical and chemical characteristics,

(b) Quantity of each major radionuclide present,

(c) Weight of the waste (total of waste and any solidification or absorbent media),

(d) Volume of the waste (total of waste and any solidification or absorbent media), and

(e) Other data necessary to demonstrate compliance with waste acceptance criteria.

\section{DOE5820.2A, Chapter V, 3.a}

3. REQUIREMENTS. DOE organizations shall develop and document their programs to provide for the surveillance, maintenance, and decommissioning of contaminated facilities. The decommissioning programs shall be implemented as follows:

\section{a. General.}

(1) Each field organization shall prepare and maintain a complete list of contaminated facilities both operational and excess under its jurisdiction. A continuous record of jurisdictional program responsibility for all contaminated facilities shall be maintained by the cognizant field organization for use in assigning decommissioning responsibility.

(2) Operational records (e.g., facility design drawings and modifications, characterization data on contamination levels, prior decontamination activities, and incident reports required by DOE Orders) for 
all contaminated facilities shall be maintained by the cognizant field organization for use in preparing decommissioning plans.

(3) Planning for facility decommissioning shall be initiated during the design phase for new facilities and prior to termination of operations for existing operational facilities. Such plans shall consider the 2 -year budget cycle to assure adequate funding availability.

(4) Program offices shall be responsible for placing the facility in a safe storage condition, providing surveillance and maintenance, and decommissioning the facilities under their jurisdiction when they become excess to programmatic needs, or for finding another programmatic sponsor for them. For multiple user facilities, the program office shall determine decommissioning liability for user program offices based on each program's overall contribution to the contamination or some other mutually acceptable basis. This cost sharing formula may be applied when the facility is placed in safe storage or during surveillance and maintenance, when appropriate.

(5) Responsibility for contaminated facilities may be transferred from one program organization to another by mutual agreement of the programs involved. The program organization to which a facility is transferred shall accept full responsibility for surveillance, maintenance, and decommissioning of the facility according to the requirements of this Order. Agreements to transfer facilities for functional purposes shall be in writing and shall identify explicitly the concurrent transfer of responsibility for surveillance, maintenance, and decommissioning.

(6) The DP and NE decommissioning programs exist for the primary purpose of managing and decommissioning the contaminated facilities currently assigned to them. Other contaminated facilities that have no programmatic sponsor, or that are excess to program needs and have a current sponsor, shall be assigned to the DP and NE programs for management and decommissioning with the approval of the program secretarial officers involved or their designees.

(7) Decommissioning expertise gained by DOE and its contractors is available at most major DOE facilities, and should be utilized by DOE programs. A computerized Decommissioning Technology data base is maintained at the Richland Operations Office. Published reports on nuclear facility decommissioning may be obtained from the Remedial Action Program Information Center at Oak Ridge National Laboratory.

\section{DOE5820.2A, Chapter V, 3.a(2)}

a(2) Operational records (e.g., facility design drawings and modifications, characterization data on contamination levels, prior decontamination activities, and incident reports required by DOE Orders) for all contaminated facilities shall be maintained by the cognizant field organization for use in preparing decommissioning plans.

\section{DOE5820.2A, Chapter V, 3.a(5)}

a(5) Responsibility for contaminated facilities may be transferred from one program organization to another by mutual agreement of the programs involved. The program organization to which a facility is transferred shall accept full responsibility for surveillance, maintenance, and decommissioning of the facility according to the requirements of this Order. Agreements to transfer facilities for functional 
purposes shall be in writing and shall identify explicitly the concurrent transfer of responsibility for surveillance, maintenance, and decommissioning.

\section{DOE5820.2A, Chapter V, 3.b}

Facilities in which radioactive or hazardous materials are utilized shall be designed to simplify decontamination and decommissioning and/or increase the potential for reuse. Features and procedures that simplify and facilitate decommissioning shall be identified during the planning and design phase based upon a proposed decommissioning method or conversion to other use.

\section{DOE5820.2A, Chapter V, 3.c}

c. Post-Operational Activities.

(1) DOE Program organizations shall identify contaminated facilities under their jurisdiction, document the potential for reuse and recovery of materials and equipment, and develop schedules for decommissioning them. Projects consisting of one or more facilities shall be identified as appropriate, and priorities shall be developed based on:

(a) Maintaining employee and public health and safety,

(b) Protection of the environment,

(c) Compliance with the National Environmental Policy Act, the Resource Conservation and Recovery Act, the Comprehensive Environmental Response, Compensation, and Liability Act, the Superfund Amendments and Reauthorization Act, and other contractual or legal requirements,

(d) Cost effective program management (e.g., maintaining manpower pools, selecting economical decommissioning alternatives), and

(e) Future site plans.

(2) Program organizations shall assure that, prior to initiation of decommissioning activities, adequate surveillance and maintenance is performed for their surplus facilities to meet applicable radiation protection (DOE 5480.1B), hazardous chemical and safety standards, to maintain physical safety and security, and to reduce potential public and environmental hazards. All high-level waste and stored hazardous materials should be removed by the operator as part of the last operational activities prior to entering into the decommissioning phase.

\section{DOE6430.1A, Section 0110-3}

\section{Flexibility}

Flexibility is a major design requirement for all facilities except those with highly specialized functions. Even in those special facilities, however, the design shall, to the maximum extent practicable, provide sufficient flexibility to accommodate for programmatic changes or operational modifications. 
The layout and type of architectural, structural, mechanical, and electrical elements of all facility elements shall address anticipated future needs. The placement of columns and beams shall be coordinated with the initial and estimated future equipment installations, utility services, operational requirements, and room and furniture layouts. Changeable, movable, and demountable materials shall be considered where functional requirements are likely to change. Design solutions shall demonstrate methods for modification and expansion including modularity, additional capacities (unless otherwise restricted in other sections of these criteria), interstitial space, access flooring systems, and other techniques when justified on an LCC basis.

\section{DOE6430.1A, Section 0200-99.0.4}

Available meteorological data shall be considered to identify conditions that may influence the design and operation of the facility. Meteorological data to be considered shall include expected annual ranges and distribution of the following variables:

$\circ$ Wind direction and speed

o Atmospheric stability

o Temperature

o Atmospheric water vapor

o Mean joint temperature and specific humidity

As a minimum, at least one year of meteorological data shall be used to properly develop estimated joint frequency distributions of wind speed and stability conditions. These data shall be used to estimate the dispersal of effluents under normal and accident conditions.

\section{DOE6430.1A, Section 101-1}

These criteria provide mandatory, minimally acceptable requirements for facility design. The predominant model building code in the region shall govern on issues not covered in these criteria.

State, municipal, county, and other local building and zoning codes and ordinances should be reviewed for possible conflicts with these criteria. While it is not mandatory that DOE projects comply with such local codes and regulations, the design professional is encouraged to cooperate with local officials and DOE personnel to accommodate the intent of local codes and regulations as much as possible.

These criteria apply to any building acquisition, new facility, facility addition and alteration, and leased facility that is required to comply with DOE $4300.1 \mathrm{~B}$. This includes on-site constructed buildings, pre-engineered buildings, plant-fabricated modular buildings, and temporary facilities. For existing facilities, original design criteria apply to the structure in general; however, additions or modifications shall comply with this Order and the associated latest editions of the references herein. Reactors and their safety systems shall be sited and designed according to DOE 5480.6. 
Appendix D - Constraints Definitions

These criteria shall be applied in the planning, design, and development of specifications for facilities, including the preparation of site-specific general design criteria and project-specific design criteria during the project planning phase.

If there are any conflicts between these criteria and DOE directives, these criteria shall govern. Any such conflicts shall be brought to the attention of the Headquarters OPFM.

Information cited in these criteria as being provided by the cognizant DOE authority shall be obtained by the design professional through the designated cognizant DOE authority.

\section{DOE6430.1A, Section 1100}

Equipment specifications shall reflect standard, commercially available equipment that allows a reasonable range of competitive bidding. At least three companies shall be capable of manufacturing equipment. In addition, major equipment, e.g., boilers and chillers, shall have had a satisfactory commercial or industrial operational experience of at least 6,000 operating hours prior to bid opening.

Special equipment that is not a standard product of a recognized manufacturer or is not offered competitively shall not be used unless it complies with 48 CFR 10 .

Full-load and part-load energy efficiencies shall be given special consideration in evaluating equipment performance. (Refer to ASHRAE Standard 90 and Section 0110-12, Energy Conservation).

All air-conditioning equipment shall comply with applicable ARI standards as a minimum requirement.

\section{DOE6430.1A, Section 1300-1.3}

Objectives

The design of special facilities shall:

- Protect the public and facility personnel from hazards associated with the use of radioactive and other hazardous materials as a result of normal operations, anticipated operational occurrences, and DBA conditions, including the effects of natural phenomena pertinent to the site, and maintain these effects ALARA.

- Ensure compliance with DOE policies regarding nuclear safety, criticality safety, radiation safety, explosives safety, industrial safety, fire protection, environmental protection, and Safeguards and Security (S\&S) protection for special nuclear material.

- Protect government property and essential operations from the effects of potential accidents.

- Minimize exposures of personnel and the general public to hazardous materials by emphasizing ALARA concerns during all design, construction, and operational phases of special facilities.

The design of new or modification of existing special facilities shall address the health hazards represented by all hazardous materials in enclosures, general work areas, and noncontaminated areas. 
The release of hazardous materials under normal operating conditions and anticipated operational upset occurrences shall be designed to be less than release guideline limits contained in applicable orders, regulations, and requirements. In addition, to the extent practical, such releases shall be maintained ALARA.

Consideration shall be given to the frequency of occurrence and the effects of DBAs in the design features of special facilities. The depth of the risk analysis involved in this consideration should be in some measure proportional to the level of risk at the facility under consideration.

Protection of employees within the facility and at nearby facilities shall be a requirement in all aspects of the design. Protection shall be provided for normal operation and for those accidents that can be anticpated as occurring during the facility lifetime such as radioactive material spills and small fires controlled by the facility fire suppression system. Occupational exposure to radiation shall be limited according to DOE 5480.11. Design goals shall be established to maintain radiation exposure of employees ALARA. The nature of the hazardous materials in the facility, including radionuclides, shall be considered in the assessment of potential employee exposure.

For mixed-use facilities, such as those combining PPHFs and PSFs, the design of either part of that facility shall not jeopardize the safety requirements of the other.

\section{DOE6430.1A, Section 1300-12.1}

\section{Coverage}

It is DOE policy to ensure that appropriate human factors technology is considered in the design, operation, and maintenance of Departmental nunreactor nuclear facilities. The criteria and requirements provided in this section are applicable to the design of the work environment and human-machine systems at DOE facilities. These criteria shall apply to new construction and to retrofitting of existing facilities. These criteria shall be considered for upgrading existing facilities where cost-benefit or risk-tradeoff analyses indicate justification for such expenditures.

This section outlines a general criteria for incorporating human factors engineering into the system design process. In addition, it provides human factors engineering considerations for system and component displays, controls, alarms, labeling, and communications that are generally applicable to a wide range of human-machine systems, and for the work environment for personnel, including such matters as ventilation, lighting, noise control, work space layout, and equipment design and layout.

\section{DOE6430.1A, Section 1300-12.4.10}

The design of equipment shall incorporate the objective of efficient maintainability. The surveillance, testing, and maintenance of a system and its restoration to operational effectiveness shall be achieved at minimum cost with a minimum level of support services. UCRL 15673 shall be considered for system design.

DOE6430.1A, Section 1300-12.4.11 
Equipment and any parts of that equipment to be used by personnel shall be identified with appropriate labels. The label shall indicate clearly and concisely the function and purpose of the item being labeled.

Permanent labels shall be attached to the specific component or equipment in such a manner that environmental conditions or usage by personnel will not remove or destroy the label.

Labeling shall be legible and conform to human visual capabilities and limitations in regard to physical characteristics such as letter and symbol size, contrast, font, simplicity, spacing and stroke width.

Specific guidelines for addressing labeling considerations are contained in NUREG 0700, Section 6.6 and MIL- STD-1472D, Section 5.5.

\section{DOE6430.1A, Section 1300-12.4.2}

\section{Human Dimension Considerations}

Equipment that is to be used by personnel shall be designed or selected to accommodate their body dimensions. This equipment includes control panels, work tables and counters, enclosures, seating, storage, special clothing, and any other equipment designed for an operator. The design of equipment for personnel shall accommodate a wide variety of body dimensions. Generally, it is recommended that equipment dimensions accommodate the fifth to ninety-fifth percentile of the user population. For recommended data representing these percentiles (from military studies), see NUREG 0700, Section 6.1, and MIL-STD-1472C, Section 5.6. These references also provide recommended dimensions and other guidance for stand-up and sit-down consoles and other work stations, for accessibility of equipment and instrumentation, for furniture and equipment layout, and for traffic flow.

\section{DOE6430.1A, Section 1300-12.4.3}

Emergency lighting systems shall be provided as required by NFPA 101. A control room emergency lighting system shall be automatically activated and immediately available for a stated minimum length of time on failure of the normal lighting system. The emergency lighting system for vital areas shall be an electronically independent system that is not degraded by failure of the normal lighting system. Control room emergency lighting levels shall be in accordance with NUREG 0700, Section 6.1.5.4.

\section{DOE6430.1A, Section 1300-12.4.6}

Displays shall provide only the information about system status and parameter values that is needed to meet task requirements in normal, abnormal and emergency situations. Status, rather than demand information, shall be displayed for important parameters. Displays shall indicate whether they reflect demand or actual values.

Each display device, including meters, CRTs, LCDs, consoles, and other electronic or mechanical media shall be formatted and designed to ensure that both the display and display content are readable, understandable, and accessible. 
Failure of a display of any type shall be easily recognized and shall not affect equipment or system performance.

Where CRTs are used, rapid, error-free access to the information required for the task shall be accomplished by ensuring that system response to any query is less that 2 seconds and that user feedback to control action is less that 0.2 seconds or faster whenever possible.

More specific information regarding these requirements is contained in NUREG 0700, Section 6.5, MIL-STD- 1472D, Section 5.2, and NUREG CR-2496.

\section{DOE6430.1A, Section 1300-12.4.8}

Warning and Annunciator Systems. An effective warning system shall alert personnel to a problem of abnormal condition and shall provide sufficient time to respond appropriately to the problem. General warning guidelines are found in MIL-STD-1472D, Section 5.3. For the special case of control room annunciators, see NUREG 0700 ,

Section 6.3. For auditory signals guidelines, see NUREG 0700, Section 6.2.

\section{DOE6430.1A, Section 1300-3.5}

The design shall consider the maintainability factors peculiar to the specific equipment to be used in the facility. Facility design shall provide for routine maintenance, repair, or replacement of equipment subject to failure. The design of all process equipment shall include features to minimize self-contamination of the equipment, piping, and confinement areas. The design of process equipment shall also include features to minimize the spread of contamination out of local areas.

\section{DOE6430.1A, Section 1300-3.6}

The design shall include provisions for periodic testing of monitoring, surveillance, and alarm systems. In addition, the design shall provide the capability to test periodically, under simulated emergency conditions, safety class items that are required to function under emergency conditions. Safety class systems shall be in place testable in terms of pressure, filtration or removal efficiency, alarm capability, leak resistance, and the like. Safety class items shall be designed to be testable on a regular schedule.

\section{DOE6430.1A, Section 1323-4.1}

\section{General}

The use of multiple barriers shall be emphasized when necessary to restrict the movement of radioactive liquid waste that has the potential for human contact or for reducing groundwater quality below the requirements in DOE5400.1.

DOE6430.1A, Section 1323-4.2 


\section{Collection Systems}

Measurement capability shall be provided to determine the volume and radioactivity of wastes fed to collection $\operatorname{tank}(\mathrm{s})$.

Individual lines shall be used for each waste stream fed to central collection tanks, where necessary, to prevent chemical reactions or introduction of contaminants such as complexing agents that could interfere with waste decontamination.

The use of traps in radioactive liquid waste lines shall be avoided, and piping shall be designed to minimize entrapment and buildup of solids in the system.

Bypasses that would allow waste streams to be routed around collection tanks shall be avoided.

\section{DOE6430.1A, Section 1323-4.3}

\section{Storage and Transfer Systems}

Equipment, waste routing, and spare storage volume shall be installed and available to transfer the contents of one tank to another if a tank shows indications of excessive leakage or other conditions that warrent taking the tank out of service. The minimum spare volume shall exceed the maximum liquid content of any one tank.

Provisions shall be made so that liquids can be analyzed prior to transfer.

All transfer lines shall have individual identification.

\section{DOE6430.1A, Section 1323-5.2}

High-Level Liquid Waste Confinement

The following shall apply to the high-level liquid waste confinement system:

- At least one confinement system shall be designed to withstand the effects of man-made events and DBAs.

- The process cell and/or secondary storage tank confinement and associated ventilation systems shall be designed to remain functional during normal operations, anticipated operational occurrences and for the DBAs they are required to withstand.

- The tertiary confinement system shall be designed to function during normal operations, anticipated operational occurrences and for the DBAs it is required to withstand. It shall be designed to ensure that it can withstand the effects of severe natural phenomena and man-made events, including the DBAs and the DBF initiated by these events, and remain functional to the extent that the guidelines in Section 1300-1.4.2, Accidental Releases, are not violated.

- Tank and piping systems used for high-level liquid waste collection, treatment, and storage shall be of 
welded construction to the fullest extent practical. Materials of construction shall be selected to minimize all forms of corrosion. Consideration shall be given to stress relieving, welding parameter controls, etc., depending on the materials used. Fatigue failure should be a design consideration where temperature cycling is required (i.e., evaporator systems, etc.).

- Potential nonuniform distribution of decay heat caused by solids in the waste shall be considered in the design of storage tanks and any associated cooling system. Agitation of tank contents shall be provided, when necessary, to maintain temperature gradients in the waste within acceptable limits.

- Double-walled piping, multi-pipe encasements, and double-walled tanks shall be used to establish the primary and secondary confinement boundaries in underground portions of high-level liquid waste systems. Provisions shall be made to detect leakage from the primary confinement to the interspace.

- Installation of spare pipe lines between transfer points shall be considered.

Process and waste storage vessels shall be vented through appropriate treatment systems that control the release of radioactive material in gaseous effluents to the extent that the guidelines referenced in Section 1300-1.4.3, Routine Releases, are not exceeded and these releases are ALARA. The design shall ensure the following:

- Off-gas will be suitably pretreated upstream of off-gas treatment equipment to remove or reduce the concentration of chemicals that may adversely affect system operation.

- The venting system will prevent overpressure or vacuum conditions from occurring within vessels.

- The venting system will prevent the buildup of hydrogen from radiolysis.

- Tank overflows will be directed to collection systems.

Integrity of the primary confinement boundary shall be determined by some or all of the following measures:

- Vessel inventory monitoring (e.g., liquid level sensors).

- On-line leakage monitoring for the interspace between double-walled vessels (e.g., airborne activity monitors, sump level sensors, conductivity cells).

- Leakage monitoring outside confinement vessels (e.g., surveillance wells to detect leakage into ground water).

- Capability for periodic visual surveillance, including remote visual surveillance with CCTV.

- Periodic evaluation of test coupons of primary tank construction materials that were installed before the tank was placed in service.

- Other surveillance or testing measures, as appropriate.

DOE6430.1A, Section 1530-1 
Fire protection systems shall comply with DOE 5480.7A.

\section{DOE6430.1A, Section 1605-1}

All systems shall comply with NFPA 70 and ANSI C2. Electrical systems shall be designed so that all components operate within their capacities for initial and projected loads. Preferred standard voltages in conformance with ANSI C84.1 shall be used, with a single-voltage level characteristic in any classification, to minimize stocks of spare equipment and to standardize operating and maintenance practices and procedures.

Electrical materials and equipment shall be UL- or FM-tested, with label attached, for the purpose intended, whenever such products are available. Where there are no UL- or FM-listed products of the type, testing and certification by another nationally recognized testing agency may be acceptable. Installation methods shall be in accordance with the manufacturer's instructions, with NFPA 70, and with other applicable requirements.

On-site acceptance testing shall be required for each major electrical system. Tests shall be specified to demonstrate that each function and important parameter is implemented. Specific criteria shall be included to determine pass/fail acceptance. Tests shall be performed in the presence of a government representative. Copies of all test results shall be submitted for approval.

\section{DOE6430.1A, Section 1630-2.3.5, Oil-Filled Equipment}

Dikes and drainage provisions shall be built as required by the local SPCC in conformance with 40 CFR 112. PCB or PCB-contaminated electrical equipment and the treatment of PCB oil spills shall comply with 40 CFR 761 . Oil-filled transformers installed near buildings shall comply with FM 5-4/14-8. Existing PCB or PCB-contaminated equipment shall be provided with warning signs and shall not be relocated or reused in other existing or new facilities. Electrical equipment cooling material shall be handled in accordance with 29 CFR 1910.1200.

\section{DOE6430.1A, Section 1630-5}

Lightning protection systems shall comply with NFPA 78. Lightning protection systems shall be considered for buildings containing facilities for the use, processing, and storage of radioactive, explosive, and similarly hazardous materials; for buildings over 50 feet in height; and for buildings containing valuable equipment. A risk assessment using the guide in Appendix I of NFPA 78 shall be made of these buildings to determine the risk of loss due to lightning.

Electric power and communication services to all buildings and facilities and to underground power cables, where connected by overhead power distribution lines, shall have lightning and surge protection.

\section{DOE6430.1A, Section 1639-1}

Grounding systems shall comply with NFPA 70 and IEEE 142. 


\section{Draft D \& D Guidance Document, Section 3.2.4}

Typically, EM will not accept a facility until deactivation (as defined in the "Interim Guidance on Facility Transition Process") has been safisfactorily completed.

3.2.4.1 EM's goal (is) to place the facility in a safe, environmentally sound, and "As Low As Economically Achievable" (ALEA) S\&M mode while the facility awaits final disposition. This will be supported with an efficiently planned and executed deactivation program. Ideally, the facility deactivation will be planned and performed by the operating program as part of cessation of operations.

\section{Effluent Treatment Facility Influent Restrictions}

Discharge of ETF effluent is permitted for discharge to the SALDS infiltration gallery only for ETF treatment of 242-A Evaporator process condensate.

The discharge of ETF effluent to SALDS for any other ETF influent stream is prohibited unless (Washington Department of) Ecology has provided the Permittee with written approval to allow an alternative ETF influent source(s).

If the Permittee proposes to run a different influent source(s) (other than 242-A evaporator condensate) through ETF, a characterization study must be sent to Ecology for approval, which includes:

1. A listing of all chemical constituents of concern which exist in the proposed influent source(s), along with expected range of concentration of each component.

2. Engineering study results which show that ETF can adequately process the proposed influent source(s) such that violation of this permit will not occur and water quality violations related to any constituents not listed in the original permit will not occur.

3. Information indicating acceptance of the proposed influent stream relating to RCRA and State Hazardous Waste Law and all other applicable authorities' acceptance of the proposed source(s).

4. A demonstration that the ETF treatment process constitutes BAT/AKART for the proposed influent source(s).

The Privatization Contractor shall:

--- Submit to DOE all technical information and analyses required to modify or comply with any affected permits to transfer secondary radioactive, mixed and non-radioactive dangerous liquid effluents to the ETF.

\section{EM-WAPS "Waste Acceptance Product Specifications for Vitrified High-Level Waste Forms"}

Acceptance of contractor vitrified HLW into the Civilian Radioactive Waste Management System (CRWMS) shall be in accordance with these specifications. 


\section{EM-WAPS 1.1}

The waste form is borosilicate waste glass.

Note: This specification is in conflict with TWRS baseline requirements. The TWRS baseline considers the possible use of other glass compositions, e.g., aluminosilicate glass. (See $4.2 \mathrm{O} 4$ Issue 1.)

\section{EM-WAPS 1.4.2}

At the time of shipment, the producer shall certify that after the initial cool-down, the waste form temperature has not exceeded $400^{\circ} \mathrm{C}$. The producer shall describe the method of compliance in the WCP.

\section{EM-WAPS 1.5}

The producer shall report in the WQR whether the waste form proposed for storage or disposal in the Civilian Radioactive Waste Management System is hazardous listed waste [5]. If the waste form is determined to be listed hazardous waste the quantity of listed waste introduced into the waste form from the feed stream shall be reported in the WQR.

The producer shall perform the "Toxicity Characteristic Leaching Procedure" (TCLP) [6] and other RCRA characteristic test(s) [7] as appropriate, using prototypical specimens of the projected bounding glass compositions to determine if the waste form is characteristic hazardous waste. The method to be used must be described in the WCP and results documented in the WQR.

If the canistered waste forms are determined to be hazardous, the producer shall include a Hazardous Waste Manifest in the Production Records.

\section{EM-WAPS 2.1}

The waste form canister, the canister label, and any secondary canister applied by the producer shall be fabricated from austenitic stainless steel. Applicable ASTM [8] or other nationally recognized alloy specifications and the compositions of the canister materials, the canister label materials, and any filler materials used in welding shall be included in the WCP. Documentation of compliance shall be included in the Production Records.

\section{EM-WAPS 2.2}

The canister fabrication and closure methods shall be identified in the WCP. The outermost closure shall be leaktight to $1 \times 10-4 \mathrm{~atm}-\mathrm{cc} / \mathrm{sec}$ helium. The method for demonstrating compliance shall be described by the producer in the WCP. The WQR shall provide evidence that the canister fabrication and closure methods are capable of complying with the leaktightness criterion. Compliance during production shall be documented in the Production Records.

\section{EM-WAPS 2.3.1}


The producer shall assign a unique alphanumeric identifier to label each outermost canister that is produced. This label shall appear on the canistered waste form and on all documentation pertinent to that particular canistered waste form.

\section{EM-WAPS 2.3.2}

Each canister shall be labeled in two locations: one visible from the top and one from the side of the canister. The identification code shall be printed in a type size of at least 92 points using a sans serif type face. A proposed layout shall be provided in the WCP. Labels shall be applied to the exterior of the outermost canister and shall not cause the dimensional limits (Specification 3.11) to be exceeded. The label shall be designed to be legible after filling and storage at the producers facility and shipment to the repository. The label shall be an integral part of the canister and shall not impair the integrity of the canister.

\section{EM-WAPS 2.4.1}

The overall length of the unfilled canister, after accounting for the closure method, shall be $3.000 \mathrm{~m}$ (+ $0.005 \mathrm{~m},-0.020 \mathrm{~m}$ ), including the neck and handling flange. The measured length of the unfilled canister shall be reported in the Production Records.

Note: This specification is in conflict with TWRS baseline requirements. The TWRS baseline requires an overall canister length of $15 \mathrm{ft}$. (4.5 m). (See $4.2 \mathrm{O} 4$ Issue 1.)

\section{EM-WAPS 2.4.2}

The outer diameter of the unfilled canister shall be $61.0 \mathrm{~cm}(+1.5 \mathrm{~cm},-1.0 \mathrm{~cm})$. The measured diameter of the unfilled canister shall be reported in the Production Records.

\section{EM-WAPS 3.1}

The producer shall ensure that the canistered waste form does not contain detectable amounts of free liquids. The producer shall describe the method of compliance in the WCP and provide documentation of the ability to comply, and of the detection limits, in the WQR.

\section{EM-WAPS 3.10}

The producer shall design a waste form to ensure that, under normal and accident conditions, a nuclear criticality accident is not possible unless at least two unlikely, independent, and concurrent or sequential changes have occurred in the conditions essential to nuclear criticality safety. The calculated effective neutron multiplication factor, keff, must be shown to be less than 0.90 after allowing for bias in the method of calculation and the uncertainty in the experiments used to validate the method of calculation. The producer shall describe the method of demonstrating compliance in the WCP and provide supporting documentation in the WQR. The WQR shall also include sufficient information on the nuclear characteristics, such as fissile density, of the canistered waste form to enable subcriticality to be 
confirmed under transportation, storage and disposal conditions.

\section{EM-WAPS 3.11}

The configuration, dimensions, and weight of the canistered waste form shall not exceed the maximum size and weight which can be received, handled, and emplaced in the repository. These parameters shall be controlled as indicated below and shall be documented at the time of shipment. The producer shall describe the method of compliance in the WCP and the basis for compliance in the WQR.

\section{EM-WAPS 3.12}

The canistered waste form shall be capable of withstanding a 7 meter drop onto a flat, essentially unyielding surface without breaching (leak rate $<1 \times 10-4 \mathrm{~atm}-\mathrm{cc} / \mathrm{sec}$ helium). The producer shall describe the method of compliance in the WCP and provide test results and any supporting analyses in the WQR. The test results shall include information on measured canister leak rates and canister deformation after the drop.

\section{EM-WAPS 3.13}

The canistered waste form shall have a concentric neck and lifting flange. The lifting flange geometry and maximum loading capacity shall be described in the WCP.

The producer shall design a grapple, suitable for use at the repository, which satisfies the following requirements:

(a) The grapple shall be capable of being remotely engaged and disengaged from the flange.

(b) The grapple, when attached to a suitable hoist, and when engaged with the flange, shall be capable of raising and lowering a canistered waste form in a vertical direction.

(c) The grapple shall be capable of engaging and disengaging the canister flange within a right-circular cylindrical cavity with a maximum diameter of $62.5 \mathrm{~cm}$.

(d) The grapple shall be designed to prevent an inadvertent release of a suspended canistered waste form when the grapple is engaged with the flange.

The producer shall describe the grapple in the WCP and provide the designs in the WQR.

\section{EM-WAPS 3.2}

The producer shall ensure that the canistered waste form does not contain detectable amounts of free gas other than air, the residuals of air, noble and radiogenic gases. The internal gas pressure immediately after closure shall not exceed $150 \mathrm{kPa}(22 \mathrm{psia})$ at $25202 \mathrm{lC}$.

\section{EM-WAPS 3.3}

The producer shall ensure that the canistered waste form does not contain detectable amounts of explosive, pyrophoric, or combustible materials. The producer shall describe the method of compliance in the WCP and provide documentation of, the detection limits, and the ability to comply with this specification for the range of waste types, in the WQR. The producer shall document in the WQR that the 
canistered waste forms remain nonexplosive, nonpyrophoric, and noncombustible after having been subjected to temperatures up to $500^{\circ} \mathrm{C}$.

\section{EM-WAPS 3.4}

The producer shall ensure that the canistered waste form does not contain detectable amounts of organic materials. The producer shall describe the method for complying with this specification in the WCP and provide documentation of the ability to comply, and of the detection limits, in the WQR.

\section{EM-WAPS 3.5}

The producer shall ensure that the contents of the canistered waste form do not cause internal corrosion of the canister which could adversely affect normal handling during storage, or during an abnormal occurrence such as a canister drop accident. The producer shall describe the method of demonstrating compliance in the WCP. Interactions between the canister and its contents, including any reaction products generated within the canistered waste form after exposure to temperatures up to 500 degrees $C$, shall be discussed in the WQR.

\section{EM-WAPS 3.6}

The producer shall fill the canister to a height equivalent to at least $80 \%$ of the volume of the empty canister. The producer shall report this height in the Production Records and describe the method of compliance in the WCP. Documentation supporting the selected method of compliance shall be provided in the WQR.

\section{EM-WAPS 3.7}

The level of removable radioactive contamination on all external surfaces of each canistered waste form shall not exceed the following limits at the time of shipment:

Alpha radiation: $220 \mathrm{dpm} / 100 \mathrm{~cm} 2$

Beta and Gamma radiation: $2200 \mathrm{dpm} / 100 \mathrm{~cm} 2$

In addition, the producer shall visually inspect each canistered waste form and remove visible waste glass from the exterior before shipment. The producer shall describe the method of compliance in the WCP and provide contamination level results in the Storage and Shipping Records.

\section{EM-WAPS 3.8.1}

The producer shall document in the WQR the expected thermal output of the canistered waste forms and the range of expected variation for each waste type, indexed to the year 2015. The method to be used for demonstrating compliance shall be described by the producer in the WCP. Projections for compositions not available for reporting in the initial WQR shall be included in an addendum to the WQR.

\section{EM-WAPS 3.8.2}


The producer shall report in the Storage and Shipping Records the estimated heat generation rate for each canistered waste form. The producer shall describe the method for compliance in the WCP.

\section{EM-WAPS 3.9.1}

The producer shall report in the WQR the expected values and the range of expected variation for both gamma and neutron dose rates indexed to the year 2015. The producer shall describe the method for demonstrating compliance in the WCP.

\section{EM-WAPS 3.9.2}

The producer shall provide in the Storage and Shipping Records either the calculated or measured values for both gamma and neutron dose rates at the time of shipment for each canistered waste form. The producer shall describe the method of compliance in the WCP.

\section{Freedom of Information Act of $\mathbf{1 9 6 6}$}

Radiological services shall be in accordance with the document "Freedom of Information Act of 1966".

\section{Hanford Site Radiological Control Manual}

Radiological services shall be performed in accordance with "Hanford Site Radiological Control Manual".

\section{Laboratory Scale Testing of Process: DOE Order 430.1, 6.e(7)(b)}

Laboratory scale testing of proposed processes shall be performed wherever possible before a processing plant design is adopted. A second choice is the use of data from demonstration scale or full-scale processing facilities operating at another site, provided that the effects of processing Hanford waste versus the waste at that site are accounted for.

OSD-T-151-00007, Operating Specifications for the 241-AN, AP, AW, AY, AZ, \& SY Tank Farm, P. 19, section 7.2.10

\subsubsection{TRANSFER LEAK DETECTION}

Variable Specification Limit

Transfer System Leak Detection Transfer system leak detection shall be verified as operable (not failed) before a transfer is initiated, or applicable diversion boxes/catch tanks shall be 
constantly surveyed with portable

conductivity probes during the transfer.

Technical Basis: Immediate detection of liquid which has leaked from primary piping to encasement, pits or diversion boxes allows corrective action to be taken promptly to minimize the risk of discharge of contaminants to the environment.

\section{OSD-T-151-00013, Operating Specification for Single Shell Waste Storage Tanks, P. 17, Section}

\subsection{3 (A)}

\subsubsection{CROSS-CONNECTION REQUIREMENTS}

A. Process Transfers

Specification

At no time shall waste be added to an SST.

Process condensate from tanks on active ventilation is not considered to be a waste or water addition, and therefore, can be returned to one of the tanks on the ventilation system per SD-WM-SAR-006, paragraph 7.5 .

Raw water additions controlled by Section 13.2.3.B are specifically excluded from this specification.

\section{OSD-T-151-00017, Operating Specifications for Aging-Waste Operations in 241-AY, and 241-AZ,} P. 15, Section 17.3.1

\subsection{AGING-WASTE TRANSFER OPERATIONS}

17.3.1 Waste Transfer Leak Detection

Variable Specification Limit

Transfer line leak detection Transfer line leak detections shall be verified as operable (not failed) before a transfer is initiated, or applicable diversion boxes or catch tanks shall be constantly surveyed with portable conductivity probes during the transfer.

Technical Basis: See SD-HS-SAR-010 OSR 11.8 Immediate detection of liquid which has leaked from primary piping to encasement, pits, or diversion boxes allows corrective action to be taken promptly to minimize the risk of discharge of radioactive material to the environment.

OSD-T-151-00030, Operating Specification for Watch List Tanks, P. 9, Section 30.2.A.3 (B)

30.2.A.3 Transfer of Waste 
Appendix D - Constraints Definitions

Variable $\quad$ Specification Limit

B. Planned transfer Requires written approval by

of waste into a tank Secretary of Energy.

\section{OSD-T-151-00030, Operating Specification for Watch List Tanks, P. 9, Section 30.2.A.3, (A)}

\subsection{A.3 Transfer of Waste Variable}

A. Transfer waste out of a tank* Requires written approval by

Tank Waste Remediation Systems, TWRS Nuclear Safety and DOE.
Specification Limit

Requires sample analysis from both

receiving and sending tanks.

*Limit does not apply to the potential Flammable Gas Watch List Tanks denoted by footnote 1 in Appendix B. This exception is a result of discussions held during a Plant Review Committee meeting on May 11, 1995. Tanks identified as potential Flammable Gas Watch List Tanks in the future as a result of a correlation between tank waste levels and atmospheric pressure will qualify for similar exemptions and will also be denoted by footnote 1 in Appendix B.

\section{Residual Volume for Closure}

Closure will follow retrieval of as much tank waste as technically possible, with tank waste residues not to exceed 360 cubic feet (cu. ft.) in each of the 100 series tanks, $30 \mathrm{cu}$. ft. in each of the 200 series tanks, or the limit of waste retrieval technology capability, whichever is less.

\section{SEN-35-91}

DOE facilities will be designed, constructed, operated, and decommissioned to assure the protection of the public, workers, and the environment.

DOE has adopted two quantitative safety goals to limit the risks of fatalities associated with its nuclear operations. These goals are the same as those established for nuclear powerplants by the Nuclear Regulatory Commission (NRC) and, like the NRC goals, should be viewed as aiming points for performance. The goals are:

The risk to an average individual in the vicinity of a DOE nuclear facility for prompt fatalities that might result from accidents should not exceed one tenth of one percent $(0.1 \%)$ of the sum of prompt fatalities resulting from other accidents to which members of the population are generally exposed. For evaluation purposes, individuals are assumed to be located within one mile of the site boundary.

The risk to the population in the area of a DOE nuclear facility for cancer fatalities that might result from operations should not exceed one tenth of one percent $(0.1 \%)$ of the sum of all cancer fatality risks resulting from all other causes. For evaluation purposes, individuals are assumed to be located within 10 miles of the site boundary.

In striving to reach these goals, DOE nuclear facilities and activities shall be designed, constructed, 
operated, and decommissioned with: a) appropriate barriers to prevent or minimize potential radioactive releases; b) engineered safety features to minimize potential releases; and c) procedural controls to mitigate the effects of potential releases. These goals shall be addressed for both new and existing facilities. Proposed modifications to existing facilities to achieve these goals shall be prioritized along with other proposed modifications based on their safety significance. DOE shall pursue the evolution of additional potential safety goals for plant and co located workers to support enhanced safe operations of its facilities.

\section{Tentative Agreement on TPA Negotiation, October 1993}

The retrieved tank waste will be separated into high-level, low-level, and transuranic fractions [February 4, 1993 Leadership Council Meeting] [Tentative Agreement on Tri-Party Agreement Negotiation, USDOE, USEPA, Washington State Department of Ecology, October 1993]

\section{The Privacy Act of 1974}

Radiological services shall be in accordance with the document "The Privacy Act of 1974".

\section{TPA - Schedule Basis}

In-Process waste consist of retrieved tank wastes, pretreated LLW and pretreated HLW waste solutions. The Hanford Federal Facility Agreement and Consent Order specifies a schedule for generation of these in-process waste solutions. Based upon the major and interim milestones contained in the Hanford Federal Facility Agreement and Consent Order, the Store In-Process Waste function must be capable of accepting in-process waste solutions generated per the following schedule:

Retrieved Tank Waste

- Initiate Retrieval of Tank 241-C-106: 10/31/1997

- Initiate Final Retrieval Demonstration of Tank 241-C-106: 06/30/2002

- Complete SST Waste Retrieval Demonstration (C-106): 9/30/2003

- Initiate Waste Retrieval from One SST: 12/31/2003

- Retrieval Waste from All Remaining SST: 09/30/2018

Pretreated Waste

- Begin generation of pretreated LLW 12/31/2004; and pretreated HLW 6/2008

- Complete pretreatment of tank wastes: 12/31/2028

Pretreated LLW for Immobilization

- Begin immobilization of pretreated LLW: 6/30/2005

- Complete immobilization of pretreated LLW: 12/31/2028

Pretreated HLW for Immobilization

- Begin immobilization of pretreated HLW: 12/31/2009

- Complete immobilization of pretreated HLW: 12/31/2028 


\section{TPA Change Control Form M-41-03.A \& B}

M-41-03.A Feb 1994 Issue request for proposal for a mobile high-level liquid waste transport cask. This cask must already be designed to meet applicable DOT and NRC licensing requirements.

M-41-03.B Date TBD Delivery of the mobile high-level liquid waste transport cask. This milestone is predicated on the response received to the procurement request. Upon award of contract, the contract delivery date will be established as this milestone date.

\section{TPA Change Control Form M-43-05}

M-43-05 Project W-314C Transfer System Upgrades

Project W-314C, will provide compliant waste transfer lines to connect the single shell tank farms with the new cross-site transfer line, being provided by Project W-058 (addressed in Milestone M-43-07). Project W-314C will provide a waste receiving station at each single shell tank farm, where waste will be collected from waste retrieval systems. Waste will then be transmitted to the cross-site transfer line system for transfer to its destination. This project is being closely coordinated with retrieval efforts to assure the transfer lines interfaces are well defined and that the lines will be in place to support retrieval schedules.

The Department of Energy and the State of Washington have agreed to participate in Study Analysis Sessions to define scope and requirements for this project. The Department of Energy will provide Washington State Department of Ecology and Department of Health invitations to these sessions with a minimum 1 week notice. The Washington State Department of Ecology and Department of Health will provide participants in these Study Analysis Sessions.

M-43-05-T01 Feb 1995 Provide the Washington State Department of Ecology the project Engineering Study, and scope statement.

M-43-05-T02 Apr 1995 Provide the Washington State Department of Ecology the project Functions and Requirements.

M-43-05-T03 Jun 1995 Provide the Washington State Department of Ecology the project Conceptual Design Statement of Work and Conceptual Design Criteria.

M-43-05A May 1996 Provide the Washington State Department of Ecology the project Conceptual Design Report.

M-43-05-T05 Sep 1996 Provide the Washington State Department of Ecology the Project Design

Criteria.

M-43-05-T06 Jun 1996 Receive DOE-HQ project validation to request congressional funding.

M-43-05-T07 Jan 1998 Start Definitive Design of W-314 C.

M-43-05-T08 Nov 2000 Complete Definitive Design of W-314 C.

M-43-05-T09 Mar 2000 Start construction of W-314 C.

M-43-05B Dec 2003 Complete construction of W-314 C.

M-43-05C Start operation.

\section{TPA Change Control Form M-45-00}

M-45-00 9/30/2024

COMPLETE CLOSURE OF ALL SINGLE SHELL TANK FARMS.

CLOSURE WILL FOLLOW RETRIEVAL OF AS MUCH TANK WASTE AS TECHNICALLY POSSIBLE, WITH TANK WASTE RESIDUES NOT TO 
EXCEED 360 CUBIC FEET (CU. FT.) IN EACH OF THE 100 SERIES TANKS, 30 CU. FT. IN EACH OF THE 200 SERIES TANKS, OR THE LIMIT OF WASTE RETRIEVAL TECHNOLOGY CAPABILITY, WHICHEVER IS LESS. IF THE DOE BELIEVES THAT WASTE RETRIEVAL TO THESE LEVELS IS NOT POSSIBLE FOR A TANK, THEN DOE WILL SUBMIT A DETAILED EXPLANATION TO EPA AND ECOLOGY EXPLAINING WHY THESE LEVELS CANNOT BE ACHIEVED, AND SPECIFYING THE QUANTITIES OF WASTE THAT THE DOE PROPOSES TO LEAVE IN THE TANK. THE REQUEST WILL BE APPROVED OR DISAPPROVED BY EPA AND ECOLOGY ON A TANK-BY-TANK BASIS. PROCEDURES FOR MODIFYING THE RETRIEVAL CRITERIA LISTED ABOVE, AND FOR PROCESSING WAIVER REQUESTS ARE OUTLINED IN THE APPENDIX TO THIS CHANGE REQUEST.

FOLLOWING COMPLETION OF RETRIEVAL, SIX OPERABLE UNITS (TANK FARMS), AS DESCRIBED IN APPENDIX C (200-BP-7, 200 -PO-3, 200-RO-4, 200-TP-5, 200-TP-6, 200-UP-3), WILL BE REMEDIATED IN ACCORDANCE WITH THE APPROVED CLOSURE PLANS. FINAL CLOSURE OF THE OPERABLE UNITS (TANKS FARMS) SHALL BE DEFINED AS REGULATORY APPROVAL OF COMPLETION OF CLOSURE ACTIONS AND COMMENCEMENT OF POSTCLOSURE ACTIONS.

FOR THE PURPOSES OF THIS AGREEMENT ALL UNITS LOCATED WITHIN THE BOUNDARY OF EACH TANK FARM WILL BE CLOSED IN ACCORDANCE WITH WAC 173-303-610. THIS INCLUDES CONTAMINATED SOIL AND ANCILLARY EQUIPMENT THAT WERE PREVIOUSLY DESIGNATED AS RCRA PAST PRACTICE UNITS. ADOPTING THIS APPROACH WILL ENSURE EFFICIENT USE OF FUNDING AND WILL REDUCE POTENTIAL DUPLICATION OF EFFORT VIA APPLICATION OF DIFFERENT REGULATORY REQUIREMENTS: WAC 173-303-610 FOR CLOSURE OF THE TSD UNITS AND RCRA SECTION 3004(U) FOR REMEDIATION OF RCRA PAST PRACTICE UNITS.

ALL PARTIES RECOGNIZE THAT THE RECLASSIFICATION OF PREVIOUSLY IDENTIFIED RCRA PAST PRACTICE UNITS TO ANCILLARY EQUIPMENT ASSOCIATED WITH THE TSD UNIT IS STRICTLY FOR APPLICATION OF A CONSISTENT CLOSURE APPROACH. UPGRADES TO PREVIOUSLY CLASSIFIED RCRA PAST PRACTICE UNITS TO ACHIEVE COMPLIANCE WITH RCRA OR DANGEROUS WASTE INTERIM STATUS TECHNICAL STANDARDS FOR TANK SYSTEMS (I.E., SECONDARY CONTAINMENT, INTEGRITY ASSESSMENTS, ETC.) WILL NOT BE MANDATED AS A RESULT OF THIS ACTION. HOWEVER, ANY EQUIPMENT MODIFIED OR REPLACED WILL MEET INTERIM STATUS STANDARDS. IN EVALUATING CLOSURE OPTIONS FOR SINGLE-SHELL TANKS, CONTAMINATED SOIL, AND ANCILLARY EQUIPMENT, ECOLOGY AND 
Appendix D - Constraints Definitions

EPA WILL CONSIDER COST, TECHNICAL PRACTICABILITY, AND POTENTIAL EXPOSURE TO RADIATION. CLOSURE OF ALL UNITS WITHIN THE BOUNDARY OF A GIVEN TANK FARM WILL BE ADDRESSED IN A CLOSURE PLAN FOR THE SINGLE-SHELL TANKS.

TPA Change Control Form M-45-01

M-45-01 9/30/1994

DEVELOP SINGLE-SHELL TANK (SST) RETRIEVAL TECHNOLOGY. (Completed)

DEVELOP SINGLE-SHELL TANK WASTE RETRIEVAL TECHNOLOGY AND COMPLETE SCALE MODEL TESTING. VARIOUS WASTE RETRIEVAL TECHNOLOGIES WILL BE EVALUATED FOR RETRIEVING EACH OF THE SEVERAL TYPES OF SINGLE-SHELL TANK WASTES. EMPHASIS WILL BE PLACED ON OPTIMIZING WASTE REMOVAL WHILE MINIMIZING PERSONNEL EXPOSURE. PROMISING TECHNOLOGIES WILL BE EVALUATED FOR EACH WASTE TYPE AND ONE OR MORE WILL BE SELECTED FOR TESTING USING SIMULATED WASTE IN A SCALE MODEL (MINIMUM 1:12) TANK.

\section{TPA Change Control Form M-45-02}

M-45-02 9/30/2017

SUBMIT ANNUAL UPDATES TO SST RETRIEVAL SEQUENCE DOCUMENT.

THIS PROVIDES FOR AN ANNUAL UPDATE OF AN SST RETRIEVAL SEQUENCE DOCUMENT THAT WILL DEFINE THE TANK SELECTION CRITERIA, TANK SELECTION RATIONALE, REFERENCE RETRIEVAL METHOD(S) FOR EACH TANK, AND THE ESTIMATED RETRIEVAL SCHEDULES. THE ANNUAL UPDATES WILL BE SUBMITTED TO ECOLOGY FOR APPROVAL.

TPA Change Control Form M-45-02.A

M-45-02A 9/30/1996

SUBMIT INITIAL SST RETRIEVAL SEQUENCE DOCUMENT FOR ECOLOGY APPROVAL.

TPA Change Control Form M-45-02.B

M-45-02B 9/30/1997

SUBMIT ANNUAL UPDATE OF SST RETRIEVAL SEQUENCE DOCUMENT FOR ECOLOGY APPROVAL.

TPA Change Control Form M-45-02.C 
Appendix D - Constraints Definitions

M-45-02C 9/30/1998

SUBMIT ANNUAL UPDATE OF SST RETRIEVAL SEQUENCE DOCUMENT FOR ECOLOGY APPROVAL.

TPA Change Control Form M-45-02.D

M-45-02D 9/30/1999

SUBMIT ANNUAL UPDATE OF SST RETRIEVAL SEQUENCE DOCUMENT FOR ECOLOGY APPROVAL.

TPA Change Control Form M-45-03.A

M-45-03A 10/31/1997

INITIATE SLUICING RETRIEVAL OF C-106.

INITIATE SLUICING RETRIEVAL OF TANK 241-C-106 TO

RESOLVE THE HIGH-HEAT SAFETY ISSUE AND DEMONSTRATE

WASTE RETRIEVAL.

TPA Change Control Form M-45-03.T01

M-45-03-T01 9/30/2003

COMPLETE SST WASTE RETRIEVAL DEMONSTRATION.

INITIATE AND COMPLETE A FULL SCALE DEMONSTRATION OF SST RETRIEVAL TECHNOLOGY. THIS DEMONSTRATION WILL BE CONSIDERED COMPLETE WHEN NO LESS THAN 99\% OF THE WASTE INVENTORY IS REMOVED FROM THE TANK.

TPA Change Control Form M-45-03.T02

M-45-03-T02 6/30/2002

INITIATE FINAL RETRIEVAL DEMONSTRATION OF C-106.

INITIATE FINAL RETRIEVAL OF 'TANK 241-C-106 TO COMPLETE INITIAL DEMONSTRATION OF SST RETRIEVAL TECHNOLOGIES.

TPA Change Control Form M-45-04.A

M-45-04A 4/30/1997

COMPLETE CONCEPTUAL DESIGN FOR THE INITIAL SST RETRIEVAL SYSTEMS. 
Appendix D - Constraints Definitions

TPA Change Control Form M-45-04.T01

M-45-04-T01 11/30/2003

PROVIDE INITIAL SINGLE-SHELL TANK RETRIEVAL SYSTEMS.

COMPLETE CONSTRUCTION AND RELATED TESTING OF THE INITIAL SST RETRIEVAL SYSTEMS. THIS MILESTONE WILL PROVIDE RETRIEVAL SYSTEMS FOR AN ENTIRE SINGLE-SHELL TANK FARM OR AN EQUIVALENT NUMBER OF TANKS.

TPA Change Control Form M-45-04.T02

M-45-04-T02 12/31/2000

COMPLETE DESIGN FOR THE INITIAL SST RETRIEVAL SYSTEMS.

TPA Change Control Form M-45-04.T03

M-45-04-T03 6/30/2003

COMPLETE CONSTRUCTION FOR THE INITIAL SST RETRIEVAL SYSTEMS.

\section{TPA Change Control Form M-45-05}

M-45-05 9/30/2018

RETRIEVE WASTE FROM ALL REMAINING SINGLE-SHELL TANKS.

COMPLETE WASTE RETRIEVAL FROM ALL REMAINING SINGLESHELL TANKS. RETRIEVAL STANDARDS AND COMPLETION DEFINITIONS ARE PROVIDED UNDER THE MAJOR MILESTONE. THE SCHEDULE REFLECTS RETRIEVAL ACTIVITIES ON A FARM-BY -FARM BASIS. IT ALSO ALLOWS FLEXIBILITY TO RETRIEVE TANKS FROM VARIOUS FARMS IF DESIRED TO SUPPORT SAFETY ISSUE RESOLUTION, PRETREATMENT OR DISPOSAL FEED REQUIREMENTS, OR OTHER PRIORITIES.

TPA Change Control Form M-45-05.T01

M-45-05-T01 12/31/2003

INITIATE TANK WASTE RETRIEVAL FROM ONE SINGLE-SHELL TANK.

TPA Change Control Form M-45-05.T02

M-45-05-T02 9/30/2004

INITIATE TANK RETRIEVAL FROM TWO ADDITIONAL SINGLE-SHELL TANKS. 
Appendix D - Constraints Definitions

TPA Change Control Form M-45-05.T03

M-45-05-T03 9/30/2005

INITIATE TANK RETRIEVAL FROM THREE ADDITIONAL SINGLE-SHELL TANKS.

TPA Change Control Form M-45-05.T04

M-45-05-T04 9/30/2006

INITIATE TANK RETRIEVAL FROM FOUR ADDITIONAL SINGLE-SHELL TANKS.

TPA Change Control Form M-45-05.T05

M-45-05-T05 9/30/2007

INITIATE TANK RETRIEVAL FROM FIVE ADDITIONAL SINGLE-SHELL TANKS.

TPA Change Control Form M-45-05.T06

M-45-05-T06 9/30/2008

INITIATE TANK RETRIEVAL FROM FIVE ADDITIONAL SINGLE-SHELL TANKS.

TPA Change Control Form M-45-05.T07

M-45-05-T07 9/30/2009

INITIATE TANK RETRIEVAL FROM SEVEN ADDITIONAL SINGLE-SHELL TANKS.

TPA Change Control Form M-45-05.T08

M-45-05-T08 9/30/2010

INITIATE TANK RETRIEVAL FROM EIGHT ADDITIONAL SINGLE-SHELL TANKS.

TPA Change Control Form M-45-05.T09

M-45-05-T09 9/30/2011

INITIATE TANK RETRIEVAL FROM TEN ADDITIONAL SINGLE-SHELL TANKS.

TPA Change Control Form M-45-05.T10

M-45-05-T10 9/30/2012

INITIATE TANK RETRIEVAL FROM 12 ADDITIONAL SINGLE-SHELL TANKS. 
Appendix D - Constraints Definitions

TPA Change Control Form M-45-05.T11

M-45-05-T11 9/30/2013

INITIATE TANK RETRIEVAL FROM 14 ADDITIONAL SINGLE-SHELL TANKS.

TPA Change Control Form M-45-05.T12

M-45-05-T12 9/30/2014

INITIATE TANK RETRIEVAL FROM 17 ADDITIONAL SINGLE-SHELL TANKS.

TPA Change Control Form M-45-05.T13

M-45-05-T13 9/30/2015

INITIATE TANK RETRIEVAL FROM 20 ADDITIONAL SINGLE-SHELL TANKS.

TPA Change Control Form M-45-05.T14

M-45-05-T14 9/30/2016

INITIATE TANK RETRIEVAL FROM 20 ADDITIONAL SINGLE-SHELL TANKS.

TPA Change Control Form M-45-05.T15

M-45-05-T15 9/30/2017

INITIATE TANK RETRIEVAL FROM 20 ADDITIONAL SINGLE-SHELL TANKS.

TPA Change Control Form M-45-06

M-45-06 9/30/2024 Complete closure of all single-shell tank farms.

The single-shell tank closure work plan will be prepared describing the work integration process for single-shell tank closures and status of work and integration process. Known issues will be identified and an explanation will be given on how these issues are being addressed. This work plan will be provided to Ecology for review/comment and will be used as a roadmap for closure of the single-shell tanks. Because of the uncertainties in the closure process, the work plan will evolve as these uncertainties are resolved and eventually it will become the SST closure/post-closure plan(s) issued for Ecology's approval under subsequent TPA interim milestones. Major work areas covered in the work plan will include waste retrieval, operable units characterization, technologies development to support closure, regulatory pathway and strategy for achieving closure.

\section{TPA Change Control Form M-45-06-T01}

M-45-06-T01 11/30/2004 SUBMIT TANK CLOSURE/POST-CLOSURE PLAN FOR SELECTED CLOSURE DEMONSTRATION OPERABLE UNIT OR TANK FARM TO ECOLOGY FOR APPROVAL. 
TPA Change Control Form M-45-06-T02

M-45-06-T02 9/30/2006 ECOLOGY WILL ISSUE FINAL CLOSURE/POST CLOSURE PLAN FOR SELECTED CLOSURE DEMONSTRATION OPERABLE UNIT OR TANK FARM.

\author{
TPA Change Control Form M-45-06-T03
}

M-45-06-T03 3/31/2012 INITIATE CLOSURE ACTIONS ON AN OPERABLE UNIT OR TANK FARM BASIS. CLOSURE SHALL FOLLOW COMPLETION OF THE RETRIEVAL ACTIONS UNDER PROPOSED MILESTONE M-45-05. CLOSURE WILL BE DEFINED IN AN APPROVED CLOSURE PLAN FOR THE DEMONSTRATION FARM. FINAL CLOSURE IS DEFINED AS REGULATORY APPROVAL OF COMPLETION OF CLOSURE ACTIONS.

TPA Change Control Form M-45-06-T04

M-45-06-T04 3/31/2014 COMPLETE CLOSURE ACTIONS ON ONE OPERABLE UNIT OR TANK FARM.

\title{
TPA Change Control Form M-45-08-T01
}

Milestone T2E-95-206

TPA M-45-08-T01

Description of this Commitment: Provide preliminary assessment report for project ed SST leakage. Such assessment to project expected environmental contamination and groundwater health risk using existing waste data.

Description of what Constitutes Completion of the Commitment: Appendix C Preliminary Risk-Based Leakage Thresholds for Hanford SSTs of WHC-SD-WM-FRD-020

Functions and Requirements for Hanford Single Shell Tank Leakage Detection and Monitoring.

Acceptance Criteria: Transmittal of Appendix C of WHC-SD-WM-FRD-021 to the State Department of Ecology by DOE-RL.

\section{TPA Change Control Form M-50-93-01}

M-50-00 December 2028 Complete pretreatment processing of Hanford tank waste M-50-01-T01 December 1994 Issue reports on cesium removal performance of Resorcinol and CS-100 resins on multiple feeds

This milestone will report Hanford progress on laboratory testing with Resorcinol and Cs-100 resins for cesium removal. Based on the laboratory results, WHC will prepare preliminary CsC ion exchange flowsheets on multiple waste streams, which will include DSSF and NCAW supernatants. These flowsheets will reflect the preliminary requirements of the low level waste pretreatment facility. 
M-50-03 March 1998 Complete evaluation of enhanced sludge washing to determine whether advanced sludge separation processes are required

The performance of sludge washing and related tank waste sludge pretreatment methods will be evaluated to determine if these processes will be capable of satisfying criteria which will be established by the three parties prior to the milestone date. The criteria will include such items as volume of HLW resulting from pretreatment, compatibility with HWL and LLW treatment processes, and processing rates. For example, sludge washing and enhanced sludge washing must result in the production of a "resonable" volume of HLW requiring repository disposal such that other established sludge treatment processes will not result in overall cost savings or schedule improvements. If the predicated performance does not meet the criteria, the need for more advanced sludge separations processes will be re-examined and changes to the HLW program will be proposed accordingly. Key elements of this evaluation include:

-Pretreatment process testing will use actual tank waste. These tanks will be chosen to represent the expected range of sludge composition. Candidate processes are those, such as water washing, caustic washing, and selective leaching, which do not require complex processing systems and which can be implemented within tanks or relatively simple facilities. -Develop candidate tank treatment and blending sequences to minimize the volume of immobilized HLW.

-Model system performance to predict the volumes of immobilized HLW produced and processing rates for candidate pretreatment processes.

M-50-03A September 1994 Define Additional Milestones for waste pretreatment leading to the decision whether advanced sludge separation processes are required will need the development of information from several TWRS functions (Pretreatment, HLW Treatment, LLW Treatment, and Retrieval) to determine if enhanced sludge washing performs satisfactorily, or if advanced sludge separation process are required. Some interim information to be on this schedule may include the development of criteria defining what HLW glass volume is acceptable, the development of the decision-making method; and the schedule to evaluate the performance of enhanced sludge washing and the acceptance of the criteria and the decision method by the interested parties. Based on this schedule, additional milestones will be proposed to lead to the completion of milestone M-50-03.

M-50-03-T01 October 1994 Issue report on current status of tank waste enhanced sludge washing This milestone will report Hanford progress in enhanced sludge washing. Included in the scope of this milestone will be the issuance of a pjlan that will define the tests to be performed on Hanford tank sludges. In addition, the enhanced sludge washing laboratory test results on Hanford sludges completed through the third quaerter of the fiscal year will be presented with expected impacts on High Level Waste Vitrification. These impacts will be illustrated in a summary of HLW glass volume projections for all Hanford waste types. Finally, the status and results of computer modelling of sludge washing of tank wastes will be presented.

M-50-03-T02 Sept. 1995 (And annually through 1997) Submit a report summarizing the testing of enhanced sludge washing and related tank waste sludge pretreatment methods for samples of tank waste sludge

Perform testing of enhanced sludge washing and related tank waste sludge pretreatment methods using actual tank waste samples. Document and issue results of testing completed to that time.

This annual report will also document preliminary candidate tank waste pretreatment and preliminary immobilization sequences and tank blending strategies. Goals for both early progress on waste immobilization and minimization of the production of high level glass will be addressed in these strategies. These preliminary strategies will be utilized to predict the production of high level waste glass asssociated with candidate enhanced sludge washing and related tank waste sludge pretreatment methods. The prediction of the HLW glass volume production will be updated.

WAC173-303 Dangerous Waste Regulations 
Contractor generation, transportation, treatment, storage and disposal of dangerous waste shall be in accordance with this Code.

\section{WAC173-303-070}

WAC 173-303-070 Designation of dangerous waste

(1) Purpose and applicability.

(a) This section describes the procedures for determining whether or not a solid waste is DW or EHW.

(b) The procedures in this section are applicable to any person who generates a solid waste (including recyclable materials) that is not exempted or excluded by this chapter or by the department. Any person who must determine whether or not their solid waste is designated must follow the procedures set forth in subsection (3) of this section. Any person who determines by these procedures that their wasteis designated DW or EHW is subject to all applicable requirements of this chapter.

(c) The requirements for the small quantity generator exemption are found in subsection (8) of this section.

(2)(a) Once a material has been determined to be a dangerous waste, then any solid waste generated from the recycling, treatment, storage, or disposal of that dangerouswaste is a dangerous waste unless and until:

(i) The generator has been able to accurately describe the variability or uniformity of the waste over time, and has been able to obtain demonstration samples which are representative of the waste's variability or uniformity; and

(ii)(A) It does not exhibit any of the characteristics of WAC 173-303-090; however, wastes that exhibit a characteristic at the point of generation may still be subject to the requirements of WAC 173-303-140(2)(a), even if they no longer exhibit a characteristic at the point of land disposal; and

(B) If it was a listed waste under WAC 173-303-080 through 173-303-083, it also has been exempted pursuant to WAC 173-303-910(3); or

(iii) If originally designated only through WAC 173-303-100, it does not meet any of the criteria of WAC 173-303-100. Such solid waste will include but not be limited to any sludge, spill residue, ash emission control dust, leachate, or precipitation run-off. Precipitation run-off will not be considered a dangerous waste if it can be shown that the run-off has not been contaminated with the dangerous waste, or that the run-off is adequately addressed under existing state laws (e.g. chapter $90.48 \mathrm{RCW}$ ), or that the run-off does not exhibit any of the criteria or characteristics described in WAC 173-303-100.

(b) Materials that are reclaimed from solid wastes and that are used beneficially (as provided in WAC 173-303-016 and 173-303-017) are not solid wastes and hence are not dangerous wastes under this section unless the reclaimed material is burned for energy recovery or used in a manner constituting disposal.

(c) Notwithstanding subsections (1) and (2) of this section and provided the debris does not exhibit a characteristic identified in WAC 173-303-090, the following materials are not subject to regulation under this chapter:

(i) Hazardous debris that has been treated using one of the required extraction or destruction technologies specified in Table 1 of 40 CFR section 268.45; persons claiming this exclusion in an enforcement action will have the burden of proving by clear and convincing evidence that the material meets all of the exclusion requirements; or

(ii) Debris that the department, considering the extent of contamination, has determined is no longer contaminated with hazardous waste. 
(3) Designation procedures.

(a) To determine whether or not a solid waste is designated as a dangerous waste a person must:

(i) First, determine if the waste is a listed discarded chemical product, WAC 173-303-081;

(ii) Second, determine if the waste is a listed dangerous waste source, WAC 173-303-082;

(iii) Third, if the waste is not listed in WAC 173-303-081 or 173-303-082, or for the purposes of compliance with the federal land disposal restrictions as adopted by reference in WAC 173-303-140, determine if the waste exhibits any dangerous waste characteristics, WAC 173-303-090; and

(iv) Fourth, if the waste is not listed in WAC 173-303-081 or 173-303-082, and does not exhibit a characteristic in WAC 173-303-090, determine if the waste meets any dangerous waste criteria, WAC 173-303-100.

(b) A person must check each section, in the order set forth, until they determine whether the waste is designated as a dangerous waste. Once the waste is determined to be a dangerous waste, further designation is not required except as required by subsection (4) or (5) of this section. If a person has checked the waste against each section and the waste is not designated, then the waste is not subject to the requirements of chapter 173-303 WAC. Any person who wishes to seek an exemption for a waste which has been designated DW or EHW must comply with the requirements of WAC 173-303-072.

(c) For the purpose of determining if a solid waste is a dangerous waste as identified in WAC 173-303-080 through 173-303-100, a person must either:

(i) Test the waste according to the methods, or an approved equivalent method, set forth in WAC 173-303-110; or

(ii) Apply knowledge of the waste in light of the materials or the process used, when:

(A) Such knowledge can be demonstrated to be sufficient for determining whether or not it designated and/or designated properly; and

(B) All data and records supporting this determination in accordance with WAC 173-303-210 (3) are retained on-site.

(4) Testing required. Notwithstanding any other provisions of this chapter, the department may require any person to test a waste according to the methods, or an approved equivalent method, set forth in WAC 173-303-110 to determine whether or not the waste is designated under the dangerous waste lists, characteristics, or criteria, WAC 173-303-080 through 173-303-100. Such testing may be required if the department has reason to believe that the waste would be designated DW or EHW by the dangerous waste lists, characteristics, or criteria, or if the department has reason to believe that the waste is designated improperly (e.g., the waste has been designated DW but should actually be designated EHW). If a person, pursuant to the requirements of this subsection, determines that the waste is a dangerous waste or that its designation must be changed, then they are subject to the applicable requirements of this chapter 173-303 WAC. The department will base a requirement to test a waste on evidence that includes, but is not limited to:

(a) Test information indicating that the person's waste may be DW or EHW;

(b) Evidence that the person's waste is very similar to another persons' already designated DW or EHW;

(c) Evidence that the persons' waste has historically been a DW or EHW;

(d) Evidence or information about a person's manufacturing materials or processes which indicate that the wastes may be DW or EHW; or

(e) Evidence that the knowledge or test results a person has regarding a waste is not sufficient for determining whether or not it designated and/or designated properly.

(5) Additional designation required. A generator must manage dangerous waste under the most stringent management 
standards that apply. Subsections (5)(a) and (c) of this section describe how waste that has been designated as DW under the dangerous waste lists, WAC 173-303-080 through 173-303-082, or characteristics, WAC 173-303-090, must also be designated under the dangerous waste criteria, WAC 173-303-100, because designation under the criteria may change how the waste must be managed. Additional designation is required when:

(a) The waste is designated as DW with a QEL of 220 pounds and the generator otherwise qualifies as a small quantity

generator. In this case, a generator must determine if their DW is also designated as a toxic EHW, WAC 173-303-100, with a QEL of 2.2 pounds; or

(b) The waste is designated as DW and the waste is to be discharged to a POTW operating under WAC 173-303-802(4) (Permits by rule). In this case, a generator must determine if the waste is also an EHW under WAC 173-303-100; or

(c) The waste is designated as a state-only DW and the waste is to be:

(i) Burned for energy recovery, as used oil, under the provisions of WAC 173-303-515; or

(ii) Land disposed within the state. In this case, a generator must determine if the waste is also an EHW under WAC 173-303-100.

(6) Dangerous waste numbers. When a person is reporting or keeping records on a dangerous waste, they must use all

the dangerous waste numbers which they know are assignable to the waste from the dangerous waste lists, characteristics, or criteria. For example, if the waste is ignitable and contains extremely hazardous concentrations of halogenated hydrocarbons, they must use the dangerous waste numbers of D001 and WP01. This will not be construed as requiring a person to designate their waste beyond those designation requirements set forth in subsections (2), (3), (4), and (5) of this section.

(7) Quantity exclusion limits; aggregated waste quantities.

(a) Quantity exclusion limits. In each of the designation sections describing the lists, characteristics, and criteria, quantity exclusion limits (QEL) are identified. The QEL are used to distinguish when a dangerous waste is only subject to the small quantity generator provisions, and when a dangerous waste is subject to the full requirements of this chapter. Any solid waste which is not excluded or exempted and which is listed by or exhibits the characteristics or meets the criteria of this chapter is a dangerous waste. Small quantity generators who produce dangerous waste below the QEL are subject to the requirements described in subsection (8) of this section.

(b) Aggregated waste quantities. A person may be generating, accumulating, or storing more than one kind of dangerous waste. In such cases, they must consider the aggregate quantity of their wastes when determining whether or not their waste amounts exceed the specific limits for waste accumulation or the specific quantity exclusion limits

(QEL) for waste generation. Waste quantities must be aggregated for all wastes with common QEL's. Example: If a

person generates 100 pounds of an ignitable waste and 130 pounds of a persistent waste, then both wastes are regulated because their aggregate waste quantity ( 230 pounds) exceeds their common QEL of 220 pounds. On the other hand, if a person generates one pound of a toxic EHW and 218 pounds of a corrosive waste, their quantities would not be aggregated because they do not share a common QEL ( 2.2 pounds and 220 pounds, respective QEL's).

(c) For the purposes of this subsection, when aggregating waste quantities, generators must include in their calculation, dangerous wastes produced by on-site treatment or recycling of dangerous wastes and dangerous wastes being accumulated or stored except for the following categories of waste that are 
excluded from the quantity determinations.

(i) Dangerous waste that is recycled and that is excluded from regulation under WAC 173-303-120(2)(a), (3)(c), (e), or ( $f$ ) is not included in the quantity determinations of this section and is not subject to any requirements of this subsection.

(ii) Spent materials that are generated, reclaimed, and subsequently reused on-site, so long as such spent materials have been counted once.

(iii) Dangerous waste that is removed from on-site storage.

(8) Small quantity generators.

(a) A person is a small quantity generator and subject to the requirements of this subsection if:

(i) Their waste is dangerous waste under subsection (3) of this section, and the quantity of waste generated per month (or the aggregated quantity if more than one kind of waste is generated) does not equal or exceed the quantity exclusion limit (QEL) for such waste (or wastes) as described in WAC 173-303-070(7); and

(ii) The quantity accumulated or stored does not exceed 2200 pounds for wastes with a 220 pound QEL and 2.2 pounds for waste with a 2.2 pound QEL. (Exception: The accumulation limit for the acute hazardous wastes described in WAC 173-303-081(2)(iv) is $220 \mathrm{lbs}$ ); and

(iii) The total quantity of dangerous waste generated in one month, all DW and EHW regardless of their QELs, does not equal or exceed 220 pounds. If a person generates any dangerous wastes that exceed the QEL or accumulates or stores waste that exceeds the accumulation limits, then all dangerous waste generated, accumulated, or stored by that person is subject to the requirements of this chapter. A small quantity generator who generates in excess of the quantity exclusion limits or, accumulates, or stores waste in excess of the accumulation limits becomes subject to the full requirements of this chapter and cannot again be a small quantity generator until after all dangerous waste on-site at the time he or she became fully regulated have been removed, treated, or disposed. Example. If a person generates four pounds of an acute hazardous waste discarded chemical product (QEL is 2.2 pounds) and 200 pounds of an ignitable waste (QEL is 220 pounds), then both wastes are fully regulated, and the person is not a small quantity generator for either waste. (Comment: If a generator generates acute hazardous waste in a calendar month in quantities greater than the QELs, all quantities of that acute hazardous waste are subject to full regulation under this chapter. "Full regulation" means the regulations applicable to generators of greater than 2200 pounds of dangerous wastes in a calendar month.)

(b) Small quantity generators will not be subject to the requirements of this chapter if they:

(i) Designate their waste in accordance with WAC 173-303-070; and

(ii) Manage their waste in a way that does not pose a potential threat to human health or the environment; and

(iii) Either treat or dispose of their dangerous waste in an on-site facility, or ensure delivery to an off-site facility, either of which is:

(A) Permitted (including permit-by-rule, interim status, or final status) under WAC 173-303-800 through 173-303-840;

(B) Authorized to manage dangerous waste by another state with a hazardous waste program approved under 40 CFR Part 271, or by EPA under 40 CFR Part 270;

(C) Permitted to manage moderate-risk waste under chapter 173-304 WAC (Minimum functional standards for solid waste handling), operated in accordance with state and local regulations, and consistent with the applicable local hazardous waste plan that has been approved by the department;

(D) A facility that beneficially uses or reuses, or legitimately recycles or reclaims the dangerous waste, or that treats the waste prior to such recycling activities;

(E) Permitted to manage municipal or industrial solid waste in accordance with state or local regulations, or in accordance with another state's solid waste laws if the waste is sent out-of-state; or 
(F) A publicly owned treatment works (POTW) provided that small quantity generator(s) comply with the provisions of the domestic sewage exclusion found in WAC 173-303-071(3)(a); and

(iv) Submit an annual report in accordance with WAC 173-303-220 if they have obtained an EPA/state identification number pursuant to WAC 173-303-060.

(c) If a small quantity generator's wastes are mixed with used oil, the mixture is subject to WAC 173-303-510 if it is destined to be burned for energy recovery. Any material produced from such a mixture by processing, blending, or other treatment is also regulated if it is destined to be burned for energy recovery.

[Statutory Authority: Chapters 70.105 and 70.105D RCW. 95-22-008 (Order 94-30), 173-303-070, filed 10/19/95, effective 11/19/95; 94-01-060 (Order 92-33), 173-303-070, filed 12/8/93, effective 1/8/94. Statutory Authority: Chapter 70.105 RCW. 93-02-050 (Order 92-32), 173-303-070, filed 1/5/93, effective 2/5/93. Statutory Authority: Chapters 70.105 and 70.105D RCW, 40 CFR Part 271.3 and RCRA 3006 (42 U.S.C. 3251). 91-07-005 (Order 90-42), 173-303-070, filed 3/7/91, effective 4/7/91. Statutory Authority: Chapter 70.105 RCW. 89-02-059 (Order 88-24), 173-303-070, filed 1/4/89; 87-14-029 (Order DE-87-4), 173-303-070, filed 6/26/87; 86-12-057 (Order DE-85-10), 173-303-070, filed 6/3/86; 84-14-031 (Order DE 84-22), 173-303-070, filed 6/27/84. Statutory Authority: Chapter 70.105 RCW and RCW 70.95.260. 82-05-023 (Order DE 81-33), 173-303-070, filed 2/10/82.]

\section{WAC173-303-071(3)(1)}

(l) Samples:

(i) Except as provided in (l)(ii) of this subsection, a sample of solid waste or a sample of water, soil, or air, which is collected for the sole purpose of testing to determine its characteristics or composition, is not subject to any requirements of this chapter, when:

(A) The sample is being transported to a lab for testing or being transported to the sample collector after testing; or

(B) The sample is being stored by the sample collector before transport, by the laboratory before testing, or by the laboratory after testing prior to return to the sample collector; or

(C) The sample is being stored temporarily in the laboratory after testing for a specific purpose (for example, until conclusion of a court case or enforcement action).

(ii) In order to qualify for the exemptions in (1)(i) of this subsection, a sample collector shipping samples to a laboratory and a laboratory returning samples to a sample collector must:

(A) Comply with United States Department of Transportation (DOT), United States Postal Service (USPS), or any other applicable shipping requirements; or

(B) Comply with the following requirements if the sample collector determines that DOT or USPS, or other shipping requirements do not apply:

(I) Assure that the following information accompanies the sample:

(AA) The sample collector's name, mailing address, and telephone number;

(BB) The laboratory's name, mailing address, and telephone number;

(CC) The quantity of the sample;

(DD) The date of shipment;

(EE) A description of the sample; and

(II) Package the sample so that it does not leak, spill, or vaporize from its packaging.

(iii) This exemption does not apply if the laboratory determines that the waste is dangerous but the laboratory is no longer meeting any of the conditions stated in (1)(i) of this subsection; 


\section{WAC173-303-072}

WAC 173-303-072 Procedures and bases for exempting and excluding wastes

(1) Purpose and applicability.

(a) The purpose of this section is to describe the procedures that will be followed by generators and the department when wastes are considered for exemption or exclusion from the requirements of this chapter. Any person(s) whose waste is exempted or excluded will not be subject to the requirements of this chapter unless the department revokes the exemption or exclusion.

(b) Any person seeking a waste exemption must submit a petition to the department according to the procedures of WAC 173-303-910(3). A petition for exemption will be assessed against the applicable bases for exemption described in subsections (3), (4), and (5) of this section.

(c) Any persons seeking to categorically exclude a class of wastes must submit a petition to the department according

to the procedures of WAC 173-303-910(4). A petition for exclusion will be assessed against the applicable bases for exclusion described in subsection (6) of this section.

(2) Department procedures. When considering, granting, or denying a petition for exemption or exclusion, the department will follow the appropriate procedures described in WAC 173-303-910(1).

(3) Bases for exempting wastes. To successfully petition the department to exempt a waste, the petitioner must demonstrate to the satisfaction of the department that:

(a) He has been able to accurately describe the variability or uniformity of his waste over time, and has been able to obtain demonstration samples which are representative of his waste's variability or uniformity; and, either

(b) The representative demonstration samples of his waste are not designated DW or EHW by the dangerous waste criteria, WAC 173-303-100; or

(c) It can be shown, from information developed by the petitioner through consultation with the department, that his waste does not otherwise pose a threat to public health or the environment. However, this basis for exemption is not applicable to wastes that exhibit any of the characteristics specified in WAC 173-303-090, except 173-303-090(6)(a)(iii).

(4) Additional bases for exempting listed wastes. In addition to the demonstrations required by subsections

(3)(a) and (b) of this section, for wastes listed in WAC 173-303-081 or 173-303-082 the petitioner must also demonstrate to the satisfaction of the department that his waste is not capable of posing a substantial present or potential threat to public health or the environment when improperly treated, stored, transported, disposed of or otherwise managed. The following factors will be considered by the department when assessing such a demonstration:

(a) Whether or not the listed waste contains the constituent or constituents which caused it to be listed. (For the purposes of this subsection, the constituents referred to will include any of the dangerous waste constituents listed in WAC 173-303-9905);

(b) The nature of the threat posed by the waste constituent(s);

(c) The concentration of the constituent(s) in the waste;

(d) The potential of the constituent(s) or any degradation product of the constituent(s) to migrate from the waste into the environment under the types of improper management considered in ( $h$ ) of this subsection;

(e) The persistence of the constituent(s) or any degradation product of the constituent(s); 
(f) The potential for the constituent(s) or any degradation product of the constituent(s) to degrade into nonharmful constituents and the rate of degradation;

(g) The degree to which the constituent(s) or degradation product of the constituent(s) bioaccumulates in ecosystems;

(h) The plausible types of improper management to which the waste could be subjected;

(i) The quantities of the waste generated at individual generation sites or on a state-wide basis. Under this factor, the department will also consider whether or not the waste is listed under WAC 173-303-081 as a discarded chemical product and occurs in a relatively pure form. Any waste discarded chemical product which exceeds the quantity exclusion limit specified in WAC 173-303-081(2) for that waste will not be exempted;

(j) The nature and severity of the public health and environmental damage that has occurred as a result of the improper management of wastes containing the constituent(s);

(k) Actions taken by other governmental agencies or regulatory programs based on the health or environmental threat posed by the waste or waste constituent(s); and

(I) Such other factors as may be appropriate.

\section{(5) Reserve.}

(6) Bases for categorically excluding classes of wastes. This subsection does not apply to any waste class that includes hazardous waste regulated under 40 CFR Part 261. To successfully petition the department to categorically exclude a class of wastes, petitioners must demonstrate to the satisfaction of the department that the petition or petitions for exclusion:

(a) Accurately describe the class of wastes for which categorical exclusion is sought and show that the class of wastes does not include any wastes which would be regulated as hazardous waste under $40 \mathrm{CFR}$ Part 261;

(b) Describe the variability or uniformity of the class of wastes over time and in relation to the individual wastes that comprise the class of waste;

(c) Discuss the generators and their individual wastes that belong to the class of wastes and, to the extent practical, any generators or individual wastes that, although belonging to the class of wastes, are not represented by the petition or petitions; and

(d) For each individual waste within the class of wastes, provide the demonstration described by subsection (3) of this section, except that where it is determined by consultation with the department to be impractical to provide the demonstration for each individual waste, the petitioner or petitioners will provide the demonstration for samples of the individual wastes determined by consultation with the department to be representative of the class of wastes.

[Statutory Authority: Chapters 70.105 and 70.105D RCW. 95-22-008 (Order 94-30), 173-303-072, filed 10/19/95, effective 11/19/95; 94-01-060 (Order 92-33), 173-303-072, filed 12/8/93, effective 1/8/94. Statutory Authority: Chapters 70.105 and 70.105D RCW, 40 CFR Part 271.3 and RCRA 3006 (42 U.S.C. 3251). 91-07-005 (Order 90-42), 173-303-072, filed 3/7/91, effective 4/7/91. Statutory Authority: Chapter 70.105 RCW. 84-14-031 (Order DE 84-22), 173-303-072, filed 6/27/84.]

\section{WAC173-303-072(3,4)- Delisting Petition Regulations}

3. Bases for exempting wastes. To successfully petition the department to exempt a waste, the petitioner must demonstrate to the satisfaction of the department that: (a)he has been able to accurately describe the variability or uniformity of his waste over time, and has been able to obtain demonstration 
samples which are representative of his waste's variability or uniformity; and, either (b)the representative demonstration samples of his waste are not designated DW or EHW by the dangerous waste criteria, WAC 173-303-100;or (c)it can be shown, from information developed by the petitioner through consultation with the department, that his waste does not otherwise pose a threat to public health or the environment. However, this basis for exemption is not applicable to wastes that exhibit any of the characteristics specified in WAC 173-303-090, except 173-303-090(6)(a)(iii).

4. Additional bases for exempting listed wastes. In addition to the demonstrations required by subsections (3)(a) and (b) of this section, for wastes listed in WAC 173-303-081 or 173-303-082 the petitioner must also demonstrate to the satisfaction of the department that his waste is not capable of posing a substantial present or potential threat to public health or the environment when improperly treated, stored, transported, disposed of or otherwise managed. The following factors will be considered by the department when assessing such a demonstration: (a)whether or not the listed waste contains the constituent or constituents which caused it to be listed. (For the purposes of this subsection, the constituents referred to will include any of the dangerous waste constituents listed in WAC 173-303-9905); (b)the nature of the threat posed by the waste constituent(s); (c)the concentration of the constituent(s) in the waste; (c)the potential of the consituent(s) or any degradation product of the constituent(s) to migrate from the waste into the environment under the types of improper management considered in (h) of this subsection; (e)the persistence of the constituent(s) or any degradation product of the constituent(s); (f)the potential for the constituent(s) or any degradation product of the constituent(s) to degrade into nonharmful constituents and the rate of degradation; (g)the degree to which the constituent(s) or degradation product of the constituent(s) bioaccumulates in ecosystems; (h)the plausible types of improper management to which the waste could be subjected; (i)the quantities of the waste generated at individual generation sites or on a state-wide basis. Under this factor, the department will also consider whether or not the waste is listed under WAC 173-303-081 as a discarded chemical product and occurs in a relatively pure form. Any waste discarded chemical product which exceeds the quantity exclusion limit specified in WAC 173-303-081(2) for that waste will not be exempted; (j)the nature and severity of the public health and environment damage that has occurred as a result of the improper management of wastes containing the constituent(s); (k)actions taken by other governmental agencies or regulatory programs based on the health or environmental threat posed by the waste or waste constituent(s); and (1)such other factors as may be appropriate.

\section{WAC173-303-090}

(1) Purpose. The purpose of this section is to set forth characteristics which a solid waste might exhibit and which would cause that waste to be a dangerous waste.

(2) Representative samples. The department will consider a sample obtained using any of the applicable sampling methods described in WAC 173-303-110(2), sampling and testing methods, to be a representative sample.

(3) Equivalent test methods. The testing methods specified in this section shall be the only acceptable methods, unless the department approves an equivalent test method in accordance with WAC 173-303-910(2).

(4) Quantity exclusion limit. A solid waste is a dangerous waste if it exhibits one or more of the dangerous waste characteristics described in subsections (5), (6), (7), and (8) of this section. If a person"s solid waste exhibits one or more of these characteristics, then he shall be a dangerous waste generator (and may not be considered a small quantity generator as provided in WAC 173-303-070(8)) if the quantity of his waste exceeds $220 \mathrm{lbs}$. $(100 \mathrm{~kg})$ per month or per batch.

(5) Characteristic of ignitability. 
(a) A solid waste exhibits the characteristic of ignitability if a representative sample of the waste has any of the following properties:

(i) It is a liquid, other than an aqueous solution containing less than 24 percent alcohol by volume, and has a flash point less than 60 degrees $C$ ( 140 degrees $F$ ), as determined by a Pensky-Martens Closed Cup Tester, using the test method specified in ASTM Standard D-93-79 or D-93-80, or a Setaflash Closed Cup Tester, using the test method specified in ASTM Standard D-3278-78;

(ii) It is not a liquid and is capable, under standard temperature and pressure, of causing fire through friction, absorption of moisture or spontaneous chemical changes and, when ignited, burns so vigorously and persistently that it creates a hazard;

(iii) It is an ignitable compressed gas as defined in 49 CFR 173.300 and as determined by the test methods described in that regulation; or,

(iv) It is an oxidizer as defined in 49 CFR 173.151.

(b) A solid waste that exhibits the characteristic of ignitability, but is not designated as a dangerous waste under any of the dangerous waste lists, WAC 173-303-080 through 173-303-084, or dangerous waste criteria, WAC 173-303-101 through 173-303-103, shall be designated DW, and shall be assigned the dangerous waste number of D001.

(6) Characteristic of corrosivity.

(a) A solid waste exhibits the characteristic of corrosivity if a representative sample of the waste has any one or more of the following properties:

(i) It is aqueous, and has a $\mathrm{pH}$ less than or equal to 2 , or greater than or equal to 12.5 , as determined by a $\mathrm{pH}$ meter using Method 5.2 in Test Methods for the Evaluation of Solid Waste, Physical/Chemical Methods, available from the department;

(ii) It is liquid, and corrodes steel (SAE 1020) at a rate greater than 0.250 inch $(6.35 \mathrm{~mm})$ per year at a test temperature of 55 degrees $C$ ( 130 degrees $F$ ) as determined by the test method specified in NACE (National Association of Corrosion Engineers) Standard TM-01-69 as standardized in Test Methods for the Evaluation of Solid Waste, Physical/Chemical Methods. The NACE Standard is available from the department; or

(iii) It is solid or semi-solid, and when mixed with an equal weight of water results in a solution, the liquid portion of which has the property specified in (a)(i) of this subsection. Procedures for preparing and extracting the solution and liquid are described in the test procedures of WAC 173-303-110 (3)(a).

(b) A solid waste that exhibits the characteristic of corrosivity, but is not designated as a dangerous waste under any of the dangerous waste lists, WAC 173-303-080 through 173-303-084, or dangerous waste criteria, WAC 173-303-101 through 173-303-103, shall be designated DW, and shall be assigned the dangerous waste number of D002.

(7) Characteristic of reactivity.

(a) A solid waste exhibits the characteristic of reactivity if a representative sample of the waste has any of the following properties:

(i) It is normally unstable and readily undergoes violent change without detonating;

(ii) It reacts violently with water;

(iii) It forms potentially explosive mixtures with water;

(iv) When mixed with water, it generates toxic gases, vapors or fumes in a quantity sufficient to present a danger to human health or the environment;

(v) It is a cyanide or sulfide bearing waste which, when exposed to $\mathrm{pH}$ conditions between 2 and 12.5 can generate toxic gases, vapors or fumes in a quantity sufficient to present a danger to human health or the environment;

(vi) It is capable of detonation or explosive reaction if it is subjected to a strong initiating source or if heated under confinement;

(vii) It is readily capable of detonation or explosive decomposition or reaction at standard temperature and pressure; or 
(viii) It is a forbidden explosive as defined in 49 CFR 173.51, or a Class A explosive as defined in 49 CFR 173.53, or a Class B explosive as defined in 49 CFR 173.88.

(b) A solid waste that exhibits the characteristic of reactivity, but is not designated as a dangerous waste under any of the dangerous waste lists, WAC 173-303-080 through 173-303-084, or dangerous waste criteria, WAC 173-303-101 through 173-303-103, shall be designated DW, and shall be assigned the dangerous waste number of $\mathrm{D} 003$.

(8) Toxicity characteristic.

(a) A solid waste exhibits the toxicity characteristic if, using the Toxicity Characteristic Leaching Procedure (TCLP, found in Appendix II of 40 CFR Part 261 or available upon request from the department) or equivalent methods approved by the department under WAC 173-303-110(5), the extract from a representative sample of the waste contains any of the contaminants listed in the toxicity characteristic list in (c) of this subsection, at concentrations equal to or greater than the respective value given in the list. When the waste contains less than 0.5 percent filterable solids, the waste itself, after filtering using the methodology outlined in the TCLP, is considered to be the extract for the purposes of this subsection.

(b) A solid waste that exhibits the toxicity characteristic, but is not designated as a dangerous waste under any of the dangerous waste lists, WAC 173-303-080 through 173-303-084, or dangerous waste criteria, WAC 173-303-101 through 173-303-103, has the dangerous waste number specified in the list which corresponds to the toxic contaminant causing it to be dangerous.

(c) Toxicity characteristic list. Two levels of concentration are established for the contaminants listed. Any waste containing one or more contaminants with concentrations at or above the EHW threshold shall cause that waste to be designated EHW. Any waste containing contaminants which occur at concentrations at or above the DW threshold only (i.e., no EHW contaminants), shall be designated DW.

TOXICITY CHARACTERISTICS LIST:

Maximum Concentration of Contaminants for the Toxicity Characteristic

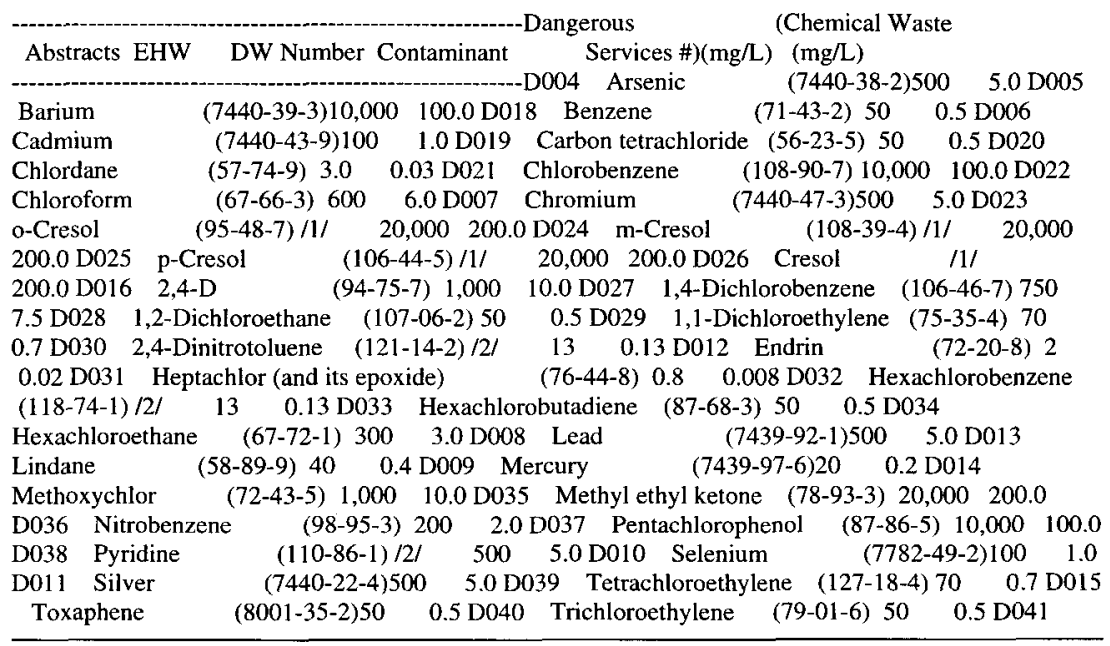


2,4,5-Trichlorophenol (95-95-4) 40,000 400.0 D042 2,4,6-Trichlorophenol (88-06-2) $200 \quad 2.0$

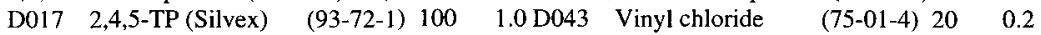

/1/ If 0-, m-, and p-Cresol concentrations cannot be differentiated, the total cresol (D026) concentration is used. The DW level for total cresol is $200 \mathrm{mg} / \mathrm{L}$ and the EHW level for total cresol is $20,000 \mathrm{mg} / \mathrm{L}$. $/ 2 /$ Quantitation limit is greater than the calculated regulatory level. The quantitation limit therefore becomes the regulatory level.

[Statutory Authority: Chapters 70.105 and 70.105D RCW, 40 CFR Part 271.3 and RCRA 3006 (42 U.S.C. 3251) . 91-07-005 (Order 90-42), 173-303-090, filed 3/7/91, effective 4/7/91. Statutory Authority: Chapter 70.105 RCW. 87-14-029 (Order DE-87-4), 173-303-090, filed 6/26/87; 86-12-057 (Order DE-85-10), 173-303-090, filed 6/3/86; 84-14-031 (Order DE 84-22), 173-303-090, filed 6/27/84. Statutory Authority: RCW 70.95.260 and chapter 70.105 RCW. 82-05-023 (Order DE 81-33), 173-303-090, filed 2/10/82.]

WAC173-303-110

WAC173-303-140

\section{WAC173-303-340(2)}

(2) Access to communications or alarms. Personnel must have immediate access to the signalling devices described in the situations below:

(a) Whenever dangerous waste is being poured, mixed, spread, or otherwise handled, all personnel involved must have immediate access to an internal alarm or emergency communication device, either directly or through visual or voice contact with another employee, unless such a device is not required in subsection (1) of this section;

(b) If there is ever just one employee on the premises while the facility is operating, he must have immediate access to a device, such as a telephone or a hand-held, two-way radio, capable of summoning external emergency assistance, unless such a device is not required in subsection (1) of this section.

\section{WAC173-303-610 Closure and postclosure}

Closure and postclosure

(1) Applicability.

(a) Subsections (2) through (6) of this section, (which concern closure), apply to the owners and operators of all dangerous waste facilities.

(b) Subsections (7) through (11) of this section, (which concern postclosure care), apply to the owners 
and operators of all regulated units (as defined in WAC 173-303-040) at which dangerous waste will remain after closure, to tank systems that are required under WAC 173-303-640(8) to meet the requirements of landfills, to surface impoundments, waste piles, and miscellancous units as specified in WAC 173-303-650(6), 173-303-660(9), and 173-303-680(4), respectively and, unless otherwise authorized by the department, to the owners and operators of all facilities which, at closure, cannot meet the removal or decontamination limits specified in subsection (2)(b) of this section.

(c) For the purposes of the closure and postclosure requirements, any portion of a facility which closes is subject to the applicable closure and postclosure standards even if the rest of the facility does not close and continues to operate.

(2) Closure performance standard. The owner or operator must close the facility in a manner that:

(a)(i) Minimizes the need for further maintenance;

(ii) Controls, minimizes or eliminates to the extent necessary to protect human health and the environment, postclosure escape of dangerous waste, dangerous constituents, leachate, contaminated run-off, or dangerous waste decomposition products to the ground, surface water, ground water, or the atmosphere; and

(iii) Returns the land to the appearance and use of surrounding land areas to the degree possible given the nature of the previous dangerous waste activity.

(b) Where the closure requirements of this section, or of WAC 173-303-630(10), 173-303-640(8), 173-303-650(6), 173-303-655(6), 173-303-655(8), 173-303-660(9), 173-303-665(6), 173-303-670(8), or 173-303-680 (2) through (4), or 40 CFR 264.1102 (incorporated by reference at WAC 173-303-695) call for the removal or decontamination of dangerous wastes, waste residues, or equipment, bases, liners, soils or other materials containing or contaminated with dangerous wastes or waste residue, then such removal or decontamination must assure that the levels of dangerous waste or dangerous waste constituents or residues do not exceed:

(i) For soils, groundwater, surface water, and air, the numeric cleanup levels calculated using residential exopsure assumptions according to the Model Toxics Control Act Regulations, chapter 173-340 WAC as now or hearafter amended. Primarily, these will be numeric cleanup levels calculated according to MTCA Method B, although MTCA Method A may be used as appropriate, see WAC 173-340-700 through 173-340-760, excluding WAC 173-340-745; and

(ii) For all structures, equipment, bases, liners, etc., clean closure standards will be set by the department on a case-by-case basis in accordance with the closure performance standards of WAC 173-303-610 (2)(a)(ii) and in a manner that minimizes or eliminates post-closure escape of dangerous waste constituents.

(3) Closure plan; amendment of plan.

(a) The owner or operator of a dangerous waste management facility must have a written closure plan. In addition, certain surface impoundments and waste piles from which the owner or operator intends to remove or decontaminate the dangerous waste at partial or final closure are required by WAC 173-303-650(6) and 173-303-660(9) to have contingent closure plans. The plan must be submitted with the permit application, in accordance with WAC 173-303-806(4), and approved by the department as part of the permit issuance procedures under WAC 173-303-840. The approved closure plan will become a condition of any permit. The department"'s decision must assure that the approved closure plan is consistent with subsections (2), (3), (4), (5), and (6) of this section, and the applicable requirements of WAC 173-303-630(10), 173-303-640(8), 173-303-650(6), 173-303-655(8), 173-303-660(9), 173-303-665(6), 173-303-670(8), and 173-303-680(2). A copy of the approved plan and all revisions to the plan must be furnished to the department upon request, including request by mail until final closure is completed and certified in accordance with subsection (6) of this section. The plan must identify steps necessary to perform partial and/or final closure of the facility at any point during its active life. The closure plan must include at least:

(i) A description of how each dangerous waste management unit at the facility will be closed in 
accordance with subsection (2) of this section;

(ii) A description of how final closure of the facility will be conducted in accordance with subsection (2) of this section. The description must identify the maximum extent of the operation which will be unclosed during the active life of the facility;

(iii) An estimate of the maximum inventory of dangerous wastes ever on-site over the active life of the facility. (Any change in this estimate is a minor modification under WAC 173-303-830(4));

(iv) A detailed description of the methods to be used during partial closures and final closure, including, but not limited to, methods for removing, transporting, treating, storing, or disposing of all dangerous wastes, and identification of the type(s) of the off-site dangerous waste management units to be used, if applicable;

(v) A detailed description of the steps needed to remove or decontaminate all dangerous waste residues and contaminated containment system components, equipment, structures, and soils during partial and final closure, including, but not limited to, procedures for cleaning equipment and removing contaminated soils, methods for sampling and testing surrounding soils, and criteria for determining the extent of decontamination required to satisfy the closure performance standard;

(vi) A detailed description of other activities necessary during the closure period to ensure that all partial closures and final closure satisfy the closure performance standards, including, but not limited to, ground water monitoring, leachate collection, and run-on and run-off control; and

(vii) A schedule for closure of each dangerous waste management unit and for final closure of the facility. The schedule must include, at a minimum, the total time required to close each dangerous waste management unit and the time required for intervening closure activities which will allow tracking of the progress of partial and final closure. (For example, in the case of a landfill unit, estimates of the time required to treat or dispose of all dangerous waste inventory and of the time required to place a final cover must be included.) Additionally, for facilities that use trust funds to establish financial assurance under WAC 173-303-620 (4) or (6) and that are expected to close prior to the expiration of the permit, an estimate of the expected year of final closure.

(b) The owner or operator must submit a written notification of or request for a permit modification to authorize a change in operating plans, facility design, or the approved closure plan in accordance with the applicable procedures in WAC 173-303-800 through 173-303-840. The written notification or request must include a copy of the amended closure plan for review or approval by the department.

(i) The owner or operator may submit a written notification or request to the department for a permit modification to amend the closure plan at any time prior to the notification of partial or final closure of the facility.

(ii) The owner or operator must submit a written notification of or request for a permit modification to authorize a change in the approved closure plan whenever:

(A) Changes in operating plans or facility design affect the closure plan; or

(B) There is a change in the expected year of closure, if applicable; or

(C) In conducting partial or final closure activities, unexpected events require a modification of the approved closure plan.

(iii) The owner or operator must submit a written request for a permit modification including a copy of the amended closure plan for approval at least sixty days prior to the proposed change in facility design or operation, or no later than sixty days after an unexpected event has occurred which has affected the closure plan. If an unexpected event occurs during the partial or final closure period, the owner or operator must request a permit modification no later than thirty days after the unexpected event. An owner or operator of a surface impoundment or waste pile that intends to remove all dangerous waste at closure and is not otherwise required to prepare a contingent closure plan under WAC 173-303-650(6) or 173-303-660(9), must submit an amended closure plan to the department no later than sixty days from the date that the owner or operator or department determines that the dangerous waste management unit must be closed as a landfill, subject to the requirements of WAC 173-303-665, or no later than thirty days from 
that date if the determination is made during partial or final closure. The department will approve, disapprove, or modify this amended plan in accordance with the procedures in WAC 173-303-800 through 173-303-840. The approved closure plan will become a condition of any permit issued.

(iv) The department may request modifications to the plan under the conditions described in (b)(ii) of this subsection. The owner or operator must submit the modified plan within sixty days of the department"'s request, or within thirty days if the change in facility conditions occurs during partial or final closure. Any modifications requested by the department will be approved in accordance with the procedures in WAC 173-303-800 through 173-303-840.

(c) Notification of partial closure and final closure.

(i) The owner or operator must notify the department in writing at least sixty days prior to the date on which he expects to begin closure of a surface impoundment, waste pile, land treatment, or landfill unit, or final closure of a facility with such a unit. The owner or operator must notify the department in writing at least forty-five days prior to the date on which he expects to begin final closure of a facility with only treatment or storage tanks, container storage, or incinerator units to be closed.

(ii)(A) The date when he "expects to begin closure" must be either no later than thirty days after the date on which any dangerous waste management unit receives the known final volume of dangerous wastes or, if there is a reasonable possibility that the dangerous waste management unit will receive additional dangerous wastes, no later than one year after the date on which the unit received the most recent volume of dangerous waste. If the owner or operator of a dangerous waste management unit can demonstrate to the department that the dangerous waste management unit or facility has the capacity to receive additional dangerous wastes and he has taken, and will continue to take, all steps to prevent threats to human health and the environment, including compliance with all applicable permit requirements, the department may approve an extension to this one-year limit.

(B) For units meeting the requirements of subsection (4)(d) of this section, no later than thirty days after the date on which the dangerous waste management unit receives the known final volume of nondangerous wastes, or if there is a reasonable possibility that the dangerous waste management unit will receive additional nondangerous wastes, no later than one year after the date on which the unit received the most recent volume of nondangerous wastes. If the owner or operator can demonstrate to the department that the dangerous waste management unit has the capacity to receive additional nondangerous wastes and he has taken, and will continue to take, all steps to prevent threats to human health and the environment, including compliance with all applicable permit requirements, the department may approve an extension to this one-year limit.

(iii) If the facility"s permit is terminated, or if the facility is otherwise ordered, by judicial decree or final order to cease receiving dangerous wastes or to close, then the requirements of (c) of this subsection do not apply. However, the owner or operator must close the facility in accordance with the deadlines established in subsection (4) of this section.

(iv) Removal of wastes and decontamination or dismantling of equipment. Nothing in this subsection shall preclude the owner or operator from removing dangerous wastes and decontaminating or dismantling equipment in accordance with the approved partial or final closure plan at any time before or after notification of partial or final closure.

(4) Closure; time allowed for closure.

(a) Within ninety days after receiving the final volume of dangerous wastes, or the final volume of nondangerous wastes if the owner or operator complies with all applicable requirements in (d) and (e) of this subsection, at a dangerous waste management unit or facility, the owner or operator must treat, remove from the unit or facility, or dispose of on site, all dangerous wastes in accordance with the approved closure plan. The department may approve a longer period if the owner or operator complies with all applicable requirements for requesting a modification to the permit and demonstrates that he has taken and will continue to take all steps to prevent threats to human health and the environment, including compliance with all applicable permit requirements, and either: 
(i) The activities required to comply with this paragraph will, of necessity, take longer than ninety days to complete; or

(ii)(A) The dangerous waste management unit or facility has the capacity to receive additional dangerous wastes, or has the capacity to receive nondangerous wastes if the owner or operator complies with (d) and (e) of this subsection;

(B) There is a reasonable likelihood that he or another person will recommence operation of the dangerous waste management unit or the facility within one year; and

(C) Closure of the dangerous waste management unit or facility would be incompatible with continued operation of the site.

(b) The owner or operator must complete partial and final closure activities in accordance with the approved closure plan and within one hundred eighty days after receiving the final volume of dangerous wastes, or the final volume of nondangerous wastes if the owner or operator complies with all applicable requirements in (d) and (e) of this subsection, at the dangerous waste management unit or facility. The department may approve an extension to the closure period if the owner or operator complies with all applicable requirements for requesting a modification to the permit and demonstrates that he has taken and will continue to take all steps to prevent threats to human health and the environment from the unclosed but not operating dangerous waste management unit or facility, including compliance with all applicable permit requirements, and either:

(i) The partial or final closure activities will, of necessity, take longer than one hundred eighty days to complete; or

(ii)(A) The dangerous waste management unit or facility has the capacity to receive additional dangerous wastes, or has the capacity to receive nondangerous wastes if the owner or operator complies with (d) and (e) of this subsection;

(B) There is reasonable likelihood that he or another person will recommence operation of the dangerous waste management unit or the facility within one year; and

(C) Closure of the dangerous waste management unit or facility would be incompatible with continued operation of the site.

(c) The demonstrations referred to in (a) and (b) of this subsection must be made as follows: The demonstrations in (a) of this subsection must be made at least thirty days prior to the expiration of the specified ninety-day period; and the demonstration in (b) of this subsection must be made at least thirty days prior to the expiration of the specified one hundred eighty-day period unless the owner or operator is otherwise subject to the deadlines in (d) of this subsection.

(d) The department may allow an owner or operator to receive only nondangerous wastes in a landfill, land treatment, or surface impoundment unit after the final receipt of dangerous wastes at that unit if:

(i) The owner or operator requests a permit modification in compliance with all applicable requirements in WAC 173-303-830 and 40 CFR Part 124 and in the permit modification request demonstrates that:

(A) The unit has the existing design capacity as indicated on the part A application to receive nondangerous wastes; and

(B) There is a reasonable likelihood that the owner or operator or another person will receive nondangerous wastes in the unit within one year after the final receipt of dangerous wastes; and

(C) The nondangerous wastes will not be incompatible with any remaining wastes in the unit, or with the facility design and operating requirements of the unit or facility under this part; and

(D) Closure of the dangerous waste management unit would be incompatible with continued operation of the unit or facility; and

(E) The owner or operator is operating and will continue to operate in compliance with all applicable permit requirements; and

(ii) The request to modify the permit includes an amended wastes analysis plan, ground water monitoring and response program, human exposure assessment required under RCRA section 3019, and closure and postclosure plan, and updated cost estimates and demonstrations of financial assurance for 
closure and postclosure care as necessary and appropriate, to reflect any changes due to the presence of dangerous constituents in the nondangerous wastes, and changes in closure activities, including the expected year of closure if applicable under subsection (3)(a)(vii) of this section, as a result of the receipt of nondangerous wastes following the final receipt of dangerous wastes; and

(iii) The request to modify the permit includes revisions, as necessary and appropriate, to affected conditions of the permit to account for the receipt of nondangerous wastes following receipt of the final volume of dangerous wastes; and

(iv) The request to modify the permit and the demonstration referred to in (d)(i) and (ii) of this subsection are submitted to the department no later than one hundred twenty days prior to the date on which the owner or operator of the facility receives the known final volume of dangerous wastes at the unit, or no later than ninety days after the effective date of this rule in the state in which the unit is located, whichever is later.

(e) In addition to the requirements in (d) of this subsection, an owner or operator of a dangerous wastes surface impoundment that is not in compliance with the liner and leachate collection system requirements in 42 U.S.C. 3004 (o) (2) or (3) or 3005 (j) (2), (3), (4) or (13) must:

(i) Submit with the request to modify the permit:

(A) A contingent corrective measures plan, unless a corrective action plan has already been submitted under WAC 173-303-645(10); and

(B) A plan for removing dangerous wastes in compliance with (e)(ii) of this subsection; and (ii) Remove all dangerous wastes from the unit by removing all dangerous liquids, and removing all dangerous sludges to the extent practicable without impairing the integrity of the liner(s), if any.

(iii) Removal of dangerous wastes must be completed no later than ninety days after the final receipt of dangerous wastes. The department may approve an extension to this deadline if the owner or operator demonstrates that the removal of dangerous wastes will, of necessity, take longer than the allotted period to complete and that an extension will not pose a threat to human health and the environment.

(iv) If a release that is a statistically significant increase (or decrease in the case of $\mathrm{pH}$ ) over background values for detection monitoring parameters of constituents specified in the permit or that exceeds the facility"s ground water protection standard at the point of compliance, if applicable, is detected in accordance with the requirements in subpart $\mathrm{F}$ of this part, the owner or operator of the unit:

(A) Must implement corrective measures in accordance with the approved contingent corrective measures plan required by (e)(i) of this subsection no later than one year after detection of the release, or approval of the contingent corrective measures plan, whichever is later;

(B) May continue to receive wastes at the unit following detection of the release only if the approved corrective measures plan includes a demonstration that continued receipt of wastes will not impede corrective action; and

(C) May be required by the department to implement corrective measures in less than one year or to cease the receipt of wastes until corrective measures have been implemented if necessary to protect human health and the environment.

(v) During the period of corrective action, the owner or operator shall provide semiannual reports to the department that describe the progress of the corrective action program, compile all ground water monitoring data, and evaluate the effect of the continued receipt of nondangerous wastes on the effectiveness of the corrective action.

(vi) The department may require the owner or operator to commence closure of the unit if the owner or operator fails to implement corrective action measures in accordance with the approved contingent corrective measures plan within one year as required in (e)(iv) of this subsection, or fails to make substantial progress in implementing corrective action and achieving the facility"s ground water protection standard or background levels if the facility has not yet established a ground water protection standard.

(vii) If the owner or operator fails to implement corrective measures as required in (e)(iv) of this 
subsection or if the department determines that substantial progress has not been made pursuant to (e)(vi) of this subsection the department shall:

(A) Notify the owner or operator in writing that the owner or operator must begin closure in accordance with the deadline in (a) and (b) of this subsection and provide a detailed statement of reasons for this determination; and

(B) Provide the owner or operator and the public, through a newspaper notice, the opportunity to submit written comments on the decision no later than twenty days after the date of the notice.

(C) If the department receives no written comments, the decision will become final five days after the close of the comment period. The department will notify the owner or operator that the decision is final, and that a revised closure plan, if necessary, must be submitted within fifteen days of the final notice and that closure must begin in accordance with the deadlines in (a) and (b) of this subsection.

(D) If the department receives written comments on the decision, it shall make a final decision within thirty days after the end of the comment period, and provide the owner or operator in writing and the public through a newspaper notice, a detailed statement of reasons for the final decision. If the department determines that substantial progress has not been made, closure must be initiated in accordance with the deadlines in (a) and (b) of this subsection.

(E) The final determinations made by the department under $(e)(v i i)(C)$ and (D) of this subsection are not subject to administrative appeal.

(5) Disposal or decontamination of equipment, structures and soils. During the partial and final closure periods, all contaminated equipment, structures and soils must be properly disposed of or decontaminated unless otherwise specified in WAC 173-303-640(8), 173-303-650(6), 173-303-655(8), 173-303-660(9), 173-303-665(6), or under the authority of WAC 173-303-680 (2) and (4). By removing any dangerous wastes or dangerous constituents during partial and final closure, the owner or operator may become a generator of dangerous waste and must handle that waste in accordance with all applicable requirements of WAC 173-303-170 through 173-303-230.

(6) Certification of closure. Within sixty days of completion of closure of each dangerous waste management unit (including tank systems and container storage areas), and within sixty days of the completion of final closure, the owner or operator must submit to the department by registered mail, a certification that the dangerous waste management unit or facility, as applicable, has been closed in accordance with the specifications in the approved closure plan. The certification must be signed by the owner or operator and by an independent registered professional engineer. Documentation supporting the independent registered professional engineer"s certification must be fumished to the department upon request until it releases the owner or operator from the financial assurance requirements for closure under WAC 173-303-620(4).

(7) Postclosure care and use of property.

(a) Postclosure care for each dangerous waste management unit subject to postclosure requirements must begin after completion of closure of the unit and continue for thirty years after that date and must consist of at least the following:

(i) Ground water monitoring and reporting as applicable; and

(ii) Maintenance and monitoring of waste containment systems as applicable.

(b) Any time preceding partial closure of a dangerous waste management unit subject to postclosure care requirements or final closure, or any time during the postclosure period for a particular unit, the department may, in accordance with the permit modification procedures in WAC 173-303-800 through 173-303-840:

(i) Shorten the postclosure care period applicable to the dangerous waste management unit, or facility, if all disposal units have been closed, if it finds that the reduced period is sufficient to protect human health and the environment (e.g., leachate or ground water monitoring results, characteristics of the dangerous waste, application of advanced technology, or altemative disposal, treatment, or reuse techniques indicate that the dangerous waste management unit or facility is secure); or 
(ii) Extend the postclosure care period applicable to the dangerous waste management unit or facility if it finds that the extended period is necessary to protect human health and the environment (e.g., leachate or ground water monitoring results indicate a potential for migration of dangerous waste at levels which may be harmful to human health and the environment).

(c) The department may require, at partial or final closure, continuation of any of the security requirements of WAC 173-303-310 during part or all of the postclosure period when:

(i) Dangerous wastes may remain exposed after completion of partial or final closure; or

(ii) Access by the public or domestic livestock may pose a hazard to human health.

(d) Postclosure use of property on or in which dangerous wastes remain after partial or final closure must never be allowed to disturb the integrity of the final cover, liner(s), or any other components of any containment system, or the function of the facility"'s monitoring systems, unless the department finds that the disturbance:

(i) Is necessary to the proposed use of the property, and will not increase the potential hazard to human health or the environment; or

(ii) Is necessary to reduce a threat to human health or the environment.

(e) All postclosure care activities must be in accordance with the provisions of the approved postclosure plan as specified in subsection (8) of this section.

(8) Postclosure plan; amendment of plan.

(a) The owner or operator of a dangerous waste disposal unit must have a written postclosure plan. In addition, certain surface impoundments and certain piles from which the owner or operator intends to remove or decontaminate the dangerous wastes at partial or final closure are required by WAC 173-303-650 and 173-303-660, respectively, to have written contingent postclosure plans. Owners or operators of surface impoundments and waste piles not otherwise required to prepare contingent postclosure plans under WAC 173-303-650 or 173-303-660 must submit a postclosure plan to the department within ninety days from the date that the owner or operator or department determines that the dangerous waste management unit must be closed as a landfill, subject to the postclosure requirements. The plan must be submitted with the permit application, in accordance with WAC 173-303-806, and approved by the department as part of the permit issuance procedures under WAC 173-303-840. The approved postclosure plan will become a condition of any permit issued.

(b) For each dangerous waste management unit subject to the requirements of this subsection, the postclosure plan must identify the activities which will be carried on after closure and the frequency of these activities, and include at least:

(i) A description of the planned ground water monitoring activities and frequencies at which they will be performed;

(ii) A description of the planned maintenance activities, and frequencies at which they will be performed, to ensure:

(A) The integrity of the cap and final cover or other containment structures where applicable; and

(B) The function of the facility monitoring equipment;

(iii) And the name, address, and phone number of the person or office to contact about the dangerous waste disposal unit or facility during the postclosure care period.

(c) Until final closure of the facility, a copy of the approved postclosure plan must be furnished to the department upon request, including request by mail. After final closure has been certified, the person or office specified in (b)(iii) of this subsection must keep the approved postclosure plan during the remainder of the postclosure period.

(d) Amendment of plan. The owner or operator must submit a written notification of or request for a permit modification to authorize a change in the approved postclosure plan in accordance with the applicable requirements of WAC 173-303-800 through 173-303-840. The written notification or request must include a copy of the amended postclosure plan for review or approval by the department.

(i) The owner or operator may submit a written notification or request to the department for a permit 
modification to amend the postclosure plan at any time during the active life of the facility or during the postclosure care period.

(ii) The owner or operator must submit a written notification of or request for a permit modification to authorize a change in the approved postclosure plan whenever:

(A) Changes in operating plans or facility design affect the approved postclosure plan; or

(B) There is a change in the expected year of final closure, if applicable; or

(C) Events which occur during the active life of the facility, including partial and final closures, affect

the approved postclosure plan.

(iii) The owner or operator must submit a written request for a permit modification at least sixty days prior to the proposed change in facility design or operation, or no later than sixty days after an unexpected event has occurred which has affected the postclosure plan. An owner or operator of a surface impoundment or waste pile that intends to remove all dangerous waste at closure and is not otherwise required to submit a contingent postclosure plan under WAC 173-303-650 or 173-303-660 must submit a postclosure plan to the department no later than ninety days after the date that the owner or operator or department determines that the dangerous waste management unit must be closed as a landfill, subject to the requirements of WAC 173-303-665. The department will approve, disapprove, or modify this plan in accordance with the procedures in WAC 173-303-800 through 173-303-840. The approved postclosure plan will become a permit condition.

(iv) The department may request modifications to the plan under the conditions described in (d)(ii) of this subsection. The owner or operator must submit the modified plan no later than sixty days after the department's request, or no later than ninety days if the unit is a surface impoundment or waste pile not previously required to prepare a contingent postclosure plan. Any modifications requested by the department will be approved, disapproved, or modified in accordance with the procedures in WAC 173-303-800 through 173-303-840.

(9) Notice to local land authority. No later than the submission of the certification of closure of each dangerous waste disposal unit, the owner or operator of a disposal facility must submit to the local zoning authority or the authority with jurisdiction over local land use and to the department a survey plat indicating the location and dimensions of landfill cells or other dangerous waste disposal units with respect to permanently surveyed benchmarks. This plat must be prepared and certified by a professional land surveyor. The plat filed with the local zoning authority or the authority with jurisdiction over local land use must contain a note, prominently displayed, which states the owner's or operator's obligation to restrict disturbance of the dangerous waste disposal unit in accordance with the applicable requirements of this section. In addition, no later than sixty days after certification of closure of each dangerous waste disposal unit, the owner or operator must submit to the local zoning authority or the authority with jurisdiction over local land use and to the department, a record of the type, location, and quantity of dangerous wastes disposed of within each cell or other disposal unit of the facility. For wastes disposed of before November 19, 1980 (March 12, 1982, for facilities subject to this chapter but not subject to $40 \mathrm{CFR}$ Part 264), the owner or operator must identify the type, location, and quantity of the dangerous wastes to the best of his knowledge and in accordance with any records he has kept.

(10) Notice in deed to property.

(a) No later than sixty days after certification of closure of each dangerous waste disposal unit, the owner or operator must submit to the local zoning authority, or the authority with jurisdiction over local land use, and to the department a record of the type, location, and quantity of dangerous wastes disposed of within each cell or other disposal unit of the facility. For hazardous wastes (as defined in WAC 173-303-040) disposed of before January 12,1981, the owner or operator must identify the type, location, and quantity of the dangerous wastes to the best of his knowledge and in accordance with any records he has kept.

(b) Within sixty days of certification of closure of the first dangerous waste disposal unit and within sixty days of certification of closure of the last dangerous waste disposal unit, the owner or operator must: 
(i) Record, in accordance with state law, a notation on the deed to the facility property, or on some other instrument which is normally examined during title search, that will in perpetuity notify any potential purchaser of the property that:

(A) The land has been used to manage dangerous wastes;

(B) Its use is restricted under this section; and

(C) The survey plat and record of the type, location, and quantity of dangerous wastes disposed of within each cell or other dangerous waste disposal unit of the facility required in subsection (9) of this section have been filed with the local zoning authority, or the authority with jurisdiction over local land use, and with the department; and

(ii) Submit a certification, signed by the owner or operator, that he has recorded the notation specified in (b)(i) of this subsection, including a copy of the document in which the notation has been placed, to the department.

(c) If the owner or operator or any subsequent owner of the land upon which a dangerous waste facility was located wishes to remove dangerous wastes and dangerous waste residues, the liner, if any, or contaminated soils, he must request a modification to the postclosure permit in accordance with the applicable requirements in WAC 173-303-800 through 173-303-840. The owner or operator must demonstrate that the removal of dangerous wastes will satisfy the criteria of subsection (7)(d) of this section. By removing dangerous waste, the owner or operator may become a generator of dangerous waste and must manage it in accordance with all applicable requirements of this chapter. If he is granted a permit modification or otherwise granted approval to conduct such removal activities, the owner or operator may request that the department approve either:

(i) The removal of the notation on the deed to the facility property or other instrument normally examined during title search; or

(ii) The addition of a notation to the deed or instrument indicating the removal of the dangerous waste.

(11) Certification of completion of postclosure care. No later than sixty days after completion of the established postclosure care period for each dangerous waste disposal unit, the owner or operator must submit to the department, by registered mail, a certification that the postclosure care period for the dangerous waste disposal unit was performed in accordance with the specifications in the approved postclosure plan. The certification must be signed by the owner or operator and an independent registered professional engineer. Documentation supporting the independent registered professional engineer's certification must be furnished to the department upon request until he releases the owner or operator from the financial assurance requirements for postclosure care under WAC 173-303-620(6).

[Statutory Authority: Chapters 70.105 and 70.105D RCW, 40 CFR Part 271.3 and RCRA 3006 (42 U.S.C. 3251). 91-07-005 (Order 90-42), 173-303-610, filed 3/7/91, effective 4/7/91. Statutory Authority: Chapter 70.105 RCW. 89-02-059 (Order 88-24), 173-303-610, filed 1/4/89; 87-14-029 (Order DE-87-4), 173-303-610, filed 6/26/87; 84-14-031 (Order DE 84-22), 173-303-610, filed 6/27/84. Statutory Authority: RCW 70.95.260 and chapter 70.105 RCW. 82-05-023 (Order DE 81-33), 173-303-610, filed 2/10/82.]

\section{WAC173-303-630 Use and management of containers}

Containers used for the storage of dangerous waste shall be stored/managed in accordance with this Code.

WAC173-303-630(1) 
(1) The regulations in this section apply to owners and operators of all dangerous waste facilities that store containers of dangerous waste.

\section{WAC173-303-630(10)}

(10) At closure, all dangerous waste and dangerous waste residues must be removed from the containment system. Remaining containers, liners, bases, and soil containing or contaminated with dangerous waste or dangerous waste residues must be decontaminated or removed.

\section{WAC173-303-630(6)}

(6) At least weekly, the owner or operator must inspect areas where containers are stored, looking for leaking containers and for deterioration of containers and the containment system caused by corrosion, deterioration, or other factors.

\section{WAC173-303-630(7)}

(7)(a) Container storage areas must have a containment system that is capable of collecting and holding spills and leaks. In addition to the necessary leak containment capacity, uncovered storage areas must be capable of holding the additional volume that would result from the precipitation of a maximum twenty-five year storm of twenty-four hours duration. The containment system must:

(i) Have a base underlying the containers which is free of cracks or gaps and is sufficiently impervious to contain leaks, spills, and accumulated rainfall until the collected material is detected and removed. The base must be sloped or the containment system must be otherwise designed and operated to drain and remove liquids resulting from leaks, spills, or precipitation, unless the containers are elevated or are otherwise protected from contact with accumulated liquids;

(ii) Be designed for positive drainage control (such as a locked drainage valve) to prevent release of contaminated liquids and so that uncontaminated precipitation can be drained promptly for convenience of operation. Spilled or leaked waste and accumulated precipitation must be removed from the containment system in as timely a manner as is necessary to prevent overflow; and

(iii) Have sufficient capacity to contain ten percent of the volume of all containers or the volume of the largest container, whichever is greater. Only containers holding free liquids, or holding wastes designated as F020, F021, F022, F023, F026, or F027 need to be considered in this determination.

(b) Run-on into the containment system must be prevented, unless the department waives this requirement in the permit after determining that the collection system has sufficient excess capacity in addition to that required in (a)(iii) of this subsection to accommodate any run-on which might enter the system.

(c) Storage areas that store containers holding only wastes that do not contain free liquids, do not exhibit either the characteristic of ignitability or reactivity as described in WAC 173-303-090 (5) or (7), and are not designated as F020, F021, F022, F023, F026, or F027, need not have a containment system as described in this subsection: Provided, That:

(i) The storage area is sloped or is otherwise designed and operated to drain and remove liquid resulting from precipitation; or

(ii) The containers are elevated or are otherwise protected from contact with accumulated liquids.

(d) EHW in containers must be protected from the elements by means of a building or other protective covering that otherwise allows adequate inspection under subsection (6) of this section. 


\section{WAC173-303-630(8)}

(8)(a) Containers holding reactive waste exhibiting a characteristic specified in WAC 173-303-090 (7)(a)(vi), (vii) or (viii) must be stored in a manner equivalent to the Uniform Fire Code"s "American Table of Distances for Storage of Explosives," Table 77-201, 1979 edition or the version adopted by the local fire district.

(b) The owner or operator shall design, operate, and maintain ignitable waste and reactive waste (other than a reactive waste which must meet (a) of this subsection) container storage in a manner equivalent with the Uniform Fire Code. Where no specific standard or requirements are specified in the Uniform Fire Code, or in existing state or local fire codes, applicable sections of the NFPA Pamphlet \# 30, "Flammable and Combustible Liquids Code," shall be used. The owner/operator shall also comply with the requirements of WAC 173-303-395 (1)(d).

\section{WAC173-303-640 Tank systems}

Tank systems used to treat or store dangerous waste shall comply with the regulations of this Code.

\section{WAC173-303-640(2)}

(2) Assessment of existing tank system's integrity.

(a) For each existing tank system, the owner or operator must determine that the tank system is not leaking or is unfit for use. Except as provided in (b) of this subsection, the owner or operator must obtain and keep on file at the facility a written assessment reviewed and certified by an independent, qualified registered professional engineer, in accordance with WAC 173-303-810 (13)(a), that attests to the tank system's integrity by January 12,1988, for underground tanks that do not meet the requirements of subsection (4) of this section and that cannot be entered for inspection, or by January 12, 1990, for all other tank systems.

(b) Tank systems that store or treat materials that become dangerous wastes subsequent to January 12 , 1989 , must conduct this assessment within twelve months after the date that the waste becomes a dangerous waste.

(c) This assessment must determine that the tank system is adequately designed and has sufficient structural strength and compatibility with the waste(s) to be stored or treated, to ensure that it will not collapse, rupture, or fail. At a minimum, this assessment must consider the following:

(i) Design standard(s), if available, according to which the tank system was constructed;

(ii) Dangerous characteristics of the waste(s) that have been and will be handled;

(iii) Existing corrosion protection measures;

(iv) Documented age of the tank system, if available (otherwise, an estimate of the age); and

(v) Results of a leak test, internal inspection, or other tank system integrity examination such that:

(A) For nonenterable underground tanks, the assessment must include a leak test that is capable of taking into account the effects of temperature variations, tank end deflection, vapor pockets, and high water table effects; and

(B) For other than nonenterable underground tanks and for ancillary equipment, this assessment must include either a leak test, as described above, or other integrity examination, that is certified by an independent, qualified, registered professional engineer, in accordance with WAC 173-303-810(13)(a), that addresses cracks, leaks, corrosion, and erosion.

Note: The practices described in the American Petroleum Institute (API) Publication, Guide for 
Inspection of Refinery Equipment, Chapter XIII, "Atmospheric and Low-Pressure Storage Tanks", 4th edition 1981, may be used, where applicable, as guidelines in conducting other than a leak test.

(d) If, as a result of the assessment conducted in accordance with (a) of this subsection, a tank system is found to be leaking or unfit for use, the owner or operator must comply with the requirements of subsection (7) of this section.

(e) The owner or operator must develop a schedule for conducting integrity assessments over the life of the tank to ensure that the tank retains its structural integrity and will not collapse, rupture, or fail. The schedule must be based on the results of past integrity assessments, age of the tank system, materials of construction, characteristics of the waste, and any other relevant factors.

\section{WAC173-303-640(3)(a)(iii)}

(iii) For new tank systems or components in which the external shell of a metal tank or any external metal component of the tank system will be in contact with the soil or with water, a determination by a corrosion expert of:

(A) Factors affecting the potential for corrosion, including but not limited to:

(I) Soil moisture content;

(II) Soil $\mathrm{pH}$;

(III) Soil sulfides level;

(IV) Soil resistivity;

(V) Structure to soil potential;

(VI) Influence of nearby underground metal structures (e.g., piping);

(VII) Existence of stray electric current;

(VIII) Existing corrosion-protection measures (e.g., coating, cathodic protection); and

(B) The type and degree of external corrosion protection that are needed to ensure the integrity of the tank system during the use of the tank system or component, consisting of one or more of the following:

(I) Corrosion-resistant materials of construction such as special alloys, fiberglass reinforced plastic, etc.;

(II) Corrosion-resistant coating (such as epoxy, fiberglass, etc.,) with cathodic protection (e.g., impressed current or sacrificial anodes); and

(III) Electrical isolation devices such as insulating joints, flanges, etc.

Note: The practices described in the National Association of Corrosion Engineers (NACE) standard, "Recommended Practice (RP-02-85)--Control of External Corrosion on Metallic Buried, Partially Buried, or Submerged Liquid Storage Systems," and the American Petroleum Institute (API) Publication 1632, "Cathodic Protection of Underground Petroleum Storage Tanks and Piping Systems," may be used, where applicable, as guidelines in providing corrosion protection for tank systems.

\section{WAC173-303-640(3)(b)}

$-640(3)$ (b) The owner or operator must develop a schedule for conducting integrity assessments over the life of the tank to ensure that the tank retains its structural integrity and will not collapse, rupture or fail. The schedule must be based on the results of past integrity assessments, age of the tank system, materials or construction, characteristics of the waste, and any other relevant factors. 
WAC173-303-640(3)(c)

(3)(c) The owner or operator of a new tank system must ensure that proper handling procedures are adhered to in order to prevent damage to the system during installation. Prior to covering, enclosing, or placing a new tank system or component in use, an independent, qualified installation inspector or an independent, qualified, registered professional engineer, either of whom is trained and experienced in the proper installation of tank systems or components, must inspect the system for the presence of any of the following items:

(i) Weld breaks;

(ii) Punctures;

(iii) Scrapes of protective coatings;

(iv) Cracks;

(v) Corrosion;

(vi) Other structural damage or inadequate construction/ installation.

All discrepancies must be remedied before the tank system is covered, enclosed, or placed in use.

\section{WAC173-303-640(3)(d)}

(3)(d) New tank systems or components that are placed underground and that are backfilled must be provided with a backfill material that is a noncorrosive, porous, homogeneous substance and that is installed so that the backfill is placed completely around the tank and compacted to ensure that the tank and piping are fully and uniformly supported.

\section{WAC173-303-640(3)(f)}

(3)(f) Ancillary equipment must be supported and protected against physical damage and excessive stress due to settlement, vibration, expansion, or contraction.

Note: The piping system installation procedures described in American Petroleum Institute (API) Publication 1615 (November 1979), "Installation of Underground Petroleum Storage Systems," or ANSI Standard B31.3, "Petroleum Refinery Piping," and ANSI Standard B31.4 "Liquid Petroleum Transportation Piping System," may be used, where applicable, as guidelines for proper installation of piping systems.

\section{WAC173-303-640(3)(g)}

(3) $(\mathrm{g})$ The owner or operator must provide the type and degree of corrosion protection recommended by an independent corrosion expert, based on the information provided under (a)(iii) of this subsection, or other corrosion protection if the department believes other corrosion protection is necessary to ensure the integrity of the tank system during use of the tank system. The installation of a corrosion protection system that is field fabricated must be supervised by an independent corrosion expert to ensure proper installation

WAC173-303-640(4)(b) 
(4)(b) Secondary containment systems must be:

(i) Designed, installed, and operated to prevent any migration of wastes or accumulated liquid out of the system to the soil, ground water, or surface water at any time during the use of the tank system; and (ii) Capable of detecting and collecting releases and accumulated liquids until the collected material is removed.

\section{WAC173-303-640(4)(c)}

(4)(c) To meet the requirements of (b) of this subsection, secondary containment systems must be at a minimum:

(i) Constructed of or lined with materials that are compatible with the waste(s) to be placed in the tank system and must have sufficient strength and thickness to prevent failure owing to pressure gradients (including static head and external hydrological forces), physical contact with the waste to which it is exposed, climatic conditions, and the stress of daily operations (including stresses from nearby vehicular traffic);

(ii) Placed on a foundation or base capable of providing support to the secondary containment system, resistance to pressure gradients above and below the system, and capable of preventing failure due to settlement, compression, or uplift;

(iii) Provided with a leak-detection system that is designed and operated so that it will detect the failure of either the primary or secondary containment structure or the presence of any release of dangerous waste or accumulated liquid in the secondary containment system within twenty-four hours, or at the earliest practicable time if the owner or operator can demonstrate to the department that existing detection technologies or site conditions will not allow detection of a release within twenty-four hours; and

(iv) Sloped or otherwise designed or operated to drain and remove liquids resulting from leaks, spills, or precipitation. Spilled or leaked waste and accumulated precipitation must be removed from the secondary containment system within twenty-four hours, or in as timely a manner as is possible to prevent harm to human health and the environment, if the owner or operator can demonstrate to the department that removal of the released waste or accumulated precipitation cannot be accomplished within twenty-four hours.

\section{WAC173-303-640(4)(d)}

(4)(d) Secondary containment for tanks must include one or more of the following devices:

(i) A liner (external to the tank);

(ii) A vault;

(iii) A double-walled tank; or

(iv) An equivalent device as approved by the department.

\section{WAC173-303-640(4)(e)}

(4)(e) In addition to the requirements of (b), (c), and (d) of this subsection, secondary containment 
systems must satisfy the following requirements:

(i) External liner systems must be:

(A) Designed or operated to contain one hundred percent of the capacity of the largest tank within its boundary;

(B) Designed or operated to prevent run-on or infiltration of precipitation into the secondary containment system unless the collection system has sufficient excess capacity to contain run-on or infiltration. Such additional capacity must be sufficient to contain precipitation from a twenty-five-year, twenty-four-hour rainfall event.

(C) Free of cracks or gaps; and

(D) Designed and installed to surround the tank completely and to cover all surrounding earth likely to come into contact with the waste if the waste is released from the tank(s) (i.e., capable of preventing lateral as well as vertical migration of the waste).

(ii) Vault systems must be:

(A) Designed or operated to contain one hundred percent of the capacity of the largest tank within its boundary;

(B) Designed or operated to prevent run-on or infiltration of precipitation into the secondary containment system unless the collection system has sufficient excess capacity to contain run-on or infiltration. Such additional capacity must be sufficient to contain precipitation from a twenty-five-year, twenty-four-hour rainfall event;

(C) Constructed with chemical-resistant water stops in place at all joints (if any);

(D) Provided with an impermeable interior coating or lining that is compatible with the stored waste and that will prevent migration of waste into the concrete;

(E) Provided with a means to protect against the formation of and ignition of vapors within the vault, if the waste being stored or treated:

(I) Meets the definition of ignitable waste under WAC 173-303-090 (5); or

(II) Meets the definition of reactive waste under WAC 173-303-090 (7), and may form an ignitable or explosive vapor.

(F) Provided with an exterior moisture barrier or be otherwise designed or operated to prevent migration of moisture into the vault if the vault is subject to hydraulic pressure.

(iii) Double-walled tanks must be:

(A) Designed as an integral structure (i.e., an inner tank completely enveloped within an outer shell) so that any release from the inner tank is contained by the outer shell;

(B) Protected, if constructed of metal, from both corrosion of the primary tank interior and of the external surface of the outer shell; and

(C) Provided with a built-in continuous leak detection system capable of detecting a release within twenty-four hours, or at the earliest practicable time, if the owner or operator can demonstrate to the department, and the department concludes, that the existing detection technology or site conditions would not allow detection of a release within twenty-four hours.

Note: The provisions outlined in the Steel Tank Institute's (STI) "Standard for Dual Wall Underground Steel Storage Tanks" may be used as guidelines for aspects of the design of underground steel double-walled tanks.

WAC173-303-640(4)(f) 
(4)(f) Ancillary equipment must be provided with secondary containment (e.g., trench, jacketing, double-walled piping) that meets the requirements of (b) and (c) of this subsection except for:

(i) Aboveground piping (exclusive of flanges, joints, valves, and other connections) that are visually inspected for leaks on a daily basis;

(ii) Welded flanges, welded joints, and welded connections, that are visually inspected for leaks on a daily basis;

(iii) Sealless or magnetic coupling pumps and sealless valves, that are visually inspected for leaks on a daily basis; and

(iv) Pressurized aboveground piping systems with automatic shut-off devices (e.g., excess flow check valves, flow metering shutdown devices, loss of pressure actuated shut-off devices) that are visually inspected for leaks on a daily basis.

\section{WAC173-303-640(4)(i)(C)}

For ancillary equipment, a leak test or other integrity assessment as approved by the Department of Ecology must be conducted at least annually.

\section{WAC173-303-640(5)}

(a) Dangerous wastes or treatment reagents must not be placed in a tank system if they could cause the tank, its ancillary equipment, or the containment system to rupture, leak, corrode, or otherwise fail.

(b) The owner or operator must use appropriate controls and practices to prevent spills and overflows from tank or containment systems. These include at a minimum:

(i) Spill prevention controls (e.g., check valves, dry disconnect couplings);

(ii) Overfill prevention controls (e.g., level sensing devices, high level alarms, automatic feed cutoff, or bypass to a standby tank); and

(iii) Maintenance of sufficient freeboard in uncovered tanks to prevent overtopping by wave or wind action or by precipitation.

(c) The owner or operator must comply with the requirements of subsection (7) of this section if a leak or spill occurs in the tank system.

(d) All tank systems holding dangerous waste shall be marked with labels or signs to identify the waste contained in the tank. The label or sign shall be legible at a distance of at least fifty feet, and shall bear a legend which identifies the waste in a manner which adequately warns employees, emergency response personnel, and the public of the major risk(s) associated with the waste being stored or treated in the tank system(s). (Note--If there already is a system in use that performs this function in accordance with local, state or federal regulations, then such system will be adequate.)

(e) All tank systems holding EHW which is acutely or chronically toxic by inhalation must be designed to prevent escape of vapors, fumes, or other emissions into the air. 


\section{WAC173-303-640(7)(a-c)}

(7) Response to leaks or spills and disposition of leaking or unfit-for-use tank systems.

A tank system or secondary containment system from which there has been a leak or spill, or which is unfit for use, must be removed from service immediately, and the owner or operator must satisfy the following requirements:

(a) Cessation of use; prevent flow or addition of wastes. The owner or operator must immediately stop the flow of dangerous waste into the tank system or secondary containment system and inspect the system to determine the cause of the release.

(b) Removal of waste from tank system or secondary containment system.

(i) If the release was from the tank system, the owner/ operator must, within twenty-four hours after detection of the leak or, if the owner/operator demonstrates that it is not possible, at the earliest practicable time, remove as much of the waste as is necessary to prevent further release of dangerous waste to the environment and to allow inspection and repair of the tank system to be performed.

(ii) If the material released was to a secondary containment system, all released materials must be removed within twenty-four hours or in as timely a manner as is possible to prevent harm to human health and the environment.

(c) Containment of visible releases to the environment. The owner/operator must immediately conduct a visual inspection of the release and, based upon that inspection:

(i) Prevent further migration of the leak or spill to soils or surface water; and

(ii) Remove, and properly dispose of, any visible contamination of the soil or surface water.

\section{WAC173-303-640(8)}

(a) At closure of a tank system, the owner or operator must remove or decontaminate all waste residues. contaminated containment system components (liners, etc.), contaminated soils, and structures and equipment contaminated with waste, and manage them as dangerous waste, unless WAC 173-303-070 (2)(a) applies. The closure plan, closure activities, cost estimates for closure, and financial responsibility for tank systems must meet all of the requirements specified in WAC 173-303-610 and 173-303-620.

(b) If the owner or operator demonstrates that not all contaminated soils can be practicably removed or decontaminated as required in (a) of this subsection, then the owner or operator must close the tank system and perform post-closure care in accordance with the closure and post-closure care requirements that apply to landfills (see WAC 173-303-665 (6)). In addition, for the purposes of closure, post-closure, and financial responsibility, such a tank system is then considered to be a landfill, and the owner or operator must meet all of the requirements for landfills specified in WAC 173-303-610 and 173-303-620

(c) If an owner or operator has a tank system that does not have secondary containment that meets the requirements of subsection (4)(b) through (f) of this section and is not exempt from the secondary containment requirements in accordance with subsection $(4)(\mathrm{g})$ of this section, then: 
(i) The closure plan for the tank system must include both a plan for complying with (a) of this subsection and a contingent plan for complying with (b) of this subsection.

(ii) A contingent post-closure plan for complying with (b) of this subsection must be prepared and submitted as part of the permit application.

(iii) The cost estimates calculated for closure and post-closure care must reflect the costs of complying with the contingent closure plan and the contingent post-closure plan, if those costs are greater than the costs of complying with the closure plan prepared for the expected closure under (a) of this subsection.

(iv) Financial assurance must be based on the cost estimates in (c)(iii) of this subsection.

(v) For the purposes of the contingent closure and post-closure plans, such a tank system is considered to be a landfill, and the contingent plans must meet all of the closure, post-closure, and financial responsibility requirements for landfills under this chapter (WAC 173-303-610 and 173-303-620).

\section{WAC173-303-645(8)(a-c)}

(8) The owner or operator must comply with the requirements of this subsection for any ground water monitoring program developed to satisfy subsections (9), (10), or (11) of this section.

(a) The ground water monitoring system must consist of a sufficient number of wells, installed at appropriate locations and depths to yield ground water samples from the uppermost aquifer that:

(i) Represent the quality of background water that has not been affected by leakage from a regulated unit;

(A) A determination of background quality may include sampling of wells that are not hydraulically upgradient of the waste management area where:

(I) Hydrogeologic conditions do not allow the owner or operator to determine what wells are hydraulically upgradient; and

(II) Sampling at other wells will provide an indication of background ground water quality that is representative or more representative than that provided by the upgradient wells; and

(ii) Represent the quality of ground water passing the point of compliance.

(iii) Allow for the detection of contamination when dangerous waste or dangerous constituents have migrated from the waste management area to the uppermost aquifer.

(b) If a facility contains more than one regulated unit, separate ground water monitoring systems are not required for each regulated unit, provided that provisions for sampling the ground water in the uppermost aquifer will enable detection and measurement at the compliance point of dangerous constituents from the regulated units that have entered the ground water in the uppermost aquifer.

(c) All monitoring wells must be cased in a manner that maintains the integrity of the monitoring well bore hole. This casing must allow collection of representative ground water samples. Wells must be constructed in such a manner as to prevent contamination of the samples, the sampled strata, and between aquifers and water bearing strata. Wells must meet the requirements set forth in Parts 1 and 3 of chapter 173-160 WAC, "Minimum standards for construction and maintenance of wells."

\section{WAC173-303-645(9)(a-c)}

(9)(a) The owner or operator must monitor for indicator parameters (e.g., $\mathrm{pH}$, specific conductance, total organic carbon (TOC), total organic halogen (TOX), or heavy metals), waste constituents, or reaction products that provide a reliable indication of the presence of dangerous constituents in ground water. The department will specify the parameters or constituents to be monitored in the facility permit, after considering the following factors:

(i) The types, quantities, and concentrations of constituents in wastes managed at the regulated unit; (ii) The mobility, stability, and persistence of waste constituents or their reaction products in the 
unsaturated zone beneath the waste management area;

(iii) The detectability of indicator parameters, waste constituents, and reaction products in ground water; and

(iv) The concentrations or values and coefficients of variation of proposed monitoring parameters or constituents in the ground water background.

(b) The owner or operator must install a ground water monitoring system at the compliance point, as specified under subsection (6) of this section. The ground water monitoring system must comply with subsection (8)(a)(ii), (b), and (c) of this section.

(c) The owner or operator must conduct a ground water monitoring program for each chemical parameter and dangerous constituent specified in the permit pursuant to (a) of this subsection in accordance with subsection $(8)(\mathrm{g})$ of this section. The owner or operator must maintain a record of ground water analytical data as measured and in a form necessary for the determination of statistical significance under subsection $(8)(h)$ of this section.

\section{WAC173-303-665(1)}

(1) The regulations in this section apply to owners and operators of facilities that dispose of dangerous waste in landfills, except as WAC 173-303-600 provides otherwise. No landfill shall be permitted to dispose of EHW, except for the Hanford facility under WAC 173-303-700 .

\section{WAC173-303-665(2)(a)}

(2)(a) A landfill (except for an existing portion of a landfill) must have:

(i) A liner that is designed, constructed, and installed to prevent any migration of wastes out of the landfill to the adjacent subsurface soil or ground water or surface water at anytime during the active life (including the closure period) of the landfill. The liner must be constructed of materials that prevent wastes from passing into the liner during the active life of the facility. The owner or operator must submit an engineering report with his permit application under WAC 173-303-806 (4) stating the basis for selecting the liner(s). The report must be certified by a licensed professional engineer. The liner must be: (A) Constructed of materials that have appropriate chemical properties and sufficient strength and thickness to prevent failure due to pressure gradients (including static head and external hydrogeologic forces), physical contact with the waste or leachate to which they are exposed, climatic conditions, the stress of installation, and the stress of daily operation;

(B) Placed upon a foundation or base capable of providing support to the liner and resistance to pressure gradients above and below the liner to prevent failure of the liner due to settlement, compression, or uplift; and (C) Installed to cover all surrounding earth likely to be in contact with the waste or leachate; and (ii) A leachate collection and removal system immediately above the liner that is designed, constructed, maintained, and operated to collect and remove leachate from the landfill. The department will specify design and operating conditions in the permit to ensure that the leachate depth over the liner does not exceed $30 \mathrm{~cm}$ (one foot). The leachate collection and removal system must be:

(A) Constructed of materials that are:

(I) Chemically resistant to the waste managed in the landfill and the leachate expected to be generated; and

(II) Of sufficient strength and thickness to prevent failure under the pressures exerted by overlying wastes, waste cover materials, and by any equipment used at the landfill; and

(B) Designed and operated to function without clogging through the scheduled closure of the landfill. 
WAC173-303-665(2)(c)

(2)(c) The owner or operator must design, construct, operate, and maintain a run-on control system capable of preventing flow onto the active portion of the landfill during peak discharge from at least a twenty-five-year storm.

\section{WAC173-303-665(2)(d)}

(2)(d) The owner or operator must design, construct, operate, and maintain a run-off management system to collect and control at least the water volume resulting from a twenty-four-hour, twenty-five-year storm.

\section{WAC173-303-665(3)(a)}

(3) Double-lined landfills; exemption from WAC 173-303-645, ground water protection requirements.

(a) The owner or operator of a double-lined landfill is not subject to regulation under WAC 173-303-645 if the following conditions are met:

(i) The landfill (including its underlying liners) must be located entirely above the seasonal high water table;

(ii) The landfill must be underlain by two liners which are designed and constructed in a manner to prevent the migration of liquids into or out of the space between the liners. Both liners must meet the specifications of subsection (2)(a)(i) of this section;

(iii) A leak detection system must be designed, constructed, maintained, and operated between the liners to detect any migration of liquid into the space between the liners; and

(iv) The landfill must have a leachate collection and removal system above the top liner that is designed, constructed, maintained, and operated in accordance with subsection (2)(a)(ii) of this section.

\section{WAC173-303-665(6)(a)}

(6)(a) At final closure of the landfill or upon closure of any cell, the owner or operator must cover the landfill or cell with a final cover designed and constructed to:

(i) Provide long-term minimization of migration of liquids through the closed landfill;

(ii) Function with minimum maintenance;

(iii) Promote drainage and minimize erosion or abrasion of the cover;

(iv) Accommodate settling and subsidence so that the cover's integrity is maintained; and

(v) Have a permeability less than or equal to the permeability of any bottom liner system or natural subsoils present.

\section{WAC173-303-670(4)(a)}

(4)(a) An incinerator burning dangerous waste must be designed, constructed, and maintained so that, when operated in accordance with operating requirements specified under subsection (6) of this section, it will meet the following performance standards:

(a)(i) Except as provided in (a)(ii) of this subsection, an incinerator burning dangerous waste must achieve a destruction and removal efficiency (DRE) of 99.99 percent for each PODC designated (under 
subsection (3) of this section) in its permit for each waste feed. DRE is determined for each PODC from the following equation:

$$
\begin{aligned}
& \text { (Win - Wout })-100 \% \\
& \text { DRE }=\frac{\text { Win }}{\text { in }}
\end{aligned}
$$

Where:

Win = Mass feed rate of one PODC in the waste stream feeding the incinerator, and

Wout $=$ Mass emission rate of the same PODC present in exhaust emissions prior to release to the atmosphere.

(ii) An incinerator burning dangerous wastes F020, F021, F022, F023, F026, or F027 must achieve a destruction and removal efficiency (DRE) of $99.9999 \%$ for each principal organic dangerous constituent (PODCs) designated (under subsection (3) of this section) in its permit. This performance must be demonstrated on PODCs that are more difficult to incinerate than tetra-, penta-, and

hexachlorodibenzo-p-dioxins and dibenzofurans. DRE is determined for each PODCs from the equation in subsection (4)(a)(i) of this section. In addition, the owner or operator of the incinerator must notify the department of his intent to incinerate dangerous wastes F020, F021, F022, F023, F026, or F027.

\section{WAC173-303-670(4)(b)}

(4)(b) Incinerators burning dangerous waste must destroy dangerous combustion byproducts designated under subsection (3) of this section so that the total mass emission rate of these byproducts emitted from the stack is no more than .01 percent of the total mass feed rate of PODCs fed into the incinerator.

\section{WAC173-303-670(4)(c)}

(4)(c)(i) An incinerator burning dangerous waste and producing stack emissions of more than 1.8

kilograms per hour (4 pounds per hour) of hydrogen chloride ( $\mathrm{HCl}$ ) must control $\mathrm{HCl}$ emissions such that the rate of emission is no greater than the larger of either 1.8 kilograms per hour or one percent of the $\mathrm{HCl}$ in the stack gas prior to entering any pollution control equipment.

(ii) An incinerator burning dangerous waste must not emit particulate matter in excess of 180 milligrams per dry standard cubic meter ( 0.08 grains per dry standard cubic foot) when corrected for the amount of oxygen in the stack gas according to the formula:

$\operatorname{Pm} \times 14$

$P c=$

$$
21-\mathrm{Y}
$$

Where $\mathrm{Pc}$ is the corrected concentration of particulate matter, $\mathrm{Pm}$ is the measured concentration of particulate matter, and $\mathrm{Y}$ is the measured concentration of oxygen in the stack gas, using the Orsat method for oxygen analysis of dry flue gas, presented in 40 CFR Part 60, Appendix A (Method 3). This correction procedure is to be used by all dangerous waste incinerators except those operating under conditions of oxygen enrichment. For these facilities, the department will select an appropriate correction procedure to be specified in the facility permit. 
Appendix D - Constraints Definitions

\section{WAC173-304}

Solid non-dangerous wastes disposal shall be in accordance with the document WAC173-304 "Minimum Functional Standards for Solid Waste Handling".

\section{WAC173-400 General Regulations for Air Pollution Sources}

Contractor air emissions shall comply with the standards identified by this Code.

\section{WAC173-400-000}

\section{Chapter 173-400 GENERAL REGULATIONS FOR AIR POLLUTION}

SOURCES

Last Update: $3 / 22 / 95$

Sections

173-400-010 Policy and purpose.

173-400-020 Applicability.

173-400-030 Definitions.

173-400-040 General standards for maximum emissions.

173-400-045 Control technology fees.

173-400-050 Emission standards for combustion and incineration units.

173-400-060 Emission standards for general process units.

173-400-070 Emission standards for certain source categories.

173-400-075 Emission standards for sources emitting hazardous air pollutants.

173-400-081 Startup and shutdown.

173-400-091 Voluntary limits on emissions.

173-400-099 Registration program.

173-400-100 Source classifications.

173-400-101 Registration issuance.

173-400-102 Scope of registration and reporting requirements.

173-400-103 Emission estimates.

173-400-104 Registration fees.

173-400-105 Records, monitoring, and reporting.

173-400-107 Excess emissions.

173-400-110 New source review (NSR).

173-400-112 Requirements for new sources in nonattainment areas.

173-400-113 Requirements for new sources in attainment or unclassifiable areas.

173-400-114 Requirements for replacement or substantial alteration of emission control technology at an existing stationary source.

173-400-115 Standards of performance for new sources.

173-400-116 New source review fees.

173-400-120 Bubble rules.

173-400-131 Issuance of emission reduction credits.

173-400-136 Use of emission reduction credits.

173-400-141 Prevention of significant deterioration (PSD). 
Appendix D - Constraints Definitions

173-400-151 Retrofit requirements for visibility protection.

173-400-161 Compliance schedules.

173-400-171 Public involvement.

173-400-180 Variance.

173-400-190 Requirements for nonattainment areas.

173-400-200 Creditable stack height and dispersion techniques.

173-400-205 Adjustment for atmospheric conditions.

173-400-210 Emission requirements of prior jurisdictions.

173-400-220 Requirements for board members.

173-400-230 Regulatory actions.

173-400-240 Criminal penalties.

173-400-250 Appeals.

173-400-260 Conflict of interest.

\section{DISPOSITION OF SECTIONS FORMERLY CODIFIED IN THIS CHAPTER}

173-400-080 Compliance schedules. [Statutory Authority: RCW 70.94.331. 80-11-059 (Order DE 80-14), 173-400-080, filed 8/20/80. Statutory Authority: RCW 43.21A.080 and 70.94.331. 79-06-012 (Order DE 78-21), 173-400-080, filed 5/8/79; Order DE 76-38, 173-400-080, filed 12/21/76. Formerly WAC 18-04-080. Repealed by 83-09-036 (Order DE 83-13), filed 4/15/83. Statutory Authority: Chapters $43.21 \mathrm{~A}$ and $70.94 \mathrm{RCW}$.

173-400-090 Sensitive area designation. [Statutory Authority: RCW 70.94.331. 80-11-059 (Order DE 80-14), 173-400-090, filed 8/20/80; Order DE 76-38, 173-400-090, filed 12/21/76. Formerly WAC 18-04-090.] Repealed by 83-09-036 (Order DE 83-13), filed 4/15/83. Statutory Authority: Chapters $43.21 \mathrm{~A}$ and $70.94 \mathrm{RCW}$.

173-400-130 Regulatory actions. [Statutory Authority: RCW 43.21 A.080 and 70.94.331. 79-06-012 (Order DE 78-21), 173-400-130, filed 5/8/79; Order DE 76-38, 173-400-130, filed 12/21/76. Formerly WAC 18-04-130.1 Repealed by 83-09-036 (Order DE 83-13), filed 4/15/83. Statutory Authority: Chapters 43.21A and 70.94 RCW.

173-400-135 Criminal penalties. [Statutory Authority: RCW 43.21A.080 and 70.94.331. 79-06-012 (Order DE 78-21), 173-400-135, filed 5/8/79.] Repealed by 83-09-036 (Order DE 83-13), filed 4/15/83. Statutory Authority: Chapters $43.21 \mathrm{~A}$ and $70.94 \mathrm{RCW}$.

173-400-140 Appeals. [Order DE 76-38, 173-400-140, filed 12/21/76. Formerly WAC 18-04-140.] Repealed by 83-09-036 (Order DE 83-13), filed 4/15/83. Statutory Authority: Chapters 43.21A and 70.94 RCW.

173-400-150 Variance. [Statutory Authority: RCW 43.21A.080 and 70.94.331. 79-06-012 (Order DE 78-21), 173-400-150, filed 5/8/79; Order DE 76-38, 173-400-150, filed 12/21/76. Formerly WAC 18-04-150.] Repealed by 83-09-036 (Order DE 83-13), filed 4/15/83. Statutory Authority: Chapters 43.21 $\mathrm{A}$ and $70.94 \mathrm{RCW}$.

173-400-160 Maintenance of pay. [Statutory Authority: RCW 43.21 A.080 and 70.94.331. 79-06-012 (Order DE 78-21), 173-400-160, filed 5/8/79.] Repealed by 83-09-036 (Order DE 83-13), filed 4/15/83. Statutory Authority: Chapters $43.21 \mathrm{~A}$ and $70.94 \mathrm{RCW}$.

173-400-170 Requirements for boards and director. [Statutory Authority: RCW 43.21A.080 and 70.94.331. 79-06-012 (Order DE 78-21), 173-400-170, filed 5/8/79.] Repealed by 83-09-036 (Order DE 83-13), filed 4/15/83. Statutory Authority: Chapters 43.21 A and 70.94 RCW. 


\section{WAC173-400-010}

WAC 173-400-010 Policy and purpose.

(1) It is the policy of the department of ecology (ecology) under the authority vested in it by chapter 43.21 A RCW to provide for the systematic control of air pollution from air contaminant sources and for the proper development of the state's natural resources.

(2) It is the purpose of this chapter to establish technically feasible and reasonably attainable standards and to establish rules generally applicable to the control and/or prevention of the emission of air contaminants.

\section{WAC173-400-020}

WAC 173-400-020 Applicability.

(1) The provisions of this chapter shall apply state-wide.

(2) An authority may enforce this chapter and may also adopt standards or requirements. These standards or requirements may not be less stringent than the current state air quality rules and may be more stringent than the current regulations. Unless properly delegated by ecology, authorities do not have jurisdiction over the following sources:

(a) Specific source categories over which the state, by separate regulation, has assumed or hereafter does assume jurisdiction.

(b) Automobiles, trucks, aircraft.

(c) Those sources under the jurisdiction of the energy facility site evaluation council.

\section{WAC173-400-030}

WAC $173-400-030$ Definitions.

Except as provided elsewhere in this chapter, the following definitions apply throughout the chapter:

(1) "Actual emissions" means the actual rate of emissions of a pollutant from an emission unit, as determined in accordance with (a) through (c) of this subsection.

(a) In general, actual emissions as of a particular date shall equal the average rate, in tons per year, at which the emissions unit actually emitted the pollutant during a two-year period which precedes the particular date and which is representative of normal source operation. Ecology or an authority shall allow the use of a different time period upon a determination that it is more representative of normal source operation. Actual emissions shall be calculated using the emissions unit's actual operating hours, production rates, and types of materials processed, stored, or combusted during the selected time period.

(b) Ecology or an authority may presume that source-specific allowable emissions for the unit are equivalent to the actual emissions of the emissions unit.

(c) For any emissions unit which has not begun normal operations on the particular date, actual emissions shall equal the potential to emit of the emissions unit on that date.

(2) "Adverse impact on visibility" means visibility impairment which interferes with the management, protection, preservation, or enjoyment of the visitor's visual experience of the Federal Class I area. This determination must be made on a case-by-case basis taking into account the geographic extent, intensity, duration, frequency, and time of visibility impairment, and how these factors correlate with (a) times of visitor use of the Federal Class I area, and (b) the frequency and timing of natural conditions that reduce 
visibility. This term does not include effects on integral vistas.

(3) "Air contaminant" means dust, fumes, mist, smoke, other particulate matter, vapor, gas, odorous substance, or any combination thereof. "Air pollutant" means the same as "air contaminant."

(4) "Air pollution" means the presence in the outdoor atmosphere of one or more air contaminants in sufficient quantities, and of such characteristics and duration as is, or is likely to be, injurious to human health, plant or animal life, or property, or which unreasonably interferes with enjoyment of life and property. For the purposes of this chapter, air pollution shall not include air contaminants emitted in compliance with chapter 17.21 RCW, the Washington Pesticide Application Act, which regulates the application and control of the use of various pesticides.

(5) "Allowable emissions" means the emission rate of a stationary source calculated using the maximum rated capacity of the stationary source (unless the stationary source is subject to federally enforceable limits which restrict the operating rate, or hours of operation, or both) and the most stringent of the following:

(a) The applicable standards as set forth in 40 CFR Part 60 or 61 ;

(b) Any applicable state implementation plan emissions limitation including those with a future compliance date; or

(c) The emissions rate specified as a federally enforceable permit condition, including those with a future compliance date.

(6) "Ambient air" means the surrounding outside air.

(7) "Ambient air quality standard" means an established concentration, exposure time, and frequency of occurrence of air contaminant(s) in the ambient air which shall not be exceeded.

(8) "Authority" means any air pollution control agency whose jurisdictional boundaries are coextensive with the boundaries of one or more counties.

(9) "Best available control technology (BACT)" means an emission limitation based on the maximum degree of reduction for each air pollutant subject to regulation under chapter $70.94 \mathrm{RCW}$ emitted from or which results from any new or modified stationary source, which the permitting authority, on a case-by-case basis, taking into account energy, environmental, and economic impacts and other costs, determines is achievable for such source or modification through application of production processes and available methods, systems, and techniques, including fuel cleaning, clean fuels, or treatment or innovative fuel combustion techniques for control of each such pollhtant. In no event shall application of the "best available control technology" result in emissions of any pollutants which will exceed the emissions allowed by any applicable standard under 40 CFR Part 60 and Part 61, as they exist on May 7 , 1993, or their later enactments as adopted by reference by the director by rule. Emissions from any source utilizing clean fuels, or any other means, to comply with this paragraph shall not be allowed to increase above levels that would have been required under the definition of BACT in the Federal Clean Air Act as it existed prior to enactment of the Clean Air Act Amendments of 1990.

(10) "Best available retrofit technology (BART)" means an emission limitation based on the degree of reduction achievable through the application of the best system of continuous emission reduction for each pollutant which is emitted by an existing stationary facility. The emission limitation must be established, on a case-by-case basis taking into consideration the technology available, the costs of compliance, the energy and nonair quality environmental impacts of compliance, any pollution control equipment in use or in existence at the source, the remaining useful life of the source, and the degree of improvement in visibility which may reasonably be anticipated to result from the use of such technology.

(11) "Bubble" means a set of emission limits which allows an increase in emissions from a given emissions unit(s) in exchange for a decrease in emissions from another emissions unit(s), pursuant to RCW 70.94.155 and WAC 173-400-120.

(12) "Capacity factor" means the ratio of the average load on equipment or a machine for the period of time considered, to the manufacturer's capacity rating of the machine or equipment.

(13) "Class I area" means any area designated pursuant to 
162 or 164 of the Federal Clean Air Act as a Class I area. The following areas are the Class I areas in Washington state:

Alpine Lakes Wilderness;

Glacier Peak Wilderness;

Goat Rocks Wilderness;

Mount Adams Wilderness;

Mount Rainier National Park;

North Cascades National Park;

Olympic National Park;

Pasayten Wildemess;

Spokane Indian Reservation.

(14) "Combustion and incineration sources" means units using combustion for waste disposal, steam production, chemical recovery or other process requirements; but excludes open burning.

(15) "Commenced construction" means that the owner or operator has all the necessary preconstruction approvals or permits and either has:

(a) Begun, or caused to begin, a continuous program of actual on-site construction of the source, to be completed within a reasonable time; or

(b) Entered into binding agreements or contractual obligations, which cannot be cancelled or modified without substantial loss to the owner or operator, to undertake a program of actual construction of the source to be completed within a reasonable time.

(16) "Concealment" means any action taken to reduce the observed or measured concentrations of a pollutant in a gaseous effluent while, in fact, not reducing the total amount of pollutant discharged.

(17) "Director" means director of the Washington state department of ecology or duly authorized representative.

(18) "Dispersion technique" means a method which attempts to affect the concentration of a pollutant in the ambient air other than by the use of pollution abatement equipment or integral process pollution controls.

(19) "Ecology" means the Washington state department of ecology.

(20) "Emission" means a release of air contaminants into the ambient air.

(21) "Emission reduction credit (ERC)" means a credit granted pursuant to WAC 173-400-131. This is a voluntary reduction in emissions.

(22) "Emission standard" and "emission limitation" means a requirement established under the FCAA or chapter $70.94 \mathrm{RCW}$ which limits the quantity, rate, or concentration of emissions of air contaminants on a continuous basis, including any requirement relating to the operation or maintenance of a source to assure continuous emission reduction and any design, equipment work practice, or operational standard promulgated under the FCAA or chapter $70.94 \mathrm{RCW}$.

(23) "Emissions unit" means any part of a stationary source or source which emits or would have the potential to emit any pollutant subject to regulation under the FCAA, chapter 70.94 or $70.98 \mathrm{RCW}$.

(24) "Excess emissions" means emissions of an air pollutant in excess of any applicable emission standard.

(25) "Excess stack height" means that portion of a stack which exceeds the greater of sixty-five meters or the calculated stack height described in WAC 173-400-200 (2).

(26) "Existing stationary facility" means a stationary source of air pollutants which has the potential to emit two hundred fifty tons per year or more of any air pollutant. In determining potential to emit, fugitive emissions, to the extent quantifiable, must be counted. For purposes of determining whether a stationary source is an existing stationary facility the term "building, structure, facility, or installation" means all of the pollutant-emitting activities which belong to the same industrial grouping, are located on one or more contiguous or adjacent properties, and are under the control of the same person (or persons under common control). Pollutant-emitting activities shall be considered as part of the same major group 
(i.e., which have the same two digit code) as described in the Standard Industrial Classification Manual, 1972 , as amended by the 1977 Supplement.

(27) "Federal Clean Air Act (FCAA)" means the Federal Clean Air Act, also known as Public Law 88-206, 77 Stat. 392, December 17, 1963, 42 U.S.C. 7401 et seq., as last amended by the Clean Air Act Amendments of 1990, P.L. 101-549, November 15, 1990.

(28) "Federal land manager" means, with respect to any lands in the United States, the Secretary of the department with authority over such lands.

(29) "Fossil fuel-fired steam generator" means a device, furnace, or boiler used in the process of burning fossil fuel for the primary purpose of producing steam by heat transfer.

(30) "Fugitive dust" means a particulate emission made airborne by forces of wind, man's activity, or both. Unpaved roads, construction sites, and tilled land are examples of areas that originate fugitive dust. Fugitive dust is a type of fugitive emission.

(31) "Fugitive emissions" means emissions which do not pass and which could not reasonably pass through a stack, chimney, vent, or other functionally equivalent opening.

(32) "General process unit" means an emissions unit using a procedure or a combination of procedures for the purpose of causing a change in material by either chemical or physical means, excluding combustion.

(33) "Good engineering practice (GEP)" refers to a calculated stack height based on the equation specified in WAC 173-400-200 (2)(a)(ii).

(34) "Incinerator" means a furnace used primarily for the thermal destruction of waste.

(35) "In operation" means engaged in activity related to the primary design function of the source.

(36) "Integral vista" means a view perceived from within a mandatory Class I federal area of a specific landmark or panorama located outside the boundary of the mandatory Class I federal area.

(37) "Lowest achievable emission rate (LAER)" means for any source that rate of emissions which reflects the more stringent of:

(a) The most stringent emission limitation which is contained in the implementation plan of any state for such class or category of source, unless the owner or operator of the proposed new or modified source demonstrates that such limitations are not achievable; or

(b) The most stringent emission limitation which is achieved in practice by such class or category of source.

In no event shall the application of this term permit a proposed new or modified source to emit any pollutant in excess of the amount allowable under applicable new source performance standards.

(38) "Mandatory Class I federal area" means any area defined in Section 162(a) of the FCAA. The mandatory Class I federal areas in Washington state are as follows:

Alpine Lakes Wilderness;

Glacier Peak Wilderness;

Goat Rocks Wilderness;

Mount Adams Wilderness;

Mount Rainier National Park;

North Cascades National Park;

Olympic National Park;

Pasayten Wilderness.

(39) "Major modification" means any physical change in or change in the method of operation of a major stationary source that would result in a significant net emissions increase of any pollutant subject to regulation under the FCAA. Any net emissions increase that is considered significant for volatile organic compounds or nitrogen oxides shall be considered significant for ozone. A physical change or change in the method of operation shall not include:

(a) Routine maintenance, repair, and replacement;

(b) Use of an alternative fuel or raw material by reason of an order under Sections 2(a) and (b) of the 
Appendix D - Constraints Definitions

Energy Supply and Environmental Supply Coordination Act of 1974 (or any superseding legislation) or by reason of a natural gas curtailment plan pursuant to the Federal Power Act;

(c) Use of an alternative fuel by reason of an order or rule under section 125 of the FCAA, 42 U.S.C. 7425 ;

(d) Use of an alternative fuel at a steam generating unit to the extent that the fuel is generated from municipal solid waste;

(e) Use of an alternative fuel or raw material by a stationary source which:

(i) The stationary source was capable of accommodating before December 21, 1976, unless such change would be prohibited under any federally enforceable permit condition which was established after December 12, 1976, in a prevention of significant deterioration permit or notice of construction approval; or

(ii) The stationary source is approved to use under any federally-enforceable notice of construction approval or a PSD permit issued by the environmental protection agency;

(f) An increase in the hours of operation or in the production rate, unless such change is prohibited under any federally enforceable permit condition which was established after December 21, 1976, in a prevention of significant deterioration permit or a notice of construction approval;

(g) Any change in ownership at a stationary source.

(40) "Major stationary source" means:

(a) Any stationary source which:

(i) Emits or has the potential to emit one hundred tons per year or more of any air contaminant regulated by the state or Federal Clean Air Acts; or

(ii) Is located in a "marginal" or "moderate" ozone nonattainment area and which emits or has the potential to emit one hundred tons per year or more of volatile organic compounds or oxides of nitrogen.

(b) Any stationary source (or group of stationary sources) which:

(i) Is located in a "serious" carbon monoxide nonattainment area where stationary sources contribute significantly to carbon monoxide levels and which emits or has the potential to emit fifty tons per year or more of carbon monoxide; or

(ii) Is located in a "serious" particulate matter (PM10) nonattainment area and which emits or has the potential to emit seventy tons per year or more of PMI0 emissions.

(c) Any physical change that would occur at a stationary source not qualifying under (a) or (b) of this subsection as a major stationary source, if the change would constitute a major stationary source by itself;

(d) A major stationary source that is major for VOCs or NOx shall be considered major for ozone;

(e) The fugitive emissions of a stationary source shall not be included in determining whether it is a major stationary source, unless the stationary source belongs to one of the following categories of stationary sources or the source is a major stationary source due to (b) of this subsection:

(i) Coal cleaning plants (with thermal dryers);

(ii) Kraft pulp mills;

(iii) Portland cements plants;

(iv) Primary zinc smelters;

(v) Iron and steel mills;

(vi) Primary aluminum ore reduction plants;

(vii) Primary copper smelters;

(viii) Municipal incinerators capable of charging more than two hundred fifty tons of refuse per day;

(ix) Hydrofluoric, sulfuric, or nitric acid plants;

(x) Petroleum refineries;

(xi) Lime plants;

(xii) Phosphate rock processing plants;

(xiii) Coke oven batteries;

(xiv) Sulfur recovery plants; 
(xv) Carbon black plants (furnace process);

(xvi) Primary lead smelters;

(xvii) Fuel conversion plants;

(xviii) Sintering plants;

(xix) Secondary metal production plants;

(xx) Chemical process plants;

(xxi) Fossil-fuel boilers (or combination thereof) totaling more than two hundred fifty million British thermal units per hour heat input;

(xxii) Petroleum storage and transfer units with a total storage capacity exceeding three hundred thousand barrels;

(xxiii) Taconite ore processing plants;

(xxiv) Glass fiber processing plants;

(xxv) Charcoal production plants;

(xxvi) Fossil fuel-fired steam electric plants of more than two hundred fifty million British thermal units per hour heat input; and

(xxvii) Any other stationary source category which, as of August 7,1980, was being regulated under sections 111 or 112 of the Federal Clean Air Act.

(f) For purposes of determining whether a stationary source is a major stationary source, the term "building, structure, facility, or installation" means all the pollutant-emitting activities which belong to the same industrial grouping, are located on one or more contiguous or adjacent properties, and are under the control of the same person (or persons under common control). Pollutant-emitting activities shall be considered as part of the same industrial grouping if they belong to the same major group (i.e., which have the same two digit code) as described in the Standard Industrial Classification Manual, 1972, as amended by the 1977 Supplement.

(41) "Masking" means the mixing of a chemically nonreactive control agent with a malodorous gaseous effluent to change the perceived odor.

(42) "Materials handling" means the handling, transporting, loading, unloading, storage, and transfer of materials with no significant chemical or physical alteration.

(43) "Modification" means any physical change in, or change in the method of operation of, a stationary source that increases the amount of any air contaminant emitted by such source or that results in the emissions of any air contaminant not previously emitted. The term modification shall be construed consistent with the definitions of modification in Section 7411, Title 42, United States Code, and with rules implementing that section.

(44) "National Emission Standards for Hazardous Air Pollutants (NESHAPS)" means the federal regulations set forth in 40 CFR Part 61.

(45) "Natural conditions" means naturally occurring phenomena that reduce visibility as measured in terms of visual range, contrast, or coloration.

(46) "Net emissions increase" means:

(a) The amount by which the sum of the following exceeds zero:

(i) Any increase in actual emissions from a particular change or change in method of operation at a source; and

(ii) Any other increases and decreases in actual emissions at the source that are contemporaneous with the particular change and are otherwise creditable.

(b) An increase or decrease in actual emissions is contemporaneous with the increase from the particular change only if it occurs between the date ten years before construction on the particular change commences and the date that the increase from the particular change occurs.

(c) An increase or decrease in actual emissions is creditable only if:

(i) It occurred no more than one year prior to the date of submittal of a complete notice of construction application for the particular change, or it has been documented by an emission reduction credit, in which 
case the credit shall expire ten years after the date of original issue of the ERC. Any emissions increases occurring between the date of issuance of the ERC and the date when a particular change becomes operational shall be counted against the ERC.

(ii) Ecology or the authority has not relied on it in issuing any permit or order of approval for the source under regulations approved pursuant to 40 CFR 51 Subpart I or the EPA has not relied on it in issuing a PSD permit pursuant to 40 CFR 52.21, which order or permit is in effect when the increase in actual emissions from the particular change occurs.

(d) An increase in actual emissions is creditable only to the extent that the new level of actual emissions exceeds the old level.

(e) A decrease in actual emissions is creditable only to the extent that:

(i) The old level of actual emissions or the old level of allowable emissions, whichever is lower, exceeds the new level of actual emissions;

(ii) It is federally enforceable at and after the time that actual construction on the particular change begins;

(iii) It has approximately the same qualitative significance for public health and welfare as that attributed to the increase from the particular change; and

(iv) Ecology or the authority has not relied on it in issuing any permit or order of approval under regulations approved pursuant to 40 CFR 51 Subpart I, the EPA has not relied on it in issuing a PSD permit pursuant to 40 CFR 52.21 , or ecology or the authority has not relied on it in demonstrating attainment or reasonable further progress.

(f) An increase that results from a physical change at a source occurs when the emission unit on which construction occurred becomes operational and begins to emit a particular pollutant. Any replacement unit that requires shakedown becomes operational only after a reasonable shakedown period, not to exceed one hundred eighty days.

(47) "New source" means:

(a) The construction or modification of a stationary source that increases the amount of any air contaminant emitted by such source or that results in the emission of any air contaminant not previously emitted; and

(b) Any other project that constitutes a new source under the Federal Clean Air Act.

(48) "New source performance standards (NSPS)" means the federal regulations set forth in 40 CFR Part 60.

(49) "Nonattainment area" means a clearly delineated geographic area which has been designated by EPA promulgation as exceeding a national ambient air quality standard or standards for one or more of the criteria pollutants.

(50) "Notice of construction application" means a written application to permit construction of a new source, modification of an existing stationary source or replacement or substantial alteration of control technology at an existing stationary source.

(51) "Opacity" means the degree to which an object seen through a plume is obscured, stated as a percentage.

(52) "Open burning" means the combustion of material in an open fire or in an outdoor container, without providing for the control of combustion or the control of the emissions from the combustion. Wood waste disposal in wigwam burners is not considered open burning.

(53) "Order" means any order issued by ecology or a local air authority pursuant to chapter $70.94 \mathrm{RCW}$, including, but not limited to RCW 70.94.332, 70.94.152, 70.94.153, and 70.94.141(3), and includes, where used in the generic sense, the terms order, corrective action order, order of approval, and regulatory order.

(54) "Order of approval" or "approval order" means a regulatory order issued by ecology or the authority to approve the notice of construction application for a proposed new source or modification, or the replacement or substantial alteration of control technology at an existing stationary source. 
(55) "Particulate matter" or "particulates" means any airborne finely divided solid or liquid material with an aerodynamic diameter smaller than 100 micrometers.

(56) "Particulate matter emissions" means all finely divided solid or liquid material, other than uncombined water, emitted to the ambient air as measured by applicable reference methods, or an equivalent or alternative method specified in 40 CFR Part 60 or by a test method specified in the Washington state implementation plan.

(57) "Parts per million (ppm)" means parts of a contaminant per million parts of gas, by volume, exclusive of water or particulates.

(58) "Person" means an individual, firm, public or private corporation, association, partnership, political subdivision, municipality, or government agency.

(59) "PM-10" means particulate matter with an aerodynamic diameter less than or equal to a nominal 10 micrometers as measured by a reference method based on 40 CFR Part 50 Appendix $J$ and designated in accordance with 40 CFR Part 53 or by an equivalent method designated in accordance with 40 CFR Part 53.

(60) "PM-10 emissions" means finely divided solid or liquid material, including condensible particulate matter, with an aerodynamic diameter less than or equal to a nominal 10 micrometers emitted to the ambient air as measured by an applicable reference method, or an equivalent or alternate method, specified in Appendix M of 40 CFR Part 51 or by a test method specified in the Washington state implementation plan.

(61) "Potential to emit" means the maximum capacity of a stationary source to emit a pollutant under its physical and operational design. Any physical or operational limitation on the capacity of the source to emit a pollutant, including air pollution control equipment and restrictions on hours of operation or on the type or amount of material combusted, stored, or processed, shall be treated as part of its design only if the limitation or the effect it would have on emissions is federally enforceable. Secondary emissions do not count in determining the potential to emit of a stationary source.

(62) "Prevention of significant deterioration (PSD)" means the program set forth in WAC 173-400-141.

(63) "Projected width" means that dimension of a structure determined from the frontal area of the structure, projected onto a plane perpendicular to a line between the center of the stack and the center of the building.

(64) "Reasonably attributable" means attributable by visual observation or any other technique the state deems appropriate.

(65) "Reasonably available control technology (RACT)" means the lowest emission limit that a particular source or source category is capable of meeting by the application of control technology that is reasonably available considering technological and economic feasibility. RACT is determined on a case-by-case basis for an individual source or source category taking into account the impact of the source upon air quality, the availability of additional controls, the emission reduction to be achieved by additional controls, the impact of additional controls on air quality, and the capital and operating costs of the additional controls. RACT requirements for any source or source category shall be adopted only after notice and opportunity for comment are afforded.

(66) "Regulatory order" means an order issued by ecology or an authority to an air contaminant source which applies to that source, any applicable provision of chapter $70.94 \mathrm{RCW}$, or the rules adopted thereunder, or, for sources regulated by a local air authority, the regulations of that authority.

(67) "Significant" means, in reference to a net emissions increase or the potential of a source to emit any of the following pollutants, a rate of emission equal to or greater than any one of the following rates:

\begin{tabular}{lc} 
Pollutant & Tons/Year \\
Carbon monoxid & \multicolumn{2}{c}{100} \\
Nitrogen oxide & 40 \\
Sulfur dioxid & 40 \\
\hline
\end{tabular}


Appendix D - Constraints Definitions

Particulate matter (PM

Fine particulate matter (PM10)

Volatile organic compounds (VOC)

Lead

Fluoride

Sulfuric acid mist

Hydrogen sulfide (H2S)

Total reduced sulfur (including $\mathrm{H} 2 \mathrm{~S}$ )

Municipal waste combustor organics

(measured as total tetra-through octa-chlorinated

dibenzo-p-dioxins and dibenzofurans

Municipal waste combustor metals (measured as PM) 15

Municipal waste combustor acid gases (measured as $\mathrm{SO} 2$

and hydrogen chloride)
25

15

40
10

0.0000035

(68) "Significant visibility impairment" means visibility impairment which interferes with the management, protection, preservation, or enjoyment of visitor visual experience of the Class I area. The determination must be made on a case-by-case basis, taking into account the geographic extent, intensity, duration, frequency, and time of the visibility impairment, and how these factors correlate with the time of visitor use of the Class I area and frequency and timing of natural conditions that reduce visibility.

(69) "Source" means all of the emissions unit(s) including quantifiable fugitive emissions, that are located on one or more contiguous or adjacent properties, and are under the control of the same person or persons under common control, whose activities are ancillary to the production of a single product or functionally related groups of products. Activities shall be considered ancillary to the production of a single product or functionally related group of products if they belong to the same major group (i.e., which have the same two digit code) as described in the Standard Industrial Classification Manual, 1972, as amended by the 1977 Supplement.

(70) "Source category" means all sources of the same type or classification.

(71) "Stack" means any point in a source designed to emit solids, liquids, or gases into the air, including a pipe or duct.

(72) "Stack height" means the height of an emission point measured from the ground-level elevation at the base of the stack.

(73) "Standard conditions" means a temperature of $20 * \mathrm{C}(68 * \mathrm{~F})$ and a pressure of $760 \mathrm{~mm}(29.92$ inches) of mercury.

(74) "Stationary source" means any building, structure, facility, or installation which emits or may emit any contaminant. This term does not include emissions resulting directly from an internal combustion engine for transportation purposes or from a nonroad engine or nonroad vehicle as defined in Section 216 of the FCAA.

(75) "Sulfuric acid plant" means any facility producing sulfuric acid by the contact process by burning elemental sulfur, alkylation acid, hydrogen sulfide, or acid sludge.

(76) "Synthetic minor" means any source whose emissions have been limited below the source's potential to emit by means of a federally enforceable order, rule, or permit condition.

(77) "Total reduced sulfur (TRS)" means the sum of the sulfur compounds hydrogen sulfide, mercaptans, dimethyl sulfide, dimethyl disulfide, and any other organic sulfides emitted and measured by EPA method 16 or an approved equivalent method and expressed as hydrogen sulfide.

(78) "Total suspended particulate" means particulate matter as measured by the method described in 40 CFR Part 50 Appendix B as in effect on July 1, 1988.

(79) "United States Environmental Protection Agency (USEPA)" shall be referred to as EPA.

(80) "Visibility impairment" means any perceptible degradation in visibility (visual range, contrast, 
coloration) not caused by natural conditions.

(81) "Visibility impairment of Class I areas" means visibility impairment within the area and visibility impairment of any formally designated integral vista associated with the area.

(82) "Volatile organic compound (VOC)" means:

(a) Any compound of carbon, excluding carbon monoxide, carbon dioxide, carbonic acid, metallic carbides or carbonates, and ammonium carbonate, which participates in atmospheric photochemical reactions. This includes any organic compound other than the following, which have negligible photochemical activity: Methane; ethane; methylene chloride (dichloromethane); 1,1,1-trichloroethane (methyl chloroform); 1,1,1-trichloro 2,2,2-trifluoroethane (CFC-1 13); trichlorofluoromethane (CFC-11); dichlorodifluoromethane (CFC-12); chlorodifluoromethane (CFC-22); trifluoromethane (FC-23); 1,1,2,2-tetrafluoroethane (CFC-114); chloropentafluoroethane (CFC-115); 1,1,1-trifluoro 2,2-dichloroethane (HCFC-123); 1,1,1,2-tetrafluoroethane (HFC-134a); 1,1-dichloro 1-fluoroethane (HCFC-141b); 1-chloro 1,1-difluoroethane (HCFC-142b); 2-chloro 1,1,1,2-tetrafluoroethane (HCFC-124); pentafluoroethane (HFC-125); 1,1,2,2-tetrafluoroethane (HFC-134); 1,1,1-trifluoroethane (HFC-143a); 1,1-difluoroethane (HFC-152a); and perfluorocarbon compounds which fall into these classes:

(i) Cyclic, branched, or linear completely fluorinated alkanes;

(ii) Cyclic, branched, or linear completely fluorinated ethers with no unsaturations; and

(iii) Sulfur containing perfluorocarbons with no unsaturations and with sulfur bonds only to carbon and fluorine.

(b) For the purpose of determining compliance with emission limits, VOC will be measured by the appropriate methods in 40 CFR Part 60 Appendix A. Where such a method also measures compounds with negligible photochemical reactivity, these negligibly-reactive compounds may be excluded as VOC if the amount of such compounds is accurately quantified, and such exclusion is approved by ecology or the authority.

(c) As a precondition to excluding these negligibly-reactive compounds as VOC or at any time thereafter, ecology or the authority may require an owner or operator to provide monitoring or testing methods and results demonstrating, to the satisfaction of ecology or the authority, the amount of negligibly-reactive compounds in the source's emissions.

\section{WAC173-400-040}

WAC 173-400-040 General standards for maximum emissions.

All sources and emissions units are required to meet the emission standards of this chapter. Where an emission standard listed in another chapter is applicable to a specific emissions unit, such standard will take precedent over a general emission standard listed in this chapter. When two or more emissions units are connected to a common stack and the operator elects not to provide the means or facilities to sample emissions from the individual emissions units, and the relative contributions of the individual emissions units to the common discharge are not readily distinguishable, then the emissions of the common stack must meet the most restrictive standard of any of the connected emissions units. Further, all emissions units are required to use reasonably available control technology (RACT) which may be determined for some sources or source categories to be more stringent than the applicable emission limitations of any chapter of Title 173 WAC. Where current controls are determined to be less than RACT, ecology or the authority shall, as provided in section 8 , chapter 252, Laws of 1993, define RACT for each source or source category and issue a rule or regulatory order requiring the installation of RACT.

(1) Visible emissions. No person shall cause or permit the emission for more than three minutes, in any one hour, of an air contaminant from any emissions unit which at the emission point, or within a 
reasonable distance of the emission point, exceeds twenty percent opacity except:

(a) When the emissions occur due to soot blowing/grate cleaning and the operator can demonstrate that the emissions will not exceed twenty percent opacity for more than fifteen minutes in any eight consecutive hours. The intent of this provision is to permit the soot blowing and grate cleaning necessary to the operation of boiler facilities. This practice, except for testing and trouble shooting, is to be scheduled for the same apptoximate times each day and ecology or the authority be advised of the schedule.

(b) When the owner or operator of a source supplies valid data to show that the presence of uncombined water is the only reason for the opacity to exceed twenty percent.

(c) When two or more sources are connected to a common stack, ecology or the authority may allow or require the use of an alternate time period if it is more representative of nomal operations.

(d) When an alternate opacity limit has been established per RCW 70.94.331 (2)(c).

(2) Fallout. No person shall cause or permit the emission of particulate matter from any source to be deposited beyond the property under direct control of the owner(s) or operator(s) of the source in sufficient quantity to interfere unreasonably with the use and enjoyment of the property upon which the material is deposited.

(3) Fugitive emissions. The owner or operator of any emissions unit engaging in materials handling, construction, demolition or any other operation which is a source of fugitive emission:

(a) If located in an attainment area and not impacting any nonattainment area, shall take reasonable precautions to prevent the release of air contaminants from the operation.

(b) If the emissions unit has been identified as a significant contributor to the nonattainment status of a designated nonattainment area, shall be required to use reasonable and available control methods, which shall include any necessary changes in technology, process, or other control strategies to control emissions of the contaminants for which nonattainment has been designated.

(4) Odors. Any person who shall cause or allow the generation of any odor from any source which may unreasonably interfere with any other property owner's use and enjoyment of his property must use recognized good practice and procedures to reduce these odors to a reasonable minimum.

(5) Emissions detrimental to persons or property. No person shall cause or permit the emission of any air contaminant from any source if it is detrimental to the health, safety, or welfare of any person, or causes damage to property or business.

(6) Sulfur dioxide.

No person shall cause or permit the emission of a gas containing sulfur dioxide from any emissions unit in excess of one thousand ppm of sulfur dioxide on a dry basis, corrected to seven percent oxygen for combustion sources, and based on the average of any period of sixty consecutive minutes, except: When the owner or operator of an emissions unit supplies emission data and can demonstrate to ecology or the authority that there is no feasible method of reducing the concentration to less than one thousand ppm (on a dry basis, corrected to seven percent oxygen for combustion sources) and that the state and federal ambient air quality standards for sulfur dioxide will not be exceeded. In such cases, ecology or the authority may require specific ambient air monitoring stations be established, operated, and maintained by the owner or operator at mutually approved locations. All sampling results will be made available upon request and a monthly summary will be submitted to ecology or the authority.

(7) Concealment and masking. No person shall cause or permit the installation or use of any means which conceals or masks an emission of an air contaminant which would otherwise violate any provisions of this chapter.

(8) Fugitive dust sources.

(a) The owner or operator of a source of fugitive dust shall take reasonable precautions to prevent fugitive dust from becoming airborne and shall maintain and operate the source to minimize emissions.

(b) The owner(s) or operator(s) of any existing source(s) of fugitive dust that has been identified as a 
significant contributor to a PM-10 nonattainment area shall be required to use reasonably available control technology to control emissions. Significance will be determined by the criteria found in WAC 173-400-113(3).

\section{WAC173-400-045}

WAC 173-400-045 Control technology fees.

(1) General. Ecology may assess and collect a fee as authorized in RCW 70.94.154 and described in subsections (2) through (5) of this section.

(2) Fee schedule for source-specific determinations where RACT analysis and determination are performed by ecology.

(a) Basic RACT analysis and determination fee:

(i) Low complexity (the analysis addresses one type of emission unit) - one thousand five hundred dollars;

(ii) Moderate complexity (the analysis addresses two to five types of emissions units) - seven thousand five hundred dollars;

(iii) High complexity (the analysis addresses more than five types of emission units) - fifteen thousand dollars.

(b) Additional charges based on criteria pollutant emissions: In addition to those fees required under (a) of this subsection, a fee will be required for a RACT analysis and determination for an emission unit or multiple emission units of uniform design that, individually or in the aggregate, emit one hundred tons per year or more of any criteria pollutant - two thousand dollars.

(c) Additional charges based on toxic air pollutant emissions: In addition to those fees required under (a) and (b) of this subsection, the following fees will be required as applicable:

(i) RACT analysis and determination for an emissions unit or multiple emissions units of uniform design that, individually or in the aggregate, emit more than two tons per year but less than ten tons per year of any toxic air pollutant - one thousand dollars; or

(ii) RACT analysis and determination for an emissions unit or multiple emissions units of uniform design that, individually or in the aggregate, emit more than ten tons per year of any toxic air pollutant two thousand dollars.

(3) Fee schedule for source-specific determinations where RACT analysis is performed by the source and review and determination conducted by ecology.

(a) Basic RACT review and determination fees:

(i) Low complexity (the analysis addresses one type of emission unit) - one thousand dollars;

(ii) Moderate complexity (the analysis addresses two to five types of emissions units) - five thousand dollars;

(iii) High complexity (the analysis addresses more than five types of emission units) - ten thousand dollars.

(b) Additional charges based on criteria pollutant emissions: In addition to those fees required under (a) of this subsection, a fee will be required for a RACT analysis and determination for an emission unit or multiple emissions units of uniform design that, individually or in the aggregate, emit one hundred tons per year or more of any criteria pollutant - one thousand dollars.

(c) Additional charges based on toxic air pollutant emissions: In addition to those fees required under (a) and (b) of this subsection, the following fees will be required as applicable:

(i) RACT analysis and determination for an emissions unit or multiple emissions units of uniform design that, individually or in the aggregate, emit more than two tons per year but less than ten tons per year of any toxic air pollutant - five hundred dollars; or 
(ii) RACT analysis and determination for an emissions unitor multiple emissions units of uniform design that, individually or in the aggregate, emit more than ten tons per year of any toxic air pollutant - one thousand dollars.

(4) Fee schedule for reviews authorized under RCW 70.94.153 for the replacement or substantial alteration of control technology.

(a) Notice of construction application. Review and approval of notice of construction application (NOCA) for replacement or substantial alteration of control technology - three hundred fifty dollars.

(b) RACT analysis and determination. Review and approval of a RACT analysis and determination for affected emission unit - five hundred dollars.

(5) Fee schedule for categorical RACT determinations. Fees for categorical RACT determinations (for categories with more than three sources) shall be assessed as shown below. The fees described in (a) of this subsection shall be based on the most complex source within a category. Except as provided in (b) and (d) of this subsection, fees for individual sources in the category will be determined by dividing the total source category fee by the number of sources within the category.

(a) RACT analysis and determination (RACT analysis performed by ecology with assistance from sources):

(i) Low complexity source category (average source emissions of individual criteria pollutants are all less than twenty tons per year, average source emissions of individual toxic air pollutants are all less than two tons per year, or the analysis addresses one type of emission unit) - twenty-five thousand dollars;

(ii) Moderate complexity source category (average source emissions of one or more individual criteria pollutants are greater than twenty tons/year and less than one hundred tons per year, average source emissions of one or more individual toxic air pollutants are greater than two tons per year and less than ten tons per year, or the analysis addresses two to five types of emissions units) - fifty thousand dollars; or

(iii) High complexity source category (average source emissions of one or more individual criteria pollutants exceed one hundred tons per year, average source emissions of one or more individual toxic air pollutants exceed ten tons per year, or the analysis addresses more than five types of emission units) - one hundred thousand dollars.

(b) If an emission unit is being evaluated for more than one categorical RACT determination within a five-year period, ecology will charge the owner or operator of that emission unit one fee and the fee will reflect the higher complexity categorical RACT determination.

(c) Ecology may adjust the fee to reflect workload savings from source involvement in source category RACT determination.

(d) Ecology may approve alternate methods for allocating the fee among sources within the source category.

(6) Small business fee reduction. The RACT analysis and determination fee identified in subsections (2) through (5) of this section may be reduced for a small business.

(a) To qualify for the small business RACT fee reduction, a business must meet the requirements of "small business" as defined in RCW 43.31.025.

(b) To receive a fee reduction, the owner or operator of a small business must include information in an application demonstrating that the conditions of (a) of this subsection have been met. The application must be signed:

(i) By an authorized corporate officer in the case of a corporation;

(ii) By an authorized partner in the case of a limited or general partnership; or

(iii) By the proprietor in the case of a sole proprietorship.

(c) Ecology may verify the application information and if the owner or operator has made false statements, deny the fee reduction request and revoke previously granted fee reductions.

(d) For small businesses determined to be eligible under (a) of this subsection, the RACT analysis and determination fee shall be reduced to the greater of:

(i) Fifty percent of the RACT analysis and determination fee; or 
(ii) Two hundred fifty dollars.

(e) If due to special economic circumstances, the fee reduction determined under (d) of this subsection imposes an extreme hardship on a small business, the small business may request an extreme hardship fee reduction. The owner or operator must provide sufficient evidence to support a claim of an extreme hardship. The factors which ecology may consider in determining whether an owner or operator hasspecial economic circumstances and in setting the extreme hardship fee include: Annual sales; labor force size; market conditions which affect the owner's or operator's ability to pass the cost of the RACT analysis and determination fees through to customers; and average annual profits. In no case will a RACT analysis and determination fee be reduced below one hundred dollars.

(7) Fee reductions for pollution prevention initiatives. Ecology may reduce RACT analysis and determination fees for an individual source if that source is using approved pollution prevention measures.

(8) Fee payments. Fees specified in subsection (4)(a) of this section shall be paid at the time a notice of construction applications is submitted to the department. Other fees specified in subsections (2) through (7) of this section shall be paid no later than thirty days after receipt of an ecology billing statement. For fees specified in subsection (5) of this section, a billing for one-half of the payment from each source will be mailed when the source category rule-making effort is commenced as noted by publication of the CR101 form in the Washington State Register. A billing for the second half of the payment will be mailed when the proposed rule is published in the Washington State Register. No order of approval or other action approving or identifying a source to be at RACT will be issued by the department until all fees have been paid by the source. All fees collected under this regulation shall be made payable to the Washington department of ecology.

(9) Dedicated account. All control technology fees collected by the department from permit program sources shall be deposited in the air operating permit account created under RCW 70.94.015. All control technology fees collected by the department from nonpermit program sources shall be deposited in the air pollution control account.

(10) Tracking revenues, time, and expenditures. Ecology shall track revenues on a source-specific basis. For purposes of source-specific determinations under subsections (2) through (4) of this section, Ecology shall track time and expenditures on the basis of source complexity categories. For purposes of categorical determinations under subsection (5) of this section, ecology shall track time and expenditures on a source-category basis.

(11) Periodic review. Ecology shall review and, as appropriate, update this section at least once every two years.

\section{WAC173-400-050}

WAC 173-400-050 Emission standards for combustion and incineration units.

(1) Combustion and incineration emissions units must meet all requirements of WAC 173-400-040 and, in addition, no person shall cause or permit emissions of particulate matter in excess of 0.23 gram per dry cubic meter at standard conditions ( 0.1 grain/dscf), except, for an emissions unit combusting wood derived fuels for the production of steam. No person shall allow or permit the emission of particulate matter in excess of 0.46 gram per dry cubic meter at standard conditions $(0.2 \mathrm{grain} / \mathrm{dscf})$, as measured by EPA method 5 or approved procedures contained in "Source Test Manual - Procedures For Compliance Testing," state of Washington, department of ecology, as of July 12, 1990, on file at ecology.

(2) For any incinerator, no person shall cause or permit emissions in excess of one hundred ppm of total carbonyls as measured by applicable EPA methods or acceptable procedures contained in "Source Test Manual - Procedures for Compliance Testing," state of Washington, department of ecology, on file at 
ecology. Incinerators shall be operated only during daylight hours unless written permission to operate at other times is received from ecology or the authority.

(3) Measured concentrations for combustion and incineration sources shall be adjusted for volumes corrected to seven percent oxygen, except when ecology or the authority determines that an alternate oxygen correction factor is more representative of normal operations.

\section{WAC173-400-060}

WAC 173-400-060 Emission standards for general process units.

General process units are required to meet all applicable provisions of WAC 173-400-040 and, no person shall cause or permit the emission of particulate material from any general process operation in excess of 0.23 grams per dry cubic meter at standard conditions ( 0.1 grain/dscf) of exhaust gas. EPA test methods from $40 \mathrm{CFR}$ Appendix A which are adopted by reference and any other approved test procedures which are contained in ecology's "Source Test Manual - Procedures For Compliance Testing" as of July 12,1990 , will be used to determine compliance.

\section{WAC173-400-070}

WAC 173-400-070 Emission standards for certain source categories.

Ecology finds that the reasonable regulation of sources within certain categories requires separate standards applicable to such categories. The standards set forth in this section shall be the maximum allowable standards for emissions units within the categories listed. Except as specifically provided in this section, such emissions units shall not be required to meet the provisions of WAC 173-400-040, $173-400-050$ and $173-400-060$.

(1) Wigwam burners.

(a) All wigwam burners shall meet all provisions of WAC 173-400-040 (2), (3), (4), (5), (6), and (7).

(b) All wigwam burners shall use RACT. All emissions units shall be operated and maintained to minimize emissions. These requirements may include a controlled tangential vent overfire air system, an adequate underfire system, elimination of all unnecessary openings, a controlled feed and other modifications determined necessary by ecology or the authority.

(c) It shall be unlawful to install or increase the existing use of any bumer that does not meet all requirements for new sources including those requirements specified in WAC 173-400-040 and 173-400-050, except operating hours.

(d) Ecology may establish additional requirements for wigwam burners located in sensitive areas as defined by chapter 173-440 WAC. These requirements may include but shall not be limited to:

(i) A requirement to meet all provisions of WAC 173-400-040 and 173-400-050. Wigwam burners will be considered to be in compliance if they meet the requirements contained in WAC 173-400-040(1). An exception is made for a startup period not to exceed thirty minutes in any eight consecutive hours.

(ii) A requirement to apply BACT.

(iii) A requirement to reduce or eliminate emissions if ecology establishes that such emissions unreasonably interfere with the use and enjoyment of the property of others or are a cause of violation of ambient air standards.

(2) Hog fuel boilers.

(a) Hog fuel boilers shall meet all provisions of WAC 173-400-040 and 173-400-050(1), except that emissions may exceed twenty percent opacity for up to fifteen consecutive minutes once in any eight 
hours. The intent of this provision is to permit the soot blowing and grate cleaning necessary to the operation of these units. This practice is to be scheduled for the same specific times each day and ecology or the authority shall be notified of the schedule or any changes.

(b) All hog fuel boilers shall utilize RACT and shall be operated and maintained to minimize emissions.

(3) Orchard heating.

(a) Burning of rubber materials, asphaltic products, crankcase oil or petroleum wastes, plastic, or garbage is prohibited.

(b) It is unlawful to burn any material or operate any orchard-heating device that causes a visible emission exceeding twenty percent opacity, except during the first thirty minutes after such device or material is ignited.

(4) Grain elevators.

Any grain elevator which is primarily classified as a materials handling operation shall meet all the provisions of WAC 173-400-040 (2), (3), (4), and (5).

(5) Catalytic cracking units.

(a) All existing catalytic cracking units shall meet all provisions of WAC 173-400-040 (2), (3), (4), (5), (6), and (7) and:

(i) No person shall cause or permit the emission for more than three minutes, in any one hour, of an air contaminant from any catalytic cracking unit which at the emission point, or within a reasonable distance of the emission point, exceeds forty percent opacity.

(ii) No person shall cause or permit the emission of particulate material in excess of 0.46 grams per dry cubic meter at standard conditions ( 0.20 grains/dscf) of exhaust gas.

(b) All new catalytic cracking units shall meet all provisions of WAC 173-400-115.

(6) Other wood waste burners.

(a) Wood waste burners not specifically provided for in this section shall meet all provisions of WAC 173-400-040.

(b) Such wood waste burners shall utilize RACT and shall be operated and maintained to minimize emissions.

(7) Sulfuric acid plants.

No person shall cause to be discharged into the atmosphere from a sulfuric acid plant, any gases which contain acid mist, expressed as $\mathrm{H} 2 \mathrm{SO} 4$, in excess of 0.15 pounds per ton of acid produced. Sulfuric acid production shall be expressed as one hundred percent $\mathrm{H} 2 \mathrm{SO} 4$.

\section{WAC173-400-075}

WAC 173-400-075 Emission standards for sources emitting hazardous air pollutants.

(1) The emission standards for hazardous air pollutants promulgated by the United States Environmental Protection Agency (EPA) as in effect on date of adoption, as contained in Title 40, Code of Federal Regulations, Part 61, are adopted by reference. The term "administrator" in 40 CFR Part 61 shall mean both the administrator of EPA and the director of ecology.

(2) Ecology or the authority may conduct source tests and require access to records, books, files, and other infor- mation specific to the control, recovery, or release of those pollutants regulated under $40 \mathrm{CFR}$ Part 61 in order to determine the status of compliance of sources of these contaminants and to carry out its enforcement responsi- bilities.

(3) Source testing, monitoring, and analytical methods for sources of hazardous air pollutants such as: Asbestos, benzene from fugitive emission sources, beryllium, mercury, or vinyl chloride shall conform with the requirements of Title 40, Code of Federal Regulations, Part 61, as promulgated prior to January 1, 1993. 
(4) This section shall not apply to any source operating pursuant to a waiver granted by EPA or an exemption granted by the president of the United States during the effective life of such waiver or exemption.

\section{WAC173-400-081}

WAC 173-400-081 Startup and shutdown.

In promulgating technology-based emission standards and making control technology determinations (e.g., BACT, RACT, LAER, BART) ecology and the authorities shall consider any physical constraints on the ability of a source to comply with the applicable standard during startup or shutdown. Where ecology or the authority determines that the source or source category, operated and maintained in accordance with good air pollution control practice, is not capable of achieving continuous compliance with an emission standard during startup or shutdown, ecology or the authority shall include in the standard appropriate emission limitations, operating parameters, or other criteria to regulate the performance of the source during startup or shutdown conditions. In modeling the emissions of a source for purposes of demonstrating attainment or maintenance of national ambient air quality standards, ecology and the authorities shall take into account any incremental increase in allowable emissions under startup or shutdown conditions authorized by an emission limitation or other operating parameter adopted under this rule. Any emission limitation or other parameter adopted under this rule which increases allowable emissions during startup or shutdown conditions over levels authorized in an approved state implementation plan shall not take effect until approved by EPA as a SIP amendment.

\section{WAC173-400-091}

WAC 173-400-091 Voluntary limits on emissions.

(1) Upon request by the owner or operator of a source, ecology or the authority with jurisdiction over the source shall issue a regulatory order that limits the source's potential to emit any air contaminant or contaminants to a level agreed to by the owner or operator and ecology or the authority with jurisdiction over the source.

(2) A condition contained in an order issued under this section shall be less than the source's otherwise allowable annual emissions of a particular contaminant under all applicable requirements of the chapter $70.94 \mathrm{RCW}$ and the FCAA, including any standard or other requirement provided for in the Washington state implementation plan. The term "condition" refers to limits on production or other limitations, in addition to emission limitations.

(3) Any order issued under this section shall include monitoring, recordkeeping and reporting requirements sufficient to ensure that the source complies with any condition established under this section. Monitoring requirements shall use terms, test methods, units, averaging periods, and other statistical conventions consistent with the requirements of WAC 173-400-105.

(4) Any order issued under this section shall be subject to the notice and comment procedures under WAC $173-400-171$.

(5) The terms and conditions of a regulatory order issued under this section shall be federally enforceable, upon approval of this section as an element of the Washington state implementation plan. Any proposed deviation from a condition contained in an order issued under this section shall require revision or revocation of the order. 


\section{WAC173-400-099}

WAC 173-400-099 Registration program.

(1) Program purpose. The registration program is a program to develop and maintain a current and accurate record of air contaminant sources. Information collected through the registration program is used to evaluate the effectiveness of air pollution control strategies and to verify source compliance with applicable air pollution requirements.

(2) Program components. The components of the registration program consist of:

(a) Initial registration and annual or other periodic reports from stationary source owners providing information on location, size, height of contaminant outlets, processes employed, nature and quantity of the air contaminant emissions, and other information that is relevant to air pollution and available or reasonably capable of being assembled. For purposes of this chapter, information relevant to air pollution may include air pollution requirements established by rule, regulatory order, or ordinance pursuant to chapter $70.94 \mathrm{RCW}$.

(b) On-site inspections necessary to verify compliance with registration requirements.

(c) Data storage and retrieval systems necessary for support of the registration program.

(d) Emission inventory reports and emission reduction credits computed from information provided by source owners pursuant to registration requirements.

(e) Staff review, including engineering analysis for accuracy and currentness of information provided by source owners pursuant to registration program requirements.

(f) Clerical and other office support in direct furtherance of the registration program.

(g) Administrative support provided in directly carrying out the registration program.

\section{WAC173-400-100}

WAC 173-400-100 Source classifications.

(1) Source classification list. In counties without an active local air pollution control authority, the owner or operator of each stationary source within the following source categories shall register the source with ecology:

(a) Agricultural chemical facilities engaging in the manufacturing of liquid or dry fertilizers or pesticides;

(b) Agricultural drying and dehydrating operations;

(c) Any category of stationary sources to which a federal standard of performance (NSPS) under 40 CFR Part 60, other than Subpart AAA (Standards of Performance for New Residential Wood Heaters) applies;

(d) Any source category subject to a National Emission Standard for Hazardous Air Pollutants

(NESHAPS) under 40 CFR Part 61, other than Subpart M (National Emission Standard for Asbestos) or a Maximum Achievable Control Technology (MACT) standard established under Section 112 of the Federal Clean Air Act;

(e) Any source, stationary source or emission unit with a significant emission as defined by WAC 173-400-030 (67);

(f) Asphalt and asphalt products production facilities;

(g) Brick and clay manufacturing plants, including tiles and ceramics;

(h) Casting facilities and foundries, ferrous and nonferrous;

(i) Cattle feedlots with operational facilities which have an inventory of one thousand or more cattle in operation between June 1 and October 1, where vegetation forage growth is not sustained over the 
majority of the lot during the normal growing season;

(j) Chemical manufacturing plants;

(k) Composting operations, including commercial, industrial and municipal, but exempting residential composting activities;

(1) Concrete product manufacturers and ready mix and premix concrete plants;

(m) Crematoria or animal carcass incinerators;

(n) Dry cleaning plants;

(o) Materials handling and transfer facilities that generate fine particulate, which may include pneumatic conveying, cyclones, baghouses, and industrial housekeeping vacuuming systems that exhaust to the atmosphere;

(p) Flexible vinyl and urethane coating and printing operations;

(q) Grain, seed, animal feed, legume, and flour processing operations, and handling facilities;

(r) Hay cubers and pelletizers;

(s) Hazardous waste treatment and disposal facilities;

(t) Ink manufacturers;

(u) Insulation fiber manufacturers;

(v) Landfills, active and inactive, including covers, gas collections systems or flares;

(w) Metal plating and anodizing operations;

(x) Metallic and nonmetallic mineral processing plants, including rock crushing plants;

(y) Mills such as lumber, plywood, shake, shingle, woodchip, veneer operations, dry kilns, pulpwood insulating board, or any combination thereof;

(z) Mineralogical processing plants;

(aa) Other metallurgical processing plants;

(bb) Paper manufacturers;

(cc) Petroleum refineries;

(dd) Plastics and fiberglass product fabrication facilities;

(ee) Rendering plants;

(ff) Soil and groundwater remediation projects;

(gg) Surface coating manufacturers;

(hh) Surface coating operations including: Automotive, metal, cans, pressure sensitive tape, labels, coils, wood, plastic, rubber, glass, paper and other substrates;

(ii) Synthetic fiber production facilities;

(ji) Synthetic organic chemical manufacturing industries;

(kk) Tire recapping facilities;

(11) Wastewater treatment plants;

( $\mathrm{mm}$ ) Any source that has elected to opt-out of the operating permit program by limiting its potential-to-emit (synthetic minor) or is required to report periodically to demonstrate nonapplicability to EPA requirements under Sections 111 or 112 of FCAA.

(2) Equipment classification list. In counties without an active local air pollution control authority, the owner or operator of the following equipment shall register the source with ecology:

(a) Boilers, all solid and liquid fuel burning boilers with the exception of those utilized for residential heating;

(b) Boilers, all gas fired boilers above 10 million British thermal units per hour input;

(c) Chemical concentration evaporators;

(d) Degreasers of the cold or vapor type in which more than five percent of the solvent is comprised of halogens or such aromatic hydrocarbons as benzene, ethylbenzene, toluene or xylene;

(e) Ethylene oxide (ETO) sterilizers;

(f) Flares utilized to combust any gaseous material;

(g) Fuel burning equipment with a heat input of more than 1 million Btu per hour; except heating, air 
conditioning systems, or ventilating systems not designed to remove contaminants generated by or released from equipment;

(h) Incinerators designed for a capacity of one hundred pounds per hour or more;

(i) Ovens, burn-out and heat-treat;

(j) Stationary internal combustion engines and turbines rated at five hundred horsepower or more;

(k) Storage tanks for organic liquids associated with commercial or industrial facilities with capacities equal to or greater than 40,000 gallons;

(1) Vapor collection systems within commercial or industrial facilities;

(m) Waste oil burners above $0.5 \mathrm{~mm}$ Btu heat output;

(n) Woodwaste incinerators.

\section{WAC173-400-101}

WAC 173-400-101 Registration issuance.

(1) General. Any person operating or responsible for the operation of an air contaminant source for which registration and reporting are required shall register the source emission unit with ecology or the authority. The owner or operator shall make reports containing information as may be required by ecology or the authority concerning location, size and height of contaminant outlets, processes employed, nature and quantity of the air contaminant emission and such other information as is relevant to air pollution and available or reasonably capable of being assembled.

(2) Registration form. Registration information shall be provided on forms supplied by ecology or the authority and shall be completed and returned within the time specified on the form. Emission units within the facility shall be listed separately unless ecology or the authority determines that certain emission units may be combined into process streams for purposes of registration and reporting.

(3) Signatory responsibility. The owner, operator, or their designated management representative shall sign the registration form for each source. The owner or operator of the source shall be responsible for notifying ecology or the authority of the existence of the source, and for the accuracy, completeness, and timely submittal of registration reporting information and any accompanying fee.

(4) Operational and maintenance plan. Owners or operators of registered sources within ecology"s jurisdiction shall maintain an operation and maintenance plan for process and control equipment. The plan shall reflect good industrial practice and shall include a record of performance and periodic inspections of process and control equipment. In most instances, a manufacturer"s operations manual or an equipment operation schedule may be considered a sufficient operation and maintenance plan. The plan shall be reviewed and updated by the source owner or operator at least annually. A copy of the plan shall be made available to ecology upon request.

(5) Report of closure. A report of closure shall be filed with ecology or the authority within ninety days after operations producing emissions permanently cease at any applicable source under this section.

(6) Report of change of ownership. A new owner or operator shall report to ecology or the authority within ninety days of any change of ownership or change in operator.

(7) Operating permit program source exemption. Permit program sources, as defined in RCW 70.94.030(17), are not required to comply with the registration requirements of WAC 173-400-100 through 173-400-104.

\section{WAC173-400-102}

WAC 173-400-102 Scope of registration and reporting requirements. 
(1) Administrative options. A source in a listed source category that is located in a county without an active local air authority will be addressed in one of several ways:

(a) The source will be required to register and report once each year. The criteria for identifying these sources are listed in subsection (2) of this section.

(b) The source will be required to register and report once every three years. The criteria for identifying these sources are listed in subsection (3) of this section.

(c) The source will be exempted from registration program requirements. The criteria for identifying these sources are listed in subsection (4) of this section.

(2) Sources requiring annual registration and inspections. An owner or operator of a source in a listed source category that meets the following criteria shall register and report once each year:

(a) The source emits one or more pollutants at rates greater than the emission rates listed in WAC 173-400-030(67);

(b) Annual registration and reporting is necessary to comply with federal reporting requirements and emission standards; or

(c) Annual registration and reporting is required in a reasonably available control technology determination for the source category.

(d) The director of ecology determines that the source poses a threat to human health and the environment.

(3) Sources requiring periodic registration and inspections. An owner or operator of a source in a listed source category that meets the following criteria shall register and report once every three years:

(a) The source emits one or more pollutants at rates greater than the emission rates listed in subsection

(5) of this section and less than the emission rates listed in WAC 173-400-030(67); or

(b) The source emits measurable amounts of one or more Class A or Class B toxic air pollutants listed in WAC $173-460-150$ and $173-460-160$.

(4) Sources exempt from registration program requirements. Any source included in a listed source category that is located in a county without an active local air authority shall not be required to register if ecology determines the following:

(a) The source emits pollutants below emission rates specified in subsection (5) of this section; and

(b) The source or emission unit does not emit measurable amounts of Class A or Class B toxic air pollutants specified in WAC 173-460-150 and 173-460-160.

(5) Criteria for defining exempt sources. The following emission rates will be used to identify listed sources that are exempt from registration program requirements:

\begin{tabular}{lc} 
Pollutant & Tons/Year \\
Carbon Monoxide & \multicolumn{2}{c}{5.0} \\
Nitrogen oxide & \multicolumn{2}{c}{2.0} \\
Sulfur dioxide & 2.0 \\
Particulate Matter (PM) & \multicolumn{2}{c}{1.25} \\
Fine Particulate (PM10) & 0.75 \\
Volatile organic compounds (VOC) & 2.0 \\
Lead 0.005 &
\end{tabular}

\section{WAC173-400-103}

WAC 173-400-103 Emission estimates.

(1) Procedure for estimating emissions. In counties without an active local air pollution control 
authority, registration may include an estimate of actual emissions taking into account equipment, operating conditions, and air pollution control measures. Registration may also include a flowchart of plant processes, operational parameters, and specifications of air pollution control equipment. The emissions estimate shall be based upon actual test data or, in the absence of such data, upon procedures acceptable to ecology. Any emission data submitted to ecology shall be verifiable using currently accepted engineering criteria. The following procedures may be used to estimate emissions from individual sources or emissions units:

(a) Source-specific testing data;

(b) Mass balance calculations;

(c) A published, verifiable emission factor that is applicable to the source;

(d) Other engineering calculations; or

(e) Other procedures to estimate emissions that are acceptable to ecology.

(2) Owner or operator review. Ecology will provide the owner or operator of the source an opportunity to review any emission estimates prepared by ecology. An owner or operator may submit additional information and any justification for not using the methods listed above. This information will be evaluated by ecology to determine whether it is based on currently accepted engineering criteria. If none of the above methods are available or applicable to the source, an appropriate method will be established and approved by ecology on a case-by-case basis.

\section{WAC173-400-104}

WAC 173-400-104 Registration fees.

(1) Registration fee determination. In counties without an active local air pollution control authority, ecology shall establish registration fees based on workload using the process outlined below. The fees collected shall be sufficient to cover the direct and indirect costs of administering the registration program within ecology's jurisdiction.

(2) Budget preparation. Ecology shall conduct a workload analysis projecting resource requirements for administering the registration program. Workload estimates shall be prepared on a biennial basis and shall estimate the resources required to perform registration program activities listed in WAC 173-400-097(2). Ecology shall prepare a budget for administering the registration program using workload estimates identified in the workload analysis for the biennium.

(3) Registration fee schedule. Ecology's registration program budget shall be distributed to sources located in its jurisdiction according to the following:

(a) Sources requiring periodic registration and inspections shall pay an annual registration fee of four hundred dollars.

(b) Sources requiring annual registration and inspections shall pay a registration fee comprised of the following three components:

(i) Flat component. This portion of a source"'s fee shall be calculated by the equal division of thirty-five percent of the budget amount allocated to annual registration sources by the total number of sources requiring annual registration.

(ii) Complexity component. Each source is assigned a complexity rating of 1,3, or 5 which is based on the estimated amount of time needed to review and inspect the source. This portion of the fee is calculated by dividing forty percent of the budget amount allocated to annually registered sources by the total complexity of sources located in ecology"s jurisdiction. The quotient is then multiplied by an individual source"s complexity rating to determine that source"s complexity portion of the fee.

(iii) Emissions component. This portion of a source"'s fee is calculated by dividing twenty-five percent of the budget amount allocated to annually registered sources by the total billable emissions from those 
sources. The quotient is then multiplied by an individual source's billable emissions to determine that source"s emissions portion of the fee. Billable emissions include all air pollutants except carbon monoxide and total suspended particulate.

(4) Regulatory orders. Owners or operators registering a source as a synthetic minor must obtain a regulatory order which limits the source"'s emissions. The owner will be required to pay a fee based on the amount of time required to research and write the order multiplied by an hourly rate of sixty dollars.

(5) Fee reductions for pollution prevention initiatives. Ecology may reduce registration fees for an individual source if that source demonstrates the use of approved pollution prevention measures or best management practices beyond those required of the source.

(6) Fee reductions for economic hardships. If a small business owner believes the registration fee results in an extreme economic hardship, the small business owner may request an extreme hardship fee reduction. The owner or operator must provide sufficient evidence to support a claim of an extreme hardship. The factors which ecology may consider in determining whether an owner or operator has special economic circumstances and in setting the extreme hardship fee include: Annual sales; labor force size; market conditions which affect the owner's or operator's ability to pass the cost of the registration fee through to customers; average annual profits, and cumulative effects of multiple site ownership. In no case will a registration fee be reduced below two hundred dollars.

(7) Fee payments. Fees specified in this section shall be paid within thirty days of receipt of ecology"s billing statement. All fees collected under this regulation shall be made payable to the Washington department of ecology. A late fee surcharge of fifty dollars or ten percent of the fee, whichever is more, may be assessed for any fee not received after the thirty-day period.

(8) Dedicated account. All registration fees collected by ecology shall be deposited in the air pollution control account.

(9) Tracking revenues, time, and expenditures. Ecology shall track revenues collected under this subsection on a source-specific basis. Ecology shall track time and expenditures on the basis of ecology budget functions.

\section{WAC173-400-105}

WAC 173-400-105 Records, monitoring, and reporting.

The owner or operator of a source shall upon notification by the director of ecology, maintain records on the type and quantity of emissions from the source and other information deemed necessary to determine whether the source is in compliance with applicable emission limitations and control measures.

(1) Emission inventory. The owner(s) or operator(s) of any air contaminant source shall submit an inventory of emissions from the source each year. The inventory may include stack and fugitive emissions of particulate matter, PM10, sulfur dioxide, carbon monoxide, total reduced sulfur compounds (TRS), fluorides, lead, VOCs, and other contaminants, and shall be submitted (when required) no later than one hundred five days after the end of the calendar year. The owner(s) or operator(s) shall maintain records of information necessary to substantiate any reported emissions, consistent with the averaging times for the applicable standards.

(2) Monitoring. Ecology shall conduct a continuous surveillance program to monitor the quality of the ambient atmosphere as to concentrations and movements of air contaminants.

As a part of this program, the director of ecology or an authorized representative may require any source under the jurisdiction of ecology to conduct stack and/or ambient air monitoring and to report the results to ecology.

(3) Investigation of conditions. Upon presentation of appropriate credentials, for the purpose of investigating conditions specific to the control, recovery, or release of air contaminants into the 
atmosphere, personnel from ecology or an authority shall have the power to enter at reasonable times upon any private or public property, excepting nonmultiple unit private dwellings housing one or two families.

(4) Source testing. To demonstrate compliance, ecology or the authority may conduct or require that a test be conducted of the source using approved EPA methods from 40 CFR 60 Appendix A which are adopted by reference, or approved procedures contained in "Source Test Manual - Procedures for Compliance Testing," state of Washington, department of ecology, as of July 12, 1990, on file at ecology. The operator of a source may be required to provide the necessary platform and sampling ports for ecology personnel or others to perform a test of an emissions unit. Ecology shall be allowed to obtain a sample from any emissions unit. The operator of the source shall be given an opportunity to observe the sampling and to obtain a sample at the same time.

(5) Continuous monitoring and recording. Owners and operators of the following categories of sources shall install, calibrate, maintain and operate equipment for continuously monitoring and recording those emissions specified.

(a) Fossil fuel-fired steam generators.

(i) Opacity, except where:

(A) Steam generator capacity is less than two hundred fifty million BTU per hour heat input; or

(B) Only gaseous fuel is burned.

(ii) Sulfur dioxide, except where steam generator capacity is less than two hundred fifty million BTU per hour heat input or if sulfur dioxide control equipment is not required.

(iii) Percent oxygen or carbon dioxide where such measurements are necessary for the conversion of sulfur dioxide continuous emission monitoring data.

(iv) General exception. These requirements do not apply to a fossil fuel-fired steam generator with an annual average capacity factor of less than thirty percent, as reported to the Federal Power Commission for calendar year 1974, or as otherwise demonstrated to ecology or the authority by the owner(s) or operator(s).

(b) Sulfuric acid plants.

Sulfur dioxide where production capacity is more than three hundred tons per day, expressed as one hundred percent acid, except for those facilities where conversion to sulfuric acid is utilized primarily as a means of preventing emissions to the atmosphere of sulfur dioxide or other sulfur compounds.

(c) Fluid bed catalytic cracking units catalyst regenerators at petroleum refineries. Opacity where fresh feed capacity is more than twenty thousand barrels per day.

(d) Wood residue fuel-fired steam generators.

(i) Opacity, except where steam generator capacity is less than one hundred million BTU per hour heat input.

(ii) Continuous monitoring equipment. The requirements of

(e) of this subsection do not apply to wood residue fuel-fired steam generators, but continuous monitoring equipment required by (d) of this subsection shall be subject to approval by ecology.

(e) Owners and operators of those sources required to install continuous monitoring equipment under this chapter shall demonstrate to ecology or the authority, compliance with the equipment and performance specifications and observe the reporting requirements contained in 40 CFR Part 51 , Appendix P, Sections 3, 4 and 5, promulgated October 6, 1975, and amended November 7, 1986, which is adopted by reference.

(f) Special considerations. If for reason of physical plant limitations or extreme economic situations, ecology determines that continuous monitoring is not a reasonable requirement, alternative monitoring and reporting procedures will be established on an individual basis. These will generally take the form of stack tests conducted at a frequency sufficient to establish the emission levels over time and to monitor deviations in these levels.

(g) Exemptions. This subsection (5) does not apply to any source which is: 
(i) Subject to a new source performance standard. These sources will be governed by WAC 173-400-115.

(ii) Not subject to an applicable emission standard.

(h) Monitoring system malfunctions. A source may be temporarily exempted from the monitoring and reporting requirements of this chapter during periods of monitoring system malfunctions provided that the source owner(s) or operator(s) shows to the satisfaction of ecology or the authority that the malfunction was unavoidable and is being repaired as expeditiously as practicable.

(6) Change in raw materials or fuels for sources not subject to requirements of the operating permit program. Any change or series of changes in raw material or fuel which will result in a cumulative increase in emissions of sulfur dioxide of forty tons per year or more over that stated in the initial inventory required by subsection (1) of this section shall require the submittal of sufficient information to ecology or the authority to determine the effect of the increase upon ambient concentrations of sulfur dioxide. Ecology or the authority may issue regulatory orders requiring controls to reduce the effect of such increases. Cumulative changes in raw material or fuel of less than 0.5 percent increase in average annual sulfur content over the initial inventory shall not require such notice.

\section{WAC173-400-107}

WAC 173-400-107 Excess emissions.

(1) The owner or operator of a source shall have the burden of proving to ecology or the authority or the decision-making authority in an enforcement action that excess emissions were unavoidable. This demonstration shall be a condition to obtaining relief under subsections (4), (5) and (6) of this section.

(2) Excess emissions determined to be unavoidable under the procedures and criteria in this section shall be excused and not subject to penalty.

(3) Excess emissions which represent a potential threat to human health or safety or which the owner or operator of the source believes to be unavoidable shall be reported to ecology or the authority as soon as possible. Other excess emissions shall be reported within thirty days after the end of the month during which the event occurred or as part of the routine emission monitoring reports. Upon request by ecology or the authority, the owner(s) or operator(s) of the source(s) shall submit a full written report including the known causes, the corrective actions taken, and the preventive measures to be taken to minimize or eliminate the chance of recurrence.

(4) Excess emissions due to startup or shutdown conditions shall be considered unavoidable provided the source reports as required under subsection (3) of this section and adequately demonstrates that the excess emissions could not have been prevented through careful planning and design and if a bypass of control equipment occurs, that such bypass is necessary to prevent loss of life, personal injury, or severe property damage.

(5) Maintenance. Excess emissions due to scheduled maintenance shall be considered unavoidable if the source reports as required under subsection (3) of this section and adequately demonstrates that the excess emissions could not have been avoided through reasonable design, better scheduling for maintenance or through better operation and maintenance practices.

(6) Excess emissions due to upsets shall be considered unavoidable provided the source reports as required under subsection (3) of this section and adequately demonstrates that:

(a) The event was not caused by poor or inadequate design, operation, maintenance, or any other reasonably preventable condition;

(b) The event was not of a recurring pattern indicative of inadequate design, operation, or maintenance; and

(c) The operator took immediate and appropriate corrective action in a manner consistent with good air 
pollution control practice for minimizing emissions during the event, taking into account the total emissions impact of the corrective action, including slowing or shutting down the emission unit as necessary to minimize emissions, when the operator knew or should have known that an emission standard or permit condition was being exceeded.

\section{WAC173-400-110}

\section{WAC 173-400-110 New source review (NSR).}

(1) Applicability.

(a) A notice of construction application must be filed by the owner or operator and an order of approval issued by ecology or an authority prior to the establishment of any new source or emission unit or modification which is listed in WAC $173-400-100$ or required to obtain a permit under RCW 70.94.161.

(b) Ecology or the authority may require that a notice of construction application be filed by the owner or operator of a proposed new source or modification and an order of approval issued by ecology or an authority prior to the establishment of any new source or emission unit or modification, other than a single family or a duplex dwelling.

(c) New source review of a modification shall be limited to the emission unit or units proposed to be added to an existing source or modified and the air contaminants whose emissions would increase as a result of the modification.

(2) Completeness determination. Within thirty days of receipt of a notice of construction application, ecology or the authority shall either notify the applicant in writing that the application is complete or notify the applicant in writing of all additional information necessary, based upon review of information already supplied, to complete the application. For a project subject to PSD review under WAC 173-400-141 a completeness determination includes a determination that the application provides all information required to conduct PSD review.

(3) Final determination.

(a) Within sixty days of receipt of a complete application, ecology or the authority shall either issue a final decision on the application or, for those projects subject to public notice, initiate notice and comment procedures under WAC 173-400-171 on a proposed decision, followed as promptly as possible by a final decision. A person seeking approval to construct or modify a source that requires an operating permit may elect to integrate review of the operating permit application or amendment required under RCW 70.94.161 and the notice of construction application required by this section. A notice of construction application designated for integrated review shall be processed in accordance with operating permit program procedures and deadlines.

(b) Every final determination on a notice of construction application shall be reviewed and signed prior to issuance by a professional engineer or staff under the direct supervision of a professional engineer in the employ of ecology or the authority.

(c) If the new source is a major stationary source or the change is a major modification, ecology or the authority shall submit any control technology determination included in a final order of approval to the RACT/BACT/LAER clearinghouse maintained by EPA.

(4) Appeals. An order of approval, any conditions contained in an order of approval, or the denial of a notice of construction application may be appealed to the pollution control hearings board as provided in chapter 43.21B RCW. Ecology or the authority shall promptly mail copies of each order approving or denying a notice of construction application to the applicant and to any other party who submitted timely comments on the application, along with a notice advising parties of their rights of appeal to the Pollution Control Hearings Board and, where applicable, to the EPA Environmental Appeals Board.

(5) Portable sources. For portable sources which locate temporarily at particular sites, the owner(s) or 
operator(s) shall be allowed to operate at the temporary location without filing a notice of construction application, providing that the owner(s) or operator(s) notifies ecology or the authority of intent to operate at the new location at least thirty days prior to starting the operation, and supplies sufficient information to enable ecology or the authority to determine that the operation will comply with the emission standards for a new source, and will not cause a violation of applicable ambient air quality standards and, if in a nonattainment area, will not interfere with scheduled attainment of ambient standards. The permission to operate shall be for a limited period of time (one year or less) and ecology or the authority may set specific conditions for operation during that period. A temporary source shall be required to comply with all applicable emission standards.

(6) Approval to construct or modify a stationary source shall become invalid if construction is not commenced within eighteen months after receipt of such approval, if construction is discontinued for a period of eighteen months or more, or if construction is not completed within a reasonable time. Ecology or the authority may extend the eighteen-month period upon a satisfactory showing that an extension is justified. This provision does not apply to the time period between construction of the approved phases of a phased construction project; each phase must commence construction within eighteen months of the projected and approved commencement date.

\section{WAC173-400-112}

WAC 173-400-112 Requirements for new sources in nonattainment areas.

Ecology or an authority reviewing an application to establish a new source or modification in a nonattainment area, shall issue an order of approval, which order shall contain such conditions as are reasonably necessary to assure the maintenance of compliance with this chapter, if they determine that the proposed project satisfies each of the following requirements:

(1) The proposed new source or modification will comply with all applicable new source performance standards, national emission standards for hazardous air pollutants, emission standards adopted under chapter $70.94 \mathrm{RCW}$ and, for sources regulated by an authority, the applicable emission standards of that authority.

(2) The proposed new source will employ BACT for all air contaminants, except that if the new source is a major stationary source or the proposed modification is a major modification it will achieve LAER for the contaminants for which the area has been designated nonattainment and for which the proposed new source or modification is major.

(3) The proposed new source will not cause any ambient air quality standard to be exceeded, will not violate the requirements for reasonable further progress established by the state implementation plan and will comply with WAC 173-400-113(3) for all contaminants for which the area has not been designated nonattainment.

(4) If the proposed new source is a major stationary source or the proposed modification is a major modification, ecology or the authority has determined, based on review of an analysis performed by the source of alternative sites, sizes, production processes, and environmental control techniques, that the benefits of the project significantly outweigh the environmental and social costs imposed as a result of its location, construction, or modification.

(5) If the proposed new source or the proposed modification is major for the contaminant for which the area is designated nonattainment, allowable emissions from the proposed new source or modification of that contaminant are offset by reductions in actual emissions from existing sources in the nonattainment area. Emission offsets must be sufficient to ensure that total allowable emissions from existing major stationary sources in the nonattainment area, new or modified sources which are not major stationary sources, and the proposed new or modified source will be less than total actual emissions from existing 
sources (prior to submittal of the application) so as to represent (when considered together with the nonattainment provisions of section 172 of the FCAA) reasonable further progress. All offsetting emission reductions must satisfy the following requirements:

(a) The proposed new level of allowable emissions of the source or emission unit(s) providing the reduction must be less than the current level of actual emissions of that source or emissions unit(s). No emission reduction can be credited for actual emissions which exceed the currentallowable emissions of the source or emissions unit(s) providing the reduction. Emission reductions imposed by local, state, or federal regulations, regulatory orders, or permits cannot be credited.

(b) The emission reductions must provide for a net air quality benefit. For marginal ozone nonattainment areas, the total emissions of volatile organic compounds or total emissions of nitrogen oxides are reduced by a ratio of 1.1 to 1 for the area in which the new source is located. For any other nonattainment area, the emissions offsets must provide a positive net air quality benefit in the nonattainment area. Determinations on whether emissions offsets provide a positive net air quality benefit will be made in accordance with the guidelines contained in 40 CFR 51 Appendix $S$.

(c) If the offsets are provided by another source, the reductions in emissions from that source must be federally enforceable by the time the new or modified source commences operation. The new source may not commence operation before the date such reductions are actually achieved. An emission reduction credit issued under WAC 173-400-131 may be used to satisfy some or all of the offset requirements of this subsection.

(6) If the proposed new source is a major stationary source or the proposed modification is a major modification, the owner or operator has demonstrated that all major stationary sources owned or operated by such person (or by any entity controlling, controlled by, or under common control with such person) in Washington are subject to emission limitations and are in compliance, or on a schedule for compliance, with all applicable emission limitations and standards under the Federal Clean Air Act, including all rules contained in an EPA-approved state implementation plan.

(7) If the proposed new source is a major stationary source or the proposed modification is a major modification for the purposes of the PSD program described in WAC 173-400-141, it meets the requirements of that program for all contaminants for which the area has not been designated nonattainment.

(8) If the proposed new source or modification will emit any toxic air pollutants regulated under chapter 173-460 WAC, the source meets all applicable requirements of that chapter.

(9) If the proposed new source is a major stationary source or the proposed modification is a major modification, ecology or the authority has complied with the visibility protection review requirements of 40 CFR 52.28(c) through (e) except for (c)(4)(i), (g), and (h), as in effect on March 3, 1993, and determined that the project meets the criteria set forth in 40 CFR $52.28(\mathrm{~g})$. For purposes of this subsection, definitions referenced in 40 CFR 52.28 (b) are incorporated by reference, except that the term "visibility protection area" means any Class I area, and terms defined in WAC 173-400-030 shall have the meanings defined in that section. References in 40 CFR 52.28 to "the Administrator" shall mean the agency (either ecology or the authority) processing the notice of construction application.

\section{WAC173-400-113}

WAC 173-400-113 Requirements for new sources in attainment or unclassifiable areas.

Ecology or an authority reviewing an application to establish a new source or modification in an area that is in attainment or unclassifiable for any air contaminant the new source would emit and that is in attainment or unclassifiable for ozone if the proposed new or modified source would emit VOCs or NOX, shall issue an order of approval, which order shall contain such conditions as are reasonably necessary to 
assure the maintenance of compliance with this chapter, if they determine that the proposed project satisfies all of the following requirements:

(1) The proposed new source or modification will comply with all applicable new source performance standards, national emission standards for hazardous air pollutants, emission standards adopted under chapter $70.94 \mathrm{RCW}$ and, for sources regulated by an authority, the applicable emission standards of that authority.

(2) The proposed new source or modification will employ BACT for all pollutants not previously emitted or whose emissions would increase as a result of the new source or modification.

(3) Allowable emissions from the proposed new source or modification will not delay the attainment date for an area not in attainment nor cause or contribute to a violation of any ambient air quality standard. This requirement will be considered to be met if the projected impact of the allowable emissions from the proposed new source or the projected impact of the increase in allowable emissions from the proposed modification at any location within a nonattainment area does not exceed the following levels for the pollutant(s) for which the area has been designated nonattainment:

\begin{tabular}{|c|c|c|c|c|c|c|}
\hline \multicolumn{2}{|c|}{ Annual } & 24-Hour & 8-Hour & 3-Hour & 1-Hour & \multirow[b]{2}{*}{ Average } \\
\hline Pollutan & Average & Average & & Average & Average & \\
\hline $\mathrm{CO}$ & - & $0.5 \mathrm{mg} / \mathrm{m}^{\wedge} 3$ & & $2 \mathrm{mg} / \mathrm{m}^{\wedge} 3$ & & \\
\hline $\mathrm{SO} 2$ & $1.0 \mathrm{~g} / \mathrm{m}^{\wedge} 3$ & $5 \mathrm{~g} / \mathrm{m}^{\wedge} 3$ & - & $25 \mathrm{~g} / \mathrm{m}^{\wedge} 3$ & $30 \mathrm{~g} / \mathrm{m}^{\wedge} 3$ & \\
\hline PMIO & $1.0 \mathrm{~g} / \mathrm{m}^{\wedge} 3$ & $5 \mathrm{~g} / \mathrm{m}^{\wedge} 3$ & - & - & - & \\
\hline $\mathrm{NO} 2$ & $1.0 \mathrm{~g} / \mathrm{m}^{\wedge} 3$ & - & - & - & & \\
\hline
\end{tabular}

An offsetting emission reduction may be used to satisfy some or all of the requirements of this subsection.

(4) If the proposed new source is a major stationary source or the proposed modification is a major modification for purposes of the PSD program described in WAC 173-400-141, it meets all applicable requirements of that chapter.

(5) If the proposed new source or the proposed modification will emit any toxic air pollutants regulated under chapter 173-460 WAC, the source meets all applicable requirements of that program.

(6) If, within the meaning of the PSD program described in WAC 173-400-141, the proposed new source is a major stationary source or the proposed modification is a major modification, ecology or the authority has complied with the visibility protection review requirements of 40 CFR 52.27(d) through (f), as in effect on March 3, 1993, and has determined that the source would not cause an adverse impact upon visibility. References in 40 CFR 52.27 to "the Administrator" shall mean the agency (either ecology or the authority) processing the notice of construction application.

\section{WAC173-400-114}

WAC 173-400-114 Requirements for replacement or substantial alteration of emission control technology at an existing stationary source.

(1) Any person proposing to replace or substantially alter the emission control technology installed on an existing stationary source or emission unit shall file a notice of construction application with the appropriate authority, or with ecology in areas or for sources over which ecology has jurisdiction. Replacement or substantial alteration of control technology does not include routine maintenance, repair or similar parts replacement.

(2) For projects not otherwise reviewable under WAC 173-400-110, ecology or the authority may: 
(a) Require that the owner or operator employ RACT for the affected emission unit;

(b) Prescribe reasonable operation and maintenance conditions for the control equipment; and

(c) Prescribe other requirements as authorized by chapter $70.94 \mathrm{RCW}$.

(3) Within thirty days of receipt of a notice of construction application under this section ecology or the authority shall either notify the applicant in writing that the application is complete or notify the applicant in writing of all additional information necessary to complete the application. Within thirty days of receipt of a complete notice of construction application under this section ecology or the authority shall either issue an order of approval or a proposed RACT determination for the proposed project.

(4) Construction shall not commence, as defined in WAC 173-400-030(15), on a project subject to review under this section until ecology or the authority issues a final order of approval. However, any notice of construction application filed under this section shall be deemed to be approved without conditions if ecology or the authority takes no action within thirty days of receipt of a complete notice of construction application.

(5) Approval to replace or substantially alter emission control technology shall become invalid if construction is not commenced within eighteen months after receipt of such approval, if construction is discontinued for a period of eighteen months or more, or if construction is not completed within a reasonable time. Ecology or the authority may extend the eighteen-month period upon a satisfactory showing that an extension is justified. This provision does not apply to the time period between construction of the approved phases of a phased construction project; each phase must commence construction within eighteen months of the projected and approved commencement date.

\section{WAC173-400-115}

WAC 173-400-115 Standards of performance for new sources.

Title 40, Code of Federal Regulations, Part 60 (standards of performance for new sources), as in effect on January 1, 1993, is adopted by reference except for sections 60.5 (determination of construction or modification) and 60.6 (review of plans). The term "administrator" in 40 CFR Part 60 shall mean both the administrator of EPA and the director of ecology.

As of January 1, 1993, the federal regulations adopted by reference hereby set standards of performance affecting facilities for the following described subparts of 40 CFR Part 60:

Subpart D Fossil fuel fired steam generators for which construction commenced after August 17, 1971, and prior to September 19,1978, which have a heat input greater than 73 megawatts but not greater than 250 megawatts

Subpart Da Electric utility steam generating units for which construction commenced after September 18, 1978, which have a heat input greater than 73 megawatts but not greater than 250 megawatts

Subpart DbIndustrial-commercial-institutional steam generating units for which construction commenced after June 19, 1984, and prior to June 19, 1986, which have a heat input greater than 29 megawatts but less than 73 megawatts

Subpart Dc Small industrial-commercial-institutional steam generating units

Subpart E Incinerators

Subpart Ea Municipal waste combustors

Subpart F Portland cement plants

Subpart G Nitric acid plants

Subpart H Sulfuric acid plants

Subpart I Asphalt concrete plants

Subpart J Petroleum refineries which produce less than 25,000 barrels per day of refined products 
Subpart K Storage vessels for petroleum liquid constructed after June 11, 1973, and prior to May 19, 1978 , which have a capacity greater than 40,000 gallons

Subpart Ka Storage vessels for petroleum liquids constructed after May 18, 1978, which have a capacity greater than 40,000 gallons

Subpart $\mathrm{Kb}$ Volatile organic liquid storage vessels (including petroleum liquid storage vessels) constructed, reconstructed, or modified after July 23, 1984

Subpart L Secondary lead smelters

Subpart MBrass and bronze ingot production plants

Subpart N Iron and steel plants

Subpart O Sewage treatment plants

Subpart P Primary copper smelters

Subpart Q Primary zinc smelters

Subpart R Primary lead smelters

Subpart S Primary aluminum reduction plants

Subpart T Phosphate fertilizer industry: Wet process phosphoric acid plants

Subpart U Phosphate fertilizer industry: Superphosphoric acid plants

Subpart V Phosphate fertilizer industry: Diammonium phosphate plants

Subpart W Phosphate fertilizer industry: Triple superphosphate plants

Subpart X Phosphate fertilizer industry: Granular triple superphosphate storage facilities

Subpart Y Coal preparation plants

Subpart Z Ferroalloy production facilities

Subpart AA Steel plants: Electric arc furnaces

Subpart AAa Steel plants: Electric arc furnaces and argon-oxygen decarburization vessels

Subpart BB Kraft pulp mills

Subpart CC Glass manufacturing plants

Subpart DD Grain elevators

Subpart EE Industrial surface coating: Metal furniture

Subpart GG Stationary gas turbines

Subpart HH Lime manufacturing plants

Subpart KK Lead-acid battery plants

Subpart LL Metallic mineral processing plants

Subpart MM Automobile and light duty truck surface coating operations

Subpart NN Phosphate rock plants

Subpart PP Ammonium sulfate manufacture

Subpart QQ Publication rotogravure printing

Subpart RR Pressure sensitive tape and label surface coating operations

Subpart SS Industrial surface coating: Large appliances

Subpart TT Industrial surface coating: Metal coils

Subpart UU Asphalt processing and asphalt roofing manufacture

Subpart VV SOCMI equipment leaks (VOC)

Subpart WW Beverage can surface coating operations

Subpart XX Bulk gasoline terminals

Subpart AAA New residential wood heaters

Subpart BBB Rubber tire manufacturing industry

Subpart DDD VOC emissions from the polymer manufacturing industry

Subpart FFF Flexible vinyl and urethane coating and printing

Subpart GGG Petroleum refineries compressors and fugitive emission sources

Subpart HHH Synthetic fiber production facilities

Subpart IIIVOC emissions from SOCMI air oxidation unit processes 
Subpart JJJ Petroleum dry cleaners

Subpart KKK Equipment leaks of VOC from onshore natural gas processing plants

Subpart LLL Onshore natural gas processing; SO2 emissions

Subpart NNN VOC emissions from SOCMI distillation operations

Subpart PPP Wool fiberglass insulation manufacturing plants

Subpart QQQ VOC emissions from petroleum refinery wastewater emissions

Subpart SSS Magnetic tape coating facilities

Subpart TTT Industrial surface coating: Surface coating of plastic parts for business machines

Subpart VVV Polymeric coating of supporting substrates facilities

Note: For fossil fuel fired steam generators referenced by Subpart D and Da above, units greater than 250 megawatts are governed by the energy facility site evaluation council (EFSEC) in Title 463 WAC.

\section{WAC173-400-116}

WAC 173-400-116 New source review fees.

(1) Applicability. Every person required to submit a notice of construction application to the department of ecology as authorized in RCW 70.94.152 for establishment of any proposed new source or emissions unit(s) shall pay fees as set forth in subsections (2) and (3) of this section. Persons required to submit a notice of construction application to a local air authority may be required to pay a fee to ecology to cover the costs of Prevention of significant deterioration (PSD) permits issued pursuant to WAC 173-400-141, Second tier analysis pursuant to WAC 173-460-090, and risk management decisions pursuant to WAC 173-460-100 as set forth in subsection (3) of this section. Fees assessed under this section shall apply without regard to whether an order of approval is issued or denied.

(2) Basic review fees. All owners or operators of proposed new sources are required to pay a basic review fee. The basic review fee covers the costs associated with preapplication assistance, completeness determination, BACT determination, technical review, public involvement and approval/denial orders. Complexity determination shall be based on the project described in the notice of construction application. Basic review fees are shown below:

(a) Low complexity new source or emission unit (emissions of individual criteria pollutants are all less than one-half of the significance levels established in WAC 173-400-030(67) or emissions of individual toxic air pollutants are all less than 2.0 tons/year) - one thousand dollars;

(b) Moderate complexity new source or emission unit (emissions of one or more individual criteria pollutants are greater than one-half of the significance levels established in WAC 173-400-030(67) or emissions of one or more toxic air pollutants are greater than 2.0 tons/year and less than ten tons/year) five thousand dollars; or

(c) High complexity new source or emissions unit (emissions of one or more criteria pollutants are greater than the significance levels established in WAC 173-400-030(67) or emissions of one or more toxic air pollutants are greater than ten tons/year) - fifteen thousand dollars.

(d) Exceptions. The following fees for new source review shall be charged instead of the applicable fees listed in (a) through (c) of this subsection and in subsection (3) of this section:

(i) Dry cleaners $\$ 200$

(ii) Gasoline stations $\$ 200$

(iii) Storage tanks

(A) $<20,000$ gallons $\$ 200$

(B) $\quad 20,000-100,000$ gallons $\$ 500$ 
(C) $>100,000 \$ 700$

(iv) Chromic acid plating and anodizing identified in WAC 173-460-060 $\$ 200$

(v) Solvent metal cleaners identified in WAC 173-460-060 $\$ 200$

(vi) Abrasive blasting identified in WAC 173-460-060 \$200

(vii) New emission units or activities that qualify as insignificant emission units under WAC 173-401-530 whether located at a chapter 401 source or nonchapter 40 l source $\$ 200$

(e) Additional units. An owner or operator proposing to build more than one identical emission unit shall be charged a fee for the additional units equal to one-third the basic review fee of the first unit.

(3) Additional charges. In addition to those fees required under subsection (2)(a) through (c) of this section, the following fees will be required as applicable:

(a) Prevention of significant deterioration review (includes ecology review of local air authority sources) - ten thousand dollars;

(b) Establishing LAER and offset requirements for a major stationary source or major modification proposing to locate in a nonattainment area - ten thousand dollars;

(c) Tier II toxics review as required under WAC 173-460-090 - seven thousand five hundred dollars;

(d) Tier III review as required under WAC 173-460-100 - five thousand dollars;

(e) State Environmental Policy Act review (where ecology is the lead agency);

(i) Determination of nonsignificance (DNS) and environmental checklist review - two hundred dollars; or

(ii) Environmental impact statement (EIS) review or preparation - two thousand dollars;

(iii) Where more than one ecology program is charging a fee for reviewing or preparing SEPA documents, ecology will not charge a SEPA review fee as part of the new source review fees;

(f) Case-by-case MACT determinations required for a new source or modification under Section 112(g) or Section 112(j) of the FCAA - five thousand dollars.

(4) Small business fee reduction. The new source review fee identified in subsections (2) and (3) of this section may be reduced for a small business.

(a) To qualify for the small business new source review fee reduction, a business must meet the requirements of "small business" as defined in RCW 43.31.025.

(b) To receive a fee reduction, the owner or operator of a small business must include information in the application demonstrating that the conditions of (a) of this subsection have been met. The application must be signed:

(i) By an authorized corporate officer in the case of a corporation;

(ii) By an authorized partner in the case of a limited or general partnership; or

(iii) By the proprietor in the case of a sole proprietorship.

(c) Ecology may verify the application information and if the owner or operator has made false statements, deny the fee reduction request and revoke previously granted fee reductions.

(d) For small businesses determined to be eligible under (a) of this subsection, the new source review fee shall be reduced to the greater of:

(i) Fifty percent of the new source review fee; or

(ii) Two hundred fifty dollars.

(e) If due to special economic circumstances, the fee reduction determined under (d) of this subsection imposes an extreme hardship on a small business, the small business may request an extreme hardship fee reduction. The owner or operator must provide sufficient evidence to support a claim of an extreme hardship. The factors which ecology may consider in determining whether an owner or operator has special economic circumstances and in setting the extreme hardship fee include: Annual sales; labor force size; market conditions which affect the owner"'s or operator's ability to pass the cost of the new source review fees through to customers; and average annual profits. In no case will a new source review fee be reduced below one hundred dollars. 
(5) Fee reductions for pollution prevention initiatives. Ecology may reduce the fees defined in subsections (2) and (3) of this section where the owner or operator of the proposed source demonstrates that approved pollution prevention measures will be used.

(6) Fee payments. Fees specified in subsections (2) through (5) of this section shall be paid at the time a notice of construction application is submitted to the department. A notice of construction application is considered incomplete until ecology has received the appropriate new source review payment. Additional charges assessed pursuant to subsection (3) of this section shall be due thirty days after receipt of an ecology billing statement. All fees collected under this regulation shall be made payable to the Washington department of ecology.

(7) Dedicated account. All new source review fees collected by the department from permit program sources shall be deposited in the air operating permit account created under RCW 70.94.015. All new source review fees collected by the department from nonpermit program sources shall be deposited in the air pollution control account.

(8) Tracking revenues, time, and expenditures. Ecology shall track revenues collected under this subsection on a source-specific basis. Ecology shall track time and expenditures on the basis of complexity categories.

(9) Periodic review. Ecology shall review and, as appropriate, update this section at least once every two years.

\section{WAC173-400-120}

WAC 173-400-120 Bubble rules.

(1) Applicability. The owner(s) or operator(s) of any source(s) may apply for a bubble for any contaminant regulated by state or federal law for which the emission requirement may be stated as an allowable limit in weight of contaminant per unit time for the emissions units involved.

(2) Conditions. A bubble may be authorized provided the following conditions have been demonstrated to the satisfaction of ecology or the authority.

(a) The contaminants exchanged must be of the same type, that is, PM10 for PM10, sulfur dioxide for sulfur dioxide, etc.

(b) The bubble will not interfere with the attainment and maintenance of air quality standards. No bubble shall be authorized in a nonattainment area unless there is an EPA-approved SIP which demonstrates attainment for that area.

(c) The bubble will not result in a delay in compliance by any source, nor a delay in any existing enforcement action.

(d) The bubble will not supersede NSPS, NESHAPS, BACT, or LAER. The emissions of hazardous contaminants shall not be increased.

(e) The bubble will not result in an increase in the sum of actual emission rates of the contaminant involved from the emissions units involved.

(f) A bubble may not be authorized only for opacity limits. However, if the emission limit for particulates for a given emissions unit is increased as part of a bubble, the opacity limit for the given emissions unit may be increased subject to the following limitations:

(i) The new opacity limit shall be specific for the given emissions unit;

(ii) The new opacity limit shall be consistent with the new particulates limit;

(iii) An opacity greater than sixty percent shall never be authorized;

(iv) If the given emissions unit emits or has the potential to emit one hundred tons per year or more of particulate matter, the opacity shall be monitored continuously.

(g) The emission limits of the bubble are equivalent to existing limits in enforceability. 
(h) Concurrent with or prior to the authorization of a bubble, each emission unit involved in a bubble shall receive or have received a regulatory order or permit that establishes total allowable emissions from the source of the contaminant being bubbled, expressed as weight of the contaminant per unit time.

(i) There will be no net adverse impact upon air quality from the establishment of new emission requirements for a specific source or emissions unit. Determination of net adverse impact shall include but not be limited to public perception of opacity and public perception of odorous contaminants.

(j) Specific situations may require additional demonstration as requested by ecology or the authority.

(3) Jurisdiction. Whenever a bubble application involves emissions units, some of which are under the jurisdiction of an authority, approval will require concurrence by both authorities. The new emission limits for each emissions unit will be enforced by the authority of original jurisdiction.

(4) Additional information. Within thirty days, after the receipt of a bubble application and all supporting data and documentation, ecology or the authority may require the submission of additional information needed to review the application.

(5) Approval. Within thirty days after all the required information has been received, ecology or the authority shall approve or deny the application, based on a finding that conditions in subsection (2)(a) through (j) of this section have been satisfied or not. If the application is approved, a regulatory order or equivalent document shall be issued which includes new allowable emissions limits expressed in weight of pollutant per unit time for each emissions unit affected by the bubble. The regulatory order or equivalent document shall include any conditions required to assure that subsection (2)(a) through (j) of this section will be satisfied. If the bubble depends in whole or in part upon the shutdown of equipment, the regulatory order or equivalent document must prohibit operation of the affected equipment.

\section{WAC173-400-131}

WAC 173-400-131 Issuance of emission reduction credits.

(1) Applicability. The owner(s) or operator(s) of any source(s) may apply to ecology or the authority for an emission reduction credit (ERC) if the source proposes to reduce its actual emissions rate for any contaminant regulated by state or federal law for which the emission requirement may be stated as an allowable limit in weight of contaminant per unit time for the emissions unit(s) involved.

(2) Time of application. The application for an ERC must be made prior to or within one hundred eighty days after the emission reduction has been accomplished.

(3) Conditions. An ERC may be authorized provided the following conditions have been demonstrated to the satisfaction of ecology or the authority.

(a) The quantity of emissions in the ERC shall be less than or equal to the old allowable emissions rate or the old actual emissions rate, whichever is the lesser, minus the new allowable emissions rate.

(b) The ERC application must include a description of all the changes that are required to accomplish the claimed emissions reduction, such as, new control equipment, process modifications, limitation of hours of operation, permanent shutdown of equipment, specified control practices, etc.

(c) The ERC must be large enough to be readily quantifiable relative to the source strength of the emissions unit(s) involved.

(d) No part of the emission reductions claimed for credit shall have been used as part of a determination of net emission increase, nor as part of an offsetting transaction under WAC 173-400-112 (4), nor as part of a bubble transaction under WAC 173-400-120, nor to satisfy NSPS, NESHAPS, BACT, or LAER.

(e) Concurrent with or prior to the authorization of an ERC, the applicant shall receive (have received) a regulatory order or permit that establishes total allowable emissions from the source or emissions unit of the contaminant for which the ERC is requested, expressed as weight of contaminant per unit time.

(f) The use of any ERC shall be consistent with all other federal, state, and local requirements of the 
program in which it is used.

(4) Additional information. Within thirty days after the receipt of an ERC application and all supporting data and documentation, ecology or the authority may require the submission of additional information needed to review the application.

(5) Approval. Within thirty days after all required information has been received, ecology or the authority shall approve or deny the application, based on a finding that conditions in subsection (3)(a) through (e) of this section have been satisfied or not. If the application is approved, ecology or the authority shall:

(a) Issue a regulatory order or equivalent document to assure that the emissions from the source will not exceed the allowable emission rates claimed in the ERC application, expressed in weight of pollutant per unit time for each emission unit involved. The regulatory order or equivalent document shall include any conditions required to assure that subsection (3)(a) through (e) of this section will be satisfied. If the ERC depends in whole or in part upon the shutdown of equipment, the regulatory order or equivalent document must prohibit operation of the affected equipment; and

(b) Issue a certificate of emission reduction credit. The certificate shall specify the issue date, the contaminant(s) involved, the emission decrease expressed as weight of pollutant per unit time, the nonattainment area involved, if applicable, and the person to whom the certificate is issued.

\section{WAC173-400-136}

WAC 173-400-136 Use of emission reduction credits.

(1) Permissible use. An ERC may be used to satisfy the requirements for authorization of a bubble under WAC 173-400-120, as a part of a determination of "net emissions increase," as an offsetting reduction to satisfy the requirements for new source review per WAC 173-400-112, 173-400-113(3) or (6), or to satisfy requirements for PSD review per WAC 173-400-113(4).

(2) Surrender of ERC certificate. When an ERC is used under subsection (1) of this section, the certificate for the ERC must be surrendered to the issuing authority. If only a portion of the ERC is used, the amended certificate will be returned to the owner.

(3) Conditions of use. An ERC may be used only for the contaminant(s) for which it was issued. Ecology or the authority may impose additional conditions of use to account for temporal and spatial differences between the emissions unit(s) that generated the ERC and the emissions unit(s) that use the ERC.

(4) Sale of an ERC. An ERC may be sold or otherwise transferred to a person other than the person to whom it was originally issued. Within thirty days after the transfer of ownership, the certificate must be surrendered to the issuing authority. After receiving the certificate, the issuing authority shall reissue the certificate to the new owner.

(5) Time of use. An unused ERC and any unused portion thereof shall expire ten years after date of original issue.

(6) Discount due to change in SIP. If reductions in emissions beyond those identified in the state implementation plan are required to meet an ambient air quality standard, if the standard cannot be met through controls on operating sources, and if the plan must be revised, an ERC may be discounted by ecology or the authority after public involvement per WAC 173-400-171. Any such discount shall not exceed the percentage of additional emission reduction needed to reach attainment.

\section{WAC173-400-141}


WAC 173-400-141 Prevention of significant deterioration (PSD).

Section 40 CFR 52.21, Subparts (b), (c), (d), (e), (f), (g), (h), (i), (j), (k), (l), (m), (n), (o), (p), (r), (t), (v), and (w), Prevention of Significant Deterioration of Air Quality, as in effect on March 3, 1993, are incorporated by reference with the following additions and modifications:

(1) Construction of "administrator." In 40 CFR 52.21 (b)(17), federally enforceable, (f)(l)(v), (f)(3), and (f)(4)(i), exclusions from increment consumption, ( $\mathrm{g}$ ), redesignation, (1) and (2), air quality models, (p)(2), federal land manager, and (t), disputed permits or redesignations, the word "administrator" shall be construed in its original meaning. In 40 CFR 52.21 (b)(3)(iii) administrator shall mean both the administrator of EPA and the director of ecology.

(2) Contemporaneous. Subpart 40 CFR 52.21 (b)(3)(ii) is changed to read: "An increase or decrease in actual emissions is contemporaneous with the increase from the particular change only if it occurs between the date ten years before construction on the particular change commences and the date that the increase from the particular change occurs. If a decrease occurred more than one year prior to the date of submittal of the notice of construction application for the particular change it can only be credited if the decrease has been documented by an emission reduction credit."

(3) Public participation. Subpart 40 CFR 51.166(q) public participation, as in effect March 3, 1993, is hereby incorporated by reference except that in 40 CFR 51.166 (q)(2)(iv), the phrase "specified time period" shall mean thirty days and the word "administrator" shall mean the EPA administrator.

(4) Section 40 CFR 51.166 Subpart (p)(1) Sources Impacting Federal Class I areas - additional requirements - Notice to EPA, as in effect on March 3, 1993, is herein incorporated by reference.

(5) Secondary emissions. Subpart 40 CFR 52.21 (b)(18) is changed to read:

Emissions which would occur as a result of the construction or operation of a major stationary source or major modification, but do not come from the major stationary source or major modification itself. For the purpose of this section, secondary emissions must be specific, well defined, quantifiable, and impact the same general area as the stationary source or modification which causes the secondary emissions. Secondary emissions may include, but are not limited to:

(a) Emissions from ships or trains coming to or from the new or modified stationary source; and

(b) Emissions from any offsite support facility which would not otherwise be constructed or increase its emissions as a result of the construction or operation of the major stationary source or major modification.

(6) Significant. The definition of "significant" in 40 CFR 52.21 (b)(23) is changed to exclude from the list of pollutants which may trigger PSD review any pollutant listed under FCAA 112.

\section{WAC173-400-151}

WAC 173-400-151 Retrofit requirements for visibility protection.

(1) Determination of best available retrofit technology (BART). Ecology shall identify and analyze each source which may reasonably be anticipated to cause or contribute to impairment of visibility in any mandatory Class I area in Washington and any adjacent state and to determine BART for the contaminant of concern and those additional air pollution control technologies that are to be required to reduce impairment from the source.

(2) Initially defined BART. The owner(s) or operator(s) of any source(s) to which significant visibility impairment of a mandatory Class I area is reasonably attributable shall apply BART for each contaminant contributing to visibility impairment that is emitted at more than 250 tons per year. Each source for which BART is required must install and operate BART as expeditiously as possible, but in no case later than five years after the conditions are included in a regulatory order. 
(3) Future definitions of BART. The owner(s) or operator(s) of any source(s) to which significant visibility impairment of a mandatory Class I area is reasonably attributable shall apply BART as new technology becomes available for a contaminant if:

(a) The source emits more than 250 tons per year of the contaminant; and,

(b) The controls representing BART have not previously been required in this section.

(4) Appeal. Any source owner or operator required by this section to install, operate, and maintain BART, may apply to the EPA administrator for an exception from that requirement pursuant to $40 \mathrm{CFR}$ 51.303 .

\section{WAC173-400-161}

WAC 173-400-161 Compliance schedules.

(1) Issuance. Whenever a source is found to be in violation of an emission standard or other provision of this chapter, ecology or the authority may issue a regulatory order requiring that the source be brought into compliance within a specified time. The order shall contain a schedule for installation, with intermediate benchmark dates and a final completion date, and shall constitute a compliance schedule. Requirements for public involvement (WAC 173-400-171) must be met.

(2) Federal action. A source shall be considered to be in compliance with this chapter if all the provisions of its individual compliance schedule included with a regulatory order are being met. Such compliance does not preclude federal enforcement action by the EPA until and unless the schedule is submitted and adopted as an amendment to the state implementation plan.

(3) Penalties for delayed compliance. Sources on a compliance schedule but not meeting emissions standards may be subject to penalties as provided in the Federal Clean Air Act.

\section{WAC173-400-171}

WAC 173-400-171 Public involvement.

(1) Applicability. Ecology or the authority shall provide public notice prior to the approval or denial of any of the following types of applications or other actions:

(a) Notice of construction application for any new or modified source or emissions unit, if a significant net increase in emissions of any pollutant regulated by state or federal law would result; or

(b) Any application or other proposed action for which a public hearing is required by PSD rules; or

(c) Any order to determine RACT; or

(d) An order to establish a compliance schedule or a variance; or

(e) The establishment or disestablishment of a nonattainment area, or the changing of the boundaries thereof; or

(f) An order to demonstrate the creditable height of a stack which exceeds the GEP formula height and sixty-five meters, by means of a fluid model or a field study, for the purposes of establishing an emission limitation; or

(g) An order to authorize a bubble; or

(h) Notice of construction application or regulatory order used to establish a creditable emission reduction;

(i) An order issued under WAC 173-400-091 which establishes limitations on a source's potential to emit; or

(j) Any application or other proposed action made pursuant to this chapter in which there is a substantial 
public interest according to the discretion of ecology or the authority.

(2) Public notice. Public notice shall be made only after all information required by ecology or the authority has been submitted and after applicable preliminary determinations, if any, have been made. The cost of providing public notice shall be borne by the applicant or other initiator of the action. Public notice shall include:

(a) Availability for public inspection in at least one location near the proposed project, of the nonproprietary information submitted by the applicant and of any applicable preliminary determinations, including analyses of the effect(s) on air quality.

(b) Publication in a newspaper of general circulation inthe area of the proposed project of notice:

(i) Giving a brief description of the proposal;

(ii) Advising of the location of the documents made available for public inspection;

(iii) Advising of a thirty-day period for submitting written comment to ecology or the authority;

(iv) Advising that a public hearing may be held if ecology or the authority determines within a thirty-day period that significant public interest exists.

(c) A copy of the notice will be sent to the EPA regional administrator.

Public participation procedures for notice of construction applications that are processed in coordination with an application to issue or modify an operating permit shall be conducted as provided in the state operating permit rule.

(3) Public comment. No final decision on any application or action of any of the types described in subsection (1) of this section, shall be made until the public comment period has ended and any comments received have been considered. Unless a public hearing is held, the public comment period shall be the thirty-day period for written comment published as provided above. If a public hearing is held the public comment period shall extend through the hearing date and thereafter for such period, if any, as the notice of public hearing may specify.

(4) Public hearings. The applicant, any interested governmental entity, any group or any person may request a public hearing within the thirty-day period published as above. Any such request shall indicate the interest of the entity filing it and why a hearing is warranted. Ecology or the authority may, in its discretion, hold a public hearing if it determines significant public interest exists. Any such hearing shall be held upon such notice and at a time(s) and place(s) as ecology or the authority deems reasonable.

(5) Other requirements of law. Whenever procedures permitted or mandated by law will accomplish the objectives of public notice and opportunity for comment, such procedures may be used in lieu of the provisions of this section.

(6) Public information. Copies of notices of construction, orders, and modifications thereof which are issued hereunder shall be available for public inspection on request at ecology or the authority.

\section{WAC173-400-180}

WAC 173-400-180 Variance.

Any person who owns or is in control of a plant, building, structure, establishment, process, or equipment may apply to ecology for a variance from provisions of this chapter governing the quality, nature, duration, or extent of discharges of air contaminants in accordance with the provisions of RCW 70.94.181.

(1) Jurisdiction. Sources in any area over which a local air pollution control authority has jurisdiction shall make application to that authority rather than ecology. Variances to state rules shall require ecology"s approval prior to being issued by an authority. Ecology or the authority may grant such variance, but only after public involvement per WAC 173-400-171 .

(2) Full faith and credit. Variances granted in compliance with state and federal laws by an authority for 
sources under their jurisdiction will be accepted as variances to this regulation.

(3) EPA concurrence. No variance or renewal shall be construed to set aside or delay any requirements of the Federal Clean Air Act except with the approval and written concurrence of the USEPA.

\section{WAC173-400-190}

WAC 173-400-190 Requirements for nonattainment areas.

The development of specific requirements for nonattainment areas shall include consultation with local government in the area and shall include public involvement per WAC 173-400-171.

\section{WAC173-400-200}

WAC 173-400-200 Creditable stack height and dispersion techniques.

(1) Applicability. These provisions shall apply to all sources except:

(a) Stacks for which construction had commenced on or before December 31, 1970, except where pollutants are being emitted from such stacks used by sources which were constructed, or reconstructed, or for which major modifications were carried out after December 31, 1970;

(b) Coal-fired steam electric generating units subject to the provisions of Section 118 of the Federal Clean Air Act, which commenced operation before July 1, 1957, and for whose stacks construction commenced before February 8, 1974;

(c) Flares;

(d) Open burning for agricultural or silvicultural purposes as covered under the smoke management plan;

(e) Residential wood combustion and open burning for which episodic restrictions apply.

These provisions shall not be construed to limit the actual stack height.

(2) Prohibitions. No source may use dispersion techniques or excess stack height to meet ambient air quality standards or PSD increment limitations.

(a) Excess stack height. Excess stack height is that portion of a stack which exceeds the greater of:

(i) Sixty-five meters, measured from the ground level elevation at the base of the stack; or

(ii) $\mathrm{Hg}=\mathrm{H}+1.5 \mathrm{~L}$

where: $\mathrm{Hg}=$ "good engineering practice" (GEP) stack height, measured from the ground level elevation at the base of the stack,

$\mathrm{H}=$ height of nearby structure(s) measured from the ground level elevation at the base of the stack, $\mathrm{L}=$ lesser dimension, height or projected width, of nearby structure(s), subject to the proviso below.

"Nearby," as used in this subsection for purposes of applying the GEP formula means that distance up to five times the lesser of the height or the width dimension of a structure, but not greater than 0.8 kilometer (1/2 mile).

(b) Dispersion techniques. Increasing final exhaust gas plume rise by manipulating source process parameters, exhaust gas parameters, stack parameters, or combining exhaust gases from several existing stacks into one stack; or other selective handling of exhaust gas streams so as to increase the exhaust gas plume rise. This does not include:

(i) The reheating of a gas stream, following the use of a pollution control system, for the purpose of returning the gas to the temperature at which it was originally discharged from the facility generating the 
gas stream;

(ii) The merging of gas streams where:

(A) The source was originally designed and constructed with such merged gas streams, as demonstrated by the source owner(s) or operator(s).

(B) Such merging is part of a change in operation at the facility that includes the installation of pollution controls and is accompanied by a net reduction in the allowable emissions of a pollutant. This exclusion shall apply only to the emission limitation for the pollutant affected by such change in operation.

(C) Before July 8,1985 , such merging was part of a change in operation at the facility that included the installation of emissions control equipment or was carried out for sound economic or engineering reasons, and not primarily motivated by an intent to gain emissions credit for greater dispersion.

(3) Exception. EPA, ecology, or an authority may require the use of a field study or fluid model to verify the creditable stack height for the source. This also applies to a source seeking credit after the effective date of this rule for an increase in existing stack height up to that established by the GEP formula. A fluid model or field study shall be performed according to the procedures described in the EPA Guideline for Determination of Good Engineering Practice Height (Technical Support Document of the Stack Height Regulations). The creditable height demonstrated by a fluid model or field study shall ensure that the emissions from a stack do not result in excessive concentrations of any air pollutant as a result of atmospheric downwash, wakes, or eddy effects created by the source itself, nearby structures or nearby terrain features.

(a) "Nearby," as used in this subsection for conducting a field study or fluid model, means not greater than $0.8 \mathrm{~km}$, except that the portion of a terrain feature may be considered to be nearby which falls within a distance of up to ten times the maximum height of the feature, not to exceed two miles if such feature achieves a height $0.8 \mathrm{~km}$ from the stack that is at least forty percent of the GEP stack height or twenty-six meters, whichever is greater, as measured from the ground-level elevation at the base of the stack. The height of the structure or terrain feature is measured from the ground-level elevation at the base of the stack.

(b) "Excessive concentration" is defined for the purpose of determining creditable stack height under this subsection and means a maximum ground-level concentration owing to a significant downwash effect which contributes to excursion over an ambient air quality standard. For sources subject to PSD review (WAC 173-400-141 and 40 CFR 52.21) an excessive concentration alternatively means a maximum ground-level concentration owing to a significant downwash effect which contributes to excursion over a PSD increment. The emission rate used in this demonstration shall be the emission rate specified in the state implementation plan, or in the absence of such, the actual emission rate of the source. "Significant downwash effect" means a maximum ground-level concentration due to emissions from a stack due in whole or in part to downwash, wakes, and eddy effects produced by nearby structures or nearby terrain features which individually is at least forty percent in excess of the maximum concentration experienced in the absence of such downwash, wakes, or eddy effects.

\section{WAC173-400-205}

WAC 173-400-205 Adjustment for atmospheric conditions.

Varying the rate of emission of a pollutant according to atmospheric conditions or ambient concentrations of that pollutant is prohibited, except as directed according to air pollution episode regulations.

\section{WAC173-400-210}


WAC 173-400-210 Emission requirements of prior jurisdictions.

Any emissions unit that was under the jurisdiction of an authority and now is under the jurisdiction of ecology, shall meet all emission requirements that were applicable prior to transfer of jurisdiction if those standards are more stringent than the standards of this chapter or the specific chapter relating to that source.

\section{WAC173-400-220}

WAC 173-400-220 Requirements for board members.

(1) Public interest. A majority of the members of any ecology or authority board shall represent the public interest. A majority of the members of such boards, shall not derive any significant portion of their income from persons subject to enforcement orders pursuant to the state and federal clean air acts. An elected public official and the board shall be presumed to represent the public interest. In the event that a member derives a significant portion of his/her income from persons subject to enforcement orders, he/she shall delegate sole responsibility for administration of any part of the program which involves these persons to an assistant.

(2) Disclosure. Each member of any ecology or authority board shall adequately disclose any potential conflict of interest in any matter prior to any action or consideration thereon, and the member shall remove themselves from participation as a board member in any action or voting on such matter.

(3) Define significant income. For the purposes of this section, "significant portion of income" shall mean twenty percent of gross personal income for a calendar year. In the case of a retired person, "significant portion of income" shall mean fifty percent of income in the form of pension or retirement benefits from a single source other than Social Security. Income derived from employment with local or state government shall not be considered in the determination of "significant portion of income."

\section{WAC173-400-230}

WAC 173-400-230 Regulatory actions.

Ecology may take any of the following regulatory actions to enforce this chapter to meet the provisions of RCW 43.21B.300 which is incorporated by reference.

(1) Enforcement actions by ecology--Notice to violators. At least thirty days prior to the commencement of any formal enforcement action under RCW 70.94.430 and 70.94.431, the department of ecology shall cause written notice to be served upon the alleged violator or violators. The noticeshall specify the provision of this chapter or the rule or regulation alleged to be violated, and the facts alleged to constitute a violation thereof, and may include an order that necessary corrective action be taken within a reasonable time. In lieu of an order, ecology may require that the alleged violator or violators appear before it for the purpose of providing ecology information pertaining to the violation or the charges complained of. Every notice of violation shall offer to the alleged violator an opportunity to meet with ecology prior to the commencement of enforcement action.

(2) Civil penalties.

(a) In addition to or as an alternate to any other penalty provided by law, any person who violates any of the provisions of chapter 70.94 or $70.120 \mathrm{RCW}$, or any of the rules in force under such chapters may incur a civil penalty in an amount as set forth in RCW 70.94.431. Each such violation shall be a separate 
and distinct offense, and in case of a continuing violation, each day"s continuance shall be a separate and distinct violation.

Any person who fails to take action as specified by an order issued pursuant to this chapter shall be liable for a civil penalty as set forth by RCW 70.94 .431 for each day of continued noncompliance.

(b) Penalties incurred but not paid shall accrue interest, beginning on the ninety-first day following the date that the penalty becomes due and payable, at the highest rate allowed by RCW 19.52 .020 on the date that the penalty becomes due and payable. If violations or penalties are appealed, interest shall not begin to accrue until the thirty-first day following final resolution of the appeal.

The maximum penalty amounts established in RCW 70.94.431 may be increased annually to account for inflation as determined by the state office of the economic and revenue forecast council.

(c) Each act of commission or omission which procures, aids, or abets in the violation shall be considered a violation under the provisions of this section and subject to the same penalty. The penalties provided in this section shall be imposed pursuant to RCW 43.21B.300.

(d) All penalties recovered under this section by ecology shall be paid into the state treasury and credited to the air pollution control account established in RCW 70.94 .015 or, if recovered by the authority, shall be paid into the treasury of the authority and credited to its funds. If a prior penalty for the same violation has been paid to a local authority, the penalty imposed by ecology under subsection (a) of this section shall be reduced by the amount of the payment.

(e) To secure the penalty incurred under this section, the state or the authority shall have a lien on any vessel used or operated in violation of this chapter which shall be enforced as provided in RCW 60.36 .050 .

(f) Public or private entities that are recipients or potential recipients of ecology grants, whether for air quality related activities or not, may have such grants rescinded or witheld by ecology for failure to comply with provisions of this chapter.

(g) In addition to other penalties provided by this chapter, persons knowingly under-reporting emissions or other information used to set fees, or persons required to pay emission or permit fees who are more than ninety days late with such payments may be subject to a penalty equal to three times the amount of the original fee owed.

(3) Assurance of discontinuance. Personnel of ecology or an authority may accept an assurance of discontinuance of any act or practice deemed in violation of this chapter. Any such assurance shall specify a time limit during which discontinuance is to be accomplished. Failure to perform the terms of any such assurance shall constitute prima facie proof of a violation of this chapter or any order issued thereunder which make the alleged act or practice unlawful for the purpose of securing an injunction or other relief from the superior court.

(4) Restraining orders, injunctions. Whenever any person has engaged in, or is about to engage in, any acts or practices which constitute or will constitute a violation of any provision of this chapter, the director, after notice to such person and an opportunity to comply, may petition the superior court of the county wherein the violation is alleged to be occurring or to have occurred for a restraining order or a temporary or permanent injunction or another appropriate order.

(5) Emergency episodes. Ecology may issue such orders as authorized by chapter 173-435 WAC via chapter $70.94 \mathrm{RCW}$, whenever an air pollution episode forecast is declared.

(6) Compliance orders. Ecology may issue a compliance order in conjunction with a notice of violation. The order shall require the recipient of the notice of violation either to take necessary corrective action or to submit a plan for corrective action and a date when such action will be initiated.

\section{WAC173-400-240}

WAC 173-400-240 Criminal penalties. 
Appendix D - Constraints Definitions

Persons in violation of Title 173 WAC may be subject to the provisions of RCW 70.94.430.

\section{WAC173-400-250}

WAC 173-400-250 Appeals.

Decisions and orders of ecology or an authority may be appealed to the pollution control hearings board pursuant to chapter 43.21B RCW and chapter 371-08 WAC.

\section{WAC173-400-260}

WAC 173-400-260 Conflict of interest.

All board members and officials acting or voting on decisions affecting air pollution sources, must comply with the Federal Clean Air Act, as it pertains to conflict of interest, and 40 CFR 103(d) which is incorporated by reference.

\section{WAC173-460 Controls for Sources of Toxic Air Emissions}

Best available control technology shall be used on new or modified sources of toxic air emissions in accordance with this Code.

\section{WAC173-460-010}

WAC 173-460-010 Purpose.

(1) Pursuant to chapter 70.94 RCW, Washington Clean Air Act, the purpose of this chapter is to establish the systematic control of new sources emitting toxic air pollutants (TAPs) in order to prevent air pollution, reduce emissions to the extent reasonably possible, and maintain such levels of air quality as will protect human health and safety. Toxic air pollutants include carcinogens and noncarcinogens listed in $\mathrm{WAC}<\mathrm{D}<12266>>173-460-150<\mathrm{D}>$ and $<\mathrm{D}<12267>>173-460-160</ \mathrm{D}>$.

(2) This chapter establishes three major requirements:

(a) Best available control technology for toxics;

(b) Toxic air pollutant emission quantification;

(c) Human health and safety protection demonstration.

(3) Policy. It is the policy of ecology to reduce, avoid, or eliminate toxic air pollutants prior to their generation whenever economically and technically practicable.

\section{WAC173-460-020}

WAC 173-460-020 Definitions.

The definitions of terms contained in chapter $<\mathrm{D}<11981>>173-400</ \mathrm{D}>$ WAC are incorporated into 
this chapter by reference. In the event of a conflict between the definitions provided in chapter $<\mathrm{D}<11981>>173-400</ \mathrm{D}>$ WAC and the definitions provided in this section, the definitions in this section shall govern. Unless a different meaning is clearly required by context, the following words and phrases as used in this chapter shall have the following meanings. Note: For copies of the above mentioned rule and any other rule cited in this chapter, contact the Department of Ecology, Records Section, P.O. Box 47600, Olympia, WA 98504-7600.

(1) "Acceptable source impact analysis" means a procedure for demonstrating compliance with WAC $<\mathrm{D}<12258>>173-460-070</ \mathrm{D}>$ and $\langle\mathrm{D}<12259>>173-460-080</ \mathrm{D}>$, that compares maximum incremental ambient airimpacts with applicable acceptable source impact levels (ASIL).

(2) "Acceptable source impact level (ASIL)" means a concentration of a toxic air pollutant in the outdoor atmosphere in any area which does not have restricted or controlled public access that is used to evaluate the air quality impacts of a single source. There are three types of acceptable source impact levels: Risk-based, threshold-based, and special. Concentrations for these three types of ASILs are determined as provided in WAC $<\mathrm{D}<12262>>173-460-110<\mathrm{D}>$. ASILs are listed in WAC $<\mathrm{D}<12266>>173-460-150<\mathrm{D}>$ and $\langle\mathrm{D}<12267>>173-460-160<\mathrm{D}\rangle$.

(3) "Authority" means an air pollution control authority activated pursuant to chapter $70.94 \mathrm{RCW}$ that has jurisdiction over the subject source. Ecology is the authority if an air pollution control authority has not been activated or if ecology has jurisdiction over the source pursuant to RCW 70.94.395.

(4) "Best available control technology for toxics (T-BACT)" applies to each toxic air pollutant (TAP) discharged or mixture of TAPs, taking in account the potency quantity and toxicity of each toxic air pollutant or mixture of TAPs discharged in addition to the meaning given in WAC $<D<11984>>$ 173-400-030 $</ \mathrm{D}>(10)$.

(5) "Carcinogenic potency factor" means the upper 95th percentile confidence limit of the slope of the dose-response curve and is expressed in units of ( $\mathrm{mg} / \mathrm{kg}$-day)- 1 .

(6) "Class A toxic air pollutant (Class A TAP)" means a substance or group of substances listed in WAC $<\mathrm{D}<12266>>173-460-150</ \mathrm{D}>$.

(7) "Class B toxic air pollutant (Class B TAP)" means any substance that is not a simple asphyxiant or nuisance particulate and that is listed in WAC $<D<12267>>173-460-160</ D>$.

(8) "EPA"'s Dispersion Modeling Guidelines" means the United States Environmental Protection Agency Guideline on Air Quality Models, EPA (Revised) 40 CFR Part 51 Appendix W, and is hereby incorporated by reference.

(9) "EPA"'s Risk Assessment Guidelines" means the United States Environmental Protection Agency"s Guidelines for Carcinogenic Risk Assessment, 51 FR 33992 (September 24, 1986) and is hereby incorporated by reference.

(10) "Increased cancer risk of one in one hundred thousand" means the 95th percent upper bound on the estimated risk of one additional cancer above the background cancer rate per one hundred thousand individuals continuously exposed to a Class $\mathrm{A}$ toxic air pollutant at a given average dose for a specified time.

(11) "Increased cancer risk of one in one million" means the 95th percent upper bound on the estimated risk of one additional cancer above the background cancer rate per one million individuals continually exposed to a Class A toxic air pollutant at a given average dose for a specified time.

(12) "Inhalation Reference Concentration (Inhalation RfC)" means a reference concentration published in the United States Environmental Protection Agency Integrated Risk Information System (IRIS).

(13) "Mixture" means a combination of two or more substances mixed in arbitrary proportions.

(14) "Modification" means any physical change in, or change in the method of operation of, a stationary source that increases the amount of any air contaminant emitted by such source or that results in the emission of any air contaminant not previously emitted. The term modification shall be construed consistent with the definition of modification in Section 7411, Title 42, United States Code, and with rules implementing that section. For purposes of this chapter, the term "air contaminant" 
shall mean "toxic air contaminant" or "toxic air pollutant" as defined in subsection (20) of this section.

(15) "New toxic air pollutant source" means:

(a) The construction or modification of a stationary source that increases the amount of any toxic air pollutant emitted by such source or that results in the emission of any toxic air pollutant not previously emitted; and

(b) Any other project that constitutes a new source under section 112 of the Federal Clean Air Act.

(16) "Second Tier Analysis" means an optional procedure used after T-BACT and acceptable source impact analysis for demonstrating compliance with WAC $<\mathrm{D}<12258>>173-460-070</ \mathrm{D}>$. The second tier analysis uses a health impact assessment as provided in WAC $<\mathrm{D}<12260>>173-460-090<\mathrm{D}>$, instead of an acceptable source impact level.

(17) "Simple asphyxiant" means a physiologically inert gas or vapor that acts primarily by diluting atmospheric oxygen below the level required to maintain proper levels of oxygen in the blood. Examples of simple asphyxiants are given in Appendix X of the TLV Booklet referred to in subsection (19) of this section and incorporated by reference.

(18) "Threshold limit value-time weighted average (TLV-TWA)" means a concentration limit recommended by the American Conference of Governmental Industrial Hygienists (ACGIH) for a normal eight-hour workday and forty-hour workweek.

(19) "TLV Booklet" means "TLVs, Threshold Limit Values and Biological Exposure Indices for 1991-92," published by the American Conference of Governmental Industrial Hygienists and is hereby incorporated by reference.

(20) "Toxic air pollutant (TAP)" or "toxic air contaminant" means any Class A or Class B toxic air pollutant listed in WAC $<\mathrm{D}<12266>>173-460-150</ \mathrm{D}>$ and $\langle\mathrm{D}<12267>>173-460-160</ \mathrm{D}\rangle$. The term toxic air pollutant may include particulate matter and volatile organic compounds if an individual substance or a group of substances within either of these classes is listed in WAC $<D<12266>>$ $173-460-150</ D>$ and $/$ or $<\mathrm{D}<12267>>173-460-160<\mathrm{D}>$. The term toxic air pollutant does not include particulate matter and volatile organic compounds as generic classes of compounds.

(21) "Upper bound unit risk factor" means the 95 percent upper confidence limit of an estimate of the extra risk of cancer associated with a continuous 70 year exposure to $1 \mathrm{ug} / \mathrm{m} 3$ of a Class A toxic air pollutant.

\section{WAC173.460-030}

WAC 173-460-030 Requirements, applicability and exemptions.

\section{(1) Applicability.}

(a) The provisions of this chapter shall apply state-wide. The authority shall enforce WAC $\langle\mathrm{D}<12252\rangle>173-460-010<\mathrm{D}\rangle,\langle\mathrm{D}<12253\rangle>173-460-020<\mathrm{D}\rangle,\langle\mathrm{D}<12254\rangle>173-460-030<\mathrm{D}\rangle$, $\langle\mathrm{D}<12255\rangle>173-460-040<\mathrm{D}\rangle,\langle\mathrm{D}<12256>>173-460-050<\mathrm{D}\rangle,\langle\mathrm{D}<12257>>173-460-060<\mathrm{D}\rangle$, $<\mathrm{D}<12258>>173-460-070<\mathrm{D}\rangle,\langle\mathrm{D}<12259>>173-460-080<\mathrm{D}>,<\mathrm{D}<12264>>173-460-130<\mathrm{D}\rangle$, $<\mathrm{D}<12265>>173-460-140<\mathrm{D}\rangle,\langle\mathrm{D}<12266>>173-460-150<\mathrm{D}\rangle$, and $<\mathrm{D}<12267>>173-460-160$ $<$ D $>$.

(b) Except as provided in this chapter, any new toxic air pollutant source listed in (b)(i), (ii), or (iii) of this subsection that may emit a Class A or Class B TAP into the ambient air is subject to these regulations:

(i) Standard industrial classifications:

(A) Major group 10-Metal mining.

(B) Major group 12-Bituminous coal and lignite mining. 
(C) Major group 13-Oil and gas extraction.

(D) Manufacturing industries major groups 20-39.

(E) Major group 49-Electric, gas, and sanitary services except 4971 irrigation systems.

(F) Dry cleaning plants, 7216.

(G) General medical surgical hospitals, 8062 .

(H) Specialty hospitals, 8069 .

(I) National security, 9711 .

(ii) Any source or source category listed in WAC $<\mathrm{D}<11993>>173-400-100<\mathrm{D}\rangle,\langle\mathrm{D}<12001>>$

173-400-115 < D $>$ (2), or $<\mathrm{D}<12311>>173-490-030<\mathrm{D}>$ (1) except $\mathrm{WAC}<\mathrm{D}<12311>>173-490-030$

$</ \mathrm{D}\rangle$ (1)(e) gasoline dispensing facilities.

(iii) Any of the following sources:

(A) Landfills.

(B) Sites subject to chapter $<$ D $<11807>>173-340<$ D $>$ WAC Model Toxics Control Act--Cleanup regulation.

(2) Exempt sources.

(a) Containers such as tanks, barrels, drums, cans, and buckets are exempt from the requirements of this chapter unless equipped with a vent other than those required solely as safety pressure release devices.

(b) Nonprocess fugitive emissions of toxic air pollutants from stationary sources, such as construction sites, unpaved roads, coal piles, waste piles, and fuel and ash handling operations are exempt from WAC $<\mathrm{D}<12257>>173-460-060<$ D $>$.

(c) The following sources are generally exempt from the requirements of WAC $<\mathrm{D}<12256>>$ $173-460-050</ \mathrm{D}\rangle,\langle\mathrm{D}<12258>>173-460-070<\mathrm{D}\rangle,\langle\mathrm{D}<12259>>173-460-080</ \mathrm{D}\rangle$, and $<\mathrm{D}<12260>>173-460-090<\mathrm{D}>$. However, the authority may on a case-by-case basis, require compliance with these sections if the authority determines that the amount of emissions, nature of pollutant, or source location indicate that the ambient impact should be evaluated.

(i) Perchloroethylene dry cleaners

(ii) Petroleum solvent dry cleaning systems

(iii) Solvent metal cleaners

(iv) Chromic acid plating and anodizing

(v) Abrasive blasting

(d) Demolition and renovation projects involving asbestos removal and disposal are exempt from the requirements of this chapter.

(e) Process vents subject to 40 C.F.R. Parts 264 and 265, Subpart AA are exempt from the requirements of this chapter.

\section{WAC173-460-040}

WAC 173-460-040 New source review.

(1) Applicability. This chapter supplements the new source review requirements of WAC $<\mathrm{D}<11997>>$ $173-400-110</ D>$ by adding additional new source review requirements for toxic air pollutant sources. If a notice of construction is required under both chapter $<D<11981>>173-400</ D>$ WAC and this chapter, the written applications shall be combined. A notice of construction is a written application to permit construction of a new source.

(a) The owner or operator of a new toxic air pollutant source listed in WAC $<\mathrm{D}<12254>>173-460-030$ $\langle\mathrm{D}\rangle(1)$ shall notify the authority prior to the construction, installation, or establishment of a new toxic air pollutant source and shall file a notice of construction application with the authority for the proposed emission unit(s). Notification and notice of construction are not required if the source is an exempt 
source listed in WAC $<D<12254>>173-460-030</ D>(2)$ or subsection (2) of this section.

(b) The notice of construction and new source review applies only to the affected emission unit(s) and the contaminants emitted from the emission unit(s).

(c) New source review of a modification shall be limited to the emission unit or units proposed to be modified and the toxic air contaminants whose emissions would increase as a result of the modification.

(2) The owner or operator of a new toxic air pollutant source listed in WAC $<D<12254>>173-460-030$

$</ D>(1)$ is not required to notify or file a notice of construction with the authority if any of the following conditions are met:

(a) Routine maintenance or repair requires equivalent replacement of air pollution control equipment; or

(b) The new source is a minor process change that does not increase capacity and total toxic air pollutant emissions do not exceed the emission rates specified in small quantity emission rate tables in WAC $<\mathrm{D}<12259>>173-460-080</ \mathrm{D}>$; or

(c) The new source is the result of minor changes in raw material composition and the total toxic air pollutant emissions do not exceed the emission rates specified in the small quantity emission rate tables in WAC $<\mathrm{D}<12259>>173-460-080</ \mathrm{D}>$.

(3) Additional information. Within thirty days of receipt of a notice of construction, the authority may require the submission of additional plans, specifications, and other information necessary for the review of the proposed new or modified source.

(4) Requirements for new toxic air pollutant sources. The authority shall review notice(s) of construction, plans, specifications, and other associated information to determine that:

(a) The source will be in accord with applicable federal, state, and authority air pollution control rules and regulations;

(b) The source will use T-BACT for emissions control for the toxic air pollutants which are likely to increase; and

(c) Sources required to use T-BACT for emission control demonstrate compliance with WAC $<\mathrm{D}<12258>>173-460-070</ \mathrm{D}>$ by using the procedures established in WAC $<\mathrm{D}<12259>>173-460-080$ $<\mathrm{D}>$ or, failing that, demonstrates compliance, by using the additional procedures in WAC $<\mathrm{D}<12260>>$ 173-460-090 </D $>$ and $/$ or $\langle\mathrm{D}<12261>>173-460-100</ \mathrm{D}\rangle$.

(5) Preliminary determination. Within thirty days after receipt of all information required, the authority shall:

(a) Make preliminary determinations on the matters set forth in this section; and

(b) Initiate compliance with the provisions of WAC $<\mathrm{D}<12009>>173-400-171</ \mathrm{D}>$ relating to public notice and public comment, as applicable.

(6) Final determination. If, after review of all information received including public comment, the authority finds that all the conditions in this section are satisfied, the authority shall issue a regulatory order to approve the notice of construction for the proposed new source or modification. If the authority finds that the conditions in this section are not satisfied, the authority shall issue an order for the prevention of construction, installation, or establishment of the toxic air pollution source(s). Where ecology has jurisdiction, it will endeavor to make final determinations as promptly as possible.

(7) Appeal of decision. A final notice of construction decision may be appealed to the pollution control hearings board pursuant to chapter 43.21B RCW.

(8) Commencement of construction. The owner(s) or operator(s) of the new source shall not commence construction until the applicable notice of construction has been approved.

(9) Operation and maintenance plan. As a condition of notice of construction approval, prior to start up, the authority may require a plan for the operation and maintenance of all equipment and procedures to assure continuous compliance with this chapter.

(a) A copy of the plan shall be filed with the authority upon request.

(b) The plan shall reflect good industrial practice and may include operating parameters and maintenance procedures, and shall be updated to reflect any changes in good industrial practice. 
(c) Submittal of all plans should coincide with the authorities reporting requirements where applicable.

(10) Jurisdiction. Emission of toxic air pollutants that exceed the acceptable source impact levels listed in WAC $<\mathrm{D}<12266>>173-460-150<\mathrm{D}>$ and $<\mathrm{D}<12267>>173-460-160<\mathrm{D}>$ requires ecology and, if applicable, authority approval as specified in WAC $<\mathrm{D}<12260>>173-460-090<\mathrm{D}>$ and $<\mathrm{D}<12261>>$ $173-460-100</ \mathrm{D}>$.

\section{WAC173-460-050}

WAC 173-460-050 Requirement to quantify emissions.

(1) New sources.

(a) When applying for a notice of construction, an owner or operator of a new toxic air pollution source shall quantify those emissions of each TAP or combination of TAPs that:

(i) Will be used for the modeling procedures in WAC $<\mathrm{D}<12259>>173-460-080</ \mathrm{D}\rangle$; and

(ii) That may be discharged after applying required control technology. The information shall be submitted to the authority.

(b) Emissions shall be quantified in sufficient detail to determine whether the source complies with the requirements of this chapter.

(2) Small quantity sources.

Sources that choose to use small quantity emission rate tables instead of using dispersion modeling shall quantify emissions as required under WAC $<\mathrm{D}<12259>>173-460-080</ \mathrm{D}>$, in sufficient detail to demonstrate to the satisfaction of the authority that the emissions are less than the applicable emission rates listed in $\mathrm{WAC}<\mathrm{D}<12259>>173-460-080<\mathrm{D}>$.

(3) Level of detail.

An acceptable source impact level analysis under WAC $<$ D $<12259>>173-460-080</ \mathrm{D}>$, may be based on a conservative estimate of emissions that represents good engineering judgment. If compliance with WAC $<\mathrm{D}<12258>>173-460-070</ \mathrm{D}>$ and $<\mathrm{D}<12259>>173-460-080</ \mathrm{D}>$ cannot be demonstrated, more precise emission estimates shall be used to demonstrate compliance with WAC $<\mathrm{D}<12260>>$ 173-460-090</D>.

(4) Mixtures of toxic air pollutants.

(a) An owner or operator of a source that may discharge more than one toxic air pollutant may demonstrate compliance with WAC $<\mathrm{D}<12258>>173-460-070<\mathrm{D}>$ and $<\mathrm{D}<12259>>173-460-080$ $</ \mathrm{D}>$ by:

(i) Quantifying emissions and performing modeling for each TAP individually; or

(ii) Calculating the sum of all TAP emissions and performing modeling for the total TAP emissions and comparing maximum ambient levels to the smallest ASIL; or

(iii) Equivalent procedures may be used if approved by ecology.

(b) Dioxin and furan emissions shall be considered together as one TAP and expressed as an equivalent emission of 2,3,7,8 TCDD based on the relative potency of the isomers in accordance with United States Environmental Protection Agency (EPA) guidelines.

Note:Copies of EPA "Interim procedures for estimating risks associated with exposures to mixtures of chlorinated dibenzo-p-dioxins and dibenzofurans (CDDs and CDFs). 1989 Update" are available by requesting EPA /625/3-89/016, March 1989 from ORD Publications (513) 684-7562.

(c) Polyaromatic hydrocarbon (PAH) emissions. The owner or operator of a source that may emit a mixture of polyaromatic hydrocarbon emissions shall quantify the following PAHs and shall consider them together as one TAP equivalent in potency to benzo(a)pyrene: benzo- (a)anthracene, 
benzo(b)fluoranthene, benzo(k)fluoranthene, chrysene, dibenzo(a,h)anthracene, indenol(1,2,3-cd)pyrene, benzo(a)pyrene. The acceptable source impact analysis shall be conducted using the polyaromatic hydrocarbon emission ASIL contained in WAC $<\mathrm{D}<12266>>173-460-150<\mathrm{D}>(3)$.

(d) Uncontrolled roof vent emissions from primary aluminum smelters. The owner or operator of a primary aluminum smelter that may emit a mixture of polyaromatic hydrocarbons from uncontrolled roof vents shall quantify PAH emissions using either of the following methods:

(i) Quantify PAH emissions using the procedures in (c) of this subsection; or

(ii) Multiply the total particulate emission mass from the uncontrolled roof vents by the percent of the particulate that is extractable organic matter. The percent extractable organic matter shall be considered one percent of total particulate matter unless ecology determines that there is compelling scientific data which demonstrates that the use of this value is inappropriate. The acceptable source impact analysis shall be conducted using the primary aluminum smelter uncontrolled roof vent PAH emission ASIL contained in WAC $<D<12266>>173-460-150<\mathrm{D}>(3)$. Note: For example, 100 grams of particulate air emission mass times one percent yields one gram of $\mathrm{PAH}$ emissions.

\section{WAC173-460-060}

WAC 173-460-060 Control technology requirements.

Except as provided for in WAC $<\mathrm{D}<12255>>173-460-040<\mathrm{D}>$, a person shall not establish, operate, or cause to be established or operated any new toxic air pollutant source which is likely to increase TAP emissions without installing and operating T-BACT. Satisfaction of the performance requirements listed below fulfill the T-BACT requirement for those particular sources. Local air pollution authorities may develop and require performance requirements in lieu of T-BACT provided that ecology approves the performance requirements as equivalent to T-BACT.

(1) Perchloroethylene dry cleaners. The entire dryer exhaust shall be vented through a control device which will reduce VOC emissions to $5 \mathrm{~kg}$ or less per $100 \mathrm{~kg}$ dry weight of cleaned articles.

(a) The control device shall meet one of the following conditions:

(i) The exhaust from a carbon adsorber shall contain less than $100 \mathrm{ppm}$ perchloroethylene as measured over a period of one minute before dilution; or

(ii) The air temperature at the outlet of a refrigerated condenser shall reach seven degrees centigrade or less during the cool-down period. A temperature gauge with a minimum range from negative thirty-two to seventy-five degrees centigrade shall be installed and maintained on the condenser outlet duct; or

(iii) The demonstrated control efficiency for any other control device shall be ninety percent or greater by weight, prior to the discharge to the atmosphere measured over a complete control cycle.

(b) The operation of any perchloroethylene dry cleaner shall meet all of the following conditions:

(i) All leaking components shall be repaired immediately; and

(ii) All filtration cartridges shall be drained in the filter housing or other enclosed container before discarding the cartridges.

(2) Petroleum solvent dry cleaning systems. A petroleum solvent dry cleaning system shall include the following:

(a) All cleaned articles are dried in a solvent recovery dryer or the entire dryer exhaust is vented through a properly functioning control device which will reduce emissions to no more than $3.5 \mathrm{~kg}$ of VOC per 100 $\mathrm{kg}$ dry weight of cleaned articles; and

(b) All cartridge filtration systems are drained in their sealed housing or other enclosed container before discarding the cartridges; and

(c) All leaking components shall be repaired immediately.

(3) Chromic acid plating and anodizing. The facility-wide uncontrolled hexavalent chromium emissions 
Appendix D - Constraints Definitions

from plating or anodizing tanks shall be reduced by at least ninety-five percent using either of the following control techniques:

(a) An antimist additive or other equally effective control method approved by ecology or authority; or

(b) The tank is equipped with:

(i) A capture system which represents good engineering practice and which shall be in place and in operation at all times electrical current is applied to the tank; and

(ii) An emission control system which limits hexavalent chromium emissions to no more than 0.15 milligrams per ampere-hour of electrical charge applied to the tank or uncontrolled emissions shall be reduced by ninety-five percent.

(4) Chromic acid plating and anodizing (greater than 1 kilogram). If the facility-wide hexavalent chromium emissions from chromic acid plating and anodizing are greater than 1 kilogram per year after the application of control techniques required by subsection (3) of this section, the facility-wide hexavalent chromium emissions shall be reduced by at least ninety-nine percent using either of the following control techniques:

(a) An antimist additive or other equally effective control method approved by ecology or authority; or

(b) The tank is equipped with:

(i) A capture system which represents good engineering practice and which shall be in place and in operation at all times electrical current is applied to the tank; and

(ii) An emissions control system which limits hexavalent chromium emissions to no more than 0.03 milligrams per ampere-hour of electrical charge applied to the tank or uncontrolled emissions shall be reduced by ninety-nine percent.

(5) Solvent metal cleaners.

(a) Any solvent metal cleaner shall include all of the following equipment:

(i) A cover for the solvent tank which shall be closed at all times except when processing work in the degreaser. However, the cover shall be closed to the maximum extent possible when parts are being degreased;

(ii) A facility for draining cleaned parts such that the drained solvent is returned to the solvent tank;

(iii) For cold solvent cleaners, a freeboard ratio greater than or equal to 0.75 ;

(iv) Vapor degreasers shall have:

(A) A high vapor cutoff thermostat with manual reset; and

(B) For degreasers with spray devices, a vapor-up thermostat which will allow spray operation only after the vapor zone has risen to the design level; and

(C) Either a freeboard ratio greater than or equal to 1.00 or a refrigerated freeboard chiller; and

(v) Conveyorized vapor degreasers shall have:

(A) A drying tunnel or a rotating basket sufficient to prevent cleaned parts from carrying liquid solvent out of the degreaser; and

(B) A high vapor cutoff thermostat with manual reset; and

(C) A vapor-up thermostat which will allow conveyor movement only after the vapor zone has risen to the design vapor level.

(b) The operation of any solvent metal cleaner shall meet the following requirements:

(i) Solvent shall not leak from any portion of the degreasing equipment;

(ii) Solvent, including waste solvent, shall be stored in closed containers and shall be disposed of in such a manner as to prevent its evaporation into the atmosphere;

(iii) For cold cleaners, cleaned parts shall be drained until dripping ceases; and

(iv) Degreasers shall be constructed to allow liquid solvent from cleaned parts to drain into a trough or equivalent device and return to the solvent tank.

(c) For open-top vapor degreasers, solvent drag-out shall be minimized by the following measures:

(i) Racked parts shall be allowed to drain fully;

(ii) The work load shall be degreased in the vapor zone until condensation ceases; 
(iii) Spraying operations shall be done within the vapor layer;

(iv) When using a powered hoist, the vertical speed of parts in and out of the vapor zone shall be less than three meters per minute (ten feet per minute);

(v) When the cover is open, the lip of the degreaser shall not be exposed to steady drafts greater than

15.3 meters per minute (fifty feet per minute); and

(vi) When equipped with a lip exhaust, the fan shall be turned off when the cover is closed.

(d) For conveyorized vapor degreasers, solvent drag-out shall be minimized by the following measures:

(i) Racked parts shall be allowed to drain fully; and

(ii) Vertical conveyor speed shall be maintained at less than three meters per minute (ten feet per minute).

(6) Abrasive blasting

(a) Abrasive blasting shall be performed inside a booth or hangar designed to capture the blast grit or overspray.

(b) Outdoor blasting of structures or items too large to be reasonably handled indoors shall employ control measures such as curtailment during windy periods and enclosure of the area being blasted with tarps.

(c) Outdoor blasting shall be performed with either steel shot or an abrasive containing less than one percent (by mass) which would pass through a No. 200 sieve.

(d) All abrasive blasting with sand shall be performed inside a blasting booth or cabinet.

\section{WAC173-460-070}

WAC 173-460-070 Ambient impact requirement.

When applying for a notice of construction under WAC $<D<12255>>173-460-040</ D>$, the owner or operator of a new toxic air pollutant source which is likely to increase TAP emissions shall demonstrate that emissions from the source are sufficiently low to protect human health and safety from potential carcinogenic and/or other toxic effects. Compliance shall be demonstrated in any area which does not have restricted or controlled public access. The source shall demonstrate compliance by using procedures established in this chapter after complying with the control technology requirements in WAC $<\mathrm{D}<12257>>173-460-060</ \mathrm{D}>$.

\section{WAC173-460-080}

WAC 173-460-080 Demonstrating ambient impact compliance.

(1) When applying for a notice of construction under WAC $<$ D $<12255>>173-460-040<$ D $>$, the owner or operator of a new toxic air pollutant source which is likely to increase TAP emissions shall complete an acceptable source impact level analysis for Class A and Class B TAPs. The authority may complete this analysis.

(2) Acceptable source impact analysis.

(a) Carcinogenic effects. The owner or operator shall use dispersion modeling to estimate the maximum incremental ambient impact of each Class A TAP from the source and compare the estimated incremental ambient values to the Class $A$ acceptable source impact levels in WAC $<D<12266>>173-460-150</ D>$. If applicable, the source may use the small quantity emission rate tables in (e) of this subsection.

(b) Other toxic effects. The owner or operator shall use dispersion modeling to estimate the maximum incremental ambient impact of each Class B TAP from the source and compare the estimated ambient 
values to the Class $B$ acceptable source impact levels in WAC $<D<12267>>173-460-160</ D>$. If applicable, the source may use the small quantity emission rate tables in (e) of this subsection.

(c) Dispersion modeling. The owner or operator shall use dispersion modeling techniques in accordance with EPA guidelines. If concentrations predicted by dispersion screening models exceed applicable acceptable source impact levels, more refined modeling and/or emission estimation techniques shall be used. Refined modeling techniques shall be approved by ecology and the authority. (Note: EPA"s Guideline on Air Quality Models, EPA 450/2-78-027R, can be obtained through NTIS (703) 487-4650 or can be downloaded from the OAQPS Technology Transfer Network electronic bulletin board system).

(d) Averaging times. The owner or operator shall use the averaging times in (d)(i), (ii), (iii) of this subsection unless alternate averaging times are approved by ecology. Ecology may allow the use of an alternate averaging time if it determines that the operating procedures of the source may cause a high concentration of a TAP for a short period and that consideration of potential health effects due to peak exposures may be warranted for the TAP.

(i) An annual average shall be used for Class A TAPs listed in WAC $<\mathrm{D}<12266>>173-460-150$ $<$ D $>$ (2).

(ii) The averaging times specified in WAC $<D<12266>>173-460-150</ D>$ (3) shall be used for Class $A$ TAPs listed in WAC $<\mathrm{D}<12266>>173-460-150<\mathrm{D}>(3)$.

(iii) A twenty-four-hour averaging time shall be used for Class B TAPs listed in WAC $<$ D $<12267>>$ 173-460-160</D>.

(e) Small quantity emission rates. Instead of using dispersion modeling to show compliance with ambient impact demonstration requirements in WAC $<\mathrm{D}<12259>>173-460-080<\mathrm{D}>$ and $<\mathrm{D}<12260>>$ $173-460-090</ D>$, a source may use the small quantity emission rate tables for all toxic air pollutants with acceptable source impact levels equal to or greater than $0.001 \mathrm{ug} / \mathrm{m} 3$. A source must first meet control technology and emission quantification requirements of WAC $<D<12256>>173-460-050</ D>$ and $\langle\mathrm{D}<12257>>173-460-060<\mathrm{D}\rangle$, then demonstrate that the source emission rate does not exceed the rates specified in the appropriate table below.

\section{SMALL QUANTITY EMISSION RATES CLASS A TOXIC AIR POLLUTANTS}

TAP Emissions

Pounds per Year

Acceptable Source Impact $(10$ meter stack

Level (Annual ug/m3) and downwash)

$\begin{array}{ll}0.001 \text { to } 0.0099 & 0.5 \\ 0.01 \text { to } 0.06 & 10 \\ 0.07 \text { to } 0.12 & 20 \\ 0.13 \text { to } 0.99 & 50 \\ 1.0 \text { to } 10 & 500\end{array}$

\section{SMALL QUANTITY EMISSION RATES CLASS B TOXIC AIR POLLUTANTS}

Acceptable Source ImpactTAP

Emissions Level (24 hour ug/m3)

\author{
Pounds per Year
}

Pounds per Hour
Less than 1

1 to 9.9

10 to 29.9

30 to 59.9

\begin{tabular}{|c|c|}
\hline 175 & 0.02 \\
\hline 175 & 0.02 \\
\hline 1,750 & 0.20 \\
\hline 5,250 & 0.60 \\
\hline
\end{tabular}


Appendix D - Constraints Definitions

60 to 99.9

100 to 129.9

130 to 250

Greater than 250

\begin{tabular}{cc}
10,500 & 1.20 \\
17,500 & \multicolumn{2}{c}{2.0} \\
22,750 & 2.6 \\
43,748 & \multicolumn{2}{c}{5.0}
\end{tabular}

(3) Criteria for compliance. Compliance with WAC $<D<12258>>173-460-070</ D>$ is demonstrated if the authority determines that, on the basis of the acceptable source impact analysis, the source's maximum incremental ambient air impact levels do not exceed the Class A or Class B acceptable source impact levels in WAC $<\mathrm{D}<12266>>173-460-150</ \mathrm{D}>$ and $\langle\mathrm{D}<12267>>173-460-160</ \mathrm{D}\rangle$; or, if applicable, the source TAP emission rates do not exceed the rates specified in subsection (2)(e) of this section.

\section{WAC173-460-090}

WAC $173-460-090$ Second tier analysis.

(1) Applicability.

(a) The owner or operator who cannot demonstrate class A or class B TAP source compliance with WAC $<\mathrm{D}<12258>>173-460-070<\mathrm{D}>$ and $<\mathrm{D}<12259>>173-460-080</ \mathrm{D}>$ using an acceptable source impact level analysis as provided in WAC $<\mathrm{D}<12259>>173-460-080</ \mathrm{D}>(2)$, may submit a petition requesting ecology perform a second tier analysis evaluation to determine a means of compliance with WAC $<\mathrm{D}<12258>>173-460-070<\mathrm{D}>$ and $<\mathrm{D}<12259>>173-460-080<$ D $>$ by establishing allowable emissions for the source. Petitions for second tier analysis evaluation shall be submitted to the local authority or ecology if ecology has jurisdiction over the source. Petitions received by local authorities shall be submitted to ecology within ten days of receipt. A second tier analysis evaluation may be requested when a source wishes to more accurately characterize risks, to justify risks greater than acceptable source impact levels, or to otherwise modify assumptions to more accurately represent risks. Risks may be more accurately characterized by utilizing updated EPA unit risk factors, inhalation reference concentrations, or other EPA recognized or approved methods. Ecology shall specify the maximum allowable emissions of any class A or class B TAP source based on ecology's second tier analysis evaluation.

(b) Ecology shall evaluate a source"'s second tier analysis only if:

(i) The authority has advised ecology that other conditions for processing the notice of construction have been met; and

(ii) Emission controls contained in the conditional notice of construction represent at least T-BACT; and

(iii) Ambient concentrations exceed acceptable source impact levels after using more refined emission quantification and air dispersion modeling techniques.

(c) Ecology shall determine whether the conditions in (b)(i), (ii), and (iii) of this subsection for a second tier analysis have been satisfied within ten working days of receipt of all information needed to make the determination. The matter shall be returned to the authority if ecology finds the conditions for a second tier analysis evaluation have not been met.

(2) Jurisdiction.

(a) Any second tier analysis application submitted by a source wishing to emit toxic air pollutants at levels greater than the acceptable source impact level contained in WAC $<\mathrm{D}<12266>>173-460-150$ $</ \mathrm{D}>$ or $<\mathrm{D}<12267>>173-460-160<\mathrm{D}>$ shall be approved or rejected by ecology.

(b) Any new emission limits approved by ecology as a result of the second tier analysis evaluation shall be enforced by the authority provided the authority approves the new emission limits.

(3) Approval criteria. 
(a) Based on the second tier analysis, ecology may approve the emissions of TAPs from a source where ambient concentrations exceed acceptable source impact levels only if it determines that emission controls represent at least T-BACT and the source demonstrates that emissions of Class A TAPs are not likely to result in an increased cancer risk of more than one in one hundred thousand. The emission of Class A TAPs at levels likely to result in an increased cancer risk of more than one in one hundred thousand requires the approval of the director after complying with $\mathrm{WAC}<\mathrm{D}<12261>173-460-100$ $</ \mathrm{D}>$.

(b) Ecology shall consider the second tier analysis and other information submitted by the applicant as well as department of health comments.

(i) Comments from other agencies and universities with appropriate expertise may also be considered in the decision to approve emissions that exceed acceptable source impact levels.

(ii) Public comments shall be considered if the source applies for a risk management decision under WAC $<$ D $<12261>>173-460-100<$ D $>$.

(4) Contents of the second tier analysis.

(a) The second tier analysis consists of a health impact assessment. The applicant shall complete and submit a health impact assessment to ecology which includes the following information. Ecology may approve the submittal of less information if it determines that such information is sufficient to perform the second tier analysis evaluation. The health impact assessment shall be prepared in accordance with EPA"'s risk assessment guidelines as defined in WAC $<D<12253>>173-460-020</ D>(9)$.

(i) Demographics such as population size, growth, and sensitive subgroups;

(ii) Toxicological profiles of all toxic air pollutants that exceed the ASIL;

(iii) Characterization of existing pathways and total daily intake for toxic air pollutants that exceed the ASIL;

(iv) Contribution of the proposed source toward total daily intake for toxic air pollutants that exceed the ASIL;

(v) Using existing data, characterization of risk from current exposure to the toxic air pollutants that exceed the ASIL. This includes existing TAP sources in the area, and anticipated risk from the new source;

(vi) Additive cancer risk for all Class A toxic air pollutants which may be emitted by the source;

(vii) Other information requested by ecology and pertinent to ecology's decision to approve the second tier application;

(viii) Uncertainty in the data; and

(ix) Length of exposure and persistence in the environment.

(b) The health assessment shall utilize current scientific information. New scientific information on the toxicological characteristics of toxic air pollutants may be used to justify modifications of upper bound unit risk factors used to calculate ASILs in WAC $<D<12266>>173-460-150<\mathrm{D}>$ and/or absorption rates of individual toxic air pollutants if ecology determines there is compelling scientific data which demonstrates that the use of EPA recognized or approved methods are inappropriate.

(5) Additional information.

(a) If approved by ecology, newly discovered scientific information which was unavailable at the time of the original submission of the health assessment may be used to justify modifications of the original health assessment. Ecology may approve the additional information if the source exercised due diligence at the time of original submission.

(b) Within thirty days after receipt of the second tier analysis and all supporting data and documentation, ecology may require the submission of additional information needed to evaluate the second tier analysis.

(6) Determination.

(a) If the second tier analysis is approved by ecology, ecology will return the petition to the authority and the authority may approve the notice of construction.

(b) The authority shall specify allowable emissions consistent with ecology"s second tier analysis 
evaluation determination expressed in weight of pollutant per unit time for each emissions unit involved in the application. The notice of construction shall also include all requirements necessary to assure that conditions of this chapter and chapter $<\mathrm{D}<11981>>173-400</ \mathrm{D}>$ WAC are satisfied.

(7) Public notification requirements.

Ecology decisions regarding second tier analysis or decisions under WAC $<\mathrm{D}<12261>>173-460-100$ $</ \mathrm{D}>$ shall comply with public notification requirements contained in WAC $<\mathrm{D}<12009>>173-400-171$ $</ \mathrm{D}\rangle$.

\section{WAC173-460-100}

WAC 173-460-100 Request for risk management decision.

(1) Applicability. The owner or operator of a source that emits Class A TAPs that are likely to result in an increased cancer risk of more than one in one hundred thousand may request that ecology establish allowable emissions for the source.

(2) Contents of the application.

The applicant shall meet the submittal requirements of WAC $<\mathrm{D}<12260>>173-460-090<\mathrm{D}>(1)$ and submit all materials required under WAC $<\mathrm{D}<12260>>173-460-090</ \mathrm{D}>$ (4) and (5). The applicant may submit the request for a risk management decision concurrently with the second tier analysis application. Prior denial of the second tier analysis application under WAC $<D<12260>173-460-090$ $</ \mathrm{D}>(6)$ is not required.

(3) Criteria for approval. Ecology may approve the emissions of TAPs from a source where ambient concentrations are likely to result in an increased cancer risk of more than one in one hundred thousand only if the source first demonstrates the following:

(a) Proposed emission controls represent all known available and reasonable technology; and

(b) Application of all known available toxic air pollution prevention methods to reduce, avoid, or eliminate toxic air pollutants prior to their generation including recycling, chemical substitution, and efforts to redesign processes; and

(c) The proposed changes will result in a greater benefit to the environment as a whole.

(4) Additional methods to reduce toxic air pollutants. In addition to the requirements in subsection (3) of this section, the owner or operator may propose and ecology may consider measures that would reduce community exposure, especially exposure of that portion of the community subject to the greatest additional risk, to comparable toxic air pollutants provided that such measures are not already required.

(5) Public involvement. Ecology will initiate public notice and comment within thirty days of receipt of a completed risk management decision application. In addition to the public notice and comment requirements of WAC $<\mathrm{D}<12009>>173-400-171<\mathrm{D}>$, the owner or operator shall hold a public hearing to:

(a) Present the results of the second tier analysis, the proposed emission controls, pollution prevention methods, additional proposed measures, and remaining risks; and

(b) Participate in discussions and answer questions.

(6) Time limitation. The owner or operator shall commence construction within eighteen months of the director"s approval.

WAC173-460-110

WAC 173-460-110 Acceptable source impact levels. 
There are three types of acceptable source impact levels: Risk-based, threshold-based, and special acceptable source impact levels. They are computed as follows:

(1) Risk-based acceptable source impact levels for Class A TAPs. Risk-based acceptable source impact levels means the annual average concentration, in micrograms per cubic meter, that may cause an increased cancer risk of one in one million. Ecology shall calculate the risk-based acceptable source impact levels for Class A TAPs in WAC $<D<12266>>173-460-150<\mathrm{D}>(2)$ using the following equation:

$\underset{(\mathrm{ug} / \mathrm{m} 3)}{\text { Risk based ASIL }}=$ URF $^{\text {RISK }}$

*Where:

RISK $=$ Cancer risk level $(1$ in $1,000,000)$

$\mathrm{URF}=$ Upper bound unit risk factor as published in IRIS data base or other appropriate sources (ug/m3)-1.

(2) Threshold-based acceptable source impact levels for Class B TAPs. Threshold-based acceptable source impact levels in WAC $<\mathrm{D}<12267>>173-460-160</ \mathrm{D}>$ shall be determined as follows:

(a) If a Class B TAP has an Environmental Protection Agency Inhalation Reference Concentration, the inhalation reference concentration and specified averaging time shall be used.

(b) Other Class B TAP acceptable source impact levels shall be determined by dividing the TLV-TWA by three hundred to calculate a twenty-four hour TWA acceptable source impact level.

(3) Special acceptable source impact levels.

(a) Ecology may establish special acceptable source impact levels for TAPs for which upper bound risk factors or TLVs have not been established, or for mixtures of compounds if it determines that the above acceptable source impact level methods are not appropriate, do not adequately protect human health or are overly stringent.

(b) The averaging times for special ASILs are listed in WAC $<\mathrm{D}<12266>>173-460-150<\mathrm{D}>(3)$.

\section{WAC173-460-120}

WAC 173-460-120 Scientific review and amendment of acceptable source impact levels and lists.

(1) Ongoing scientific review.

(a) To use the best available scientific information, ecology shall conduct an ongoing review of information concerning whether to add or delete toxic air pollutants to $\mathrm{WAC}<\mathrm{D}<12266>>173-460-150$ $</ \mathrm{D}>$ or $<\mathrm{D}<12267>>173-460-160<\mathrm{D}>$, what acceptable source impact levels should be used to review emissions of TAPs, source applicability and exemptions.

(b) A complete review shall be made at least once every three years at which time ecology shall consider scientific information developed by the E.P.A., Washington department of health, other states or other scientific organizations, scientific information provided by any person, and results of second tier analyses evaluations.

(2) Criteria for listing as Class A or Class B TAP.

(a) Ecology shall list a substance or group of substances as Class A or Class B TAPs if the department has reason to believe that the compound or group of compounds are likely to be emitted to the air from an air pollution source and the air emission of such compound or compounds could impact public health. The compounds shall be removed from the list if ecology determines that these conditions no longer exist. 
(b) Ecology may list mixtures of compounds as Class A and/ or Class B TAPs if ecology determines that the health impact of the emission mixture is likely to be different from the known individual chemical impacts.

(3) Acceptable source impact level (ASIL).

Ecology may adopt an ASIL only if ecology determines that concentrations at that level will not unreasonably endanger human health.

\section{WAC173-460-130}

WAC $173-460-130$ Fees.

(1) Pursuant to RCW 70.94.152, ecology or the authority may charge a fee for the review of notices of construction.

(2) The fee imposed under this section may not exceed the cost of reviewing plans, specifications, and other information and administering such notice.

\section{WAC173-460-140}

WAC 173-460-140 Remedies.

Violations of this chapter are subject to the penalty provisions and/or other remedies provided in chapter $70.94 \mathrm{RCW}$.

\section{WAC173-460-150-Table 1}

WAC 173-460-150 Class A toxic air pollutants: Known, probable and potential human carcinogens and acceptable source impact levels.

(1) TABLE I

CLASS A TOXIC AIR POLLUTANTS

Known and Probable Carcinogens

\section{CAS \#}

75-07-0

53-96-3

79-06-1

107-13-1

309-00-2

117-79-3

97-56-3

92-67-1

61-82-5

62-53-3

\section{SUBSTANCE}

Acetaldehyde

2-Acetylaminofluorene

Acrylamide

Acrylonitrile

Aldrin

Aluminum smelter polyaromatic hydrocarbon emissions

2-Aminoanthraquinone

o-Aminoazotoluene

4-Aminobiphenyl

Amitrole

Aniline 
Appendix D - Constraints Definitions

\begin{tabular}{|c|c|}
\hline $90-04-0$ & o-Anisidine \\
\hline C $7440-38-2$ & Arsenic and inorganic arsenic compounds \\
\hline $1332-21-4$ & Asbestos \\
\hline $2465-27-2$ & Auramine (technical grade) \\
\hline $71-43-2$ & Benzene \\
\hline $92-87-5$ & Benzidine and its salts \\
\hline $56-55-3$ & Benzo(a)anthracene \\
\hline $50-32-8$ & Benzo(a)pyrene \\
\hline $205-99-2$ & Benzo(b)fluoranthene \\
\hline $205-82-3$ & Benzo(j)fluoranthene \\
\hline $207-08-9$ & Benzo(k)fluoranthene \\
\hline 1694-09-3 & Benzyl violet $4 b$ \\
\hline $7440-41-7$ & Beryllium and compounds \\
\hline $111-44-4$ & Bis(2-chloroethyl)ether \\
\hline $117-81-7$ & Bis(2-ethylhexyl)phthalate (DEHP) \\
\hline $542-88-1$ & Bis(chloromethyl)ether \\
\hline $75-25-2$ & Bromoform \\
\hline $106-99-0$ & 1,3-Butadiene \\
\hline $3068-88-0$ & B-Butyrolactone \\
\hline $7440-43-9$ & Cadmium and compounds \\
\hline $56-23-5$ & Carbon tetrachloride \\
\hline $57-74-9$ & Chlordane \\
\hline $510-15-6$ & Chlorobenzilate \\
\hline $67-66-3$ & Chloroform \\
\hline $107-30-2$ & Chloromethyl methyl ether (technical-grade) \\
\hline $108-43-0$ & Chlorophenols \\
\hline $126-99-8$ & Chloroprene \\
\hline C $7440-47-3$ & $\begin{array}{l}\text { Chromium, hexavalent metal and compounds } \\
\text { Coke oven emissions }\end{array}$ \\
\hline $8001-58-9$ & Creosote \\
\hline $135-20-6$ & Cupferron \\
\hline $94-75-7$ & $2,4-\mathrm{D}$ and esters \\
\hline $3547-04-4$ & DDE (p,p"'-Dichlorodiphenyldichloroethylene) \\
\hline $50-29-3$ & DDT $(1,1,1$ Trichloro-2,2-Bis(p-chlorophenyl)-ethane) \\
\hline $613-35-4$ & N,N-Diacetylbenzidine \\
\hline $101-80-4$ & 4,4"'-Diaminodiphenyl ether \\
\hline $226-36-8$ & Dibenz(a,h)acridine \\
\hline $53-70-3$ & Dibenz(a,h)anthracene \\
\hline $224-42-0$ & Dibenz $(a, j)$ acridine \\
\hline $132-64-9$ & Dibenzofurans \\
\hline $189-64-0$ & Dibenzo(a,h)pyrene \\
\hline $191-30-0$ & Dibenzo(a,l)pyrene \\
\hline $189-55-9$ & 1,2,7,8-Dibenzopyrene (dibenzo(a,i)pyrene) \\
\hline $192-65-4$ & Dibenzo(a,e)pyrene \\
\hline $764-41-0$ & 1,4-Dichloro-2-butene \\
\hline $28434-86-8$ & 3,3"'-Dichloro-4,4"'diaminodiphenyl ether \\
\hline $106-46-7$ & 1,4-Dichlorobenzene \\
\hline $91-94-1$ & 3,3"'-Dichlorobenzidine \\
\hline $107-06-2$ & 1,2-Dichloroethane (ethylene chloride) \\
\hline
\end{tabular}


Appendix D - Constraints Definitions

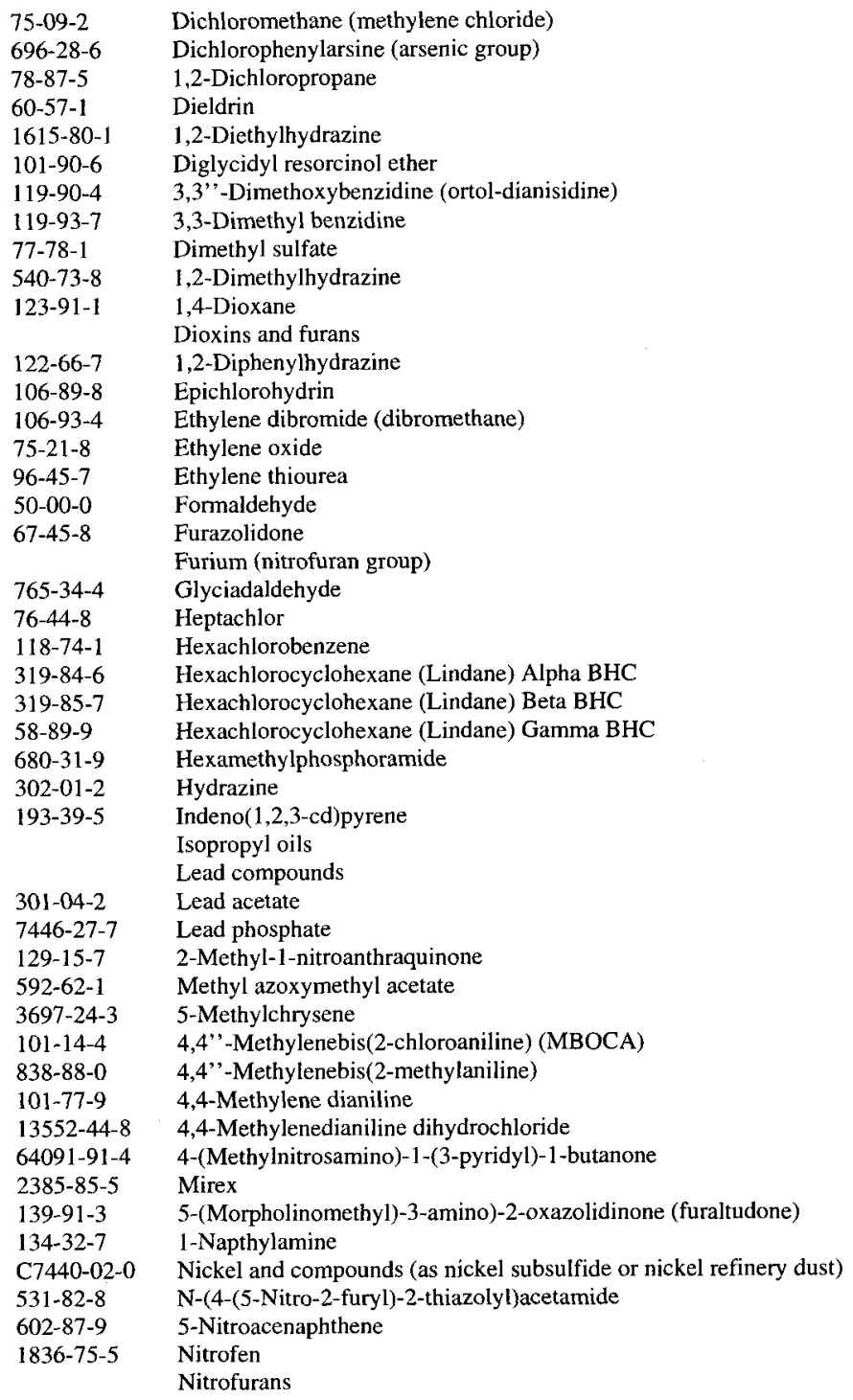


Appendix D - Constraints Definitions

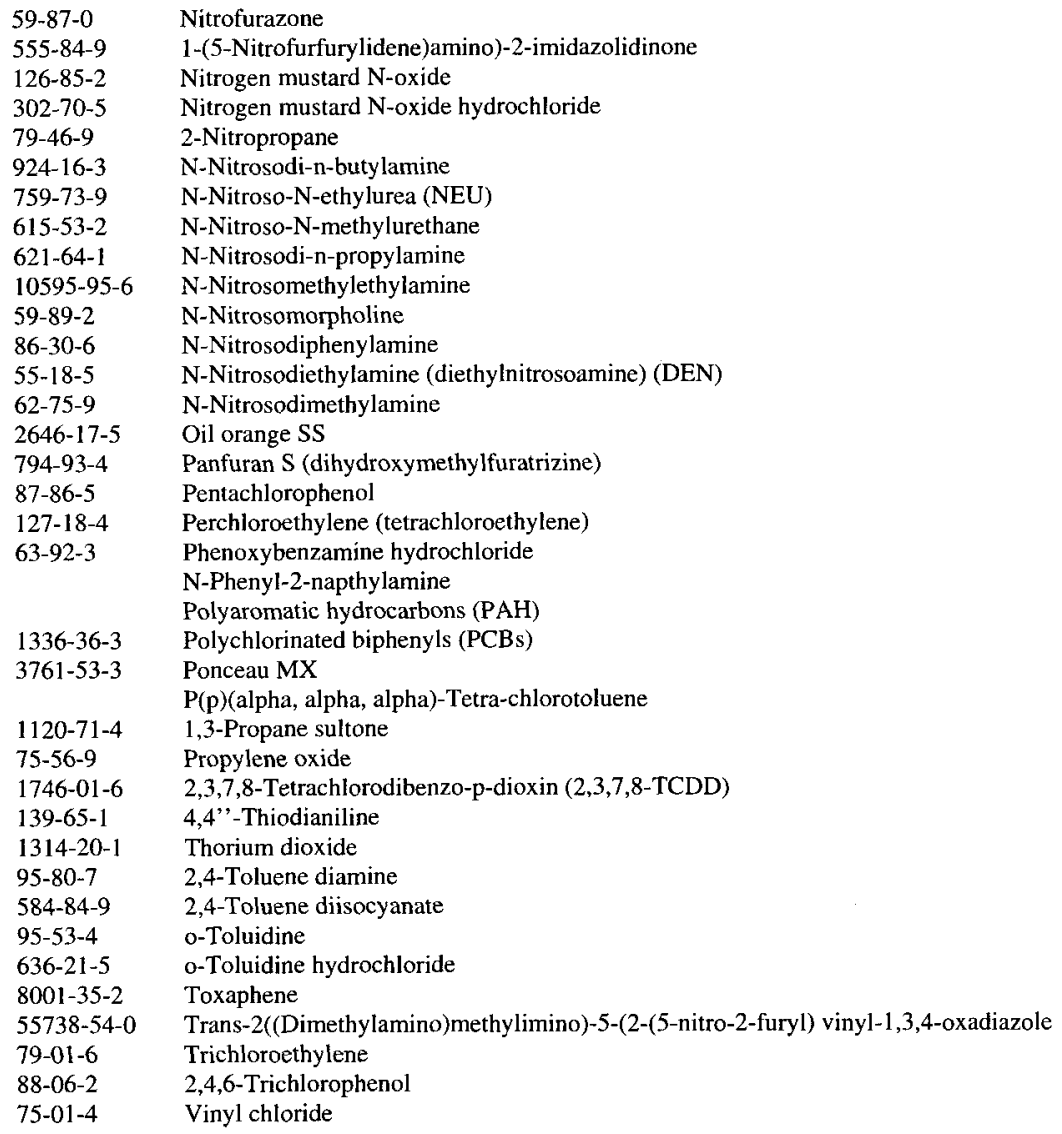

\section{WAC173-460-150-Table 2}

WAC 173-460-150 Class A toxic air pollutants: Known, probable and potential human carcinogens and acceptable source impact levels.

(2) TABLE II

CLASS A TOXIC AIR POLLUTANTS WITH ESTABLISHED ACCEPTABLE SOURCE IMPACT LEVELS 
10-6 RISK

\begin{tabular}{|c|c|c|}
\hline ASIL & MICROGRAMS/M^3 & ANNUAL AVERAGE \\
\hline $75-07-0$ & Acetaldehyde & 0.4500000 \\
\hline $79-06-1$ & Acrylamide & 0.0007700 \\
\hline $107-13-1$ & Acrylonitrile & 0.0150000 \\
\hline $309-00-2$ & Aldrin & 0.0002000 \\
\hline $62-53-3$ & Aniline & 6.3000000 \\
\hline C7440-38-2 & $\begin{array}{l}\text { Arsenic and inorganic } \\
\text { arsenic compounds }\end{array}$ & 0.0002300 \\
\hline $1332-21-4$ & Asbestos (Note: fibers $/ \mathrm{ml}$ ) & 0.0000044 \\
\hline $71-43-2$ & Benzene & 0.1200000 \\
\hline $92-87-5$ & Benzidine and its salts & 0.0000150 \\
\hline $50-32-8$ & Benzo(a)pyrene & 0.0004800 \\
\hline $7440-41-7$ & Beryllium and compounds & 0.0004200 \\
\hline $111-44-4$ & Bis(2-chloroethyl)ether & 0.0030000 \\
\hline $117-81-7$ & $\begin{array}{l}\text { Bis(2-ethylhexyl)phthalate } \\
\text { (DEHP) }\end{array}$ & 2.5000000 \\
\hline $542-88-1$ & Bis(chloromethyl)ether & 0.0000160 \\
\hline $75-25-2$ & Bromoform & 0.9100000 \\
\hline $106-99-0$ & 1,3-Butadiene & 0.0036000 \\
\hline $7440-43-9$ & Cadmium and compounds & 0.0005600 \\
\hline $56-23-5$ & Carbon tetrachloride & 0.0670000 \\
\hline $57-74-9$ & Chlordane & 0.0027000 \\
\hline $510-15-6$ & Chlorobenzilate & 0.2000000 \\
\hline $67-66-3$ & Chloroform & 0.0430000 \\
\hline $108-43-0$ & Chlorophenols & 0.1800000 \\
\hline C7440-47-3 & $\begin{array}{l}\text { Chromium, hexavalent } \\
\text { metal and compounds } \\
\text { Coke oven emissions }\end{array}$ & $\begin{array}{l}0.0000830 \\
0.0016000\end{array}$ \\
\hline $3547-04-4$ & DDE (p,p'-dichlorodipheny & ldichloroethylene) \\
\hline $50-29-3$ & $\begin{array}{l}\text { DDT }(1,1,1 \text { Trichloro-2,2-Bi } \\
\text { (p-chlorophenyl)-ethane) }\end{array}$ & 0.0100000 \\
\hline $764-41-0$ & 1,4-Dichloro-2-butene & 0.0003800 \\
\hline $106-46-7$ & 1,4-Dichlorobenzene & 1.5000000 \\
\hline $91-94-1$ & 3,3"'-Dichlorobenzidine & 0.0770000 \\
\hline $107-06-2$ & $\begin{array}{l}\text { 1,2-Dichloroethane } \\
\text { (ethylene chloride) }\end{array}$ & 0.0380000 \\
\hline $75-09-2$ & $\begin{array}{l}\text { Dichloromethane } \\
\text { (methylene chloride) }\end{array}$ & 0.5600000 \\
\hline $60-57-1$ & Dieldrin & 0.0002200 \\
\hline $119-93-7$ & 3,3-Dimethyl benzidine & 0.0038000 \\
\hline $123-91-1$ & 1,4-Dioxane & 0.0320000 \\
\hline $122-66-7$ & 1,2-Diphenylhydrazine & 0.0045000 \\
\hline $106-89-8$ & Epichlorohydrin & 0.8300000 \\
\hline $106-93-4$ & $\begin{array}{l}\text { Ethylene dibromide } \\
\text { (dibromethane) }\end{array}$ & 0.0045000 \\
\hline $75-21-8$ & Ethylene oxide & 0.0100000 \\
\hline
\end{tabular}


Appendix D - Constraints Definitions

$\begin{array}{llc}96-45-7 & \text { Ethylene thiourea } & 1.0000000 \\ 50-00-0 & \text { Formaldehyde } & 0.0770000 \\ 76-44-8 & \text { Heptachlor } & 0.0007700 \\ 118-74-1 & \text { Hexachlorobenzene } & 0.0022000 \\ 58-89-9 & \text { Hexachlorocyclohexane } & \\ & \text { (Lindane) gamma BHC } & 0.0026000 \\ 302-01-2 & \text { Hydrazine } & 0.0002000 \\ \text { C7440-02-0 } & \text { Nickel and compounds } \\ & \text { (as nickel subsulfide or } \\ & \text { nickel refinery dust) } & 0.0021000 \\ 924-16-3 & \text { N-Nitrosodi-n-butylamine } & 0.0006300 \\ 55-18-5 & \text { N-Nitrosodiethylamine } \\ & \text { (diethylnitrosoamine)(DEN)0.0000230 } \\ 62-75-9 & \text { N-Nitrosodimethylamine } & 0.0000710 \\ 79-46-9 & \text { 2-Nitropropane } & 0.0003700 \\ 87-86-5 & \text { Pentachlorophenol } & 0.3300000 \\ 127-18-4 & \text { Perchloroethylene } & \\ & \text { (tetrachloroethylene) } & 1.1000000 \\ 1336-36-3 & \text { Polychlorinated biphenyls } & \\ & \text { (PCB) } & 0.0045000 \\ 75-56-9 & \text { Propylene oxide } & 0.2700000 \\ 1746-01-6 & \text { 2,3,7,8-Tetrachlorodibenzo-p-dioxin } \\ & \text { (2,3,7,8-TCDD) } & 0.00000003 \\ 95-80-7 & \text { 2,4-Toluene diamine } & 0.0110000 \\ 95-53-4 & \text { o-Toluidine } & 0.1400000 \\ 636-21-5 & \text { o-Toluidine hydrochloride } & 0.1400000 \\ 8001-35-2 & \text { Toxaphene } & 0.0031000 \\ 79-01-6 & \text { Trichloroethylene } & 0.5900000 \\ 88-06-2 & 2,4,6-T r i c h l o r o p h e n o l \\ 75-01-4 & \text { Vinyl chloride } & 0.3200000 \\ & & 0.0120000 \\ & & \end{array}$

WAC173-460-150-Table 3

WAC 173-460-150 Class A toxic air pollutants: Known, probable and potential human carcinogens and acceptable source impact levels.

(3) TABLE III

CLASS A TOXIC AIR POLLUTANTS WITH SPECIAL ACCEPTABLE SOURCE IMPACT LEVELS

\begin{tabular}{|c|c|c|c|}
\hline \multirow[t]{2}{*}{$\begin{array}{l}\text { ASIL } \\
\text { CAS \# }\end{array}$} & SUBSTANCE & $\begin{array}{l}\text { MICRO- } \\
\text { GRAMS/M^3 }\end{array}$ & $\begin{array}{l}\text { AVERAGING } \\
\text { TIME }\end{array}$ \\
\hline & $\begin{array}{l}\text { Primary aluminum smelter } \\
\text { uncontrolled roof vent polyarom } \\
\text { (PAH) emissions (Note: Quanti } \\
\text { to WAC }<\text { D }<12256>>173-460\end{array}$ & $\begin{array}{l}0.0013 \\
\text { latic hydrocarbon } \\
\text { ify according } \\
-050</ D>(4)(d))\end{array}$ & Annual \\
\hline $61-82-5$ & Amitrole & 0.06 & 24 hour \\
\hline $90-04-0$ & o-Anisidine & 1.7 & 24 hour \\
\hline
\end{tabular}


Appendix D - Constraints Definitions

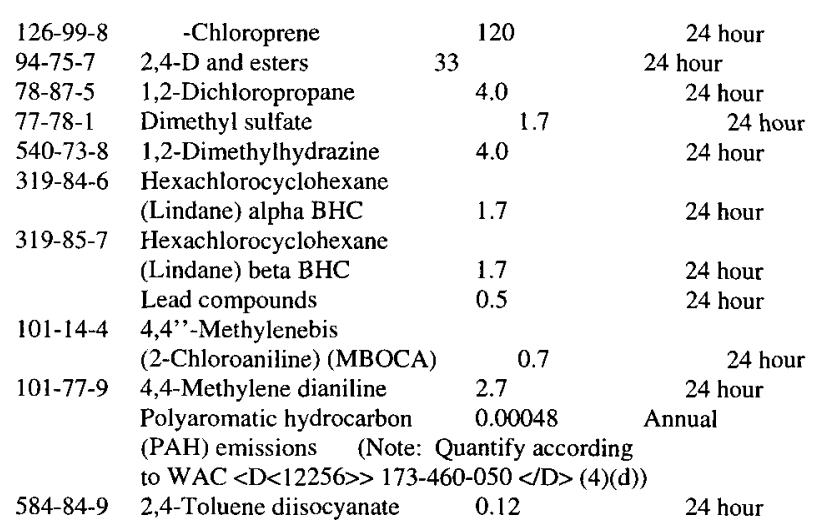

\section{WAC173-460-160}

WAC 173-460-160 Class B toxic air pollutants and acceptable source impact levels.

The following table lists Class B toxic air pollutants and acceptable source impact levels:

\section{CLASS B TOXIC AIR POLLUTANTS AND ACCEPTABLE SOURCE IMPACT LEVELS}

\begin{tabular}{llc}
$\begin{array}{l}\text { ASIL } \\
\text { CAS\# }\end{array}$ & SUBSTANCE & $\begin{array}{l}\text { TWENTY-FOUR } \\
\text { AVERAGE }\end{array}$ \\
$86-88-4$ & ANTU & 1.0 \\
$60-35-5$ & Acetamide & \multicolumn{2}{c}{83} \\
$64-19-7$ & Acetic acid & 67 \\
$108-24-7$ & Acetic anhydride & 5900 \\
$67-64-1$ & Acetone & 220 \\
$75-05-8$ & Acetonitrile & \multicolumn{2}{|c}{} \\
$98-86-2$ & Acetophenone & 47 \\
$79-27-6$ & Acetylene tetrabromide & 0.02 \\
$107-02-8$ & Acrolein & \multicolumn{2}{c}{0.30} \\
$79-10-7$ & Acrylic acid & 17 \\
$107-18-6$ & Allyl alcohol & 1.0 \\
$107-05-1$ & Allyl chloride & 77 \\
$106-92-3$ & Allyl glycidyl ether (AGE) & \multicolumn{2}{c}{40.0} \\
$2179-59-1$ & Allyl propyl disulfide & \multicolumn{2}{c}{6.7} \\
C7429-90-5 & Aluminum, Al alkyls & \multicolumn{2}{c}{33} \\
$7429-90-5$ & Aluminum, as AL metal dust & 17 \\
C7429-90-5 & Aluminum, as AL pyro powders & \multicolumn{2}{c}{17}
\end{tabular}


C7429-90-5

C7429-90-5

504-29-0

$7664-41-7$

12125-02-9

3825-26-1

$7773-06-0$

628-63-7

626-38-0

62-53-3

29191-52-4

C7440-36-0

1309-64-4

7784-42-1

8052-42-4

1912-24-9

86-50-0

C7440-39-3

17804-35-2

98-07-7

94-36-0

100-44-7

92-52-4

1304-82-1

1304-82-1

C1303-96-4

C1303-96-4

C1303-96-4

1303-86-2

10294-33-4

76737-07-2

314-40-9

7726-95-6

7789-30-2

106-97-8

111-76-2

123-86-4

105-46-4

540-88-5

141-32-2

71-36-3

78-92-2

75-65-0

1 189-85-1

2426-08-6

138-22-7

109-79-5

109-73-9

89-72-5
Aluminum, as Al soluble salts

Aluminum, as Al welding fumes

2-Aminopyridine

Ammonia

Ammonium chloride fume

Ammonium perfluorooctanoate

Ammonium sulfamate

n-Amyl acetate

sec-Amyl acetate

Aniline \& homologues

Anisidine (0-,p- isomers)

Antimony \& compounds as $\mathrm{Sb}$

Antimony trioxide, as $\mathrm{Sb}$

Arsine

Asphalt (petroleum) fumes

Atrazine

Azinphos-methyl

Barium, soluble compounds Ba

Benomyl

Benzotrichloride

Benzoyl Peroxide

Benzyl chloride

Biphenyl

Bismuth telluride

Bismuth telluride Se doped

Borates, anhydrous

Borates, decahydrate

Borates, pentahydrate

Boron oxide

Boron tribromide

Boron trifluoride

Bromacil

Bromine

Bromine pentafluoride

Butane

2-Butoxyethanol

n-Butyl acetate

sec-Butyl acetate

tert-Butyl acetate

Butyl acrylate

n-Butyl alcohol

sec-Butyl alcohol

tert-Butyl alcohol

tert-Butyl chromate, as $\mathrm{CrO} 3$

n-Butyl glycidyl ether (BGE)

n-Butyl lactate

n-Butyl mercaptan

n-Butylamine

o-sec-Butylphenol
6.7

17

6.3

100

33

0.33

33

1800

2200

1.0

1.7

1.7

0.53

17

17

0.67

1.7

33

17

17

4.3

33

17

3.3

17

3.3

33

9.3

33

2.2

2.4

6300.0

400

2400

3200

3200

170

500

1000

1000

0.33

440

83

6.0

50.0

100 
Appendix D - Constraints Definitions

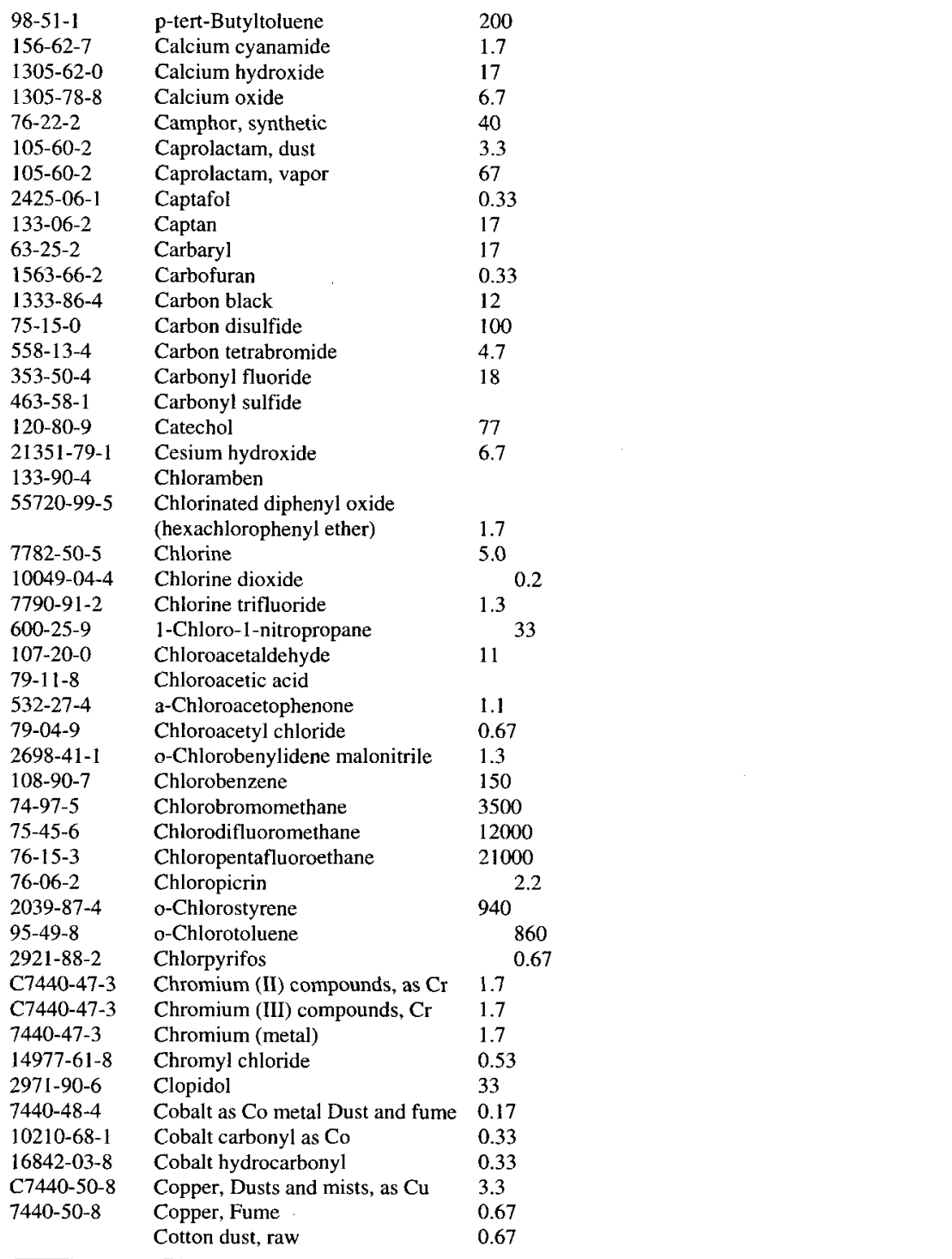


Appendix D - Constraints Definitions

\begin{tabular}{|c|c|c|}
\hline $1319-77-3$ & Cresol, all isomers & 73 \\
\hline $4170-30-3$ & Crotonaldehyde & 20 \\
\hline $299-86-5$ & Crufomate & 17 \\
\hline $98-82-2$ & Cumene & 820 \\
\hline $420-04-2$ & Cyanamide & 6.7 \\
\hline $5 !-12-5$ & Cyanides, as $\mathrm{CN}$ & 17 \\
\hline $460-19-5$ & Cyanogen & 67 \\
\hline $506-77-4$ & Cyanogen chloride & 2.5 \\
\hline $110-82-7$ & Cyclohexane & 3400 \\
\hline $108-93-0$ & Cyclohexanol & 690 \\
\hline $108-94-1$ & Cyclohexanone & 330 \\
\hline $110-83-8$ & Cyclohexene & 3400 \\
\hline $108-91-8$ & Cyclohexylamine & 140 \\
\hline $121-82-4$ & Cyclonite & 5.0 \\
\hline $542-92-7$ & Cyclopentadiene & 680 \\
\hline $287-92-3$ & Cyclopentane & 5700 \\
\hline $13121-70-5$ & Cyhexatin & 17 \\
\hline $17702-41-9$ & Decaborane & 0.83 \\
\hline $8065-48-3$ & Demeton & 0.37 \\
\hline $123-42-2$ & Diacetone alcohol & 790 \\
\hline $333-41-5$ & Diazinon & 0.33 \\
\hline $334-88-3$ & Diazomethane & 1.1 \\
\hline $19287-45-7$ & Diborane & 0.37 \\
\hline $96-12-8$ & 1,2-Dibromo-3-chloropropane & 0.20 \\
\hline $107-66-4$ & Dibutyl phosphate & 29 \\
\hline $84-74-2$ & Dibutyl phthalate & 17 \\
\hline $102-81-8$ & 2-N-Dibutylaminoethanol & 47 \\
\hline $594-72-9$ & 1,1-Dichloro-1-nitroethane & 40 \\
\hline \multirow[t]{2}{*}{$118-52-5$} & 1,3-Dichloro-5,5- & \\
\hline & Dimethyl hydantoin & 0.67 \\
\hline $7572-29-4$ & Dichloroacetylene & 1.3 \\
\hline \multirow[t]{2}{*}{$95-50-1$} & o-Dichlorobenzene & \\
\hline & (1,2-Dichlorobenzene) & 1000 \\
\hline $75-71-8$ & Dichlorodifluoromethane & 16000 \\
\hline $75-34-3$ & 1,1-Dichloroethane & 2700 \\
\hline $540-59-0$ & 1,2-Dichloroethylene & 2600 \\
\hline $75-43-4$ & Dichlorofluoromethane & 130 \\
\hline $542-75-6$ & Dichloropropene & 20 \\
\hline $75-99-0$ & 2,2-Dichloropropionic acid & 19 \\
\hline $76-14-2$ & Dichlorotetrafluoroethane & 23000 \\
\hline $62-73-7$ & Dichlorvas & 3.3 \\
\hline $141-66-2$ & Dicrotophos & 0.83 \\
\hline $77-73-6$ & Dicyclopentadiene & 100 \\
\hline $102-54-5$ & Dicyclopentadienyl iron & 33 \\
\hline $111-42-2$ & Diethanolamine & 43 \\
\hline $96-22-0$ & Diethyl ketone & 2300 \\
\hline $84-66-2$ & Diethyl phthalate & 17 \\
\hline $64-67-5$ & Diethyl sulfate & \\
\hline $109-89-7$ & Diethylamine & 100 \\
\hline
\end{tabular}


Appendix D - Constraints Definitions

\begin{tabular}{|c|c|c|}
\hline $100-37-8$ & Diethylaminoethanol & 170 \\
\hline $111-40-0$ & Diethylene triamine & 14 \\
\hline $75-61-6$ & Difluorodibromomethane & 2900 \\
\hline $2238-07-5$ & Diglycidyl ether & 1.7 \\
\hline $108-83-8$ & Diisobutyl ketone & 480 \\
\hline $108-18-9$ & Diisopropylamine & 67 \\
\hline $127-19-5$ & Dimethyl acetamide & 120 \\
\hline $60-11-7$ & Dimethyl aminoazobenzene & \\
\hline $79-44-7$ & Dimethyl carbamoyl chloride & \\
\hline $124-40-3$ & Dimethylamine & 60 \\
\hline $121-69-7$ & Dimethylaniline & 83 \\
\hline $68-12-2$ & Dimethylformamide & 30 \\
\hline $57-14-7$ & 1,1-Dimethylhydrazine & 4.0 \\
\hline $131-11-3$ & Dimethylphthalate & 17 \\
\hline $148-01-6$ & Dinitolmide & 17 \\
\hline $534-52-1$ & Dinitro-o-cresol & 0.67 \\
\hline $528-29-0$ & Dinitrobenzene, all isomers & 3.3 \\
\hline $51-28-5$ & 2,4-Dinitrophenol & \\
\hline $121-14-2$ & 2,4-Dinitrotoluene & 5.0 \\
\hline $78-34-2$ & Dioxathion & 0.67 \\
\hline $122-39-4$ & Diphenylamine & 33 \\
\hline $123-19-3$ & Dipropyl ketone & 780 \\
\hline $34590-94-8$ & $\begin{array}{l}\text { Dipropylene glycol } \\
\text { methyl ether }\end{array}$ & 2000 \\
\hline $85-00-7$ & Diquat & 1.7 \\
\hline $97-77-8$ & Disulfiram & 6.7 \\
\hline $298-04-4$ & Disulfuton & 0.33 \\
\hline $128-37-0$ & 2,6-Ditert. butyl-p-cresol & 33 \\
\hline $330-54-1$ & Diuron & 33 \\
\hline $1321-74-0$ & Divinyl benzene & 180 \\
\hline $2104-64-5$ & EPN & 1.7 \\
\hline $115-29-7$ & Endosulfan & 0.33 \\
\hline $72-20-8$ & Endrin & 0.33 \\
\hline $13838-16-9$ & Enflurane & 1900 \\
\hline $106-88-7$ & 1,2-Epoxybutane & 20 \\
\hline $141-43-5$ & Ethanolamine & 25 \\
\hline $563-12-2$ & Ethion & 1.3 \\
\hline $110-80-5$ & 2-Ethoxyethanol & 200 \\
\hline $111-15-9$ & 2-Ethoxyethyl acetate & 90 \\
\hline $141-78-6$ & Ethyl acetate & 4800 \\
\hline $140-88-5$ & Ethyl acrylate & 66 \\
\hline $64-17-5$ & Ethyl alcohol & 6300 \\
\hline $541-85-5$ & Ethyl amyl ketone & 440 \\
\hline $100-41-4$ & Ethyl benzene & 1000 \\
\hline $74-96-4$ & Ethyl bromide & 3000 \\
\hline $106-35-4$ & Ethyl butyl ketone & 780 \\
\hline $51-79-5$ & Ethyl carbamate & \\
\hline $75-00-3$ & Ethyl chloride & 10000 \\
\hline $60-29-7$ & Ethyl ether & 4000 \\
\hline
\end{tabular}


Appendix D - Constraints Definitions

\begin{tabular}{|c|c|c|}
\hline $109-94-4$ & Ethyl formate & 1000 \\
\hline $75-08-1$ & Ethyl mercaptan & 4.3 \\
\hline $78-10-4$ & Ethyl silicate & 280 \\
\hline $75-04-7$ & Ethylamine & 60 \\
\hline $107-07-3$ & Ethylene chlorohydrin & 11 \\
\hline $107-15-3$ & Ethylene diamine & 83 \\
\hline $107-21-1$ & Ethylene glycol & 420 \\
\hline $628-96-6$ & Ethylene glycol dinitrate & 1.0 \\
\hline $151-56-4$ & Ethylenimine & 2.9 \\
\hline $16219-75-3$ & Ethylidene norbornene & 83 \\
\hline $100-74-3$ & N-Ethylmorpholine & 77 \\
\hline $22224-92-6$ & Fenamiphos & 0.33 \\
\hline $115-90-2$ & Fensulfothion & 0.33 \\
\hline $55-38-9$ & Fenthion & 0.67 \\
\hline $14484-64-1$ & Ferbam & 33 \\
\hline \multirow[t]{3}{*}{$12604-58-9$} & Ferrovanadium dust & 3.3 \\
\hline & Fibrous glass dust & 33 \\
\hline & Fine mineral fibers & 33 \\
\hline $16984-48-8$ & Fluorides, as $\mathrm{F}$ & 8.3 \\
\hline $7782-41-4$ & Fluorine & 5.3 \\
\hline $944-22-9$ & Fonofos & 0.33 \\
\hline $75-12-7$ & Formamide & 60 \\
\hline $64-18-6$ & Formic acid & 31 \\
\hline $98-01-1$ & Furfural & 26 \\
\hline $98-00-1$ & Furfuryl alcohol & 130 \\
\hline $7782-65-2$ & Germanium tetrahydride & 2.1 \\
\hline $111-30-8$ & Glutaraldehyde & 2.5 \\
\hline \multirow[t]{2}{*}{$556-52-5$} & Glycidol & 250 \\
\hline & Glycol ethers & \\
\hline $7440-58-6$ & Hafnium & 1.7 \\
\hline $151-67-7$ & Halothane & 1300 \\
\hline $142-82-5$ & Heptane (n-Heptane) & 5500 \\
\hline $87-68-3$ & Hexachlorobutadiene & 0.70 \\
\hline $77-47-4$ & Hexachlorocyclopentadiene & 0.33 \\
\hline $67-72-1$ & Hexachloroethane & 32 \\
\hline $1335-87-1$ & Hexachloronaphthalene & 0.67 \\
\hline $684-16-2$ & Hexafluoroacetone & 2.3 \\
\hline $822-06-0$ & Hexamethylene diisocyanate & 0.11 \\
\hline \multirow[t]{2}{*}{$100-54-3$} & Hexane (n-Hexane) & 200 \\
\hline & Hexane, other isomers & 5900 \\
\hline $591-78-6$ & 2-Hexanone (MBK) & 67 \\
\hline $108-84-9$ & sec-Hexyl acetate & 980 \\
\hline $107-41-5$ & Hexylene glycol & 400 \\
\hline $10035-10-6$ & Hydrogen bromide & 33 \\
\hline $7647-01-0$ & Hydrogen chloride & 7.0 \\
\hline $74-90-8$ & Hydrogen cyanide & 37 \\
\hline $7664-39-3$ & Hydrogen fluoride, as F & 8.7 \\
\hline $7722-84-1$ & Hydrogen peroxide & 4.7 \\
\hline $7783-07-5$ & Hydrogen selenide, as Se & 0.53 \\
\hline
\end{tabular}


Appendix D - Constraints Definitions

\begin{tabular}{|c|c|c|}
\hline $7783-06-4$ & Hydrogen sulfide & 0.9 \\
\hline $123-31-9$ & Hydroquinone & 6.7 \\
\hline $999-61-1$ & 2-Hydroxypropyl acrylate & 9.3 \\
\hline $95-13-6$ & Indene & 160 \\
\hline C7440-74-6 & Indium, \& compounds as In & 0.33 \\
\hline $7553-56-2$ & Iodine & 3.3 \\
\hline $75-47-8$ & Iodoform & 33 \\
\hline $1309-37-1$ & Iron oxide fume, $\mathrm{Fe} 2 \mathrm{O} 3$ as $\mathrm{Fe}$ & 17 \\
\hline \multirow[t]{2}{*}{$13463-40-6$} & Iron pentacarbonyl, as $\mathrm{Fe}$ & 0.83 \\
\hline & Iron salts, soluble as Fe & 3.3 \\
\hline $123-92-2$ & Isoamyl acetate & 1700 \\
\hline $123-51-3$ & Isoamyl alcohol & 1200 \\
\hline $110-19-0$ & Isobutyl acetate & 2400 \\
\hline $78-83-1$ & Isobutyl alcohol & 510 \\
\hline $26952-21-6$ & Isocytl alcohol & 890 \\
\hline $78-59-1$ & Isophorone & 93 \\
\hline $4098-71-9$ & Isophorone disocyanate & \\
\hline $109-59-1$ & Isopropoxyethanol & 350 \\
\hline $108-21-4$ & Isopropyl acetate & 3500 \\
\hline $67-63-0$ & Isopropyl alcohol & 3300 \\
\hline $108-20-3$ & Isopropyl ether & 3500 \\
\hline $4016-14-2$ & Isopropyl glycidyl ether (IGE) & 790 \\
\hline $75-31-0$ & Isopropylamine & 40 \\
\hline $768-52-5$ & N-Isopropylaniline & 37 \\
\hline $463-51-4$ & Ketene & 2.9 \\
\hline $3687-31-8$ & Lead arsenate, as $\mathrm{Pb} 3(\mathrm{~A} 2 \mathrm{O} 4) 2$ & 0.50 \\
\hline $7758-97-6$ & Lead chromate, as $\mathrm{Cr}$ & 0.040 \\
\hline $68476-85-7$ & Liquified petroleum gas & 6000 \\
\hline $7580-67-8$ & Lithium hydride & 0.080 \\
\hline $1309-48-4$ & Magnesium oxide fume & 33 \\
\hline $121-75-5$ & Malathion & 33 \\
\hline $108-31-6$ & Maleic anhydride & 3.3 \\
\hline C7439-96-5 & Manganese dust \& compounds & 0.40 \\
\hline C7439-96-5 & Manganese fume & 3.3 \\
\hline $12079-65-1$ & $\begin{array}{l}\text { Manganese cyclopentadienyl } \\
\text { tricarbonyl }\end{array}$ & 0.33 \\
\hline C7439-97-6 & Mercury, Aryl \& inorganic cmpd & 0.33 \\
\hline C7439-97-6 & Mercury, as $\mathrm{Hg}$ Alkyl compounds & 0.33 \\
\hline C7439-97-6 & Mercury, vapors except alkyl & 0.17 \\
\hline $141-79-7$ & Mesityl oxide & 200 \\
\hline $79-41-4$ & Methacrylic acid & 230 \\
\hline $16752-77-5$ & Methomyl & 8.3 \\
\hline $72-43-5$ & Methoxychlor & 33 \\
\hline $109-86-4$ & 2-Methoxyethanol & 20 \\
\hline $110-49-6$ & 2-Methoxyethyl acetate & 80 \\
\hline $150-76-5$ & 4-Methoxyphenol & 17 \\
\hline $137-05-3$ & Methyl 2-cyanoacrylate & 30 \\
\hline $79-20-9$ & Methyl acetate & 2000 \\
\hline $74-99-7$ & Methyl acetylene & 5500 \\
\hline
\end{tabular}


Appendix D - Constraints Definitions

\begin{tabular}{|c|c|c|}
\hline $59355-75-8$ & $\begin{array}{l}\text { Methyl acetylene-propadiene } \\
\text { mixture (MAPP) }\end{array}$ & 5500 \\
\hline $96-33-3$ & Methyl acrylate & 120 \\
\hline $67-56-1$ & Methyl alcohol & 870 \\
\hline $100-61-8$ & N-Methyl aniline & 7.3 \\
\hline $74-83-9$ & Methyl bromide & 5.0 \\
\hline $74-87-3$ & Methyl chloride & 340 \\
\hline \multirow[t]{2}{*}{$71-55-6$} & Methyl chloroform & \\
\hline & (1,1,1-Trichloroethane) & 6400 \\
\hline $8022-00-2$ & Methyl demeton & 1.7 \\
\hline $78-93-3$ & Methyl ethyl ketone (MEK) & 1000 \\
\hline $1338-23-4$ & Methyl ethyl ketone peroxide & 5.0 \\
\hline $107-31-3$ & Methyl formate & 820 \\
\hline $60-34-4$ & Methyl hydrazine & 1.2 \\
\hline $74-88-4$ & Methyl iodide & 40 \\
\hline $110-12-3$ & Methyl isoamyl ketone & 780 \\
\hline $108-11-2$ & Methyl isobutyl carbinol & 350 \\
\hline $108-10-1$ & Methyl isobutyl ketone (MIBK) & 680 \\
\hline $624-83-9$ & Methyl isocyanate & 0.16 \\
\hline $563-80-4$ & Methyl isopropyl ketone & 2300 \\
\hline $74-93-1$ & Methyl mercaptan & 3.3 \\
\hline $80-62-6$ & Methyl methacrylate & 1400 \\
\hline $110-43-0$ & Methyl n-amyl ketone & 780 \\
\hline $591-78-6$ & Methyl n-butyl ketone & 67 \\
\hline $298-00-0$ & Methyl parathion & 0.67 \\
\hline $107-87-9$ & Methyl propyl ketone & 2300 \\
\hline $681-84-5$ & Methyl silicate & 20 \\
\hline $1634-04-4$ & Methyl tert-butyl ether & 500 \\
\hline $98-83-9$ & a-Methyl styrene & 810 \\
\hline $126-98-7$ & Methylacrylonitrile & 9.0 \\
\hline $109-87-5$ & Methylal & 10000 \\
\hline $74-89-5$ & Methylamine & 43 \\
\hline $108-87-2$ & Methylcyclohexane & 5400 \\
\hline $25639-42-3$ & Methylcyclohexanol & 780 \\
\hline $583-60-8$ & o-Methylcyclohexanone & 760 \\
\hline \multirow[t]{2}{*}{$12108-13-3$} & Methylcyclopentadienyl & \\
\hline & manganese tricarbonyl & 0.67 \\
\hline \multirow[t]{2}{*}{$5124-30-1$} & Methylene bis & \\
\hline & (4-cyclo-hexylisocyanate) & 0.18 \\
\hline $101-68-8$ & Methylene bis(phenyl isocyanate) & 0.2 \\
\hline $21087-64-9$ & Metribuzin & 17 \\
\hline $7786-34-7$ & Mevinphos & 0.33 \\
\hline C7439-98-7 & Molybdenum, as Mo soluble cpds & 17 \\
\hline C7439-98-7 & Molybdenum, insoluble cpds & 33 \\
\hline $6923-22-4$ & Monocrotophos & 0.83 \\
\hline $110-91-8$ & Morpholine & 240 \\
\hline $300-76-5$ & Naled & 10 \\
\hline $91-20-3$ & Napthalene & 170 \\
\hline $54-11-5$ & Nicotine & 1.7 \\
\hline
\end{tabular}


Appendix D - Constraints Definitions

\begin{tabular}{|c|c|c|}
\hline $1929-82-4$ & Nitrapyrin & 33 \\
\hline $7697-37-2$ & Nitric acid & 17 \\
\hline $10102-43-9$ & Nitric oxide & 100 \\
\hline $100-01-6$ & p-Nitroaniline & 10 \\
\hline $98-95-3$ & Nitrobenzene & 1.7 \\
\hline $100-00-5$ & p-Nitrochlorobenzene & 2.0 \\
\hline $79-24-3$ & Nitroethane & 1000 \\
\hline $7783-54-2$ & Nitrogen trifluoride & 97 \\
\hline $92-93-3$ & 4-Nitrobiphenyl & \\
\hline $55-63-0$ & Nitroglycerin & 1.5 \\
\hline $75-52-5$ & Nitromethane & 830 \\
\hline $100-02-7$ & 4-Nitrophenol & \\
\hline $108-03-2$ & 1-Nitropropane & 20 \\
\hline $684-93-5$ & $\mathrm{~N}-\mathrm{Nitroso}-\mathrm{N}$-methylurea & \\
\hline $88-72-2$ & Nitrotoluene & 37 \\
\hline $111-84-2$ & Nonane & 3500 \\
\hline 2234-13-1 & Octachloronaphthalene & 0.33 \\
\hline $111-65-9$ & Octane & 4700 \\
\hline $8012-95-1$ & Oil mist, mineral & 17 \\
\hline $20816-12-0$ & Osmium tetroxide, as Os & 0.0053 \\
\hline $144-62-7$ & Oxalic acid & 3.3 \\
\hline $7783-41-7$ & Oxygen difluoride & 0.37 \\
\hline $8002-74-2$ & Parafin wax fume & 6.7 \\
\hline $4685-14-7$ & Paraquat & 4.5 \\
\hline $56-38-2$ & Parathion & 0.33 \\
\hline $19624-22-7$ & Pentaborane & 0.043 \\
\hline $1321-64-8$ & Pentachloronaphthalene & 1.7 \\
\hline $82-68-8$ & $\begin{array}{l}\text { Pentachloronitrobenzene } \\
\text { (quintobenzene) }\end{array}$ & 1.7 \\
\hline $109-66-0$ & Pentane & 6000 \\
\hline $594-42-3$ & Perchloromethyl mercaptan & 2.5 \\
\hline $7616-94-6$ & Perchloryl fluoride & 43 \\
\hline $108-95-2$ & Phenol & 63 \\
\hline $92-84-2$ & Phenothiazine & 1.7 \\
\hline $101-84-8$ & Phenyl ether & 23 \\
\hline $122-60-1$ & Phenyl glycidyl ether & 2000 \\
\hline $108-98-5$ & Phenyl mercaptan & 7.7 \\
\hline $106-50-3$ & p-Phenylenediamine & 0.33 \\
\hline $100-63-0$ & Phenylhydrazine & 1.5 \\
\hline $638-21-1$ & Phenylphosphine & 0.77 \\
\hline $298-02-2$ & Phorate & 0.17 \\
\hline $75-44-5$ & Phosgene & 1.3 \\
\hline $7803-51-2$ & Phosphine & 1.3 \\
\hline $7664-38-2$ & Phosphoric acid & 3.3 \\
\hline $7723-14-0$ & Phosphorus & 0.33 \\
\hline $10025-87-3$ & Phosphorus oxychloride & 2.1 \\
\hline 10026-13-8 & Phosphorus pentachloride & 2.8 \\
\hline $1314-80-3$ & Phosphorus pentasulfide & 3.3 \\
\hline $7719-12-2$ & Phosphorus trichloride & 3.7 \\
\hline
\end{tabular}


Appendix D - Constraints Definitions

\begin{tabular}{|c|c|c|}
\hline $85-44-9$ & Phthalic anhydride & 20 \\
\hline $626-17-5$ & m-Phthalodinitrile & 17 \\
\hline 1918-02-1 & Picloram & 33 \\
\hline $88-89-1$ & Picric acid & 0.33 \\
\hline $83-26-1$ & Pindone & 0.033 \\
\hline $142-64-3$ & Piperazine dihydrochloride & 17 \\
\hline $7440-06-4$ & Platinum, Metal & 3.3 \\
\hline C7440-06-4 & Platinum, Soluble salts as $\mathrm{Pt}$ & 0.0067 \\
\hline $1310-58-3$ & Potassium hydroxide & 6.7 \\
\hline $107-19-7$ & Propargyl alcohol & 7.7 \\
\hline $57-57-8$ & B-Propiolactone & 5.0 \\
\hline $123-38-6$ & Propionaldehyde & \\
\hline $114-26-1$ & Propoxur & 1.7 \\
\hline $79-09-4$ & Propionic acid & 100 \\
\hline $109-60-4$ & n-Propyl acetate & 2800 \\
\hline $71-23-8$ & n-Propyl alcohol & 1600 \\
\hline $627-13-4$ & n-Propyl nitrate & 360 \\
\hline $6423-43-4$ & Propylene glycol dinitrate & 1.1 \\
\hline $107-98-2$ & Propylene glycol monomethyl eth & ther 2000 \\
\hline $75-55-8$ & Propylene imine & 16 \\
\hline $8003-34-7$ & Pyrethrum & 1.7 \\
\hline $110-86-1$ & Pyridine & 53 \\
\hline $91-22-5$ & Quinoline & \\
\hline $106-51-4$ & Quinone & 1.5 \\
\hline $108-46-3$ & Resorcinol & 150 \\
\hline $7440-16-6$ & Rhodium Metal & 3.3 \\
\hline C7440-16-6 & Rhodium, Insoluble compounds & 3.3 \\
\hline C7440-16-6 & Rhodium, Soluble compounds & 0.033 \\
\hline $299-84-3$ & Ronnel & 33 \\
\hline \multirow[t]{2}{*}{$83-79-4$} & Rotenone & 17 \\
\hline & Rubber solvent (Naphtha) & 5300 \\
\hline C7782-49-2 & Selenium compounds, as $\mathrm{Se}$ & 0.67 \\
\hline $7783-79-1$ & Selenium hexafluoride, as $\mathrm{Se}$ & 0.53 \\
\hline $136-78-7$ & Sesone & 33 \\
\hline $7803-62-5$ & Silicon tetrahydride & 22 \\
\hline $7440-22-4$ & Silver, Metal & 0.33 \\
\hline C7440-22-4 & Silver, soluble compounds as $\mathrm{Ag}$ & 0.033 \\
\hline $26628-22-8$ & Sodium azide & 1.0 \\
\hline $7631-90-5$ & Sodium bisulfite & 17 \\
\hline $62-74-8$ & Sodium fluoroacetate & 0.17 \\
\hline $1310-73-2$ & Sodium hydroxide & 6.7 \\
\hline $7681-57-4$ & Sodium metabisulfite & 17 \\
\hline $7803-52-3$ & Stibine & 1.7 \\
\hline $57-24-9$ & Strychnine & 0.5 \\
\hline $100-42-5$ & Styrene & 1000 \\
\hline $96-9-3$ & Styrene oxide & \\
\hline $1395-21-7$ & Subtilisins & 0.0002 \\
\hline $3689-24-5$ & Sulfotep & 0.67 \\
\hline $2551-62-4$ & Sulfur hexafluoride & 20000 \\
\hline
\end{tabular}


Appendix D - Constraints Definitions

\begin{tabular}{|c|c|c|}
\hline $10025-67-9$ & Sulfur monochloride & 18 \\
\hline $5714-22-7$ & Sulfur pentafluoride & 0.33 \\
\hline $7783-60-0$ & Sulfur tetrafluoride & 1.5 \\
\hline $7664-93-9$ & Sulfuric acid & 3.3 \\
\hline $2699-79-8$ & Sulfuryl fluoride & 67 \\
\hline $35400-43-2$ & Sulprofos & 3.3 \\
\hline $93-76-5$ & $2,4,5-\mathrm{T}$ & 33 \\
\hline $107-49-3$ & TEPP & 0.16 \\
\hline C7440-25-7 & Tantalum, metal \& oxide dusts & 17 \\
\hline C13494-80-9 & Tellurium \& compounds as $\mathrm{Te}$ & 0.33 \\
\hline $7783-80-4$ & Tellurium hexafluoride, as $\mathrm{Te}$ & 0.33 \\
\hline $3383-96-8$ & Temephos & 33 \\
\hline $26140-60-3$ & Terphenyls & 16 \\
\hline $76-12-0$ & 1,1,2,2-Tetrachloro- 1 , & \\
\hline & 2-difluoroethane & 14000 \\
\hline $76-11-9$ & 1,1,1,2-Tetrachloro-2, & \\
\hline & 2-difluoroethane & 14000 \\
\hline $79-34-5$ & 1,1,2,2-Tetrachloroethane & 23 \\
\hline $1335-88-2$ & Tetrachloronaphthalene & 6.7 \\
\hline $78-00-2$ & Tetraethyl lead, as $\mathrm{Pb}$ & 0.33 \\
\hline $109-99-9$ & Tetrahydrofuran & 2000 \\
\hline $75-74-1$ & Tetramethyl lead, as $\mathrm{Pb}$ & 0.5 \\
\hline $3333-52-6$ & Tetramethyl succinonitrile & 9.3 \\
\hline $509-14-8$ & Tetranitromethane & 27 \\
\hline $7722-88-5$ & Tetrasodium pyrophosphate & 17 \\
\hline $479-45-8$ & Tetryl & 5.0 \\
\hline C7440-28-0 & Thallium, soluble compounds, $\mathbf{T} 1$ & 0.33 \\
\hline $96-69-5$ & 4,4-Thiobis(6-tert, & \\
\hline & butyl-m-cresol) & 33 \\
\hline $68-11-1$ & Thioglycolic acid & 13 \\
\hline $7719-09-7$ & Thionyl chloride & 16 \\
\hline $137-26-8$ & Thiram & 3.3 \\
\hline $7440-31-5$ & Tin, Metal & 6.7 \\
\hline C7440-31-5 & Tin, Organic compounds, as $\mathrm{Sn}$ & 0.33 \\
\hline $7440-31-5$ & Tin, oxide \& inorganic & \\
\hline & except $\mathrm{SnH} 4$ & 6.7 \\
\hline $7550-45-0$ & Titanium tetrachloride & \\
\hline $108-88-3$ & Toluene & 400 \\
\hline $108-44-1$ & m-Toluidine & 29 \\
\hline $106-49-0$ & p-Toluidine & 29 \\
\hline $126-73-8$ & Tributyl phosphate & 7.3 \\
\hline $76-13-1$ & 1,1,2-Trichloro-1,2, & \\
\hline & 2-trifluorethane & 27000 \\
\hline $76-03-9$ & Trichloroacetic acid & 22 \\
\hline $120-82-1$ & 1,2,4-Trichlorobenzene & 120 \\
\hline $79-00-5$ & $1,1,2$-Trichloroethane & 180 \\
\hline $75-69-4$ & Trichlorofluoromethane & 19000 \\
\hline $1321-65-9$ & Trichloronaphthalene & 17 \\
\hline $95-95-4$ & 2,4,5-Trichlorophenol & \\
\hline
\end{tabular}




\begin{tabular}{|c|c|c|}
\hline $96-18-4$ & 1,2,3-Trichloropropane & 200 \\
\hline $121-44-8$ & Triethylamine & 7.0 \\
\hline $75-63-8$ & Trifluorobromomethane & 20000 \\
\hline 1582-09-8 & Trifluralin & \\
\hline $552-30-7$ & Trimellitic anhydride & 0.13 \\
\hline $2551-13-7$ & Trimethyl benzene & 420 \\
\hline $540-84-1$ & 2,2,4-Trimethylpentane & \\
\hline $121-45-9$ & Trimethyl phosphite & 33 \\
\hline $75-50-3$ & Trimethylamine & 80 \\
\hline $118-96-7$ & 2,4,6-Trinitrotoluene & 1.7 \\
\hline $78-30-8$ & Triorthocresyl phosphate & 0.33 \\
\hline $603-34-9$ & Triphenyl amine & 17 \\
\hline $115-86-6$ & Triphenyl phosphate & 10 \\
\hline C7440-33-7 & Tungsten, Insoluble compounds & 17 \\
\hline C 7440-33-7 & Tungsten, Soluble compounds & 3.3 \\
\hline $8006-64-2$ & Turpentine & 1900 \\
\hline C7440-61-1 & Uranium, insoluble \& soluble & 0.67 \\
\hline $8032-32-4$ & VM \& P Naphtha & 4600 \\
\hline $110-62-3$ & n-Valeraldehyde & 590 \\
\hline $1314-62-1$ & Vanadium, as V2O5 & 0.17 \\
\hline $108-05-4$ & Vinyl acetate & 200 \\
\hline $593-60-2$ & Vinyl bromide & 73 \\
\hline $106-87-6$ & Vinyl cyclohexene dioxide & 200 \\
\hline $75-35-4$ & Vinylidene chloride & 67 \\
\hline $25013-15-4$ & Vinyl toluene & 800 \\
\hline \multirow[t]{2}{*}{$81-81-2$} & Warfarin & 0.33 \\
\hline & Welding fumes & 17 \\
\hline $1477-55-0$ & m-Xylene a,a"-diamine & 0.33 \\
\hline $1330-20-7$ & Xylenes (m-,o-,p-isomers) & 1500 \\
\hline $1300-73-8$ & Xylidine & 8.3 \\
\hline C7440-65-5 & Yttrium, metal and cpds as $Y$ & 3.3 \\
\hline $7646-85-7$ & Zinc chloride fume & 3.3 \\
\hline $13530-65-9$ & Zinc chromates & 0.033 \\
\hline $1314-13-2$ & Zinc oxide, fume & 17 \\
\hline C7440-67-7 & Zirconium compounds, as $\mathrm{Zr}$ & 17 \\
\hline
\end{tabular}

\section{WAC173-480-040}

Emissions of radionuclides in the air shall not cause a maximum accumulated dose equivalent of more than $25 \mathrm{mrem} / \mathrm{yr}$ to the whole body or $75 \mathrm{mrem} / \mathrm{yr}$ to a critical organ of any member of the public. Doses due to radon-220, radon-222, and their respective decay products are excluded from these limits. Compliance with the standard shall be determined by procedures in WAC 173-480-070.

\section{WAC173-480-060}

Emission standards for new and modified emission units. 
(1) Whenever the construction, installation or establishment of a new emission unit subject to this chapter is contemplated, the project shall utilize best available radionuclide control technology (BARCT).

(2) Addition to, enlargement, modification, replacement, alteration of any process or emission unit or replacement of air pollution control equipment which will significantly change potential radionuclide emissions or significantly change the dose equivalent will require the proposed project to utilize best available radionuclide control technology (BARCT) for emission control.

[Statutory Authority: RCW 70.94.331. 86-10-053 (Order 86-04), 173-480-060, filed 5/7/86.]

\section{WAC173-480-070}

Emission monitoring and compliance procedures.

(1) The procedures specified in chapter 402-80 WAC shall be used to determine compliance with the standard. Radionuclide emissions shall be determined and dose equivalents to members of the public shall be calculated using department of social and health services approved sampling procedures, department of social and health services approved models, or other procedures, including those based on environmental measurements that department of social and health services has determined to be suitable.

(2) Compliance with this standard shall be determined by calculating, the dose to members of the public at the point of maximum annual air concentration in an unrestricted area where any member of the public may be.

[Statutory Authority: RCW 70.94.331. 86-10-053 (Order 86-04), 173-480-070, filed 5/7/86.]

\section{WAC246-220-007}

Statement of philosophy. In accordance with the recommendations of the Environmental Protection Agency, formerly the Federal Radiation Council, approved by the president of the United States of America, persons engaged in activities under licenses issued by the Washington state department of health pursuant to the Atomic Energy Act of 1954, as amended, shall, in addition to complying with the requirements set forth in chapter 246-221 WAC, make every reasonable effort to maintain radiation exposures, and releases of radioactive materials in effluents to unrestricted areas, as low as is reasonably achievable. Such persons should make particular efforts to keep the radiation exposure of an embryo or fetus as low as is reasonably achievable during the entire gestation period as recommended by the National Council on Radiation Protection and Measurements. The term "as low as is reasonably achievable" means making every reasonable effort to maintain exposures to radiation as far below the dose limits in these regulations as is practical, consistent with the purpose for which the licensed or registered activity is undertaken, taking, into account the state of technology, the economics of improvements in relation to the state of technology, the economics of improvements in relation to benefits to the public health and safety, and other socioeconomic considerations, and in relation to the utilization of nuclear energy, ionization radiation, and radioactive materials in the public interest.

[Statutory Authority: RCW 70.98.050. 94-01-073, 246-220-007, filed 12/9/93, effective 1/9/94. Statutory Authority: RCW 70.98.050 and 70.98.080.91-15-112 91-15-112 (Order 184), 246-220-007, filed 7/24/91, effective 8/24/91. Statutory Authority: RCW 43.70.040. 91-02-049 (Order 121), recodified 
as 246-220-007, filed 12/27/90, effective 1/31/91. Statutory Authority: RCW 70.98.050. 81-01-011 (order 1570), 402-10-010, filed 12/8/80; Order 1095, 402-10-010, filed 2/6/76.]

\section{WAC246-247 Radiation Protection - Air Emissions}

Contractor monitoring, collecting, and reporting of airborne radionuclide emissions shall be performed in accordance with procedures established by this Code.

\section{WAC246-247-001}

WAC 246-247-001 Purpose.

The purpose of this chapter is to establish application requirements and procedures for the issuance of a radioactive air emissions license and for the regulation of those emissions by the department of health (hereinafter referred to as "the department") to assure compliance with the standards for radioactive air emissions set by the department of ecology pursuant to RCW 70.94.331, promulgated in chapter $<D<12290>>173-480<\mathrm{D}>$ WAC, and with the rules and regulations of this chapter.

\section{WAC246-247-002}

WAC 246-247-002 Authority.

(1) Rules and regulations set forth herein are adopted and enforced by the department pursuant to the provisions of chapter $70.98 \mathrm{RCW}$ which:

(a) Designate the department as the state's radiation control agency having sole responsibility for the administration of the regulatory, licensing, and radiation control provisions of chapter $70.98 \mathrm{RCW}$;

(b) Vest in the department the authority to formulate, adopt, promulgate, and repeal codes, rules, and regulations related to the control of sources of ionizing radiation;

(c) Authorize the department to implement an independent state-wide program to monitor radioactive air emissions from sources within the state;

(d) Authorize the department to conduct inspections of facilities, both private and public, to determine whether or not there is compliance with or violation of the provisions of chapter $70.98 \mathrm{RCW}$ and rules and regulations issued thereunder; and

(e) Authorize the department to require registration of sources of ionizing radiation.

(2) In addition, RCW 70.94.422 (Washington Clean Air Act) grants to the department the enforcement powers contained in that chapter.

\section{WAC246-247-010}

WAC 246-247-010 Applicability.

(1) The standards and requirements of this chapter apply state-wide at the following types of facilities that emit radionuclides to the air:

(a) Facilities licensed by the department or by the United States Nuclear Regulatory Commission (NRC); 
(b) United States Department of Energy (DOE) facilities;

(c) Non-DOE federal facilities;

(d) Uranium fuel cycle facilities;

(e) Uranium mills that are processing material; and

(f) Any other facility that the department determines emits or has the potential to emit radionuclides to the ambient air.

(2) The standards and requirements of this chapter apply to point sources, nonpoint sources, and fugitive emissions.

(3) The standards and requirements of this chapter apply to stationary and mobile emission units, whether temporary or permanent.

(4) The control technology standards and requirements of this chapter apply to the abatement technology and indication devices of facilities and emission units subject to this chapter. Control technology requirements apply from entry of radionuclides into the ventilated vapor space to the point of release to the environment.

(5) In accordance with RCW 70.94.161(10), air operating permits issued under chapter $\langle\mathrm{D}<12020\rangle\rangle$ $173-401</ \mathrm{D}>$ WAC shall incorporate all applicable requirements of this chapter. Therefore, all facilities listed in subsection (1) of this section that are also subject to the operating permit regulations in chapter $<\mathrm{D}<12020>>173-401</ \mathrm{D}>$ WAC shall be considered in compliance with the requirements of this chapter if they comply with all the applicable requirements of the air operating permit issued under chapter $<\mathrm{D}<12020>>173-401<\mathrm{D}>$ WAC. These applicable requirements shall be contained in the radioactive air emissions license which shall be incorporated as part of the air operating permit. In accordance with RCW 70.94.422(1), the department shall enforce all the requirements contained in the radioactive air emissions license.

(6) Should any of the federal regulations that have been adopted by reference in this chapter be rescinded, the affected facilities shall nonetheless comply with all other applicable requirements of this chapter.

(7) An applicant may obtain a copy of any document referenced in this chapter by contacting the department's division of radiation protection, air emissions and defense wastes section at (206) 586-5504. Mail reports, applications, and other written correspondence to the Air Emissions and Defense Wastes Section at Airdustrial Park, Building 5, P.O. Box 47827, Olympia, Washington, 98504-7827.

\section{WAC246-247-020}

WAC 246-247-020 Exemptions.

(1) The following types of facilities or sources of radiation are exempt from the requirements of this chapter because they release no airborne radioactivity, or they prima facie comply with the standards in $\mathrm{WAC}<\mathrm{D}<17754>>246-247-040</ \mathrm{D}>$, or they are already adequately regulated under other requirements:

(a) Users of only sealed sources;

(b) Sealed sources;

(c) Accelerators less than $200 \mathrm{MeV}$;

(d) Nuclear-powered vessels underway or moored dockside unless under a maintenance condition with a potential-to-emit;

(e) Uranium mill tailings piles disposed of under 40 CFR Part 192.

(2) Exemption determinations.

(a) Any exemptions shall be consistent with 40 CFR 61 . No exemptions from the standards in WAC $<\mathrm{D}<17754>>246-247-040<$ D $>$ will be granted. 
(b) A nonfederal facility may request exemption from some of the requirements of WAC $<\mathrm{D}<17755>>$ 246-247-060 </D $>$ and $<\mathrm{D}<17757>>246-247-075<$ D $>$ if the potential-to-emit, for the emission unit(s) under consideration, results in compliance at level $\mathbf{I}$ of the COMPLY computer code or level I of the NCRP' 's Commentary No. 3, or equivalent as approved by the department.

(c) A federal facility may request exemption from some of the requirements of WAC $<\mathrm{D}<17755>>$ 246-247-060 </D $>$ and $<\mathrm{D}<17757>>246-247-075<$ D $>$ if the potential-to-emit, for the emission unit(s) under consideration, results in a TEDE to the MEI from all pathways less than $0.1 \mathrm{mrem} / \mathrm{yr}$.

(d) The facility shall submit all the data necessary to make the exemption determinations of (b) and (c) of this subsection. The department shall determine if any exemptions apply.

(e) Commercial nuclear power plants may request exemption from some of the requirements of this chapter in order to minimize dual regulation with the NRC.

(3) The department may require a facility with exempt emission units to submit a radioactive air emissions report to confirm compliance with applicable standards. The department reserves the right to conduct inspections and audits of the facility to confirm the status of its exempt emission units.

(4) Naturally occurring airborne radionuclides are exempt from the requirements of this chapter unless the concentrations or rates of emissions have been enhanced by industrial processes.

\section{WAC246-247-030}

WAC 246-247-030 Definitions.

Terms used in this chapter have the definitions set forth below with reference to radioactive air emissions.

(1) "Abatement technology" means any mechanism, process or method that has the potential to reduce public exposure to radioactive air emissions. Abatement control features include automatic mechanisms and administrative controls used in the operation and control of abatement technology from entry of radionuclides into the ventilated vapor space to release to the environment.

(2) "Administrative control" means any policy or procedure that limits the emission of radionuclides.

(3) "ALARA" means as low as reasonably achievable making every reasonable effort to maintain exposures to radiation as far below the dose standards in this chapter as is practical, consistent with the purpose for which the licensed activity is undertaken, taking into account the state of technology, the economics of improvements in relation to the state of technology, the economics of improvements in relation to benefits to the public health and safety, and other socioeconomic considerations, and in relation to the utilization of nuclear energy, ionizing radiation, and radioactive materials in the public interest. See WAC $<\mathrm{D}<17499>>246-220-007</ \mathrm{D}>$.

(4) "As low as reasonably achievable control technology" (ALARACT) means the use of radionuclide emission control technology that achieves emission levels that are consistent with the philosophy of ALARA. ALARACT compliance is demonstrated by evaluating the existing control system and proposed nonsignificant modifications in relation to applicable technology standards and other control technologies operated successfully in similar applications. In no event shall application of ALARACT result in emissions of radionuclides that could cause exceedance of the applicable standards of WAC $<\mathrm{D}<17754>>246-247-040<\mathrm{D}>$. See the definition of ALARA in this section. Note that ALARACT is equivalent to, but replaces, RACT in the May 7, 1986, version of chapter $<\mathrm{D}<12290>>173-480</ \mathrm{D}\rangle$ WAC.

(5) "Annual possession quantity" means the sum of the quantity of a radionuclide on hand at the beginning of the calendar year and the quantity of that radionuclide received or produced during the calendar year.

(6) "Best available radionuclide control technology" (BARCT) means technology that will result in a 
radionuclide emission limitation based on the maximum degree of reduction for radionuclides from any proposed newly constructed or significantly modified emission units that the licensing authority determines is achievable on a case-by-case basis. A BARCT compliance demonstration must consider energy, environmental, and economic impacts, and other costs through examination of production processes, and available methods, systems, and techniques for the control of radionuclide emissions. A BARCT compliance demonstration is the conclusion of an evaluative process that results in the selection of the most effective control technology from all known feasible alternatives. In no event shall application of BARCT result in emissions of radionuclides that could exceed the applicable standards of WAC $<$ D $<17754>>246-247-040</ D>$. Control technology that meets BARCT requirements also meets ALARACT requirements. See WAC $<D<12293>>173-480-030<D>$ and $<D<17762>>246-247-120$ $</ \mathrm{D}>$.

(7) "Committed effective dose equivalent" (CEDE) means the sum of the products of absorbed dose from internally deposited radionuclides and appropriate factors to account for differences in biological effectiveness due to the quality of radiation and its distribution in the body of reference man over a fifty-year period.

(8) "Construction" means fabrication, erection, or installation of a new building, structure, plant, process, or operation within a facility that has the potential to emit airborne radionuclides. Construction includes activities of a permanent nature aimed at completion of the emission unit, such as pouring concrete, putting in a foundation, or installing utilities directly related to the emission unit. It does not include preliminary activities such as tests to determine site suitability, equipment procurement and storage, site clearing and grading, and the construction of ancillary buildings.

(9) "Decommissioning" means actions taken to reduce or eliminate the potential public health and safety impacts of a building, structure, or plant that has permanently ceased operations, including, but not limited to, actions such as decontamination, demolition, and disposition.

(10) "Emission unit" means any single location that emits or has the potential to emit airborne radioactive material. This may be a point source, nonpoint source, or source of fugitive emissions.

(11) "Facility" means all buildings, structures, plants, processes, and operations on one contiguous site under control of the same owner or operator.

(12) "Fugitive emissions" are radioactive air emissions which do not and could not reasonably pass through a stack, vent, or other functionally equivalent structure, and which are not feasible to directly measure and quantify.

(13) "Indication device" means any method or apparatus used to monitor, or to enable monitoring, the operation of abatement controls or the potential or actual radioactive air emissions.

(14) "License" means a radioactive air emissions license, either issued by the department or incorporated by the department as an applicable portion of an air operating permit issued by the department of ecology or a local air pollution control authority, with requirements and limitations listed therein to which the licensed or permitted party must comply. Compliance with the license requirements shall be determined and enforced by the department.

(15) "Maximally exposed individual" (MEI) means any member of the public (real or hypothetical) who abides or resides in an unrestricted area, and may receive the highest TEDE from the emission unit(s) under consideration, taking into account all exposure pathways affected by the radioactive air emissions.

(16) "Modification" means any physical change in, or change in the method of operation of, an emission unit that could increase the amount of radioactive materials emitted or may result in the emission of any radionuclide not previously emitted. This definition includes the cleanup of land contaminated with radioactive material, the decommissioning of buildings, structures, or plants where radioactive contamination exists, and changes that will cause an increase in the emission unit"s operating design capacity. This definition excludes routine maintenance, routine repair, replacement-in-kind, any increases in the production rate or hours of operation, provided the emission unit does not exceed the release quantities specified in the license application or the operating design capacity approved by the 
department, addition of abatement technology as long as it is not less environmentally beneficial than existing, approved controls, and changes that result in an increase in the quantity of emissions of an existing radionuclide that will be offset by an equal or greater decrease in the quantity of emissions of another radionuclide that is deemed at least as hazardous with regard to its TEDE to the MEI.

(17) "Monitoring" means the measurement of radioactive material released to the ambient air by means of an in-line radiation detector, and/or by the withdrawal of representative samples from the effluent stream. Ambient air measurements may be acceptable for nonpoint sources and fugitive emissions.

(18) "Nonpoint source" is a location at which radioactive air emissions originate from an area, such as contaminated ground above a near-surface waste disposal unit, whose extent may or may not be well-defined.

(19) "Notice of construction" (NOC) is an application submitted to the department by an applicant that contains information required by WAC $<\mathrm{D}<17755>>246-247-060</ \mathrm{D}>$ for proposed construction or modification of a registered emission unit(s), or for modification of an existing, unregistered emission unit(s).

(20) "Point source" is a discrete, well-defined location from which radioactive air emissions originate, such as a stack, vent, or other functionally equivalent structure.

(21) "Potential-to-emit" means the rate of release of radionuclides from an emission unit based on the actual or potential discharge of the effluent stream that would result if all abatement control equipment did not exist, but operations are otherwise normal. Determine the potential-to-emit by one of the following methods:

(a) Multiply the annual possession quantity of each radionuclide by the release fraction for that radionuclide, depending on its physical state. Use the following release fractions:

(i) 1 for gases;

(ii) $10^{\wedge}-3$ for liquids or particulate solids; and

(iii) $10^{\wedge}-6$ for solids.

Determine the physical state for each radionuclide by considering its chemical form and the highest temperature to which it is subjected. Use a release fraction of one if the radionuclide is subjected to temperatures at or above its boiling point; use a release fraction of $10^{\wedge}-3$ if the radionuclide is subjected to temperatures at or above its melting point, but below its boiling point. If the chemical form is not known, use a release fraction of one for any radionuclide that is heated to a temperature of one hundred degrees Celsius or more, boils at a temperature of one hundred degrees Celsius or less, or is intentionally dispersed into the environment. Other release fractions may be used only with the department"'s approval; or

(b) Perform a back-calculation using measured emission rates and in situ measurements of the control equipment efficiencies, as approved by the department; or

(c) Measure the quantities of radionuclides captured in each control device, coupled with in situ measurements of the control equipment efficiencies, as approved by the department; or

(d) Sample the effluent upstream from all control devices, as approved by the department; or

(e) Use an alternative method approved by the department.

(22) "Replacement-in-kind" means the substitution of existing systems, equipment, components, or devices of an emission unit"'s control technology with systems, equipment, components, or devices with equivalent, or better, performance specifications that will perform the same function(s).

(23) "Routine" means:

(a) Maintenance, repair, or replacement-in-kind performed on systems, equipment, components, or devices of an emission unit"'s abatement technology as a planned part of an established inspection, maintenance, or quality assurance program that does not increase the emission unit"s operating design capacity; or

(b) Normal, day-to-day operations of a facility.

(24) "Sealed source" means radioactive material that is permanently bonded or fixed in a capsule or 
matrix, or radioactive material in airtight containers, designed to prevent release and dispersal of the radioactive material under the most severe conditions encountered in normal use and handling.

(25) "Significant" means the potential-to-emit airborne radioactivity at a rate that could increase the TEDE to the MEI by at least $1.0 \mathrm{mrem} / \mathrm{yr}$ as a result of a proposed modification.

(26) "Total effective dose equivalent" (TEDE) means the sum of the dose equivalent due to external exposures and the CEDE due to internal exposures.

(27) "Uranium fuel cycle" means the operations of milling uranium ore, chemical conversion of uranium, isotopic enrichment of uranium, fabrication of uranium fuel, generation of electricity in a nuclear power plant that uses uranium fuel, and reprocessing of spent uranium fuel, to the extent that these operations solely support the production of electrical power for public use. Excluded are mining operations, waste disposal sites, transportation of any radioactive material, and the reuse of recovered nonuranium special nuclear and by-product materials from the cycle.

\section{WAC246-247-040}

WAC 246-247-040 Standards.

(1) Standards for radioactive air emissions in the state of Washington are contained in WAC $<\mathrm{D}<12294>>173-480-040<\mathrm{D}>,<\mathrm{D}<12295>>173-480-050</ \mathrm{D}>$, and $<\mathrm{D}<12296>>173-480-060$ $</ D>$ and in 40 CFR Part 61, subparts H and I published in the Federal Register on December 15, 1989. In accordance with WAC $<D<12295>>173-480-050</ D>(3)$, the department shall enforce the most stringent standard in effect, notwithstanding any agreement between EPA and any other agency, including those agreements made pursuant to 42 USC 7412(d)(9).

(2) In addition to the radioactive air emission standards of subsection (1) of this section, the department" s radioactive materials licensees shall comply with the limitations on radioactive air emissions contained in WAC $<\mathrm{D}<17524>>246-221-070</ \mathrm{D}>$.

(3) All new construction and significant modifications of emission units commenced after August 10, 1988 (the date this chapter originally became effective) shall utilize BARCT (see Appendix B).

(4) All existing emission units and nonsignificant modifications shall utilize ALARACT (see Appendix C).

(5) In order to implement these standards, the department may set limits on emission rates for specific radionuclides from specific emission units and/or set requirements and limitations on the operation of the emission unit(s) as specified in a license.

(6) All emissions of radionuclides, including those due to emergency conditions resulting from startup, shutdown, maintenance activities, or process upsets are subject to the standards of this section and, therefore, subject to the enforcement actions of WAC $<D<17760>>246-247-100</ D>$.

\section{WAC246-247-060}

WAC 246-247-060 Applications, registration and licensing.

This section describes the information requirements for approval to construct, modify, and operate an emission unit. Any notice of construction (NOC) requires the submittal of the information listed in Appendix A. Complex projects may require additional information. The applicant should contact the department early in the conceptual design phase for guidance on applicable control technologies to consider.

Appendices B and C outline the procedures to demonstrate compliance with the BARCT and 
ALARACT standards. Based on the Appendix A information provided, the department may advise the applicant which subset of technologies to consider as candidates for meeting BARCT or ALARACT requirements.

For those facilities subject to the operating permit regulations in chapter $\langle\mathrm{D}<12020\rangle>173-401<\mathrm{D}\rangle$ WAC, the radioactive air emissions license will be incorporated as an applicable portion of the air operating permit issued by the department of ecology or a local air pollution control authority. The department will be responsible for determining the facility" s compliance with and enforcing the requirements of the radioactive air emissions license.

(1) Requirements for new construction or modification of emission units.

(a) Early in the design phase, the applicant shall submit a NOC containing the information required in Appendix A.

(b) Within thirty days of receipt of the NOC, the department shall inform the applicant if additional information is required. The department may determine, on the basis of the information submitted, that the requirements of BARCT or ALARACT have been met, or may require the applicant to submit a BARCT or ALARACT demonstration compatible with Appendix B or C, respectively.

(c) Within sixty days of receipt of all required information, the department shall issue an approval or denial to construct. The department may require changes to the final proposed control technology.

(d) The applicant may request a phased approval process by so stating and submitting a limited application. The department may grant a conditional approval to construct for such activities as would not preclude the construction or installation of any control or monitoring equipment required after review of the completed application.

(e) The department shall issue a license, or amend an existing license, authorizing operation of the emission unit(s) when the proposed new construction or modification is complete. For facilities subject to the air operating permit requirements of chapter $\langle\mathrm{D}<12020>>173-401<\mathrm{D}\rangle$ WAC, the license shall become part of the air operating permit issued by the department of ecology or a local air pollution control authority. For new construction, this action shall constitute registration of the emission unit(s).

(2) Requirements for modification of unregistered emission units that are not exempt from these regulations.

(a) The applicant shall submit an application containing the information required in Appendix A.

(b) Within thirty days of receipt of the application, the department shall inform the applicant if additional information is required. The department may determine, on the basis of the information submitted, that the requirements of BARCT or ALARACT have been met, or may require the applicant to submit a BARCT or ALARACT demonstration compatible with Appendix B or C, respectively.

(c) Within sixty days of receipt of all required information, the department shall issue or amend the license. For facilities subject to the air operating permit requirements of chapter $<D<12020>>173-401$ $\angle$ D $>$ WAC, the license shall become part of the air operating permit issued by the department of ecology or a local air pollution control authority. This action shall constitute registration of the emission unit(s). A determination of noncompliance may result in the issuance of a notice of violation.

(d) The department reserves the right to require the owner of an existing, unregistered emission unit to make modifications necessary to comply with the applicable standards of WAC $<D<17754>>$ 246-247-040</D>.

(3) If an emission unit is in violation of any standards contained in WAC $<$ D $<17754>>246-247-040$ $\langle$ D $>$, the facility shall either submit a compliance plan which describes how it intends to achieve compliance with the standards, and/or cease operation of the emission unit(s). The facility shall submit the compliance plan within forty-five days of the notice of violation. The cessation of operation of the emission unit(s) shall not necessarily exempt the facility from the requirements of this chapter if active or passive ventilation and radioactive air emission controls will still be required. The department reserves the right to take further enforcement action, if necessary, in accordance with WAC $<\mathrm{D}<17760>>$ $246-247-100<$ /D $>$. 
(4) The facility shall notify the department at least seven calendar days prior to any planned preoperational tests of new or modified emission units that involve emissions control, monitoring, or containment systems of the emission unit(s). The department reserves the right to witness or require preoperational tests involving the emissions control, monitoring, or containment systems of the emission unit(s).

(5) The license shall specify the requirements and limitations of operation to assure compliance with this chapter. The facility shall comply with the requirements and limitations of the license.

(6) All radioactive air emissions licenses issued by the department, except those issued to radioactive materials licensees, shall have an expiration date of five years from date of issuance or as specified in the air operating permit. For radioactive material licensees, the requirements and limitations for the operation of emission units shall be incorporated into their radioactive materials license, and shall expire when the radioactive materials license expires.

(7) Each federal facility that comes under the authority of this chapter shall hold one license for each site, base, or installation. When applicable, the license shall be part of the facility"s air operating permit.

(8) Facilities may request a single categorical license which identifies limits and conditions of operation for similar multipurpose temporary and/or portable emission units. When applicable, the license shall be part of the facility"'s air operating permit.

(9) All facilities with licensed emission units, except for radioactive materials licensees, shall submit a request to the department for renewal of their radioactive air emissions license at least sixty days prior to expiration of the license or as required by the air operating permit. All renewal requests shall include a summary of the operational status of all emission units, the status of facility compliance with the standards of WAC $<D<17754>>246-247-040</ D>$, and the status of any corrective actions necessary to achieve compliance with the requirements of this chapter. Facilities with licensed emission units that also hold a radioactive materials license issued by the department shall submit this information along with their radioactive material license renewal submittal. If the department is unable to renew a radioactive air emissions license before its expiration date, the existing license, with all of its requirements and limitations, remains in force until the department either renews or revokes the license.

(10) For commercial nuclear power plants or any other thermal energy facility subject to chapter 80.50 RCW and to the requirements of this chapter, the radioactive air emissions license and amendments thereto shall be issued pursuant to a memorandum of agreement between the energy facility site evaluation council (EFSEC) and the department.

\section{WAC246-247-065}

WAC 246-247-065 Fees.

(I) All facilities under the authority of this chapter shall submit fees in accordance with WAC $<\mathrm{D}<17834>>246-254-160<\mathrm{D}>$.

(2) Those facilities required by WAC $<\mathrm{D}<17834>>246-254-160</ \mathrm{D}>(2)$ to submit an application fee, shall submit the fee with the application.

\section{WAC246-247-075}

WAC 246-247-075 Monitoring, testing and quality assurance.

(1) All radioactive air emissions monitoring, testing, and quality assurance requirements of 40 CFR 61 , Subparts $\mathrm{H}$ and I published in the Federal Register on December 15, 1989, are adopted by reference, as 
applicable as specified by the referenced subparts.

(2) Equipment and procedures used for the continuous monitoring of radioactive air emissions shall conform, as applicable, to the guidance contained in ANSI N13.1, ANSI N42.18, ANSI N323, ANSI N317, reference methods 1, 1A, 2, 2A, 2C, 2D, 4, 5, and 17 of 40 CFR Part 60, Appendix A, 40 CFR Part 52, Appendix $\mathrm{E}$, and any other methods approved by the department.

(3) The operator of an emission unit with a potential-to-emit of less than $0.1 \mathrm{mrem} / \mathrm{yr}$ TEDE to the MEI may estimate those radionuclide emissions, in lieu of monitoring, in accordance with 40 CFR 61 Appendix D, or other procedure approved by the department. The department may require periodic confirmatory measurements (e.g., grab samples) during routine operations to verify the low emissions. Methods to implement periodic confirmatory monitoring shall be approved by the department.

(4) The department may allow a facility to use alternative monitoring procedures or methods if continuous monitoring is not a feasible or reasonable requirement.

(5) The following types of facilities shall determine radionuclide emissions in accordance with either a methodology referenced in subsections (1) through (4) of this section or the respective document referenced below:

(a) Nuclear power reactors licensed by the NRC: Offsite Dose Calculation Manual;

(b) Fuel fabrication plants licensed by the NRC: NRC''s Regulatory Guide 4.16, dated December 1985;

(c) Uranium mills that are processing material: NRC'"s Regulatory Guide 4.14, dated April 1980.

(6) Licensed facilities shall conduct and document a quality assurance program. Except for those types of facilities specified in subsection (5) of this section, the quality assurance program shall be compatible with applicable national standards such as ANSVASME NQA-1-1988, ANSI/ASME NQA-2-1986, QAMS-004, and QAMS-005.

(7) Those types of facilities specified in subsection (5) of this section shall conduct and document a quality assurance program compatible with either the applicable national standards referenced in subsection (6) of this section or the NRC"'s Regulatory Guide 4.15, dated February 1979.

(8) Facilities shall monitor nonpoint and fugitive emissions of radioactive material.

(9) The department may conduct an environmental surveillance program to ensure that radiation doses to the public from emission units are in compliance with applicable standards. The department may require the operator of any emission unit to conduct stack sampling, ambient air monitoring, or other testing as necessary to demonstrate compliance with the standards in WAC $<D<17754>>246-247-040</ D>$.

(10) The department may require the owner or operator of an emission unit to make provision, at existing emission unit sampling stations, for the department to take split or collocated samples of the emissions.

(11) The planning for any proposed new construction or significant modification of the emission unit must address accidental releases with a probability of occurrence during the expected life of the emission unit of greater than one percent.

(12) All facilities must be able to demonstrate that appropriate supervisors and workers are adequately trained in the use and maintenance of emission control and monitoring systems, and in the performance of associated test and emergency response procedures.

(13) All facilities must be able to demonstrate the reliability and accuracy of the radioactive air emissions monitoring data.

\section{WAC246-247-080}

WAC 246-247-080 Inspections, reporting, and recordkeeping.

(1) The department reserves the right to inspect and audit all construction activities, equipment, operations, documents, data, and other records related to compliance with the requirements of this 
chapter. The department may require a demonstration of ALARACT at any time.

(2) All reporting and recordkeeping requirements of 40 CFR 61, Subparts $\mathbf{H}$ and I published in the Federal Register on December 15,1989, are adopted by reference, as applicable as specified by the referenced subparts.

(3) The facility shall annually submit to the department the information requirements adopted in subsection (2) of this section, as applicable, along with the following additional information, as applicable:

(a) The results of emission measurements for those emission units subject only to periodic confirmatory measurements;

(b) Wind rose or joint frequency table;

(c) Annual average ambient temperature;

(d) Annual average emission unit gas temperature, if available;

(e) Annual total rainfall;

(f) Annual average emission unit flow rate and total volume of air released during the calendar year.

If this additional information is available in another annual report, the facility may instead provide a copy of that report along with the information requirements in this subsection. Annual reports are due by June 30 for the previous calendar year"s operations.

(4) Any report or application that contains proprietary or procurement-sensitive information shall be submitted to the department with those portions so designated. The department shall hold this information confidential, unless required to release the information pursuant to laws, regulations, or court order.

(5) The facility shall notify the department within twenty-four hours of any shutdown, or of any transient abnormal condition lasting more than four hours or other change in facility operations which, if allowed to persist, would result in emissions of radioactive material in excess of applicable standards or license requirements. If requested by the department, the facility shall submit a written report within ten days including known causes, corrective actions taken, and any preventive measures taken or planned to minimize or eliminate the chance of recurrence.

(6) The facility shall file a report of closure with the department whenever operations producing emissions of radioactive material are permanently ceased at any emission unit (except temporary emission units) regulated under this chapter. The closure report shall indicate whether, despite cessation of operations, there is still a potential for radioactive air emissions and a need for an active or passive ventilation system with emission control and/or monitoring devices. If decommissioning is planned and will constitute a modification, a NOC is required, as applicable, in accordance with WAC $<\mathrm{D}<17755>>$ 246-247-060<اD>.

(7) The facility shall maintain a log for each emission unit that has received categorical approval under WAC $<\mathrm{D}<17755>>246-247-060</ \mathrm{D}>(8)$. The log shall contain records of important operations parameters including the date, location, and duration of the release, measured or calculated radionuclide concentrations, the type of emissions (liquid, gaseous, solid), and the type of emission control and monitoring equipment.

(8) The facility shall maintain readily retrievable storage areas for all records and documents related to, and which may help establish compliance with, the requirements of this chapter. The facility shall keep these records available for department inspection for at least five years.

(9) The facility shall ensure all emission units are fully accessible to department inspectors. In the event the hazards associated with accessibility to a unit require training and/or restrictions or requirements for entry, the facility owner or operator shall inform the department, prior to arrival, of those restrictions or requirements. The owner or operator shall be responsible for providing the necessary training, escorts, and support services to allow the department to inspect the facility.

(10) The facility shall make available, in a timely manner, all documents requested by the department for review. The facility shall allow the department to review documents in advance of an inspection. The 
facility shall allow access to classified documents by representatives of the department with the appropriate security clearance and a demonstrable need-to-know.

(11) The facility shall respond in writing in a timely manner, or within a time limit set by the department, toinspection results which require the facility to implement corrective actions or any other actions so directed by the department.

\section{WAC246-247-085}

W:AC 246-247-085 Compliance determination for existing emission units and facilities.

(1) All procedures for determining compliance with the dose equivalent standards of 40 CFR 61 , Subparts H and I published in the Federal Register on December 15, 1989, are adopted by reference, as applicable as specified by the referenced subparts.

(2) Facilities subject to 40 CFR 61 shall use computer codes or procedures approved by the EPA to determine the TEDE to the MEI; all other facilities shall use computer codes or procedures approved by the department.

(3) The determination of compliance with the dose equivalent standard of WAC $<\mathrm{D}<17754>>$ 246-247-040 $</ D>$ shall include all radioactive air emissions resulting from routine and nonroutine operations for the past calendar year.

\section{WAC246-247-100}

WAC 246-247-100 Enforcement actions.

(1) In accordance with RCW 70.94.422, the department may take any of the following actions to enforce compliance with the provisions of this chapter:

(a) Notice of violation and compliance order (RCW 70.94.332).

(b) Restraining order or temporary or permanent injunction (RCW 70.94.425; also RCW 70.98.140).

(c) Penalty: Fine and/or imprisonment (RCW 70.94.430).

(d) Civil penalty: Up to ten thousand dollars for each day of continued noncompliance (RCW 70.94.431 (1) through (7)).

(e) Assurance of discontinuance (RCW 70.94.435).

(2) The department, in accordance with RCW 70.98.050(4)(1), may issue subpoenas in order to compel attendance of witnesses and/or production of records or documents in connection with any adjudicative or other administrative proceeding.

(3) The department, in accordance with RCW 70.98.160, may impound sources of ionizing radiation.

(4) The secretary of the department, in accordance with RCW 43.70.190, is authorized to bring an action to prohibit a violation or a threatened violation of any department rules or regulation, or to bring any legal proceeding authorized by law to a county superior court.

(5) Any party, against which an enforcement action is brought by the department, has the right to submit an application for the adjudicative process in accordance with chapter $<\mathrm{D}<17183>>246-10<\mathrm{D}>$ WAC and chapter $34.05 \mathrm{RCW}$.

\section{Waste Form Technical Position - Cement Stabilization}

The NRC Waste Form Technical Position, rev 1 (NRC 1991) Appendix A shall be followed to the 
maximum extent that is reasonable, if cementitous materials are used to solidify and stabilize LLW.

\section{Waste Form Technical Position - Part 2: Stability of LLW}

The NRC Waste Form Technical Position, rev I (NRC 1991) Subpart C (2) shall be followed to the maximum extent that is reasonable for design, testing, and producing a stable waste form.

\section{Waste Form Technical Position - Part 3: Radiation Stability of Organic Resins}

The NRC Waste Form Technical Position, rev 1 (NRC 1991) Subpart C (3) shall be followed to the maximum extent that is reasonable, if disposing of organic ion-exchange resins.

\section{Waste Form Technical Position - Part 4: High Integrity Containers}

The NRC Waste Form Technical Position, rev 1 (NRC 1991) Subpart C (4) shall be followed to the maximum extent that is reasonable for design, testing, and producing high integrity LLW containers.

\section{Waste Form Technical Position - Part 5: Filter Cartridge Wastes}

The NRC Waste Form Technical Position, rev 1 (NRC 1991) Subpart C (5) shall be followed to the maximum extent that is reasonable, if disposing of filter cartridge wastes.

\section{Waste Form Technical Position - Part 6: Reporting Mishaps}

The NRC Waste Form Technical Position, rev 1 (NRC 1991) Subpart C (6) shall be followed to the maximum extent that is reasonable. The TWRS program will require mishap reporting in the spirit of Subpart C (6).

\section{Waste Form Technical Position, rev 1 (NRC 1991) Subpart C (6)}

6. Reporting of Mishaps

In all future reviews and approvals of stabilization media and high integrity containers, waste generators, vendors and processors will, as a condition of approval, be asked to commit to reporting any knowledge they may have of misuse or failure of their waste forms and containers. Such mishaps include, but are not necessarily limited to, the following:

a. The failure of high integrity containers used to ensure structural stability. Such failure may be evidenced by changed container, dimensions, cracking, or injury from mishandling (e.g., dropping or impacting against another object). 
b. The misuse of high integrity containers, as evidenced by $i$ quantity of free liquid greater than one percent of container volume, or an excessive void space within the container; (such use is in violation of 10 CFR 61.56(a)).

c. The production of a solidified Class 8 or $\mathrm{C}$ waste form that has any of the following characteristics;

1. greater than 0.5 percent volume of free liquid.

2. concentrations of radionuclides greater than the concentrations demonstrated to be stable in the waste form in qualification testing accepted by the regulatory agency.

3. greater or lessor amounts of solidification media than were used in qualification testing accepted by the regulatory agency.

4. contains chemical ingredients not present or accounted in qualification testing accepted by the regulatory agency.

5. shows instability evidenced by crumbling, cracking, spalling, voids, softening, disintegration, nonhomogeneity, or change in dimensions.

6. evidences processing phenomena that exceed the limiting processing conditions identified in applicable topical reports or process control programs, such as foaming, excessive temperature, premature or slow hardening, production of volatile material, etc.

Waste form mishaps should be reported to the NRC's Director of the Division of Low-Level Waste Management and Decommissioning and the designated State disposal site regulatory authority within 30 days of knowledge of the incident. For any such waste form mishap occurrence, the affected waste form should not be shipped off-site until approval is obtained from the disposal site regulatory authority. The reason for this ,is that the low-level waste generators and processors are required by 10 CFR 20.311 to certify that their waste forms meet all applicable requirements of $10 \mathrm{CFR}$ Part 61 , and waste forms that are subject to the types of mishaps mentioned above may not possess the required long-term structural stability. When mishaps of the nature described above occur, it is expected that, before the waste form is shipped to a disposal facility, either adequate mitigation of 'the potential effects on the waste form or an acceptable justification concerning the lack of any potential significant effects of the affected waste form on the overall performance of the disposal facility would be provided. 


\section{Worker Radiological Safety: Hanford Site Radiological Control Manual, Chapter 1, Part 1, Section 111 and Section 112}

PART I Department of Energy (DOE) Radiological Control Manual

Partl Hanford Site

Since 1992, the U.S. Department of Energy (DOE) Office of Health has been developing a comprehensive system of radiological control requirements and guidance that clearly defines the DOE objectives and expectations for radiological control activities throughout the DOE complex. These requirements and guidance address provisions of the Atomic Energy Act (as amended), the Price Anderson Amendments Act, and recommendations of the Defense Nuclear Facilities Safety Board. These requirements and guidance are organized into a hierarchy that includes policy, basic requirements (Rules and Orders), supplemental and complimentary information documents providing acceptable methods for implementation of basic requirements (Safety Guides and Implementation Guides), and detailed technical guidance (Technical Standards.)

The Radiological Health and Safety Policy provides the general framework for the conduct of radiological control activities throughout the DOE complex. Below the policy statement are both regulatory and contractual systems of basic requirements established through $10 \mathrm{CFR} 835$, which is enforced through a regulatory system established in $10 \mathrm{CFR} 820$, and DOE Order 5480.11, which is enforced through contractual commitments. The requirements of the Rule are augmented by complementary guidance provided in Implementation Guides while the requirements of the Order are augmented by complementary guidance provided in the DOE Radiological Control Manual.

The Hanford Site Radiological Control Manual (HSRCM) has been developed through a cooperative effort between the DOE Richland Operations Office (RL) and the Hanford contractors. As required by Article 114.1, the HSRCM has been approved by the senior site executives of the Hanford contractors and provides the basis for consistent and uniform implementation of radiological control requirements for the Hanford Site. 
WHC-SD-WM-FRD-020

Revision 1

This page intentionally left blank. 
Appendix E - Performance Requirements Definitions

(DOE memo: "Apportionment of Groundwater Resource Protection Standard for the Tank Waste Remediation System (TWRS) Low Activity Waste (LAW)")

(DOE Order 5820.2A)

(DOE5820.2A, Chapter III, 3.d)

(DOE5820.2A, Chapter III, 3.e(4))

(Low Activity Waste Acceptance Specifications -- Rationale)

(NUREG-1293, Rev. 1)

(NUREG/BR-0204)

(SW-846, Method 9095, Rev. 0)

(Technical Position on Waste Form, Rev. 1)

(WAC 173-303)

(WAC173-303 Dangerous Waste Regulations)

(WAC173-303-070)

(WAC173-303-072)

(WAC173-303-090)

(WAC173-303-110)

(WAC173-303-140)

(WAC173-303-370)

(Waste Form Technical Position, rev 1 (NRC 1991))

\section{Specification 3: Entrained Solids}

3.1 Scope: This Specification defines the requirements for the Entrained Solids product, one of the intermediate waste products identified in Section C. 4 of this Statement of Work. The separated Entrained Solids product may be mixed with 90 Strontium and Transuranics (90Sr/TRU) product if the Contractor does not provide High-Level Waste services under this Contract.

The Contractor is not required to produce an Entrained Solids product under this Contract. The Contractor shall determine the degree of Entrained Solids removal required to comply with the requirements of Specification 2, Immobilized Low-Activity Waste.

3.2 Requirements:

\subsubsection{References: None}

3.2.2 Product Requirements:

3.2.2.1 Limitation on 137Cs Content: The total quantity of $137 \mathrm{Cesium}$ (137Cs) returned to DOE in the Entrained Solids product and in the 90Sr/TRU product (see Specification 6, 90Strontium and Transuranics) shall be less than 5 percent of the total $137 \mathrm{Cs}$ provided by DOE in the LowActivity Waste (LAW) feed.

3.2.2.2 Limitation on 99Tc Content: The total quantity of 99Technetium (99Tc) returned to DOE in the Entrained Solids product and in the 90Sr/TRU product (see Specification 6, 90Strontium and Transuranics) shall be less than 5 percent of the total 99Tc provided by DOE in the LAW feed. 